\title{
The Empirical Validation of House Energy Rating (HER) Software for Lightweight Housing in Cool Temperate Climates
}

Mark Dewsbury

B Arch, B Env. Design, Grad. Cert. Management

Submitted in total fulfilment of the requirements of the degree of Doctor of Philosophy

September 2011

School of Architecture \& Design

Faculty of Science, Engineering \& Technology

The University of Tasmania 

This is to certify that:

This thesis contains no material which has been accepted for a degree or diploma by the University or any other institution, except by way of background information and duly acknowledged in the thesis, and to the best of the my knowledge and belief no material previously published or written by another person except where due acknowledgement is made in the text of the thesis, nor does the thesis contain any material that infringes copyright.

The thesis is less than 100,000 words in length, exclusive of tables, maps, bibliographies, appendices and footnotes.

Mark Andrew Dewsbury

September 2011

This thesis may be made available for loan and limited copying and communication in accordance with the Copyright Act 1968. 



\section{Preface}

Paul Ritter first postulated that human activity is an integral part of the biosphere of this planet and our actions can enhance or detract from our ability to live in harmony with other creatures and the physical environment that surrounds and supports us (Ritter 1817). In our modern approach to sustainability the United Nations established that:

"Ecologically Sustainable development is development that meets the needs of the present without compromising the ability of future generations to meet their own needs." (UN 1987, p. 54)

With a good deal of intention and naivety, my partner and I built a load bearing mud brick house in the early 1990s in an attempt to limit our impact on the biosphere by minimising the use of resources to construct, operate and maintain a home, but this path is followed by few.

How do we improve the method of house-making in an ever more complicated existence? My research derives from two distinct passions.

The first research focus follows the references above and is concerned with the environmental and resource aspects of house making. The resources we use to build, maintain and operate our new and existing homes, including matters pertaining but not limited to: resource depletion, energy resources and Greenhouse gas emissions.

The second focus is more social in nature, as it is concerned with our society's capacity to provide a minimum standard of habitable housing for all. In many societies, it is those with the least wealth who are confronted with houses that require the most resources to operate and make habitable through summer and winter. In the Tasmanian context, many existing houses have internal temperatures as low as $0^{\circ} \mathrm{C}$ in winter.

As a society, we need to understand how new and existing buildings work thermally and to put in place legislation and suitable, non-product based guides to inform owners and tenants of methods to improve the liveability of their homes.

And one day we will have Net Zero and/or Zero Carbon Homes. 



\section{Abstract}

Against a background of a recognised need to reduce Australia's energy consumption and hence greenhouse gas emissions, the Building Code of Australia (BCA), in 2003, introduced its first thermal performance requirements for residential buildings. It mandated a minimum performance rating of 4 Stars for new housing, when assessed by an approved rating method. While the introduction of a 4 Star requirement had a minor impact on construction practices, that of 5 Stars (from 2006) and 6 Stars (from 2010) imposed considerable changes, especially in the use of timber platform floors. The adoption of the prescribed energy efficiency measures in the BCA raised concerns from industry and manufacturing groups, as to the accuracy of AccuRate software used to model the building envelope. This software was developed by the CSIRO and as a result of the thermal performance requirements, had evolved from a design tool to a regulatory tool. Both industry and government recognised the need to validate empirically the National House Energy Rating Scheme (NatHERS) benchmark software 'AccuRate'.

The University of Tasmania, in collaboration with Forest and Wood Products Australia, the Australian Government, the CSIRO and industry, constructed three test buildings for the purpose of validating empirically the AccuRate software, in particular for cool temperate climates. The test buildings followed standard residential construction practices and represented the three most common forms of construction: unenclosed-perimeter platform-floored, enclosed-perimeter platform-floored and concrete slab-on-ground floor. An array of environmental measuring equipment was installed to measure actual thermal performance in each of the test cells. A detailed house energy rating simulation was completed and a comparison of the measured and simulated data was undertaken.

This research presents the findings of the graphical and statistical analyses of variations between the measured and simulated data from the three test cells. The findings demonstrate that while the AccuRate software modelled energy flows well, discrepancies were measured between the simulated and measured temperatures of the test cells. In particular the analyses identified relationships between the discrepancies in all zones and outside air temperature, wind speed, global solar radiation and diffuse solar radiation, and possibly the ground model. Consequently, these require further investigation and resolution for the ongoing improvement and calibration of the AccuRate software. 



\section{Acknowledgements}

This research would never have been appropriately informed or guided without many individuals and organisations who over the last five years have given immeasurable advice and support.

My first thanks go to my primary supervisor, Professor Roger Fay; without whose ongoing support and intellect this research may not have been completed to the degree that it has.

Also to my secondary supervisor, Dr Florence Soriano who, aside from providing an open door to many questions, coming from an engineering background provided invaluable support through the data cleaning, statistical analysis and thesis writing stages.

My third supervisor, Associate Professor Gregory Nolan, established the original concepts and industry support for the building thermal performance research that has become an integrated part of the Centre for Sustainable Architecture with Wood.

Being trained for Architecture, Statistics was never an area I thought I would encounter and utilise to the extent I have for the last twelve months. This only occurred due to the guidance and assistance of Dr Desmond FitzGerald, School of Mathematics and Physics, University of Tasmania.

The AccuRate software has been developed by the CSIRO over many years. My personal and formal relationship with Dr Angelo Delsante (retired) provided invaluable guidance from both a national and international perspective. Dr Delsante was Australia's representative in the IEA tasks associated with building thermal simulation validation and software development. Dr Delsante was an intellectual partner in many parts of the research. When Dr Delsante retired, Dr Dong Chen assumed the mantle for the ongoing development of the AccuRate Software. Dr Chen has provided ongoing guidance as to the machinations within the AccuRate software. There have been many other discussions with a wide range of scientists from the CSIRO from the areas of climate, building physics and building simulation softwares. 

Special thanks must go to:

- the test cell research team from the University of Newcastle, especially Dr Heber Sugo, who provided early advice from their personal experiences

- Dr Robert Vale, who was of great assistance during the first nine months of the research, which focused on the design of a Zero Energy House

- Dr Mark Luther who pointed me down the path of ASHRAE

- My co-researchers: Detlev Geard, Philip McLeod and Sabrina Sequera who have tested my knowledge continuously but have also provided immense inspiration to this field of research.

- There have been many industry sponsors during the research period, without which the buildings would not have been built and the research would not have occurred. A list of the sponsors is visible at HTTP://oak.arch.utas.edu.au/testcells/

My final thanks must go to a very patient and understanding family. My partner Vicki, who has put up with late nights and unlimited child caring for the last five years. My three children: Lucienne (11), Gabrielle (8) and Everette (5), whose Dad has always been at 'uni' or doing 'uni' work.

To all, I hope I can repay some of my indebtedness in the years to come. 
The Empirical Validation of House Energy Rating (HER) software for lightweight housing in cool temperate climates.

Dewsbury 


\section{Table of Contents}

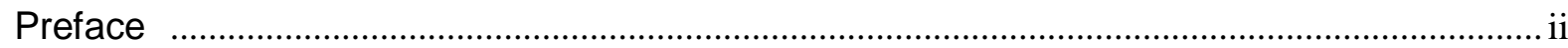

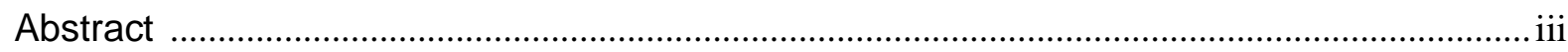

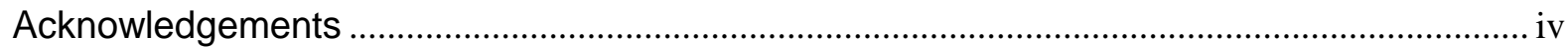

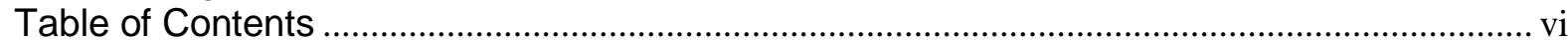

List Of Appendices ................................................................................................................. viii

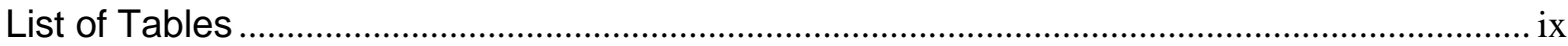

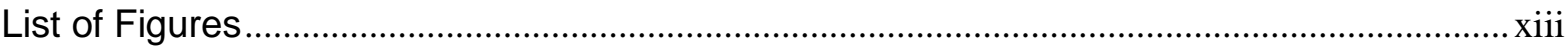

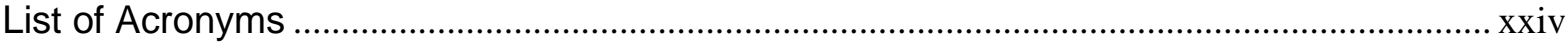

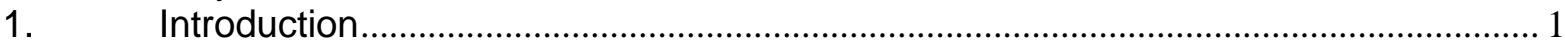

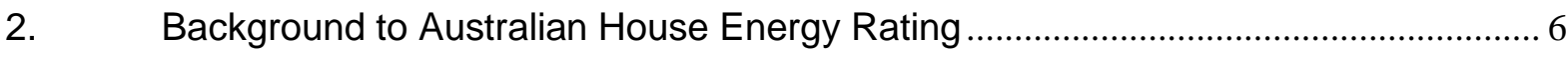

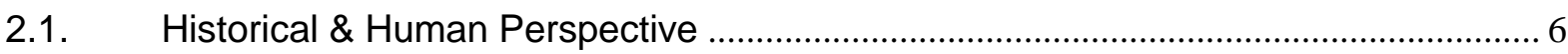

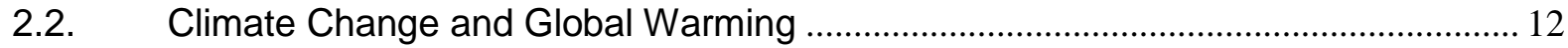

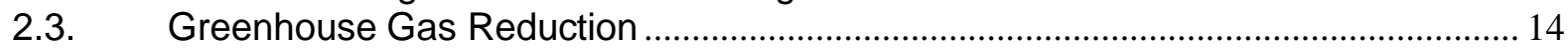

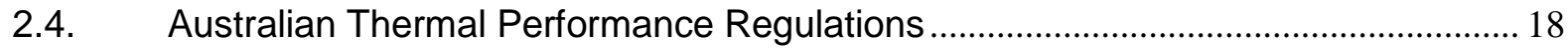

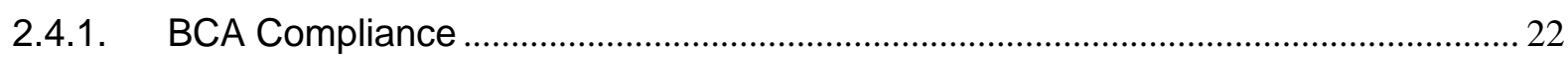

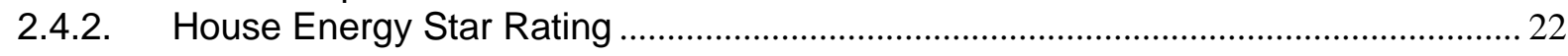

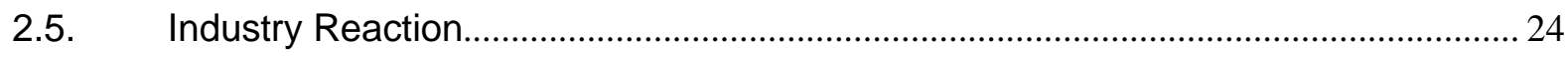

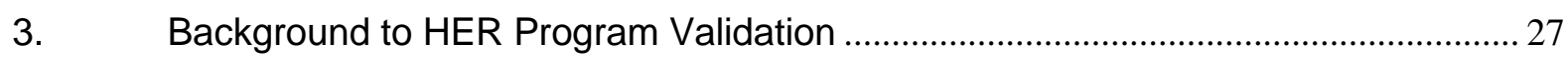

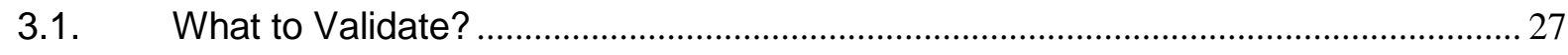

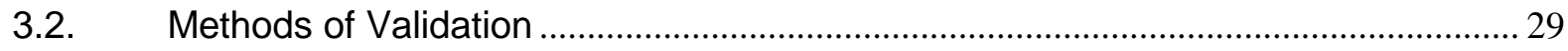

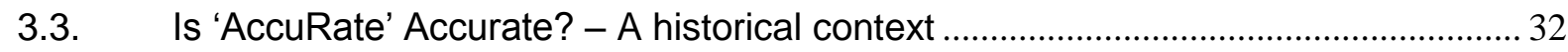

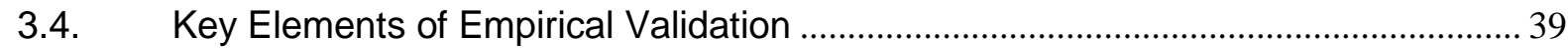

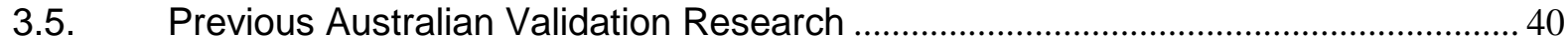

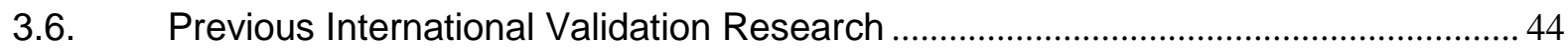

3.7. Background to Test Buildings for Empirical Validation..............................................50

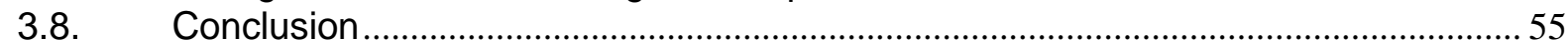

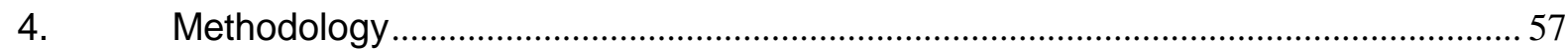

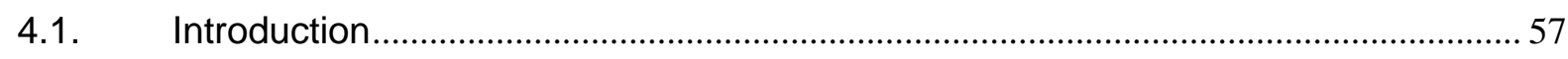

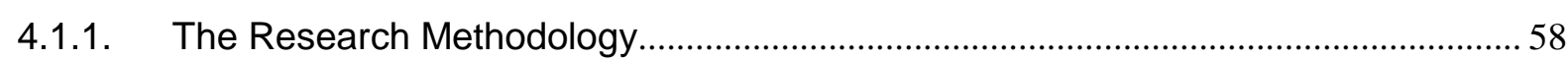

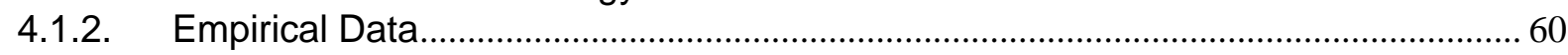

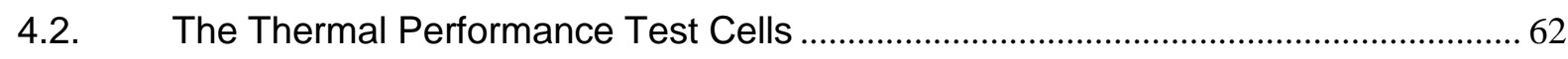

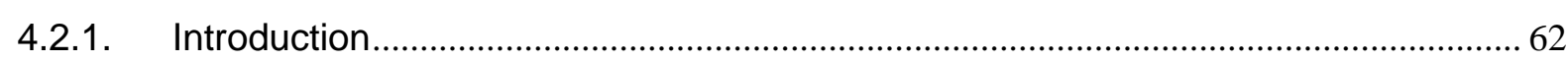

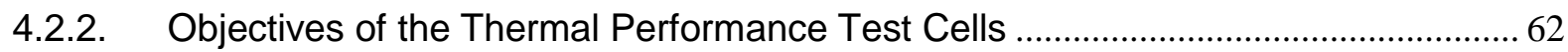

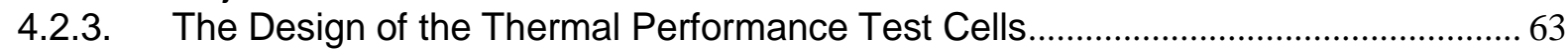

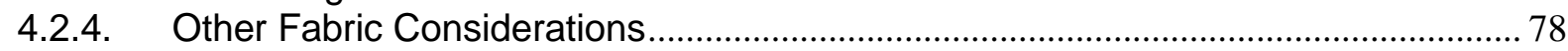

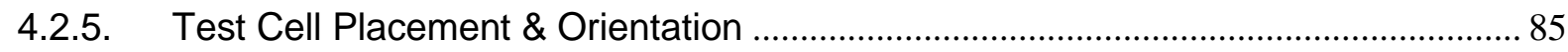

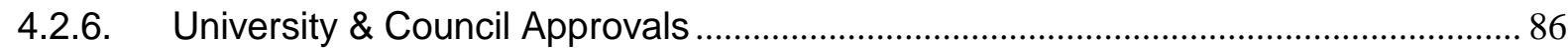

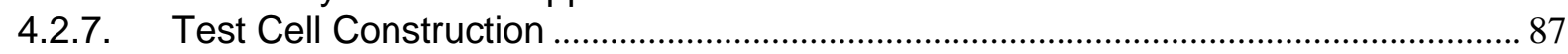

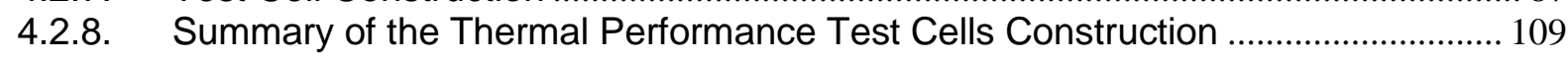

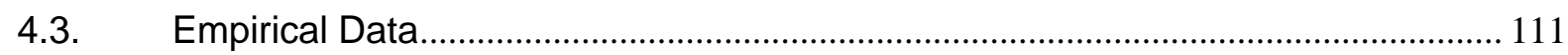

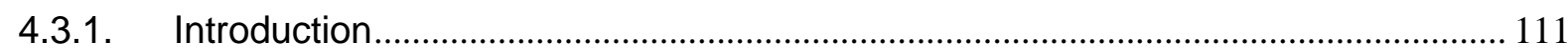

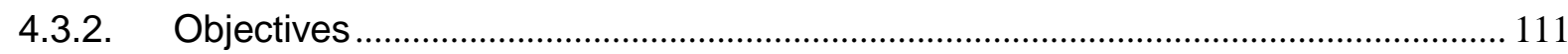

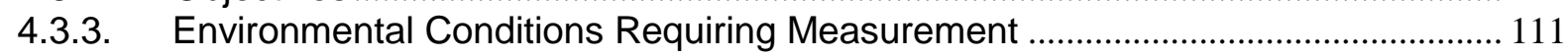

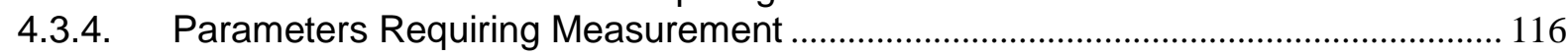

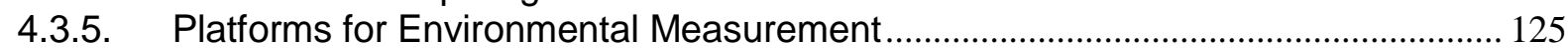

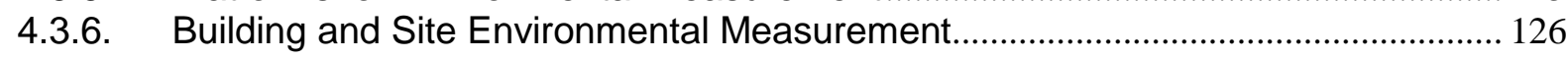

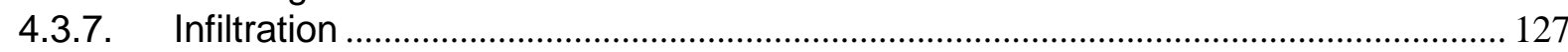

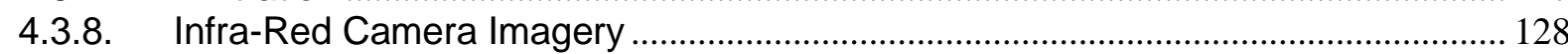


4.3.9. Defining Room Temperature

4.3.10. The Fabrication, Installation and Calibration of Environmental Measuring Equipment 134

4.3.11. Calibration of Environmental Measuring Equipment.

4.3.12. Operational Control of the Thermal Performance Test Cells .................................. 146

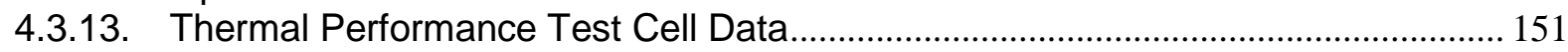

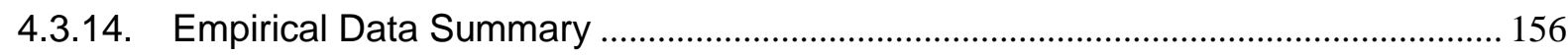

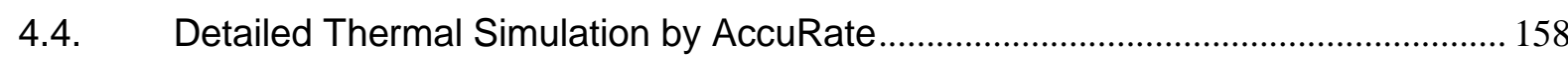

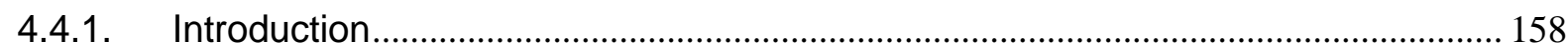

4.4.2. Objectives of the AccuRate Detailed Thermal Simulation ........................................ 159

4.4.3. The AccuRate House Energy Rating Software ........................................................ 161

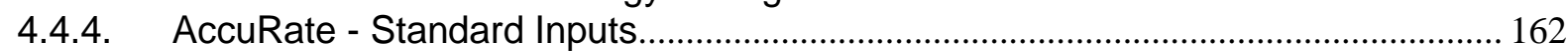

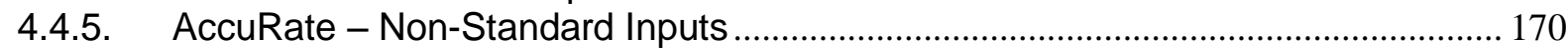

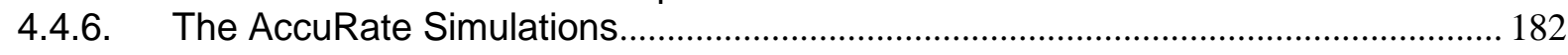

4.4.7. Summary of the Detailed Thermal Simulation by AccuRate...................................... 185

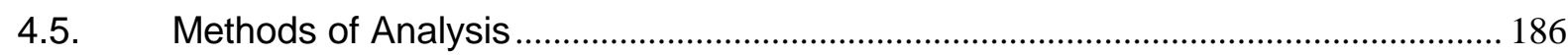

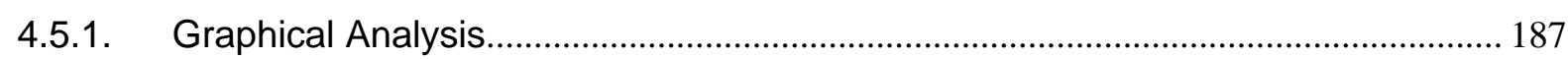

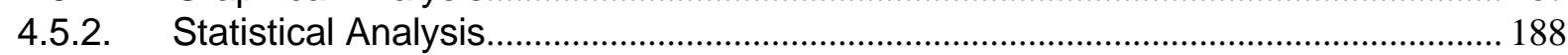

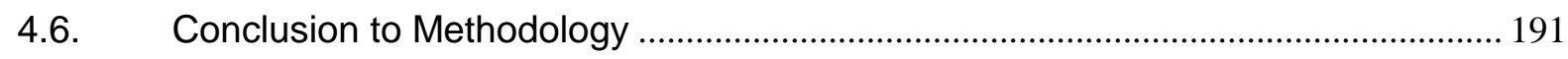

5. Results, Analysis and Discussion of Empirical Validation........................................ 194

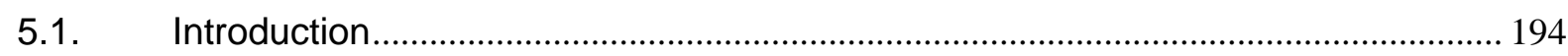

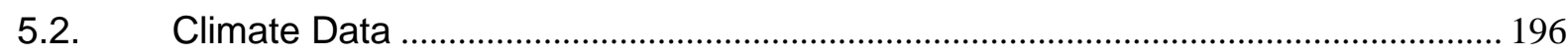

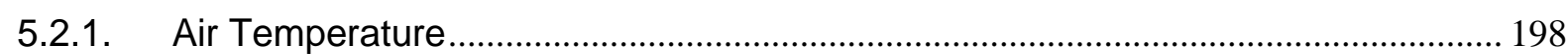

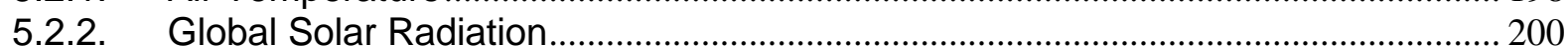

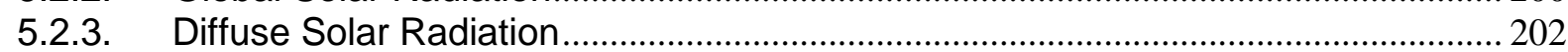

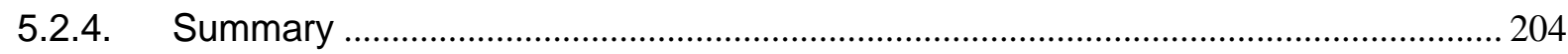

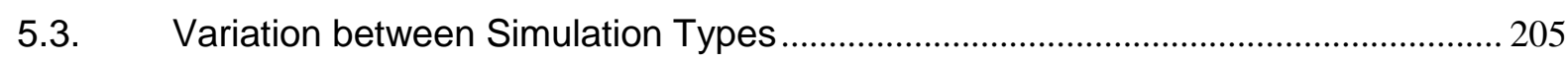

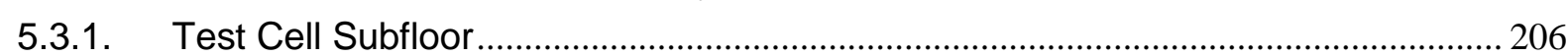

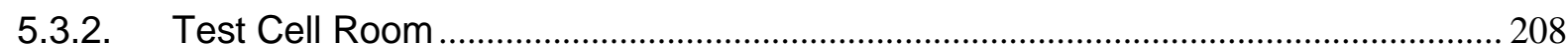

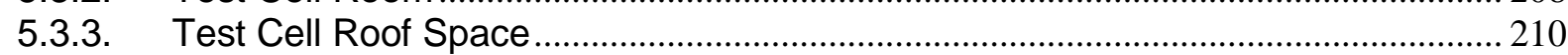

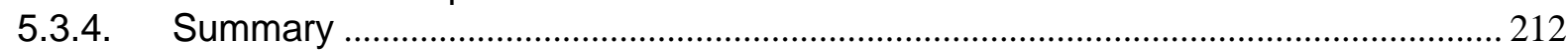

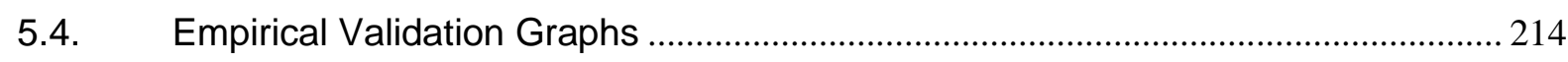

5.4.1. Unenclosed-perimeter Platform-floored Test Cell ........................................................ 214

5.4.2. Enclosed-perimeter Platform-floored Test Cell........................................................ 224

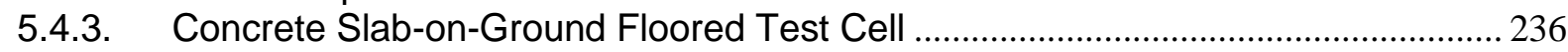

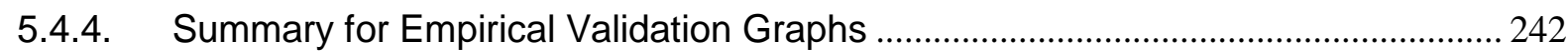

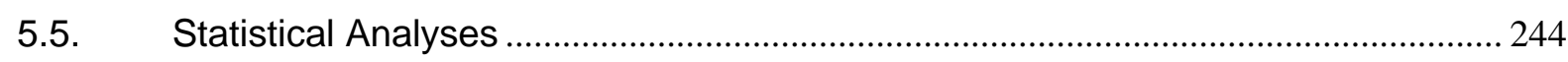

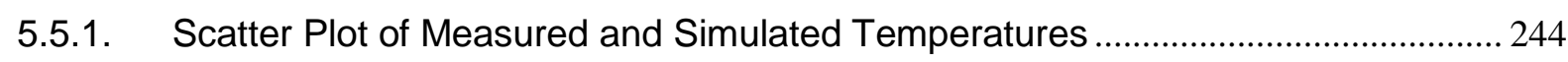

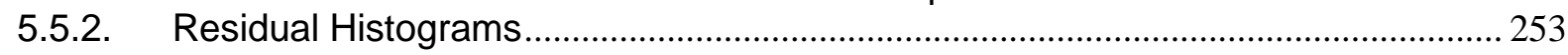

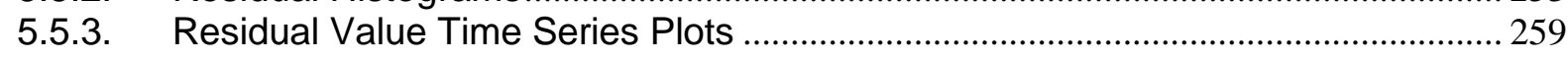

5.5.4. Correlation of Adjoining Zone Residual Values ....................................................... 265

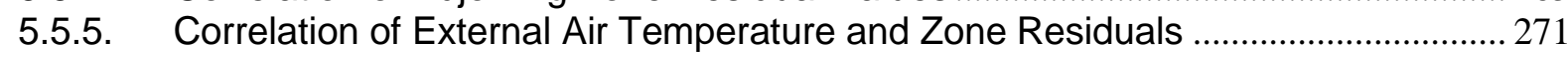

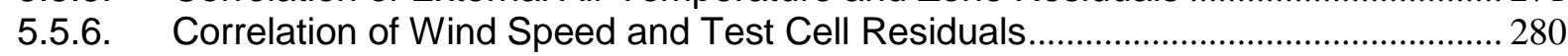

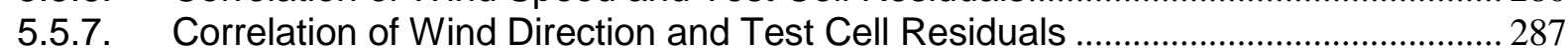

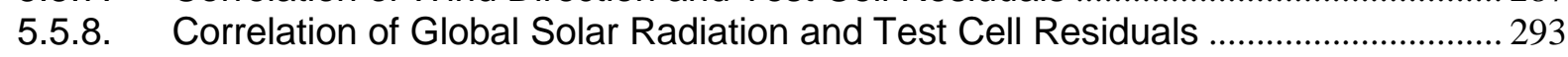

5.5.9. Correlation of Diffuse Solar Radiation and Test Cell Residuals.............................. 301

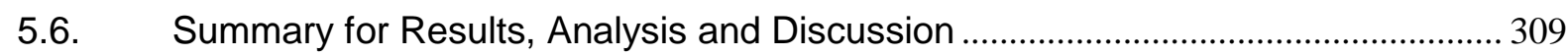

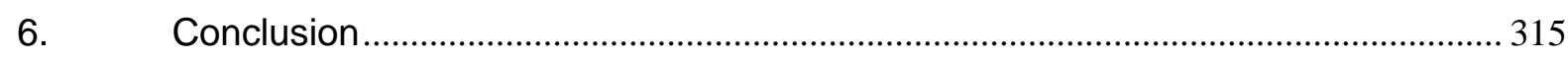

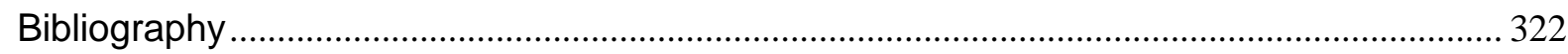




\section{List Of Appendices}

Pages

Appendix $1 \quad$ Examples of Other Test Buildings $\quad 1-14$

Appendix 2 Test Cell Construction Information 1-51

$\begin{array}{lrr}\text { Appendix } 3 \quad \text { Test Cells Construction Journal } & 1-62\end{array}$

$\begin{array}{lll}\text { Appendix } 4 \quad \text { Environmental Measurement } & 1-48\end{array}$

$\begin{array}{lll}\text { Appendix } 5 \quad \text { Detailed Envelope Simulation by AccuRate } & 1-77\end{array}$

$\begin{array}{llr}\text { Appendix } 6 & \text { Results of Empirical Validation } & 1-170\end{array}$ 


\section{List of Tables}

Table 2.1: Wall Thermal Resistance Values for Tasmanian Housing 1926 \& 2002 ................. 9

Table 2.2: Ceiling thermal resistance Values for Tasmanian Housing 1926 \& 2002 ............... 10

Table 2.3: Breakdown of residential energy end uses - 1990 Australia .................................... 10

Table 2.4: End use of residential energy consumption in Australia, 1979-80 ........................... 11

Table 2.5: Action to Reduce Greenhouse Gas Emissions ......................................................... 17

Table 2.6: Electricity use Per Year AGO, 2008, End Use ........................................................ 18

Table 2.7: Star Bands for Launceston \& Sydney ( $\mathrm{MJ} / \mathrm{m}^{2}$.annum conditioned floor area) ....... 21

Table 3.1: Advantages \& Disadvantages of HER Software Validation Methods ...................... 30

Table 3.2: BESTEST and NatHERS heating \& cooling values for type 600 building .............. 37

Table 3.3: University of Newcastle test building fabric matrix (2003) ........................................ 43

Table 3.4: Compliance of recent Australian validation tasks to Lomas criteria.......................... 44

Table 3.5: Software validation during IEA Task 34 research....................................................... 47

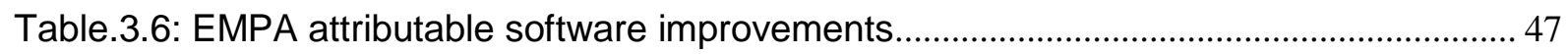

Table 3.7: Survey of test building for validation of detailed building simulation programs...... 54

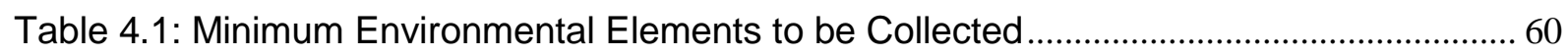

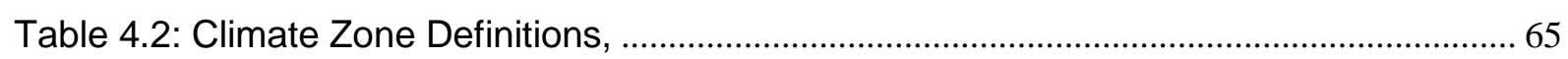

Table 4.3: Summary of Monthly Climate Statistics for Ti Tree Bend, Launceston ................... 66

Table 4.4: Dwelling Units Approved, Australia .............................................................................. 70

Table 4.5: The Dimensions of the Launceston Thermal Performance Test Cells ..................... 74

Table 4.6: Thermal performance test cell detailed fabric matrix ................................................ 78

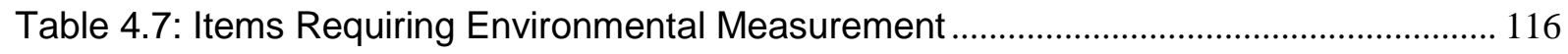

Table 4.8: Environmental measurement heights as specified by ASHRAE Standard 55 ..... 120

Table 4.9: Vertical Measurement Profile of the Launceston Thermal Performance Test Cells

Table 4.10: Horizontal Measurement Profile, Providing Supporting Data, of the Launceston

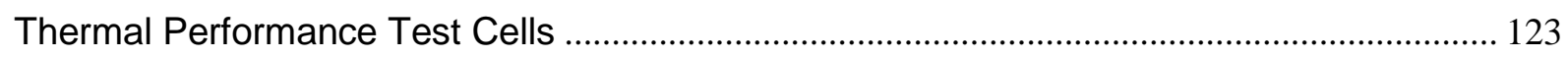

Table 4.11: Probes and Sensors for Test Cells and Site Weather Station.............................. 127

Table 4.12: Test Cell 1: Comparison of Minimum \& Maximum Values for Mean Room

Temperature....

Table 4.13: Test Cell 3: Comparison of Minimum \& Maximum Values for Mean Room

Temperature.

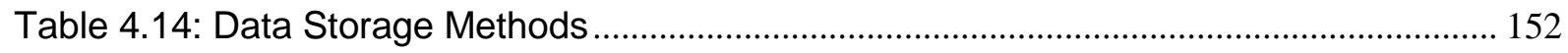

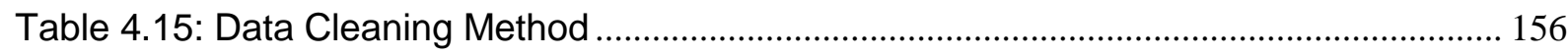


Table 4.16: Default Fabric / Default Climate, Default Fabric / Measured Climate, As-Built Fabric / Default Climate, As-Built Fabric / Measured Climate data entry iterations .... 163

Table 4.17: Project Data - Data entry for thermal performance test cells ............................... 165

Table 4.18: Project Data - Iteration variations for data entry .................................................... 165

Table 4.19: Construction Data - Iteration variations for data entry ......................................... 165

Table 4.20: Zone types and definitions (AccuRate V1.1.4.1) .................................................. 166

Table 4.21: Zone types chosen for thermal performance test cells ......................................... 167

Table 4.22: Eave width calculations for thermal performance test cells .................................. 167

Table 4.23: Built elements' data input requirements for each zone in the Unenclosedperimeter Test Cell

Table 4.24: Built elements' data input requirements for each zone in the Enclosed-perimeter Test Cell

Table 4.25: Built elements' data input requirements for each zone in the Concrete Slab-onground Test Cell..

Table 4.26: As-built Scratch File Modifications 1 - Concrete Slab-on-ground Floored Test Cell

Table 4.27: Climate File Input Sources

Table 4.28: As-built Scratch File Modifications 2 - Concrete Slab-on-ground Floored Test Cell

Table 4.29: Wall-framing Area - Concrete Slab-on-ground Floored Test Cell ... 176

Table 4.30: Calculation of Conductivity and Resistance Values for Plasterboard Lining...... 177

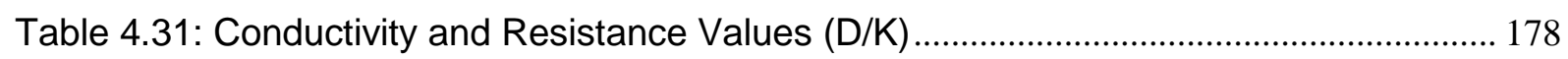

Table 4.32: Parallel Paths Method \& Isotherm Planes Method Comparison ........................... 180

Table 4.33: Description of the Empirical Validation Data Used in This Study......................... 186

Table 4.34: Quantity of External and Internal Environmental Parameters Measured............ 187

Table 4.35: Univariate and Multivariate Analysis Tasks Completed........................................ 190

Table 5.1: Levels of importance of climatic values for AccuRate simulation............................ 197

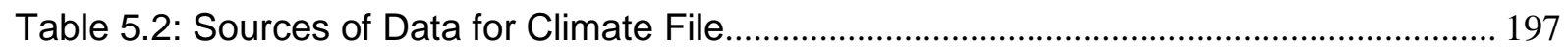

Table 5.3: Measured and TMY Climate File Air Temperatures (19/02/2007 - 24/02/2007). 199

Table 5.4: Measured and Default Climate File Air Temperatures (19/06/2007 - 23/06/2007)

Table 5.5: Measured and TMY Climate File Global Solar Radiation (16/04/2007-20/04/2007)

Table 5.6: Measured and TMY Climate File Global Solar Radiation (19/06/2007-23/06/2007) 
Table 5.7: Measured and TMY Climate File Global Solar Radiation (14/01/2007-18/01/2007)

Table 5.8: Measured and Default Climate File Global Solar Radiation (19/06/2007-

23/06/2007)..... 203

Table 5.9: Test Cell 2: Comparison of Minimum \& Maximum Values of Simulated Subfloor Air Temperature (19/06/2007-22/06/2007)

Table 5.10: Test Cell 3: Comparison of Minimum Values of Simulated Test Cell Room Air Temperature (15/01/2007-18/01/2007)

Table 5.11: Measured Roof Space Infiltration Rates

Table 5.12: Test Cell 2: Comparison of Minimum \& Maximum Values of Simulated Test Cell

Roof Space Air Temperature (15/01/2007-18/01/2007)

Table 5.13: Average Difference between Measured and Simulated Minimum \& Maximum

Temperatures (Unenclosed-perimeter Platform-floored Test Cell).....

Table 5.14: Minimum Measured Temperatures Unenclosed-perimeter Platform-floored Test

Cell

Table 5.15: Average Difference between Measured and Simulated Minimum \& Maximum Temperatures (Enclosed-perimeter Platform-floored Test Cell)

Table 5.16: Enclosed-perimeter Platform-floored Test Cell Subfloor Surface Areas............. 226

Table 5.17: Enclosed-perimeter Platform-floored Test Cell Room Surface Areas.

Table 5.18: Average Difference between Measured - Simulated Minimum \& Maximum

Temperatures (Concrete Slab-on-ground Floored Test Cell) .................................................... 236

Table 5.19: Concrete Slab-on-ground Floored Test Cell Room Surface Areas ...................... 240

Table 5.20: Test Cell 1 Measured Temperature and Simulated Temperature Correlation

Ratios.

Table 5.21: Test Cell 2 Measured Temperature and Simulated Temperature Correlation

Ratios.

Table 5.22: Test Cell 3 Measured Temperature and Simulated Temperature Correlation

Ratios.

Table 5.23: Unenclosed-perimeter Platform-floored Test Cell Mean Residual Values ......... 255

Table 5.24: Enclosed-perimeter Platform-floored Test Cell Mean Residual Values .............. 257

Table 5.25: Concrete Slab-on-Ground Floored Test Cell Mean Residual Values................... 259

Table 5.26: Unenclosed-perimeter Platform-floored Test Cell Minimum and Maximum

Residual Values $\left({ }^{\circ} \mathrm{C}\right)$.

Table 5.27: Enclosed-perimeter Platform-floored Test Cell Minimum and Maximum Residual Values $\left({ }^{\circ} \mathrm{C}\right)$. 
Table 5.28: Enclosed-perimeter Platform-floored Test Cell Minimum and Maximum Residual

Values $\left({ }^{\circ} \mathrm{C}\right)$ 264

Table 5.29: Test Cell Subfloor and Air Temperature Correlation Ratios 273

Table 5.30: Test Cell Room and Air Temperature Correlation Ratios. 276

Table 5.31: Test Cell Roof space and Air Temperature Correlation Ratios 279

Table 5.32: Test Cell 1 Zone Residual Values and Wind Speed Correlation Ratios 282

Table 5.33: Test Cell 2 Zone Residual Values and Wind Speed Correlation Ratios 284

Table 5.34: Test Cell 3 Zone Residual Values and Wind Speed Correlation Ratios 286

Table 5.35: Test Cell 1 Zone Residual Values and Wind Direction Correlation Ratios. 289

Table 5.36: Calculated Roof Space Infiltration Values 289

Table 5.37: Test Cell 2 Zone Residual Values and Wind Direction Correlation Ratios 291

Table 5.38: Test Cell 3 Zone Residual Values and Wind Direction Correlation Ratios 292

Table 5.39: Test Cell 1 Residual Value and Global Solar Radiation Correlation Ratios ....... 295

Table 5.40: Test Cell 2 Residual Values and Global Solar Radiation Correlation Ratios ..... 297

Table 5.41: Test Cell 3 Residual Values and Global Solar Radiation Correlation Ratios ..... 300

Table 5.42: Variation in Zone Residual Value when Global Solar Radiation Equals Zero ... 301

Table 5.43: Test Cell 1Residual Values and Diffuse Solar Radiation Correlation Ratios ..... 304

Table 5.44: Test Cell 2 Residual Values and Diffuse Solar Radiation Correlation Ratios .... 306

Table 5.45: Test Cell 3 Residual Values and Diffuse Solar Radiation Correlation Ratios .... 307 


\section{List of Figures}

Figure 2.1 - Dwelling with hearth $\sim 1,500 \mathrm{BC}$

Figure 2.2 - School Building \& Dwelling with hearth in each room, mid-1800s Tasmania...... 7

Figure 2.3 - Dwelling with hearth in each room, 1926 Tasmania ............................................... 8

Figure 2.4 - Trends in residential total energy consumption - Australia ................................... 11

Figure 2.5 - Energy Consumption (PJ) - Space heating in Australia ....................................... 12

Figure 2.6 - Per capita fossil fuel emissions 2003 - 10kg carbon/year/person. ....................... 13

Figure 2.7 - Diagram of communication with the Australian government with respect to

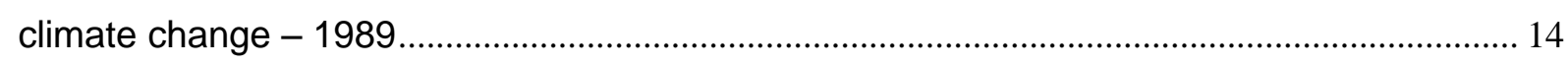

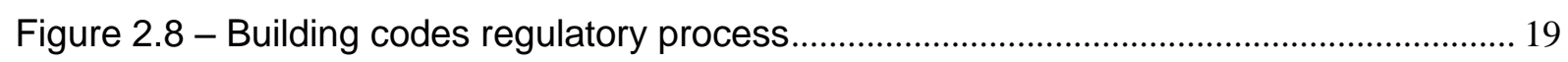

Figure 2.9 - HER Star Rating report produced by the AccuRate software ............................... 23

Figure 3.1 - Schematic of Accurate software process to establish an HER Star Rating ........ 29

Figure 3.2 - Muncey \& Spencer Matrix calculation method ...................................................... 33

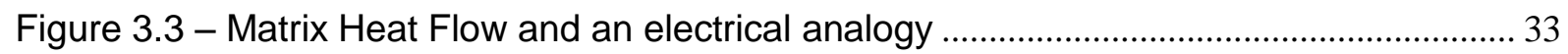

Figure 3.4 - BESTEST results for low-mass annual heating requirement ................................ 36

Figure 3.5 - BESTEST results for low-mass annual cooling requirement.................................. 36

Figure 3.6 - EnergyPlus BESTEST results for low-mass annual heating requirement........... 38

Figure 3.7 - EnergyPlus BESTEST results for low-mass annual cooling requirement........... 38

Figure 3.8 - European Network of PASLINK/PASSYS Test Facilities...................................... 52

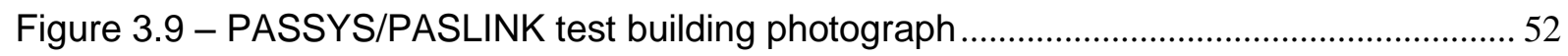

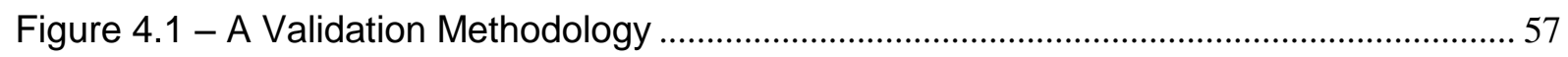

Figure 4.2 - Launceston Test Cell Methodology ......................................................................... 59

Figure 4.3 - A Building is affected by many differing non-constant environmental inputs..... 63

Figure 4.4 - Climate Zone Map, Building Code of Australia......................................................... 64

Figure 4.5 - Site Plan, Newnham Campus, University of Tasmania........................................... 67

Figure 4.6 - Site Plan 2, Newnham Campus, University of Tasmania ..................................... 68

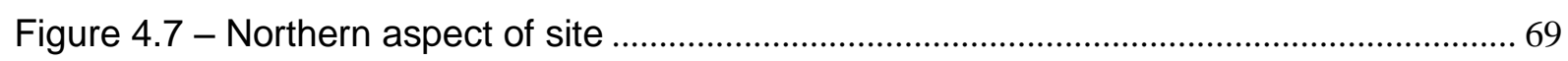

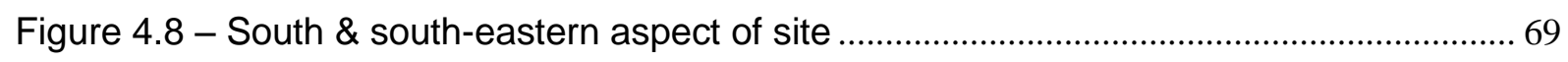

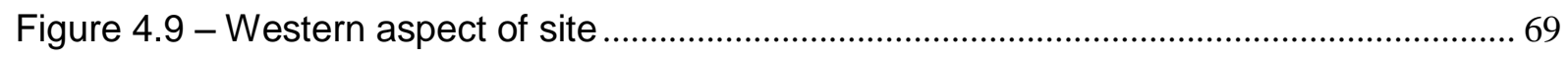

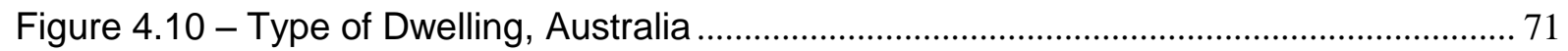

Figure 4.11 - University of Newcastle Test Buildings................................................................ 71

Figure 4.12 - Diagram from section 3.12.1.1, Volume 2 BCA, 2005 ........................................ 72

Figure 4.13 - Unenclosed platform-floored test cell - wall cavity infiltration control.................. 79

Figure 4.14 - Enclosed platform-floored test cell subfloor and wall cavity infiltration control.. 79 


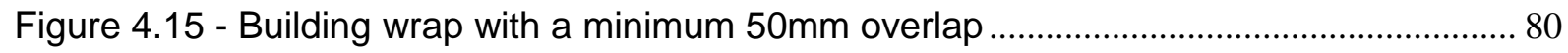

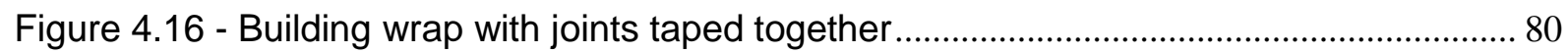

Figure 4.17 - Common practice of pulling roof sarking taut during installation .......................... 82

Figure 4.18 - Method for test cells - Sarking installed over rafters, under battens .................. 82

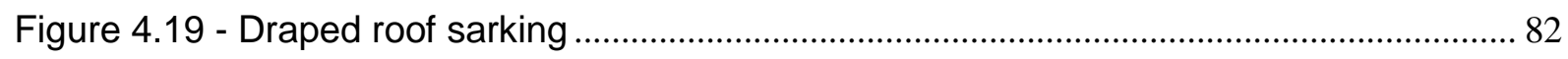

Figure 4.20 - Door Frame Infiltration reduction measures ....................................................... 83

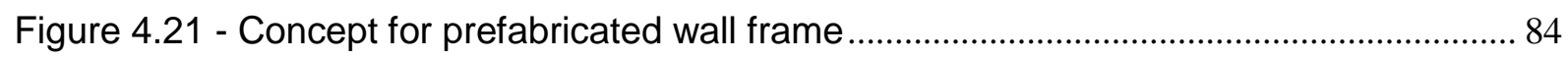

Figure 4.22 - Control joints in brickwork for knock-out wall panel.............................................. 84

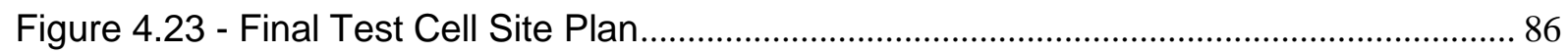

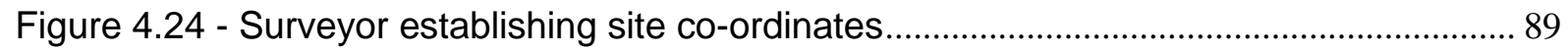

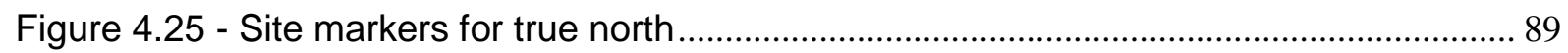

Figure 4.26 - Test Cell corner marker ......................................................................................... 90

Figure 4.27 - Exclusion fence and commencement of Test Cells set out (June 5, 2006) ....... 91

Figure 4.28 - Turning the first sod - Top soil removal for test cell 3 (June 6, 2006)............... 91

Figure 4.29 - Excavation for footings of test cell 2 (June 7, 2006) ............................................ 91

Figure 4.30 - Poles in place before concrete put in footings, test cell 2 (June 13, 2006) ....... 91

Figure 4.31 - The two-man process stage of erecting the prefabricated wall frames (June 20,

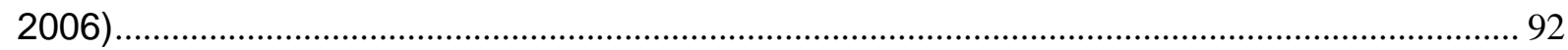

Figure 4.32 - Roof trusses erected on test cell 2 (June 21, 2006) ............................................ 92

Figure 4.33 - Site photograph at the completion of works on June 30, 2006. test cell 1 to test cell 3 in receding order.

Figure 4.34 - After the storm. Much of the building wrap and roof sarking was removed by

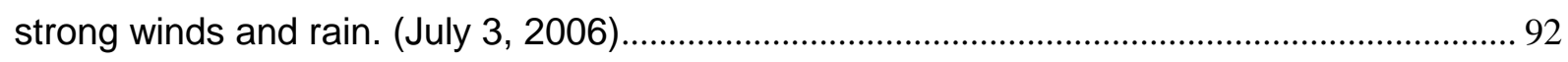

Figure 4.35 - Test cell 2 - rockwool wall batt insulation (July 5, 2006) ..................................... 92

Figure 4.36 - Test cell 3 - glasswool ceiling batt insulation installed (July 6, 2006) ................ 92

Figure 4.37 - Another rainy day halts external works (July 5, 2006) ....................................... 93

Figure 4.38 - Test cell 1 - Application of wall and ceiling plasterboard (July 6, 2006)............ 93

Figure 4.39 - Test cell 3 - Bricklaying well under way with knock-out panels being left till last

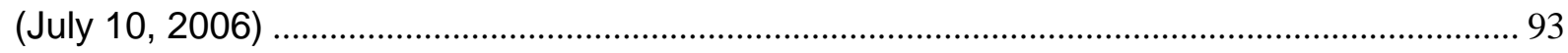

Figure 4.40 - Gap between door jamb and wall frame is clearly visible (July 17, 2006) ........ 94

Figure 4.41 - Daylight is visible at the base of the gap between door jamb and wall frame (July 17, 2006)

Figure 4.42 - The installation of closed cell foam rubber in gap between door jamb and wall frame (July 17, 2006)

Figure 4.43 - Closed cell foam rubber is installed in gap between door jamb and wall frame (July 17, 2006) 
Figure 4.44 - Application of high density foam rubber tape to prefabricated insert (July 21, 2006) 96

Figure 4.45 - Pushing prefabricated insert hard-up against the plasterboard ceiling (July 21, 2006) .96

Figure 4.46 - Close up-view of high density foam rubber compressed between prefabricated insert and ceiling (July 21, 2006) .96

Figure 4.47 - High density foam rubber and particle board sheet affixed to top face of access hatch (July 21, 2006). .96

Figure 4.48 - Photograph of wall cavity sealing for test cell 1 (August 2006) ..... 97

Figure 4.49 - Photograph of subfloor and wall cavity separation of test cell 2 . .97

Figure 4.50 - Sample of polypropylene rod (July 21, 2006) .98

Figure 4.51 - Close up view of polypropylene rod inserted into construction joint (July 21, 2006) 98

Figure 4.52 - Polypropylene rod inserted into construction joint (July 21, 2006)..................... 98

Figure 4.53 - External flexible sealant in construction joint (July 21, 2006) ............................. 98

Figure 4.54 - The surface mounting of electrical services (July 10, 2006) .... .99

Figure 4.55 - Detail of surface mounted circuit board, conduits and general purpose outlet (July 10, 2006) .99

Figure 4.56 - Detail of surface mounted lamp and lamp switch (July 11, 2006)... .99

Figure 4.57 - Surface mounted electrical services when finished (August, 2006) 99

Figure 4.58 - The School technical assistant screw-fixing the heater mounting box to test cell internal wall (July 11, 2006) 101

Figure 4.59 - The heater mounting box fixed to test cell internal wall (July 11, 2006)... 101 Figure 4.60 - Wall photograph showing proximity of heater to circuit board, and height above floor (July 11, 2006)

Figure 4.61 - Heater being inserted and screw-fixed into mounting box (July 11, 2006) ...... 101

Figure 4.62 - Steel staples used to affix building wrap and roof sarking 103

Figure 4.63 - Building wrap torn off staples during construction process ..... 103

Figure 4.64 - Building wrap torn during construction process 103

Figure 4.65 - Reflective foil tape repairs to building wrap during construction 103

Figure 4.66 - The pattern of holes shows the location of staples and the effect of insulation installation. 104

Figure 4.67 - Gap in ceiling corner between wall and ceiling plasterboard... 105

Figure 4.68 - Diagram showing potential unrestricted infiltration losses. 105

Figure 4.69 - Billowing of building wrap as a result of insulation installation. 107

Figure 4.70 - Insulation installation in test cell 1 - third attempt 107 
Figure 4.71: Four additional vertical members inserted into wall for fixing plywood cladding

Figure 4.72: Five additional vertical members inserted into wall for fixing plywood cladding 108

Figure 4.73 - Triple jamb studs to support lintel in knock-out wall panel. 108

Figure 4.74 - Double top plate 108

Figure 4.75: Official opening of thermal performance test cells ( 29 August, 2006) 109

Figure 4.76: Thermal performance test cells ( 30 August, 2006). 110

Figure 4.77 - Accurate weather file format. 113

Figure 4.78 - Sample of AccuRate Output Temperature file. 115

Figure 4.79 - Longitudinal section of the NBS passive solar test building 118

Figure 4.80 - PASSLINK Test Building 118

Figure 4.81 - Thermal principles of PASSLINK Test Building 118

Figure 4.82 - Interior of EMPA Test Building

Figure 4.83 - Vertical measurement profile for the unenclosed-perimeter and enclosedperimeter platform floored test cells.

Figure 4.84 - Vertical environmental measurement profile for the concrete slab-on-ground floored test cell

Figure 4.85 - Horizontal measurement profile for the unenclosed-perimeter and enclosedperimeter platform floored test cells.

Figure 4.86 - Horizontal measurement profile for the concrete slab-on-ground floored test cell.

Figure 4.87 - External infra-red image of the concrete slab-on-ground floored test cell ...... 128

Figure 4.88 - Internal infra-red image documenting the variation of surface temperatures associated with the wall frame bottom plate connection

Figure 4.89 - Stratification of temperatures: Unenclosed-perimeter, platform-floored test cell (July 29 to August 3, 2007)

Figure 4.90 - Stratification of temperatures: Enclosed-perimeter, platform-floored test cell (July 29 to August 3, 2007)

Figure 4.91 - Stratification of temperatures: Concrete slab-on-ground floored test cell (July 29 to August 3, 2007).

Figure 4.92 - Mean Room Temperature Calculations: Unenclosed-perimeter, platformfloored test cell (July 29 to August 3, 2007)

Figure 4.93 - Mean Room Temperature Calculations: Concrete Slab-on-ground floored test cell (July 29 to August 3, 2007).

Figure 4.94 - Wiring diagram for environmental measuring equipment. 135

Figure 4.95 - Sample of DT500 channel allocation spreadsheet. 135 
Figure 4.96 - Newly arrived DT500 data loggers and channel expansion modules. 138 Figure 4.97 - DT500 data loggers and channel expansion module in secure metal case after primary wiring was installed between channels and RJ45 terminals 138

Figure 4.98 - Interior view of metal data logger box and RJ45 terminals .............................. 138

Figure 4.99 - Exterior view of metal data logger box and RJ45 sockets................................ 138

Figure 4.100 - Sample of data logger programming 141

Figure 4.101 - Krone terminal: RJ45 type data plug with eight wire data cable on the right and red/white bell wire, which connects to an individual sensor, connected to the Krone terminal.

Figure 4.102 - Connection diagram for Local Area Network connectivity of the thermal performance test cells.

Figure 4.103 - Wiring diagram for relay control of thermal performance test cell room heater

Figure $4.104-3.6 \mathrm{~kW}$ wall heater being installed during thermal performance test cell construction

Figure 4.105 - Relay control for heater installed within box enclosing current transducer sensors

Figure 4.106 - AccuRate Detailed Simulation Matrix

Figure 4.107 - Test Cell 3 - Southern wall . 175

Figure 4.108 - Test Cell 3 - Northern wall 175

Figure 4.109 - Brick Veneer Wall Detail.... 177

Figure 4.110 - Ceiling Detail 177

Figure 4.111 - Wall type suitable for Zone Method 179

Figure 4.112 - Energy.txt AccuRate Output file 183

Figure 4.113 - Output.txt AccuRate Output file 184

Figure 4.114 - AccuRate Temperature.tem Report. 184

Figure 4.115 - Time-series based graphical analysis 188

Figure 5.1 - Graph of Measured \& TMY Air Temperature Values: February 2007. 198

Figure 5.2 - Graph of Measured \& TMY Air Temperature Values: June 2007 199

Figure 5.3 - Graph of Measured \& TMY Global Solar Radiation Values: April 2007. 200

Figure 5.4 - Graph of Measured \& TMY Global Solar Radiation Values: June 2007. 201

Figure 5.5 - Graph of Measured \& TMY Diffuse Solar Radiation Values: January 2007 ..... 202 Figure 5.6 - Graph of Measured \& TMY Diffuse Solar Radiation Values: February 2007.... 203 Figure 5.7 - Test Cell 2 Subfloor: B-B, B-C, AB-B, AB-C Results: June 2007 ....................... 206 Figure 5.8 - Test Cell 3 Room: B-B, B-C, AB-B, AB-C Results: January 2007 ….................. 208 Figure 5.9 - Test Cell 2 Roof Space: B-B, B-C, AB-B, AB-C Results: January 2007 211 
Figure 5.10 - Test Cell 1 Subfloor: AB-C \& Measured Results: February 2007 215

Figure 5.11 - Test Cell 1 Subfloor: AB-C \& Measured Results: April 2007 216

Figure 5.12 - Test Cell 1 Subfloor: AB-C \& Measured Results: May 2007. 217

Figure 5.13 - Test Cell 1 Subfloor: AB-C \& Measured Results: June 2007 217

Figure 5.14 - Test Cell 1 Roof Space: AB-C \& Measured Results: February 2007 218

Figure 5.15 - Test Cell 1 Roof Space: AB-C \& Measured Results: April 2007 218

Figure 5.16 - Test Cell 1 Roof Space: AB-C \& Measured Results: May 2007 219

Figure 5.17 - Test Cell 1 Roof Space: AB-C \& Measured Results: June 2007 220

Figure 5.18 - Un-insulated Eave with Compressed Cement Sheet Cladding 220

Figure 5.19 - Test Cell 1 Room: AB-C \& Measured Results: February 2007. 221

Figure 5.20 - Test Cell 1 Room: AB-C \& Measured Results: April 2007. 222

Figure 5.21 - Test Cell 1 Room: AB-C \& Measured Results: May 2007 223

Figure 5.22 - Test Cell 1 Room: AB-C \& Measured Results: June 2007. 224

Figure 5.23 - Test Cell 2 Subfloor: AB-C \& Measured Results: March 2007 226

Figure 5.24 - Test Cell 2 Subfloor: AB-C \& Measured Results: April 2007 227

Figure 5.25 - Test Cell 2 Subfloor: AB-C \& Measured Results: May 2007 227

Figure 5.26 - Test Cell 2 Subfloor: AB-C \& Measured Results: June 2007 228

Figure 5.27 - Test Cell 2 Roof Space: AB-C \& Measured Results: March 2007 230

Figure 5.28 - Test Cell 2 Roof Space: AB-C \& Measured Results: April 2007 230

Figure 5.29 - Test Cell 2 Roof Space: AB-C \& Measured Results: May 2007 231

Figure 5.30 - Test Cell 2 Roof Space: AB-C \& Measured Results: June 2007 231

Figure 5.31 - Test Cell 2 Room: AB-C \& Measured Results: February 2007. 233

Figure 5.32 - Test Cell 2 Room: AB-C \& Measured Results: April 2007. 233

Figure 5.33 - Test Cell 2 Room: AB-C \& Measured Results: May 2007. 234

Figure 5.34 - Test Cell 2 Room: AB-C \& Measured Results: June 2007 235

Figure 5.35 - Test Cell 3 Roof Space: AB-C \& Measured Results: February 2007 237

Figure 5.36 - Test Cell 3 Roof Space: AB-C \& Measured Results: April 2007 237

Figure 5.37 - Test Cell 3 Roof Space: AB-C \& Measured Results: May 2007 238

Figure 5.38 - Test Cell 3 Roof Space: AB-C \& Measured Results: June 2007. 239

Figure 5.39 - Test Cell 3 Room: AB-C \& Measured Results: February 2007. 240

Figure 5.40 - Test Cell 3 Room: AB-C \& Measured Results: April 2007. 240

Figure 5.41 - Test Cell 3 Room: AB-C \& Measured Results: May 2007 241

Figure 5.42 - Test Cell 3 Room: AB-C \& Measured Results: June 2007. 241

Figure 5.43 - TC1 Subfloor Measured v Simulated: January to June $2007(r=0.97) \ldots \ldots . .246$

Figure 5.44 - TC1 Subfloor Measured v Simulated: March/April $2007(r=0.96)$................. 246

Figure 5.45 - TC1 Room Measured v Simulated: January to June $2007(r=0.97)$ 246 
Figure 5.46 - TC1 Room Measured v Simulated: March/April $2007(r=0.96)$.................... 246

Figure 5.47 - TC1 Roof Measured v Simulated: January to June $2007(r=0.99) \ldots \ldots \ldots \ldots . . . .246$

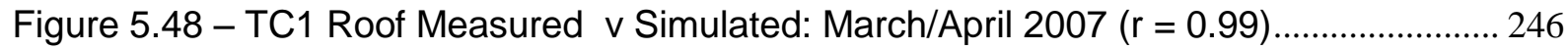

Figure 5.49 - TC2 Subfloor Measured v Simulated: March to June $2007(r=0.96) \ldots \ldots . . . . . .248$

Figure 5.50 - TC2 Subfloor Measured v Simulated: April $2007(r=0.85)$............................. 248

Figure 5.51 - TC2 Room Measured v Simulated: January to June $2007(r=0.98) \ldots \ldots \ldots . . .249$

Figure 5.52 - TC2 Room Measured v Simulated: March/April 2007 ( $r=0.93)$..................... 249

Figure 5.53 - TC2 Roof Measured v Simulated: March to June $2007(r=0.97) \ldots \ldots . . . . . . . . . . . .249$

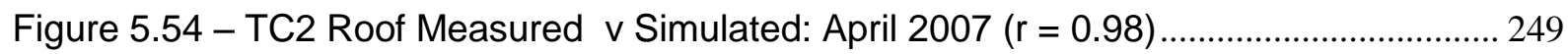

Figure 5.55 - TC3 Room Measured v Simulated: January to June $2007(r=0.99) \ldots \ldots \ldots . . . .251$

Figure 5.56 - TC3 Room Measured v Simulated: March/April 2007 ( $r=0.98)$..................... 251

Figure 5.57 - TC3 Roof Measured v Simulated: January to June $2007(r=0.97) \ldots \ldots \ldots \ldots . . . .252$

Figure 5.58 - TC3 Roof Measured v Simulated: March/April $2007(r=0.97)$....................... 252

Figure 5.59 - TC1 Subfloor Residual January to June 2007 ................................................... 254

Figure 5.60 - TC1 Subfloor Residual January 2007 ................................................................. 254

Figure 5.61 - TC1 Room Residual January to June 2007 .................................................... 254

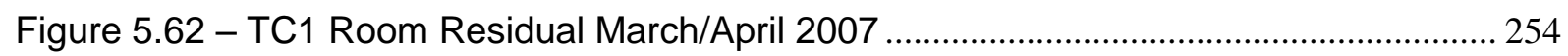

Figure 5.63 - TC1 Roof Space Residual January to June 2007 ….......................................... 255

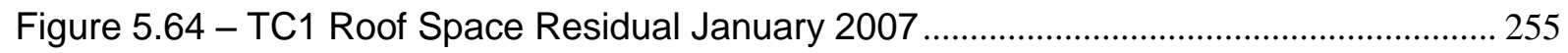

Figure 5.65 - TC2 Subfloor Residual March to June 2007 .................................................... 256

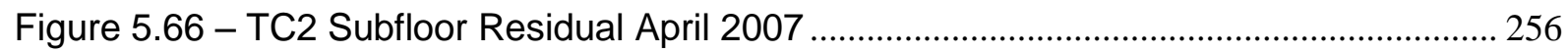

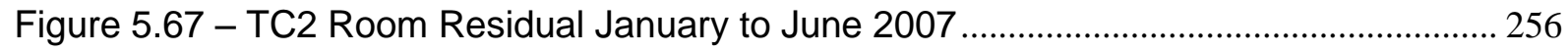

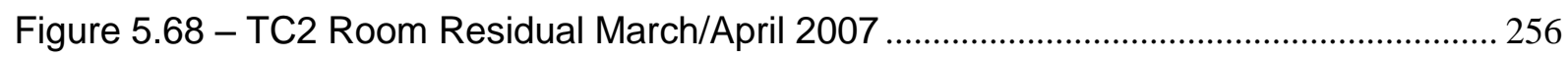

Figure 5.69 - TC2 Roof Space Residual March to June 2007 ............................................... 257

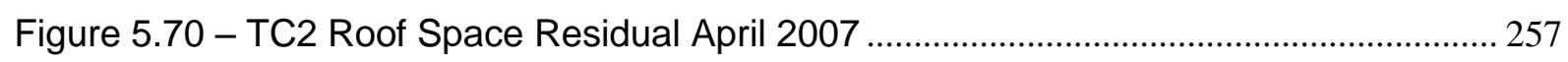

Figure 5.71 - TC3 Room Residual January to June 2007 ...................................................... 258

Figure 5.72 - TC3 Room Residual March/April 2007 .............................................................. 258

Figure 5.73 - TC3 Roof Space Residual January to June 2007 …........................................ 258

Figure 5.74 - TC3 Roof Space Residual March/April 2007 .................................................. 258

Figure 5.75 - TC1 Subfloor Residual Time Series Plot January to June 2007 ...................... 260

Figure 5.76 - TC1 Room Residual Time Series Plot January to June 2007.......................... 260

Figure 5.77 - TC1 Roof Space Residual Time Series Plot January to June 2007 ................ 261

Figure 5.78 - TC2 Subfloor Residual Time Series Plot March to June 2007 ......................... 262

Figure 5.79 - TC2 Room Residual Time Series Plot January to June 2007........................... 262

Figure 5.80 - TC2 Roof Space Residual Time Series Plot March to June 2007 ................... 263

Figure 5.81 - TC3 Room Residual Time Series Plot January to June 2007........................... 264 
Figure 5.82 - TC3 Roof Space Residual Time Series Plot January to June 2007 264

Figure 5.83 - TC1 Room \& Subfloor Residual Correlation: January to June 2007 ( $r=0.68) 267$

Figure 5.84 - TC1 Room \& Subfloor Residual Correlation: March/April 2007 ( $r=0.71)$....... 267

Figure 5.85 - TC1 Room \& Roof Space Residual Correlation: January to June 2007 ( $r=$

$0.77)$

Figure 5.86 - TC1 Room \& Roof Space Residual Correlation: March/April $2007(r=0.78) 267$

Figure 5.87 - TC2 Room \& Subfloor Residual Correlation: March to June $2007(r=0.85) .268$

Figure 5.88 - TC2 Room \& Subfloor Residual Correlation: April $2007(r=0.88)$ 268

Figure 5.89 - TC2 Room \& Roof Space Residual Correlation: March to June 2007 ( $r=0.37)$

Figure 5.90 - TC2 Room \& Roof Space Residual Correlation: April 2007 ( $r=0.50)$

Figure 5.91 - TC3 Room \& Roof space Residual Correlation: January to June 2007 ( $r=0.42)$

Figure 5.92 - TC3 Room \& Roof space Residual Correlation: March/April $2007(r=0.64)$. 270

Figure 5.93 - TC1 Subfloor Residual \& Air Temperature Correlation: January to June 2007 $(r=-0.52)$

Figure 5.94 - TC1 Subfloor Residual \& Air Temperature Correlation: March/April 2007 ( $r=-$

Figure 5.95 - TC2 Subfloor Residual \& Air Temperature Correlation: March to June 2007 ( $r$ = -0.47)

Figure 5.96 - TC2 Subfloor Residual \& Air Temperature Correlation: April $2007(r=-0.76) 272$ Figure 5.97 - TC1 Room Residual \& Air Temperature Correlation: January to June 2007 ( $r=$ $-0.59)$

Figure 5.98 - TC1 Room Residual \& Air Temperature Correlation: March/April 2007 ( $r=-$ 0.83)

Figure 5.99 - TC2 Room Residual \& Air Temperature Correlation: January to June 2007 ( $r$ = $-0.27)$

Figure 5.100 - TC2 Room Residual \& Air Temperature Correlation: March/April 2007 ( $r$ = -

Figure 5.101 - TC3 Room Residual \& Air Temperature Correlation: January to June 2007 (r $=0.33$ )

Figure 5.102 - TC3 Room Residual \& Air Temperature Correlation: March/April 2007 (r = 0.37)

Figure 5.103 - TC1 Roof Space Residual \& Air Temperature Correlation: January to June ( $r$ $=-0.46)$ 
Figure 5.104 - TC1 Roof Space Residual \& Air Temperature Correlation: March/April 2007 $(r=-0.66)$

Figure 5.105 - TC2 Roof Space Residual \& Air Temperature Correlation: March to June $2007(r=-0.72)$

Figure 5.106 - TC2 Roof Space Residual \& Air Temperature Correlation: April 2007 ( $r=-$ $0.76)$

Figure 5.107 - TC3 Roof Space Residual \& Air Temperature Correlation: January to June $2007(r=-0.50)$.

Figure 5.108 - TC3 Roof Space Residual \& Air Temperature Correlation: March/April 2007 ( $r$ $=-0.77)$.

Figure 5.109 - TC1 Subfloor Residual \& Wind Speed Correlation: January to June 2007 ( $\mathrm{r}=$ $0.17)$

Figure 5.110 - TC1 Roof Space Residual \& Wind Speed Correlation: January to June 2007 $(r=-0.31)$ 281

Figure 5.111 - TC1 Room Residual \& Wind Speed Correlation: January to June 2007 ( $r=-$ $0.40)$ 282

Figure 5.112 - TC1 Room Residual \& Wind Speed Correlation: May 2007 ( $r=-0.43) \ldots \ldots . . .282$ Figure 5.113 - TC2 Subfloor Residual \& Wind Speed Correlation: March to June 2007 ( $r$ = $0.31)$ 283

Figure 5.114 - TC2 Roof Space Residual \& Wind Speed Correlation: March to June 2007 (r $=-0.42)$.

Figure 5.115 - TC2 Room Residual \& Wind Speed Correlation: January to June 2007 ( $r=-$

Figure 5.116 - TC2 Room Residual \& Wind Speed Correlation: May $2007(r=-0.40)$.. 283 Figure 5.117 - TC3 Room Residual \& Wind Speed Correlation: January to June 2007 ( $r=-$ 0.06)

Figure 5.118 - TC3 Roof Space Residual \& Wind Speed Correlation: January to June 2007 $(r=-0.40)$ 285

Figure 5.119 - TC3 Room Residual \& Wind Speed Correlation: February $2007(r=-0.26) 285$ Figure 5.120 - TC3 Room Residual \& Wind Speed Correlation: May 2007 ( $r=-0.18) \ldots \ldots . . .285$ Figure 5.121 - TC3 Room Residual \& Wind Speed Correlation: June $2007(r=-0.21)$....... 285 Figure 5.122 - TC1 Subfloor Residual \& Wind Direction Correlation: January to June 2007 288

Figure 5.123 - TC1 Room \& Wind Direction Correlation: January to June 2007 288 Figure 5.124 - TC1 Roof Space Residual \& Wind Direction Correlation: January to June 2007 288 
Figure 5.125 - TC2 Subfloor Residual \& Wind Direction Correlation: January to June 2007

Figure 5.126 - TC2 Roof Space Residual \& Wind Direction Correlation: March to June 2007

Figure 5.127 - TC2 Room Residual \& Wind Direction Correlation: January to June 2007 .. 290

Figure 5.128 - TC3 Room Residual \& Wind Direction Correlation: January to June 2007 .. 292

Figure 5.129 - TC3 Roof Space Residual \& Wind Direction Correlation: January to June 2007

Figure 5.130 - TC1 Subfloor Residual \& Global Solar Radiation Correlation: January to June 2007

Figure 5.131 - TC1 Subfloor Residual \& Global Solar Radiation Correlation: March/April 2007

Figure 5.132 - TC1 Room Residual \& Global Solar Radiation Correlation: January to June 2007

Figure 5.133 - TC1 Room Residual \& Global Solar Radiation Correlation: May 2007

Figure 5.134 - TC1 Roof Space Residual \& Global Solar Radiation Correlation: January to June 2007

Figure 5.135 - TC1 Roof Space Residual \& Global Solar Radiation Correlation: March/April 2007

Figure 5.136 - TC2 Subfloor Residual \& Global Solar Radiation Correlation: March to June 2007

Figure 5.137 - TC2 Room Residual \& Global Solar Radiation Correlation: January to June 2007

Figure 5.138 - TC2 Roof Space Residual \& Global Solar Radiation Correlation: March to June 2007

Figure 5.139 - TC2 Roof Space Residual \& Global Solar Radiation Correlation: April 2007

Figure 5.140 - TC3 Room Residual \& Global Solar Radiation Correlation: January to June 2007

Figure 5.141 - TC3 Room Residual \& Global Solar Radiation Correlation: February 2007. 298 Figure 5.142 - TC3 Room Residual \& Global Solar Radiation Correlation: March/April 2007

Figure 5.143 - TC3 Room Residual \& Global Solar Radiation Correlation: June 2007.

Figure 5.144 - TC3 Roof Space Residual \& Global Solar Radiation Correlation: January to June 2007 
Figure 5.145 - TC3 Roof Space Residual \& Global Solar Radiation Correlation: March/April 2007

Figure 5.146 - TC1 Subfloor Residual v Diffuse Solar Radiation January to June 2007 ..... 302

Figure 5.147 - TC1 Subfloor Residual v Diffuse Solar Radiation March/April 2007 .............. 302

Figure 5.148 - TC1 Room Residual v Diffuse Solar Radiation January to June 2007 .......... 303

Figure 5.149 - TC1 Room Residual v Diffuse Solar Radiation March/April 2007 ................. 303

Figure 5.150 - TC1 Roof Space Residual v Diffuse Solar Radiation January to June 2007303

Figure 5.151 - TC1 Roof Space Residual v Diffuse Solar Radiation March/April 2007........ 303

Figure 5.152 - TC2 Subfloor Residual v Diffuse Solar Radiation March to June 2007......... 304

Figure 5.153 - TC2 Room Residual v Diffuse Solar Radiation January to June 2007 .......... 304

Figure 5.154 - TC2 Subfloor Residual v Diffuse Solar Radiation March 2007 ....................... 305

Figure 5.155 - TC2 Room Residual v Diffuse Solar Radiation March/April 2007 .................. 305

Figure 5.156 - TC2 Roof Space Residual v Diffuse Solar Radiation March to June 2007... 305

Figure 5.157 - TC2 Roof Space Residual v Diffuse Solar Radiation March 2007 ................. 305

Figure 5.158 - TC3 Room Residual v Diffuse Solar Radiation January to June 2007 .......... 306

Figure 5.159 - TC3 Room Residual v Diffuse Solar Radiation March/April 2007 .................. 306

Figure 5.160 - TC3 Roof Space Residual v Diffuse Solar Radiation January to June 2007307

Figure 5.161 - TC3 Roof Space Residual v Diffuse Solar Radiation March/April 2007 ........ 307

Figure 6.1 - Ranking of Areas for Future Research ............................................................... 321 


\section{List of Acronyms}

$\begin{array}{ll}\text { ABCB } & \text { Australian Building Codes Board } \\ \text { AGO } & \text { Australian Greenhouse Office } \\ \text { BCA } & \text { Building Code of Australia } \\ \text { BESTEST } & \text { Building Energy Simulation Test } \\ \text { BOM } & \text { Bureau of Meteorology, Australia }\end{array}$

CSIRO Commonwealth Scientific and Industrial Research Organisation

COAG Council of Australian Governments

DCC Department of Climate Change

DCCEE Department of Climate Change and Energy Efficiency

DEWHA Department of Environment, Water, Heritage and the Arts

DSP Detailed Simulation Program

HER House Energy Rating

IEA International Energy Agency

NatHERS National House Energy Rating Scheme

PASLink Passive Solar Systems Research Network (now known as Dynastee)

PASSYS Passive Solar Systems

TMY Typical Meteorological Year 



\section{Introduction}

This dissertation is concerned with the capability of Australia's prescribed house energy rating software, AccuRate, to predict zone temperatures.

The house is the principal place of dwelling for most forms of human settlement. In Australia, human settlements exist in hot humid, hot dry, temperate and cool temperate climates. The dwellings in these climates have required the use of artificial forms of heating and/ or cooling to create thermally comfortable internal environments. As the general wealth of Australians has increased, so has the amount of income spent on improving the internal environment of their homes. This has included the capacity to condition an entire home instead of just a single room. The increase in energy consumption has created a commensurate increase in greenhouse gas emissions. Until the recent past, anthropogenic greenhouse gas emissions have been of little concern to most Australians, or indeed, the government.

Internationally, over the past five decades, there has been a growing awareness of the occurrence of climate change, more specifically referred to as 'global warming'. There is now widespread acceptance that climate change is caused by human activities, leading to increasing quantities of greenhouse gases in the atmosphere. In response to international concern, many nations have put in place measures to reduce and limit the growth of activities which emit excessive greenhouse gases (Olesen 2007). Within Australia, reports from federal agencies and the Commonwealth Scientific and Industrial Research Organisation (CSIRO) have identified causes of greenhouse gas emissions and the likely economic effects of national and international actions to reduce them.

The Australian government's National Greenhouse Strategy established for the first time, a range of measures to account for and limit future greenhouse gas emissions (AGO 1998). This included the objective that all buildings should be improved to reduce the energy required in the operation of cooling or heating equipment to make buildings thermally comfortable. In 1990, 43\% of Australian residential energy was consumed for space heating and/or cooling and this portion had increased to $51.4 \%$ by 2007 , with an increasing percentage from electricity provided by coal-fired power stations (DEWHA 2008). In the cool temperate climates of Victoria and Tasmania residential buildings consume 66\% of Australia's space heating energy. It is expected that by 2020, with the ever-increasing desire for greater human 
comfort and the effect of climate change, that energy use for space heating and cooling in Australian homes will increase from the 2007 value of 161.4 to 191.6 peta-joules by 2020 .

In this context, in 2003, the Building Code of Australia (BCA) introduced its first thermal performance requirements for residential buildings. It mandated a minimum performance rating of 4 Stars when assessed by approved rating methods. This requirement has been progressively increased to 5 Stars in 2006 and 6 Stars in 2010. While the introduction of a 4 Stars requirement had only a minor impact on construction practices, the move from 4 to 5 and 6 Stars has forced considerable changes, especially to the use of timber platform floors in cool temperate climates.

The Australian domestic building sector was worth approximately \$38 billion in 2006 (Australian Bureau of Statistics 2007). The representatives of the construction industry were generally supportive of the energy efficiency requirements, but were concerned about possible problems in the methods employed to measure the thermal performance of building designs. Changes to building regulations could have a significant impact on the selection and use of particular construction options. Consequently, they could also have significant economic impacts on building companies or materials' manufacturers' viability. While the introduction of a 4 Star thermal performance requirement in 2003 appeared to have a relatively minor impact on construction practices and building material companies, the move to the 5 Star and 6 Star requirements resulted in changes in material selection and building practices (ABCB 2003b, 2006a, 2007, 2010; Marceau et al. 1999).

In response to these changes, various industry groups raised several concerns about the energy efficiency requirements, including: industry educational needs, material availability, technical support and the House Energy Rating (HER) software's validity. The concerns regarding software validity included its capacity to accurately predict room temperatures and whether the software unfairly disadvantages one building type over another. The star-rating calculation method relies on the estimated energy used to heat or cool a conditioned room. The amount of energy is relative to the difference between a human comfort bandwidth and a predicted room temperature. If the software under or over predicts a room temperature consistently and significantly, the star-rating would not reflect the actual thermal performance and as such would be considered unreliable and therefore invalid as a tool for modelling building thermal performance. 
Australian residential construction comprises primarily lightweight detached housing with three principal types of construction: unenclosed-perimeter platform-floored buildings, enclosed-perimeter platform-floored buildings and concrete slab-on-ground floored buildings. Each of these construction types has differing insulation, infiltration and thermal capacitance properties, dependent on structural, cladding and lining systems (Coldicutt et al. 1978). Therefore, if the software's capacity to model the building types is inconsistent, it would favour one type over another. This would provide incorrect advice to designers, builders and regulators, with regard to the thermal effectiveness of a house's constructional variations, resulting in misguided building practices. The effect of building typology errors would have a direct economic impact on the material manufacturers. Aside from testing the software's capability to model current building materials, the industry groups would like to confirm that the software could be easily modified to include future methods that may be shown to economically improve the thermal performance of particular construction types.

In Australia, the benchmark software is the CSIRO-developed AccuRate HER program. This means that other HER softwares are required to have a similar output to the AccuRate software, and the second generation of the NatHERS administration protocol required that all Australian softwares incorporate the AccuRate thermal simulation engine within their software. Although other softwares had a different front end data entry, they are required to use the same thermal simulation engine and software specific outputs. If there were errors in the AccuRate thermal simulation software, all the other softwares would be equally affected.

As a result of these concerns, some state governments deferred the adoption of the 5 Star requirements. In consultation with a mix of manufacturers, industry representative bodies, state government regulators, the CSIRO and Federal government agencies, it was acknowledged that the AccuRate software should be validated at this early stage of energy efficiency regulation within Australia. The validation would inform industry and government of the capacity of the software to predict a room temperature accurately and guide software developers on specific aspects of the software that may require improvement. 


\section{The aim of this research was to validate empirically the AccuRate house energy rating software for lightweight buildings in a cool temperate climate.}

As this task has not been undertaken previously in Australia, it represents a gap in our knowledge. The research suggested four key hypotheses:

1. The predicted temperature produced by a detailed thermal simulation, using the AccuRate software, is not identical to the observed temperature within a lightweight detached building located in a cool temperate climate.

2. The external environmental inputs representing climate are not appropriately accounted for by the AccuRate software.

3. The effect of infiltration through the built fabric and its relationship to the external climate are not appropriately accounted for by the AccuRate software (climate and infiltration).

4. Some elements of the built fabric of contemporary lightweight detached housing are not accounted for by the AccuRate software.

To test these hypotheses, a suitable type and method of validation for the AccuRate software was established. A building was constructed to the prevalent Australian practices for lightweight detached housing and required detailed environmental measurement and thermal simulation. From this research platform, two forms of data were obtainable: the observed and simulated thermal performance of the building. The two data sets were to be analysed to:

1. establish if the observed and simulated data sets were similar;

2. establish any correlation between external environmental influences and the differences between observed and calculated temperatures;

3. establish any correlation between observed infiltration values and the differences between observed and calculated temperatures; and

4. establish any correlation between built fabric and the differences between observed and calculated temperatures. 
Several tasks were completed in a logical order to answer these questions. The first stage of the research, as discussed in Chapter 2, was to establish the purpose and reason for the building thermal performance regulations within Australia. As strong research linkages were established with the CSIRO, Chapter 3 discusses the history and relevance of house energy rating software validation activities within Australia and internationally.

The second stage was to establish methods and systems to validate empirically the AccuRate software. This is provided by a general overview of the methodology in Chapter 4.1. This is followed by the details of each stage of the research where:

- Chapter 4.2 addresses the design and construction of the buildings

- Chapter 4.3 addresses the design and installation of the equipment to measure the internal and external environment of the buildings. This section also discusses the methods used for data acquisition and storage, and the processes used for data cleaning.

- Chapter 4.4 addresses the tasks undertaken to perform the detailed thermal simulation of the buildings with the AccuRate software.

These activities provided several data sets, with the final detailed thermal simulation providing a data set for comparison with the measured temperatures within the test buildings. Chapter 4.5 addresses the graphical and statistical methods that were established to analyse the two data sets the measured and simulated data sets. The results of the graphical comparison and statistical analysis of the simulated and observed data are presented and discussed in Chapter 5.

The conclusions and areas of future research identified in this study are discussed in Chapter 6. Extensive relevant documentation was required to undertake and complete this research. This is found in the Appendix contained in the accompanying compact disc. The Appendix includes architectural drawings of the three test buildings, construction and instrumentation journals, AccuRate software input files and the full set of graphical and statistical analysis tables that were completed. 


\section{Background to Australian House Energy Rating}

This chapter discusses the context of space heating and its associated energy use in Australian residential buildings. The use of heating is then considered in the context of Australian greenhouse gas emissions and the recent acceptance of the need to stabilise and then reduce emissions. To achieve a reduction in residential greenhouse gas emissions, a range of measures have been developed by industry and government. One of these measures to reduce the energy for heating and cooling due to poor building envelope designs was to introduce residential house energy star-ratings for new Australian housing (Delsante 1996). A number of industry groups raised concerns with regard to the effectiveness and capabilities of the HER star-rating softwares. These are discussed in Chapter 2, Chapter 3 then discusses the history and complexities of house energy rating software validation.

\subsection{Historical \& Human Perspective}

Even before the first built shelters, humans utilised elements to improve thermal comfort. As the first shelters evolved, the hearth was used to both cook and provide warmth (Figure 2.1). In warmer climates dwellings provided shade and ventilation, whilst in cooler climates shelters became more structured and enclosed. In the cooler climates the evolution of the house included the desire to keep the cold out and the warmth in. As these built structures grew to two or more rooms, the number of heating sources increased accordingly.

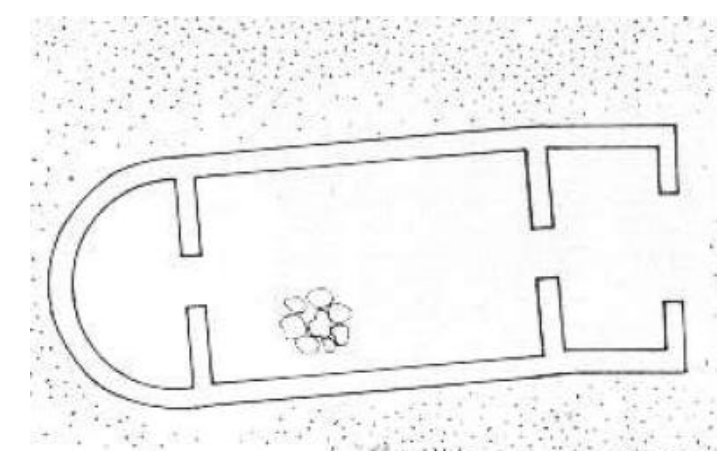

Figure 2.1 - Dwelling with hearth $\sim 1,500$ BC

(Kostof 1995, p. 99)

When Europeans settled in Australia, it was not uncommon for each room of the house to have an open fireplace (Figure 2.2). For households on a wood budget, the family would gather around the combustion stove in the kitchen, which also provided a place for cooking 
and provided hot water. For wealthier households, friends and family would gather around the much less efficient but physiologically and psychologically appealing, large open fire. In the $20^{\text {th }}$ century when wood became scarcer in urban environments, other alternatives for heating were explored including: coal, petrochemical, gas and electrical. However in both urban and non-urban locations the fireplace prevailed (Figure 2.3).

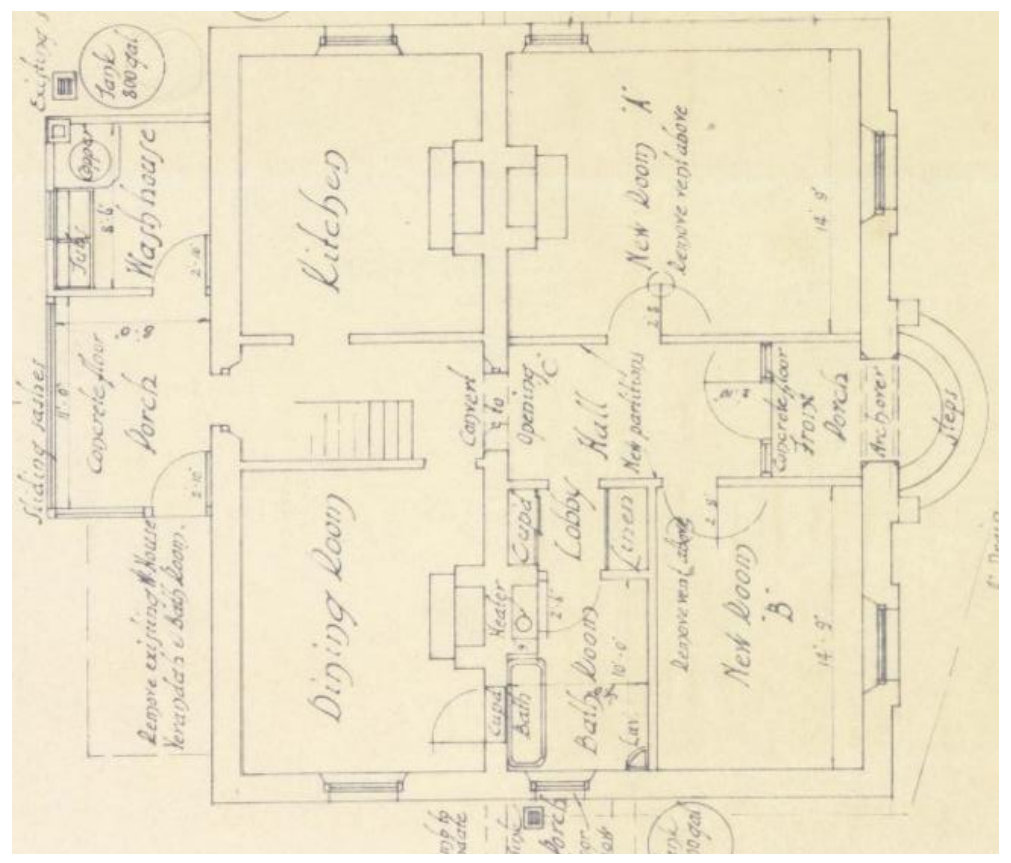

Figure 2.2 - School Building \& Dwelling with hearth in each room, mid-1800s Tasmania.

(Department of Public Works 1850)

As Australian residential development evolved in the twentieth century, society was moving from a principally agrarian type, where the house was used throughout the day, to a society of commuting workers. This had many impacts on the use of the home. In the agrarian model, all meals were usually prepared and eaten in the house. The house was regularly opened up for ventilation and windows, doors and blinds were used to assist in the control of heat gain or heat loss. These houses often had small windows, as the house was seen as a refuge from the outdoors (Tawa 1988). As more people became commuters to the interiors of other buildings, the desire to have a more transparent relationship between the house and the outdoors increased (Mithraratne 2007; Tawa 1988). To allow for the experience of the outdoors, there was an increase in the area of glazing and doors and a resultant decrease in wall area. Even an uninsulated wall had a better insulation value than a single glazed leaky door or window. 
Depending on climatic region, this reduction in the insulation qualities of the built fabric resulted in an increased requirement for heating and/ or cooling, to maintain human comfort. This change in house type and occupant wealth also created a change in heating patterns, where the heating or cooling of the entire house instead of a single room became more common (Hastings \& Wall 2007).

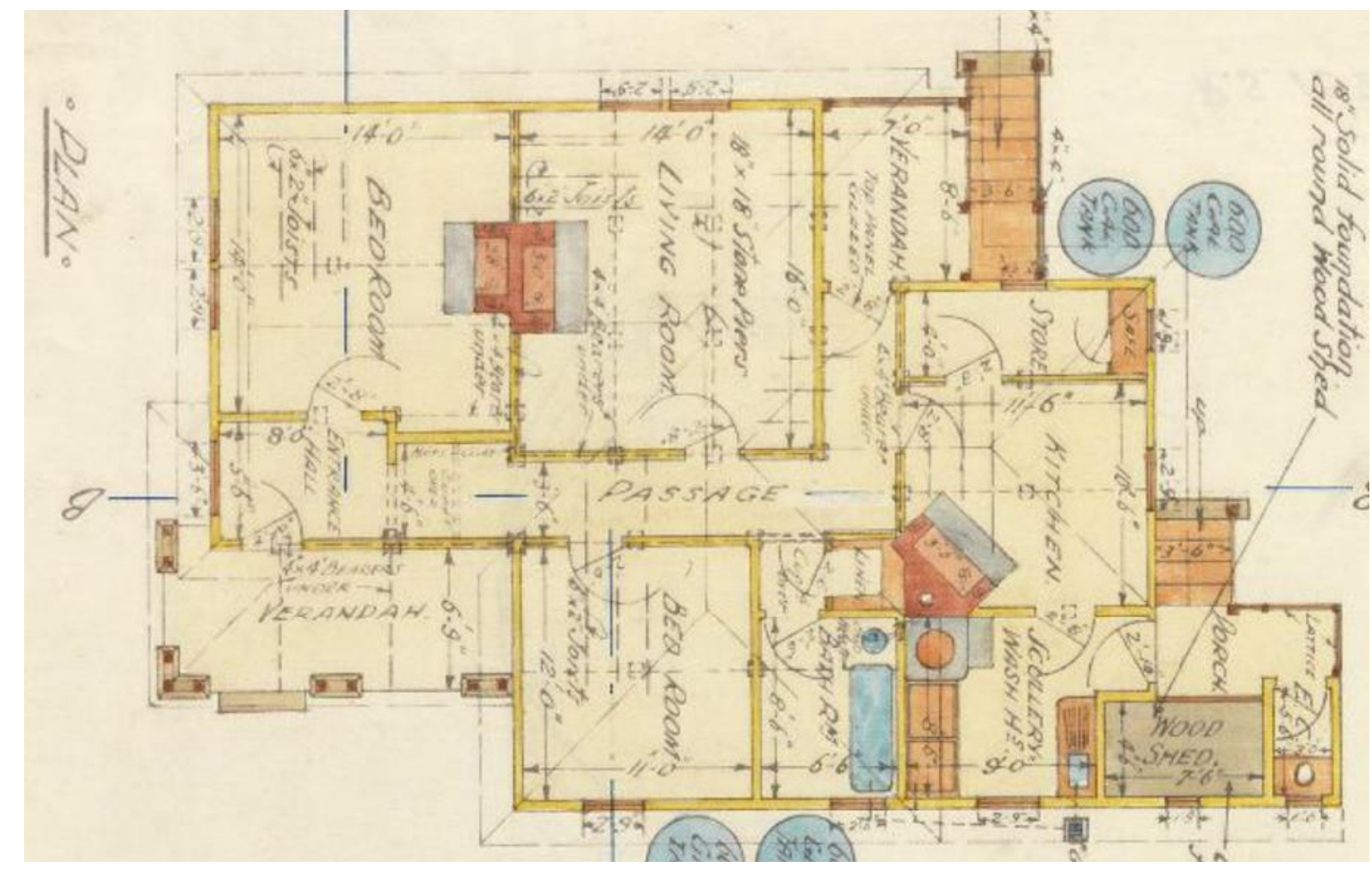

Figure 2.3 - Dwelling with hearth in each room, 1926 Tasmania

(Department of Public Works 1926)

In a medium-to-large sized town, like Launceston (Tasmania), residents might have had access to coal-based town gas and if the house was near a pipeline, gas was available for cooking, heating and lighting. The household wood budget migrated to gas. As the gas heater was placed in a more enclosed room, there was less heat loss, but health issues with regard to air quality and moisture became apparent, and are still present today in some low-income housing (enHealth 2007).

The advent of grid-supplied electricity and the kerosene heater introduced the principle of portable heating. The dirty fireplace was removed and the heater was moved from room to room, depending on household budget. As electricity became more accessible, the 
development of portable electric heating became increasingly attractive, as it involved less fuel fetching and associated cleaning. Launceston (Tasmania) had hydro power available in 1895. The use of the clean and portable electric heating became more common but was still more expensive than wood or coal. Due to the cost difference between firewood and electricity, there was and still is, a significant reliance on wood-based heating in many parts of cool temperate Australia, which included 34.5\% of Tasmania's residential heating requirement in 2007 (DEWHA 2008).

At the time of establishing benchmark values for greenhouse gas emissions, (from 1990 to 1998), $21 \%$ of space heating was provided by wood fuels. For most of Australia, with the exception of Tasmania, electricity was used to provide the majority of space heating and cooling requirements (DEWHA 2008). For Tasmania, the majority of non-wood-based space heating and space cooling was provided by portable electrical appliances (AGO 1999). The recent advances in personal wealth and residential "heat pump" technology has allowed for a cleaner alternative to the open fire, but with a corresponding increase in electricity consumption. Despite house improvements, (including the installation of insulation) more energy was being used to make the entire house comfortable (AGO 1999). The method of building houses had not changed for some time in Australia. The most visible change was a gradual shift from timber to brick veneer cladding. Most jurisdictions in 2002 had a minimal or nil requirement for the installation of subfloor, wall or ceiling insulation in new homes (ABCB 2002). For Tasmania, as in many other Australian states, new personal wealth was used to make houses larger, rather than better insulated, as shown in Table 2.1 and Table 2.2.

Table 2.1: Wall Thermal Resistance Values for Tasmanian Housing 1926 \& 2002

$\begin{gathered}1926 \text { Tasmanian House } \\
\text { (Figure 2.3) }\end{gathered}$
\begin{tabular}{|l|c|}
\hline \multicolumn{1}{|c|}{ Material } & R Value \\
\hline OS Surface & 0.03 \\
\hline 25 Weatherboard & 0.16 \\
\hline 100 Stud/Air Space & 0.13 \\
\hline 25 Plaster & 0.02 \\
\hline IS Surface & 0.12 \\
\hline & \\
\hline Total R & 0.46 \\
\hline
\end{tabular}

2002 Tasmanian House
(ABCB 2002)
\begin{tabular}{|l|c|}
\hline \multicolumn{1}{|c|}{ Material } & R Value \\
\hline OS Surface & 0.03 \\
\hline 110 Clay Brick & 0.18 \\
\hline 40 Cavity & 0.13 \\
\hline 90 Stud/Air Space & 0.13 \\
\hline 10 Plasterboard & 0.06 \\
\hline IS Surface & 0.12 \\
\hline Total R & 0.65 \\
\hline
\end{tabular}


Table 2.2: Ceiling thermal resistance Values for Tasmanian Housing 1926 \& 2002

\begin{tabular}{|c|c|c|c|}
\hline \multicolumn{2}{|c|}{$\begin{array}{c}1926 \text { Tasmanian House } \\
\text { (Figure 2.3) }\end{array}$} & \multicolumn{2}{|c|}{$\begin{array}{l}2002 \text { Tasmanian House } \\
\text { (ABCB 2002) }\end{array}$} \\
\hline Material & R Value & Material & R Value \\
\hline OS Surface & 0.03 & OS Surface & 0.03 \\
\hline 25 Plaster & 0.02 & 10 Plasterboard & 0.06 \\
\hline IS Surface & 0.12 & IS Surface & 0.12 \\
\hline Total R & 0.17 & Total R & 0.21 \\
\hline
\end{tabular}

There is evidence of new Tasmanian homes, (even in 2010), having internal temperatures similar to those of the outdoor environment in both summer and winter (Dewsbury 20052010). Regardless of the approach adopted, depending on financial capability, the householder was heating a room or the whole house for their comfort. As the general wealth of Australians has grown, houses that were uncomfortable by design became comfortable through the use of artificial heating and cooling. In Tasmania, 50\% of residential energy was used for space heating, as in Table 2.4 (AURORA 2006; Pearman 1987). The Australian Greenhouse Office report in 2008 (DEWHA 2008), documented that $43 \%$ of national household energy use in 1990 was for space heating or cooling (Table 2.3).

Table 2.3: Breakdown of residential energy end uses - 1990 Australia.

\begin{tabular}{|c|c|c|}
\hline Purpose & Fuel Source & Percentage \\
\hline \multirow{3}{*}{ Space Heating } & Electrical & $4 \%$ \\
\cline { 2 - 3 } & Wood & $21 \%$ \\
\cline { 2 - 3 } & LPG & $1 \%$ \\
\cline { 2 - 3 } & Mains gas & $16 \%$ \\
\hline Space Cooling & Electrical & $1 \%$ \\
\hline \multirow{3}{*}{ Water Heating } & LPG & $1 \%$ \\
\cline { 2 - 3 } & Mains gas & $11 \%$ \\
\cline { 2 - 3 } & Electrical & $16 \%$ \\
\hline \multirow{3}{*}{ Cooking } & LPG & $<1 \%$ \\
\cline { 2 - 3 } & Mains gas & $2 \%$ \\
\cline { 2 - 3 } & Electrical & $3 \%$ \\
\hline \multirow{2}{*}{ Appliances } & Mains gas & $<1 \%$ \\
\cline { 2 - 3 } & Electrical & $24 \%$ \\
\hline
\end{tabular}

(DEWHA 2008) 
Table 2.4: End use of residential energy consumption in Australia, 1979-80

\begin{tabular}{lccc}
\hline \multicolumn{1}{c}{ State } & $\begin{array}{c}\text { Space heating } \\
\text { and cooling }\end{array}$ & Water heating & Other \\
\hline Tasmania & $50 \%$ & $30 \%$ & $20 \%$ \\
Victoria & $50 \%$ & $25 \%$ & $25 \%$ \\
South Australia & $35 \%$ & $30 \%$ & $35 \%$ \\
New South Wales & $30 \%$ & $35 \%$ & $35 \%$ \\
Western Australia & $25 \%$ & $35 \%$ & $40 \%$ \\
Queensland & $15 \%$ & $45 \%$ & $40 \%$ \\
\hline Australia & $35 \%$ & $35 \%$ & $30 \%$ \\
\hline
\end{tabular}

(Pearman 1987, p. 603)

The growing use of energy to heat or cool homes had a direct impact on household energy use, energy expenditure and greenhouse gas emissions (Figure $2.4 \&$ Figure 2.5). In an attempt to curb Australia's growing greenhouse gas emissions, regulations were developed to improve the external fabric of buildings with the intention of making buildings more comfortable, while reducing heating and cooling energy and related greenhouse gas emissions (Delsante 1996).

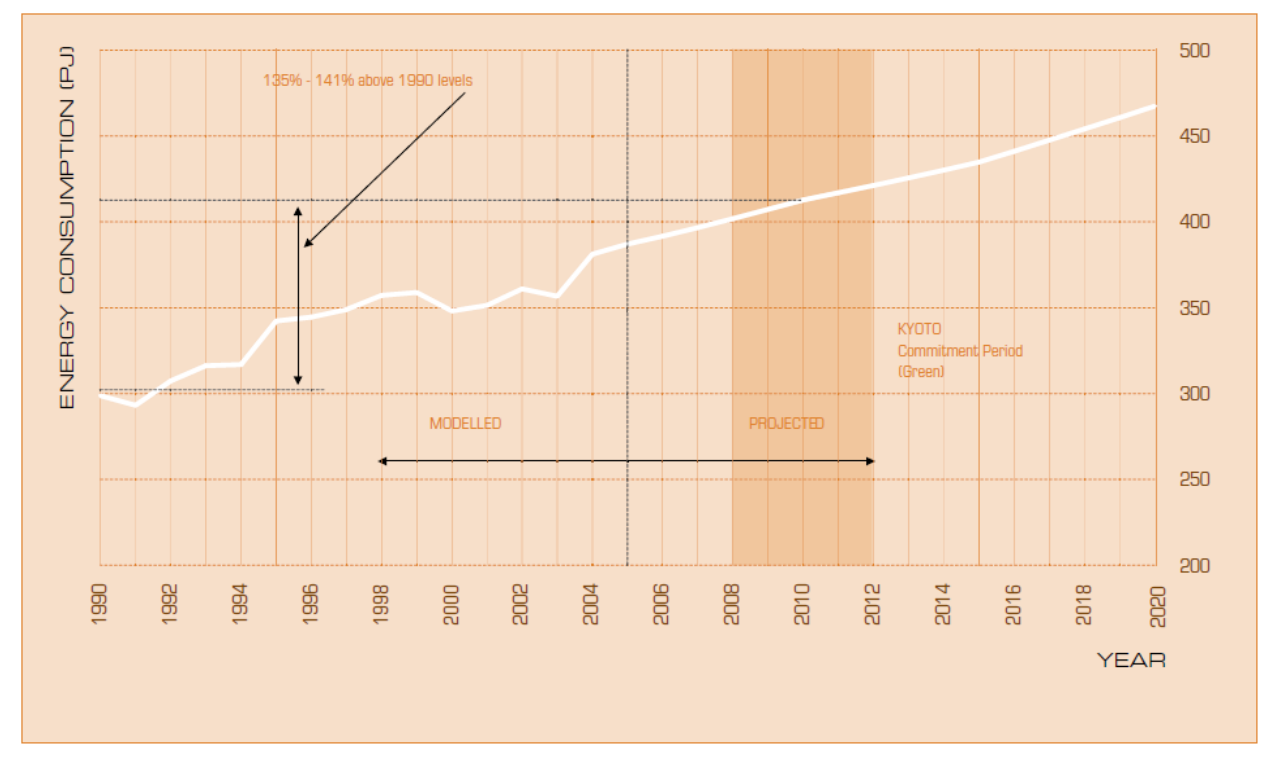

Figure 2.4 - Trends in residential total energy consumption - Australia

(DEWHA 2008, p. 20) 


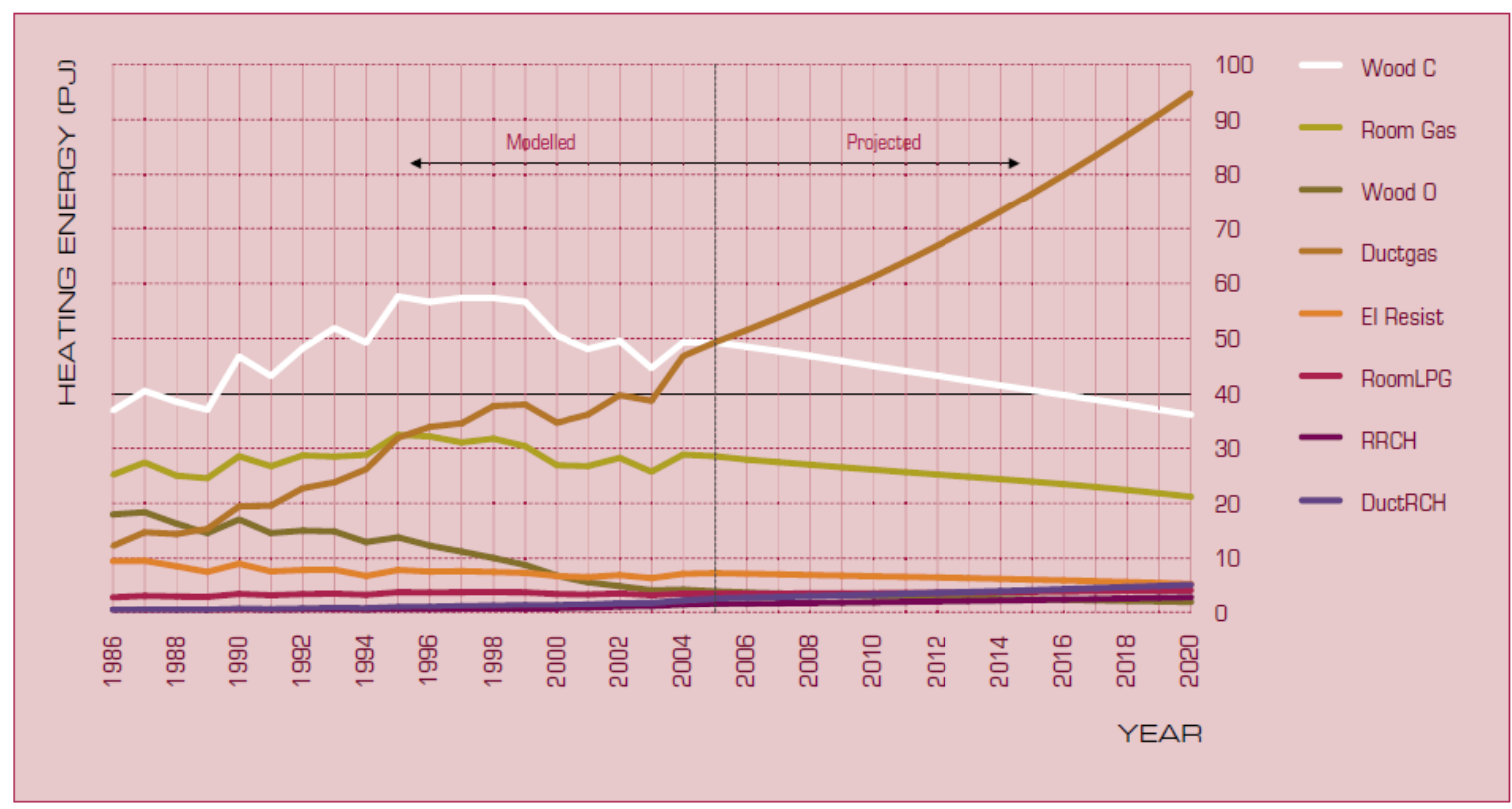

Figure 2.5 - Energy Consumption (PJ) - Space heating in Australia

(DEWHA 2008, p. 50)

\subsection{Climate Change and Global Warming}

Climate change and global warming entered the arena of scientific discussion in the 1960s (O'Brien 1990). Since that time there has been a growing debate for and against the theory of global warming and its relationship to anthropogenic greenhouse gas emissions (Carter \& de Freitas 2007; Demeritt 2010; IPCC 2001, 2007; Watson et al. 2001). The general research community (Camilleri, Jaques \& Isaacs 2001; Flohn 1980; Papanek 1995; Schellnhuber et al. 2006; Stern 2006; White 2004), the United Nations (UNEP 2010) and the World Climate Research Group have documented the likely future effects of unchecked and checked climate change affecting:

- Internally and externally displaced refugees

- Disease

- Food supply

- Water supply

- Species extinctions (flora \& fauna) 
- Sea level change

- Temperature change

- General change in weather patterns

Internationally in the 1980 s, it was agreed that nations should stabilise or reduce their green house gas emissions (Hamilton 2007; Vale \& Vale 1991). To assist this process, each nation established past, current and projected greenhouse gas emissions. The benchmarks for each nation provided an awareness of the sources of greenhouse gas emissions and possible directions for greenhouse gas reduction. At that early stage it was accepted that Australia was reasonably efficient at energy generation but very inefficient in its use of energy (O'Brien 1990) and that Australia was a very high contributor to greenhouse emissions on a per capita basis (Figure 2.6). The Australian government, in response to international pressure, commissioned a range of studies from its federal agencies (Drogemuller et al. 1999; Hamilton 2007; Norton \& Williams 1990). The reports were used to inform the government on possible actions, benefits and threats from climate change, as in Figure 2.7 (AGO 2000b, 2007a; CIE 2007; Energy Partners 2006; Lambeck 2008; O'Brien 1990).

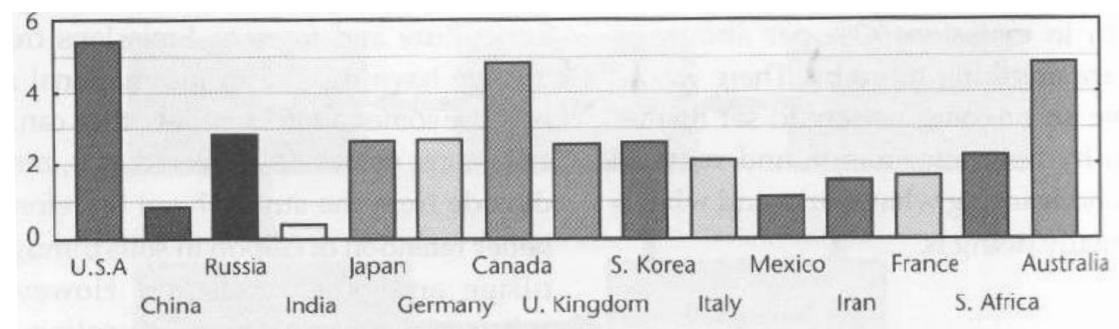

Figure 2.6 - Per capita fossil fuel emissions 2003 - 10kg carbon/year/person.

(Pittock 2009, p. 158) 


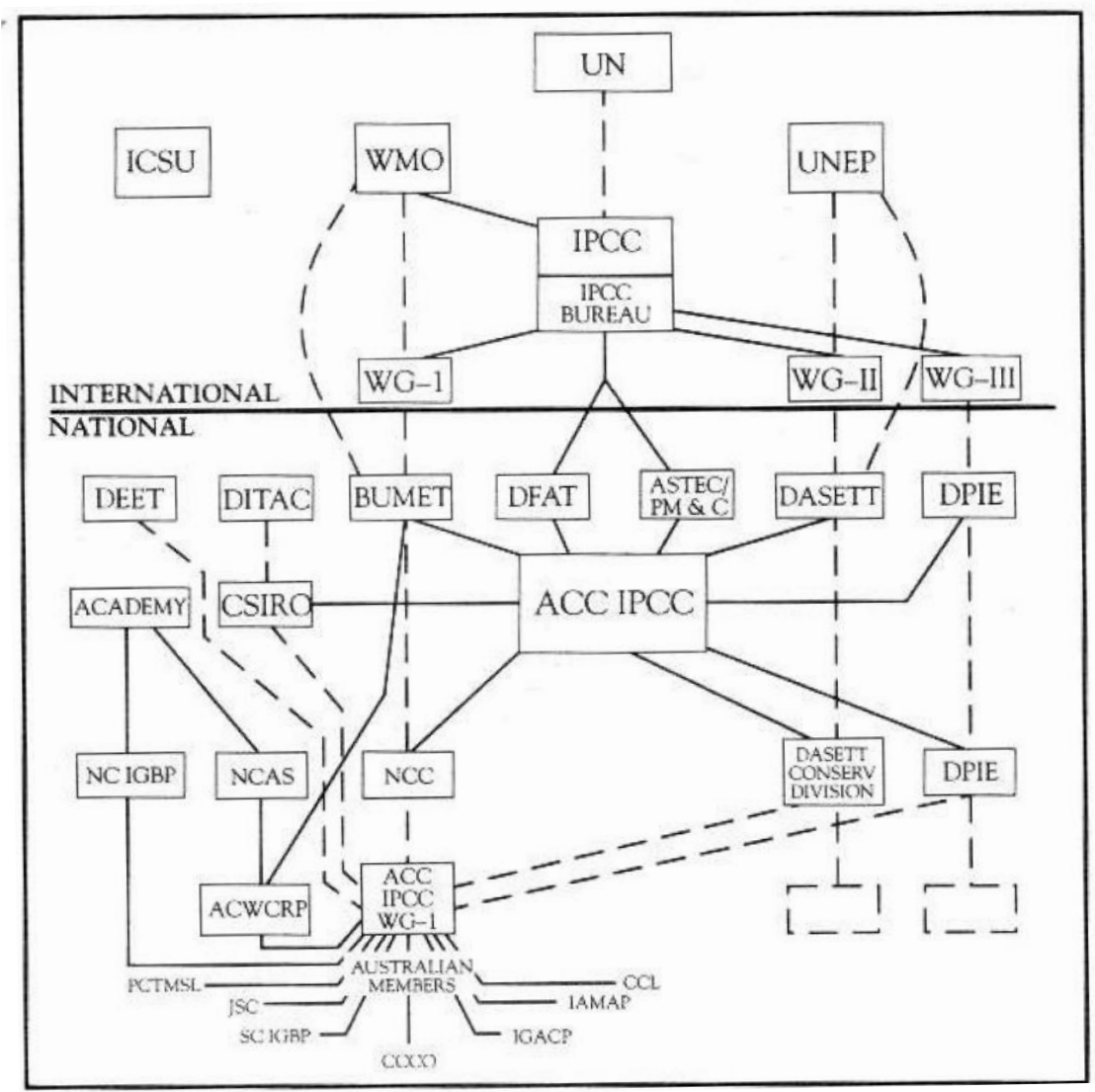

Figure 2.7 - Diagram of communication with the Australian government with respect to climate change - 1989

(O'Brien 1990, p. 26)

\subsection{Greenhouse Gas Reduction}

With the acknowledged need to reduce greenhouse gas emissions, it was accepted that limited new efficiencies could be obtained from power generation but much higher gains in end use efficiency were possible (ARUP Research \& Development 2005; IEA 2001a, 2001b; Walsh, $P$ 1988). The greenhouse gas accounting completed by each nation, not only listed where emissions occurred by sector, but also subgroups within each sector (AGO 2002a, 2005, 2007b; DCC 2009; US EPA 2010). In an attempt to reduce immediately the long term effects of global warming or climate change and to meet their Kyoto Agreement (1987) obligations, many nations developed strategies or policies to reduce emissions by focusing on the 'low hanging fruit' first. These were areas where it was accepted that with a minimal effect on economic health, a nation could reduce its greenhouse emissions (CIE 2007; Downey et al. 2008; Green 2006; Gullu, Caglar \& Akdeniz 2001). Many reports included in this group the emissions from space conditioning residential and commercial buildings (AGO 2002b, 2004b; 
Cadima 2007; Carbon Trust 2006; Daly 2007; Do et al. 2007; Eckstein 2006; EU 2003; Harrington \& Foster 1999; Isaacs, N 1999; Jeeninga \& Kets 2004; Kavgic et al. 2009; Kim \& Moon 2009; Lomas et al. 2010; Parker, Rowlands \& Scott 2003; SEAV 2004). It was estimated that up to $50 \%$ of greenhouse gas emissions were caused by the construction, operation and maintenance of buildings (Boardman et al. 2005; Kavgic et al. 2009; Kim \& Moon 2009; Konstantinos, Papakostas \& Vlahakis 2005; NIFES Consulting Group 1993; Sahlin et al. 2003).

The Council of Australian Governments (COAG) endorsed the National Greenhouse Response Strategy in 1992 (Williamson, T et al. 1995). In the 1997 Prime Ministers' Greenhouse Gas Reduction Statement, the government was seeking realistic, cost-effective reductions of emissions in key sectors (ABCB 2006c; AGO 1999). In November 1998, the Australian governments endorsed the 'National Greenhouse Strategy' (AGO 1998), committing themselves to the first stage of an ongoing national greenhouse response. The strategy explored and documented for the first time in Australia:

- An inventory of greenhouse gases

- An understanding of climate change and its impacts

- Possible methods to reduce greenhouse gas emissions

- Energy efficiency and supply

- Transport and urban planning and

- Carbon storage

The significant quantity of Australian emissions which could be attributed to the built environment was now recognised. It was considered that improving the built fabric of buildings would immediately reduce the energy used to maintain thermal comfort (ABCB 2006c; Bennet 1999; Tucker et al. 2002). Module 4.9 of the strategy "Energy Efficiency Standards for Residential and Commercial Buildings" voiced the first principles to develop minimum energy performance standards for the building sector (AGO 1998). Consequently, the Commonwealth Government announced its intention to pursue a strategy that included two elements: 
- the encouragement of voluntary measures by industry, and

- the introduction of minimum mandatory (thermal performance) requirements in the Building Code of Australia (ABCB 2006c).

A scoping study was completed in 1999 by the CSIRO, for the Australian Greenhouse Office, which explored the minimum energy performance requirements that could be incorporated into the BCA (AGO 2000a; Allan, Pullen \& Wyeld 2003; Drogemuller et al. 1999). The study was completed by the CSIRO Division of Building, Construction and Engineering. The study recommended two forms of compliance for energy efficiency, which fitted within the current BCA methods of prescriptive or alternative solution to meet a set performance requirement. The study recommended:

- The further development of an accreditation scheme and administrative body within the National House Energy Rating Scheme (NatHERS)

- The further development of the NatHERS and other softwares for the thermal simulation of small to large houses

- The development of insulated fabric systems that could be incorporated within the BCA. These systems would produce a similar star rating to a house that was modelled with a NatHERS accredited software.

- The establishment of suitable climate zones within Australia

- The exploration of other energy improvement measures, that were presently outside the scope of the BCA

Internationally and nationally these types of initiatives were queried by members of the building industry; academics who raised concerns about these recommendations, as they focused primarily on the energy needed to heat or cool a building and the inherent errors that may exist in this process (AGO 2004a; Allan, Pullen \& Wyeld 2003; Ballinger \& Cassell 1994; de Souza et al. 2006; Gann, Wang \& Hawkins 1998; Harris, J et al. 2008; Hui 2003; Kordjamshidi \& King 2009; Kordjamshidi, King \& Prasad 2005; Productivity Commission 2004; Seo et al. 2005; Soebarto \& Williamson 2001; Stein 1997; Williamson, T 2004; 
Williamson, T, Plaves \& Hart 2007). Two primary types of energy are used in a building: embodied and operational energy (Birkeland 2002; Blanchard \& Reppe 1998; Papamichael 2000). Embodied energy is the energy used to manufacture, transport, install the materials and to construct, maintain and dispose of a building (Crawford \& Treloar 2003; Fay, Treloar \& Iyer-Raniga 2000). Operational energy is the energy used during a building's service life: in heating, cooling, lighting, fixed and portable appliances, hot water and other energy consuming services, which is greatly affected by occupant behaviour and their perceived level of thermal comfort (Ballinger \& Cassell 1994; Brohus et al. 2009; Chappells \& Shove 2005; Coldicutt et al. 1978; Delsante 2005f; Fung, Porteous \& Sharpe 2007; Johansson \& Bagge 2009; Kalamees et al. 2008; Kane, Fuller \& Treloar 2006; Kordjamshidi, King \& Prasad 2005; Stein 1997; Stein \& Meier 2000; Stoecklein, Pollard \& Bishop 1998; Stoecklein et al. 1998; Williamson, T 2004; Williamson, T, Plaves \& Hart 2007). In an attempt to reduce the emissions from these various activities they were broken into subcategories, as shown in Table 2.5 (AGO 2000b). Initially it was hoped that efficiencies would be a market-driven mechanism, but as energy was relatively inexpensive in Australia, energy consumption only increased (ABCB 2006c; Wilkenfield, Hamilton \& Saddler 1995). This led to the gradual development and introduction of a range of legislation to mandate minimum energy efficiency requirements, or labelling systems, to inform purchasers of the relative energy use of houses or appliances (ABCB 2006c; Drogemuller et al. 1999; Millis 2006).

Table 2.5: Action to Reduce Greenhouse Gas Emissions

\begin{tabular}{|l|l|}
\hline \multicolumn{1}{|c|}{ Energy Use } & \multicolumn{1}{c|}{ Action } \\
\hline Energy for heating \& cooling a building & $\begin{array}{l}\text { Regulate minimum requirements for building } \\
\text { fabric to reduce heat loss or heat gain }\end{array}$ \\
\hline Appliances for heating \& cooling a building & $\begin{array}{l}\text { Provide a star rating system for all forms of } \\
\text { heating and cooling appliances }\end{array}$ \\
\hline Hot water services & Provide a star rating for hot water systems \\
\hline Household appliances & $\begin{array}{l}\text { Provide a star rating or minimum } \\
\text { performance requirements for all appliances }\end{array}$ \\
\hline Embodied energy of buildings & To be further investigated and quantified \\
\hline
\end{tabular}

The average household in Tasmania used around 11,000 kilowatt hours of electricity per year (DEWHA 2008). The energy end use is broken into the sub-groups of: space heating, space cooling, hot water and appliances, as shown in Table 2.6. The large presence of wood-based space heating in Tasmania, results in use of $56.2 \%$ of electrical energy for space heating (DEWHA 2008). Tasmania provided a representative example of cool temperate energy use 
within Australia, where any reduction in space heating requirements would have an immediate impact on greenhouse gas emissions.

Table 2.6: Electricity use Per Year AGO, 2008, End Use

\begin{tabular}{|c|c|c|}
\hline Energy End Use & Tasmania & Australia \\
\hline Space heating & $65 \%$ & $38 \%$ \\
\hline Space cooling & $0 \%$ & $3 \%$ \\
\hline Hot water & $14 \%$ & $23 \%$ \\
\hline Appliances & $18 \%$ & $31 \%$ \\
\hline Space cooling & $4 \%$ & \\
\hline
\end{tabular}

\subsection{Australian Thermal Performance Regulations}

In January 2001 the AGO and the Australian Building Codes Board (ABCB) agreed to develop and include energy efficiency measures for new Australian buildings in the BCA, which is the national code for construction practice and all new buildings in Australia must comply with its requirements (ABCB 2006c). The BCA was developed by the ABCB, which included representatives from: federal and state government, research groups, the manufacturing sector and construction industry groups (ABCB 2006c; Davis 2005). The BCA was given regulatory force by enabling legislation in each state. The process for identifying and applying new inclusions follows the process shown in Figure 2.8. 


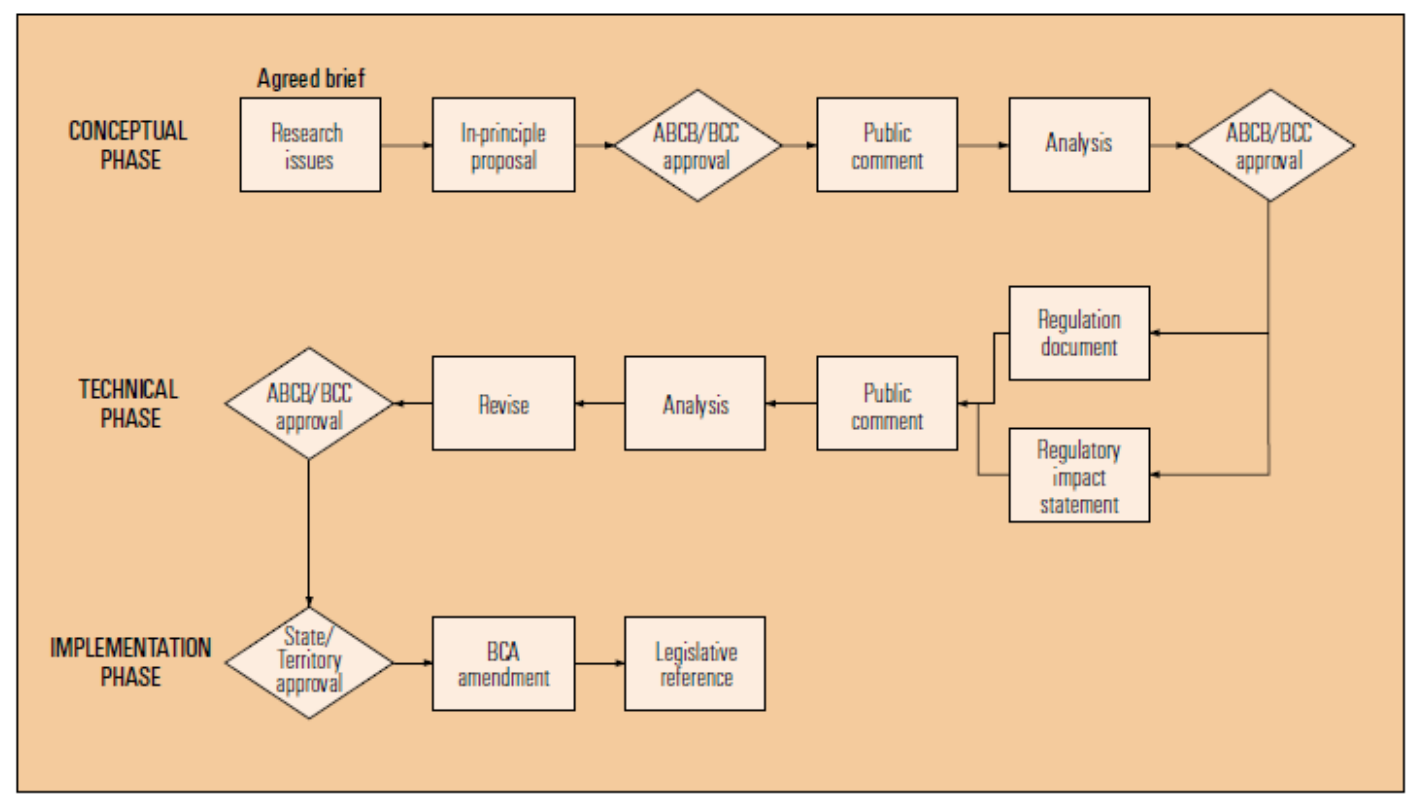

Figure 2.8 - Building codes regulatory process

(Drogemuller et al. 1999, p. 9)

The BCA is divided into two volumes: volume One is generally for larger buildings, and includes: residential apartment buildings, commercial, industrial and public buildings; volume Two applies to simpler residential stand-alone and attached dwellings (ABCB 2010). As there were no mechanisms to measure the thermal performance of new housing, NatHERS was established in 1993 (Ballinger \& Cassell 1994; Delsante 1996; Thwaites 1995). The scheme was administered by the federal government which in co-operation with industry groups and state government members, established standards for:

- Star bands for heating and/or cooling energy use relative to climate type

- Climate zones for Australia

- Building material libraries

- Internal heat loads

- Occupancy settings

- Cooling and heating thermostat settings

- Input and output requirements for House Energy Rating softwares 
The most contentious requirement was the star band system (Davis 2005; Delsante 1996; Rowell 2006-2008). This was debated by stakeholder representatives, who identified problematic issues including changes to building practice and the type of energy that a house might use, as all energy sources have differing amounts of green house gas emissions. The source of household energy might be:

- renewable: Large percentage of hydro power in Tasmania,

- brown coal: Large percentage of Victorian power

- black coal: large percentage of New South Wales power

- natural gas

Once an acknowledgement of current building practices was obtained, a staged improvement for the building stock in all states of Australia was established. It was agreed that existing construction practices in most states resulted in houses with a star rating between 1 star and 3 stars (AGO 1999, 2000a). This was established by completing thermal simulations of 360 house plans of 1990 and 1999 typical new housing from all jurisdictions (ABCB 2006c; Anderson, C 2002; Delsante 2005f; Drogemuller et al. 1999). It was agreed that the new national benchmark establish a minimum requirement for all new housing of 3.5 star or 4 stars, depending on climate zone (Davis 2005). The star rating bands were a sliding scale that assigned an arbitrary quantity of energy that may be used to heat or cool a house (ABCB 2005b, 2006c). It used a stepped ranking from zero to ten stars. A house with a zero star rating had poor thermal performance, whilst a house with a ten star rating requires no energy for heating or cooling to maintain thermal comfort (ABCB 2006c; NatHERS 2009b, 2009d). As it was more difficult to maintain a thermally comfortable house in areas that are regularly hot or cold, star rating bands were established for different climate zones. The energy allowed to achieve a Five Star rating in Sydney's generally temperate climate was $84 \mathrm{MJ} / \mathrm{m}^{2}$ per annum, whereas a house in the colder Launceston climate was allowed to consume $142 \mathrm{MJ} / \mathrm{m}^{2}$ per annum (Table 2.7). 
Table 2.7: Star Bands for Launceston \& Sydney ( $\mathrm{MJ} / \mathrm{m}^{2}$.annum conditioned floor area)

\begin{tabular}{|c|c|c|c|c|c|c|c|c|c|c|c|}
\hline Star Rating & 0.5 & 1.0 & 2.0 & 3.0 & 4.0 & 5.0 & 6.0 & 7.0 & 8.0 & 9.0 & 10.0 \\
\hline Launceston & 748 & 675 & 549 & 446 & 361 & 291 & 231 & 177 & 123 & 67 & 2 \\
\hline Sydney & 264 & 231 & 176 & 135 & 105 & 84 & 68 & 56 & 43 & 29 & 10 \\
\hline
\end{tabular}

Amendment 12 of the BCA in 2003 included, for the first time, a performance objective to reduce greenhouse gas emissions by using energy efficiently (ABCB 2003b; Allan, Pullen \& Wyeld 2003; BMW 2009). The first regulations applied to Class 1 buildings, houses, and required the minimum performance rating equivalent to 3.5 Stars or 4 Stars (ABCB 2003a, 2003b; Davis 2005). This requirement was generally accepted with little opposition and adopted (with some state variations) in 2003 and 2004. The 2005 edition of the BCA extended the minimum requirement to most other types of buildings (ABCB 2005a). The requirement for Class 1 buildings was increased to a performance rating of 5 Stars in the 2006 edition (ABCB 2006a). Several states, including Tasmania, New South Wales and Queensland, deferred the adoption of this requirement for new housing. The 2010 edition of the BCA increased the requirement to 6 stars (ABCB 2009d, 2010). Some jurisdictions only adopted the 5 Star requirement in mid 2010 and others have a range of state-based exemptions and guidelines (ABCB 2010).

Since 2004, with each annual review of the energy performance requirements, additional energy saving measures have been included for housing. These have comprised: improvements to infiltration controls, the insulation of hot water plumbing, the use of fixed shading, methods of limiting perforations of built fabric and limits to artificial lighting. It was expected that hot water systems, fixed heating/cooling appliances and embodied energy would come under greater scrutiny between 2010 and 2020 (COAG 2009). Long term, the star rating system will be applied to all energy consuming elements or products included in building operation, in an attempt to have a more comprehensive incentive to reduce energy consumption (Pitt \& Sherry 2010). However in 2010 the star rating requirements within the BCA principally affected the energy used for space heating and cooling only (ABCB 2010; Delsante 1996). 


\subsubsection{BCA Compliance}

The BCA provided two methods for buildings to comply with the thermal performance requirements: deemed-to-satisfy provisions and performance-based alternative solutions (ABCB 2010). The deemed-to-satisfy provision provided a relatively simple, but conservative, manual method to determine the external fabric matrix that would deliver the required thermal performance. Developed after numerous thermal simulations of different house types, they included: detailed descriptions and diagrams of satisfactory building practices and specific requirements for insulation, glazing, shading, building sealing and other factors that affect the heating and cooling of a house (ABCB 2009c).

A house design that did not comply with the deemed-to-satisfy provisions, or which sought to use a less conservative estimation method, required a performance-based alternative solution before it could demonstrate compliance and be approved for construction. This required that the house design obtain a minimum house energy star rating using a NatHERS accredited thermal calculation method (ABCB 2005b; Davis 2005). Within the NatHERS framework three software products were approved for use to undertake the thermal simulation and produce a star rating report. They were: AccuRate, First Rate and BERS (Delsante 2007; Foliente, Seo \& Tucker 2004; Major 2006). The AccuRate software had been developed by the CSIRO over more than 40 years. The First-Rate software was a correlation software developed by the state government of Victoria (Kordjamshidi, King \& Prasad 2005). The BERS software was developed by a private researcher in Queensland, utilised the CHEENATH engine and was principally used in that state (Kordjamshidi, King \& Prasad 2005; Q-BEARS 2009; Willrath 1998). The only software that was initially suitable for all Australian jurisdictions was the AccuRate house energy rating software.

\subsubsection{House Energy Star Rating}

To determine the house energy star rating using the alternative solution, the house's thermal performance was simulated, based on information from the architectural drawings and specifications of a new house. If the resultant star rating met the standard requirement, then the plans were certified appropriately and (subject to other code requirements), the building permit was issued (ABCB 2005a). If the house did not meet the minimum required star rating, improvements were made to the external fabric elements until the minimum requirement was met. To conduct a thermal simulation, the house energy rating software required adequate 
input data for: external fabric; internal fabric; room usage and volume; local climatic information; and building orientation.

From these inputs, the software performed a thermal simulation and produced an estimated room temperature for each room of the house. From the estimated temperature, an energy calculation model within the software converted the heating and cooling requirement into an annual quantity of energy for the whole house (Kordjamshidi \& King 2009). As there is no method to input specific heater capabilities (Delsante 1996), which would consider the relative efficiencies of different forms of heating equipment, the heating model is based on a coefficient of performance of 1.0 (Delsante 2005-2010). The annual energy quantity was then divided by the conditioned floor area to obtain a $\mathrm{MJ} / \mathrm{m}^{2}$.annum (Figure 2.9).

\begin{tabular}{|c|c|c|c|c|}
\hline HOUSI & $\begin{array}{r}\text { AccuRat } \\
\text { Oct } 2005 \\
\text { Natio }\end{array}$ & $\begin{array}{l}\text { Regulator } \\
\text { expires } 31 \\
\text { vide House } \\
\text { ating Schen }\end{array}$ & $\begin{array}{l}\text { Version } \\
\text { ec 2005) } \\
\text { ergy }\end{array}$ & HOUSE; \\
\hline \multicolumn{5}{|c|}{ Project Details } \\
\hline \multicolumn{4}{|c|}{ Project Name: 5 Star house timber floor } & Postcode: 7000 \\
\hline \multirow{2}{*}{\multicolumn{5}{|c|}{$\begin{array}{l}\text { File Name: C:AccuRatelProjects } 2005-12-12 \text { - } 5 \text { star timber.PRO } \\
\text { Design Option: Des } 8 \text { Timb no foil }\end{array}$}} \\
\hline & & & & \\
\hline \multicolumn{5}{|c|}{ Description: a. External Wall - Kool wall / Air Space with non reflective foil vapour } \\
\hline \multicolumn{5}{|c|}{${\text { CALCULATED ENERGY REQUIREMENTS } *{ }^{*}}$} \\
\hline Heating & Cooling (sensible) & Cooling (latent) & Total Energy & Units \\
\hline 214.9 & 12.4 & 1.5 & 228.8 & $\mathrm{MJ} / \mathrm{m}^{2}$.annum \\
\hline \multicolumn{5}{|c|}{$\begin{array}{l}\text { * These energy requirements have been calculated using a standard set of occupant behaviours and so do not necessarily represent the usage pattern or lifestyle } \\
\text { of the intended occupants. They should be uued solely for the purposes of rating the building. They should not be used to infer actual energy consumption or } \\
\text { running costs The settings used for the simulation are shown in the building data report. }\end{array}$} \\
\hline \multicolumn{5}{|c|}{ AREA-ADJUSTED ENERGY REQUIREMENTS } \\
\hline Heating & Cooling (sensible) & Cooling (latent) & Total Energy & Units \\
\hline \multirow{2}{*}{\multicolumn{5}{|c|}{\begin{tabular}{|c|c|c|} 
& 10.3 & 1.2 \\
Conditioned floor area & $102.7 \mathrm{~m}^{2}$ \\
\end{tabular}}} \\
\hline & & & & \\
\hline \multicolumn{5}{|c|}{ Star Rating } \\
\hline & 东市 & 人从 & TAR & \\
\hline
\end{tabular}

Figure 2.9 - HER Star Rating report produced by the AccuRate software 


\subsection{Industry Reaction}

The Australian domestic building sector provides a key indicator of Australian economic growth. The sector includes: manufacturing, transport, wholesale and retail services, builders and associated trades, the building design profession, engineers, private and public sector researchers and government regulators. When the thermal performance provisions were suggested for inclusion in the BCA, a protracted negotiation commenced between the regulators and representatives from the many construction sector stakeholders listed above. The need for this was apparent due to the fact that any change in the type of materials or how they are used could have a significant impact on the requirements of designers, builders and manufacturers (Dewsbury, Nolan \& Fay 2007; Iskra 2004; Murphy et al. 2005; Nolan \& Dewsbury 2007). Further, the changes could significantly affect the affordability of the house and the training required for architectural, engineering and construction practices (ABCB 2006c; Arreaza, Reyes \& Almao 2007; Building Control Branch 2009; Energy Partners 2006; Henderson 2005; HIA 2004; Marceau et al. 1999; MBA 2008; Productivity Commission 2004; Tucker et al. 2002; Williamson, T, Plaves \& Hart 2007). Depending on the type of change, it could dramatically affect the economic viability of some businesses.

Generally, the representatives of the construction industry were supportive of the energy efficiency requirements but were concerned about possible problems in the methods employed to measure building designs (Anderson, C 2002; Delsante 2007; Henderson 2005; HIA 2004; Kordjamshidi \& King 2006; Nolan 2005; Williamson, T et al. 1995). Primarily, they were concerned with the method of obtaining a star rating and the capacity of the house energy rating softwares to accurately calculate room temperatures and subsequent energy requirements, and in turn deliver a reduction in greenhouse gas emissions (ABCB 2009c; AGO 2004a; Delsante 2005f; Williamson, T \& Delsante 2006). The adoption of the 4 Star requirements in 2003 appeared to have a relatively minor effect on the material and construction practices for new houses. However the move to the 5 Star requirements in 2006 and the 6 Star requirements in 2010 introduced far-reaching changes to what had been relatively unchanged construction practices for many years (DewsburySoriano et al. 2009; Williamson, T \& Beauchamp 2005).

In response to this, various industry groups and building researchers raised concerns about the energy efficiency requirements, including: industry educational and training needs, material 
availability, technical support, HER software capacity, how the proposed reduction in greenhouse gas emissions was to be measured and how Australian housing compared to that of other nations (ABCB 2000, 2006c; AGO 2000a, 2004b; Bassett \& Stoecklein 1998; BCB 2009; Campbell, Macfarlane \& Macdonald 2006; Delsante 2007; Energy Partners 2006; Horne \& Hayles 2008; Marceau et al. 1999; Millis 2006; Nolan \& Dewsbury 2007; Williamson, T \& Beauchamp 2005). The size of Australian houses continued to grow (ABCB 2006c; AGO 2000a, 2000b; Bromberek, Beall \& Hinds 2003; Delsante 2005a; Martin 2009) and some concerns were raised as to the checking mechanism that would sit behind the legislative requirement to reduce greenhouse gas emissions (Kordjamshidi, King \& Prasad 2005; Productivity Commission 2004; Williamson, T 2004; Williamson, T, Plaves \& Hart 2007).

The concerns regarding the HER softwares were primarily focused on their capacity to predict a room temperature and whether or not one building type performed better than another, due to assumptions within the software (Macdonald, Macfarlane \& Campbell 2005; Williamson, $\mathrm{T}$ 2004). The industry became more concerned when it was decided that the $2^{\text {nd }}$ generation of the NatHERS protocol would require that all HER softwares incorporate the CSIRO developed thermal simulation software (NatHERS 2007). The CSIRO developed HER software was generally accepted as the most tested and most thorough within Australia. A software developer could develop their own form of front and back end user interfaces, but the principal simulation engine would be identical for all softwares. The second generation requirements were introduced along with the 5 Star Requirements in 2006. As a part of this process, several improvements were made to the CSIRO software. As the software had never been validated empirically, there were concerns that any imperfections in the software could disproportionately advantage or prejudice one building type over another (Dewsbury et al. 2007; Henderson 2005; Iskra 2004).

There are three principal types of construction typologies within the Australian residential sector:

- unenclosed-perimeter platform-floored buildings

- enclosed-perimeter platform-floored buildings

- concrete slab-on-ground floored buildings. 
Each of these building types is lightweight by most international standards and has differing insulation, infiltration and thermal capacitance properties, dependent on structural, cladding and lining systems (Dewsbury, Fay \& Nolan 2008). If the software's capacity to model the three building types in significantly different climates differs, it would not reflect the true thermal performance of a building type and misinform the building industry in matters concerning building thermal performance and preferred forms of building practice (Thomas 2010). Such errors would potentially have a corresponding economic impact on material manufacturers (ABCB 2006c; Building Control Branch 2009; Campbell, Macfarlane \& Macdonald 2006; Dewsbury, Nolan \& Fay 2007; Kordjamshidi, King \& Prasad 2005).

When the 5 Star requirements occurred in 2006, four of Australia's eight jurisdictions refused to adopt the increased requirements in the BCA (ABCB 2006a). When the $6 \mathrm{Star}$ requirements occurred in 2010, five of Australia's eight jurisdictions refused to adopt the increased requirements (ABCB 2010).

In consultation with representatives of manufacturers, industry representative bodies, state government regulators, the CSIRO and federal government agencies in 2005, it was acknowledged that the AccuRate software should be validated at this early stage of energy efficiency regulation within Australia (Delsante 2005e; Dewsbury et al. 2007; Dewsbury, Fay \& Nolan 2008; Dewsbury, Nolan \& Fay 2007). The validation would inform industry and government of the capacity of the software to predict room temperature and guide software developers to areas of the software that may require improvement. This study would require an adequate understanding of available validation methods, and which method was appropriate for validating the AccuRate software. This information is discussed in detail in chapter 3. 


\section{Background to HER Program Validation}

The previous chapter discussed our natural desire to make spaces, and especially our houses, thermally comfortable. As houses have become bigger and personal wealth has increased, the amount of energy consumed to create comfort has increased (Harvey 2006). In recent years the anthropogenic creation and use of energy, including that to condition houses, has been linked to climate change. In response to the threat of climate change, many governments have instigated methods to reduce the production of greenhouse gases, which has included thermal performance targets for new and existing housing. This has led to the adoption of detailed thermal simulation programs to evaluate the possible thermal performance of a particular house in a given climate. In response to these new government regulations, many building industry and related groups have raised concern as to the capacity and validity of the house energy rating softwares adopted within Australia to predict room temperatures. These groups have requested the software be validated, modified and calibrated, to give the Australian community confidence in and acceptance of the house energy rating softwares (Dewsbury, Nolan \& Fay 2007).

Internationally and within Australia there have been many such projects that have been referred to as validation exercises. Close reading of these projects highlighted dramatic differences in approaches taken. To determine the best practice approach of what should be measured to empirically validate the AccuRate software, an evaluation of what and how should be built, measured and simulated was undertaken. This provided an informed framework for the methods used to validate the AccuRate software.

\subsection{What to Validate?}

The Accurate software calculates a room temperature, then an energy calculation is completed, which informs the resultant climate based HER star rating (Figure 2.9). Validation aims to establish the accuracy of the house energy rating software and determine its sensitivity to key factors of climate and construction practice. The process entails the comparison of AccuRate output data with other data sets. A comparison can be undertaken in three different levels of complexity (Allen et al. 1985; ASHRAE 2009; Delsante 2005c; Lomas 1991a; Strachan et al. 2006), namely: 
- Complete software comparison: The whole software comparison was the most complex possible and requires a lengthy process where the both the envelope and heating outputs were compared as separate elements, prior to being combined for a whole of software capability comparison. Each comparison is a separate research task and as much as this is acknowledged as an ideal long term research goal, its complexity and time to undertake the tasks makes this approach undesirable.

- Envelope component comparison: An envelope output comparison is a lengthy process, as it requires the detailed simulation of a suitable building and the comparison of the software output data with a suitable data set from another source. However it is argued that this was a sensible starting point for software validation, as the difference between room temperature and an acceptable temperature for human comfort was used to calculate heating of cooling energy and the resultant HER star rating.

- Heating and cooling energy component comparison: The comparison of the energy outputs relies on the heating and cooling requirements obtained by the means of envelope simulation. As many HER softwares use a simplistic heating and cooling calculation model, there are acknowledged weaknesses with this part of the software. The NatHERS protocol did not require, for example, the specification of heating or cooling equipment and there is no formal system in place within Australia, where a database or library of heating options is available (Delsante 1996). Primarily this is due to the nature of Australia's climate (Soebarto \& Williamson 2001), the historical use of portable heating and cooling equipment and the relatively recent adoption of fixed heating and cooling plant within residential buildings. As much as this was acknowledged as an area of research interest, it is not seen as suitable for the first stages of the validation process for the NatHERS system and the AccuRate software. However, once an envelope validation has been completed, a heating or cooling comparison can be undertaken. 


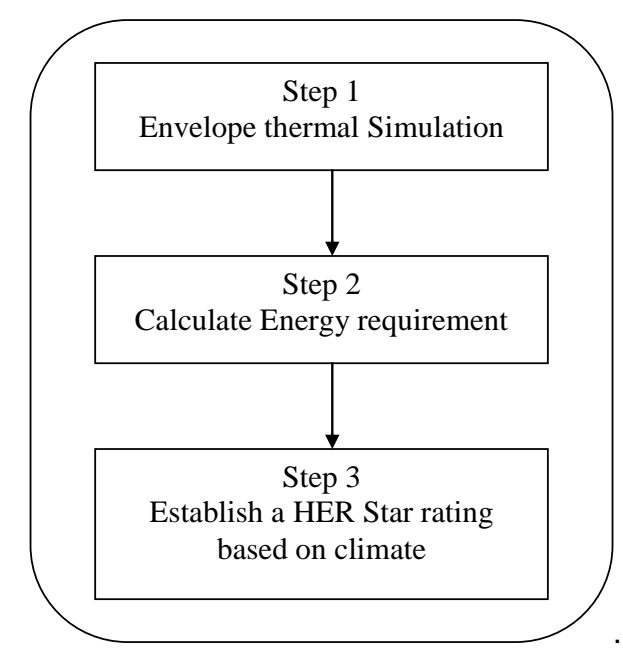

Figure 3.1 - Schematic of Accurate software process to establish an HER Star Rating

Considering the assessment above, this study focused on the validation of AccuRate's envelope component, as being the most suitable form of validation to give some credibility to the software. The results would enable the software developers to calibrate or improve AccuRate's envelope simulation model (Agami Reddy, Maor \& Panjapornpon 2007; Clarke, Strachan \& Pernot 1994; Delsante 2006b; Donn 2007; Strachan 2008). Once this portion of the software is validated, work on the other modules within the software, (including the heating and cooling modules) can commence.

\subsection{Methods of Validation}

To validate the envelope component of the AccuRate software, there were three principal forms of comparison which could be undertaken: mathematical, software comparison and empirical validation (Allen et al. 1985; ASHRAE 2009; Bloomfield 1988, 1999; Bowman \& Lomas 1985; del Mar Izquierdo et al. 1995; Guyon, G, Moinard \& Ramdani 1999b; Haberl 2004; Strachan, Kokogiannakis \& MacDonald 2005). Each of these methods has varying degrees of complexity and requires appropriate amounts of time and resources to complete. Each method also provides different degrees of validation and had respective advantages and disadvantages (Table 3.1).

To choose which method was most appropriate, the principal purpose of the research and the methods by which the AccuRate software calculated a room temperature were investigated. The required inputs for a normal house energy rating using the software included the detailed information of the built fabric and a climate file. The climate file provided hourly values for a 
range of climatic inputs that would impact on the thermal performance of a building. With these inputs provided, the software then performed a thermal simulation for each room, for each hour of a calendar year. The software calculated the room temperature and from this information a heating and/or cooling requirement was established. Numerous calculations were completed during the building's thermal simulation process. The chosen validation method should allow for the analysis and comparison of the AccuRate inputs and outputs.

Table 3.1: Advantages \& Disadvantages of HER Software Validation Methods

\begin{tabular}{|c|l|l|}
\hline Method & \multicolumn{1}{|c|}{ Advantages } & \multicolumn{1}{|c|}{ Disadvantages } \\
\hline Analytical/Mathematical & $\begin{array}{l}\text { Limitation of input uncertainty, } \\
\text { Pure mathematical modelling, } \\
\text { Limited expense of the desktop form of } \\
\text { research. }\end{array}$ & $\begin{array}{l}\text { Limitation of calculations that would be } \\
\text { economically undertaken } \\
\text { The presumption that the current } \\
\text { mathematical models were correct } \\
\text { Does the data bear resemblance to real } \\
\text { buildings }\end{array}$ \\
\hline Software Comparison & $\begin{array}{l}\text { Level of complexity was researcher and } \\
\text { software dependent } \\
\text { Certainty of input variables } \\
\text { Various aspects of the software could be } \\
\text { analysed separately } \\
\text { Limited expense of the desktop form of } \\
\text { research. }\end{array}$ & $\begin{array}{l}\text { The presumption that the current } \\
\text { mathematical models within the software } \\
\text { is correct } \\
\text { Does the data bear resemblance to real } \\
\text { buildings? }\end{array}$ \\
\hline $\begin{array}{l}\text { The comparison of software outputs to } \\
\text { measurements from real buildings } \\
\text { Complexity is defined by the test } \\
\text { buildings } \\
\text { Modelling certainties if the building is } \\
\text { known }\end{array}$ & $\begin{array}{l}\text { Experimental uncertainties in the form of } \\
\text { equipment calibration and tolerances } \\
\text { Modelling uncertainties if the building is } \\
\text { unknown } \\
\text { Detailed measurement is expensive and } \\
\text { time-consuming } \\
\text { Types of validation are dependent on } \\
\text { fabric variables that can be changed in } \\
\text { the test building }\end{array}$ \\
\hline
\end{tabular}

(ASHRAE 2001, 2009; Delsante 2005c; Judkoff, R \& Neymark 2006; Kummert, Bradley \& McDowell 2004; Rees, S, Xiao \& Spitler 2002)

The comparison of the AccuRate output values to mathematically calculated values would have been the simplest and least time consuming method, however it had limitations. The program was the resultant assemblage of more than forty years of building science research and the development of many mathematical models. In the process of developing the program, many simplifications were made to allow for a suitable range of variables that a program user could modify (Clarke 2001; Soebarto \& Williamson 2001; Travesi et al. 2001). The mathematical comparison could bear little resemblance to the real thermal condition within a building and was seen as an unsuitable method by industry and the CSIRO (Delsante 2005c). 
The comparison of program outputs to other accepted programs is an internationally recognised method to validate a building simulation program (Agami Reddy, Maor \& Panjapornpon 2007; ASHRAE 2009; Beausoleil-Morrison et al. 2009; Judkoff, R \& Neymark 2006). The CSIRO software developers had previously compared modules of the AccuRate program to other programs (Delsante 2005e). This method was adopted by the NatHERS protocols, where other residential HER softwares were required to have similar output values to the AccuRate software (NatHERS 2007). Internationally, both the BESTEST (Haddad \& Beausoleil-Morrison 2001; Hayez et al. 2001; Henninger \& Witte 2004; Henninger, Witte \& Crawley 2003; NeymarkJudkoffAlexander et al. 2008; Tsai \& Milne 2003) and the ASHRAE Standard 140 (ASHRAE 2001, 2004b; Judkoff, RD \& Neymark 1999; Strachan et al. 2006) have been adopted for many HER program validation research activities (Haberl 2004; Judkoff, R \& Neymark 1995; Neymark \& Judkoff 1997; Roujol et al. 2003). Internationally, from the early 1970s to the present, differences were being observed between building simulation program outputs and observed temperatures in buildings. The purpose of this research was to check the program's capacity to predict a room temperature and there was no certainty that other softwares could predict the room temperature, considering Australian residential construction practices. As the CSIRO was keen to validate and calibrate the AccuRate software, this method was viewed as unsuitable (Delsante 2005b, 2005c, 2005d, 2005-2010).

The empirical validation method required the most resources and would take the longest time to produce results but offered the critical advantage of controlling and quantifying many elements of the research (Strachan \& Vandaele 2008). If the test buildings are designed and constructed under close supervision, variations between the buildings can be kept to a minimum (Strachan \& Vandaele 2008). If the insights from previous studies on building thermal performance are considered, data acquisition from this study could be better informed. This was the only validation method that could provide the CSIRO and industry with conclusive findings that would lead to possible improvements or calibration requirements for the AccuRate program. The results of a credible empirical validation process are a critical component of the legal basis for policies on building fabric thermal efficiency.

To validate the AccuRate program empirically required comparison of simulation output data and observed data from appropriate buildings (Rahni et al. 1999; Strachan 2008). It was 
promptly established that purpose-built test buildings, similar in principle to existing test buildings were required, as purpose-built test buildings:

- Allow complete documentation of the built fabric and construction method (Lomas 1991b)

- Allow verification of thermal modelling components (Lomas 1991a)

- Support the need for uninterrupted detailed thermal measurements (Lomas 1991a)

These were the three key elements of the validation method used in this study. The construction of one or more test buildings, and the materials and building practices used to make the buildings was to be controlled and completely documented. If more than one building was constructed, they should conform in nature to contemporary Australian residential construction practice and ideally have minimal variation between buildings. The buildings would be observed extensively for a substantial period, so as to provide an adequate quantity of measured data for comparison to the simulated data set. The data collected must be similar in form to the output data provided by the AccuRate program.

\subsection{Is 'AccuRate' Accurate? - A historical context}

A strong interest in building thermal physics was evident with many universities from the early 1900s (Haberl 2004). From the 1940s the development of building thermal theory moved to newly established building and national research organisations. The Carslaw and Jaeger book, "Conduction of Heat in Solids" (1947), documented the parallel path method, which is still in use today. At the Building Research Congress in 1951, various articles discussed the processes, practicalities and problems associated with the use of a single heat path method (Bruckmeyer 1951; Mackey 1951; Mackey \& Wright 1944, 1946). As early as 1942, researchers were using the analogy of electrical theory (Billington 1951; Paschkis 1942; Paschkis \& Baker 1942; Van Gorcum 1950) or hydraulic theory (Leopold 1948a, 1948b) to describe the heat flow through solid materials. For various reasons, the electrical analogy had become the predominant approach by the early 1950s.

As early as 1953, Australia researchers from the CSIRO, were publishing methods and principles for calculating the internal temperatures of buildings, in an ever-changing external environment (Muncey, R 1953). During the period from 1953 to 1969, Muncey, Spencer, 
Holden and others from the CSIRO commenced the development of what has become the AccuRate software in use today. At the same time, they were developing the electrical analogy (Figure 3.2) and the use of matrix algebra to account for the multi-variate inputs required to model the heat flows in a building (Clarke 2001; Davies 1974; Holden 1963; Muncey, R \& Holden 1967; Muncey, R \& Spencer 1966, 1969). As the capacity of computers increased throughout the late 1960s and early 1970s, the matrix method, as in Figure 3.3, was further developed to include many more inputs (Milbank \& Harrington-Lynn 1974; Rao \& Chandra 1966).

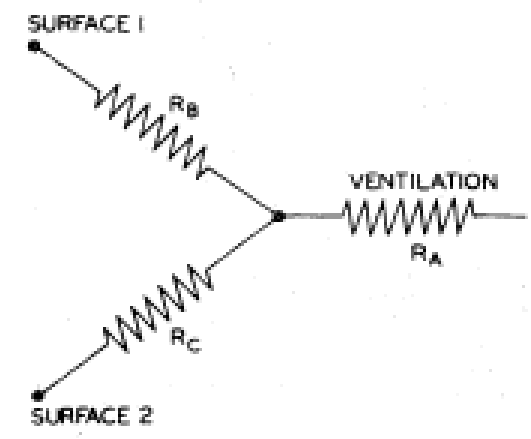

Figure 3.2 - Muncey \& Spencer Matrix calculation method

(Muncey, R \& Spencer 1969, p. 228)

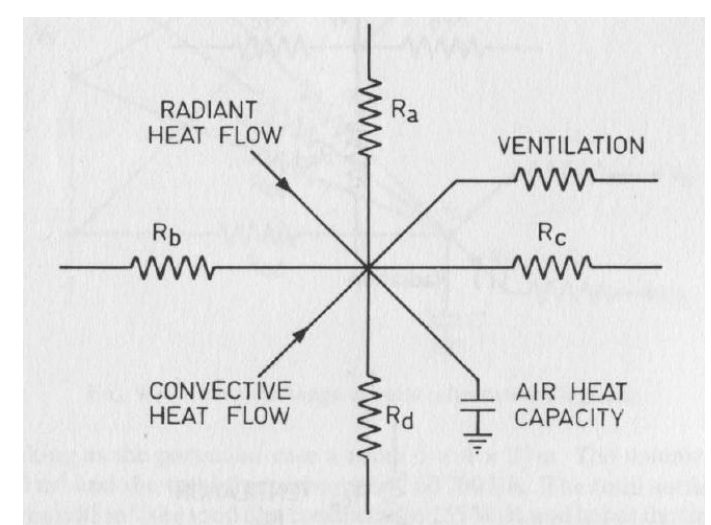

Figure 3.3 - Matrix Heat Flow and an electrical analogy

(Muncey, R 1979, p. 93)

As soon as computers became useful for building theory applications, these same national research organisations commenced developing building thermal simulation programs (Haberl 2004). The first of these building thermal simulation programs had limited input and output capabilities, as they were dependent on their state of computer technology. However there was ongoing debate and growth of knowledge on calculating the room temperature within buildings. With the developing capacity of computers to perform a greater number of calculations in the early 1970s, the interest in and capacity to broaden the HER software accelerated (Clarke 2001; Isaacs, T 2005). Government and industry funded projects were established to develop detailed building simulation programs (DSP). These early DSPs were the predecessors to the current range of House Energy Rating computer programs.

In Australia, the first formal detailed simulation program developed by the CSIRO was completed in the mid 1970s and was named STEP. The STEP program was able to model a 
single room for each hour for a period of three days. Over the following decades, as computer capabilities increased and major improvements to programming were made, the next generations of the software became ZSTEP 1 to 3, CHEETAH, CHENATH and NatHERS (Ahmad, Q \& Szokolay 1993; Delsante 1988, 1996, 1997; Delsante, Stokes \& Walsh 1983; Landman \& Delsante 1987; Walsh, PJ \& Delsante 1983). Throughout this evolution the capabilities of the software improved, as follows:

- Number of subfloor, internal and roof zones able to be modelled increased to 99

- The simulation calculates the zone temperature for each hour of a full year

- A climate file with hourly input variables was introduced

- The ground model for concrete slab-on-ground floored buildings was developed

- The ground model for platform-floored buildings was developed

- A simplistic model for the calculation of heating and cooling loads was developed

In the early 1990s, Federal and State agencies within Australia agreed to develop a National House Energy Rating Scheme and subsequently the CSIRO developed the CHEETAH software further, to meet the requirements of this scheme (Delsante 1996, 2005e). The program was reviewed and improved to meet the imminent energy rating requirements for new residential buildings (CSIRO 1997; Thwaites 1995). Throughout these improvements the program maintained its single dimension thermal modelling methodology (Boland 2002), which has been found to have between a $22 \%$ and $41 \%$ discrepancy from two and three dimensional models (Adjali et al. 2000; Belusko, Bruno \& Saman 2010; Stazi et al. 2007).

The NatHERS program, which principally used the CHEETAH thermal simulation engine, had modules tested with the IEA BESTEST validation method in the early 1990s (Ahmad, Q \& Szokolay 1993; Delsante 1995b, 1996). This validation was in response to concerns raised by industry about the imminent use of the software to produce star ratings for regulatory approval of house designs (Henriksen 2003). As a result of the BESTEST validation a range of improvements was made. This established the first generation of NatHERS with the CHENATH simulation program operating behind the AccuRate front end user interface. As more improvements were made, the second generation of NatHERS was released, with a new 
version number of the AccuRate program (ABCB 2006c; AGO 2004a; Chen, White \& Wonhas 2010; Delsante 1989, 1993, 1996, 2005a, 2005e; Delsante \& Mason 1990; Energy Partners 2007; Isaacs, T 2005, 2008; Lee et al. 2005; Lee, Snow \& Stokes 2005; Li \& Delsante 2001; Li et al. 2001; Li, Delsante \& Symons 2000; Marker 2005; NatHERS 2009a). Elements of the software that were improved included:

- Improved materials library

- Improved windows and roof windows library and modelling

- Improved ventilation model to suit modes of natural ventilation

- Improved modelling of platform-floored subfloor zones

- Improved roof space modelling

- Improved ground model

- Increased number of climate zones

- Improved internal solar radiation modelling

After these improvements were completed the program was validated once again via the BESTEST method and the results classed the software as satisfactory (Delsante 2005a, 2005e). Williamson (2009) noted however, that the BESTEST method did not include any assessment of the natural ventilation models. The results of the calculated energy requirement for heating and cooling of a low-mass building are shown in Figure 3.4 and Figure 3.5, respectively. These two figures illustrated that the BESTEST validation method was allowing a substantial variation between programs (Kummert, Bradley \& McDowell 2004) of approximately $1.2 \mathrm{MWh}$ for heating and 1.8MWh for cooling. The BESTEST 600 building is a single-roomed building of $48 \mathrm{~m}^{2}$ (Judkoff, R \& Neymark 1995; NeymarkJudkoffAlexander et al. 2008). If the heating and cooling values were considered to be of a similar nature to those in the Australian NatHERS Star Ratings, as in Table 3.2 (ABCB 2006b), the allowable variance between programs could have a dramatic impact on a house's energy star rating. The broad range allowable in the energy calculations may be a result of software developmental legacy from the time of much less capable computers. It would be expected with more 
modern computer capability and a greater understanding of building physics, that the range variance would be tightened. In Australia this concern can be attributed to the simplifications in algorithms in the software, as acknowledged by the CSIRO (Delsante 1996).

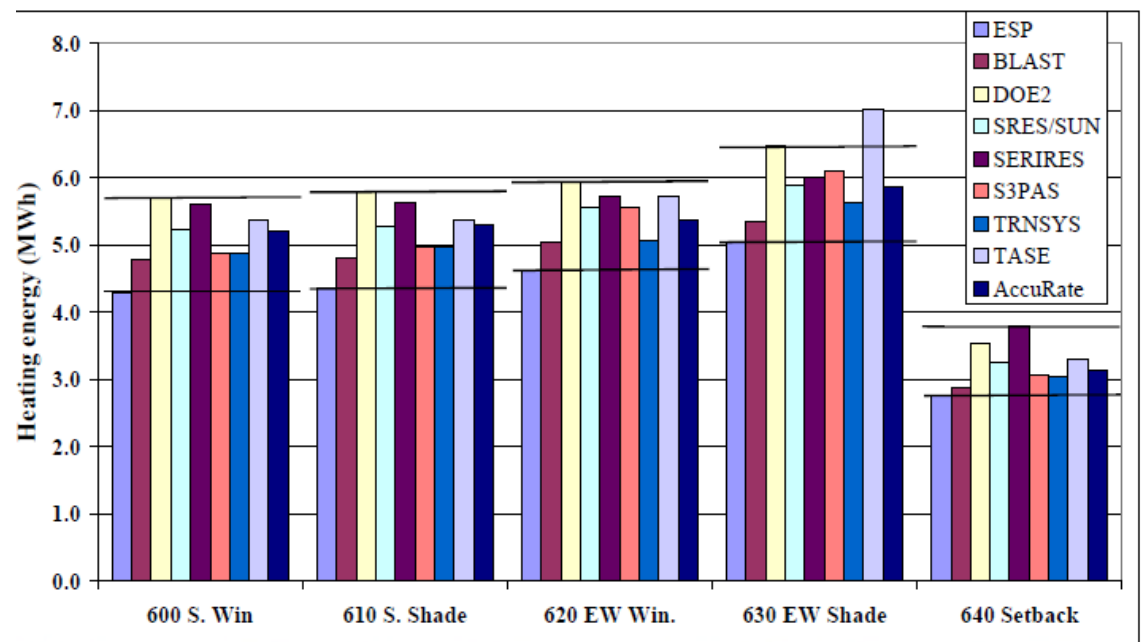

Figure 3.4 - BESTEST results for low-mass annual heating requirement

(Delsante 2005d)

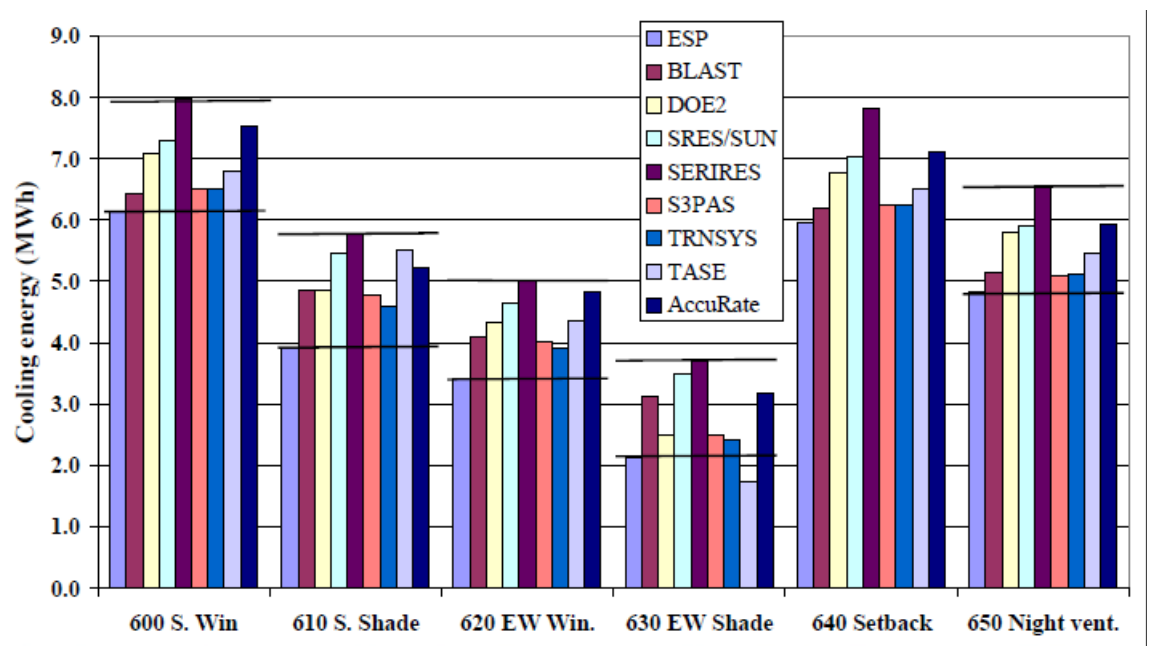

Figure 3.5 - BESTEST results for low-mass annual cooling requirement

(Delsante 2005d) 
Table 3.2: BESTEST and NatHERS heating \& cooling values for type 600 building

\begin{tabular}{|c|c|c|c|c|}
\hline & Allowable BESTEST & NatHERS Equivalent & \multicolumn{2}{|c|}{ Effective Star Value } \\
\cline { 3 - 4 } & Variation & $48 \mathrm{~m}^{2}$ & Launceston & Sydney \\
\hline Heating & $1.2 \mathrm{MWh}$ & $25 \mathrm{KWh} / \mathrm{m}^{2}$.annum & 0.4 Stars & 1.2 Stars \\
\hline Cooling & $1.8 \mathrm{MWh}$ & $38 \mathrm{KWh} / \mathrm{m}^{2}$.annum & 0.5 Stars & 1.8 Stars \\
\hline & Combined Total & $63 \mathrm{KWh} / \mathrm{m}^{2}$.annum & 0.9 Stars & 3.0 Stars \\
\hline
\end{tabular}

Note: based on the 4.0 to 5.0 Star rating step (ABCB 2006b)

Internationally, many detailed simulation programs have come under tighter scrutiny than AccuRate as their capability to predict room temperature and to calculate energy requirements to meet ever increasing building thermal performance guidelines, has been questioned (BREDEM 2006; Crawley et al. 2005). One of the BESTEST validations of the ENERGYPLUS software in 2004 (Henninger \& Witte 2004) revealed some dramatic differences between the twelve software programs used for the comparative validation (Figure $3.6 \&$ Figure 3.7$)$. For the low-mass building the variations were up to $2.4 \mathrm{MWh}$ in annual cooling energy and 1.5MWh in annual heating energy. In many of the BESTEST reports there was discussion with regard to calculated average values for minimum, maximum and mean temperatures (Judkoff, R \& Neymark 1995; Neymark \& Judkoff 1997). All energy calculations by the programs were based on the actual varying minimum and maximum values, when the heating or cooling requirement was invoked and not the mean or average temperatures. It was these daily extremes which were of greatest importance for validation purposes. 


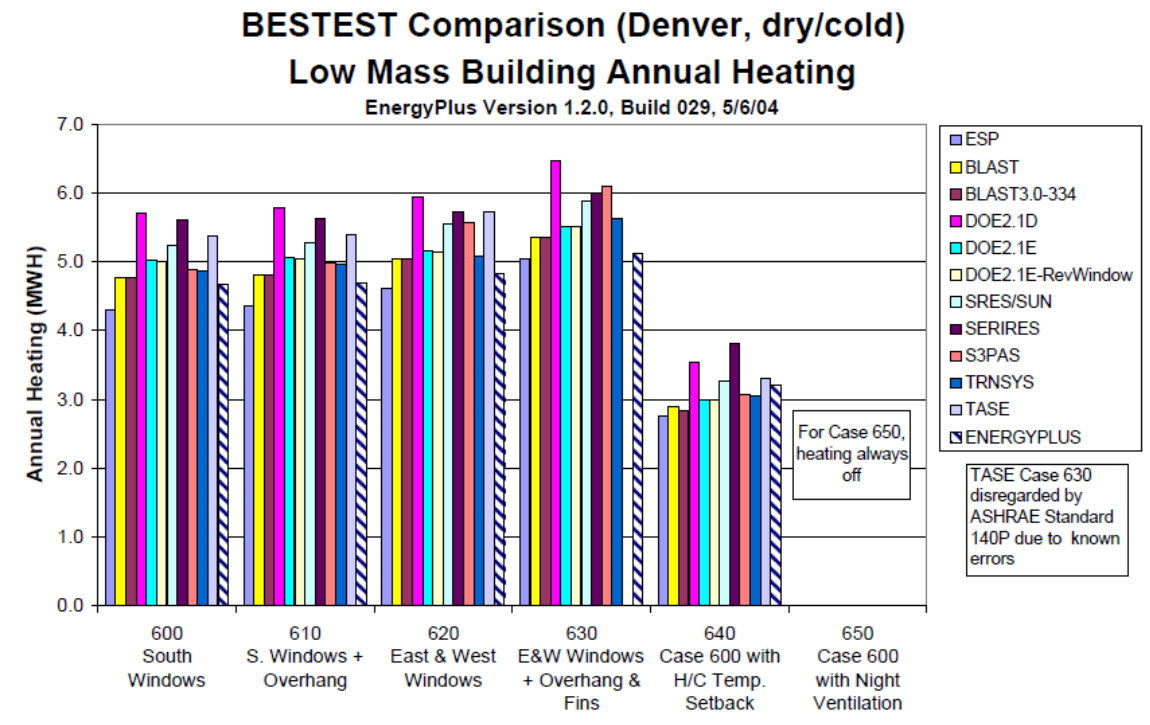

Figure 3.6 - EnergyPlus BESTEST results for low-mass annual heating requirement

(Henninger \& Witte 2004)

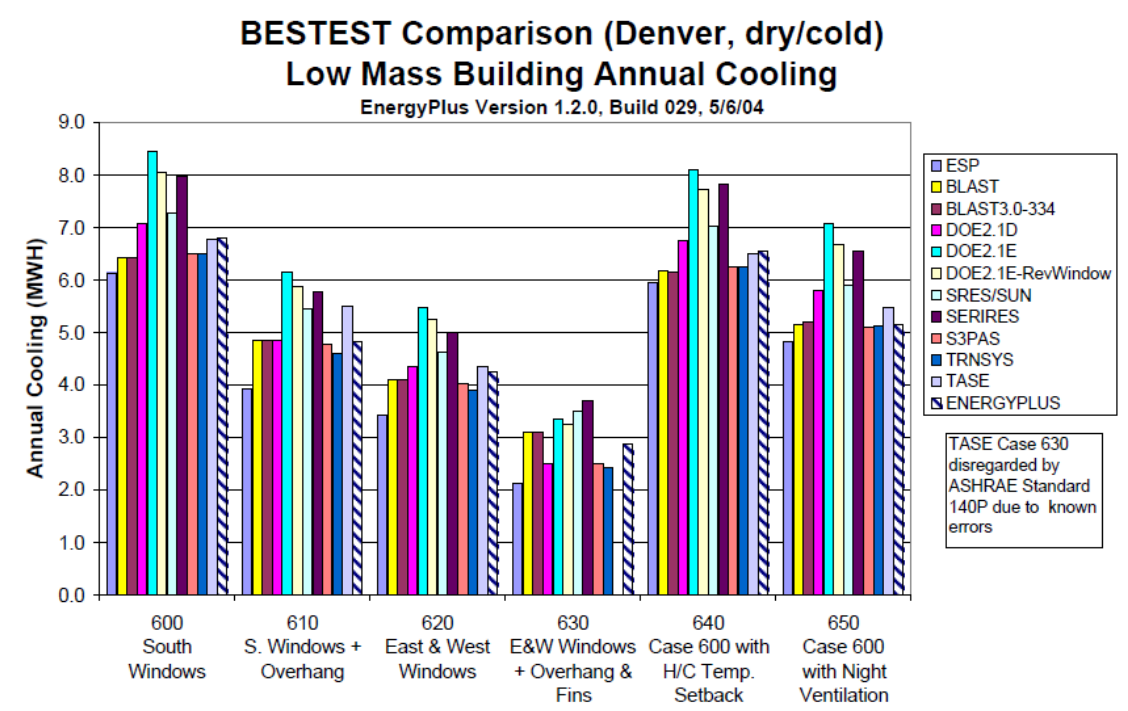

Figure 3.7 - EnergyPlus BESTEST results for low-mass annual cooling requirement

(Henninger \& Witte 2004)

One problem with the software comparison approach for housing in many parts of Australia was that there was a reduced need for controlled heating, ventilation and air-conditioning on a daily basis (Kordjamshidi, King \& Prasad 2005). The Australian climate can, (depending on building fabric), allow a house to operate without the use of heating or cooling for some portions of the day, but may require heating or cooling, at times of minimum and maximum outdoor temperatures (Kordjamshidi \& King 2009). For southern Australia, with its 
predominant heating requirement, a difference in the calculated minimum temperature would have dramatic impact on the energy calculation and the resultant star rating. What was evident to industry and of concern to the government and the CSIRO, was the need to validate the AccuRate program empirically, for the purpose of modification, improvement or calibration of the program (TPC 2005). The methods to validate the software empirically were investigated and these are discussed below.

\subsection{Key Elements of Empirical Validation}

Several reports and research projects over the last twenty years have discussed and provided a growing list of key considerations for any project attempting to validate a detailed simulation program empirically. Many of these documents refer back to Lomas, who specified key data requirements for a validation process (Bowman \& Lomas 1985; Delsante 2005b; Lomas 1991a, 1991b; LomasEppel et al. 1994). These included the following key elements:

- The building did not include active solar space heating or cooling systems

- Weather data must be collected on site

- All observed data for site weather and building thermal performance must be collected at hourly or smaller intervals

- Observed site weather data should include air temperature, wind speed, direct and diffuse solar radiation

- $\quad$ The building must be unoccupied

- The building must not contain any features of a solar passive nature that can not be modelled

- If the building is multi-zoned, each zone should have its own heating and cooling plant

- Zone and inter-zone infiltration should be measured 
- The building should contain no features that the detailed building simulation software is unable to model

This list of key elements provided a useful guide in the validation and assessment of Australian and international detailed simulation and house energy rating programs.

\subsection{Previous Australian Validation Research}

The BESTEST validation previously discussed in section 3.3, is just one of several research projects, that undertook some form of validation of the CHEETAH, CHENATH and AccuRate programs. Each validation took a different approach and focused on different aspects of the house energy rating program. Research has been undertaken to analyse the effects of substituting building materials, such as the effect this had on thermal performance and the resultant star rating, but with no comparison to observed values from buildings in situ (Willrath 1998). Some research involved a comparative analysis of HER program outputs between two building types but with limited comparison to observed buildings (Heathcote \& Moor 2007; Isaacs, T 2005; James, Anda \& Mathew 2004, 2006; Sugo, Page \& Moghtaderi 2004). This approach created a situation where there was little consistency in the process or the validation of the Australian house energy rating programs. None of the projects so far, has validated the software empirically. Although in recent years, the University of Newcastle, University of South Australia, University of Adelaide, Deakin University and other universities have completed research under their own direction, or in partnership with an Australian Federal or State agencies and the CSIRO.

In 1992 the CHEETAH simulation software was compared to observed data from the Energy Monitoring Company (EMC) test buildings in the UK, as part of the International Energy Agency's empirical validation of thermal building simulation programs using test room data (Delsante 1995a; LomasEppel et al. 1994). From this exercise, aspects of the software were identified as requiring improvement. In 1994-1995, after a range of improvements were made, the validation exercise was repeated with improved results; modules of the program were then tested via the BESTEST method, as discussed earlier (Delsante 1995b). The improved software was re-named CHENATH, which subsequently became the NatHERS software. The observed data from the EMC test buildings were taken over two ten-day periods: in October 
1987 and May 1990. These periods did not show the extremes in climate that the continual warm days in summer or continual cool days in winter create, (and which require consistent cooling or heating or both heating and cooling in the same day). Although the task did allow for a comparison of the capacity of the CHEETAH and CHENATH softwares with other internationally accepted softwares, most of the softwares, as a result of the 1992 IEA research, did require some form of improvement. In personal discussions with Delsante between 2005 and 2007, it became evident that many researchers queried the construction method and materials of the test buildings, due to variations between observed and simulated temperatures. In some instances, researchers attended the demolition of the buildings to confirm the test building fabric composition. This highlighted the differences that could occur between simplified physical science based models and how a building of mixed fabric is actually built (Kokogiannakis, Strachan \& Clarke 2008) and responds to the multiple variant inputs of the real world (Hui 2003; Kummert, Bradley \& McDowell 2004).

In recent years, the Mobile Architecture and Built Environment Laboratory (MABEL), a research unit from the School of Architecture and Building at Deakin University, has been engaged to assist in the measurement of selected buildings. In partnership with the CSIRO, this has included a mud-brick house in Victoria, conventional housing in the Northern Territory (Luther \& Horan 2009) and the test cell buildings at the University of Newcastle. In each case, environmental measurements were taken both inside and outside the buildings.

The mud brick house analysis involved detailed environmental measurement over a period of seven days in June 2005 and was conducted as a partnership between the CSIRO and MABEL (Delsante 2006a; Luther \& Atkinson 2008). The house was operated in a freerunning state for four days and with controlled heating for the remaining three days. Due to errors with the heating energy measurement, only the free-running observations were suitable for comparison with simulation results from the AccuRate program. Delsante also raised concerns regarding other site-based observations, where mathematical methods, averaging, and multiple simulations with the program were used to establish revised input variables. The research did show a reasonable correlation between the simulated and observed temperatures with the exception of the peaks and their subsequent downward trends. But a consistent yearlong variation between the peaks and the downward trends would impact on the annual heating and cooling requirement for the house. Given that the external walls consisted of a single material and it was a concrete slab-on-ground floored building, the envelope of the 
building was very simple. Most Australian houses have an external wall which is a combination of materials and cavities, providing a substantially different thermal modelling requirement to the single skinned mud-brick wall. In the greater context of Australian residential construction, the single skin mud brick type of house occupies a very small segment of new and existing housing. Although the research met most of the Lomas criteria (Table 3.4), Delsante stated that the analysis was not an adequate validation exercise due to the limited measurement period and the problems identified with the observations.

In 2006, the CSIRO and MABEL partnered in the detailed measurement and AccuRate simulation of two houses located in Darwin. This research was to establish the effectiveness of the AccuRate software to simulate houses in the hot and humid climates of northern Australia. Particular emphasis was to be placed on the ventilation modelling within the software. This research was not completed and no documents have as yet been published in the public domain (Luther \& Atkinson 2008).

The University of Newcastle constructed and instrumented two brick test buildings in 20022003 (Clark, Sugo \& Page 2003), which were modelled from Burch's research in the U.S. (Burch et al. 1982). The built fabric of the two test buildings is described in Table 3.3. In 2004, the university constructed a third test building which had brick veneer walls, similar to Test Building 2 in Table 3.3, but including a window in the northern wall (Sugo 2006a, 2007). The recorded thermal measurements of the test buildings and their external environment were quite comprehensive, but were not intended for empirical validation. MABEL was engaged to measure infiltration rates and other internal and external environmental conditions, but due to equipment problems, this data has not been used for validation purposes (Sugo 2006b). The research to date has focused only on the comparative performance and analytical analysis of the three test buildings (Alasha'ary et al. 2009; Sugo, Page \& Moghtaderi 2004, 2005). There was one short validation exercise where an AccuRate simulation was compared to observed data for a short period. However, no modifications were made to the simulation inputs to account for the as-built fabric, actual infiltration rates (Sugo 2006b) and site climate inputs. Depending on the quality of the data that has been collected, a retrospective empirical validation can still be conducted, once the input variables above have been determined and integrated into the detailed HER simulation. The test buildings included air-conditioning HVAC plant for cooling and heating. In personal discussions with researchers, it was found that problems were experienced in controlling the operation and measurement of cooling 
output and energy use (Moghtaderi 2005; Sugo 2005-2009). This type of problem was also recognised by LOMAS when the IEA test building task was undertaken and for air recirculating, convective type heaters were preferred (LomasEppel et al. 1994).

Research at the University of South Australia in 2007, included a study that aimed to establish the thermostat settings for cooling operation within AccuRate (Saman et al. 2008). The research was considered as a validation exercise and compared the calculated energy requirement by AccuRate with the energy used by the occupied houses of varying thermal performance. They found little correlation between the calculated and observed energy quantities for cooling the houses. The research did use concurrent weather data to create a weather file, however no internal temperature measurements were taken. There is no data on what temperatures the occupants were cooling the houses to, or what temperature the thermostats of the cooling equipment inside the houses were set to. Without this key input, the amount of energy used to cool the houses cannot be correctly calibrated or correlated to the software outputs (Stein \& Meier 2000). Based on this limited information, changes were proposed to the thermostat set points within the software. This research has also been cited by others to call into question the capabilities of the AccuRate software to predict cooling energy use.

Table 3.3: University of Newcastle test building fabric matrix (2003)

\begin{tabular}{|c|c|c|}
\hline Element & Test Building 1 & Test Building 2 \\
\hline Roof & $\begin{array}{l}\text { Timber truss, } \\
\text { Reflective foil sarking, } \\
\text { Clay tiles }\end{array}$ & $\begin{array}{l}\text { Timber truss, } \\
\text { Reflective foil sarking, } \\
\text { Clay tiles }\end{array}$ \\
\hline Ceiling & $\begin{array}{l}10 \text { m Plasterboard, } \\
\text { R3.5 ceiling batts }\end{array}$ & $\begin{array}{l}\text { 10mm Plasterboard, } \\
\text { R3.5 ceiling batts }\end{array}$ \\
\hline External Walls & $\begin{array}{l}110 \mathrm{~mm} \text { clay brick, } \\
50 \mathrm{~mm} \text { cavity, } \\
110 \mathrm{~mm} \text { clay brick, } \\
10 \mathrm{~mm} \text { render }\end{array}$ & $\begin{array}{l}110 \mathrm{~mm} \text { clay brick, } \\
50 \mathrm{~mm} \text { cavity, } \\
\text { Reflective vapour barrier, } \\
70 \mathrm{~mm} \text { frame with no } \\
\text { insulation, } \\
10 \mathrm{~mm} \text { plasterboard }\end{array}$ \\
\hline Floor & Concrete slab-on-ground & Concrete slab-on-ground \\
\hline
\end{tabular}

A comparison of the inputs of these various projects to the minimum criteria discussed by Lomas $(1991,1994)$, as summarised in Table 3.4, clearly demonstrates that there has been no validation of an empirical nature of AccuRate which could be used to identify problems 
within the program. This knowledge further underpinned the building sector's concerns as to the AccuRate program's unproven capabilities (Dewsbury 2006; Nolan 2006b).

Table 3.4: Compliance of recent Australian validation tasks to Lomas criteria

\begin{tabular}{|c|c|c|c|}
\hline Element & $\begin{array}{l}\text { Mud-brick } \\
\text { House }\end{array}$ & $\begin{array}{l}\text { Newcastle Test } \\
\text { Cells }\end{array}$ & $\begin{array}{c}\text { SA Energy } \\
\text { Consumption }\end{array}$ \\
\hline No active solar heating & Yes & Yes & Yes \\
\hline No active solar cooling & Yes & Yes & Yes \\
\hline Site weather data & Incomplete & $\begin{array}{l}\text { Collected / not } \\
\text { used }\end{array}$ & Weather Station \\
\hline Hourly collection of data & Incomplete & Yes & No Internal data \\
\hline Unoccupied building & Yes & Yes & No \\
\hline No features that cannot be modelled & $\# 1$ & \#2 & \#3 \\
\hline Each zone has its own HVAC plant & Free-running & Yes & \#4 \\
\hline Infiltration measured & Incomplete & No & No \\
\hline Time Period & 4 Days & Ongoing & Min 5 months \\
\hline \multicolumn{4}{|c|}{$\begin{array}{l}\text { \#1: Single skin external walls } \\
\# 2 \text { : As built modifications have not been made to input files for AccuRate simulations } \\
\# 3 \text { : As built modifications have not been made to input files for AccuRate simulations }\end{array}$} \\
\hline
\end{tabular}

\subsection{Previous International Validation Research}

Many countries have completed research to validate, improve and calibrate their detailed building thermal simulation programs for residential and commercial buildings (Guyon, G \& Rahni 1997; Lomas 1991a; Neymark et al. 2005; Tuomaala \& Piira 1997). The International Energy Agency's research has been quite extensive, encompassing more than forty different task areas (Judkoff, R 1985, 2008; Strachan 2000; Strachan, Kokogiannakis \& MacDonald 2005). The 1992 empirical validation task (Lomas 1994; LomasEppel et al. 1994; LomasMartin et al. 1994) brought together many nations and their respective detailed simulation programs (Strachan, Kokogiannakis \& MacDonald 2005; Sullivan \& Winkelmann 1998). Prior to and after this work, several nations constructed test buildings for the purpose of testing building systems and calibrating building thermal simulation software. Within Europe and the U.K. this has included collaboration through the PASSYS, 1986-1993 (CSTB 1990; Neymark et al. 2005; Strachan, Kokogiannakis \& MacDonald 2005; Van Dijk \& van der Linden 1993) and PASLINK research programs (Clarke, Strachan \& Pernot 1994; Leal \& Maldonado 2008). The U.S. Department of Energy and other national governments have funded many projects to assist in the development, improvement and calibration of detailed simulation programs (Clarke 2001; Guyon, G 1997). 
The focus of the International Energy Agency's Annex 21 task was the calculation of energy and environmental performance of buildings. Research projects that have included the empirical validation of detailed thermal simulation programs for building fabric have included:

- Task 12/21: BRE/DMU tests (Strachan 2000; Strachan 2008)

- Task 22: RADTEST, HVAC BESTEST, Essais Thermique en climat Naturel et Artificiel (ETNA) and GENEC test cell models (Girault 1994; Guyon, G, Moinard \& Ramdani 1999a, 1999b; Moinard \& Guyon 1999; Neymark et al. 2005; Palomo del Barrio \& Guyon 2002; Strachan, Kokogiannakis \& MacDonald 2005)

- Task 34/43: EMPA Shading, Day-lighting and Load tests (Loutzenhiser et al. 2006; Manz, H et al. 2006), ERS Shading, Day-lighting and Load tests (Strachan 2008) and Double Skin Facades Tests (Judkoff, R 2008)

Task 12, undertaken from 1989 to 1994, was the first empirical validation project undertaken by the IEA, with involvement from nine countries and seventeen detailed simulation programs (Lomas 1994; LomasEppel et al. 1994; LomasMartin et al. 1994; Strachan, Kokogiannakis \& Macdonald 2008). Observed data was originally collected from sites in the UK, USA, Switzerland, Canada and other participating nations. Due to unacceptable errors, or uncertainties in observations from the original broad range of test buildings, the final empirical validation only considered the data from the UK Energy Monitoring Company (EMC) single zone test buildings. The EMC test buildings were purpose-built and their design and construction is discussed further in section 3.7. The research found that amongst the seventeen programs analysed during the free-running stage that:

- six programs failed to predict maximum and minimum temperatures within agreed error bandwidths for an opaque-glazed room

- Only five programs predicted maximum and minimum temperatures within agreed error bandwidths for a double-glazed room

- Only two programs predicted maximum and minimum temperatures within agreed error bandwidths for a single-glazed room 
- There was a general tendency by the programs to under-predict room temperatures

- The calculated peak temperature for a day in May in a double-glazed room varied from $26.0^{\circ} \mathrm{C}$ to $35^{\circ} \mathrm{C}$

- The calculated minimum temperature for the double-glazed room varied by $2.5^{\circ} \mathrm{C}$

- When examining the improved thermal performance of a double-glazed window over an opaque window, the softwares' predicted improvements ranging from $9.8^{\circ} \mathrm{C}$ to $17.2^{\circ} \mathrm{C}$

This IEA research established benchmarks for the minimum required observations for future projects aiming to validate thermal simulation programs empirically. The report also discussed possible shortcomings, which included experimental uncertainty and modelling issues. Due to the variation in software calculated temperatures, there was some debate as to the true construction of the test buildings. As much as this project set the benchmark for future research, the observed data consisted of only twenty days, in contrast to the full calendar year in a standard simulation. The twenty days consisted of ten days each from March and October respectively. This extremely limited period would not have allowed for the testing of a detailed simulation program's capacity to capture the seasonal effects of thermal capacitance that is: longer periods of cool temperatures in winter, longer periods of warmer temperatures and the general variability of the external environment, including the cycles of days with rain, intermittent cloud cover, variant solar radiation and consistently changing wind speed and direction.

The final report for the Task 34 program of 2008 (Judkoff, R 2008) lists twenty-four detailed simulation programs that were tested. The CSIRO was listed as a participant, but the CHENATH/AccuRate programs were not evaluated in this task. The six research areas of the task included: the assessment of inter-zone conduction and shading, natural and forced airflow, lighting, mechanical equipment, double-skin facades and limited validation tests. Some of these functions were beyond the current capabilities of the AccuRate program. The validation tests included the collection of observed data from the EMPA test cells. The EMPA data included: the capacity to test conductance, capacitance, the effect of glazing and various forms of internal and external shading (Manz, $\mathrm{H}$ et al. 2006). The collected data allowed for 
the comparison of a wide range of predicted and observed values. None of the twenty-four programs were compared to the outputs from the six different research areas (Table 3.5). The majority of programs performed a comparison with only one of the six research areas.

Table 3.5: Software validation during IEA Task 34 research

\begin{tabular}{|l|c|}
\hline Softwares compared to 1 of the 6 research areas & 18 \\
\hline Softwares compared to 2 of the 6 research areas & $\begin{array}{c}3 \\
\text { (CODYRUN, HTB2, TRYNSIS-16) }\end{array}$ \\
\hline Softwares compared to 3 of the 6 research areas & $\begin{array}{c}1 \\
\text { (VA-114) }\end{array}$ \\
\hline Softwares compared to 4 of the 6 research areas & $\begin{array}{c}2 \\
\text { (EnergyPlus, ESP-r) }\end{array}$ \\
\hline
\end{tabular}

The data collected by the EMPA test cells which allowed for the comparison of inter-zone conduction and shading, was only used for nine of the twenty-four programs. It was noted that the research led directly to the improvement and modification of the simulation programs involved. In the case of the EMPA data, thirty-two improvements were made to the programs involved in that portion of the research (Table.3.6). The final report recommended that further model development and validation was essential.

Table.3.6: EMPA attributable software improvements

\begin{tabular}{|l|c|}
\hline Number of Detailed simulation programs involved & 9 \\
\hline Number of identified disagreements & 48 \\
\hline Number of fixed disagreements & 32 \\
\hline Unresolved disagreements & 6 \\
\hline
\end{tabular}

The U.S. DOE building energy simulation programs (DOE-1, DOE-2, EnergyPlus) have been through many validation exercises from 1981 to the present. At various stages, reports have discussed aspects of programs that appeared to be working well and those that required further inputs, improvement or calibration (Bowman \& Lomas 1985; Crawley et al. 1999; Ellis 2003; Ghatti et al. 2003; Haberl 2004; Henninger \& Witte 2004; Lomas 1991a; Sullivan \& Winkelmann 1998; Witte, M \& Henninger 2004; Witte, MJ et al. 2001). The validation exercises have, over time, addressed calculated temperatures, heating and cooling energy, or individual modules within the software. Validation studies have included the use of test buildings, houses and commercial buildings. Each release and revised version of the softwares has included a growing list of improvements to: the climate files, built fabric, heating, 
cooling, ventilation and energy calculation models within the program. Recent empirical validation studies included the following:

- Sacramento public housing 1993-1995: Analysis of the observed performance of evaporative cooling, ground-source heat pumps, effects of roof surface treatment and building orientation. The effects of building orientation compared observed air temperature data to the predicted temperatures for a period of nearly five months. Some variance was observed between temperature peaks and the effects of natural ventilation. This lead to improvements to the natural ventilation algorithms in the software (Vincent \& Huang 1996).

- Pala Test Houses 1995: The detailed measurement of a low-mass and a high-mass test building, each with a floor area of $27 \mathrm{~m}^{2}$. Each test building included two rooms and a vented attic. The buildings were unoccupied and free-running during the data collection period. Four types of building test were conducted, with data collected for each for six days. From this research, improvements were noted for the algorithms and models associated with the warm-up period, ground model and ground surface temperatures. During the six day periods it was found that the mean deviation between the predicted and observed temperatures varied by 0.2 to $1.0 \mathrm{~K}$ (Meldem \& Winklemann 1995, 1998).

- IEA Empirical validation using EMC test buildings (1989-1994): Observed air temperatures during free-running period in May and observed air temperatures and heater energy use in October. Of the ten days of observed data in October, only seven were suitable for validation purposes, due to the building warm-up stage. In both the May and October comparisons, the DOE program had a variation between $1{ }^{\circ} \mathrm{C}$ and $4^{\circ} \mathrm{C}$ from the observed temperature within the test building (LomasEppel et al. 1994).

Research prior to 1999 included a range of test cells and house observations (Birdsall 1985; Burch et al. 1982; Colborne, Hall \& Wilson 1984; Diamond, Cappiello \& Hunn 1985; Goldberg 1985; Judkoff, R 1985; Judkoff, R, Wortman \& Burch 1983a, 1983b; Lomas 1991a; NAHB 1999; Robertson 1985; Sorrell, Luckenback \& Phelps 1985; Wagner 1984). In many of these activities the data collection period for validation was as short as one day, with some using between six and seven days of data. Only a few projects collected observed data for 
longer periods, for the purpose of empirical validation. It is evident from all the published works that the DOE software was improved incrementally as a result of each activity.

The IEA Task 22, Empirical Validation of ETNA (Girault 1994; Guyon, G, Moinard \& Ramdani 1999a, 1999b) and GENEC (Moinard \& Guyon 1999) test cell models compared the observed temperatures and energy use from free-running and heated test cells. The research included ten detailed simulation programs from Europe, UK and the USA. The research was conducted in three stages: ETNA1 (23 days), ETNA2 (41 days) and GENEC (14 days). In each validation the detailed simulation included the use of default and modified simulations. The methods of thermal simulation are discussed further in Section 4.4. The predicted maximum air temperature for the test building room, varied between participating programs by up to $5^{\circ} \mathrm{C}$. The conclusions for each of the three stages are the following:

- The non-consideration by programs of the actual average conductivity value of built elements affected thermal simulation results. This included elements within the built fabric which caused thermal bridging or reduce insulation capacity.

- Discrepancies were observed for the surface film co-efficient

- The type of heater impacted on room temperature when in operation

- The effect of solar radiation differed between programs

- Generally some programs either under-predicted or over-predicted day time temperatures and conversely, over-predicted or under-predicted night time temperatures

The ongoing improvement and validation of the CLIM2000 software in 1999 identified five key aspects requiring improvement (Rahni et al. 1999), namely:

- Conductivity of wall air gaps

- Concrete slab-on-ground density

- Internal heat transfer coefficients for floors

- Conductivity values for floor insulation 
- Conductivity values for glazing.

Similarly, several researchers (Kummert, Bradley \& McDowell 2004; Palomo del Barrio \& Guyon 2002; Strachan, Kokogiannakis \& MacDonald 2005; Strachan, Kokogiannakis \& Macdonald 2008) have stressed several key aspects for the development of any detailed building simulation program which include:

- Empirical and other forms of validation are an ongoing process in program development

- For validation to be effective, its findings must be embedded within the development, improvement and calibration of simulation programs

Internationally the leading detailed building simulation programs have been through extensive comparative and empirical validation analyses. While this appears impressive, as it is much greater than any comparison that the CHENATH and AccuRate programs have been subjected to, it can also lead to some false assumptions, as many of these comparisons have been performed based on as little as 20 days or less of observed data. Empirical validation should include: the hotter periods of summer, the consistently cooler periods of winter and the more moderate weather of the equinoxes. To support the development of an improved empirical validation method, for this study, the test buildings in the IEA and other reports were reviewed. The following section (3.7) summarises this review.

\subsection{Background to Test Buildings for Empirical Validation}

A survey of thermal performance test buildings for the purpose of empirically validating detailed building simulation programs revealed a mix of approaches, methods and types. Most were built to match the typical fabric and element assemblages for residential and commercial buildings at the time of their construction. As insights into the construction of thermal test buildings evolved, construction methods were modified. The form and composition of test buildings evolved from the earlier small buildings to co-joined test rooms and super-insulated test chambers. 
The majority of current (2010) building fabric thermal performance testing now occurs in test chambers which internationally are referred to as the PASLINK test facilities, previously known as the PASSYS test facilities (Baker \& van Dijk 2008; CSTB 1990; Leal \& Maldonado 2008; Strachan \& Vandaele 2008; Van Dijk \& van der Linden 1993). Only a few test facilities currently exist which consist of free-standing single-roomed small buildings and some of the free-standing buildings contain multiple thermal test chambers. The evolution from small building to test chamber seemed to reflect and acknowledge several issues including:

- A large portion of residential construction, internationally, was shifting from low to medium or high density building systems. This meant a change from each residence having four external walls to only one or two

- Many previous studies, which used whole buildings experienced complications due to the quality of measurement of indoor and outdoor environmental conditions

- Many previous studies, which used whole buildings, experienced complications due to the limited control of construction practice, which dramatically affected building simulation input data

- The need to understand commercial, as differentiated from residential, building thermal performance

- The need to limit the number of experimental variables as much as possible for researchers to better understand building thermal physics for the development of detailed simulation programs

An international network of facilities located in various climatic zones (Figure 3.8), was sponsored by the European Commission and existed under the banner of the PASSYS and PASLink research programs (Baker, P 2008; CSTB 1990; Strachan \& Vandaele 2008). The PASSYS \& PASLINK test facilities met many of these criteria, where the test buildings were pre-fabricated, shipped to site and consisted of a super-insulated building with an interchangeable wall panel (Baker 2003; Strachan \& Baker 2008). In most cases, the test building could be rotated to allow for the observation and measurement of a fabric assemblages' performance in both solar and non solar orientations, as in Figure 3.9 (Clarke, 
Strachan \& Pernot 1994; Jimenez, Madsen \& Andersen 2008; Van Dijk \& van der Linden 1993).

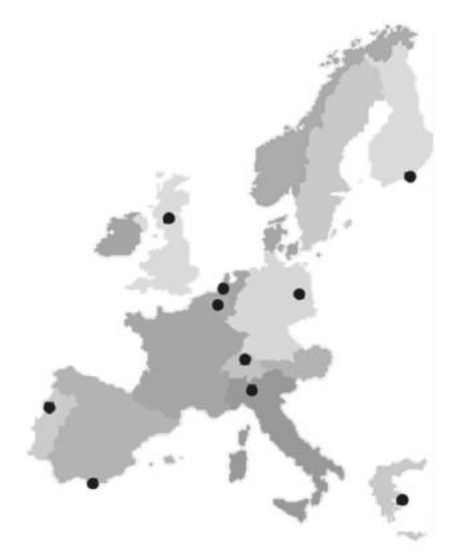

Figure 3.8 - European Network of PASLINK/PASSYS Test Facilities

(Baker, P 2008, p. 182)

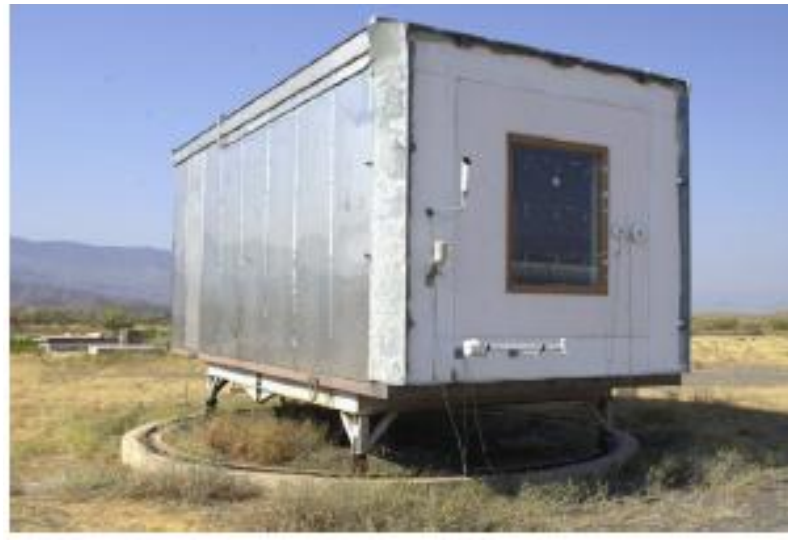

Figure 3.9 - PASSYS/PASLINK test building photograph

(Jimenez \& Madsen 2008, p. 157)

The PASSYS/PASLINK test buildings were located in Europe, but detailed building simulation program developers from the USA and Canada (in some instances) compared their program outputs to the test results from these buildings. At the same time, the ETNA and other test facilities in Europe, the UK, Canada and the USA, were still being used for empirical validation studies to improve: the thermal transmittance, thermal capacity, ventilation and HVAC elements of jurisdiction-based detailed simulation programs.

However, in Australia limited research was undertaken in this area. Traditionally, this area of research had been conducted by the CSIRO, but due to nationally based research priorities, this was not seen as an area of importance. Instead, the Australian federal government had adopted a market based approach, where the market would demand products and industry would meet the market's demand. Due to the affordability of energy in Australia and Australia's limited action on greenhouse gas emissions, there was very little market interest in the development of buildings with better thermal performance, or programs for use in the design and assessment of a proposed building's thermal performance (Wilkenfield, Hamilton \& Saddler 1995). Despite the lack of government and industry support, concern by some stakeholders within the housing construction industry prompted some university researchers to conduct validation studies. Small test buildings were constructed at the University of Technology Sydney (UTS) and the University of Newcastle. 
The UTS test buildings were constructed principally for the purposes of comparative thermal analysis of three types of external wall construction: mud-brick, brick veneer and autoclaved aerated concrete veneer. All three test cells had a concrete slab-on-ground floor (Heathcote \& Moor 2007). Similarly, the University of Newcastle constructed two test cells to compare the thermal performance of cavity clay brick and clay brick veneer external wall construction (Clark, Sugo \& Page 2003; Sugo 2006a). Like the UTS test cells, they both had a concrete slab-on-ground floor. Later a third test cell of clay brick veneer with a northern window and a concrete slab-on-ground floor was added to the Newcastle test cells. Research involving the Newcastle test cells has concentrated on comparative analysis (Sugo, Page \& Moghtaderi 2004, 2005).

A survey of the test buildings discussed above is included in Table 3.7. The key aspects of the review of the previously built test buildings included:

- The type of test building: Test chamber with a single interchangeable panel, free standing single or co-joined building

- The area, depth and volume of the thermal test rooms

- The built fabric of the test buildings or chamber

The variety of construction systems that exist in the test buildings reflected the local practices or research questions, at the time of construction. This was observable in the EMC ETSU (Lomas 1994; LomasEppel et al. 1994), NBS Maryland (Lomas 1991c), ETNA (Girault 1994), Canadian direct gain (Judkoff, R 1985), PASSYS (CSTB 1990), UTS (Heathcote \& Moor 2007) and the University of Newcastle test buildings (Clark, Sugo \& Page 2003). To validate empirically the AccuRate program, any new test buildings should be similar in nature to contemporary and conventional residential construction practices within Australia. 


\section{Table 3.7: Survey of test building for validation of detailed building simulation programs}

\begin{tabular}{|c|c|c|c|c|c|c|c|c|}
\hline Name & Country & Type & Width & Depth & Height & Floor Area & Volume & Description \\
\hline EMC ETSU & U.K & $\begin{array}{c}\text { Co-joined pairs, with } \\
\text { heavily insulated party-wall }\end{array}$ & 1.51 & 2.35 & 2.28 & $3.54 m^{2}$ & $8.07 \mathrm{~m}^{3}$ & Super-insulated with sun-facing changeable wall panel \\
\hline $\begin{array}{l}\text { PCL Test } \\
\text { Cells }\end{array}$ & U.K. & $\begin{array}{l}\text { Two Co-joined pairs, with } \\
\text { heavily insulated party-wall }\end{array}$ & $\sim 1.65$ & $\sim 2.10$ & $\sim 3.00$ & $\sim 3.46 \mathrm{~m}^{2}$ & $\sim 10.40 \mathrm{~m}^{3}$ & Super-insulated with sun-facing changeable wall panel \\
\hline EMC Gas & U.K & $\begin{array}{c}\text { Single free standing test } \\
\text { cell }\end{array}$ & 2.03 & 2.03 & 2.33 & $4.14 m^{2}$ & $9.66 m^{3}$ & $\begin{array}{l}\text { Fixed construction but thermal mass and HVAC } \\
\text { changed over time }\end{array}$ \\
\hline ETNA & France & $\begin{array}{l}\text { Semi-detached cells, with } \\
\text { heavily insulated partition }\end{array}$ & 3.50 & 4.65 & 2.54 & $16.28 m^{2}$ & $41.30 \mathrm{~m}^{3}$ & Super-insulated with sun-facing changeable wall panel \\
\hline NBS & U.S.A & $\begin{array}{l}\text { Four co-joined cells, with } \\
\text { heavily insulated party-wall }\end{array}$ & $\sim 3.60$ & $\sim 8.20$ & $\begin{array}{c}\sim 2.50 \\
\# 1\end{array}$ & $29.52 \mathrm{~m}^{2}$ & $\sim 87.10 \mathrm{~m}^{3}$ & $\begin{array}{l}\text { Each test cells has access to a clerestory window. } \\
\# 1 \text { : Plus clerestory }\end{array}$ \\
\hline $\begin{array}{c}\text { NBS } \\
\text { Los Alamos }\end{array}$ & U.S.A. & $\begin{array}{l}\text { Co-joined pair, with heavily } \\
\text { insulated party-wall }\end{array}$ & 1.57 & 2.18 & 3.05 & $3.42 m^{2}$ & $10.45 m^{3}$ & Super-insulated with sun-facing changeable wall panel \\
\hline $\begin{array}{l}\text { NBS } \\
\text { Maryland }\end{array}$ & U.S.A. & $\begin{array}{l}\text { Six stand alone test } \\
\text { buildings }\end{array}$ & 6.10 & 6.10 & 2.30 & $37.21 \mathrm{~m}^{2}$ & $85.58 m^{3}$ & $\begin{array}{l}\text { Insulated lightweight wood, uninsulated lightweight } \\
\text { wood, insulated masonry outside mass, uninsulated } \\
\text { masonry, log, insulated masonry inside mass }\end{array}$ \\
\hline $\begin{array}{l}\text { Trombe } \\
\text { Wall }\end{array}$ & Switzerland & $\begin{array}{c}\text { Stand Alone Single Test } \\
\text { Cell }\end{array}$ & $\sim 2.30$ & $\sim 2.30$ & $\sim 2.30$ & $\sim 5.30 \mathrm{~m}^{2}$ & $\sim 12.20 \mathrm{~m}^{3}$ & Super-insulated with sun-facing Trombe wall \\
\hline $\begin{array}{l}\text { Direct Gain } \\
\text { building }\end{array}$ & Canada & $\begin{array}{l}\text { Co-joined pair, with heavily } \\
\text { insulated party-wall }\end{array}$ & 2.81 & 4.38 & 2.40 & $12.31 m^{2}$ & $29.54 m^{3}$ & $\begin{array}{l}5 \text { Rooms, } 2 \times \text { solar-facing, } 2 \times \text { non-solar, } 1 \text { service } \\
\text { corridor. Super-insulated with sun-facing changeable } \\
\text { window }\end{array}$ \\
\hline $\begin{array}{l}\text { PASSYS / } \\
\text { PASLINK } \\
\text { Test Cells }\end{array}$ & $\begin{array}{l}\text { Belgium, Denmark, } \\
\text { France, Germany, Italy, } \\
\text { Netherlands \& U.K. }\end{array}$ & $\begin{array}{c}\text { Stand Alone Single Test } \\
\text { Cell }\end{array}$ & 2.75 & 5.00 & 2.75 & $13.75 m^{2}$ & $37.81 \mathrm{~m}^{3}$ & $\begin{array}{l}\text { Super-insulated with sun-facing changeable wall } \\
\text { panel. Some on turntable to allow for rotation of test } \\
\text { cell }\end{array}$ \\
\hline $\begin{array}{l}\text { UTS Test } \\
\text { Cells }\end{array}$ & Australia & $\begin{array}{l}\text { Three stand alone cells with } \\
\text { concrete slab-on-ground } \\
\text { floor }\end{array}$ & 4.00 & 4.00 & 2.40 & $16.00 \mathrm{~m}^{2}$ & $38.40 \mathrm{~m}^{3}$ & $\begin{array}{l}\text { One of Mud-brick, Brick veneer \& AAC veneer } \\
\text { construction }\end{array}$ \\
\hline $\begin{array}{l}\text { University } \\
\text { Newcastle } \\
\text { Test Cells }\end{array}$ & Australia & $\begin{array}{l}\text { Three stand alone cells with } \\
\text { concrete slab-on-ground } \\
\text { floor }\end{array}$ & $\begin{array}{l}5.44 \\
5.52\end{array}$ & $\begin{array}{l}5.44 \\
5.52\end{array}$ & $\begin{array}{l}2.45 \\
2.45\end{array}$ & $\begin{array}{l}29.59 m^{2} \\
30.47 m^{2}\end{array}$ & $\begin{array}{l}72.50 m^{3} \\
74.65 m^{3}\end{array}$ & $\begin{array}{l}\text { Brick cavity Construction } \\
\text { Brick veneer construction }\end{array}$ \\
\hline
\end{tabular}

Sample plans, elevations, sections and photographs of some test buildings discussed in Table 3.7 are located in Appendix 1 


\subsection{Conclusion}

The validation of a detailed simulation program requires the comparison of a simulation output with data from another source. This research aimed to provide guidance to the CSIRO as to aspects of the software which may require improvement and calibration. Based on this review and in consultation with the CSIRO, industry groups and government agencies, it was agreed that the most suitable form of validation would be of the empirical type.

A review of the empirical validation of detailed simulation programs completed in other countries over the last thirty years, established key areas of guidance for future empirical validation research. This included the construction of purpose-built test buildings, which allow for the fabric inputs, for the program being evaluated to be appropriately modified to correspond to the as-built condition (Baker, P 2008). The test building should include current building materials, assemblages and construction practices, to enable the verification of the program's capacity to model the building and its ability to calculate the temperature and energy use of the building. The test building would allow for modifications over time, to allow for the testing and retesting of the program being evaluated, so that continual improvement and calibration could occur. This process would be quite lengthy, as a full empirical validation would include the assessment of a program's capacity to calculate room temperature and energy use so to maintain a comfortable environment. For the immediate needs of government and industry, this research would concentrate on validating the capacity of the AccuRate program to predict the room temperature. The test buildings would be constructed to enable future validation of the heating energy model.

As with the previous Australian experience, many projects have not captured the essential data to perform an empirical validation of the program in question. From the review of test buildings and associated research for the purpose of validating detailed simulation and house energy rating programs, it was established that suitable test buildings should be constructed in an appropriate climate zone within Australia. The buildings and the site should be suitably measured, to enable the collection of appropriate data for comparison to an AccuRate simulation output temperature data. The methodology for this research, as discussed in Chapter 4, established:

- the general methodology that was established for the research program (Chapter 4.1) 
- $\quad$ the type of test buildings (Chapter 4.2)

- the method of building thermal and climate measurement (Chapter 4.3)

- the process of undertaking a detailed thermal simulation with the AccuRate software (Chapter 4.4) and

- $\quad$ the methods to compare the simulated and observed temperatures (Chapter 4.5). 


\section{Methodology}

\subsection{Introduction}

Much has been published on the principles and practices of empirical validation (Agami Reddy, Maor \& Panjapornpon 2007; DewsburySoriano et al. 2009; Lomas 1991a; LomasEppel et al. 1994; Raftery, Keane \& Costa 2009). In all of these studies, there were general principles that were followed and these are represented in Figure 4.1 - A Validation Methodology.
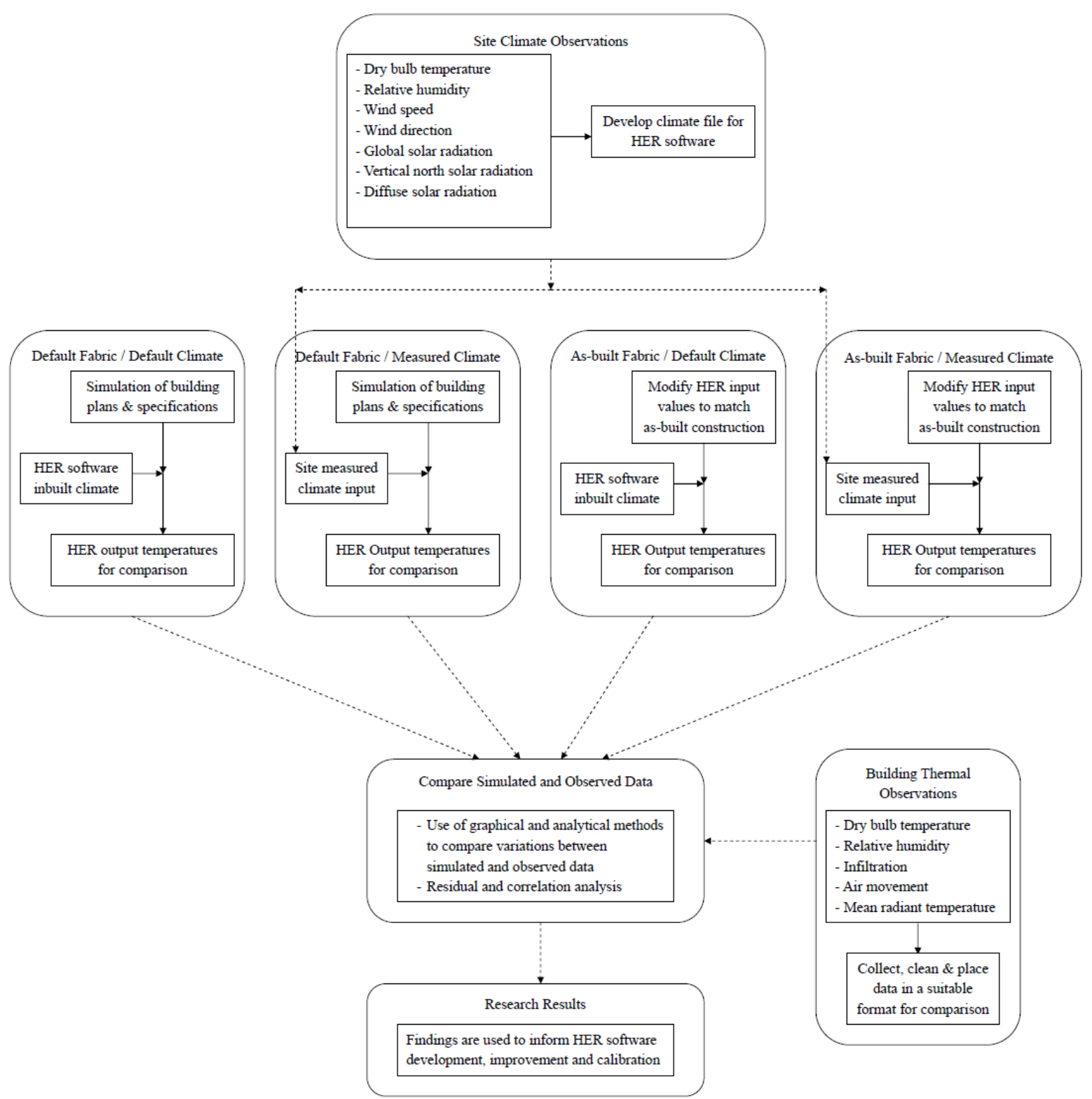

Figure 4.1 - A Validation Methodology 
Figure 4.1 shows four distinct types of house energy rating simulation, site climate observations and building thermal observations. The site climate observations are used for two of the house energy rating simulation types. Once the data is obtained from the HER simulation and the building thermal observations, a comparison can occur between the two data sets. The type of validation is dependent on the type of HER simulation. As the principle objective of the research was to validate the AccuRate software empirically, the as-built / measured climate type of house energy rating simulation was the desired method.

\subsubsection{The Research Methodology}

In empirically validating the house energy rating software AccuRate in cool temperate climates in Australia, the test cell method was adopted due to a mix of resource and financial constraints. The test cell type of building and typical research resource constraints required some aspects of the methodology in Figure 4.1 to be further refined and developed, as per Figure 4.2, without compromising the empirical validation process (Agami Reddy, Maor \& Panjapornpon 2007; Dewsbury 2009). This methodology allowed the separation of the research tasks and a structured progression through the research program (Lomas 1991a; LomasEppel et al. 1994). 


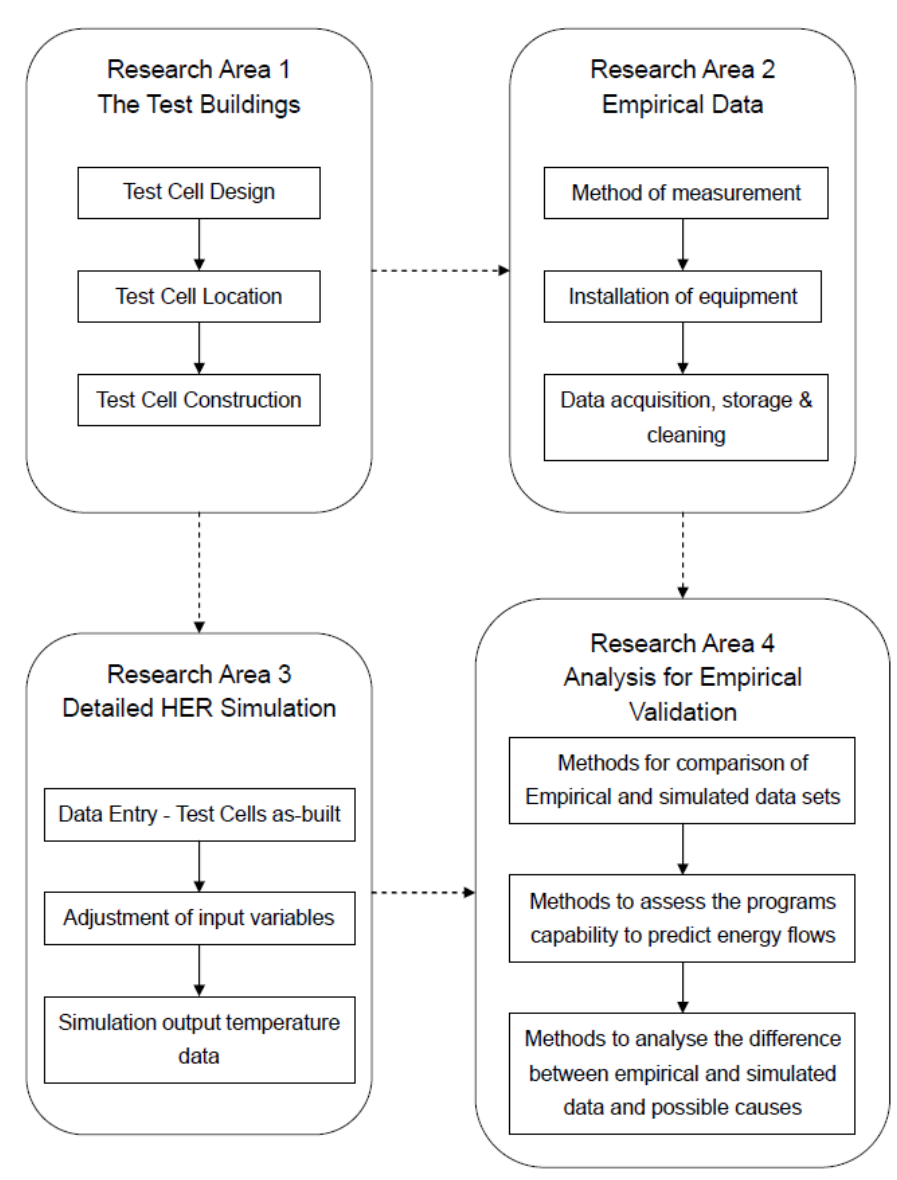

Figure 4.2 - Launceston Test Cell Methodology

The research process was divided into four distinct stages, which assisted and promoted the separation of activities and functions during the research (Lomas 1994). As many researchers involved in the building thermal performance area have had extensive experience, there can be an unconscious tendency to rationalise the data or the results based on personal experience, rather than allowing the data to tell its own story. The separation of the data by the staged approach to the research should correct this tendency. The four distinct elements for the empirical validation, as illustrated in Figure 4.2, were:

1. A suitable physical building which can be measured

2. The measurement of the building and its external climate to obtain empirical data

3. A detailed HER software simulation, which provided suitable outputs for comparison

4. Methods to analyse and compare the empirical and simulated data sets. 
Each of these stages is detailed in much greater depth in sections: 4.2 The Thermal Performance Test Cells, 4.3 Empirical Data, 4.4 Detailed Thermal Simulation by AccuRate and 4.5 Methods of Analysis of this chapter. The analysis of the As-built / Climate simulated data led to a greater understanding of the input variables within AccuRate and the refinement of some building fabric inputs.

The empirical validation results and analysis is discussed in Chapter 5.

\subsubsection{Empirical Data}

Empirical validation requires the collection of empirical data. The term empirical infers that the data has been obtained by means of experience, measurement or observation during the experiment. For the empirical validation of the HER software two key areas of empirical data are required (Agami Reddy, Maor \& Panjapornpon 2007; Bowman \& Lomas 1985; LomasEppel et al. 1994). Figure 4.1 and Figure 4.2 illustrate the need to collect climate and building thermal performance data. Further investigation of other research and HER software inputs established the key elements as listed in Table 4.1.

Table 4.1: Minimum Environmental Elements to be Collected

\begin{tabular}{|l|l|}
\hline \multicolumn{1}{|c|}{ Building Data } & \multicolumn{1}{c|}{ Climate Data } \\
\hline Dry Bulb Temperature & Dry bulb Temperature \\
\hline Relative Humidity & Relative Humidity \\
\hline Mean Radiant Temperature & Wind Speed \& Wind Direction \\
\hline Air Movement & Direct Beam Solar Irradiance \\
\hline Infiltration & Horizontal Solar Irradiance \\
\hline Roof Space Data & Diffuse Solar Irradiance \\
\hline & Site Shading \\
\hline & Atmospheric Pressure \\
\hline & Cloud Cover \\
\hline & Solar Azimuth \& Altitude \\
\hline
\end{tabular}

The building data to be collected, as listed in Table 4.1, requires environmental measurement for all zones of the building. For all buildings this would include both the roof space and the room spaces and for buildings with a subfloor, detailed observations of the subfloor thermal condition are required. The collection of the empirical data provides a minimum thermal performance data set (Loutzenhiser, Manz \& Maxwell 2007) which can be used for comparison and analysis against the various simulation methods discussed above. The empirical building data can also be compared with other co-located test building empirical 
data. The collected empirical climate data is the minimum required to create a site specific climate file for use by the HER software to undertake a simulation for empirical validation purposes (Bowman \& Lomas 1985; Lomas 1991a). 


\subsection{The Thermal Performance Test Cells}

\subsubsection{Introduction}

The purpose of the research was to empirically validate the house energy rating software or detailed simulation programs in a cool temperate climate, with a specific emphasis on the Australian government sponsored software AccuRate. The thermal performance test cells formed a key element in the empirical validation of the HER software AccuRate for cool temperate climates. Figure 4.2, above, illustrates the four distinct stages of this empirical validation research. The focus of this chapter is research area 1: 'The Test Cell Buildings'. Research areas 2, 3 and 4 respectively are discussed in the following sections of this chapter.

\subsubsection{Objectives of the Thermal Performance Test Cells}

The research literature discussed in Chapter 3: Background to HER Program Validation, determined a number of factors critical to empirical validation. The primary objective of the thermal performance test cells was to provide buildings that would be thermally measured, for the purpose of empirically validating the HER software Accurate in a cool temperate climate. From this primary objective, critical elements were identified which required attention (Dewsbury et al. 2007; Dewsbury, Nolan \& Fay 2007), namely:

- The location of the test buildings

- The construction materials and systems of the test buildings

- The identification of a building fabric matrix, with known quantifiable properties, that could be factored into the HER thermal simulation

- A carefully managed construction process that would ensure that the physical material properties of the buildings are carefully controlled

- Buildings should support the requirements of adequate environmental measurements, resulting in an empirical validation data set 


\subsubsection{The Design of the Thermal Performance Test Cells}

The thermal performance test cells were designed to measure the effect of the external environment on the internal environment of a lightweight residential building. The empirical validation would be performed by comparing the measured data from the building with HER software simulation data. This physical experiment was affected by a number of non-constant inputs (Figure 4.3). Furthermore, the design of the test cell buildings required consideration of methods that minimised unmeasurable effects, like unknown fabric variations and ensured accurate measurement of relevant environmental values, such as air temperature (Dewsbury, Nolan \& Fay 2007; LomasEppel et al. 1994). The objectives of the research would inform: the location of the test buildings, the type of structure, size and fabric of the buildings.

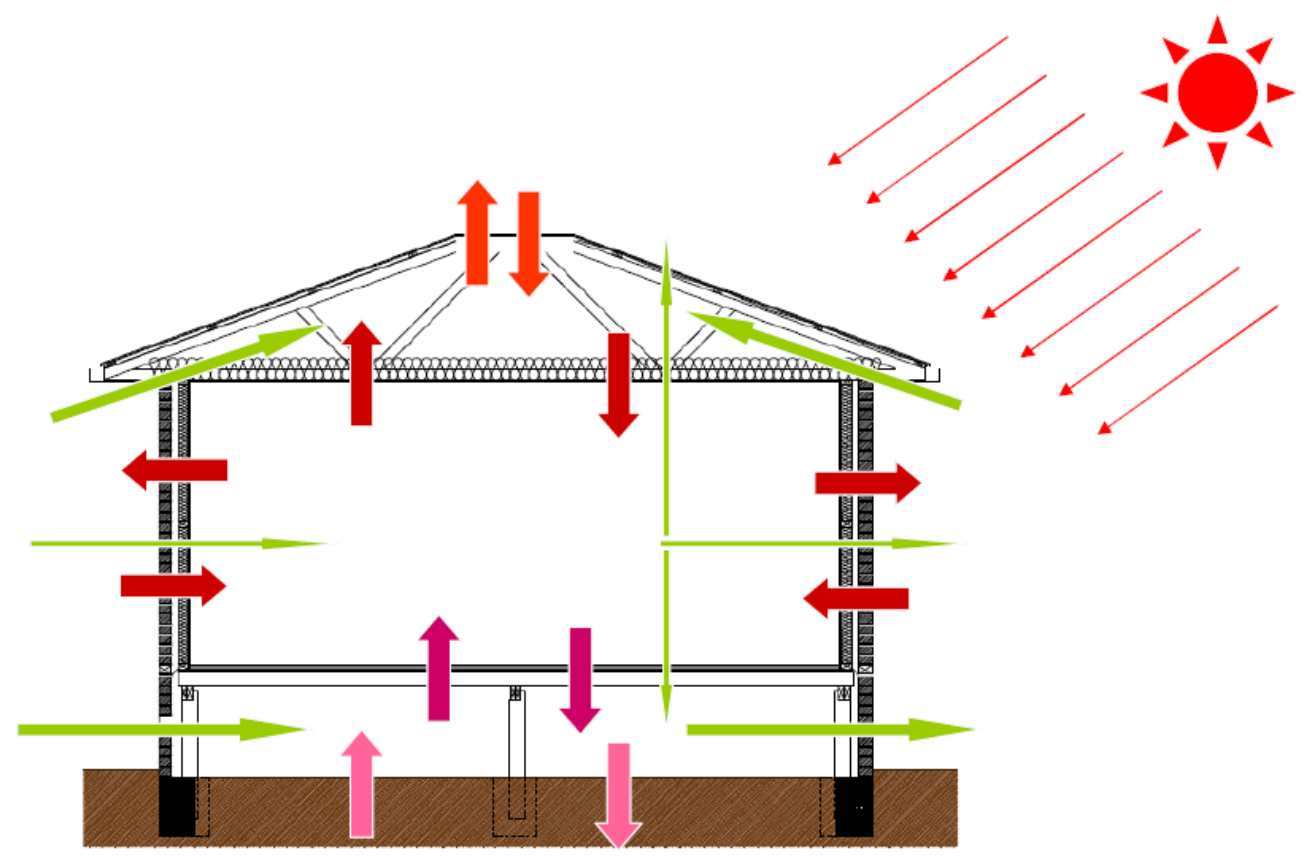

Figure 4.3 - A Building is affected by many differing non-constant environmental inputs

\section{Test Cell Location}

A cool temperate climate is often referred to as pleasant, or mild to warm, during summer but snowfall may still occur in mountainous regions and the winter is generally cold (BOM 
2005b). The Building Code of Australia divides Australia into eight climate zones as per Figure 4.4 (ABCB 2009a).

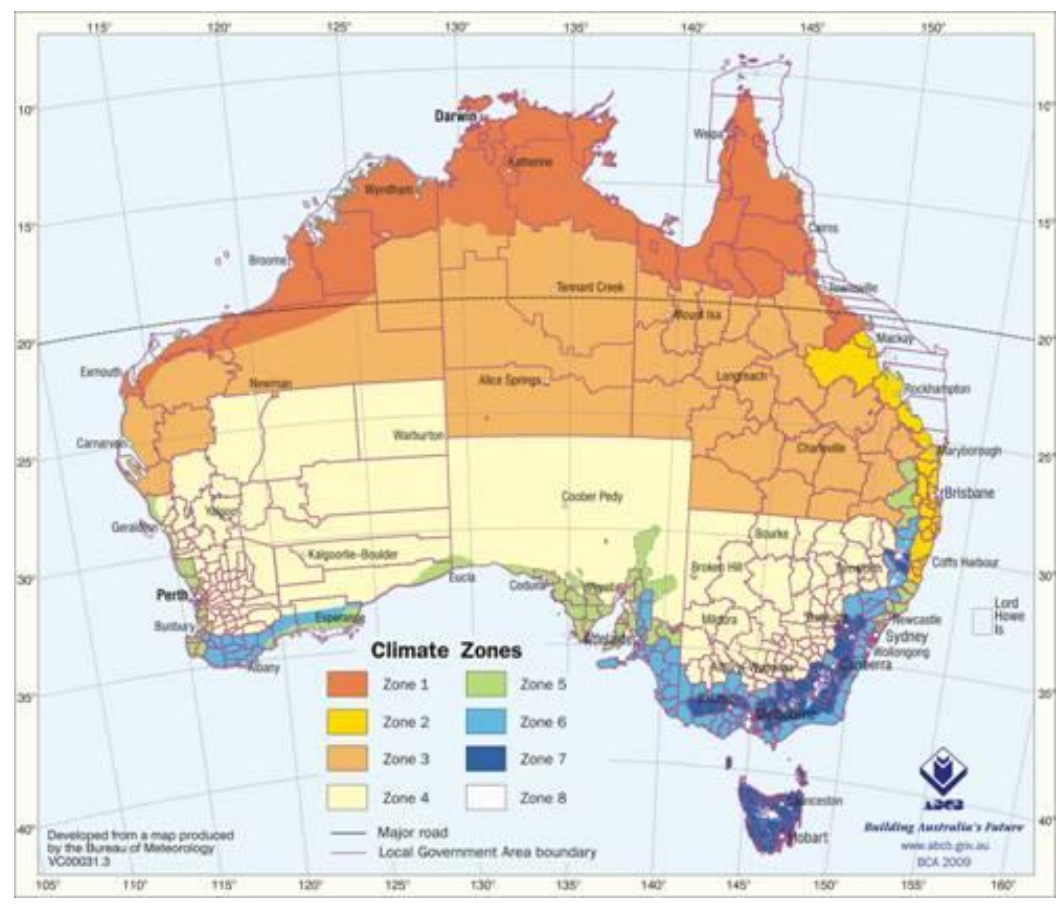

Figure 4.4 - Climate Zone Map, Building Code of Australia

(ABCB 2009b)

The BCA climate zone map of Australia in Figure 4.4 reflects the approach suggested in "Energy Research for the Building Code of Australia Volume 1" (AGO 2000a) which adopts a balance between accuracy and simplicity. This is clearly seen in climate zones 3 and 4 , where the boundary follows state borders as opposed to a probable climatic line. This is similarly being experienced in Tasmania, where there is an ongoing debate about the climate zone allocated to the milder east coast region of Tasmania. The definitions of the climate zones within the Building Code of Australia are further explained in the 'Guide to the BCA 2009' (Table 4.2) and are best described as:

- Zones 1 \& 2: Predominantly require cooling

- Zones 3, 4, 5 \& 6: Require both cooling and heating, to various degrees

- Zones 7 \& 8: Predominantly require heating 
Table 4.2: Climate Zone Definitions,

\begin{tabular}{|c|l|c|c|c|c|}
\hline $\begin{array}{c}\text { Climate } \\
\text { zones }\end{array}$ & \multicolumn{1}{|c|}{ Description } & $\begin{array}{c}\text { Average } \\
3 \text { pm } \\
\text { January } \\
\text { water } \\
\text { vapour } \\
\text { pressure }\end{array}$ & $\begin{array}{c}\text { Average } \\
\text { January } \\
\text { maximum } \\
\text { temperature }\end{array}$ & $\begin{array}{c}\text { Average July } \\
\text { mean } \\
\text { temperature }\end{array}$ & $\begin{array}{c}\text { Average } \\
\text { annual } \\
\text { heating } \\
\text { degree days }\end{array}$ \\
\hline 1 & $\begin{array}{l}\text { High humidity } \\
\text { summer, warm winter }\end{array}$ & $\geq 2.1 \mathrm{kPa}$ & $\geq 30^{\circ} \mathrm{C}$ & - & - \\
\hline 2 & $\begin{array}{l}\text { Warm humid summer, } \\
\text { mild winter }\end{array}$ & $\geq 2.1 \mathrm{kPa}$ & $\geq 30^{\circ} \mathrm{C}$ & - & - \\
\hline 3 & $\begin{array}{l}\text { Hot dry summer, } \\
\text { warm winter }\end{array}$ & $<2.1 \mathrm{kPa}$ & $<30^{\circ} \mathrm{C}$ & $\geq 14^{\circ} \mathrm{C}$ & - \\
\hline 4 & $\begin{array}{l}\text { Hot dry summer, cool } \\
\text { winter }\end{array}$ & $<2.1 \mathrm{kPa}$ & $\geq 30^{\circ} \mathrm{C}$ & $<14{ }^{\circ} \mathrm{C}$ & - \\
\hline 5 & Warm temperate & $<2.1 \mathrm{kPa}$ & $<30^{\circ} \mathrm{C}$ & - & $\leq 1,000$ \\
\hline 6 & Mild temperate & $<2.1 \mathrm{kPa}$ & $<30^{\circ} \mathrm{C}$ & - & 1,000 to 1,999 \\
\hline 7 & Cool temperate & $<2.1 \mathrm{kPa}$ & $<30^{\circ} \mathrm{C}$ & - & $\begin{array}{c}\geq 2,000 \text { other } \\
\text { than Alpine } \\
\text { areas }\end{array}$ \\
\hline 8 & & & & & - \\
\hline
\end{tabular}

(ABCB 2009e)

In the process of choosing the best location to build in a cool temperate climate, (as defined by the BCA), southern Australia and Tasmania were considered. Using the BCA climate zones as a guide, the location of the test cells would be limited to the mountainous regions of Victoria, most of Tasmania, or extra cool snowy locations of Victoria or Tasmania. The Launceston climate fits well into the cool temperate definition, where the mountains that surround the city can have some snow cover in summer and the winters are generally cold. The University of Tasmania has a campus on the suburban fringes of Launceston. Even though Launceston is built at the head of a tidal river, it is approximately fifty kilometres from the open sea and is minimally influenced by maritime weather conditions. A sample of Launceston climate data is shown in Table 4.3, as recorded by the Bureau of Meteorology (BOM) and displays the cool climatic nature of Launceston. 
Table 4.3: Summary of Monthly Climate Statistics for Ti Tree Bend, Launceston

\begin{tabular}{|l|r|r|r|r|r|r|}
\hline \multicolumn{1}{|c|}{ Statistic Element } & January & April & July & August & December & Annual \\
\hline Mean maximum temperature (Degrees C) & 24.2 & 18.8 & 12.5 & 13.8 & 22.4 & 18.4 \\
\hline Mean number of days >= 30 Degrees C & 1.7 & 0.0 & 0.0 & 0.0 & 0.8 & 4.4 \\
\hline Mean minimum temperature (Degrees C) & 12.2 & 7.5 & 2.2 & 3.6 & 10.6 & 7.2 \\
\hline Mean number of days <= 2 Degrees C & 0.0 & 2.3 & 16.7 & 11 & 0.0 & 60.1 \\
\hline Mean daily ground minimum temperature Degrees C & 8.9 & 4.6 & 0.1 & 0.9 & 7.3 & 4.4 \\
\hline Lowest ground temperature Degrees C & -2.7 & -6 & -9.1 & -8.5 & -3.2 & -9.1 \\
\hline Mean number of days ground min. temp. <= -1 Degrees C & 0.2 & 3.1 & 13.8 & 11.8 & 0.5 & 63 \\
\hline Mean rainfall (mm) & 46.3 & 51.7 & 76.8 & 86.1 & 46.3 & 669.6 \\
\hline Mean daily solar exposure (MJ/(m*m)) & 25.5 & 10.9 & 5.9 & 9.0 & 25.8 & 15.3 \\
\hline Mean number of clear days & 5.0 & 4.7 & 3.5 & 3.6 & 3.5 & 49.9 \\
\hline Mean number of cloudy days & 12.5 & 12.9 & 16.2 & 16.1 & 12.5 & 163.9 \\
\hline Mean 9am temperature (Degrees C) & 16.6 & 11.7 & 5.2 & 7.1 & 15.7 & 11.3 \\
\hline Mean 3pm temperature (Degrees C) & 22.7 & 17.8 & 11.7 & 12.8 & 20.9 & 17.3 \\
\hline
\end{tabular}

(BOM 2005a)

Therefore, the decision was made to locate the test cells on vacant land at the Newnham campus. Several key building elements required consideration for site selection, namely:

- No or minimal overshadowing during winter as maintaining a fully exposed situation for the thermal performance test cell buildings during winter was paramount.

- Access to electricity: The monitoring equipment, building operation and building construction required the use of electricity.

- Ready access to data transport through, LAN \& WAN services: The long term plan was that the thermal performance test cells would be operated remotely, which would minimise access to the buildings and disruption to data collection. This required a location that was near or within the bounds of the existing University of Tasmania data network.

- Ready access to storm water services: All new buildings, with roof catchment, require connection to an existing storm water service or the appropriate on-site management of roof-based rain water.

- University approval to build the test cells on the land selected

With these criteria in mind, three possible locations were explored (Figure 4.5). Each potential site was modelled with a three-dimensional computer-aided drafting software. 
Seasonal sun studies were undertaken to analyse potential site shading from trees and buildings (LomasEppel et al. 1994). The agreed site, shown in Figure 4.6, is predominantly open, with the majority of the wind and rain in Launceston coming from the north-west.

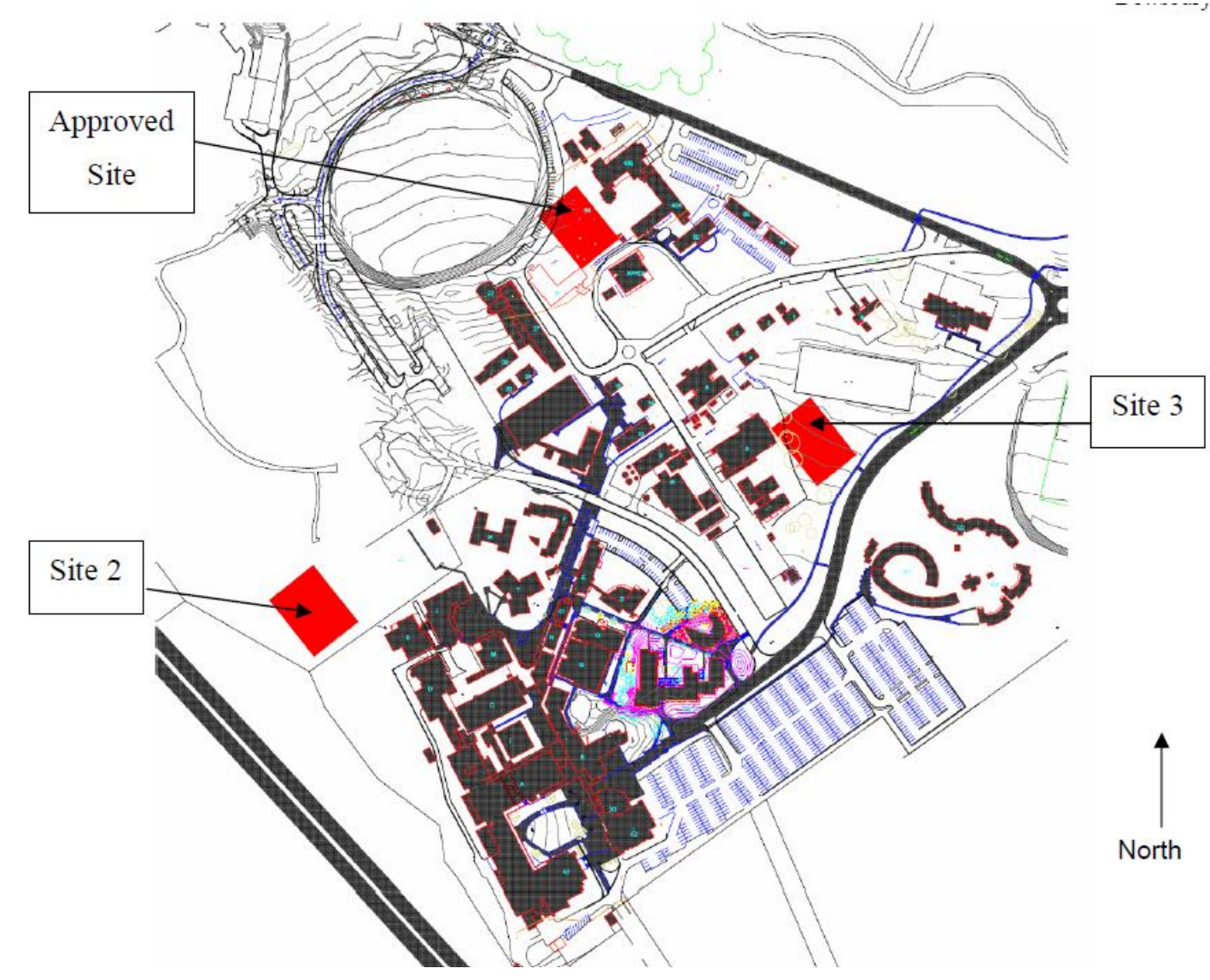

Figure 4.5 - Site Plan, Newnham Campus, University of Tasmania 


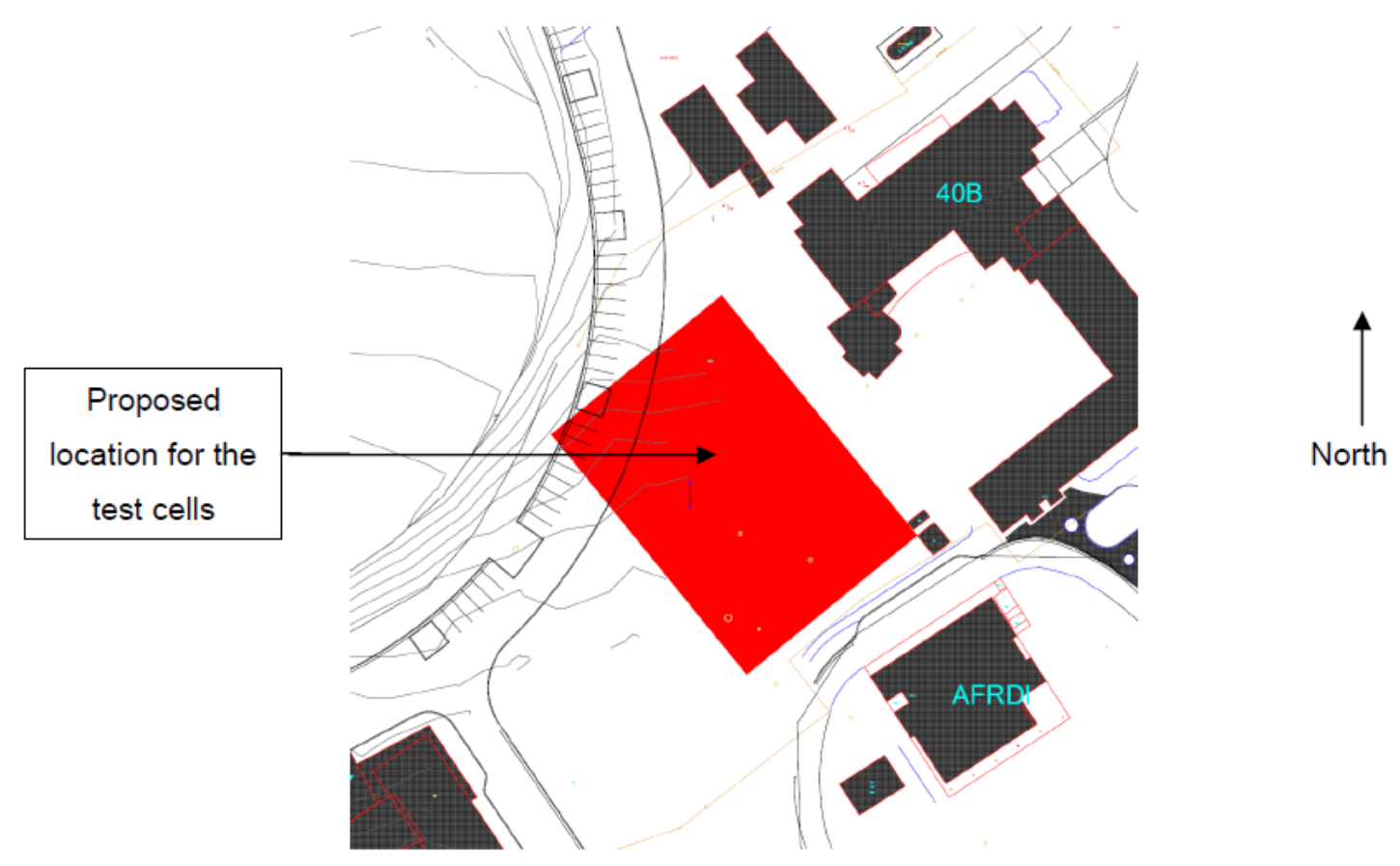

Figure 4.6 - Site Plan 2, Newnham Campus, University of Tasmania

The site consists of:

- Open grass for approximately 20 metres to the north-east

- Single-storey buildings which provide a site boundary 23 metres to the north (Figure 4.7)

- Open grass for approximately forty metres before the two-storey AFRDI building to the south-east (Figure 4.8)

- A car park and sports oval along the western boundary (Figure 4.9)

- $\quad$ Some well-established trees to the south (Figure 4.8)

Once the site was approved by the University, further detailed analysis, both on site and with three dimension computer-aided drafting was undertaken. The detailed analysis was to better evaluate shadow and weather shielding effects from nearby trees and buildings. During this assessment some trees of minor significance were noted on the northern boundary the chosen site. These trees were removed prior to construction. This allowed for an empirical evaluation 
of the winter shading effect of the existing northern buildings, considering that it was late in May 2006, and there was less than a month until the shortest day in the year.

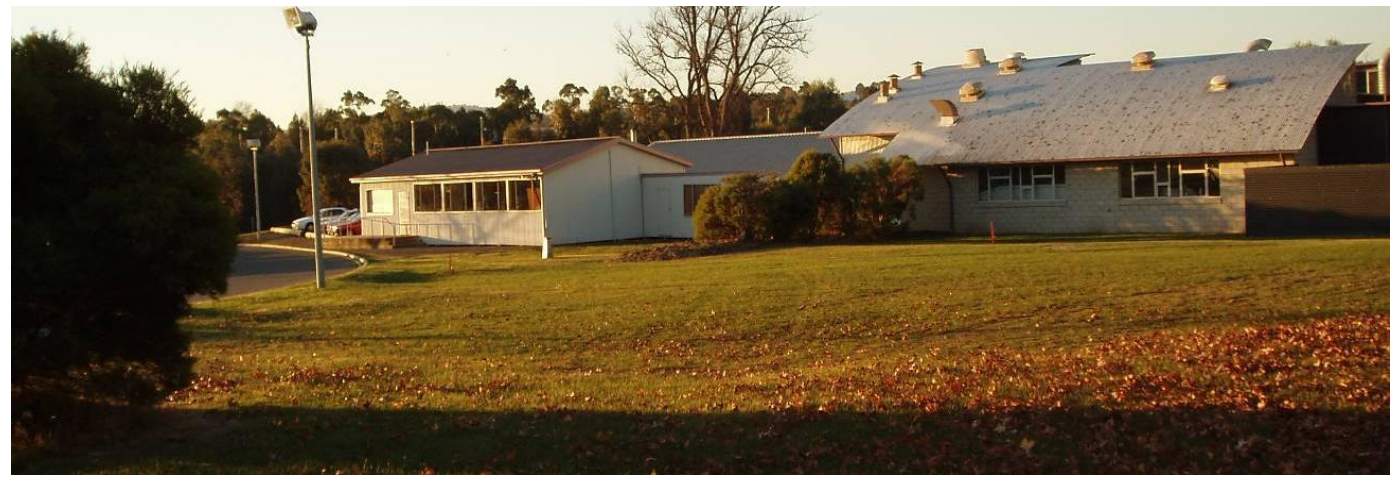

Figure 4.7 - Northern aspect of site

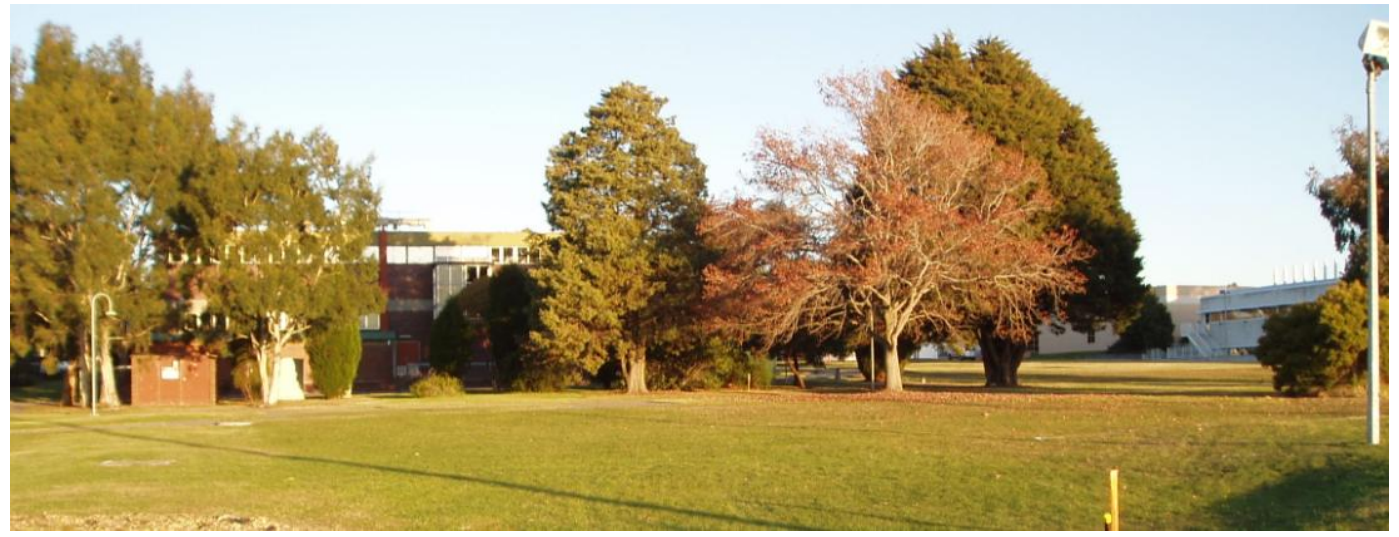

Figure 4.8 - South \& south-eastern aspect of site

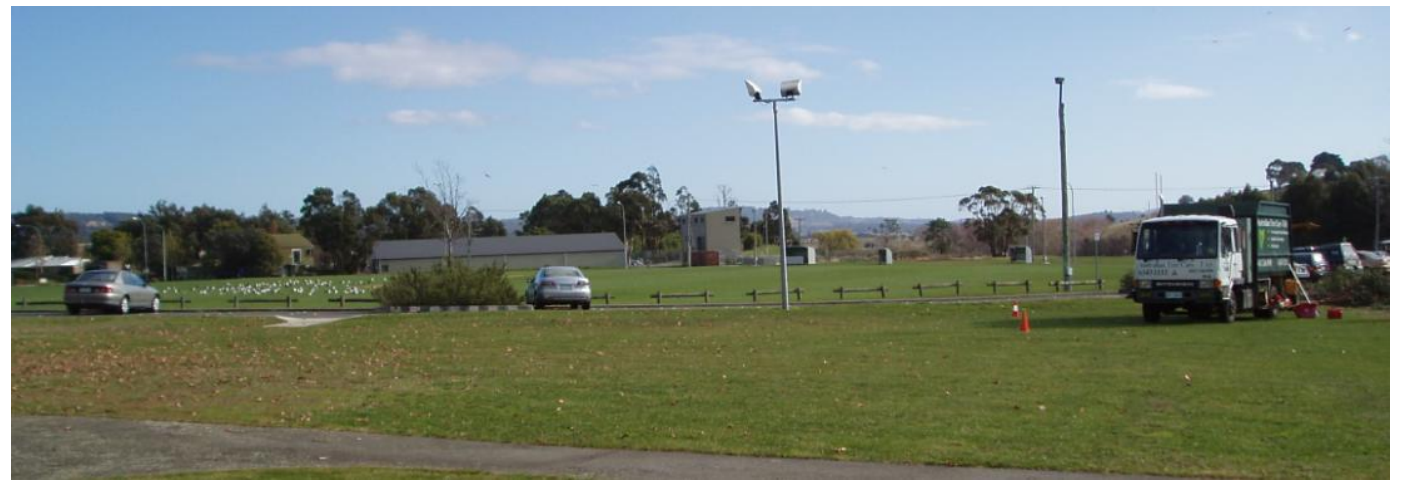

Figure 4.9 - Western aspect of site 
Having selected an appropriate location for the test cells, the next step was to determine the design of the test cells themselves.

\section{Test Cell Building Types}

A survey of thermal performance test buildings is discussed in Chapter 3. The survey revealed a mix of approaches, methods and purposes for test buildings constructed in various countries and climatic zones. As the thermal performance test buildings were to be utilised for testing Australian building practices and Australian house energy rating software, building types similar to standard Australian residential buildings were of greatest interest.

The Australian Bureau of Statistics collects data on dwelling type and dwelling approvals within Australia. Dwelling approvals for Australia from 1991 to 2007, as shown in Table 4.4, are broken into two groups: houses and other residential buildings. A graphical representation of this data is shown Figure 4.10. What is apparent in both groups of data representing dwelling approvals is that on average, $70 \%$ or more of Australian residential accommodation is provided by freestanding houses. The focus of thermal performance test buildings for this project should therefore be freestanding buildings.

Table 4.4: Dwelling Units Approved, Australia

\begin{tabular}{|c|c|c|c|c|c|}
\hline Period & Houses no. & $\%(\mathrm{a})$ & $\begin{array}{c}\text { Other residential } \\
\text { buildings no.(b) }\end{array}$ & $\%(\mathrm{a})$ & $\begin{array}{c}\text { Total dwelling } \\
\text { units no.(c) }\end{array}$ \\
\hline $1991-92$ & 110863 & 73.8 & 39337 & 26.2 & 150200 \\
\hline $1992-93$ & 123586 & 72.5 & 46970 & 27.5 & 170556 \\
\hline $1999-00$ & 123343 & 71.0 & 50284 & 29.0 & 173627 \\
\hline $2000-01$ & 80116 & 67.8 & 37981 & 32.2 & 118097 \\
\hline $2005-06$ & 104440 & 70.2 & 44436 & 29.8 & 148876 \\
\hline $2006-07$ & 106038 & 70.0 & 45517 & 30.0 & 151555 \\
\hline $\begin{array}{l}\text { (a) Percentage of total dwellings units. } \\
\text { (b) Includes semi-detached, row and terrace houses: flats, units and apartments. } \\
\text { (c) Includes dwellings attached to non-residential buildings. }\end{array}$ \\
\hline
\end{tabular}

(ABS 2008a) 


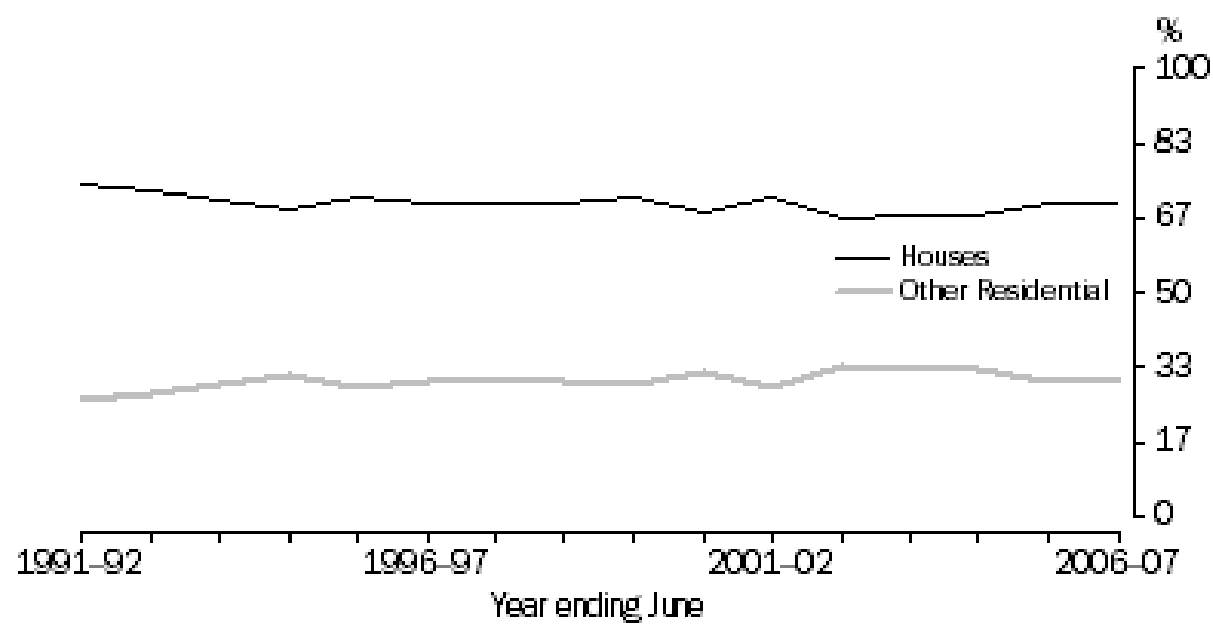

(a) Proportion of new residential dwellings

Figure 4.10 - Type of Dwelling, Australia

(ABS 2008b)

The University of Newcastle test buildings, (discussed in section 3.7), were constructed to measure the benefits of thermal mass in the Newcastle climate. The research was funded by clay brick industries and the building types reflected the prevailing residential building systems, using clay brick cladding and concrete slab-on-ground floors, in the Hunter Valley of New South Wales.

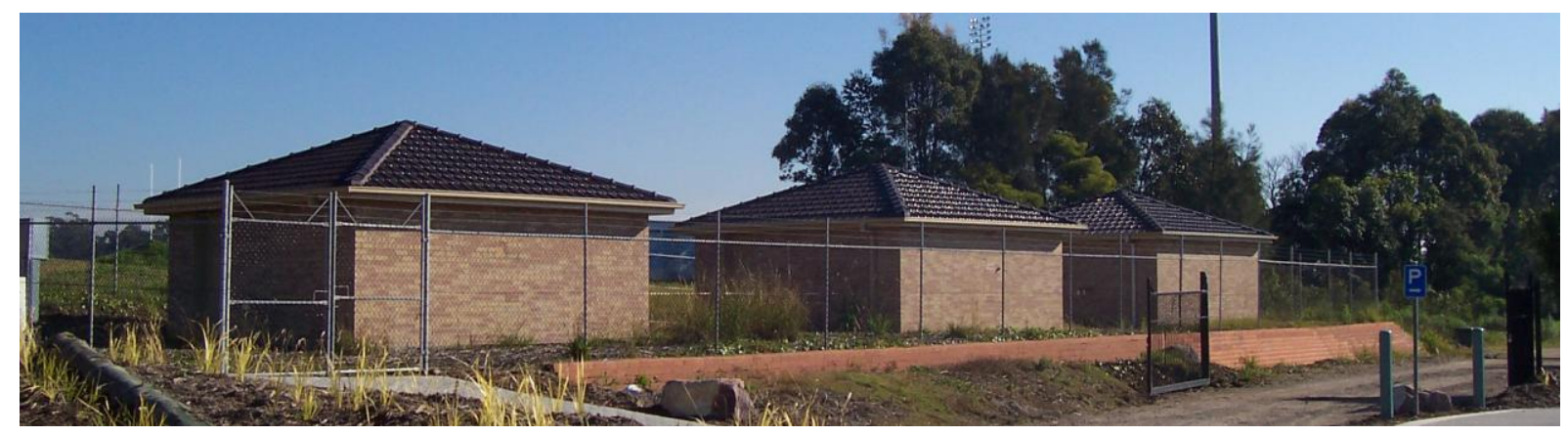

Figure 4.11 - University of Newcastle Test Buildings

(Photograph courtesy of Dr Heber Sugo)

The choice of building type is further substantiated by the BCA. The BCA has a diagram representing the three standard building types for residential construction, as shown in Figure 4.12. The building types are described as: (i) unenclosed-perimeter platform floor, (ii) enclosed-perimeter platform floor and (iii) concrete slab-on-ground floor (ABCB 2005a). These are drawn as freestanding dwellings and not as a dwelling as part of a greater building. 
As the BCA is the Australian reference for standard and common construction practice, it was decided that the type of test building should resemble methods and practices as set out in the BCA.

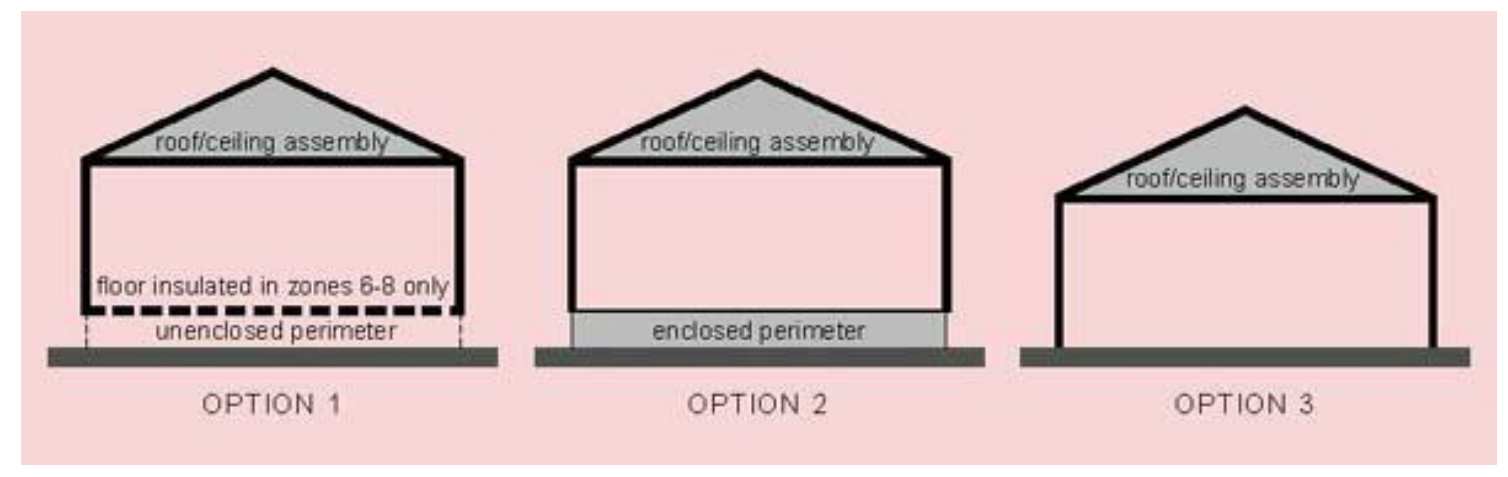

Figure 4.12 - Diagram from section 3.12.1.1, Volume 2 BCA, 2005

By following this rationale, the research team and an industry advisory group (Dewsbury, Nolan \& Fay 2007; Nolan 2006a) agreed that three appropriately sized test buildings should be built to reflect the BCA diagram in Figure 4.12. It was decided that:

- Test Cell 1 is an unenclosed-perimeter platform-floored building

- Test cell 2 is an enclosed-perimeter platform-floored building

- Test Cell 3 is a concrete slab-on-ground floored building

By adopting this rationale some of the concerns raised by various building and industry bodies could be tested. The concerns included:

- The accuracy of the house energy rating software AccuRate to predict internal temperatures

- Whether there was any unintentional bias in the thermal simulation of timber floor types compared to concrete floor types, where the elements of thermal mass and insulation may not be considered correctly.

The opportunity to build test cells having three standard flooring typologies, representative of the majority of Australian housing, would allow for: 
- a close analysis of the effect of the differential thermal performance of the floor types

- the effect of each floor type on house energy rating thermal simulation

- the empirical validation of the simulated thermal performance of the three floor types

\section{Test Cell Size}

To establish the size (width, depth $\&$ height) of the test cells, international and national examples were examined (refer Chapter 3). The major concern discussed in other research was the requirement that the test cell should not be too small, such that normal room thermal fluid dynamics would be affected (Burch et al. 1982; Guyon, G, Moinard, S.,\& Ramdani, N. 1999; LomasEppel et al. 1994; LomasMartin et al. 1994; Rees, S, Xiao, D., Spitler, J. 2002). The buildings were required to be large enough to allow for internal stratification and laminar airflows. In this context, most test cells were built to standard room heights.

In Australia the standard minimum room height for residential buildings as specified in BCA Volume 2, Section 3.8.2.2 Ceiling Heights is 2400mm (ABCB 2005a). This is the height between the ceiling and the finished floor, including floor coverings. A survey of building practices showed a variety of construction methods for wall frames, with heights ranging from $2420 \mathrm{~mm}$ to $2440 \mathrm{~mm}$. To allow for the future installation of floor coverings, a ceiling height of $2440 \mathrm{~mm}$ was adopted for all three test cells.

Three test cells were constructed at the University of Newcastle in 2004-2005, as shown in Figure 4.11 (Clark, Sugo \& Page 2003; Sugo, Page \& Moghtaderi 2005). The University of Newcastle test buildings were constructed to an external dimension of $6 \mathrm{~m}$ with a $2400 \mathrm{~mm}$ internal room height. So that future comparison across different climate zones can be made, it was decided to mimic the volumetric principles of the University of Newcastle test cells. Their major difference is that the Tasmanian thermal performance test cells would use the internal volume and not the external dimension as the basic building measurement. The University of Newcastle's method of adopting an external measurement could create differing volumes for different building types, due to varying external fabric thicknesses. As the purpose of the University of Tasmania research was to provide empirical validation and 
comparative analysis, it was decided that the internal areas and volumes of all three tests buildings had to be identical. Collaboration with the University of Newcastle test cell research team provided a quality benchmark and the opportunity to learn from their positive and negative experiences. The sizes of the Launceston thermal performance test cells were established as detailed in Table 4.5.

Table 4.5: The Dimensions of the Launceston Thermal Performance Test Cells

\begin{tabular}{|l|c|}
\hline \multicolumn{1}{|c|}{ Element } & Size \\
\hline Internal Length & $5480 \mathrm{~mm}$ \\
\hline Internal Width & $5480 \mathrm{~mm}$ \\
\hline Internal Height & $2440 \mathrm{~mm}$ \\
\hline Internal Floor Area & $30.03 \mathrm{~m}^{2}$ \\
\hline Internal Volume & $73.3 \mathrm{~m}^{3}$ \\
\hline External Length \& Width & Determined by building fabric \\
\hline Orientation & Solar North \\
\hline
\end{tabular}

\section{Construction Materials}

The materials used to construct the thermal performance test cells were informed by:

- the building type

- minimising fabric variables to allow for comparative analysis

- the standard building systems used in cool temperate climates

The building type informed the possible cladding systems which could be used on the test cells. The unenclosed platform test cell dictated, as is the norm in Australia, a lightweight cladding system whilst the enclosed platform and concrete slab-on-ground test cells, required a lightweight or massive cladding system.

To produce an adequate comparative analysis between a platform-floored building and a concrete slab-on-ground floored building, the fabric matrices of the enclosed-perimeter platform-floored test cell and the concrete slab-on-ground floored test cell were made as similar as possible. Empirical validation entails a framework for a thorough comparison of measured and simulated data, wherein the input and fabric variables were minimised. In the 
conceptual stage, subtle differences in the fabric of three test buildings were accepted, as follows:

- Test cells 1 and 2 would have a subfloor structure, where-as test cell 3 was a concrete slab-on-ground floored building

- The external cladding for test cell 1, would be different from that of test cells 2 and 3

Australian residential construction practice includes many forms and materials but the majority of volume builders have adopted fairly similar construction systems. A simple examination of standard residential building systems was undertaken to establish the appropriate systems and materials for the test cells (Dewsbury, Nolan \& Fay 2007). The material selection was also influenced by industry sponsorship for the research, as many of the materials were provided by industry sponsors.

- Subfloor structure: The subfloor structure of the two platform-floored test cells was informed by the Australian Standard 1684.2-2006, which detailed residential timberframed construction (Standards Australia 1999, 2006). Treated pine poles set in concrete were specified. Hardwood was prescribed so that the required span for the bearers could be met. The joists, having a much smaller span and load carrying capacity, were specified as softwood.

- Wall structure: Timber wall framing is divided into two segments: hardwood and softwood timber products. Hardwood is considerably more expensive than softwood, resulting in a large portion of new residential construction incorporating softwood stick built or prefabricated wall framing. The use of prefabricated wall frames was adopted to minimise construction variables between the wall structures of the three test cells.

- Ceiling and roof structure: The majority of new residential construction incorporates the use of softwood trusses which provide the structure for both the ceiling and roof. The use of trusses is often based on cost, but there are considerable savings from reduced material wastage in using prefabricated building systems. The use of prefabricated trusses, as opposed to stick-built roof, minimised construction variation between the three test cell ceiling and roof systems. 
- Lightweight wall cladding: The unenclosed platform test cell required lightweight cladding. In contemporary Australian construction practice, plywood is the preferred cladding from a material and labour cost perspective. Additionally one of the major sponsors has plywood in their product range.

- Other wall cladding: In Australian residential construction, the most common form of cladding is clay brick veneer, which is used for both concrete slab-on-ground and enclosed platform building systems. Clay bricks provided by an industry sponsor were used for the test cells.

- Roof cladding: The two most commonly used roof cladding systems in Australia are sheet metal and clay or cement tiles. The extra weight of the tile systems required a greater volume of timber in each truss and an increased number of trusses. To keep costs of residential construction down, builders resort to the use of sheet metal roofing. To mirror current residential building trends sheet metal roofing was adopted.

- Access door: Each test cell had a single solid core access door. The use of a solid core construction also allowed for a better estimation of the door conductivity value.

- Wall linings: The majority of new residential construction in Australia use 10mm paper-faced gypsum plasterboard for internal wall linings. This wall sheet is often glue and nailed or screw fixed to the wall structure.

- Ceiling lining: The majority of new residential construction in Australia use 10mm paper-faced gypsum plasterboard for ceiling lining. The ceiling sheet is either screw fixed to the ceiling structure or to steel furring channels. The method of fixing ceiling sheet is defined by truss spacing and the manufacturer specifications.

- Platform Flooring: The construction of platform floors required a safe working platform. It was common practice that particleboard sheet is laid as a base regardless of the final floor covering. The thickness of the particleboard sheet is based on the span between supporting joists and the load carried by the floor.

- Concrete Flooring: The floor for the concrete slab-on-ground floored test cell adhered to contemporary practices as detailed in the Australian Standard: Residential Slabs and Footings - construction (Standards Australia 1996). 
- Wall insulation: Common materials used for insulating the stud cavity of a wall frame in Australia include wool, polyester, glasswool and rockwool batts. At the time the test cells were being designed, the minimum required additional wall insulation for a clay cavity brick wall system was R1.36. The highest resistance value wall batt insulation available, which would fit in a 90mm stud wall, was the R2.5 Rockwool wall batt. As it was intended that the test cells be constructed for long term research the R2.5 rockwool wall batt was specified.

- Ceiling insulation: The most economical, hence most commonly used form of roof insulation in Australia is glass wool batt insulation. The minimum BCA requirement for roof insulation in the Launceston climate zone during the design process was R3.4 for sheet metal roofing. The highest thermal resistance value glasswool batt available at the time of the test cell design and construction was the R4.0. As it was intended that the test cells be constructed for long term research the R4.0 Glasswool batt was specified. The roof space would allow for additional layers of glasswool batts in future research.

- Building wrap: Building wraps within Australia consist of reflective or non-reflective and breathable or non-breathable. All four types are used for the purpose of providing a vapour barrier (Anis, Quirouette \& Rousseau 2007; CMHS 1982; Currie 2005; Lstiburek 2004, 2007; US DOE 2000) and to reduce infiltration losses (Swinton, Brown \& Chown 1990). As CSR Building Products was a major sponsor for the project, advice was sought as to the most suitable and most commonly used product. The CSR Bradford's Enviroseal product was used for both wall and roof wrapping.

- Roof sarking: The sarking of roof spaces assists in reducing roof space infiltration losses (Lstiburek 2006) and in the reduction of external moisture entering the roof space. As mentioned in Building Wrap, above, the CSR Bradford's Enviroseal product was suggested for roof wrapping.

- Floor coverings: To minimise construction variation in the first stage of the thermal performance test cell research, no floor coverings were installed as these would impact on the insulation, infiltration and thermal mass simulation input values. 
Through an iterative process of analysing current residential building practice, industry sponsors and long term research implications of the thermal performance test cells, a fabric matrix was finalized as shown in Table 4.6.

Table 4.6: Thermal performance test cell detailed fabric matrix

\begin{tabular}{|l|l|l|l|}
\hline \multicolumn{1}{|c|}{ Element } & \multicolumn{1}{c|}{$\begin{array}{c}\text { Test Cell 1 } \\
\text { Unenclosed-perimeter }\end{array}$} & \multicolumn{1}{c|}{$\begin{array}{c}\text { Test Cell 2 } \\
\text { Enclosed-perimeter }\end{array}$} & \multicolumn{1}{c|}{$\begin{array}{c}\text { Test Cell 3 } \\
\text { Slab-on-ground }\end{array}$} \\
\hline Roof & Colorbond sheet metal roofing \\
\hline Roof Sarking & CSR Bradford Enviroseal Reflective foil sarking \\
\hline Roof Insulation & R4.0 glass wool batt insulation \\
\hline Ceiling Material & $10 \mathrm{~mm}$ plasterboard, screw fixed to furring channel \\
\hline Access Door & $40 \mathrm{~mm}$ solid core door \\
\hline Wall Framing & Prefabricated 90mm x 35mm pine frames & \\
\hline Wall Lining & $10 \mathrm{~mm}$ plasterboard, glue and screw fixed to wall framing \\
\hline Wall Insulation & R2.5 rock wool wall batt $(86 \mathrm{~mm})$ & 50mm reflective \\
\hline Building Wrap & CSR Bradford Enviroseal Reflective foil sarking & $110 \mathrm{~mm}$ clay brick \\
\hline Wall Cavity & $21 \mathrm{~mm}$ reflective & $50 \mathrm{~mm}$ reflective & Concrete slab-on-ground \\
\hline Wall Cladding & $12 \mathrm{~mm}$ plywood & $110 \mathrm{~mm}$ clay brick & Not applicable \\
\hline Floor & $19 \mathrm{~mm}$ particle board & $19 \mathrm{~mm}$ particle board & \\
\hline Subfloor Structure & $\begin{array}{l}\text { Hardwood joists, } \\
\text { hardwood bearers, } \\
\text { treated pine poles }\end{array}$ & $\begin{array}{l}\text { Hardwood joists, } \\
\text { hardwood bearers, } \\
\text { treated pine poles }\end{array}$ & Not applicable \\
\hline Subfloor enclosure & Nil & $110 \mathrm{~mm}$ clay brick &
\end{tabular}

\subsubsection{Other Fabric Considerations}

One of the aims of investing in the construction of the three test cells was to provide the opportunity for long term thermal performance studies of residential fabric systems, including the effect of glazing in various orientations. Care was required so that construction provisions for the future research were accommodated, without imposing too many initial fabric input variables. This resulted in design and construction practices which were not common in current residential construction. Some of these construction methods were used to further limit input variables for measuring the thermal performance of the three test cells. These design and construction practices are discussed below. It is worth noting that these practices are closer to best practice than those normally adopted by the house construction sector.

\section{Sealing of Wall Cavity}

There was the opportunity to provide a seal between the wall cavity and the sub floor zone, which is recommended for cooler climates in accordance with the BCA (ABCB 2009a). This condition can be accounted for in the AccuRate HER software. By inserting an air barrier 
between the subfloor zone and the wall cavity, there is a reduction in the chimney venting of the wall cavity. This practice promotes the possibility of a still air cavity. A reflective still air space has a much greater insulation value than a reflective ventilated air space (AFIA 2004; Baker, J 2008; Handisyde \& Melluish 1971; Hassall 1977). The diagram in Figure 4.13 details the design of the cavity seal to the unenclosed platform-floored, plywood clad test cell. The diagram in Figure 4.14 details the design of the cavity seal in the enclosed platformfloored, brick veneer test cell.

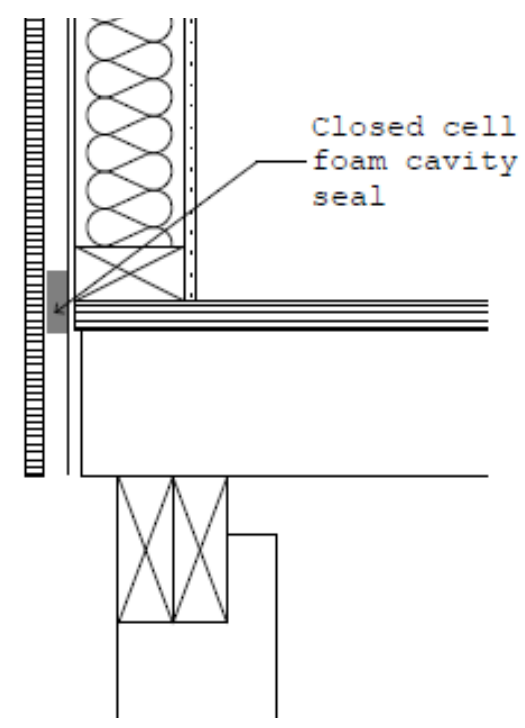

Figure 4.13 - Unenclosed platform-floored test cell - wall cavity infiltration control

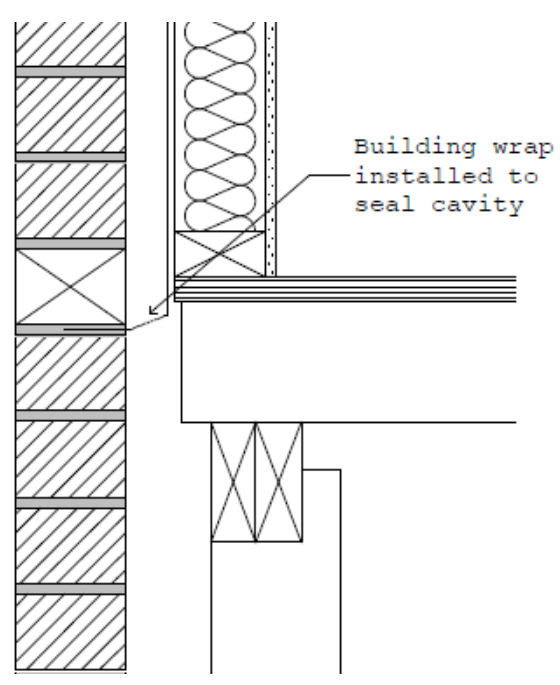

Figure 4.14 - Enclosed platform-floored test cell subfloor and wall cavity infiltration control

\section{Reducing External Wall Infiltration}

Examination of literature on building thermal performance reveals an ever-increasing awareness that building infiltration affects building thermal performance (Anis, Quirouette \& Rousseau 2007; Biggs \& Bennie 1988; Biggs, Bennie \& Michell 1987; Coldicutt et al. 1978; Guyon, G et al. 1999; OEENR 2004; Quirouette 1986; Rudd, Chandra \& Tooley 1993; Sherman 2006; Willrath 1997). Past research (Swinton, Brown \& Chown 1990; US DOE 2000) and manufacturers (CSR 2003) recommend the careful installation and taping of building wraps. In volume 2, section 3.12.1.1.B.IV of the 2004 edition of the BCA (ABCB 2004) there are two methods described for installing building wrap: either an overlap of not less than 50mm, or with joints taped together (Figure 4.15 and Figure 4.16). In both methods 
the wrap is fixed to the wall frame with steel staples. For this research, the joints were to be taped as a means of reducing infiltration.

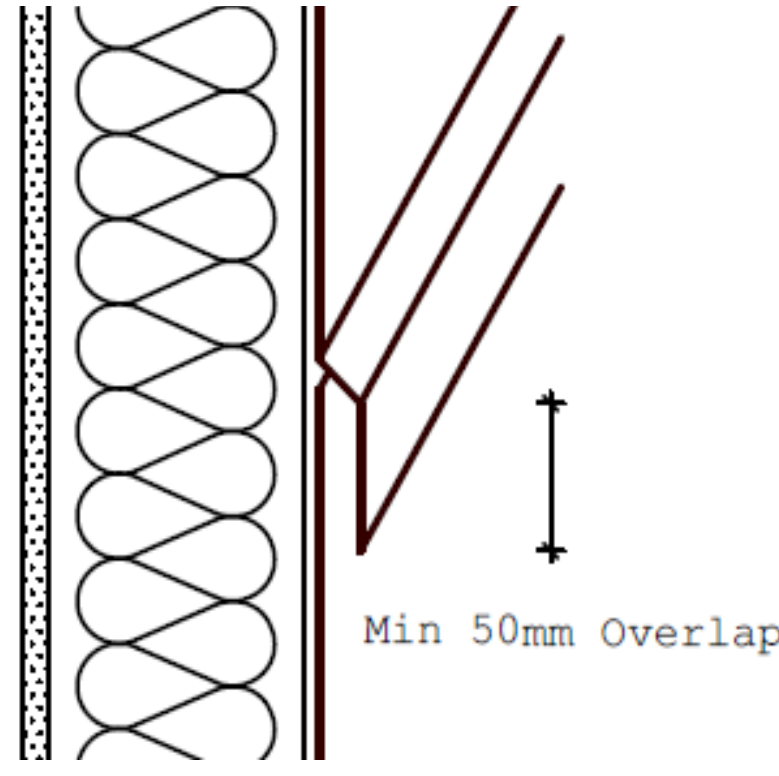

Figure 4.15 - Building wrap with a minimum $50 \mathrm{~mm}$ overlap

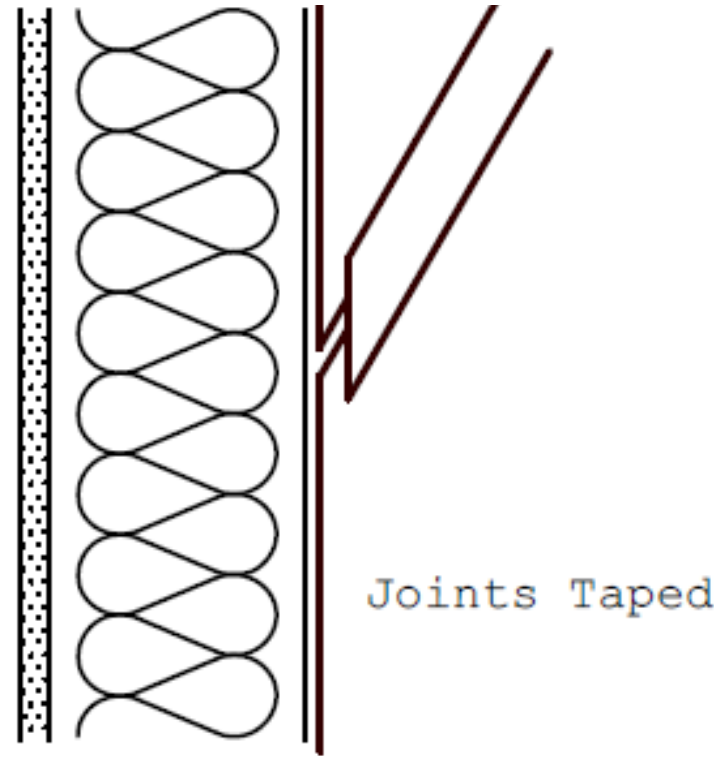

Figure 4.16 - Building wrap with joints taped together

\section{Roof Space Infiltration and Reflective Insulation}

Similarly the roof construction of the three test cells are identical (i.e., with the same truss, roofing and reflective foil sarking). In discussions with CSR Bradford's, one of the research sponsors and a manufacturer of reflective foil sarking (or roof wrap) and industry representatives concern was raised, with regard to current construction practice as opposed to installation guidelines for reflective foil roof sarking. The five principal purposes of installing reflective foil roof sarking are:

- to reflect heat back towards the roofing material

- to reflect heat back into the roof space

- to provide an insulation air space between the sarking and the roofing material

- to provide a location for moisture to condense and be drained from the roof space

- $\quad$ to reduce roof space infiltration rates 
The two important factors to be considered at this stage of the research were the reduction of infiltration rates (Coldicutt et al. 1978; Hendron et al. 2003; Lstiburek 2006; OEENR 2004) and the maintenance of the reflective air space between the roofing and sarking materials (CSR 2003). To reduce heat losses or gains due to infiltration, the same taping of joints approach to be used for the wall wrap was adopted. The roof sarking was to be taped equally for all three test cells.

Additionally, for the reflective foil sarking to reflect heat, it required an air space (AFIA 2004; Hassall 1977). In the AccuRate software, the resistance value provided by reflective foil sarking varies from R0.0 for a contact joint between the sarking and sheet metal roofing to a possible R0.942 for a highly reflective sarking material with a nominal $40 \mathrm{~mm}$ vented air gap (AccuRate 2007). In the draped method of installation, the reflective foil sarking is to be draped between battens to maintain a reflective air space and to reduce bridging, which inhibit condensation forming on the outside surface of the material, as in Figure 4.19 (Chadderton 2000). In many cases seen by the researchers and industry representatives, the sarking was pulled tight during installation (Figure 4.17). This practice gives the assembly a cleaner appearance and makes installation easier. However, this method negates most of the insulation functions of the reflective foil sarking and has been observed to promote an increase of moisture and condensation in the roof space (Anis, Quirouette \& Rousseau 2007). In order to assess the ease of installation and guarantee the insulation functions of the reflective foil roof sarking, the research team agreed to install the sarking under the battens and over the rafters, as in Figure 4.18, in all three test cells. This method of installation guaranteed a batten depth $(35 \mathrm{~mm})$ air gap between the sheet metal roofing and the reflective foil sarking. 


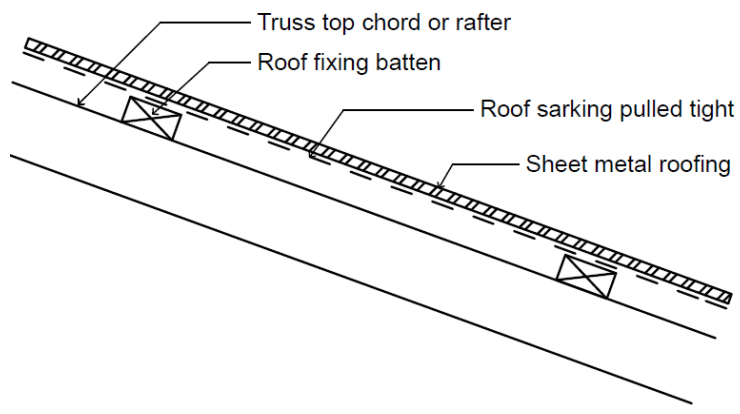

Figure 4.17 - Common practice of pulling roof sarking taut during installation

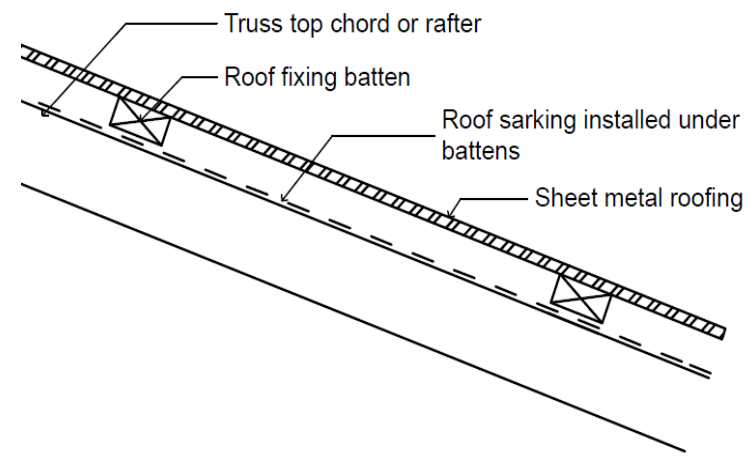

Figure 4.18 - Method for test cells - Sarking installed over rafters, under battens

FIG 9.

PITCHED METAL DECK WITH

HORIZONTAL CEILING

(NO INSULATION IN CEILING).

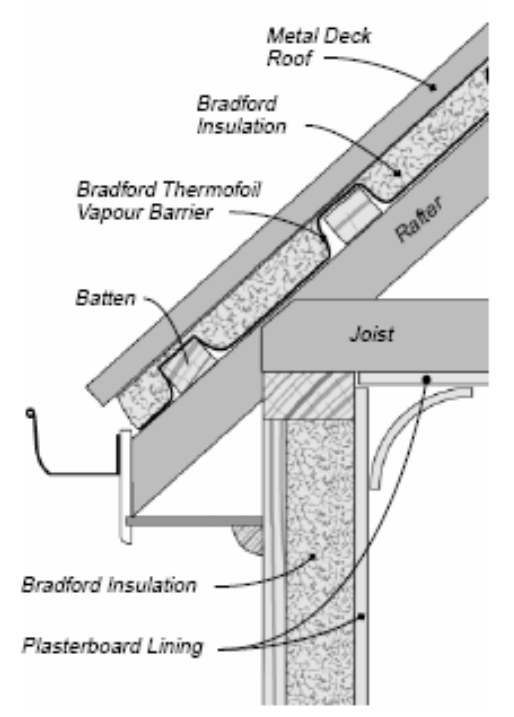

Figure 4.19 - Draped roof sarking

(CSR 2003, p. 26)

\section{Reducing Infiltration Losses at Door Gaps \& Services Penetrations}

In an attempt to further reduce infiltration, some further measures were adopted to make the test cells 'tighter'. A closed cell foam strip was to be installed in the joint between the wall frame and the door frame (Figure 4.20) and the building wrap was to be taped to the door 
jamb prior to fixing external trims. No electrical or data services were to be installed in the walls. All electrical services were installed within polyvinylchloride (PVC) conduits which were to be fixed to the inside face of the test cell external wall. All electrical and data services were to enter the test cells via a PVC conduit in the floor, which was sealed with silicone sealant.

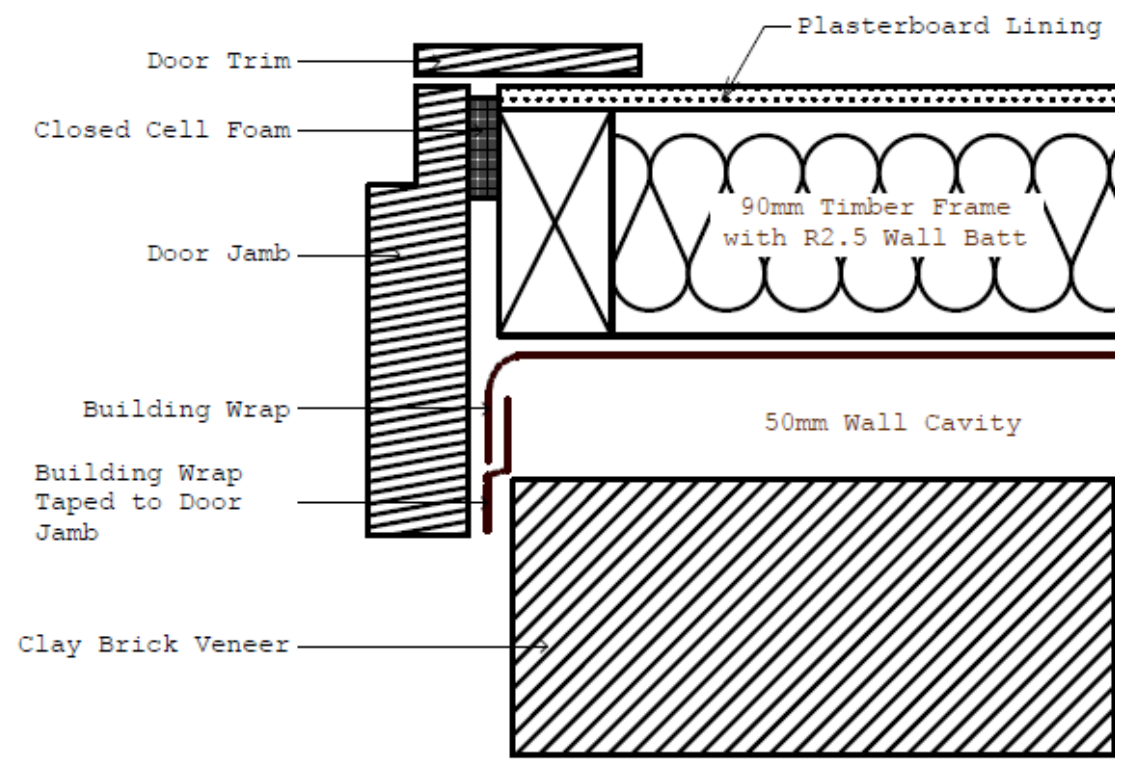

Figure 4.20 - Door Frame Infiltration reduction measures

\section{Window Framing}

The test cells were purposely designed and constructed to be initially without windows for this first stage of empirical validation. Future research involving assessment of solar gain and heat loss will necessitate the installation of windows. To install windows in the future with minimal structural impact, the prefabricated wall frames included a 'knock-out' panel. The panel size would allow for the installation of a standard $2100 \mathrm{~mm} \times 1800 \mathrm{~mm}$ glazed sliding door unit. The panel included jamb studs and a lintel. This would allow for windows of varying sizes up to $2100 \mathrm{~mm} \times 1800 \mathrm{~mm}$ to be installed in future thermal performance research. The panel in each of the four external walls were identical, to enable a study of the thermal performance of windows on all four orientations. Figure 4.21 shows the concept for the prefabricated wall frame with the knock-out panel in place. Appendix 2 includes the final 
framing plans of the three test cells. In order to support the future addition of the window in the brick veneer cladding, control joints were place at the same point in the brickwork, as in Figure 4.22.

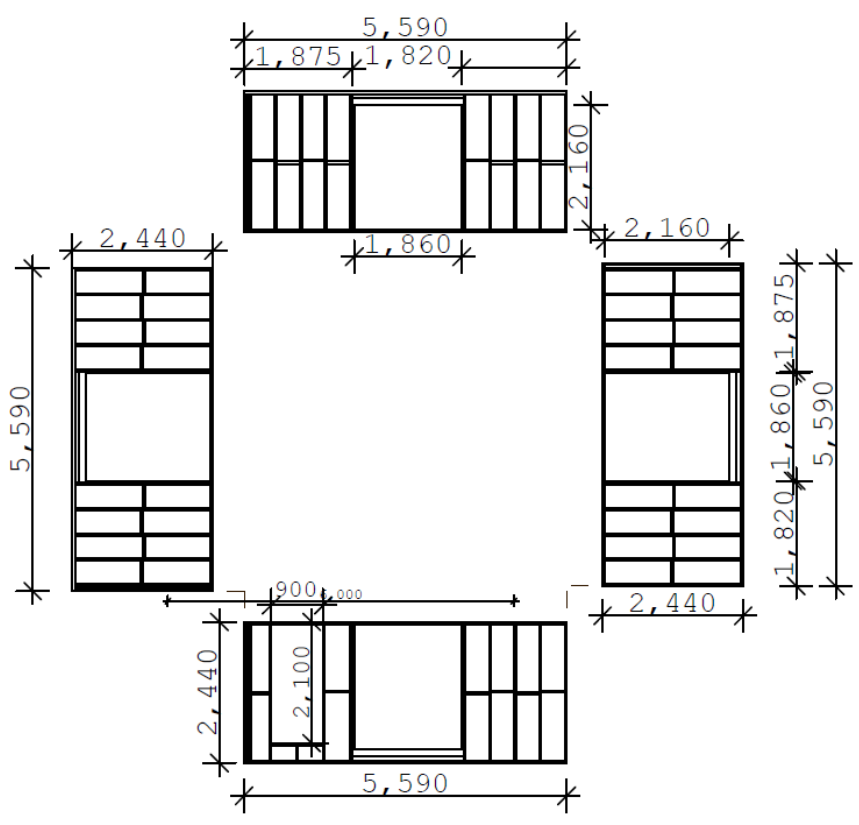

Figure 4.21 - Concept for prefabricated wall frame

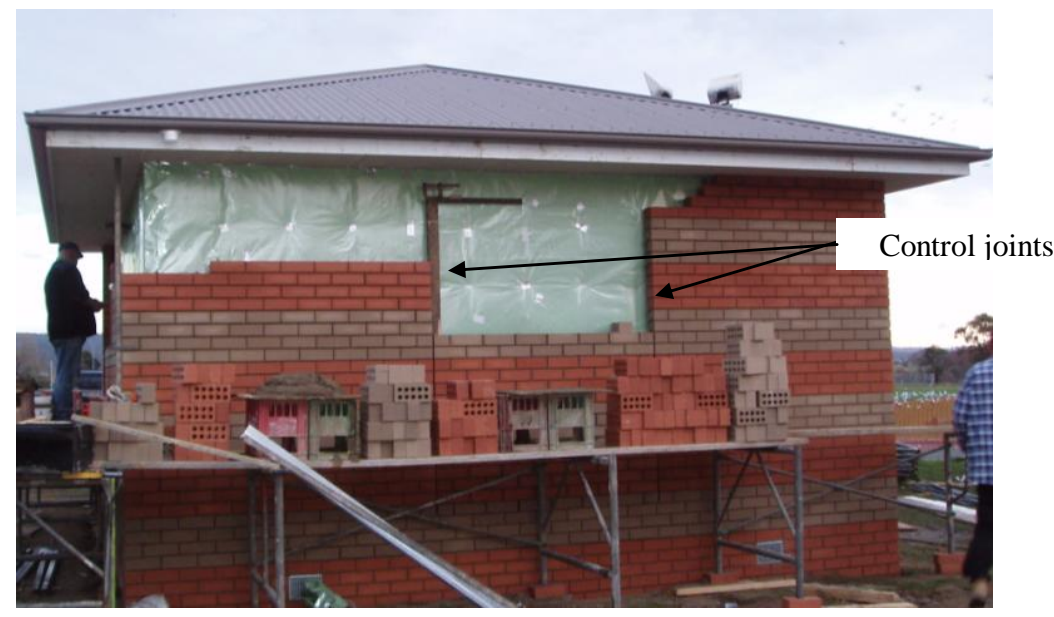

Figure 4.22 - Control joints in brickwork for knock-out wall panel 


\subsubsection{Test Cell Placement \& Orientation}

Once the size and volume of the test cells were decided, the test cell positioning and overshadowing was analysed. The site was drawn in three-dimensional computer-aided drafting (CAD) software. All surrounding buildings and trees were included in the model for the purpose of undertaking sun and shading studies. Sun study movies were generated for the summer solstice, winter solstice and equinox. Based on the movies, the placement and orientation of the test cells were determined, based on:

- the minimal set back from the northern elements (shrubs and one-storey building)

- $\quad$ the southern setback as provided by the established trees

- the western setback as provided by the road

- an eastern setback as defined by the shading provided by the two storey AFRDI building (see Figure 4.6) and

- a suitable shade limited zone within the possible building area allotted for the test cells

Within the suitable zone, nine test cell arrangements were explored which included the location and distance required between test cells to eliminate overshadowing. After extensive studying of the most suitable options, a final site plan and arrangement was adopted, as shown in Figure 4.23. This was principally a solar north-south arrangement. As the site sloped gently down-hill in the northern direction, a distance between the test cells of $7500 \mathrm{~mm}$ eliminated winter overshadowing. 


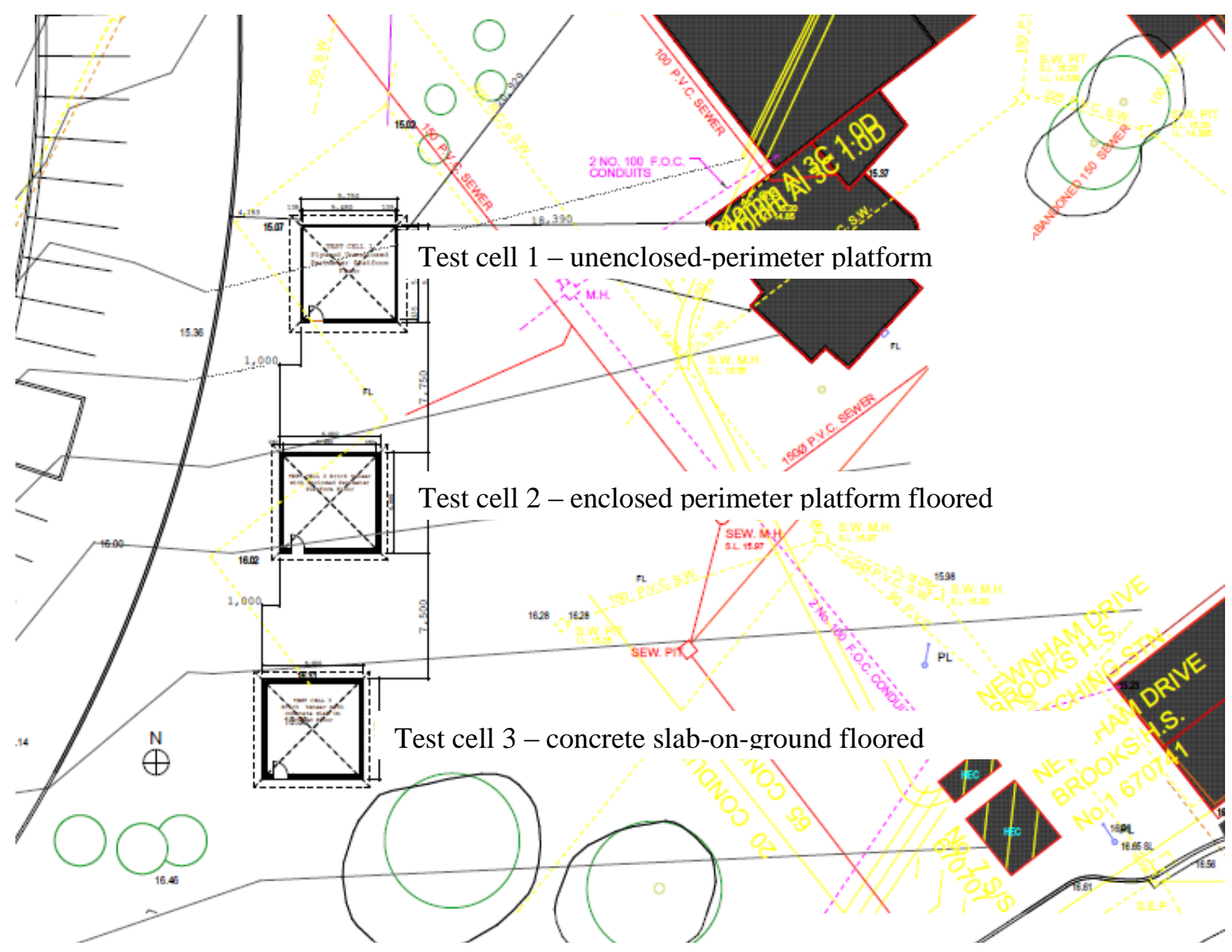

Figure 4.23 - Final Test Cell Site Plan

\subsubsection{University \& Council Approvals}

As the project design evolved, as for any other university building project, approvals were sought from the university and the local council. Frequent discussions were conducted with the University Asset Management staff, to ensure that the University's requirements were being met. Once University approval was obtained for the project, the required planning and building applications for local council approval were undertaken. As the author was an accredited building practitioner, all documentation for the university and council were generated by the author. A local building surveyor firm provided certification. 


\subsubsection{Test Cell Construction}

The bulk of the test cells' construction occurred in June and July 2006. Final finishing occurred in August 2006. The construction method for the test cells was to be as close as possible to the minimum allowable construction practice as possible, with the exception of insulation and infiltration improvements mentioned earlier. The minimum standards for residential construction are defined by the BCA and a range of Australian Standards which the BCA refers to. The author coordinated construction of the test cells. To achieve the desired research outcome, regular meetings were required with: university staff, the builder, the builder's subcontractors (all trades) and environmental measurement consultants. The meetings ranged from general issues of programming to detailed meetings discussing BCA and Australian Standard requirements, as many contractors were not familiar with the BCA, nor pertinent Australian Standards.

During construction, the researcher was on site several times a day to assist and advise the builder or sub-contractors. This, in essence, was a construction supervision exercise. Rewarding relationships were developed between the researcher and key sub-contractors. The researcher became more aware of issues affecting the quality of construction practice and the sub-contractors were made aware of building thermal performance theory and BCA and Australian Standard requirements.

Industry sponsors provided many of the building materials, as it was a collaborative project of the University and the construction and allied industries. Materials provided by industry sponsors were:

- reinforcing steel

- Concrete

- all timber materials

- clay bricks

- plasterboard lining

- wall and ceiling batt insulation 
- truss and prefabricated wall assembly

- $\quad$ roof space reflective foil sarking

- $\quad$ sheet metal roofing

- all minor items and construction fixing materials were purchased by the project.

The construction of the test cells was broken up into four stages, namely:

- preliminary works

- primary construction works

- finishing and

- the installation of environmental measuring equipment

\section{Preliminary to Construction}

Preliminary works were required to set project building parameters and to plan what the project would entail in terms of physical, financial and human resources. For this project this included the 'set-out' of the site and the project planning with the builder and university.

A Launceston surveyor was engaged to provide the site 'set out'. The site survey would define the location and orientation of the test cell buildings. A surveyor was engaged so that the test cells were positioned according to the results of the three dimensional computer modelling and sun studies. Once the site co-ordinates were established (Figure 4.24), markers were put in place to identify True North. A line was marked to the side of the proposed building area, as a permanent reference during the construction process (Figure 4.25). The surveyor then placed markers for the corners of the Test Cell buildings to ensure accuracy and consistency in the placement of the test cells during construction. 


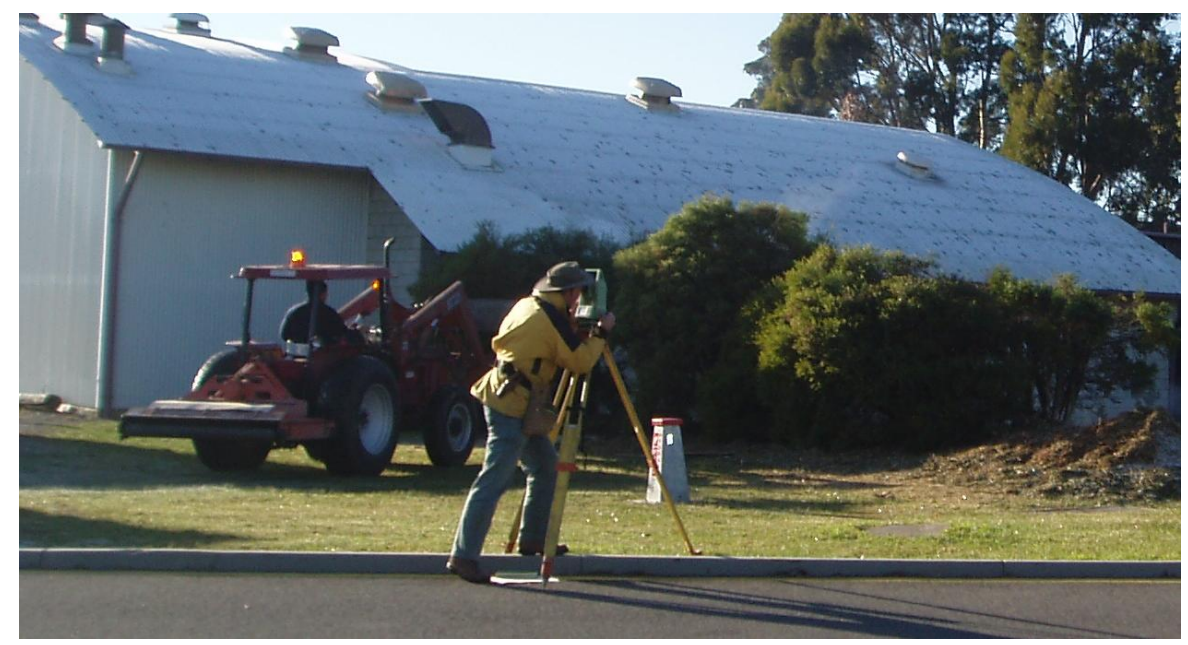

Figure 4.24 - Surveyor establishing site co-ordinates
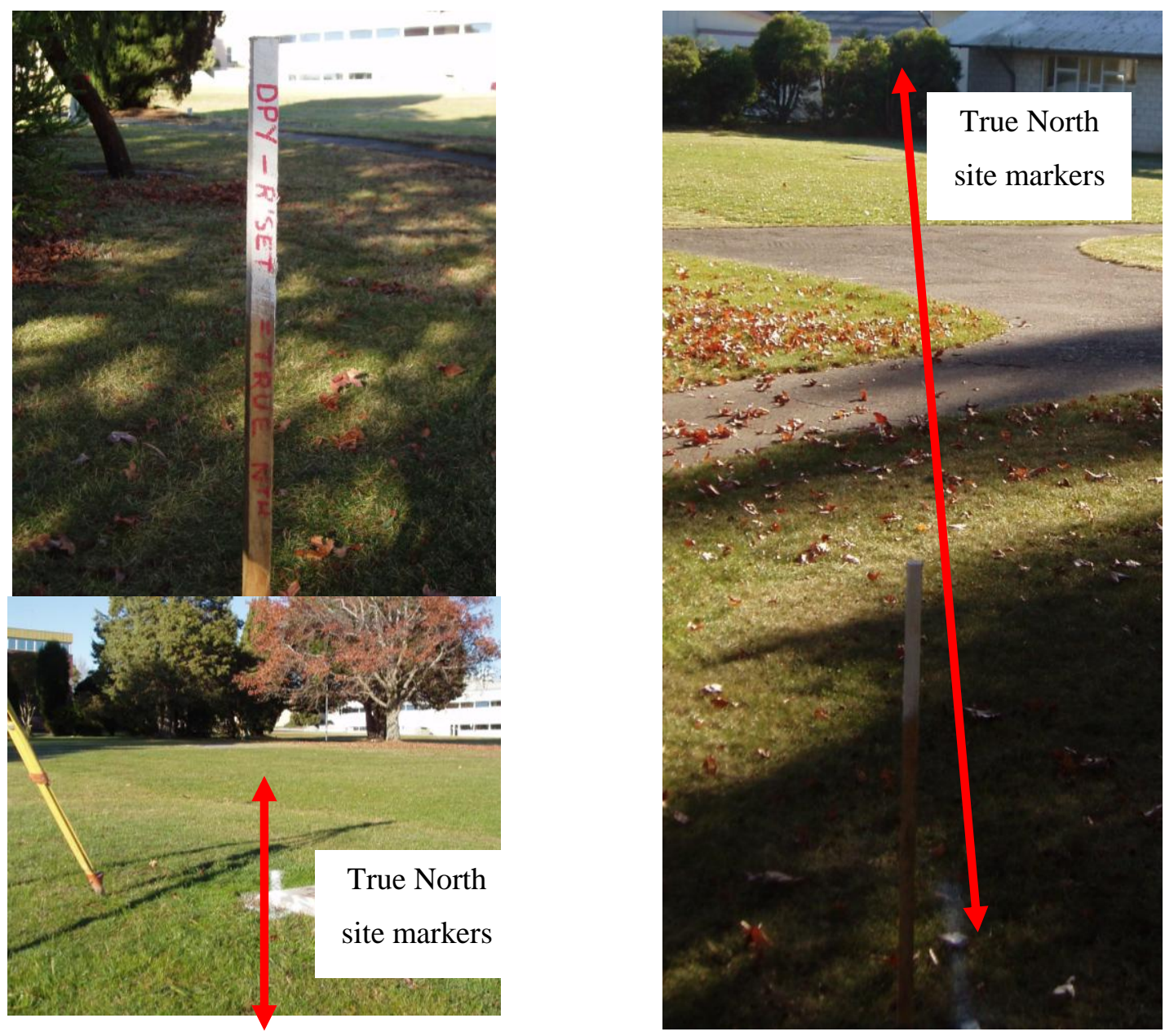

Figure 4.25 - Site markers for true north 


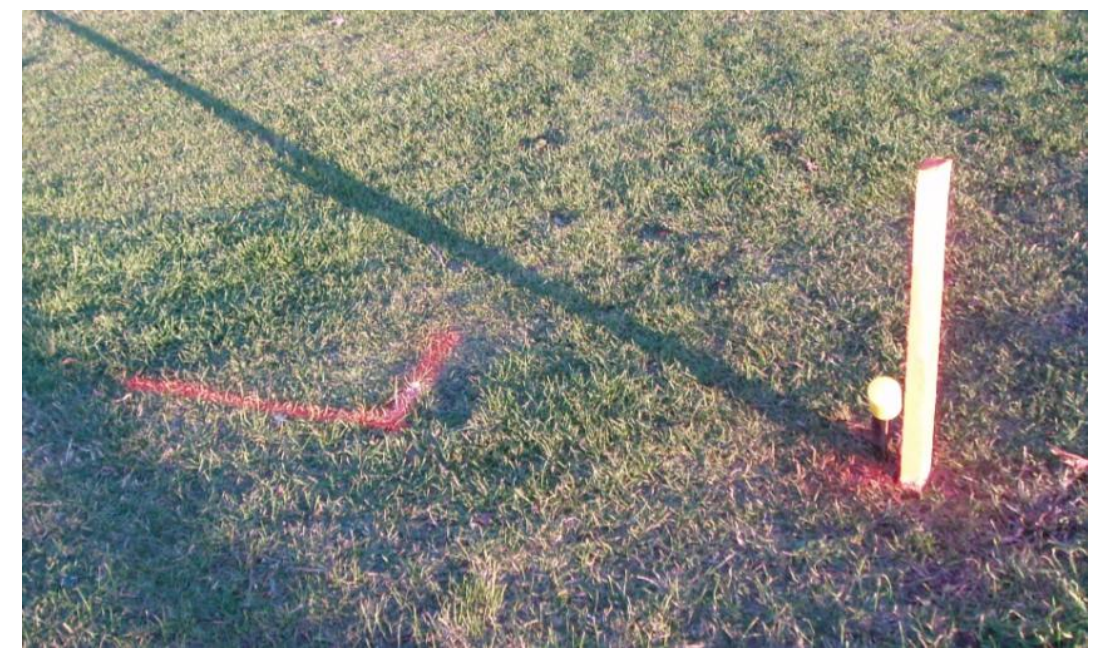

Figure 4.26 - Test Cell corner marker

Meetings were undertaken between the builder and university staff to establish construction goals and requirements. One of the first roles of the builder was to provide a proposed project program. The project program, which detailed construction stages, not only assisted the builder with co-ordination of subcontractor trades but allowed the researcher to:

- Ensure that the building process and site practices met university requirements

- Co-ordinate supply of sponsored materials

- Co-ordinate the supply and staged installation of environmental measuring equipment

- Co-ordinate relevant university staff to ensure test cell building connection to existing university services

It was also agreed during this stage that the builder and the researcher would have a formal meeting once a week to discuss financial, human and physical resource issues and to revise the project plan. Furthermore, the researcher would be available most days to assist and guide the builder during the construction process. Guidance was required to inform the builder on specific construction methods desired and to ensure that the high quality of construction required for the test cells would be achieved. 


\section{Primary Construction of Test Cells}

The builder commenced site works on June 5, 2006 and an official opening of the test cells occurred on August 23, 2006 to mark the completion of the test cell construction. Like any outdoor construction project, the works were subject to the vagaries of the weather. Several construction days were lost in late June and July due to consistent rain. A strong wind storm on the weekend of July 1 and July 2 removed the building wrap, which had been carefully installed in the days before. Key milestones during the construction of the test cells are shown in Figure 4.27 to Figure 4.39 below. To best illustrate the construction process of the test cells, a condensed version of the construction process, detailing key events from each day are shown in Appendix 3.

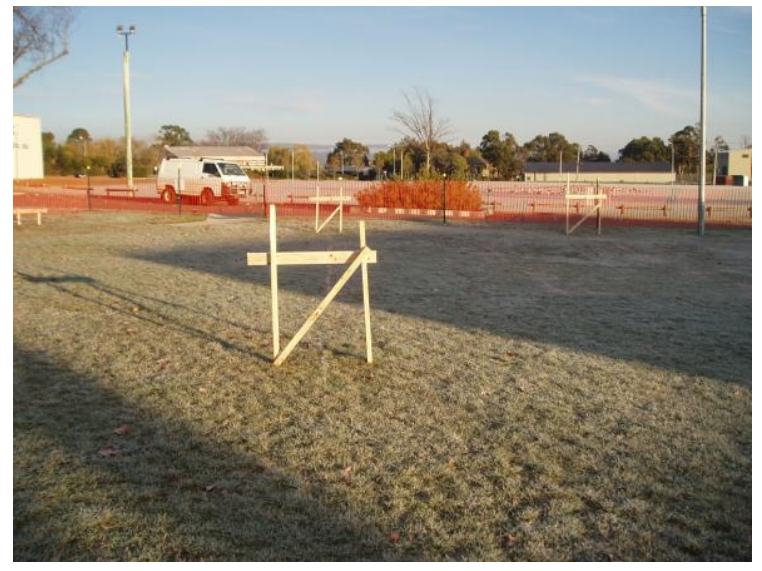

Figure 4.27 - Exclusion fence and commencement of Test Cells set out (June 5, 2006)

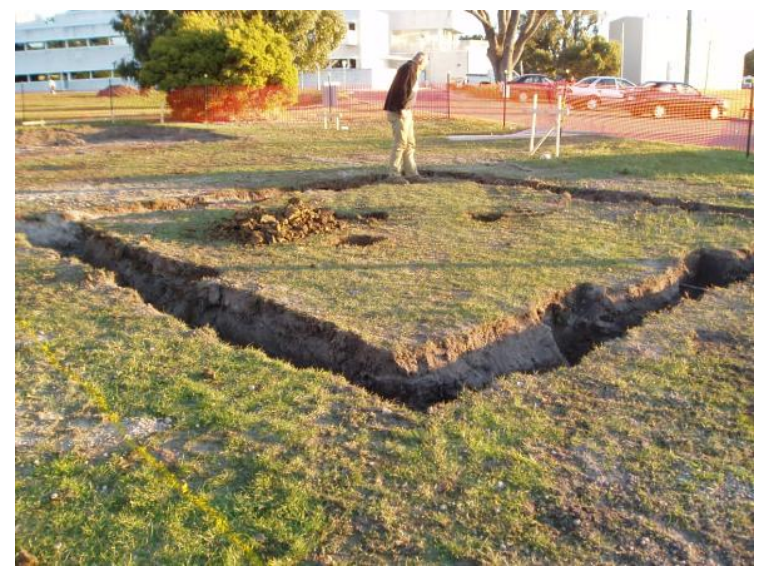

Figure 4.29 - Excavation for footings of test cell 2 (June 7, 2006)

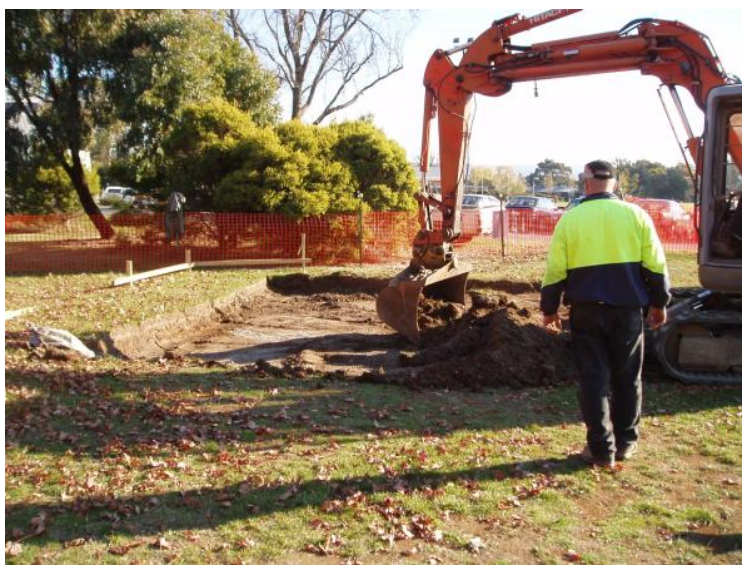

Figure 4.28 - Turning the first sod - Top soil removal for test cell 3 (June 6, 2006)

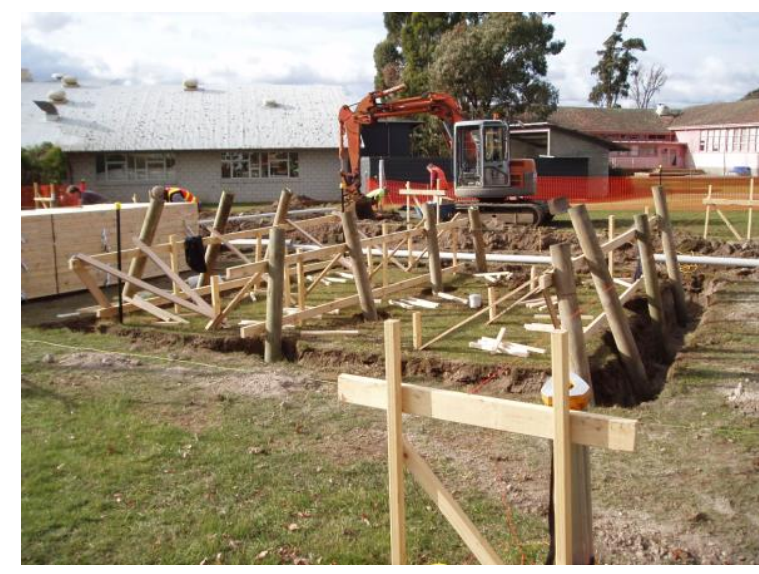

Figure 4.30 - Poles in place before concrete put in footings, test cell 2 (June 13, 2006) 


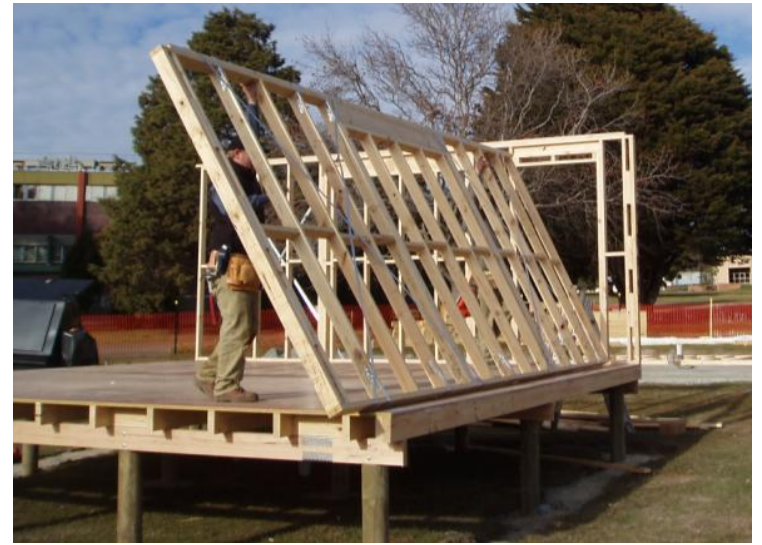

Figure 4.31 - The two-man process stage of erecting the prefabricated wall frames (June 20, 2006)

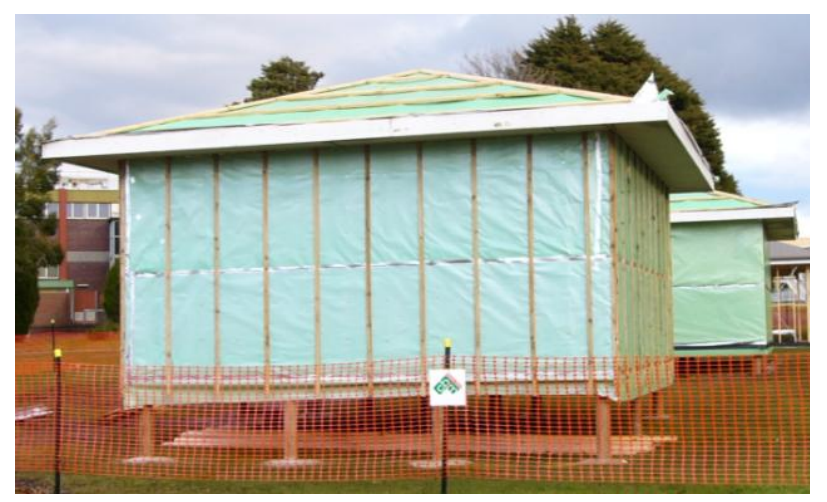

Figure 4.33 - Site photograph at the completion of works on June 30,2006 . test cell 1 to test cell 3 in receding order

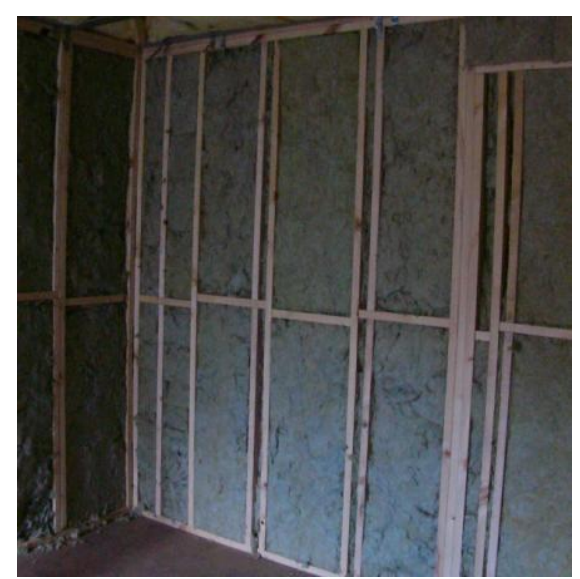

Figure 4.35 - Test cell 2 - rockwool wall batt insulation (July 5, 2006)

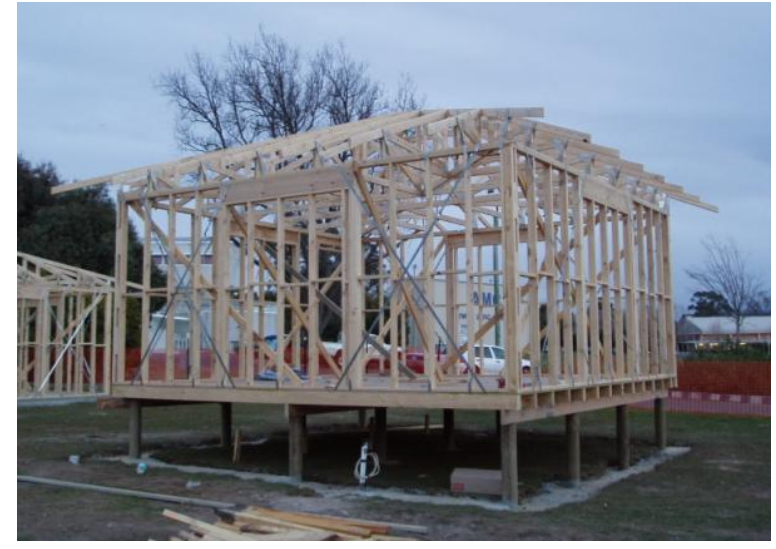

Figure 4.32 - Roof trusses erected on test cell 2 (June 21, 2006)

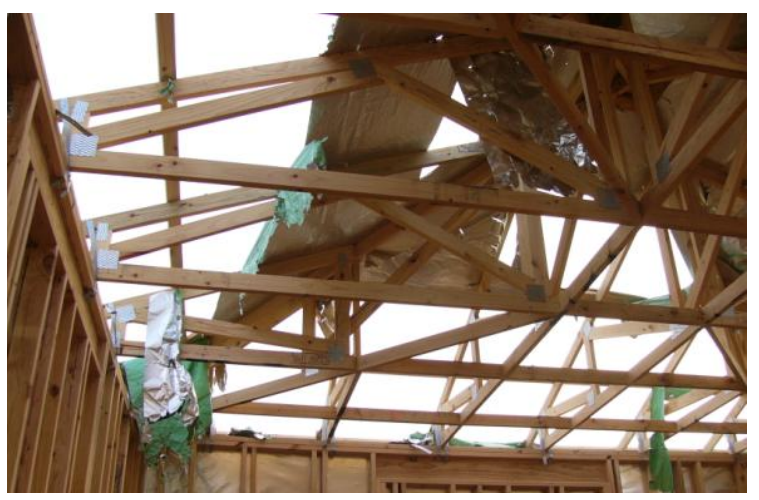

Figure 4.34 - After the storm. Much of the building wrap and roof sarking was removed by strong winds and rain. (July 3, 2006)

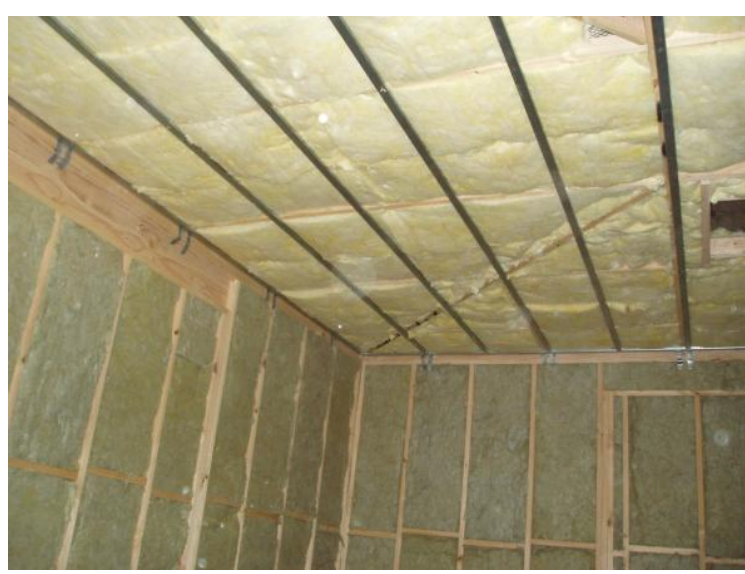

Figure 4.36 - Test cell 3 - glasswool ceiling batt insulation installed (July 6, 2006) 


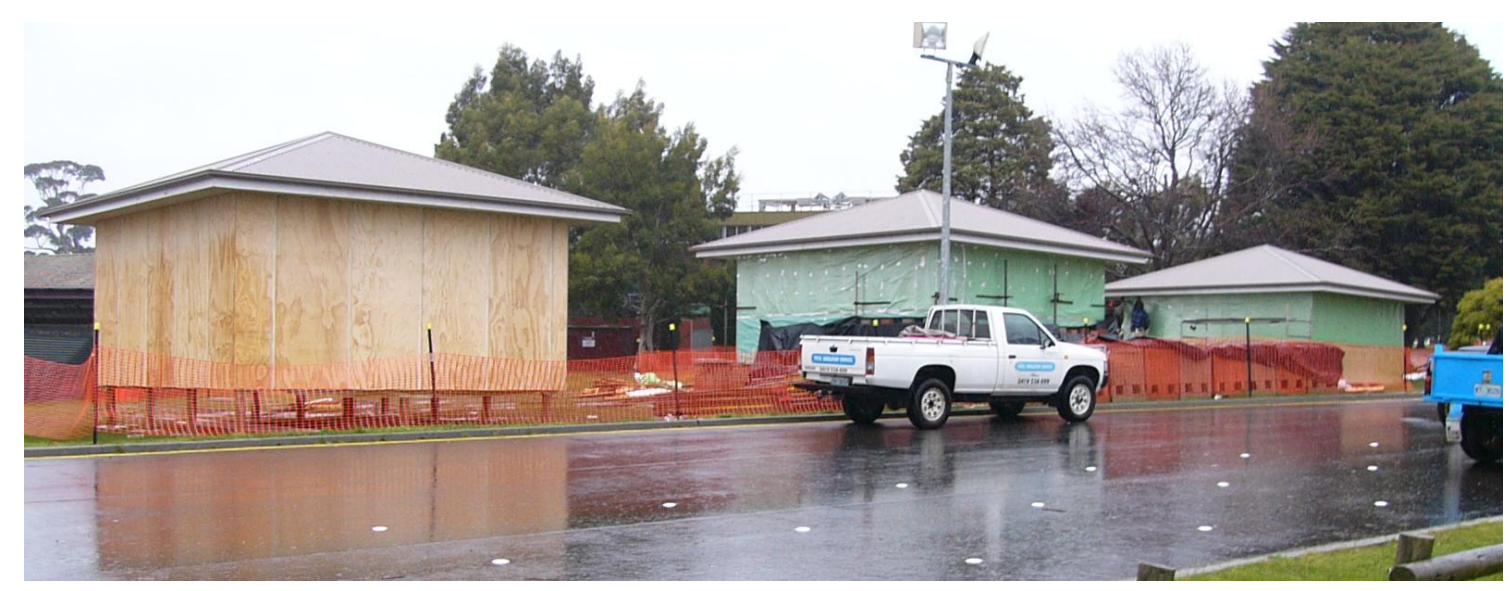

Figure 4.37 - Another rainy day halts external works (July 5, 2006)

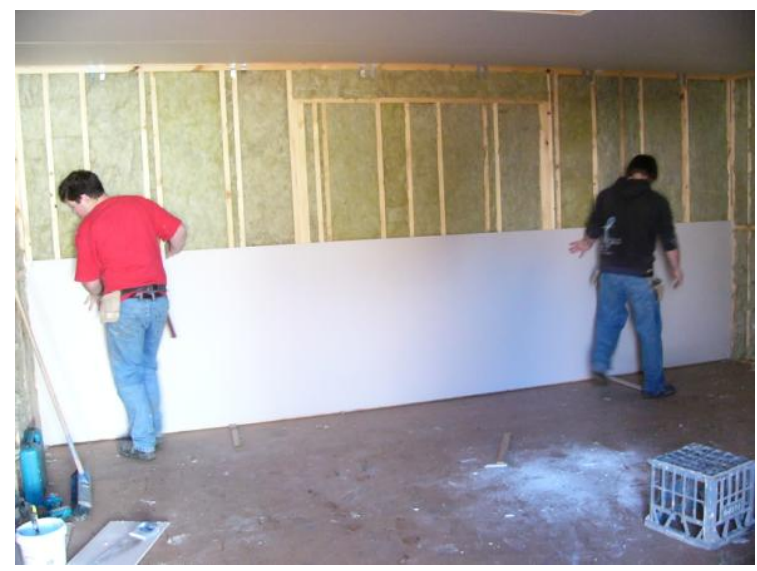

Figure 4.38 - Test cell 1 - Application of wall and ceiling plasterboard (July 6, 2006)

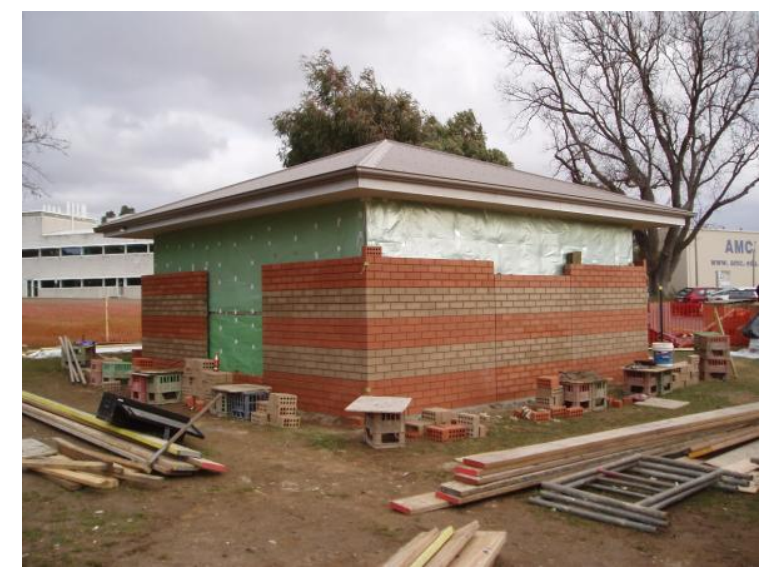

Figure 4.39 - Test cell 3 - Bricklaying well under way with knock-out panels being left till last (July 10, 2006)

\section{Additional Infiltration Control Measures}

Internationally, infiltration control has been recognised as an important aspect of building thermal performance (Biggs \& Bennie 1988; Biggs, Bennie \& Michell 1987; Coldicutt et al. 1978; Nolan \& Dewsbury 2007; Rudd, Chandra \& Tooley 1993; Sherman 2006). Aside from the quality of building wall wrap and roof sarking, other elements of the building were examined during the construction process. As a part of this process two key areas were identified: the gaps between wall frame and door jamb and the standard method of affixing an 
access hatch to the roof space. Both of these areas received additional attention as described below.

\section{Air Gap between Door Jamb and Wall Frame}

Gaps between the door jamb and wall frame ranged from $10 \mathrm{~mm}$ to $30 \mathrm{~mm}$ in width (Figure 4.40). This is a non-insulated zone and when examined carefully, daylight is often visible (Figure 4.41). This indicates that this zone would be a direct conduit for air leakage and infiltration (Potter, I 1999). As a remedy, a closed cell foam rubber bar was installed and forced into the gap at both sides and the top of the door jamb (Figure $4.42 \&$ Figure 4.43).

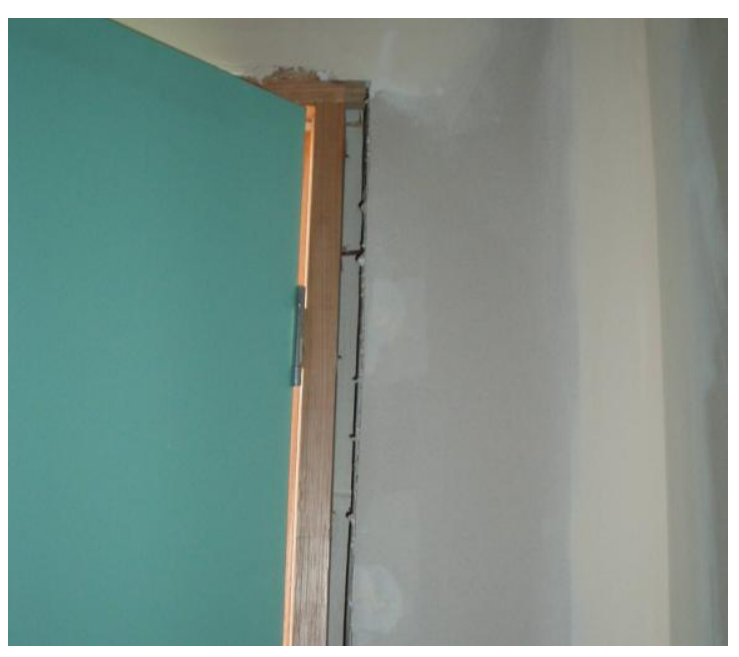

Figure 4.40 - Gap between door jamb and wall frame is clearly visible (July 17, 2006)

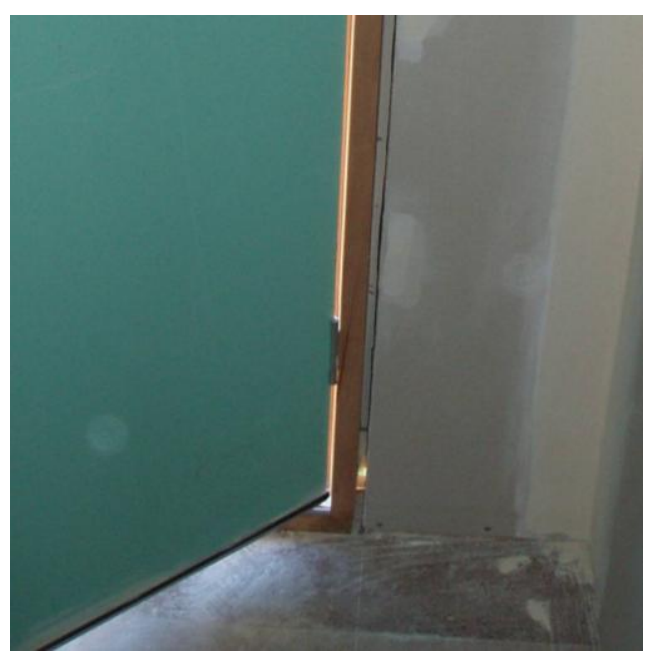

Figure 4.41 - Daylight is visible at the base of the gap between door jamb and wall frame (July 17, 2006) 


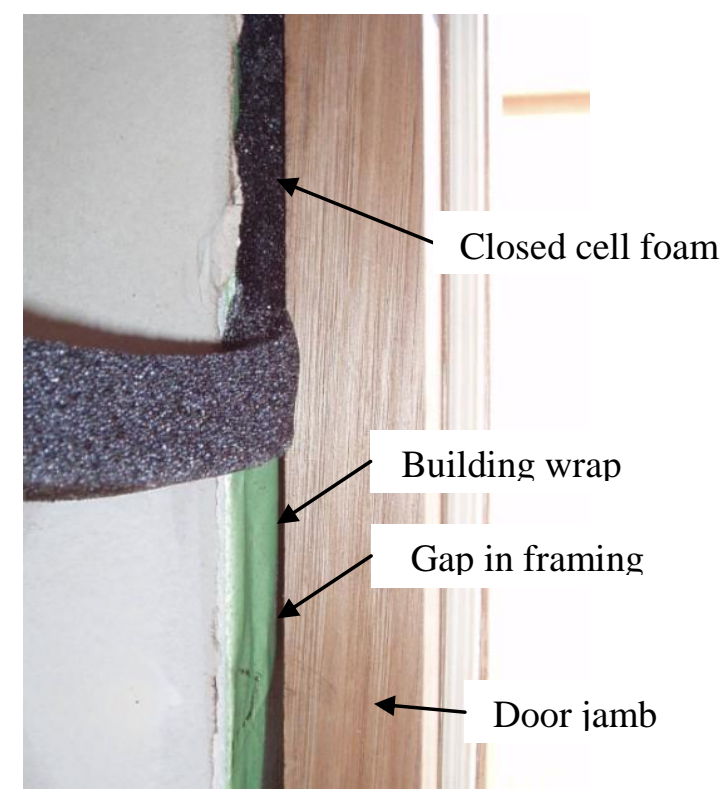

Figure 4.42 - The installation of closed cell foam rubber in gap between door jamb and wall frame (July 17, 2006)

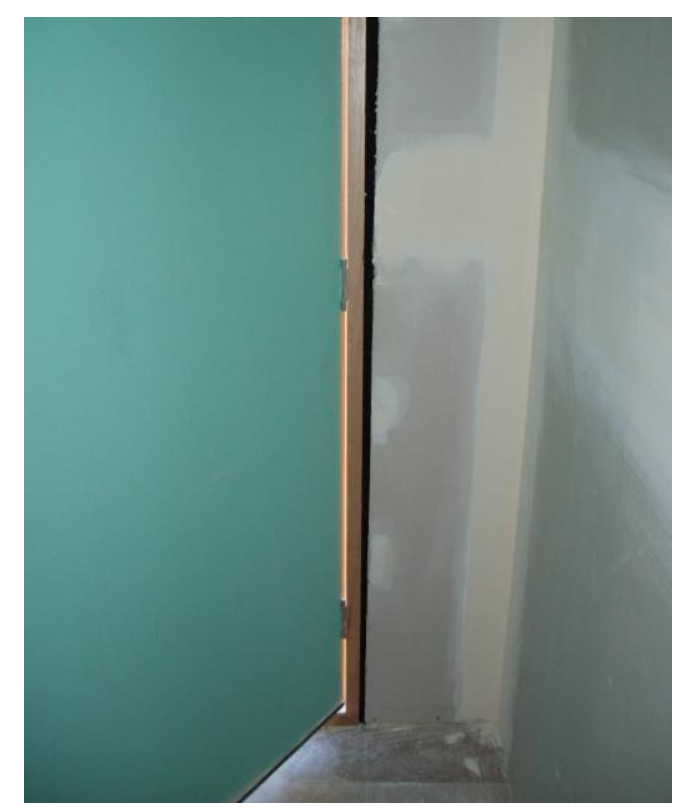

Figure 4.43 - Closed cell foam rubber is installed in gap between door jamb and wall frame (July 17, 2006)

\section{Access Hatch to Roof Space}

The standard access hatch is made from formed plastic and is screw-fixed to a sub-frame in the roof. Gaps of approximately $5 \mathrm{~mm}$ exist on all four sides of the prefabricated insert. Then a square of plasterboard is cut to fit loosely within the frame. Both the gaps at the side of the insert and gaps around the plasterboard square provide ample opportunity for air leakage and infiltration losses. Additionally, under normal circumstances, changes in air pressure can make the access hatch rattle, due to air moving between the room and roof spaces.

To counteract each of these issues the following actions were undertaken for all three thermal performance test cells:

- High density foam rubber tape was applied as a backing rod, to the prefabricated plastic insert (Figure 4.44). The insert was then compressed against the ceiling plasterboard (Figure 4.45) and screw-fixed.

- To stop the hatch from lifting due to air pressure changes, high density foam rubber double sided tape was applied around the edges of the plasterboard sheet. Then two layers of $19 \mathrm{~mm}$ particle board were affixed to the plasterboard (Figure 4.47). This 
gave the access hatch considerable weight, reducing the chance of air movement between the test cell room and roof spaces.

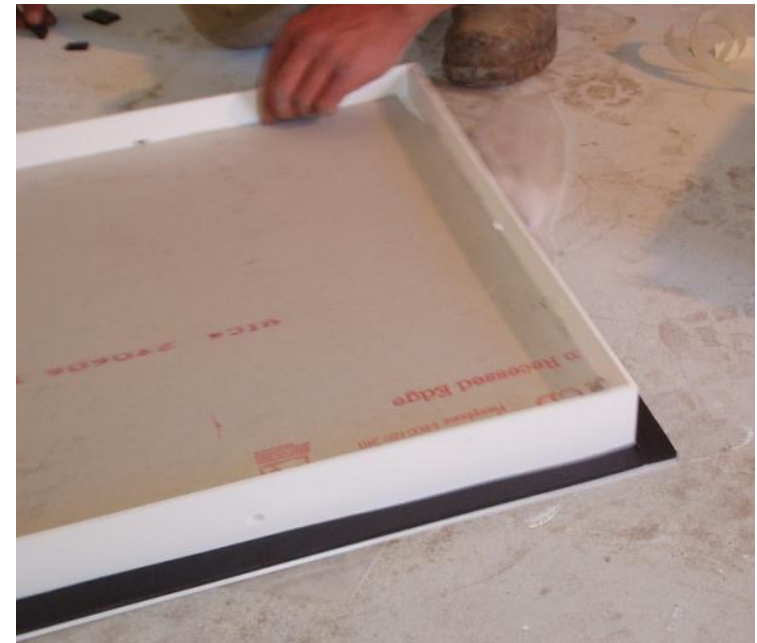

Figure 4.44 - Application of high density foam rubber tape to prefabricated insert (July 21, 2006)

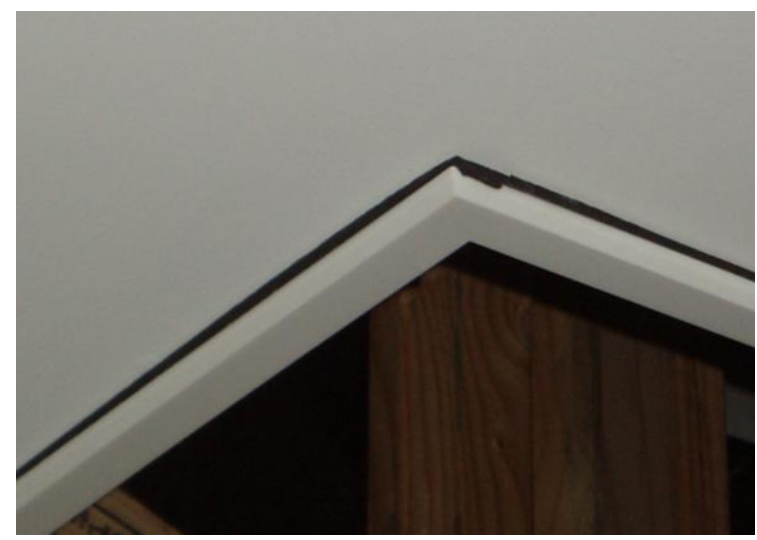

Figure 4.46 - Close up-view of high density foam rubber compressed between prefabricated insert and ceiling (July 21, 2006)

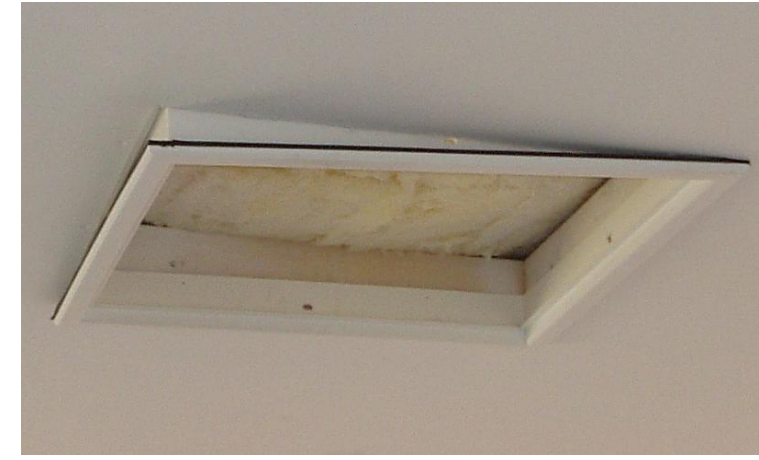

Figure 4.45 - Pushing prefabricated insert hard-up against the plasterboard ceiling (July 21, 2006)

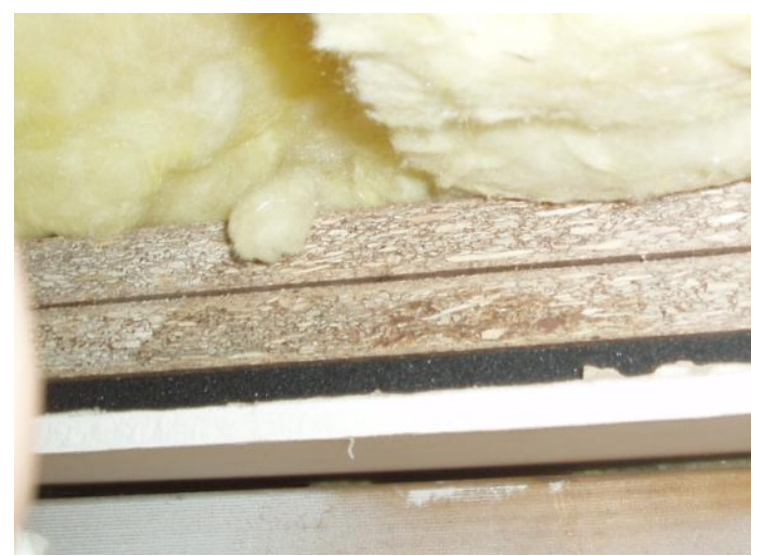

Figure 4.47 - High density foam rubber and particle board sheet affixed to top face of access hatch (July $21,2006)$

\section{Test Cell 1 and Test cell 2 Wall Cavity}

The design of Test Cell 1 and 2 included a still-air reflective foil cavity between the plywood cladding and brick veneer wall and the prefabricated wall frame. As built, the cavity would 
provide a chimney vent and not provide the benefit of a still air reflective cavity. Closed cell foam rubber bar was installed at the line of the bottom plate, between the plywood cladding and the prefabricated wall frame of test cell 1 (Figure 4.48). A plastic damp proof course was installed at the line of the bottom plate between the brick veneer wall and the prefabricated wall frame of test cell 2 (Figure 4.49).

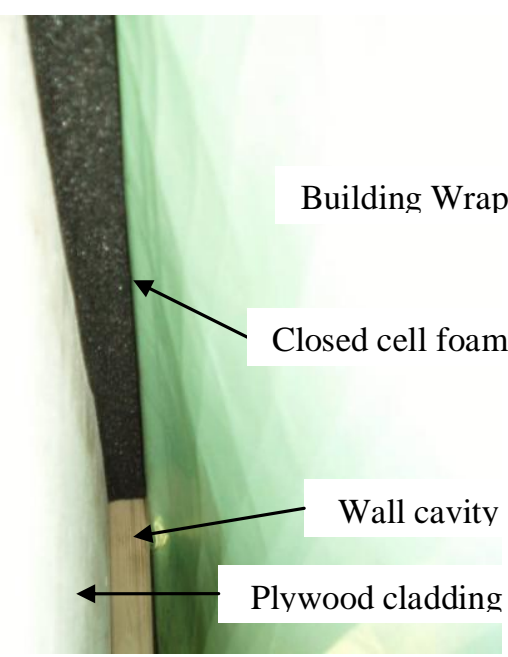

Figure 4.48 - Photograph of wall cavity sealing for test cell 1 (August 2006)

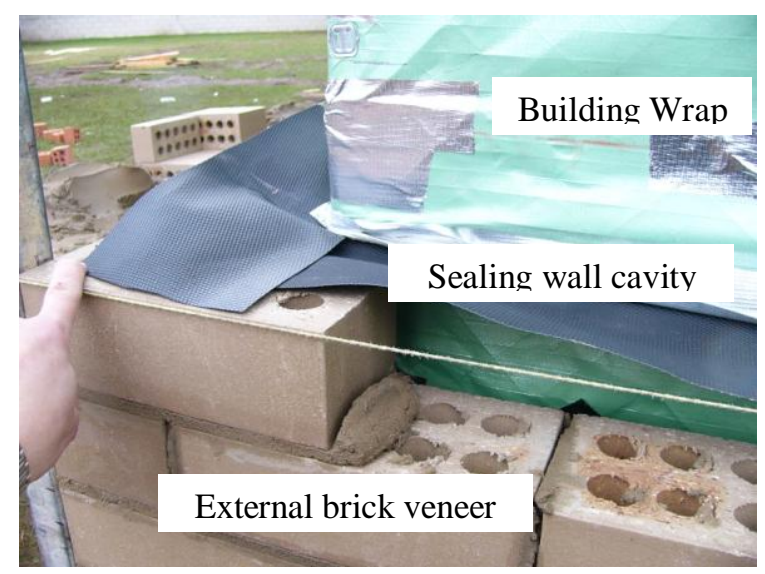

Figure 4.49 - Photograph of subfloor and wall cavity separation of test cell 2

\section{Construction Joint in Brick Veneer Walls}

The wall cavities of the brick veneered test cells were considered a relatively still-air space, with an accepted insulation value. The inclusion of the knock-out panel in each of the four external walls introduced a construction joint into the wall, providing egress for air into and out of the cavity. To maintain the still-air cavity, the construction joint had a polypropylene rod pushed into the gap (Figure $4.51 \&$ Figure 4.52). The gap was then back-filled with an external flexible sealant (Figure 4.53). 


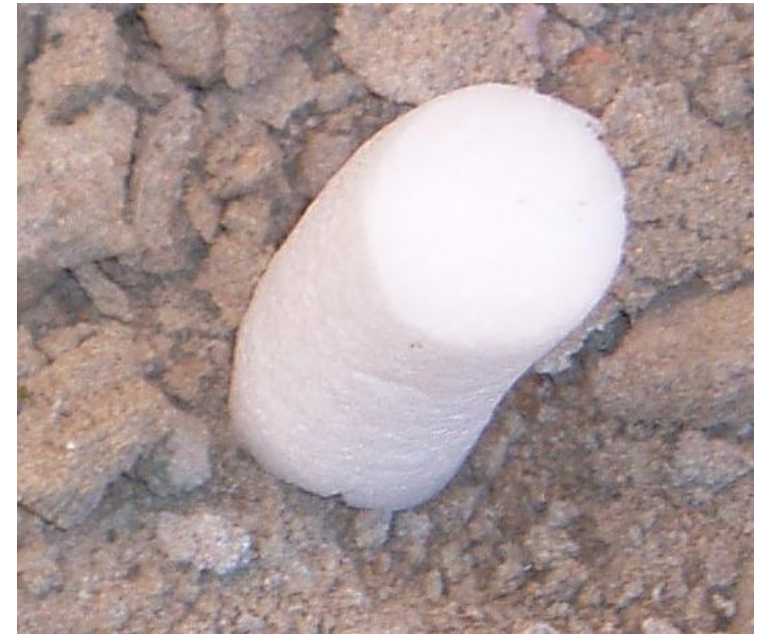

Figure 4.50 - Sample of polypropylene rod (July 21, 2006)

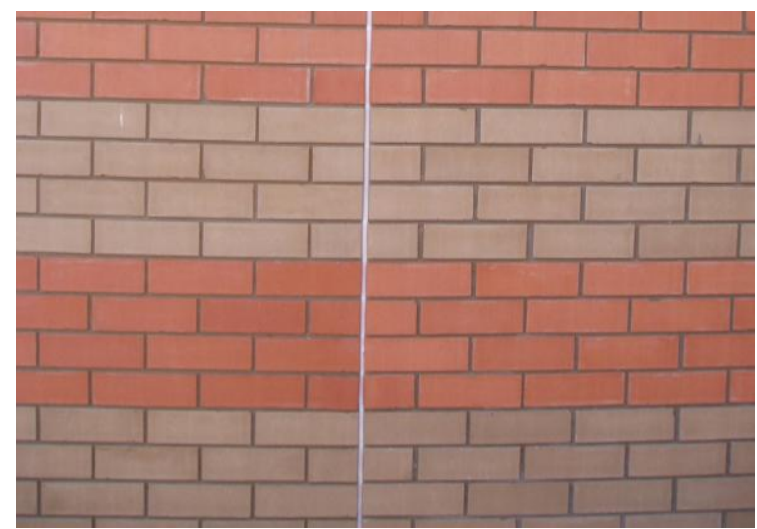

Figure 4.52 - Polypropylene rod inserted into construction joint (July 21, 2006)

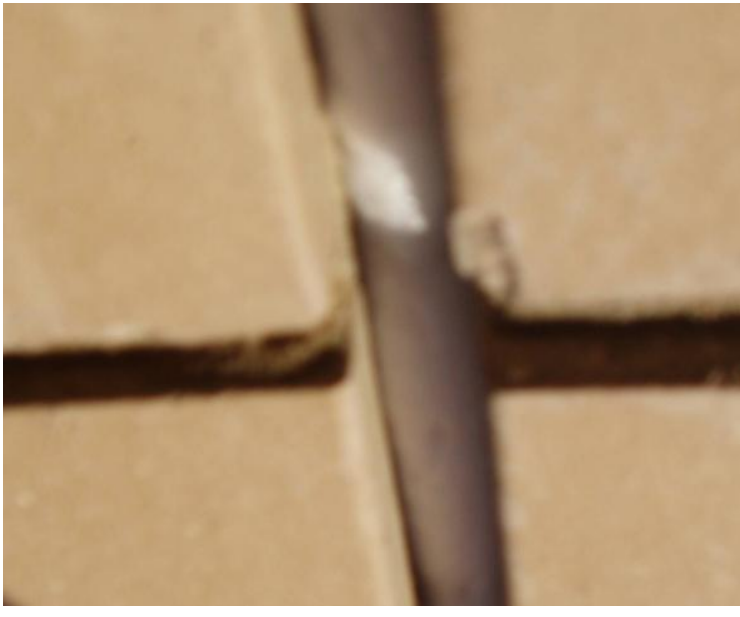

Figure 4.51 - Close up view of polypropylene rod inserted into construction joint (July 21, 2006)

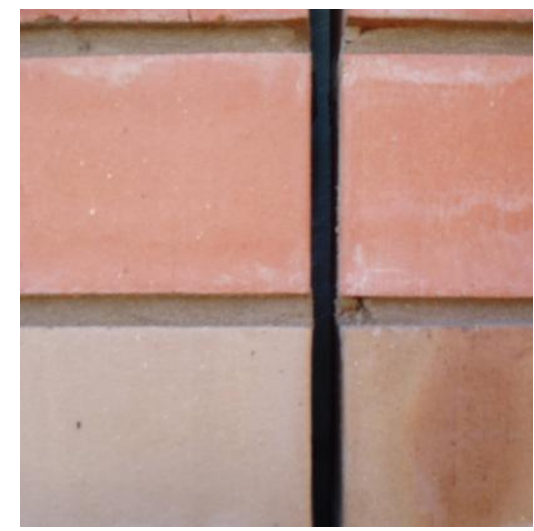

Figure 4.53 - External flexible sealant in construction joint (July 21, 2006)

\section{The Electrical and Data Services}

An important consideration for the installation of electrical and data services was to minimise impact on the building fabric (Anis, Quirouette \& Rousseau 2007). To achieve this, no penetrations were made by the electrical services into the floor, walls or ceiling. All conduits, outlets, circuit boards and lamps were surface mounted (Figure 4.54). The only penetration was a single hole through the floor of test cell 1 and test cell 2, for the conduit to bring the electrical and data services into the building. The gap between the conduit and particle board floor was sealed with silicone sealant, which was injected into the conduit to fill the gaps 
between the cables and the conduit. The electrical and data services for the concrete slab test cell were brought up from underground through the concrete slab.

One concern was the electrical instability that may occur in a test cell. To reduce the risk of one test cell's electrical instability affecting another, each test cell had a separate power supply from the main switch board located in an adjoining building. All power circuits were monitored to ascertain electrical consumption.

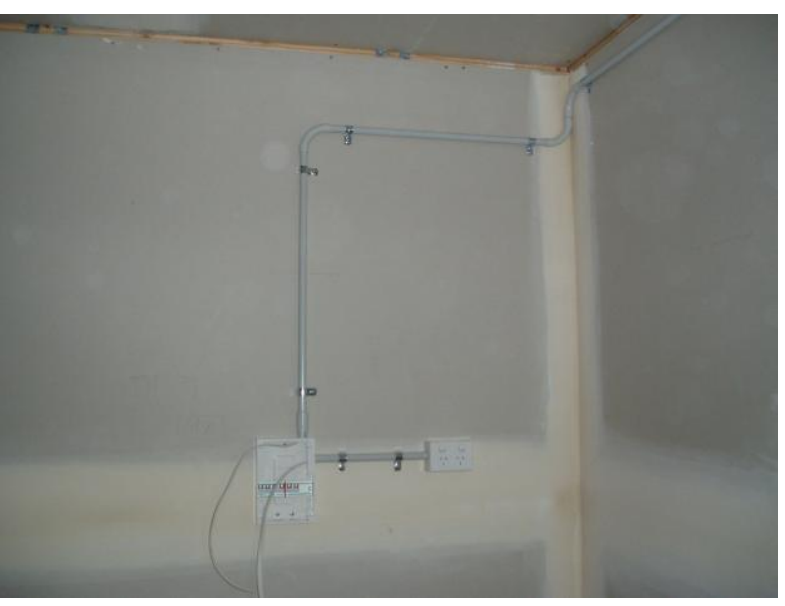

Figure 4.54 - The surface mounting of electrical services (July 10, 2006)

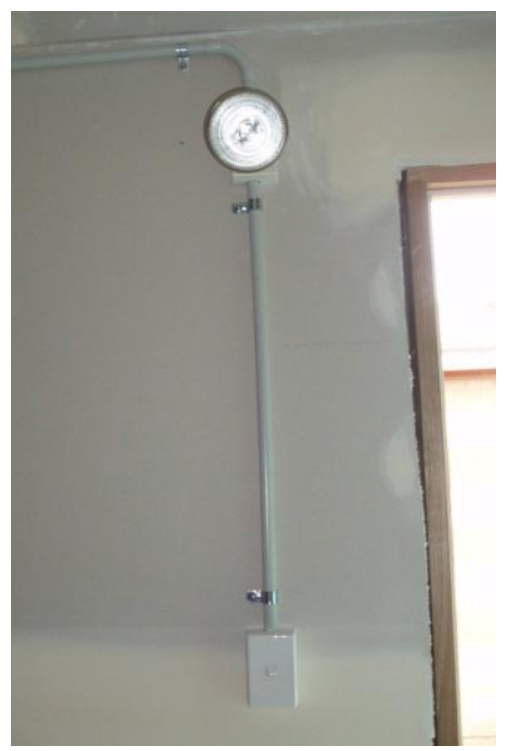

Figure 4.56 - Detail of surface mounted lamp and lamp switch (July 11, 2006)

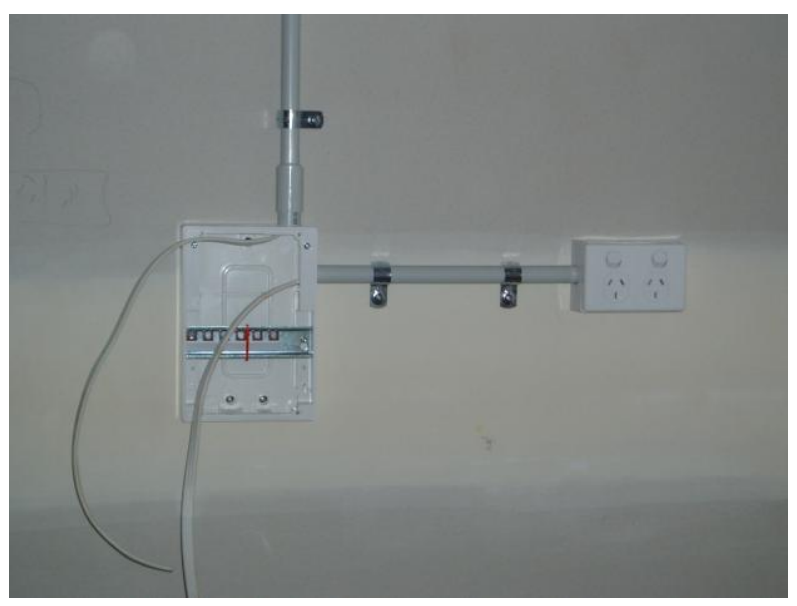

Figure 4.55 - Detail of surface mounted circuit board, conduits and general purpose outlet (July 10, 2006)

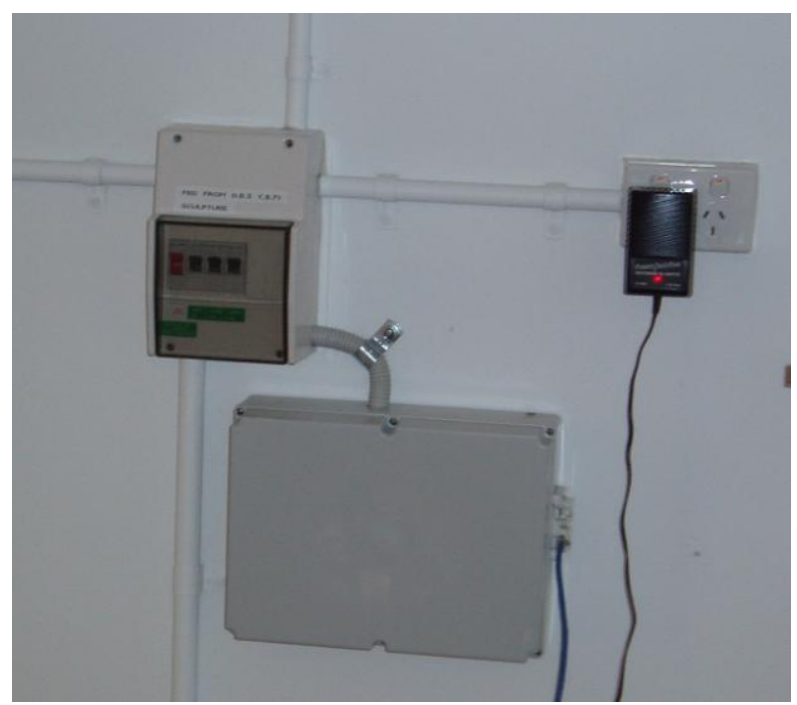

Figure 4.57 - Surface mounted electrical services when finished (August, 2006) 


\section{Test Cell Heating}

The test cell design included the consideration of various modes of test cell operation which could include free-running, constant heated and intermittent heating. The purpose of providing these various modes of operation was to mimic internal loads and to further test the capacity of HER software to simulate the building envelope and calculate heating energy requirements (LomasEppel et al. 1994; Strachan et al. 2006; Travesi et al. 2001). In the freerunning mode no heating or cooling is applied. In the constant-heated mode, a temperature is set and the energy required to maintain the set temperature is measured. In the intermittentheat mode, an attempt is made to mimic a typical house operation with no overnight heating, but heating during the day and evening.

This required the consideration of the heater type, heater placement and heater control. An investigation was undertaken into the common types of heaters in use, including radiant, fan with resistor coil and heat pump systems. This choice of heaters was reduced, as the heat was required to be circulated throughout the test cell room and the radiant heater would be unable to perform this task. Discussions by the researcher with fellow researchers at the University of Newcastle cautioned against the use of the heat pump method, due to difficulties experienced by the University of Newcastle team in trying to quantify energy in and energy out equations. This left the fan-assisted resistor coil type of heater.

The use of the HER software provided a peak heating requirement projection of almost 2400 watts. This was discussed with researchers from CSIRO and it was agreed that the fan assisted resistor coil heater would be installed in all three test cells. It was also agreed that the heater would be of a 2400 watt capacity. A 2400 watt heater could run sensibly on a single phase power circuit with minimal current effect on lamp and measuring equipment power supply.

The heater was located in the middle of the western wall, low to the floor, to be close to the test cell circuit board and to maximise warm air distribution within the test cell. To continue the practice of not penetrating the wall fabric, plywood boxes were designed to suit the heater installation requirements and for surface mounting. The mounting boxes were cut on the computer controlled router at the School of Architecture. They were fabricated and installed onsite by the researcher and the School of Architecture technical assistant. 


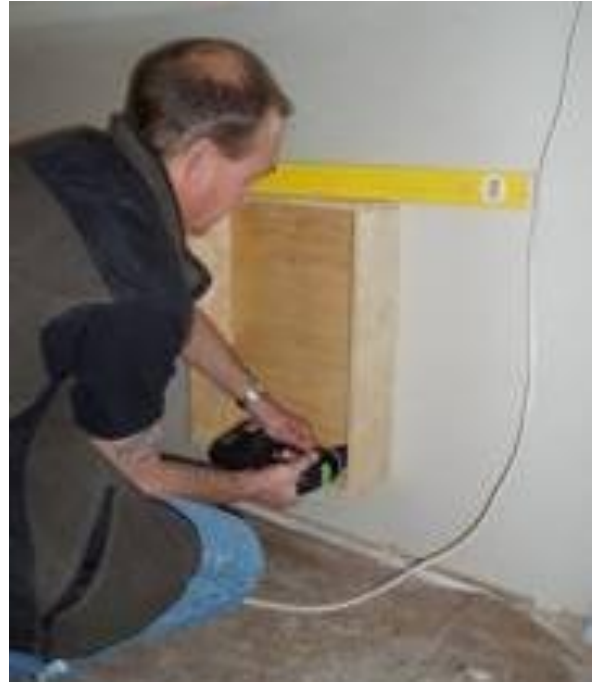

Figure 4.58 - The School technical assistant screwfixing the heater mounting box to test cell internal wall (July 11, 2006)

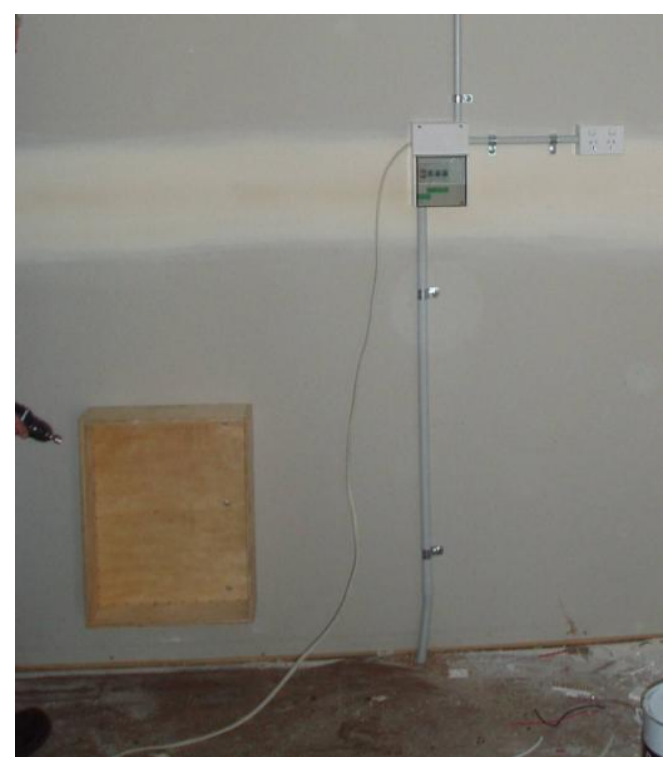

Figure 4.60 - Wall photograph showing proximity of heater to circuit board, and height above floor

(July 11, 2006)

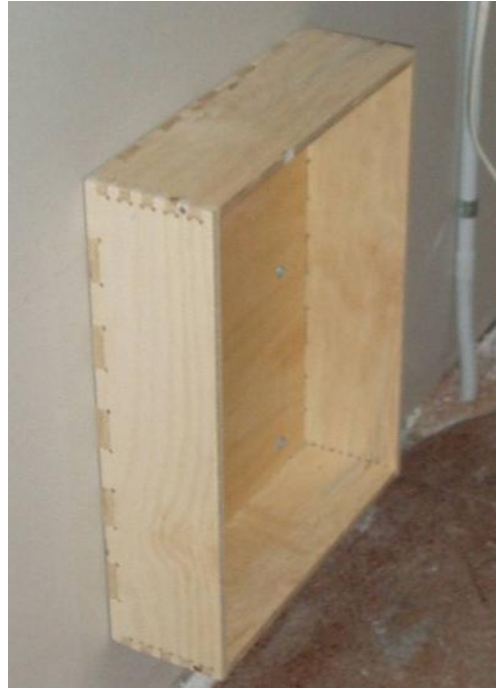

Figure 4.59 - The heater mounting box fixed to test cell internal wall (July 11, 2006)

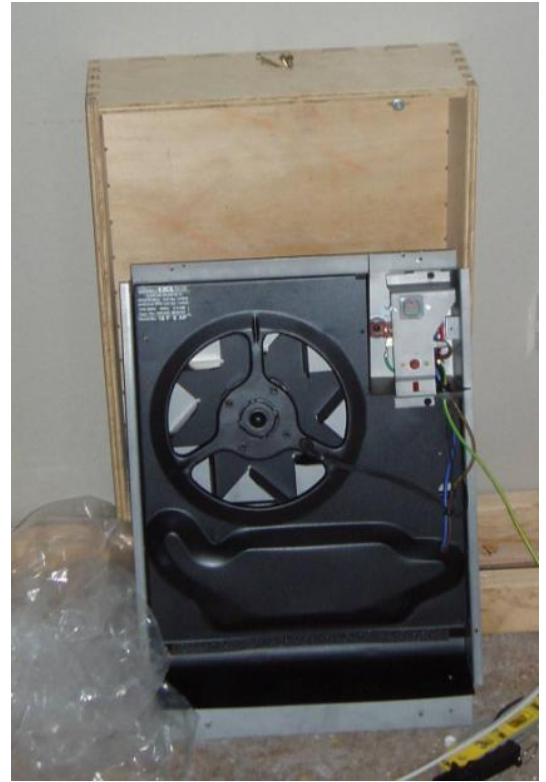

Figure 4.61 - Heater being inserted and screw-fixed into mounting box (July 11, 2006) 


\section{Other Factors Addressed During Construction}

The design and construction of the three thermal performance test cells was an exhaustive and intensive learning experience for the researcher. Most weeks during the construction period were seven day working weeks, with work starting prior to 7.00am and finishing well after $6.00 \mathrm{pm}$. During the construction period the researcher was either on site, or readily available to the contractors. The researcher learnt much from all trades on site, as discussions centred on differences between current practices, training and legislated standards. Some key issues became apparent during the construction process which required continuous attention. The application and care of building wrap and roof sarking, an understanding of the effect of infiltration, insulation installation and an understanding of the effect of framing factors were all lacking within the tradespeople present.

\section{Building Wrap and Roof Sarking}

The purpose of wrapping a building or applying roof sarking of a reflective nature is to provide a reflective insulation, an insulative air cavity (AFIA 2004; Hassall 1977), provide a vapour barrier (Anis, Quirouette \& Rousseau 2007; CMHS 1982; Lstiburek 2004; Mumovic et al. 2005; Quirouette 1986; US DOE 2000), and reduce infiltration losses from the building (Hendron et al. 2003; Lstiburek 2006; Swinton, Brown \& Chown 1990). To provide the vapour barrier and infiltration functions, a consistent quality of material with no discontinuity is required. As observed in this project, conventional construction practises damaged the building wrap and roof sarking. The lack of knowledge by tradesmen involved with the project, particularly on the functions of the wrap and sarking, became apparent early in the construction process. Consistent supervision and awareness was required to maintain the constructed integrity of the building wrap and roof sarking. The contractors cooperated by using rolls of reflective foil tape, supplied by the researcher, to make repairs during the construction process. Repair of the building wrap and roof sarking is not a common practise, hence it is reasonable to suspect that many new buildings would have limited infiltration control and possible vapour barrier limitations.

The problems that were experienced during the construction included:

- Steel staples used to attach the building wrap and roof sarking would tear the material (Figure 4.62) 
- General lack of care by all trades resulting in puncturing and tearing of building wrap and roof sarking (Figure $4.63 \&$ Figure 4.64)

- Brick layer forms puncturing and tearing building wrap

- The insulation is installed by pushing the material into the timber framed wall until it stops. As the fixing of the building wrap is intermittent, often the wrap was torn off the steel staples, due to the forces exerted by the insulation installation.

Due to vigilance by the researcher and the diligent repairs to the building wrap (Figure 4.65) and roof sarking, it was felt that the integrity of the building wrap and roof sarking was achieved.

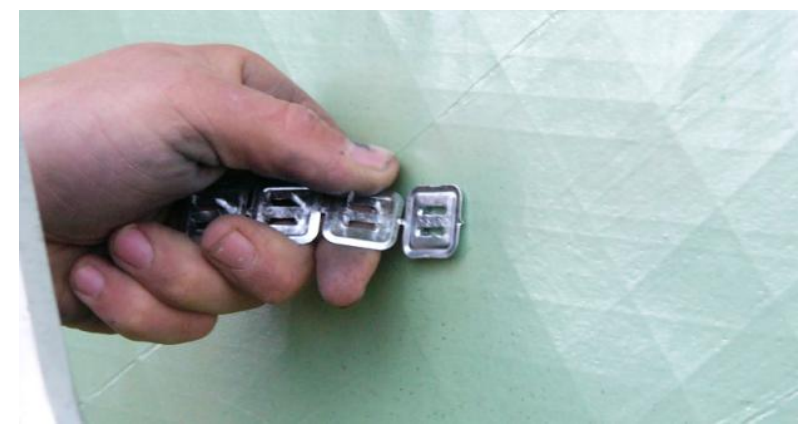

Figure 4.62 - Steel staples used to affix building wrap and roof sarking

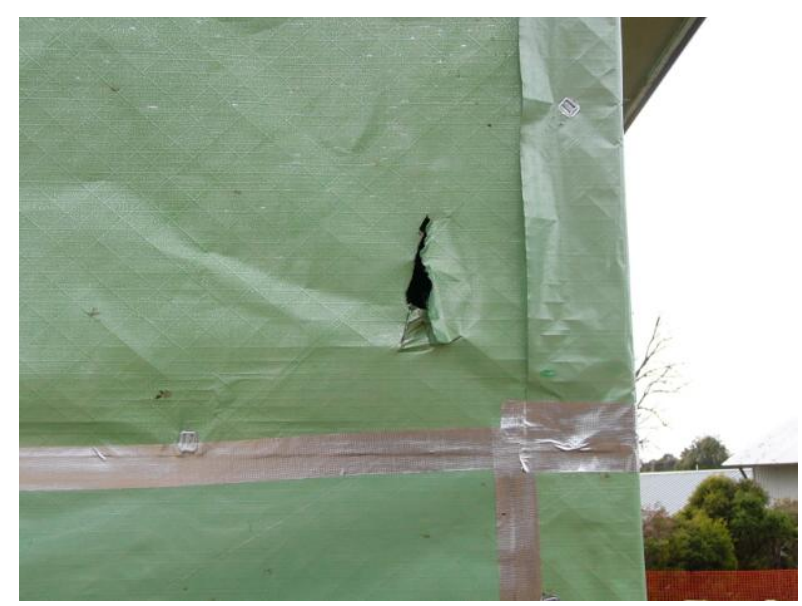

Figure 4.64 - Building wrap torn during construction process

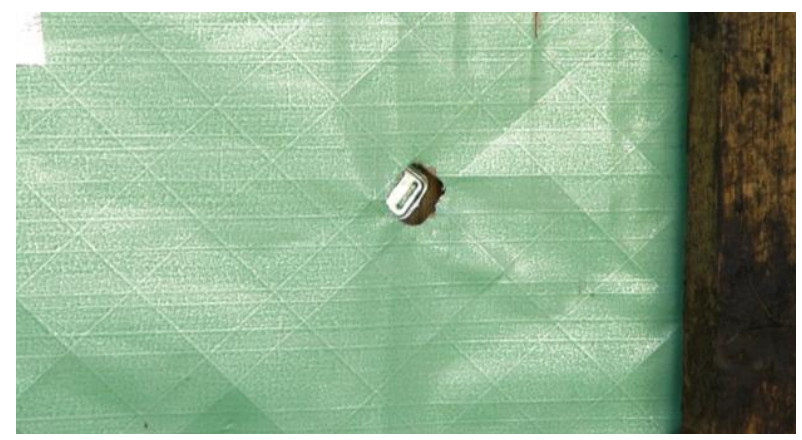

Figure 4.63 - Building wrap torn off staples during construction process

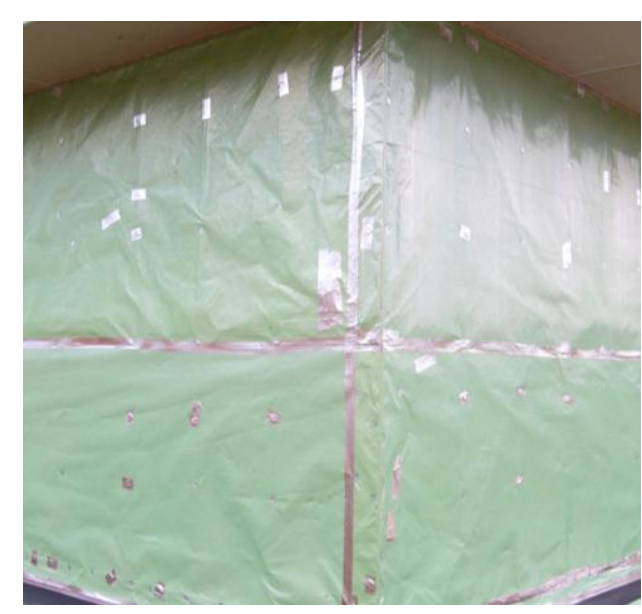

Figure 4.65 - Reflective foil tape repairs to building wrap during construction 


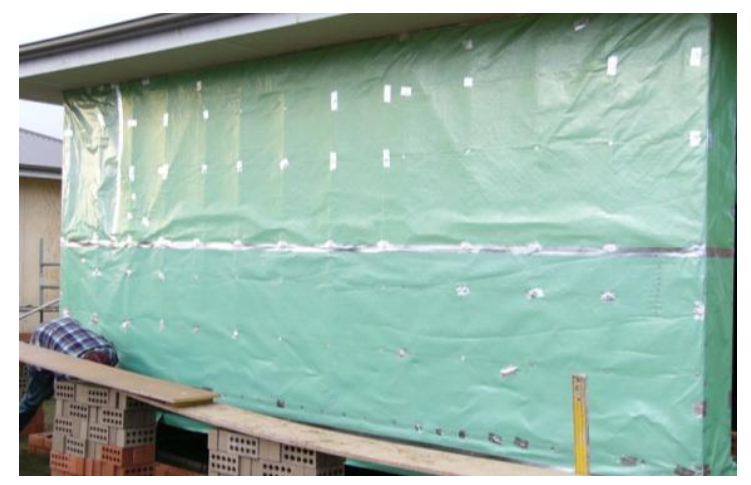

Figure 4.66 - The pattern of holes shows the location of staples and the effect of insulation installation

\section{Building Infiltration}

Building infiltration control is an area rarely discussed in Australian residential construction practice. Much has been written on the amount of energy loss due to poor control of infiltration (Gettings, McCold \& Schlegel 1988; Nolan \& Dewsbury 2007). For the thermal performance test cells there were three areas that posed opportunities for infiltration control. Two of these were addressed during construction and discussed earlier, namely: i) the gaps between wall frame and the door jambs and ii) the roof space hatch.

The third area which provides an opportunity to reduce infiltration was the corner joint between the plasterboard walls and ceiling. The gap between plasterboard sheets was up to $50 \mathrm{~mm}$ (Figure 4.67). The only elements that could reduce infiltration were the cornices and the bulk ceiling insulation (Figure 4.68). Depending on how the building wall wrap was applied to the outside face of the wall frame top plate, infiltration could also occur into the wall. Currently, the cornice is glued across this joint for presentation purposes, more than infiltration control. As these are lightweight buildings, the walls frames move over time; In addition an issue was the uncertainty of life expectancy of the cornice glue which apparently provides infiltration control. 


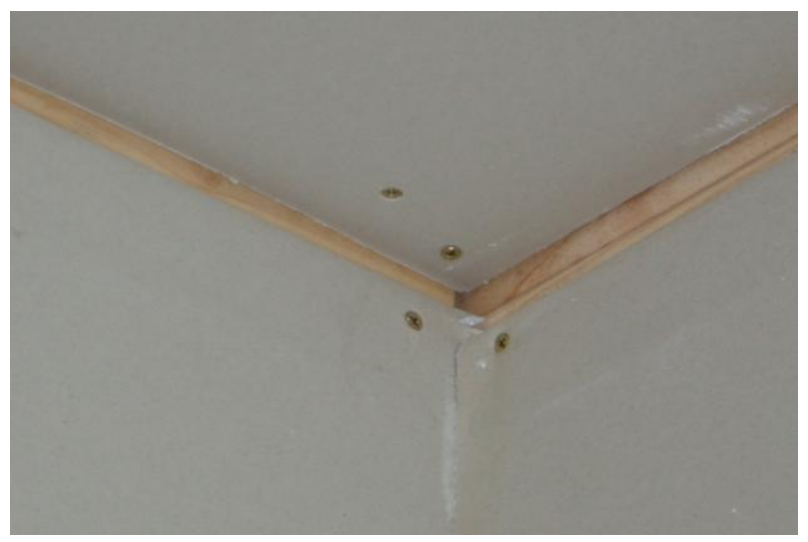

Figure 4.67 - Gap in ceiling corner between wall and ceiling plasterboard

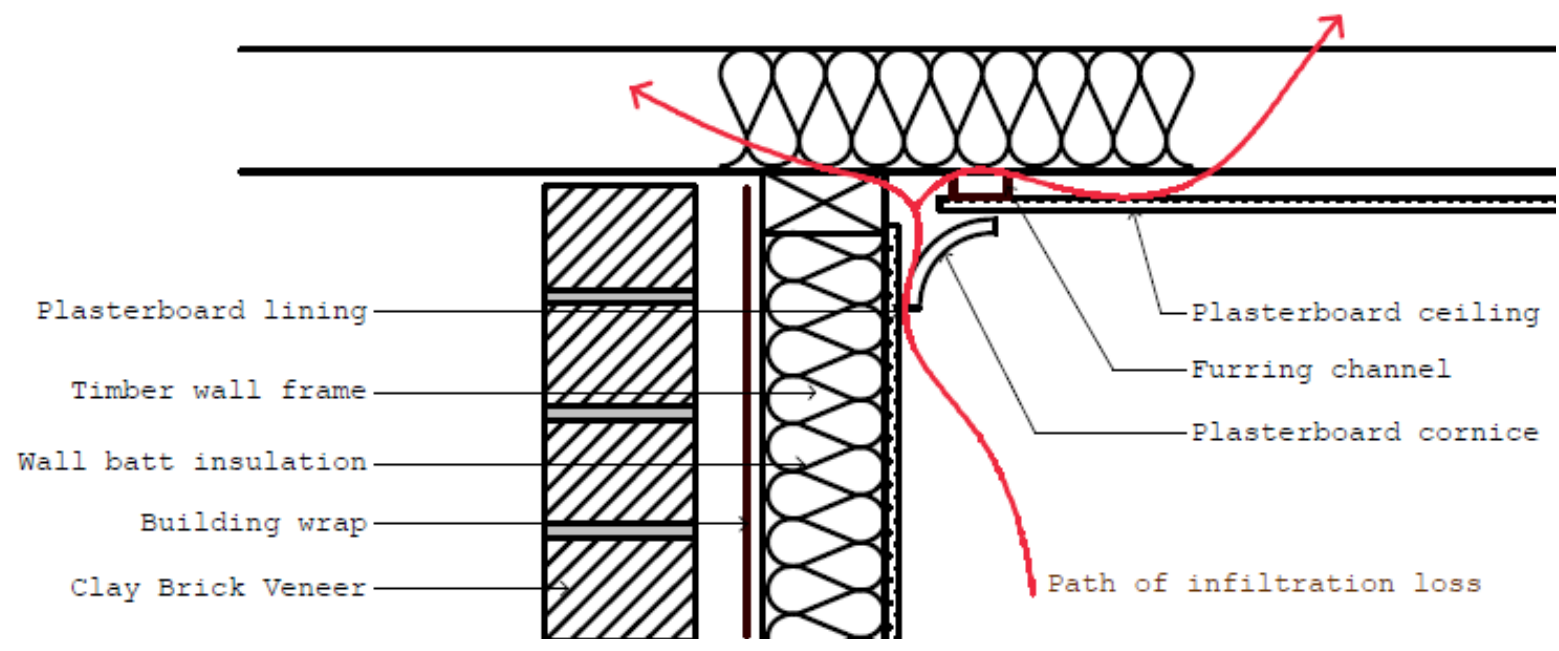

Figure 4.68 - Diagram showing potential unrestricted infiltration losses.

\section{The Installation of Insulation}

The installation of insulation raised three areas of critical concern in contemporary Tasmanian insulation installation practice. These were: the gaps in insulation; the method of installation and its impact on building wrap and air cavities and framing practices which leave portions of external walls uninsulated.

In the construction of the thermal performance test cells, the contractors had a reputation for better than average installation of insulation. Even with this reputation, the contractor was unaware of the Australian Standard (Standards Australia 1992) which describes the 
installation of insulation. They were also not aware of the effect of gaps in insulation. The installation of the wall batt insulation in the first test cell took three attempts before it finally satisfied the requirements of the Australian Standard and manufacturers specifications (Figure 4.70). Assuming that the first attempt was better than average installation practise, there must be a lot of poorly insulated homes being built. Due to persistent pressure for quality installation, in this project the ceiling batts were installed more carefully, with only minor gaps requiring filling.

Another major concern with regard to insulation installation was the method of pushing the batts into the wall frame until something stopped the batt (Figure 4.69). In the case of the thermal performance test cells, a lot of the building wrap was torn from its staples by using this method. Only after the researcher showed the contractors the resultant damage to the building wrap, did they slow down and take more care.

The third aspect affecting insulation installation practice is caused by Australian residential framing practice and the use of double studs in external corners. As insulation contractors normally come to the building site after a building has had its wall wrap applied, there is no easy way of retrofitting the external corners of the timber frame and as such the corners remain uninsulated. In the case of the thermal performance test cells the researcher and Associate Professor Greg Nolan retrofitted insulation into the external corners.

Due to the diligence of the researcher, the final installation quality of insulation very satisfactorily met BCA and Australian Standard requirements. 


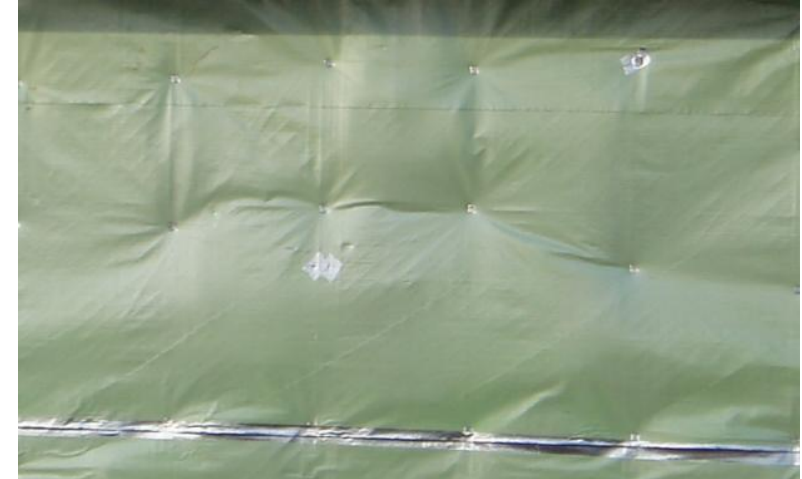

Figure 4.69 - Billowing of building wrap as a result of insulation installation

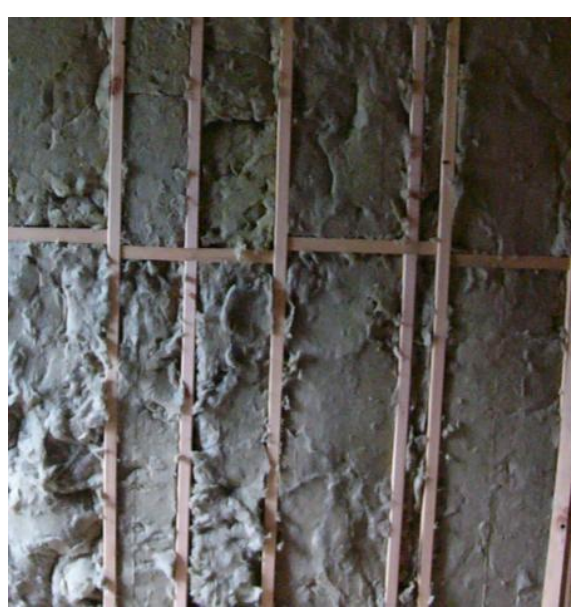

Figure 4.70 - Insulation installation in test cell 1 third attempt

\section{Framing Factor}

The framing factor is a numerical value given to the proportion of the area occupied by the wall-framing to the entire plane of wall. As the amount of timber framing in a wall increases, the amount of wall insulation decreases. Various researchers have written with regard to the effect of the framing factor on overall wall conductivity values (Bell \& Overend 2001; Fricker 2003; Kosny, Yarbrough \& Childs 2006a, 2006b; Kosny et al. 2007; Lstuburek 2010; Syed \& Kosny 2006). In the test cells, two different issues were encountered with regard to the framing factor.

All three test cells had identical roof framing. However, as much of the prefabricated wall frame for all three test cells was identical, additional timber members were placed within the wall of test cell 1, to assist in the fixing of the plywood cladding (Figure 4.71 and Figure 4.72). In discussions with the builders, it appeared that this was a common practice. This increased the ratio of timber framing as opposed to wall insulation in the external walls of the test cell 1 . 


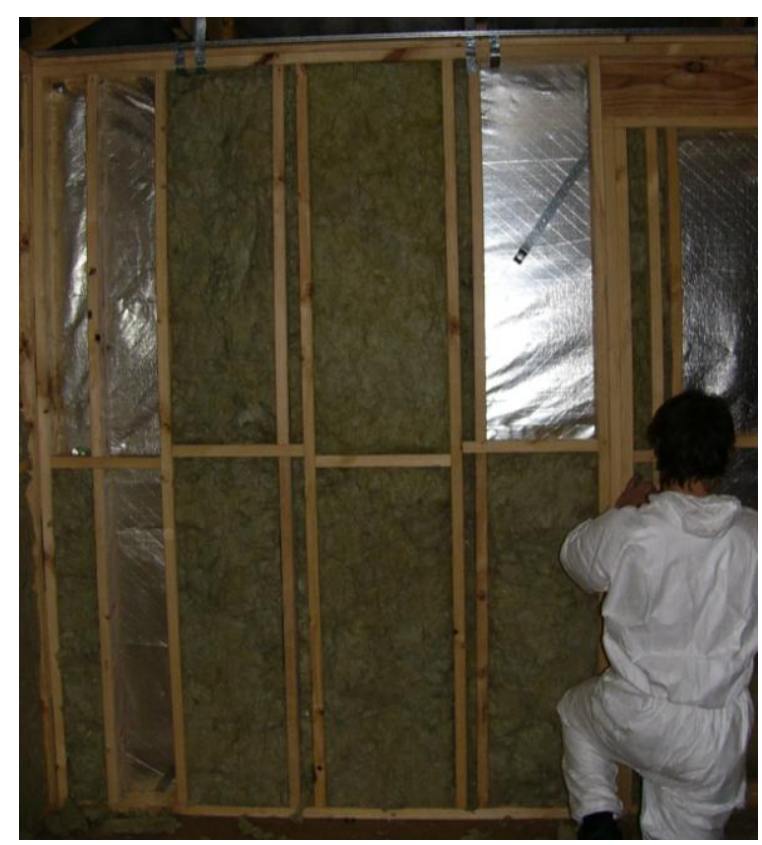

Figure 4.71: Four additional vertical members inserted into wall for fixing plywood cladding

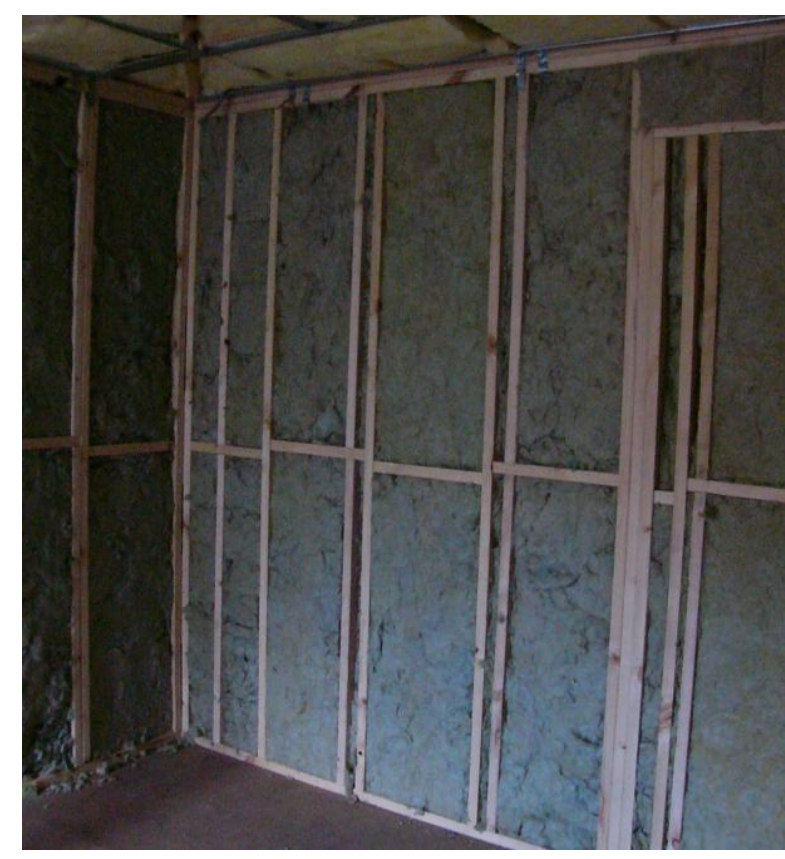

Figure 4.72: Five additional vertical members inserted into wall for fixing plywood cladding

The framing factor was determined from data supplied by the framing prefabricator and site photographs. On examination of some current construction practises, there were some uninformed reductions to the insulation capacity of the walls and ceiling (DewsburyWallis et al. 2009; Trethowen, HA 2004). Current wall framing practice includes: double top plates (Figure 4.74) and double, triple and quadruple jamb studs (Figure 4.73).

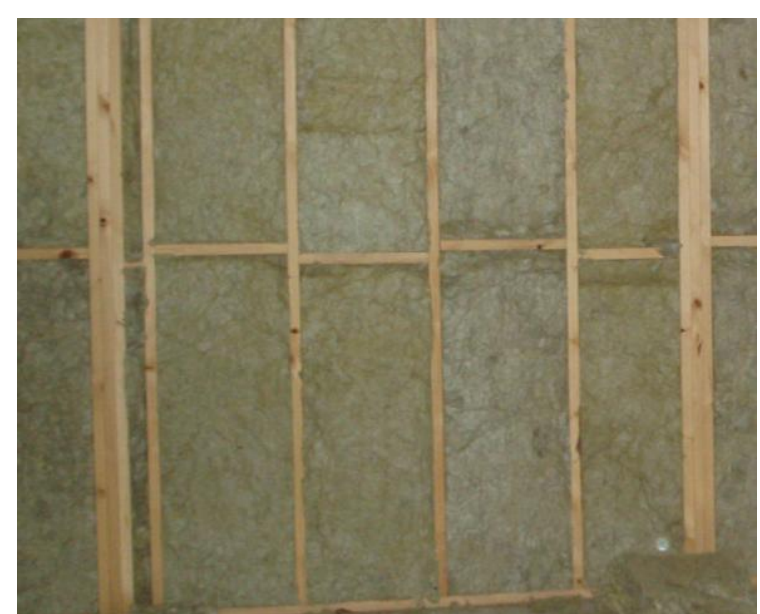

Figure 4.73 - Triple jamb studs to support lintel in knock-out wall panel

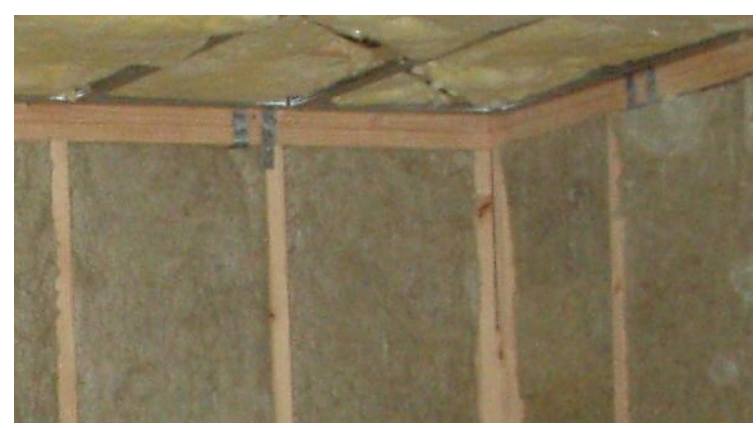

Figure 4.74 - Double top plate 


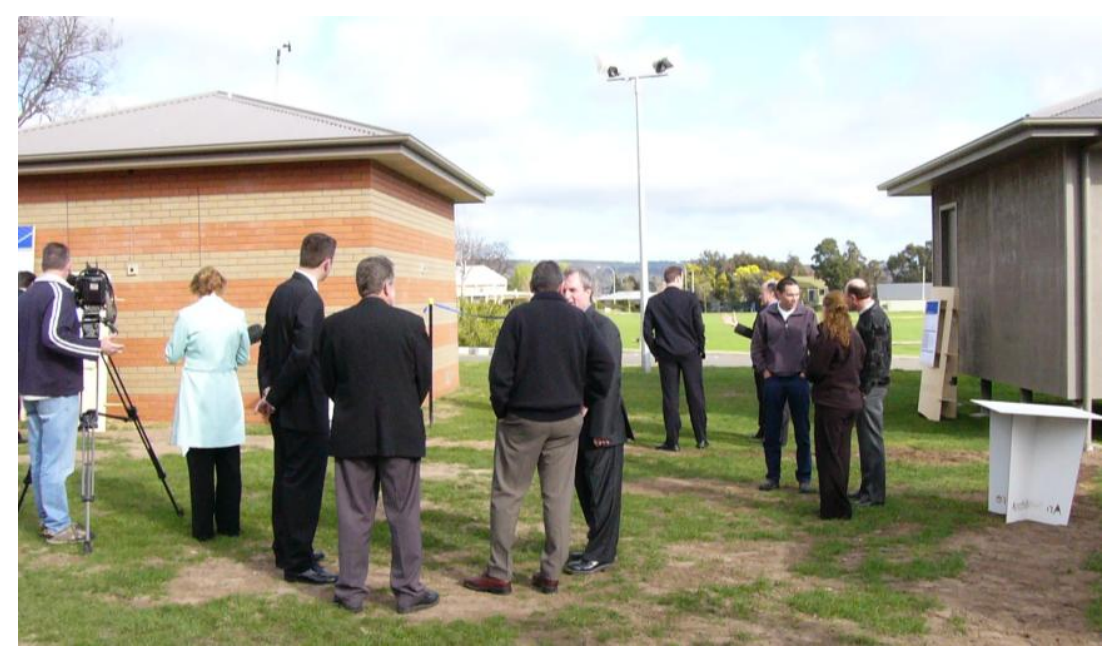

Figure 4.75: Official opening of thermal performance test cells ( 29 August, 2006)

\subsubsection{Summary of the Thermal Performance Test Cells Construction}

The objective of building the thermal performance test cells was to provide a research platform for the empirical validation of the AccuRate House Energy Rating software in a cool temperate climate.

To achieve this, three thermal performance test cells were designed and constructed in Launceston, an area of Australia defined as being a cool temperate climate based on an analysis of current materials and building systems, in consultation with industry. The typology of the three thermal performance test cells was aligned to the BCA residential construction methods, namely:

- Unenclosed-perimeter platform floored

- Enclosed-perimeter platform floored

- Concrete slab-on-ground floored

The construction of the thermal performance test cells was closely supervised to ensure a consistent quality of construction, which met Building Code of Australia and Australian 
Standard guidelines. The supervision also allowed for the rectification or repair of insulation installation, building wall warp and roof sarking quality and infiltration controls. The detailed accounting of the framing factor of the thermal performance test cells was aimed at establishing modified planar conductivity values that were needed for the detailed thermal simulation of the test cells. Through strict supervision and implementation of relevant standards during the construction process, the physical properties of the thermal performance test cells were controlled based on establishing a quantitative fabric matrix. These provide the critical inputs for simulating the test cells' thermal performance (Agami Reddy, Maor \& Panjapornpon 2007; Lomas 1991c) using the AccuRate HER software for empirical validation purposes which are discussed in sections, 4.3 - Empirical Data, 4.4 - Detailed Thermal Simulation by AccuRate and 4.5 - Methods of Analysis respectively.

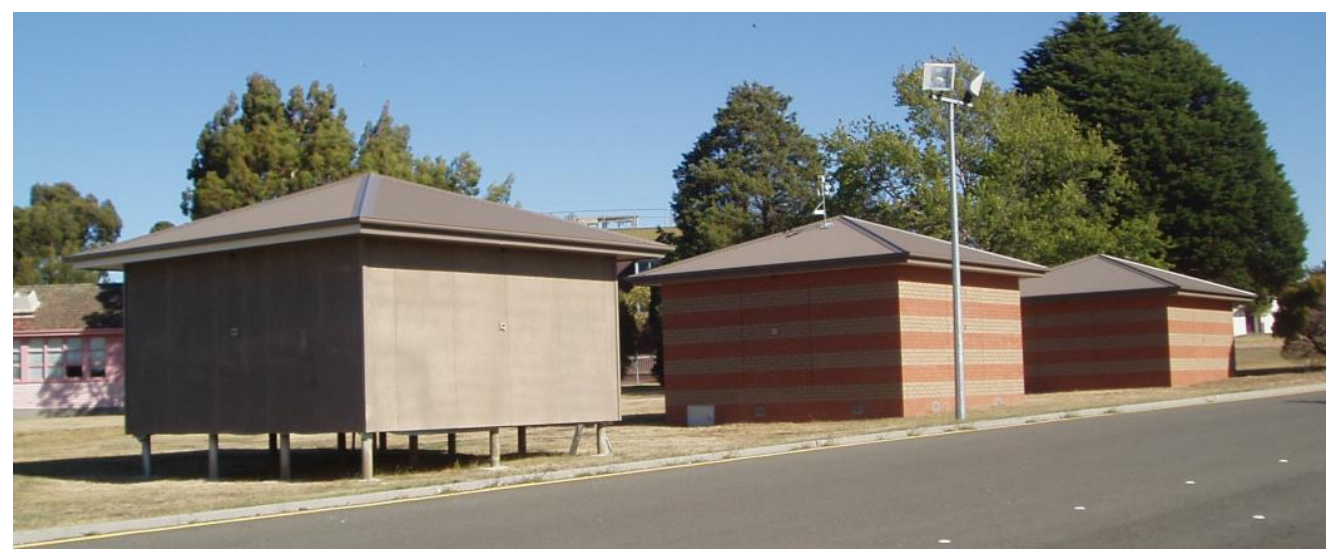

Figure 4.76: Thermal performance test cells ( 30 August, 2006) 


\subsection{Empirical Data}

\subsubsection{Introduction}

Empirical validation required the comparison of empirical data with output data from the AccuRate HER software. The purpose of this stage of the research was to obtain empirical data from the test cells and the external climate. Detailed environmental measurement was required to obtain the empirical data, which involved data acquisition and data management. This section discusses the methods and systems that were developed in order to obtain an empirical data set.

\subsubsection{Objectives}

To obtain empirical data required the measurement of the thermal performance of the test cells and the site weather condition (Agami Reddy, Maor \& Panjapornpon 2007; Lomas 1991a). A review of the issues was undertaken, in order that appropriate data were available for the comparative analysis (Delsante 2005c; Dewsbury, Nolan \& Fay 2007), as follows:

- The output data from the house energy rating software, AccuRate, which established the minimum required data for comparison

- Methods of environmental measurement

- Methods of data storage

- Methods of data cleaning to provide a final data set for the empirical validation process

\subsubsection{Environmental Conditions Requiring Measurement}

The environmental measurement would require particular measuring equipment, data acquisition equipment, data storage and associated support systems. To determine the appropriate environmental measuring equipment, an assessment of the house energy rating software Accurate was undertaken. Once this assessment was undertaken, the required minimum group of environmental parameters to be measured was established (Delsante 2005c). Then an examination of measurement platforms and supporting equipment was 
undertaken. Following this, a more detailed assessment (of which environmental aspects required measurement and how to measure them) was undertaken.

\section{AccuRate Data}

The house energy rating software AccuRate has both input data requirements and resultant thermal simulation output data. The assessment of AccuRate (AccuRate 2007) established the required environmental input data and the environmental data that is provided in the output files.

\section{AccuRate Input Data}

Inputs into the thermal simulation of AccuRate include the built fabric and the weather file. The built fabric is discussed in Chapters 4.2 and 4.4. The weather file provides a matrix of climate data, which the software uses to apply heating and cooling effects to the building being simulated. The AccuRate weather file consists of 27 inputs, as shown in Figure 4.77.

Of the 27 inputs there are 14 inputs of significance for performing the thermal simulation. The relevant inputs are:

- $\quad$ Month number

- Day number

- Hour Number

- Dry bulb (air) temperature (tenths of degree Celsius)

- Moisture content (tenths gram per kilogram)

- Atmospheric (air) pressure (tenths of kilopascal)

- Wind speed (tenths of metres per second)

- Wind direction (0 to 16 )

- Cloud cover (0 to 8) 
- Global solar radiation $\left(\mathrm{Wh} / \mathrm{m}^{2}\right)$

- Diffuse solar radiation $\left(\mathrm{Wh} / \mathrm{m}^{2}\right)$

- $\quad$ Normal direct solar radiation $\left(\mathrm{Wh} / \mathrm{m}^{2}\right)$

- Solar altitude (0 to 90 degrees)

- Solar Azimuth (degrees)

Columns 1 and 2 contain a two letter code for the site (eg AD for Adelaide)

Columns 3 and 4 contain the last two digits of the year number eg 67 for 1967

Columns 5 and 6 contain the month number (zero-filled) eg 01 for January

Columns 7 and 8 contain the day number (zero-filled) eg 01 for first of the month

Columns 9 and 10 contain the hour number $0-23(0=$ midnight, $1=1 \mathrm{am}$ etc $)$

Columns 11 to 14 contain the Dry Bulb (Air) temperature in tenths of degrees C

Columns 15 to 17 contain the Moisture Content in tenths of g per $\mathrm{kg}$

Columns 18 to 21 contain the Atmospheric (Air) Pressure in tenths of $\mathrm{kPa}$

Columns 22 to 24 contain the Wind Speed in tenths of metres per second

Columns 25 to 26 contain the Wind Direction 0-16 $(0=\mathrm{CALM}, 1=\mathrm{NNE}, \ldots, 16=\mathrm{N})$

Columns 27 contains the Cloud Cover $0-8(0=$ no cloud, .., $8=$ full cloud $)$

Column 28 contains the Flag for Dry Bulb Temp. ( $0=$ Actual, $1=$ Estimated)

Column 29 contains the Flag for Moisture Content $(0=$ Actual, $1=$ Estimated $)$

Column 30 contains the Flag for Atmospheric Pressure ( $0=$ Actual, $1=$ Estimated $)$

Column 31 contains the Flag for Wind Speed $(0=$ Actual, $1=$ Estimated $)$

Column 32 contains the Flag for Cloud Cover $(0=$ Actual, $1=$ Estimated $)$

Column 33 contains the Flag for Wind Direction ( $0=$ Actual, $1=$ Estimated $)$

Columns 34 to 37 contain Global Solar Radiation on a horizontal plane (Wh/m $\left.\mathrm{m}^{2}\right)$

Columns 38 to 40 contain Diffuse Solar Radiation on a horizontal plane (Wh $/ \mathrm{m}^{2}$ )

Columns 41 to 44 contain the Normal Direct Solar Radiation (Wh/ $\mathrm{m}^{2}$ )

Columns 45 to 46 contain Solar Altitude in degrees (0 to 90)

Columns 47 to 49 contain the Solar Azimuth in degrees ( 0 to $359,0=\mathrm{N}, 90=\mathrm{E}, \ldots)$

Column 50 contains the Flag for Global Solar Radiation. $(0=$ Actual, $1=$ Estimated $)$

Column 51 contains the Flag for Diffuse Solar Radiation ( $0=$ Actual, $1=$ Estimated $)$

Column 52 contains Flag for Normal Direct Solar Radiation ( $0=$ Actual, 1=Estim.)

Columns 53 and 54 contain the first two digits of the year number eg 19 for 1967

Columns 55 to 60 are blank

Figure 4.77 - Accurate weather file format

(ACDB 2006, p. Appendix: ACDB Climate Data Format )

The minimum requirement for site environmental measurement necessitated the direct collection of appropriate data to measure the items detailed above, or measure items from which the essential data could be calculated. 
Other AccuRate inputs for the purposes of thermal simulation include default values for infiltration and internal heat loads in all zones (Delsante 2006b). The infiltration rate is referred to as the 'air change rate' and is quantified by a value of air changes per hour. A measurement of the air change rate per hour of relevant zones in all three test cells was required. Similarly, the internal energy consumption of the thermal performance test cells required measurement to establish internal heat gains. The actual measured value for infiltration and internal heat loads replaced the default value within the AccuRate software in the validation simulation.

\section{AccuRate Output Data}

When a house energy rating simulation is undertaken by the AccuRate software, four output reports are created. The output reports include (AccuRate 2007; Delsante 1996):

- $\quad$ Temperature file $(*$. tem $)$

- Energy.txt

- Output.txt

- Star Rating Report

The AccuRate temperature file shows the thermal simulations' resultant hourly temperature for each zone (Figure 4.78). In AccuRate the house is divided into conditioned and nonconditioned zones. For the conditioned zones there are default values for heat inputs based on each zone's purpose. The non-conditioned zones also include the roof and subfloor areas of the house. The parameters and default values of AccuRate zones are discussed further in Section 4.4. Figure 4.78 shows the data from the enclosed-perimeter platform-floored test cell. They are listed as:

- $\quad$ Month number (1=January)

- Day number (1to 31)

- Hour number (1 to 24) 
- Outdoor temperature ( from AccuRate weather file)

- Test Cell ( the resultant predicted temperature of the test cell room)

- $\quad$ Roof Space (the resultant predicted temperature of the test cell roof space)

- Sub Floor ( the resultant predicted temperature of the test cell enclosed subfloor)

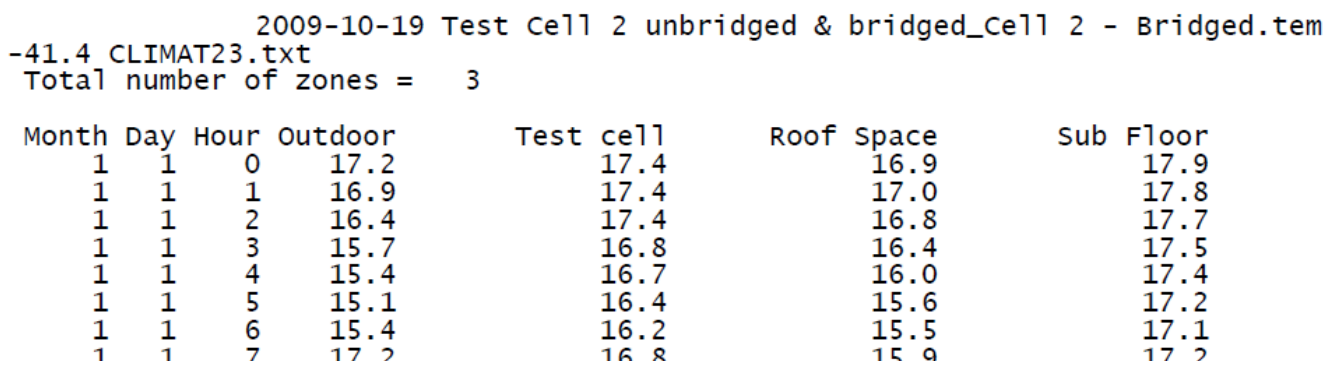

Figure 4.78 - Sample of AccuRate Output Temperature file

What was identified and subsequently informed the environmental measurement brief was that the predicted values from the AccuRate simulation were accurate to one tenth of a degree Celsius (or to one decimal place). Therefore, the equipment required would need to record data to a similar level of accuracy for the validation comparison.

The energy file provides the resultant calculated required energy to maintain a particular temperature bandwidth within conditioned zones of the simulated building.

The output.txt file details the calculated daily energy required to condition relevant zones. The information also includes a daily total and a peak energy requirement value.

The Star Rating report is the public front end document which is used for verification methods under the Nationwide House Energy Rating Scheme.

The energy.txt file, output.txt file and *.tem file are all discussed in detail in Section 4.4.6.

From the analysis of the AccuRate output data, the only report of significance in relation to environmental measurement is the temperature file. Therefore, the minimum requirement of 
the environmental measurement process was to collect empirical data that could be compared with the AccuRate calculated temperature output file.

\subsubsection{Parameters Requiring Measurement}

Based on the assessment of the Accurate input and output files and other international examples, a minimum data set of site-measured data was established. The items to be measured included the site and building elements. This was the starting point from which further research confirmed each of the values and methods that could be used to obtain environmental measurements. The brief to assess data acquisition platforms was also established. To further confirm what to measure, the experiences of a number of key international and Australian projects were assessed (Bowman \& Lomas 1985; Lomas 1991a). These comprised: IEA projects (Judkoff, R 2008; LomasEppel et al. 1994; Loutzenhiser, Manz \& Maxwell 2007; Torcellini et al. 2005a), PASSYSS \& PASLINK projects (CSTB 1990; Leal \& Maldonado 2008; Strachan 2008; Strachan \& Vandaele 2008) and the University of Newcastle project (Clark, Sugo \& Page 2003). By combining the output data from Accurate and the types of environmental measurements taken by previous projects, the minimum data collection requirements were established, as in Table 4.7.

Table 4.7: Items Requiring Environmental Measurement

\begin{tabular}{|c|c|}
\hline Site Measurements & $\begin{array}{l}\text { Dry bulb (air) temperature(tenths of degree Celsius) } \\
\text { Moisture content (tenths gram per kilogram) } \\
\text { Atmospheric (air) pressure (tenths of kilopascal) } \\
\text { Wind speed (tenths of metres per second) } \\
\text { Wind direction } \\
\text { Cloud cover in Octaves } \\
\text { Global solar radiation }\left(\mathrm{Wh} / \mathrm{m}^{2}\right) \\
\text { Diffuse solar radiation }\left(\mathrm{Wh} / \mathrm{m}^{2}\right) \\
\text { Normal direct solar radiation }\left(\mathrm{Wh} / \mathrm{m}^{2}\right)\end{array}$ \\
\hline $\begin{array}{l}\text { Thermal Performance Test } \\
\text { Cell Measurements }\end{array}$ & $\begin{array}{l}\text { Test Cell Room temperature (tenths of degree Celsius) } \\
\text { Test Cell Roof Space temperature (tenths of degree Celsius) } \\
\text { Test Cell Subfloor Space temperature (tenths of degree Celsius) }\end{array}$ \\
\hline
\end{tabular}

\section{Additional Environmental Measurements (or supporting data)}

The vast difference in approaches to measure environmental performance of buildings became apparent when examining other projects. The exterior environment was easily defined by the 
AccuRate inputs and other international publications (ASHRAE 1997, 2005; Lomas 1991a, 1994; Strachan 2008; Torcellini et al. 2005b). In many projects the default climate file within the house energy rating software was used, rather than providing site-measured data . In other examples, data from the closest weather station was used. However, this research found temperature variations of up to five degrees Celsius between the local weather station and the temperature at the thermal performance test cells site (Dewsbury, Nolan \& Fay 2007). These variations would have a dramatic impact on the final data set provided by the simulation software.

Many papers have discussed the comparison of measured building data with simulation output data but there have been inconsistencies in measuring methodology. Recent projects in Australia placed Hobo sensors on bench tops or walls to establish room temperature (James, Anda \& Mathew 2006). The problem with this approach was twofold in that the height of the sensor above the floor varied from room to room and that one sensor may receive a greater proportion of the mean radiant temperature of a surface, if the sensor is near it, as opposed to sensing the general temperature of the room. A historical analysis of the test buildings discussed in Section 3.7 and other relevant research (Chasar, Moyer \& Rudd 2002; D'Cruz \& Duncan 1994) found the need to maximise data collection points, which is well-illustrated in Figure 4.79.

Researchers of current test buildings who form the PASLINK research group have developed a comparable method of measuring the temperatures within the test buildings, as in Figure 4.80, Figure 4.81 and Figure 4.82 (Baker, P 2008; Baker \& van Dijk 2008; Jimenez \& Madsen 2008; Jimenez, Madsen \& Andersen 2008; Strachan 2008). In Australia, the University of Newcastle test cell research team has developed a task-specific installation of measuring equipment to examine the effects of thermal mass in test cell buildings (Clark, Sugo \& Page 2003; Sugo 2005-2009, 2006a). As the Launceston Thermal performance test cells were being built to specifically validate the AccuRate software, the methodology of the PASLink and Newcastle test cells was adopted, to provide comparative research with the Newcastle buildings and an adequate depth of data to support the key data requirements. Section 3.7 provides a more in-depth analysis of some international and Australian thermal performance test buildings. 


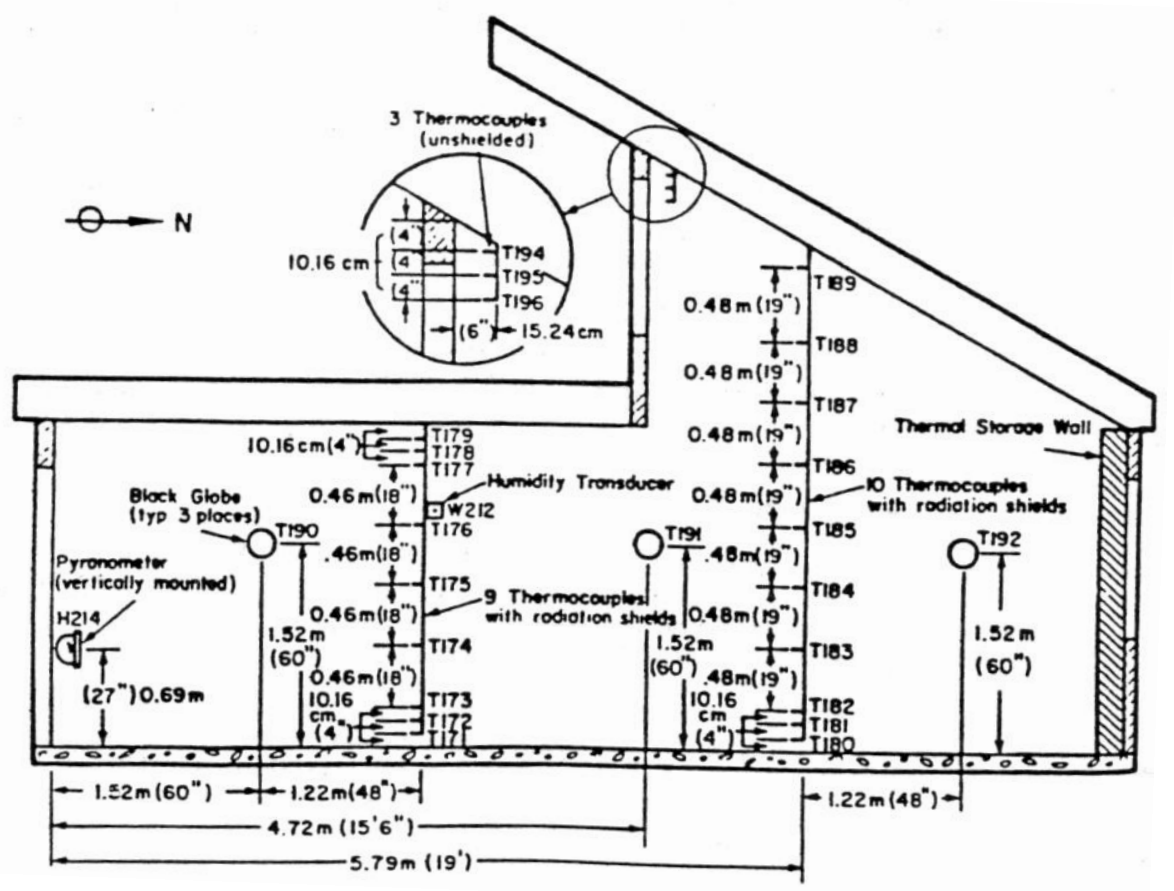

Figure 4.79 - Longitudinal section of the NBS passive solar test building

(Lomas 1991c, p. Fig 15)

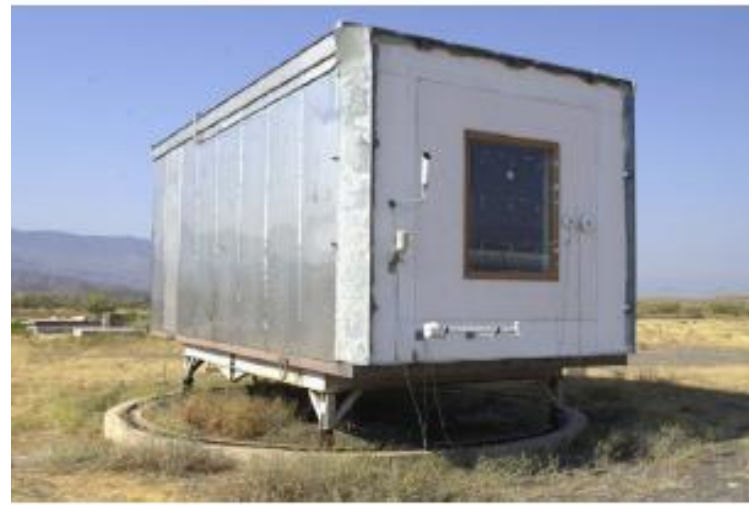

Figure 4.80 - PASSLINK Test Building

(Jimenez \& Madsen 2008, p. 157)

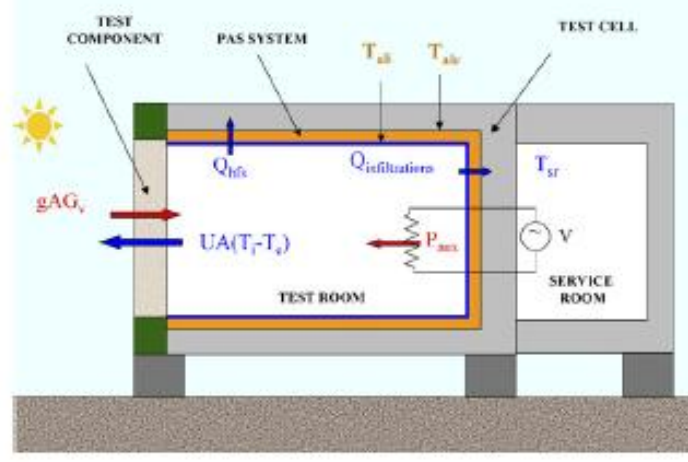

Figure 4.81 - Thermal principles of PASSLINK Test Building

(Jimenez \& Madsen 2008, p. 157) 


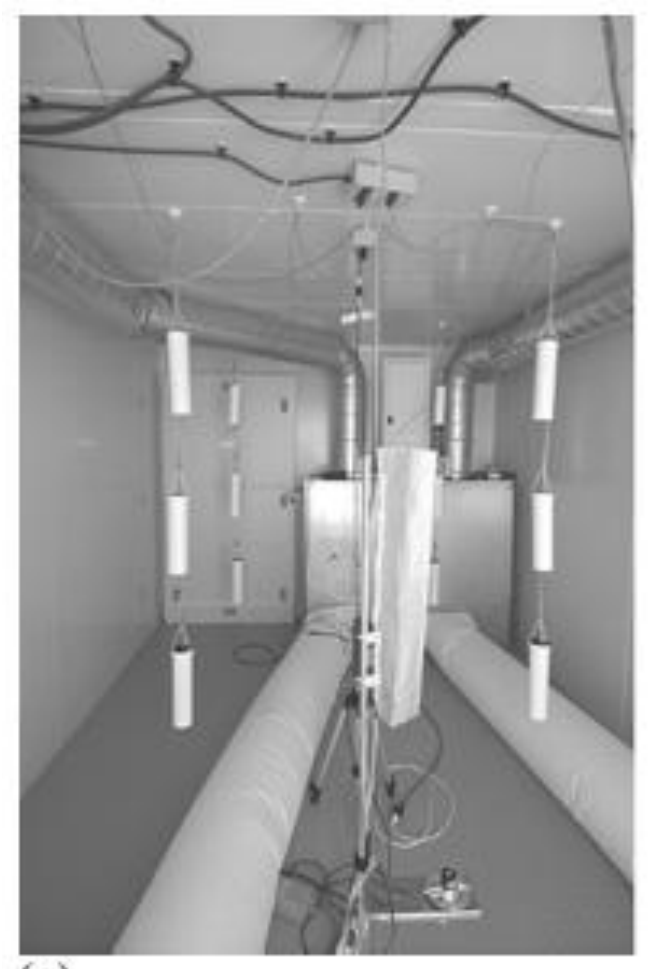

Figure 4.82 - Interior of EMPA Test Building

(Loutzenhiser et al. 2006)

When analysing similar international research, particular differences in the approach to environmental measurement became apparent: some projects adopted the ASHRAE Standard 55 (ASHRAE 2004a), whilst other projects had a more generalist approach to the placement of measuring equipment. The focus of the ASHRAE Standard 55 is the measurement of "Thermal Environmental Conditions for Human Occupancy". The standard specifies the measurement of the environmental condition at the heights shown in Table 4.8. The heights specified were based on how an average human occupant would experience the environment. An understanding of the environment under these parameters allows for the appropriate design of heating and cooling plant (Bannister 2009; de Carli \& Olesen 2002). The more generalist approach of providing an array of environmental measurements, in plan and elevation within the test building, is an endeavour to establish the average room temperature. As the primary purpose of the thermal performance test cells was the empirical validation of AccuRate, the research was not concerned with levels of comfort for human occupancy. Instead, the research was concerned with and needed to comprehend and measure the average room temperate within the thermal performance test cells. Based on the analysis of the approach taken by previous test building researchers and in consultation with CSIRO HER software developers and industry sponsors, it was agreed that the approach taken should be 
similar in nature to the PASLINK test buildings, where an array of temperature sensors would be installed initially and selected sensors would be used to establish an average room temperature.

Table 4.8: Environmental measurement heights as specified by ASHRAE Standard 55

\begin{tabular}{|l|l|l|}
\hline Height Above Floor & Seated Occupants & Standing Occupants \\
\hline $100 \mathrm{~mm}$ & Ankle & Ankle \\
\hline $600 \mathrm{~mm}$ & Waist & \\
\hline $1100 \mathrm{~mm}$ & Neck & Waist \\
\hline $1700 \mathrm{~mm}$ & & Neck \\
\hline
\end{tabular}

\section{The Measurement Profile of the Thermal Performance Test Cells}

Based on the examination of the data requirements to empirically validate AccuRate and the analysis of other thermal performance test buildings, a measurement method was established. The choice of measurement locations allowed for a minimum group of essential sensors for the empirical validation exercise. A range of other sensors was installed to collect additional data, to support the minimum data set and to enable further study of the results. The method included the environmental measurement of horizontal and vertical profiles of the three thermal performance test cells. The environmental measurement vertical profile established for the thermal performance test cells is detailed in Table 4.9, Figure 4.83 and Figure 4.84. The environmental measurement horizontal profile established for the thermal performance test cells is detailed in Table 4.10, Figure 4.85 and Figure 4.86.

Table 4.9: Vertical Measurement Profile of the Launceston Thermal Performance Test Cells

\begin{tabular}{|l|l|l|}
\hline \multicolumn{1}{|c|}{ Title } & \multicolumn{1}{|c|}{ Description } & $\begin{array}{c}\text { Minimum data or } \\
\text { supporting data }\end{array}$ \\
\hline $\begin{array}{l}\text { Outside sheet metal roof dry } \\
\text { bulb surface temperature }\end{array}$ & $\begin{array}{l}\text { To measure the external surface temperature of } \\
\text { the sheet metal roofing }\end{array}$ & Supporting data \\
\hline $\begin{array}{l}\text { Inside sheet metal roof dry } \\
\text { bulb surface temperature }\end{array}$ & $\begin{array}{l}\text { To measure the internal surface temperature of } \\
\text { the sheet metal roofing }\end{array}$ & Supporting data \\
\hline $\begin{array}{l}\text { Inside reflective sarking dry } \\
\text { bulb surface temperature }\end{array}$ & $\begin{array}{l}\text { To measure the internal surface temperature of } \\
\text { the reflective foil sarking. }\end{array}$ & Supporting data \\
\hline $\begin{array}{l}\text { Mid roof space dry bulb air } \\
\text { temperature }\end{array}$ & $\begin{array}{l}\text { To measure the air temperature of the middle of } \\
\text { the roof space }\end{array}$ & Minimum data \\
\hline $\begin{array}{l}\text { Mid roof space vertical air } \\
\text { flow }\end{array}$ & $\begin{array}{l}\text { To measure if there is any thermal chimney } \\
\text { effect in the roof space }\end{array}$ & Supporting data \\
\hline $\begin{array}{l}\text { Mid roof space relative } \\
\text { humidity }\end{array}$ & $\begin{array}{l}\text { To measure the relative humidity of the roof } \\
\text { space }\end{array}$ & Supporting data \\
\hline $\begin{array}{l}\text { Top of insulation dry bulb } \\
\text { surface temperature }\end{array}$ & $\begin{array}{l}\text { To measure the outside surface temperature of } \\
\text { the ceiling batt insulation }\end{array}$ & Supporting data \\
\hline Outside plasterboard ceiling & To measure the outside surface temperature of & Supporting data \\
\hline
\end{tabular}




\begin{tabular}{|c|c|c|}
\hline Title & Description & $\begin{array}{l}\text { Minimum data or } \\
\text { supporting data }\end{array}$ \\
\hline dry bulb surface temperature & the plasterboard ceiling & \\
\hline $\begin{array}{l}\text { Inside plasterboard ceiling dry } \\
\text { bulb surface temperature }\end{array}$ & $\begin{array}{l}\text { To measure the inside surface temperature of } \\
\text { the plasterboard ceiling }\end{array}$ & Supporting data \\
\hline $\begin{array}{l}\text { Centre of room }+1800 \mathrm{~mm} \text { dry } \\
\text { bulb air temperature }\end{array}$ & $\begin{array}{l}\text { To measure the air temperature at a height of } \\
1800 \mathrm{~mm} \text { in the centre of the room }\end{array}$ & Minimum data \\
\hline $\begin{array}{l}\text { Perimeter of room }+1800 \mathrm{~mm} \\
\text { dry bulb air temperature }\end{array}$ & $\begin{array}{l}\text { Eight poles around the internal perimeter of the } \\
\text { test cell to measure the air temperature at a } \\
\text { height of } 1800 \mathrm{~mm}\end{array}$ & Supporting data \\
\hline $\begin{array}{l}\text { Centre of room }+1200 \mathrm{~mm} \text { dry } \\
\text { bulb air temperature }\end{array}$ & $\begin{array}{l}\text { To measure the air temperature at a height of } \\
1200 \mathrm{~mm} \text { in the centre of the room }\end{array}$ & Minimum data \\
\hline $\begin{array}{l}\text { Perimeter of room }+1200 \mathrm{~mm} \\
\text { dry bulb air temperature }\end{array}$ & $\begin{array}{l}\text { Eight poles around the internal perimeter of the } \\
\text { test cell to measure the air temperature at a } \\
\text { height of } 1200 \mathrm{~mm}\end{array}$ & Supporting data \\
\hline $\begin{array}{l}\text { Centre of room }+1200 \mathrm{~mm} \\
\text { relative humidity }\end{array}$ & $\begin{array}{l}\text { To measure the relative humidity at a height of } \\
1200 \mathrm{~mm} \text { in the centre of the room }\end{array}$ & Supporting data \\
\hline $\begin{array}{l}\text { Centre of room }+1200 \mathrm{~mm} \\
\text { mean radiant temperate }\end{array}$ & $\begin{array}{l}\text { To measure the mean radiant temperature in the } \\
\text { centre of the room at a height of } 1200 \mathrm{~mm}\end{array}$ & Minimum data \\
\hline $\begin{array}{l}\text { Perimeter of room }+1200 \mathrm{~mm} \\
\text { mean radiant temperate }\end{array}$ & $\begin{array}{l}\text { Eight poles around the internal perimeter of the } \\
\text { test cell to measure the mean radiant } \\
\text { temperature at a height of } 1200 \mathrm{~mm}\end{array}$ & Supporting data \\
\hline $\begin{array}{l}\text { Centre of room }+600 \mathrm{~mm} \text { dry } \\
\text { bulb air temperature }\end{array}$ & $\begin{array}{l}\text { To measure the air temperature at a height of } \\
600 \mathrm{~mm} \text { in the centre of the room }\end{array}$ & Minimum data \\
\hline $\begin{array}{l}\text { Perimeter of room }+600 \mathrm{~mm} \\
\text { dry bulb air temperature }\end{array}$ & $\begin{array}{l}\text { Eight poles around the internal perimeter of the } \\
\text { test cell to measure the air temperature at a } \\
\text { height of } 600 \mathrm{~mm}\end{array}$ & Supporting data \\
\hline $\begin{array}{l}\text { Inside carpet dry bulb surface } \\
\text { temperature }\end{array}$ & $\begin{array}{l}\text { To measure the inside surface temperature of } \\
\text { the carpet }\end{array}$ & Supporting data \\
\hline $\begin{array}{l}\text { Inside Particle-board floor dry } \\
\text { bulb surface temperature }\end{array}$ & $\begin{array}{l}\text { To measure the inside surface temperature of } \\
\text { the particle board floor of the unenclosed- } \\
\text { perimeter and enclosed-perimeter platform } \\
\text { floored test cells }\end{array}$ & Supporting data \\
\hline $\begin{array}{l}\text { Inside concrete slab floor dry } \\
\text { bulb surface temperature }\end{array}$ & $\begin{array}{l}\text { To measure the inside surface temperature of } \\
\text { the concrete slab floor of the concrete slab-on- } \\
\text { ground floored test cell. }\end{array}$ & Supporting data \\
\hline $\begin{array}{l}\text { Outside Particle-board floor } \\
\text { dry bulb surface temperature }\end{array}$ & $\begin{array}{l}\text { To measure the outside surface temperature of } \\
\text { the particle board floor of the unenclosed- } \\
\text { perimeter and enclosed-perimeter platform } \\
\text { floored test cells }\end{array}$ & Supporting data \\
\hline $\begin{array}{l}\text { Outside slab floor dry bulb } \\
\text { surface temperature }\end{array}$ & $\begin{array}{l}\text { To measure the outside surface temperature of } \\
\text { the concrete slab-on-ground floored test cell. }\end{array}$ & Supporting data \\
\hline $\begin{array}{l}\text { Outside subfloor insulation } \\
\text { dry bulb surface temperature }\end{array}$ & $\begin{array}{l}\text { To measure the outside surface temperature of } \\
\text { the subfloor insulation of the unenclosed- } \\
\text { perimeter and enclosed-perimeter platform } \\
\text { floored test cells }\end{array}$ & Supporting data \\
\hline $\begin{array}{l}\text { Mid-subfloor space dry bulb } \\
\text { air temperature }\end{array}$ & $\begin{array}{l}\text { To measure the air temperature in the centre of } \\
\text { the subfloor space (unenclosed-perimeter and } \\
\text { enclosed-perimeter platform floored test cells) }\end{array}$ & Minimum data \\
\hline $\begin{array}{l}\text { Mid-subfloor air speed } \\
\text { measurement (adjustable for } \\
\text { vertical and horizontal air } \\
\text { flows) }\end{array}$ & $\begin{array}{l}\text { To measure subfloor horizontal air flow and } \\
\text { whether or not there is any vertical chimney } \\
\text { affect in the subfloor space (unenclosed- } \\
\text { perimeter and enclosed-perimeter platform } \\
\text { floored test cells) }\end{array}$ & Supporting data \\
\hline $\begin{array}{l}\text { Mid-subfloor space relative } \\
\text { humidity }\end{array}$ & $\begin{array}{l}\text { To measure the relative humidity at the middle of } \\
\text { the subfloor space (unenclosed-perimeter and } \\
\text { enclosed-perimeter platform floored test cells) }\end{array}$ & Supporting data' \\
\hline $\begin{array}{l}\text { Centre subfloor area ground } \\
\text { air temperature }\end{array}$ & $\begin{array}{l}\text { To measure the air temperature at ground level } \\
\text { in the middle of the subfloor space (unenclosed- } \\
\text { perimeter and enclosed-perimeter platform } \\
\text { floored test cells) }\end{array}$ & Supporting data \\
\hline $\begin{array}{l}\text { Centre of building }-1000 \mathrm{~mm} \\
\text { dry bulb surface temperature }\end{array}$ & $\begin{array}{l}\text { To measure the ground temperature } 1000 \mathrm{~mm} \\
\text { below ground surface. }\end{array}$ & Supporting data \\
\hline
\end{tabular}




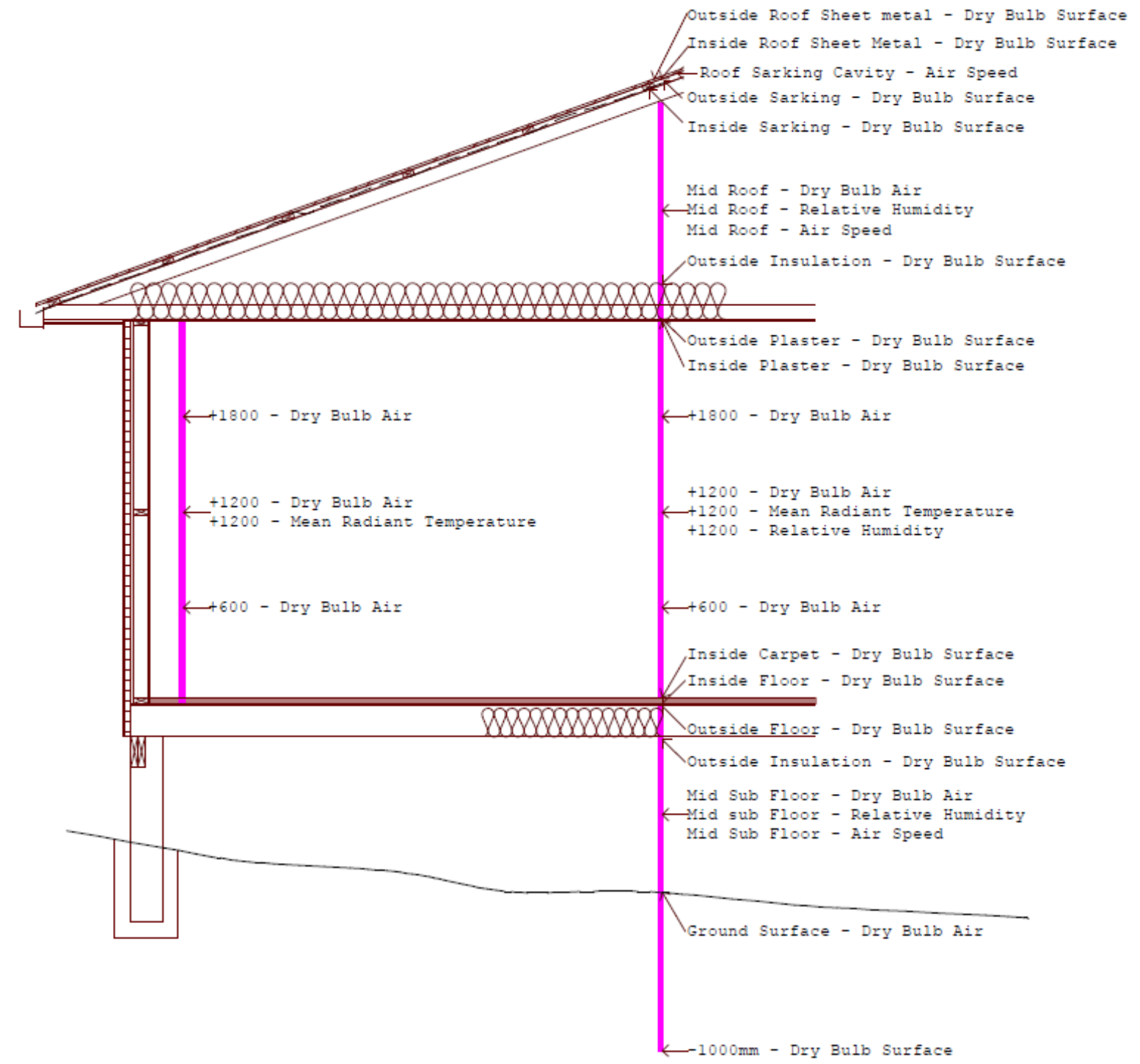

Figure 4.83 - Vertical measurement profile for the unenclosed-perimeter and enclosed-perimeter platform floored test cells 


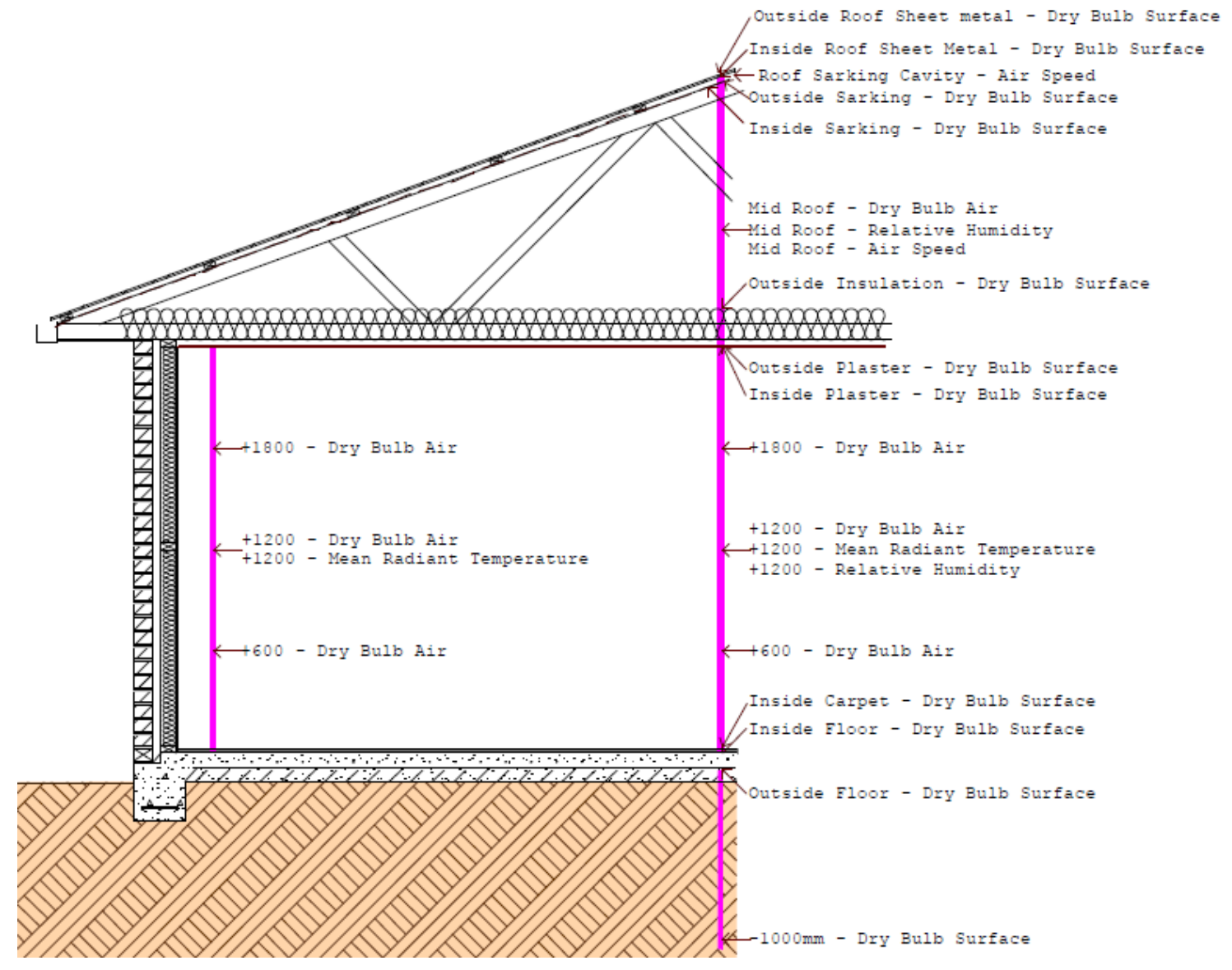

Figure 4.84 - Vertical environmental measurement profile for the concrete slab-on-ground floored test cell

Table 4.10: Horizontal Measurement Profile, Providing Supporting Data, of the Launceston Thermal Performance Test Cells

\begin{tabular}{|l|l|}
\hline \multicolumn{1}{|c|}{ Title } & \multicolumn{1}{c|}{ Description } \\
\hline $\begin{array}{l}\text { Outside brick veneer or plywood cladding dry bulb } \\
\text { surface temperature (North \& South Walls) }\end{array}$ & $\begin{array}{l}\text { To measure the external surface temperature of the Brick } \\
\text { Veneer or Plywood cladding }\end{array}$ \\
\hline $\begin{array}{l}\text { Inside brick veneer or plywood cladding dry bulb } \\
\text { surface temperature (North \& South Walls) }\end{array}$ & $\begin{array}{l}\text { To measure the internal surface temperature of the Brick } \\
\text { Veneer or Plywood cladding }\end{array}$ \\
\hline $\begin{array}{l}\text { Outside reflective foil building wrap dry bulb surface } \\
\text { Temperature (North \& South Walls) }\end{array}$ & $\begin{array}{l}\text { To measure the outside surface temperature of the } \\
\text { reflective foil building wrap }\end{array}$ \\
\hline $\begin{array}{l}\text { Inside reflective foil building wrap dry bulb surface } \\
\text { Temperature (North \& South Walls) }\end{array}$ & $\begin{array}{l}\text { To measure the inside surface temperature of the } \\
\text { reflective foil building wrap }\end{array}$ \\
\hline Wall frame relative humidity (North \& South Walls) & $\begin{array}{l}\text { To measure whether or not there are dangerously high } \\
\text { relatively humidity levels within the wall-insulation batts in } \\
\text { a cool temperate. }\end{array}$ \\
\hline $\begin{array}{l}\text { Outside plasterboard dry bulb surface temperature } \\
\text { (North \& South Walls) }\end{array}$ & $\begin{array}{l}\text { To measure the outside surface temperature of the } \\
\text { plasterboard wall lining }\end{array}$ \\
\hline $\begin{array}{l}\text { Inside plasterboard dry bulb surface temperature } \\
\text { (North \& South Walls) }\end{array}$ & $\begin{array}{l}\text { To measure the inside surface temperature of the } \\
\text { plasterboard wall lining }\end{array}$ \\
\hline $\begin{array}{l}\text { Outside plasterboard ceiling dry bulb surface } \\
\text { temperature }\end{array}$ & $\begin{array}{l}\text { To measure the outside surface temperature of the } \\
\text { plasterboard ceiling }\end{array}$ \\
\hline Solar Radiation (North, West, South \& East Walls) & $\begin{array}{l}\text { To measure the amount of solar radiation hitting all } \\
\text { external walls of the test cells. }\end{array}$ \\
\hline
\end{tabular}




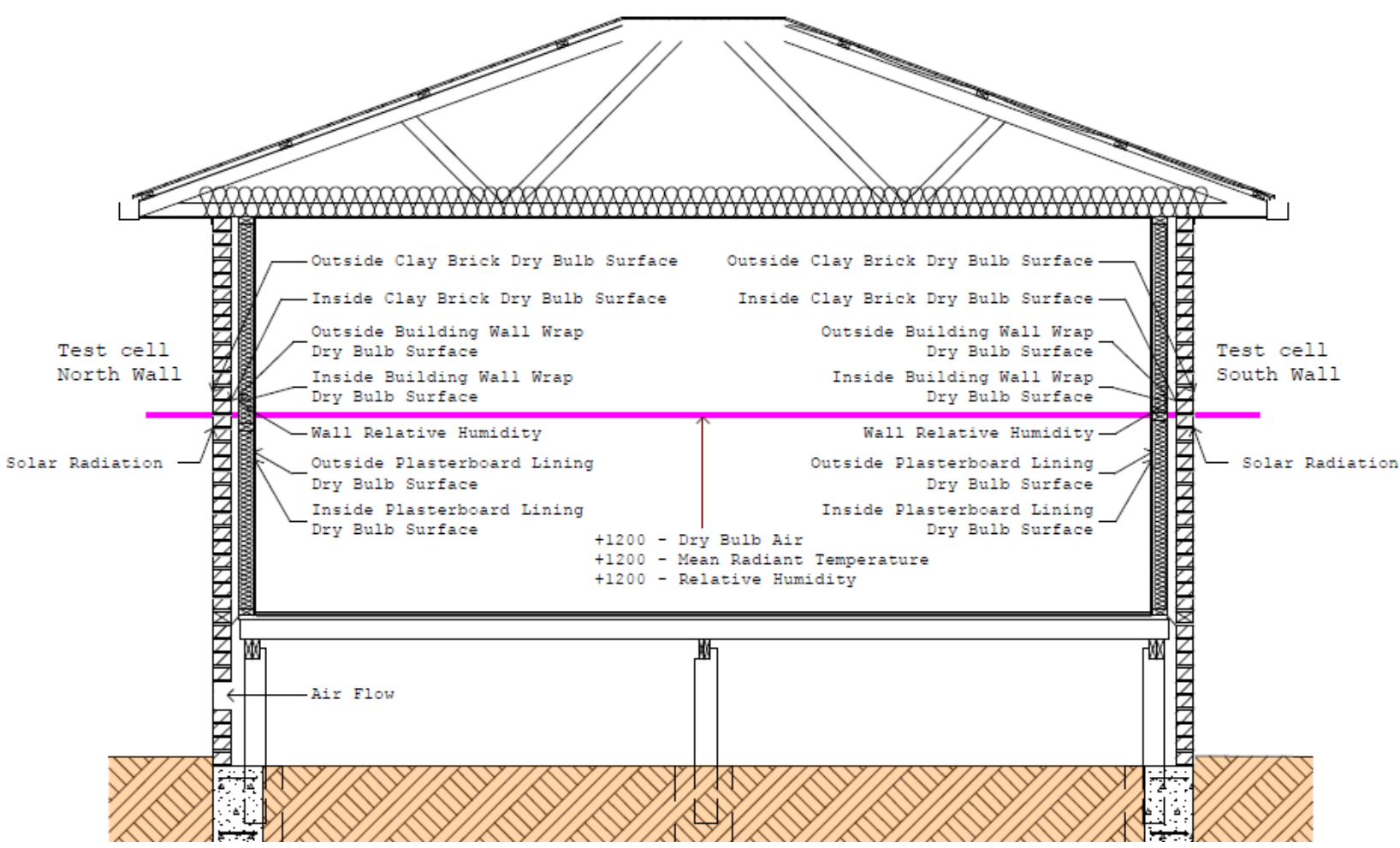

Figure 4.85 - Horizontal measurement profile for the unenclosed-perimeter and enclosed-perimeter platform floored test cells

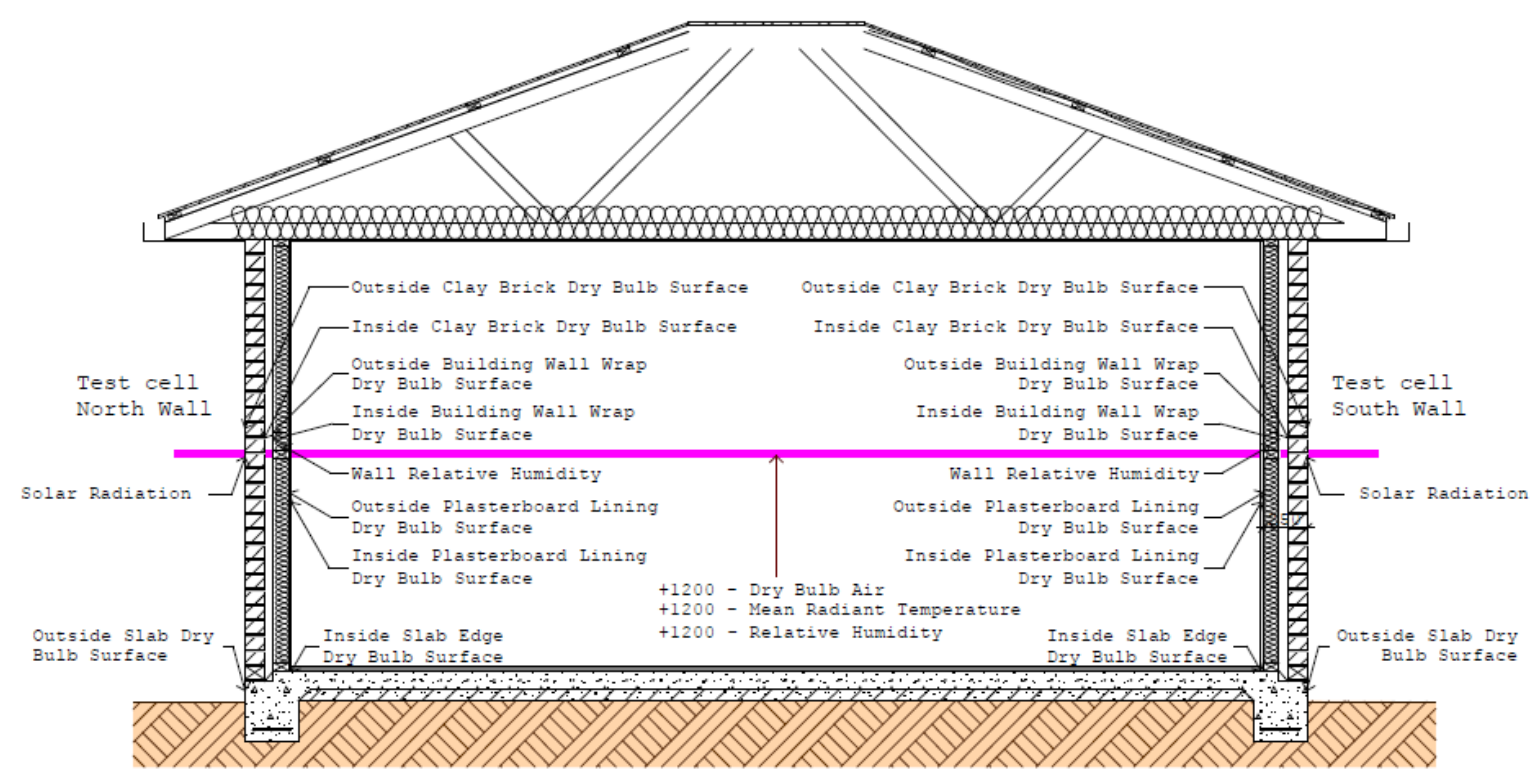

Figure 4.86 - Horizontal measurement profile for the concrete slab-on-ground floored test cell 
Once the location and purpose of environmental measuring equipment had been ascertained, the next step was to further define the environmental sensor types and the equipment that would be required to support the sensors.

A more detailed record of the decision making processes for the selection and installation of the environmental measuring equipment for the test cell site and of the test cells themselves is available in Appendix 4.

\subsubsection{Platforms for Environmental Measurement}

The brief for the environmental measurement of the thermal performance test cells was to support the notion of a long term research program, with the objective of providing a long term research platform. This brief required the following key elements:

- A flexibility of approach to allow for relocation of equipment to other building environmental measurement projects

- A flexibility of approach to allow for adding and removing sensors as the research questions evolved

- A system which could be owned and managed by the research centre

- A system which could be technically managed by the research centre technical, information technology and research staff

While CSAW was in its infancy, there appeared to be a growing demand for the environmental assessment of residential and commercial buildings in Australia. Australia was increasing its regulation with regard to building thermal performance and as a result industry and government were discussing the need to verify building environmental performance. Shortly after the completion of the construction of the Thermal Performance Test Cells, another developer provided three houses for environmental measurement. This research is currently being undertaken by a fellow $\mathrm{PhD}$ candidate.

It was accepted that during the initial stages of the research that many sensors would still be in transit. This would require that sensors could be gradually added to the logging system over time. It was also accepted that as the research progressed, new questions might arise and 
sensors might need to be removed or added depending on the research question. This would require a flexible platform from which the sensors could operate.

A survey of logging and measuring systems revealed three principle approaches: Building Management Systems, Digital Systems and Analogue Devices. Each of these approaches was investigated for their suitability for this research program. All the factors affecting data acquisition were considered, including:

- the types of probes or sensors that could be connected to equipment

- $\quad$ ease of operation and programming

- power supply requirements

- Portability

- affordability

It was decided that the analogue data acquisition platform was the preferred method of acquiring data for the thermal performance test cells. This selection was based on the experience of many previous international projects, which emphasised the need for a stable data acquisition platform. This is discussed further in Appendix 4.

\subsubsection{Building and Site Environmental Measurement}

As the purpose of sensors and the platform from which the sensors would operate had been defined, the next step was the selection of the specific sensing equipment that would be suitable for the task of environmental measurement of the thermal performance test cells. This aspect required the assessment of the technical skills available within CSAW and the technical resources available to manage the daily, weekly and monthly needs of the thermal performance test cells. Due to the innovative nature of the research, most of the tasks associated with all aspects of the thermal performance test cells would be the responsibility of the researcher. As there was limited technical support for the researcher, the selection of precalibrated equipment became the preferred option. This approach enabled an installation of 
equipment with the expectation of a certain level of performance. The accuracy of each sensor was checked during installation.

After the review of equipment capabilities as described in Appendix 4, the resultant probes or sensors that formed the basis of the environmental measurement were the items listed in Table 4.11 .

Table 4.11: Probes and Sensors for Test Cells and Site Weather Station

\begin{tabular}{|l|l|}
\hline \multicolumn{1}{|c|}{ Purpose } & \multicolumn{1}{|c|}{ Description } \\
\hline Dry bulb air temperature $\left({ }^{0} \mathrm{C}\right)$ & AD592CN \\
\hline Mean radiant temperature $\left({ }^{0} \mathrm{C}\right)$ & AD592CN suspended within a 150mm copper ball \\
\hline Relative humidity & Vaisala HMW40U \\
\hline Air movement & TSI 8455 hot wire air velocity transducer \\
\hline Solar radiation & SolData 80SPC pyranometer \\
\hline $\begin{array}{l}\text { Site weather station air temperature and } \\
\text { relative humidity }\end{array}$ & Vaisala HUMICAP HMP45A/D \\
\hline $\begin{array}{l}\text { Site weather station wind speed and wind } \\
\text { direction }\end{array}$ & Pacific data Systems, PDS-WD/WS-10 \\
\hline Electricity consumption & Solid core CS-450 current transducer \\
\hline
\end{tabular}

\subsubsection{Infiltration}

The measurement of infiltration was required to amend the default input values within the AccuRate software (Bowman \& Lomas 1985; Dewsbury, Nolan \& Fay 2007; Lomas 1991a, 1994; Torcellini et al. 2005b). Measurements were required for:

- The roof space of all three test cells

- The room of all three test cells

- The subfloor of the enclosed-perimeter platform-floored test cell

After a review of airflow measurement methods (ATTMA 2006; Cosmulescu 1997; Feustel \& Rayner-Hooson 1990; Hancock, Norton \& Hendron 2002; McWilliams 2002; Palmiter \& Francisco 1996; Potter, I 1999; Potter, N \& Knights 2004; Sherman 1998) it was established that the measurement of infiltration losses required expert technical capabilities and associated equipment. As the research group had informal linkages with the Mobile Architecture \& Built Environment Laboratory (MABEL) from Deakin University, MABEL 
was engaged to undertake the assessment of infiltration losses for the thermal performance test cells.

\subsubsection{Infra-Red Camera Imagery}

Infra-red imagery has been observed as a suitable method to gain initial insights into the thermal performance of the built fabric (Pearson 2002; Torcellini et al. 2005b). During the research, infra-red images were taken of the exterior and interior of the test cells. In the early stages this service was provided by the MABEL research team. After CSAW obtained its own infrared camera, the researcher took infra-red images at various stages. This was to inform and clarify the effects of construction practices on the test cell thermal performance (Dewsbury 2009; DewsburySoriano et al. 2009; Fricker 2003). A sample of some infra-red images can be seen in Figure 4.87 and Figure 4.88.

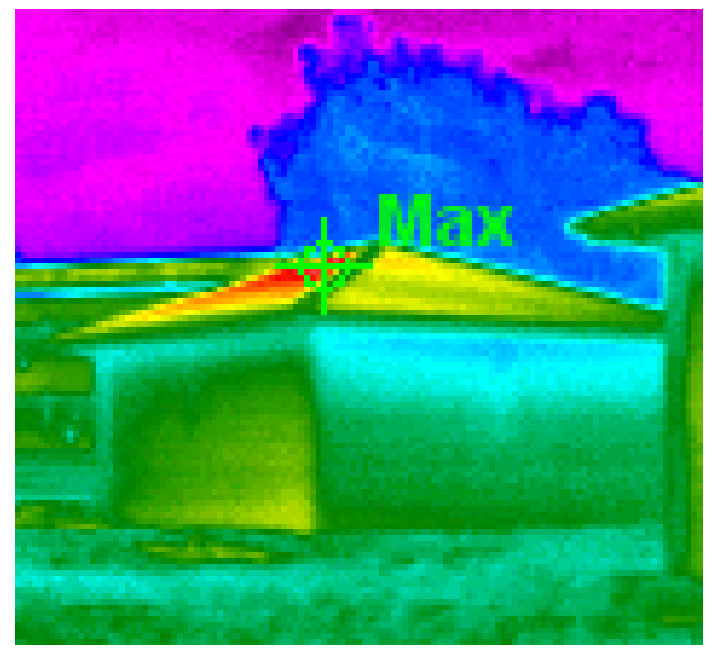

Figure 4.87 - External infra-red image of the concrete slab-on-ground floored test cell

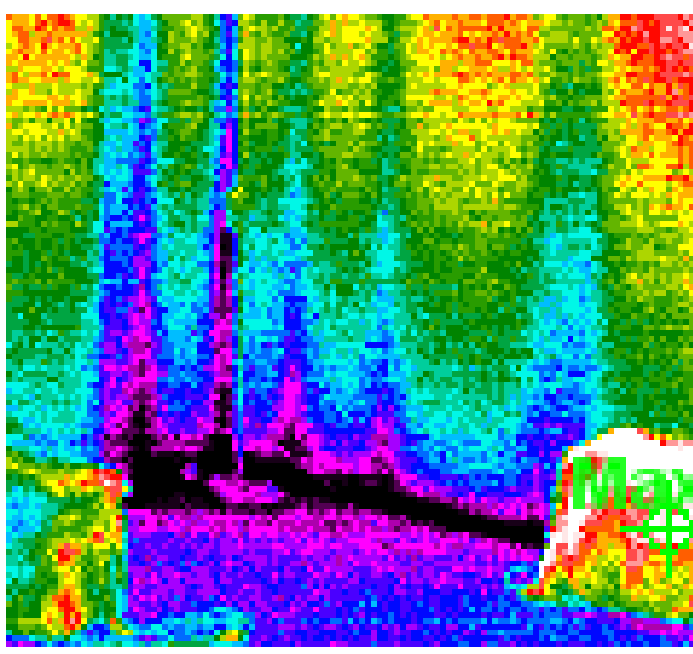

Figure 4.88 - Internal infra-red image documenting the variation of surface temperatures associated with the wall frame bottom plate connection

\subsubsection{Defining Room Temperature}

Much has been written about the temperature that an HER software produces. The output temperature has been described as: an environmental temperature, a mean radiant temperature and as a combination of air and surface temperatures. Davies (Davies 1990) described the temperature as undefinable. This problem appears to arise from the method used to calculate the heat flows through a building fabric. The equations consider heat flow through materials and the subsequent surface film conductance before room air temperature is affected (Clarke 
2001; Muncey, R 1979). This is an aspect that has been queried in other research (Barnaby, Spitler \& Xiao 2005; Davies et al. 2005; LomasEppel et al. 1994; Loutzenhiser et al. 2006; Wong 1990). In the test cell room with a wall, floor and ceiling surface area of $112.7 \mathrm{~m}^{2}$ there was a surface film conductance of $338 \mathrm{~W} / \mathrm{K}$.

Analogue devices were used to measure air temperature at $600 \mathrm{~mm}, 1200 \mathrm{~mm}$ and $1800 \mathrm{~mm}$, within the thermal performance test cells. Each of the analogue device probes was located within a PVC tube to reduce any effect by convective currents within the test cell and to reduce radiant errors (ASHRAE 2005, 2009; Guyon, G \& Rahni 1997; Loutzenhiser et al. 2006; Sugo 2005-2009). During the periods when measurements were taken, the test cells were closed, with no ventilation. The only change to the test cells' air was caused through infiltration. Muncey (1979) and others (Ahmad, Q \& Szokolay 1993; Beausoleil-Morrison \& Strachan 1999; Dewsbury, Fay \& Nolan 2008) have recognised that temperature gradients are established in rooms with relatively still air. The simulation software presumes that the air within a room is well-mixed (LomasEppel et al. 1994; Muncey, R \& Holden 1967; Strachan et al. 2006). This infers that any stratification is removed due to the mixing of the air. In the thermal performance test cells, stratification was observed in all buildings (Figure 4.89, Figure 4.90, Figure 4.91). Acknowledging this affect, CSIRO AccuRate software developers requested that the temperature used for the empirical validation comparison be an average of the $600 \mathrm{~mm}, 1200 \mathrm{~mm}$ and $1800 \mathrm{~mm}$ analogue temperature probe measurements.

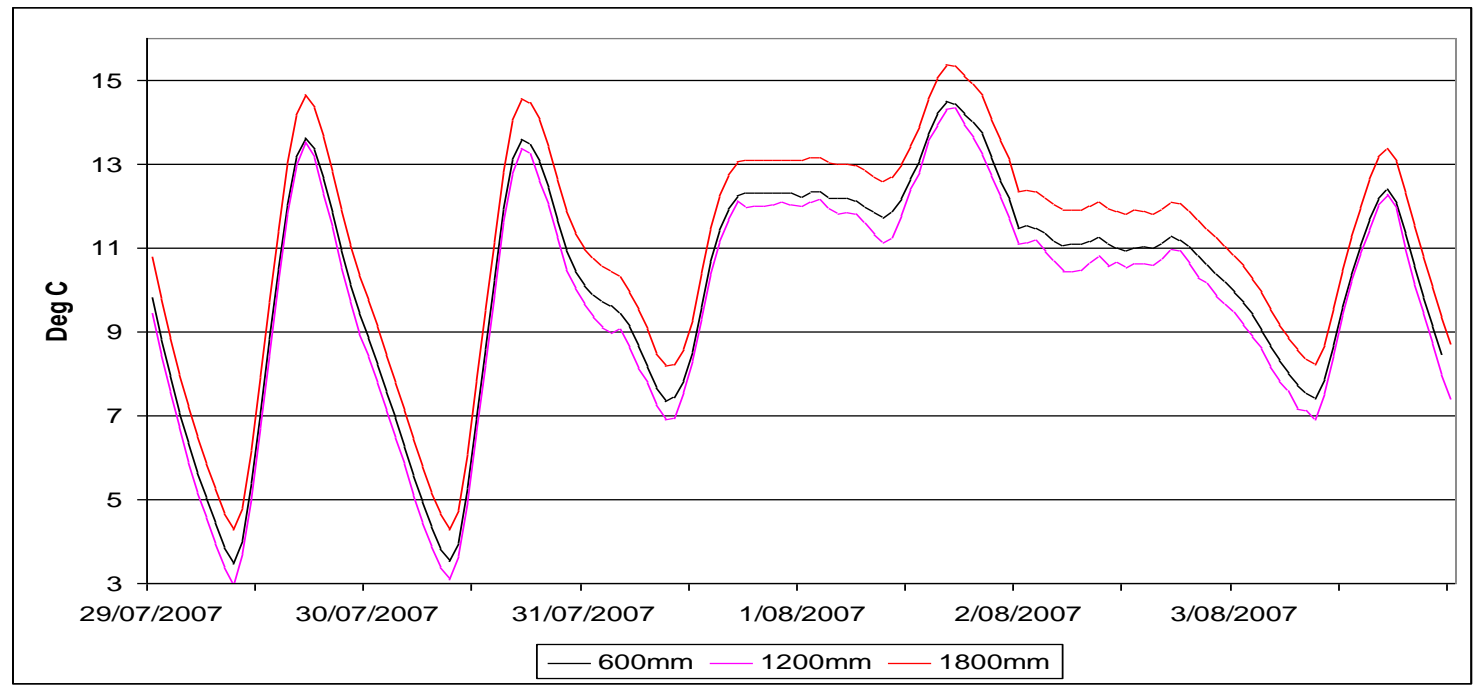

Figure 4.89 - Stratification of temperatures: Unenclosed-perimeter, platform-floored test cell (July 29 to August 3, 2007) 


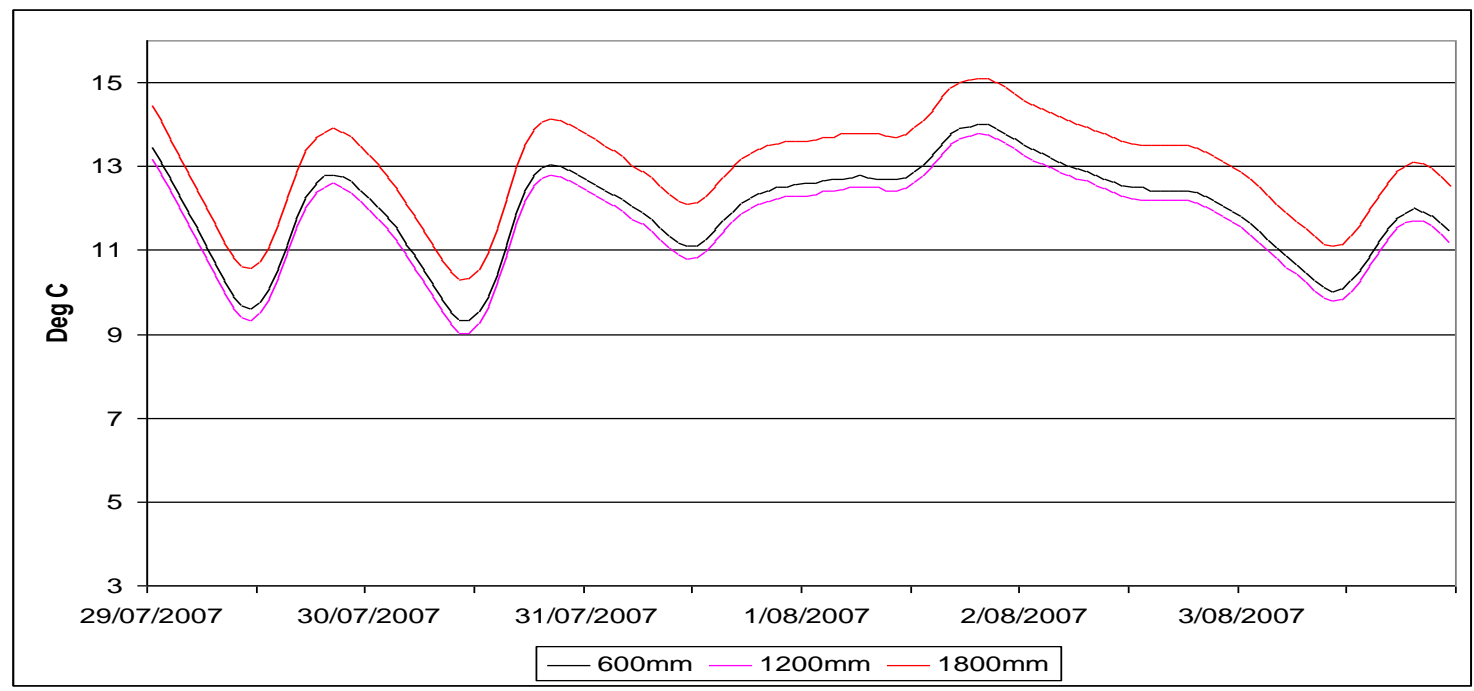

Figure 4.90 - Stratification of temperatures: Enclosed-perimeter, platform-floored test cell (July 29 to August 3, 2007)

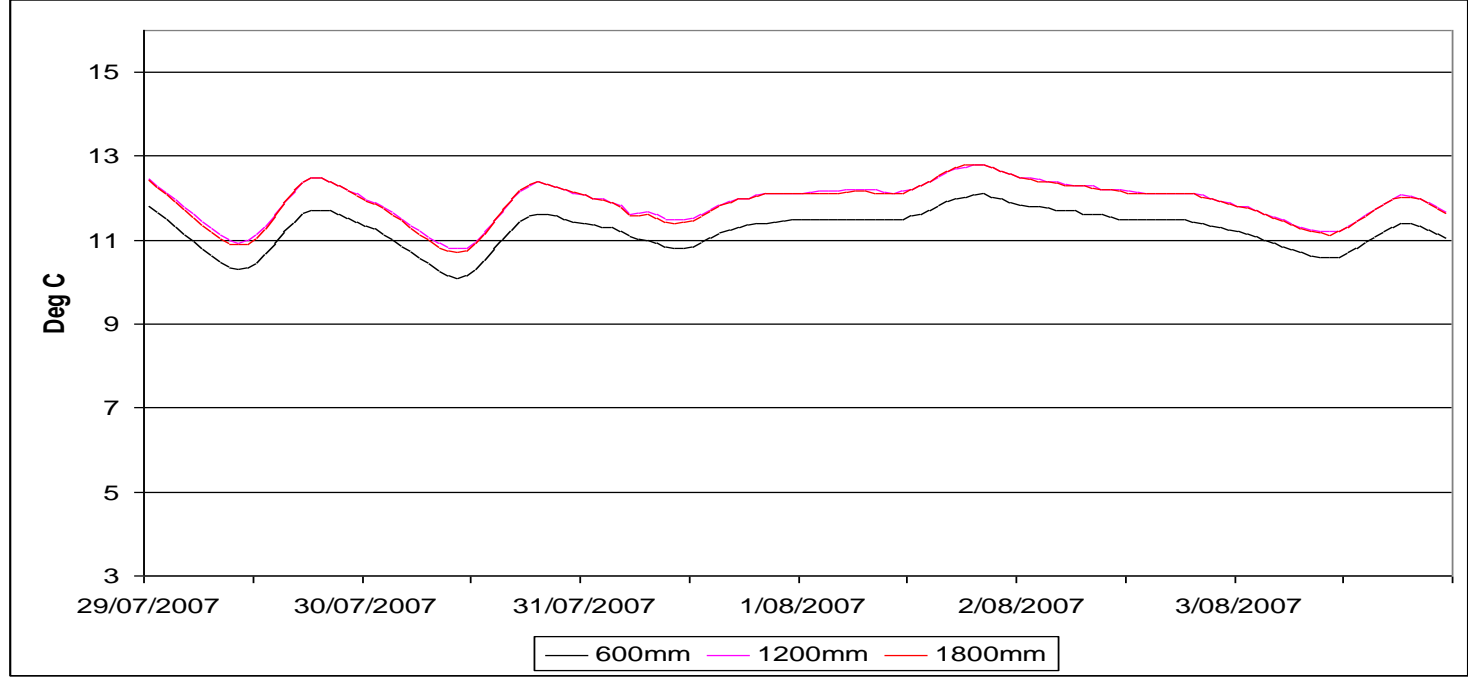

Figure 4.91 - Stratification of temperatures: Concrete slab-on-ground floored test cell (July 29 to August 3, 2007)

The temperature calculated by the software is an average temperature for the whole room (Clarke 2001; Muncey, R 1979). As the software calculates heat flow through planes, this room temperature is a mix of air and mean radiant temperature. In considering the relationship between the mean radiant temperature and the air temperature in a room with no ventilation, of similar volume to the thermal performance test cells, Muncey established that the mean 
radiant temperature and room air temperature are equal (Ahmad, Q \& Szokolay 1993; Muncey, R 1979).

During the period that the thermal performance test cells were observed, globe thermometers had not yet been fabricated. Globe thermometers were fabricated in late June 2007 and installed within the thermal performance test cells. To establish possible mean room temperatures of the test cell rooms, a simple survey is provided below, as shown in Figures 4.92 and 4.93, and Tables 4.12 and 4.13). The comparisons show the values for:

- $\quad$ Average measured air temperature $((600 \mathrm{~mm}+1200 \mathrm{~mm}+1800 \mathrm{~mm}) / 3)$

- $\quad$ Room Globe measurement

- $\quad$ Danter (1974) and Loudon (1970) ratio of 1:2

- $\quad$ Muncey \& Spencer (1966) ratio of 2:5

- $\quad$ ASHRAE Ratio: Equation 4.1 (ASHRAE 2009)

Equation 4.1 - Radiant Temperature Equation

$$
\bar{t}_{r}=\left[\left(t_{g}+273\right)^{4}+\frac{1.10 \times 10^{8} V_{a}^{0.6}}{\varepsilon D^{0.4}}\left(t_{g}-t_{a}\right)\right]^{1 / 4}-273
$$

\section{where}

$\bar{t}_{r}=$ mean radiant temperature, ${ }^{\circ} \mathrm{C}$

$t_{g}=$ globe temperature, ${ }^{\circ} \mathrm{C}$

$V_{a}=$ air velocity, $\mathrm{m} / \mathrm{s}$

$t_{a}=$ air temperature, ${ }^{\circ} \mathrm{C}$

$D=$ globe diameter, $\mathrm{m}$

$\varepsilon=$ emissivity ( 0.95 for black globe)

(ASHRAE 2009, p. F36.29) 


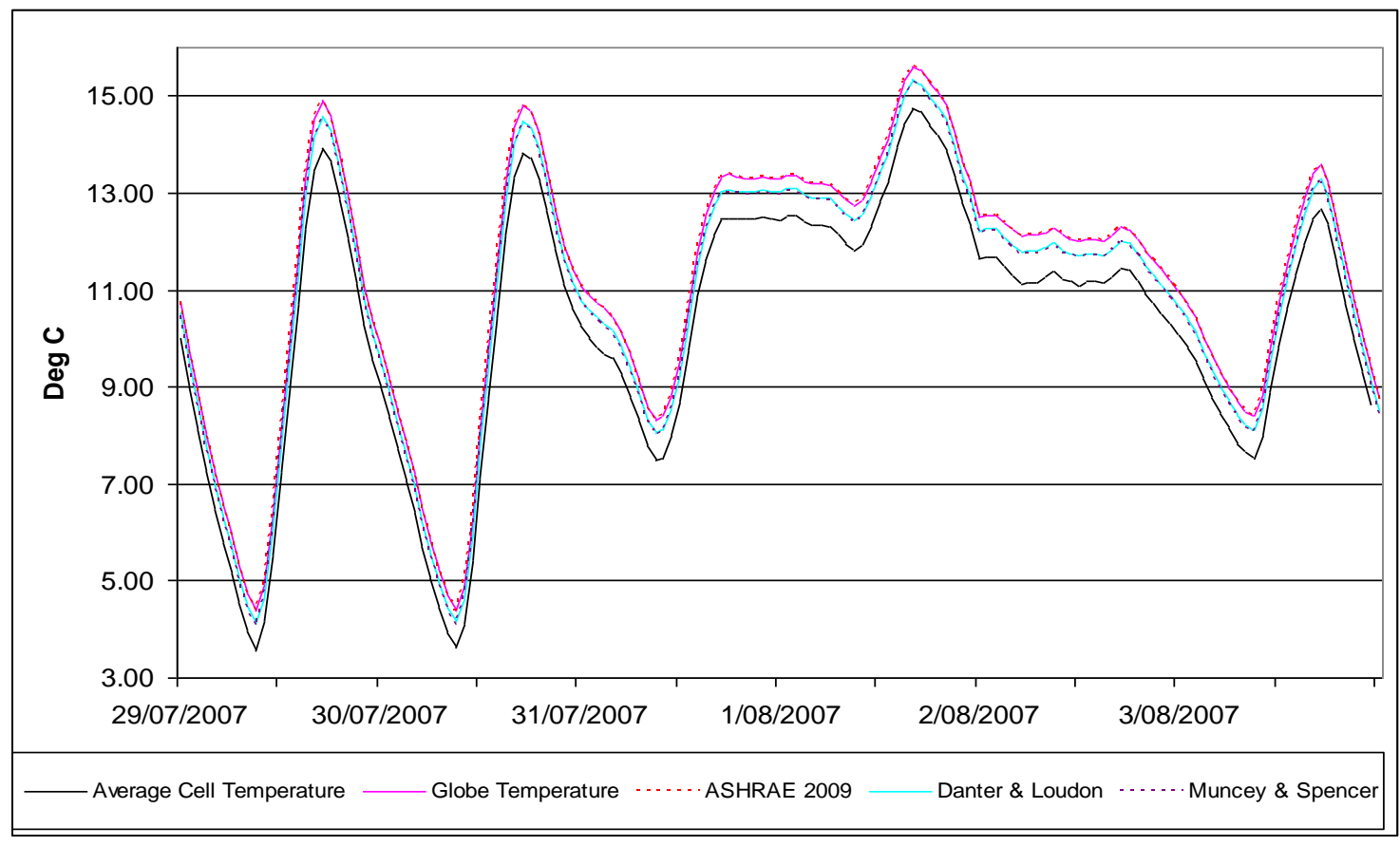

Figure 4.92 - Mean Room Temperature Calculations: Unenclosed-perimeter, platform-floored test cell (July 29 to August 3, 2007)

Table 4.12: Test Cell 1: Comparison of Minimum \& Maximum Values for Mean Room Temperature (July 29 to August 3, 2007)

\begin{tabular}{|r|r|r|r|r|r|r|r|r|r|}
\hline \multicolumn{2}{|c|}{ Room Ave } & \multicolumn{2}{c|}{ Room Globe } & \multicolumn{2}{c|}{ ASHRAE 2009} & \multicolumn{2}{c|}{ Danter } & \multicolumn{2}{c|}{$\begin{array}{c}\text { Muncey \& } \\
\text { Spencer }\end{array}$} \\
\hline Min & \multicolumn{1}{c|}{ Max } & \multicolumn{1}{c|}{ Min } & \multicolumn{1}{c|}{ Max } & \multicolumn{1}{c|}{ Min } & \multicolumn{1}{c|}{ Max } & \multicolumn{1}{c|}{ Min } & \multicolumn{1}{c|}{ Max } & \multicolumn{1}{c|}{ min } & Max \\
\hline 3.6 & 13.9 & 4.4 & 14.9 & 4.4 & 14.9 & 4.1 & 14.6 & 4.2 & 14.5 \\
\hline 3.6 & 13.8 & 4.4 & 14.8 & 4.4 & 14.8 & 4.1 & 14.5 & 4.1 & 14.4 \\
\hline 7.5 & 12.6 & 8.3 & 13.4 & 8.3 & 13.4 & 8.0 & 13.1 & 8.1 & 13.0 \\
\hline 11.8 & 14.7 & 12.8 & 15.6 & 12.8 & 15.6 & 12.4 & 15.3 & 12.4 & 15.3 \\
\hline 11.1 & 11.5 & 12.0 & 12.3 & 12.0 & 12.3 & 11.7 & 12.0 & 11.6 & 12.0 \\
\hline 7.5 & 12.7 & 8.4 & 13.6 & 8.4 & 13.6 & 8.1 & 13.3 & 8.1 & 13.2 \\
\hline
\end{tabular}

(ASHRAE 2009; Danter 1974; Muncey, R \& Spencer 1966) 


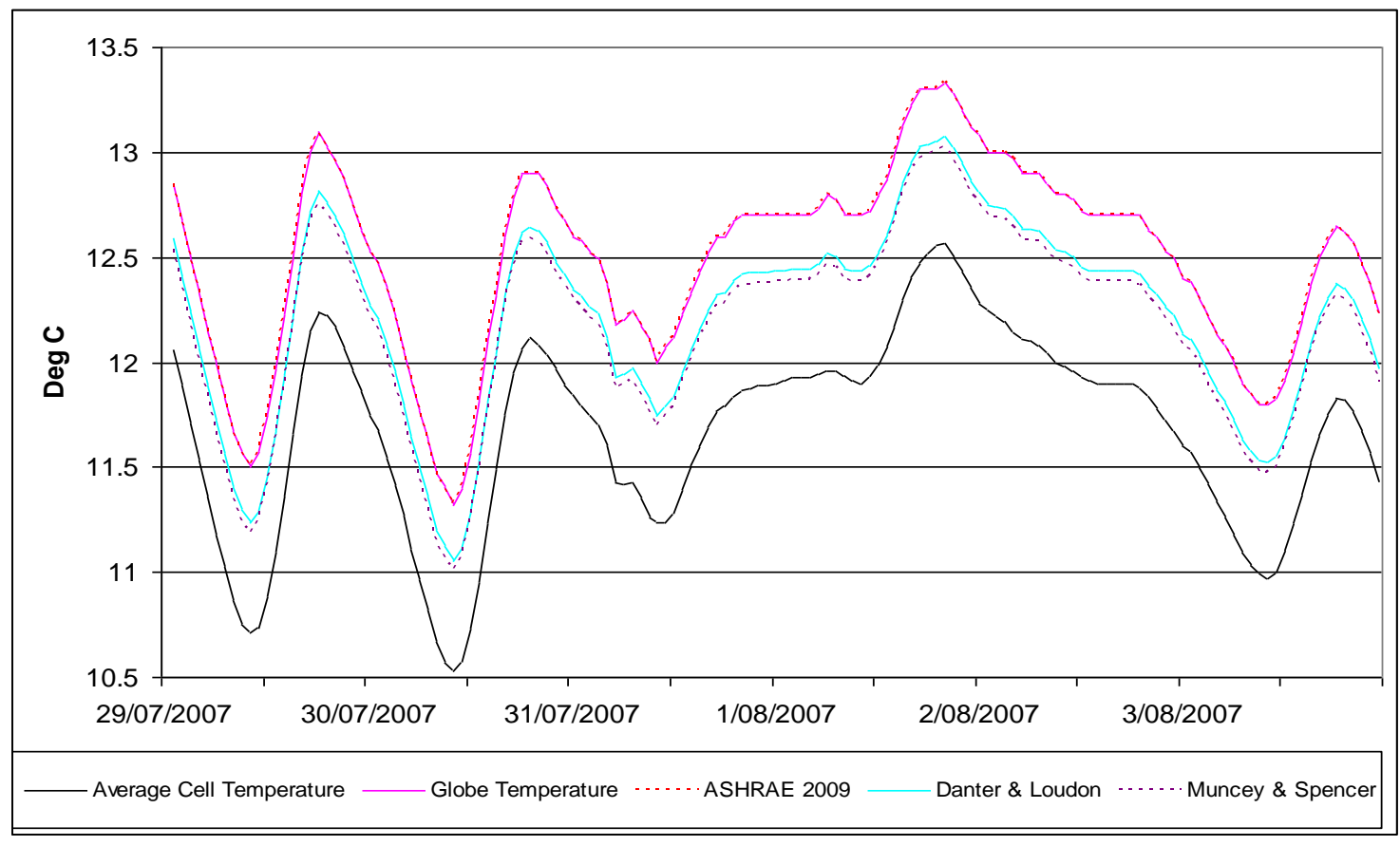

Figure 4.93 - Mean Room Temperature Calculations: Concrete Slab-on-ground floored test cell (July 29 to August 3, 2007)

Table 4.13: Test Cell 3: Comparison of Minimum \& Maximum Values for Mean Room Temperature (July 29 to August 3, 2007)

\begin{tabular}{|r|r|r|r|r|r|r|r|r|r|}
\hline \multicolumn{2}{|c|}{ Room Ave } & \multicolumn{2}{c|}{ Room Globe } & \multicolumn{2}{c|}{ ASHRAE 2009 } & \multicolumn{2}{c|}{ Danter } & \multicolumn{2}{c|}{ Muncey \& Spencer } \\
\hline Min & \multicolumn{1}{c|}{ Max } & \multicolumn{1}{c|}{ Min } & \multicolumn{1}{c|}{ Max } & \multicolumn{1}{c|}{ Min } & \multicolumn{1}{c|}{ Max } & \multicolumn{1}{c|}{ Min } & \multicolumn{1}{c|}{ Max } & \multicolumn{1}{c|}{$\min$} & \multicolumn{1}{c|}{ Max } \\
\hline 10.7 & 12.2 & 11.5 & 13.1 & 11.5 & 13.1 & 11.3 & 12.8 & 11.2 & 12.8 \\
\hline 10.5 & 12.1 & 11.3 & 12.9 & 11.3 & 12.9 & 11.0 & 12.6 & 11.0 & 12.6 \\
\hline 11.2 & 12.0 & 12.0 & 12.8 & 12.0 & 12.8 & 11.7 & 12.5 & 11.7 & 12.5 \\
\hline 11.9 & 12.6 & 12.7 & 13.3 & 12.7 & 13.3 & 12.4 & 13.1 & 12.4 & 13.0 \\
\hline 11.9 & 11.9 & 12.7 & 12.7 & 12.7 & 12.7 & 12.4 & 12.4 & 12.4 & 12.4 \\
\hline 11.0 & 11.8 & 11.8 & 12.7 & 11.8 & 12.7 & 11.5 & 12.4 & 11.5 & 12.3 \\
\hline
\end{tabular}

The variation between the various methods of calculating average room temperature and the observed average room air temperature ranges from $+0.6^{\circ} \mathrm{C}$ to $+0.9^{\circ} \mathrm{C}$. This issue of room temperature for empirical validation requires further investigation and could utilise surface temperatures of the walls, floor and ceiling that were observed during the research period. A review of past research noted that many only used dry bulb air temperature for their analysis (Travesi et al. 2001). For this empirical validation, the method requested by the CSIRO AccuRate software developers was used, which was the average of the $600 \mathrm{~mm}, 1200 \mathrm{~mm}$ and $1800 \mathrm{~mm}$ air temperature probes. 


\subsubsection{The Fabrication, Installation and Calibration of Environmental Measuring Equipment}

The manufacture, installation and calibration of the environmental measuring equipment took more than a year to complete. The primary design of the environmental measuring system and its devices required completion by December 2005, to enable equipment to be ordered and installed within the desired time frame of the research program. The orders for equipment commenced in December 2005 and the building construction (which commenced in June 2006), required allowances during construction for the placement of some devices. As the principles of the environmental measuring system were known, a range of tests were carried out on each item of equipment as it arrived, (prior to installation) to reduce the number of system or device faults that occurred. Many essential elements were installed within the thermal performance test cells prior to August 29, 2006 but a general debugging of equipment continued to occur until January 2007. There were many late nights and seven day working weeks during the primary installation stage of the environmental measuring equipment. The installation of new equipment continued until February 2008. A journal of the installation process is included in Appendix 5. As the objectives included the need for system flexibility and mobility, several system wide options were explored.

The requirement for systemic flexibility led the principal researcher down the path of LAN \& WAN network principles. The researcher had been involved in projects in the late 1990s with regard to data and telephony integration for the NSW government. The concept, as shown in Figure 4.94, consisted of:

- DataTaker DT500 data loggers and channel expansion modules for primary data acquisition

- Wiring from data logger terminals to RJ45 terminal blocks

- Eight wire data cable from RJ45 terminal blocks to Krone connector near to the location of the particular measuring device

- Two wires from Krone connector providing power to and return signal from each individual measuring device 


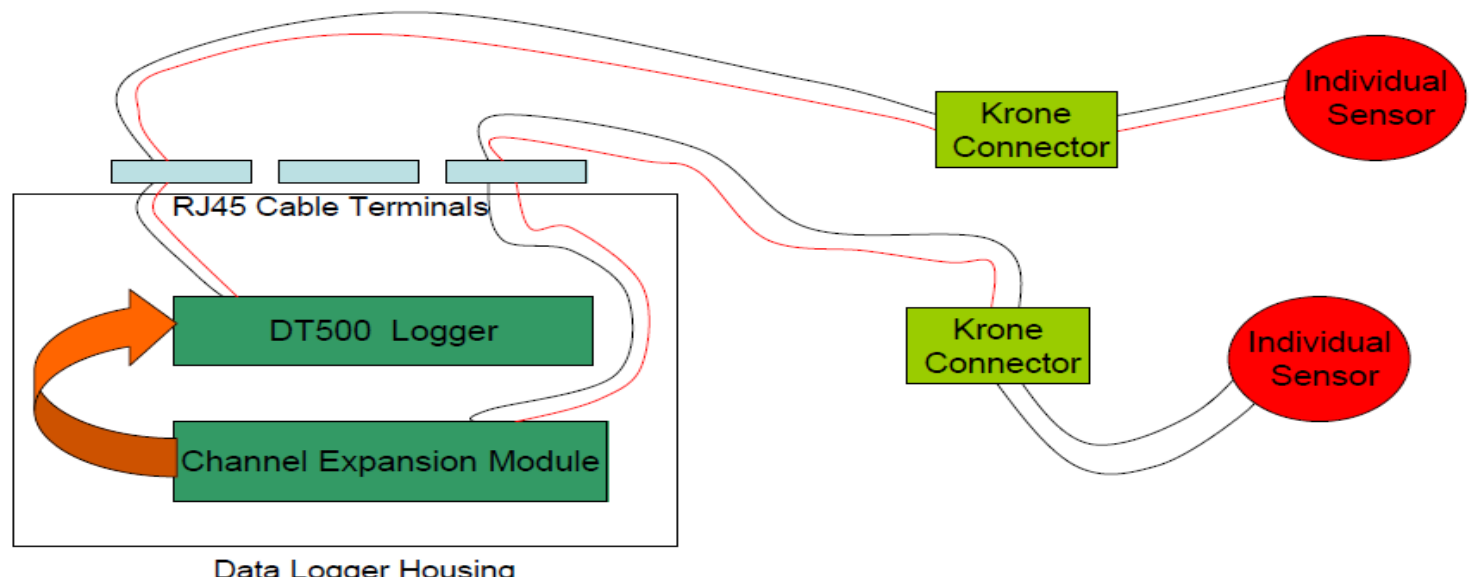

Figure 4.94 - Wiring diagram for environmental measuring equipment

From concept to execution took several months of testing and some experiences are discussed here and in Appendix 4. The chosen analogue environmental measuring devices required a two-wire connection. The adoption of an eight-wire data cable methodology enabled each data cable to carry the signal of four individual devices. Extensive planning and design of the measuring devices and their configuration was undertaken, to maximise the benefits of data cable connections. Figure 4.95 shows a sample of one of the channel allocation spreadsheets for Test Cell 2, Logger A. This methodology considered equipment type and requirements from an early planning stage, as each item of equipment required a different method of connection to the data logger.

\section{Cell 2: Logger A:}

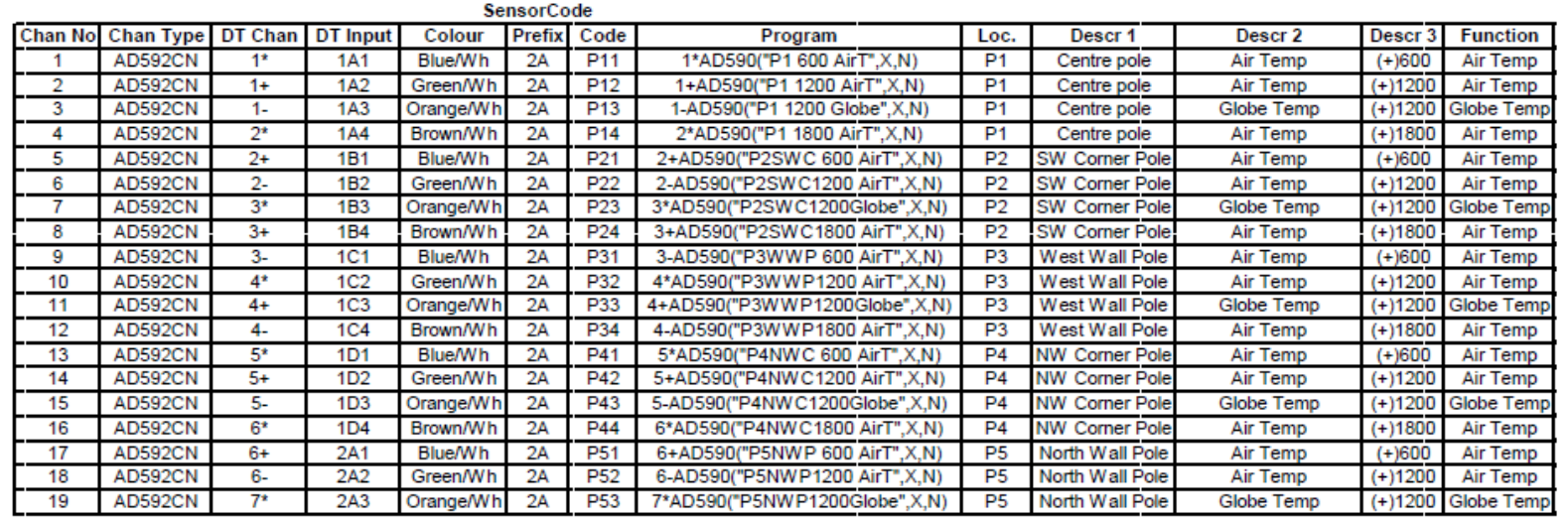

Figure 4.95 - Sample of DT500 channel allocation spreadsheet. 
Initially, each thermal performance test cell utilised two data loggers. A simple naming convention of test cell number (1,2 or 3) and data logger A or B was adopted. The columns of the channel allocation spreadsheet provided the following functionality:

- Channel Number: Each data logger and channel expansion module could accommodate 30 analogue two wire sensors. This tally column allowed an easy reference to the number of sensors allocated to the data logger.

- Channel Type: This was where a sensor type was first noted. This allowed for planning of data logger connection requirements (i.e., AD592CN, Voltage, Voltage 4$20 \mathrm{~mA})$.

- DT Channel: Data logger channel allocation where $1 *$ referred to data logger channel connection point and $31^{*}$ referred to the first channel on the channel expansion module.

- DT Input: This was the first reference to the RJ45 cable terminals. Each wall fixing plate could accommodate four RJ45 outlets. 1A3 referred to Wall Plate 1, RJ45 socket A and the third pair of wires (orange/white).

- Colour: this detailed the colour of the pair of data cable wires which were allocated to the sensor.

- Prefix: Test cell and data logger identification.

- Code: Each type of sensor was allocated an alphabetical prefix. Each type of sensor received a tally $(\mathrm{P} 42=\mathrm{AD} 992 \mathrm{CN}$ number 42$)$.

- Program: This was the specific program wording that was used within the data logger.

- Location: Location of sensor within test cell $(\mathrm{P} 1=$ Pole 1$)$.

- Description 1-3: This described the location of the sensor within the test cell building (Centre of test cell room, measuring air temperature, at a height of $600 \mathrm{~mm}$ ).

- Function: The function of the sensor, for example: Air temperature, surface temperature, relative humidity. 
The channel allocation spreadsheets became an integral document for the planning and implementation of the environmental measurement of the thermal performance test cells. From the broad nature of the planning and co-ordination of the thermal performance test cells, individual elements of the environmental measurement required equal levels of detailed consideration and calibration.

\section{DT500 DataTaker Data Loggers}

The DT500 data loggers were the primary tools for data acquisition. Each data logger and channel expansion module was purchased new and arrived with a calibration certification. Even with the manufacturer's calibration certification, the data loggers were tested before any further work progressed. A range of tests, (which included the checking of the data logger system, battery, power supply, integrated circuit integrity and earthing) were completed for each DT500 data logger and channel expansion module.

The appropriate wiring between the data logger or channel expansion module and the RJ45 terminals was then installed offsite by an appropriately skilled contractor (Figure 4.96 to Figure 4.99). After the wiring to the RJ45 terminal was installed, each channel was checked again to make sure the data logger was still reading a nil or zero value. The data logger and connected channel expansion module were then installed into a secure metal box and delivered to the University. 


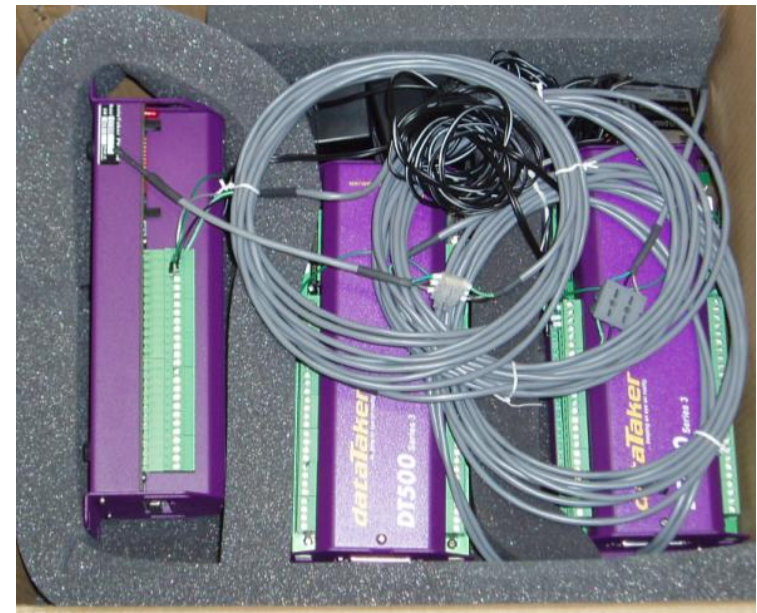

Figure 4.96 - Newly arrived DT500 data loggers and channel expansion modules

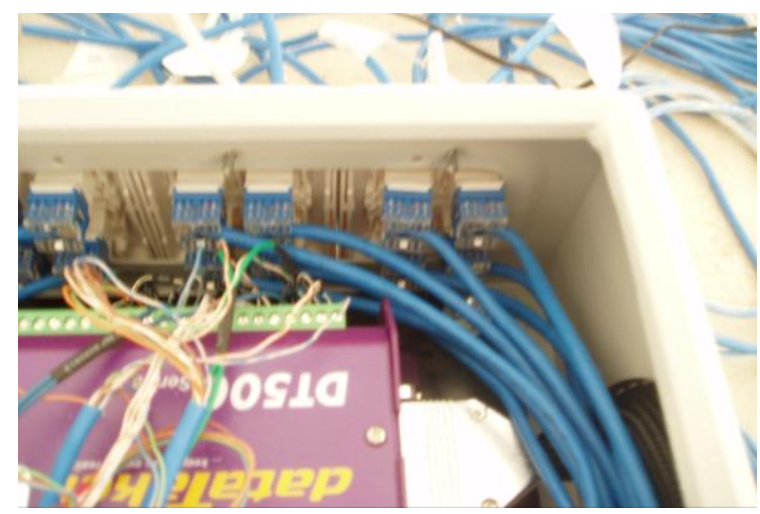

Figure 4.98 - Interior view of metal data logger box and RJ45 terminals

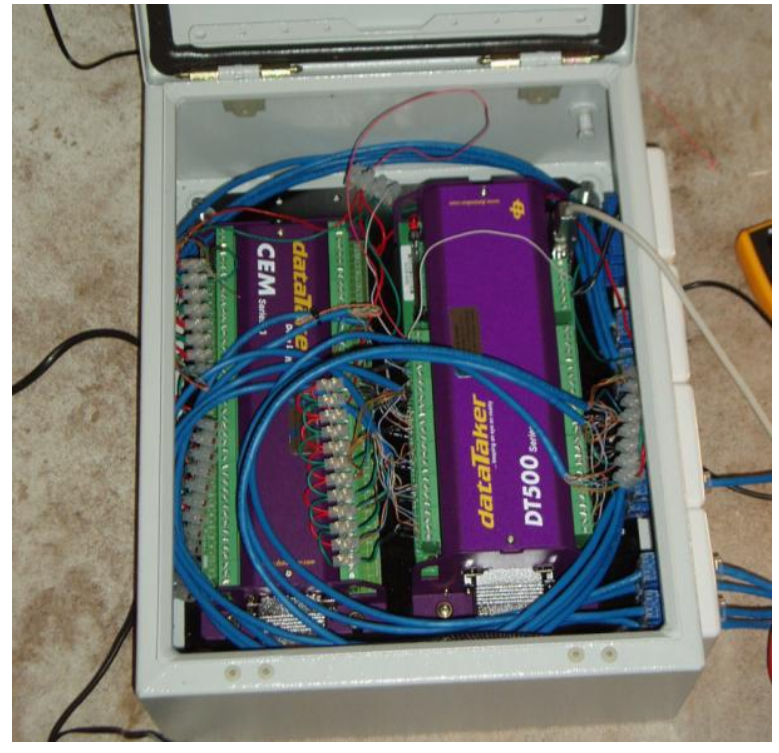

Figure 4.97 - DT500 data loggers and channel expansion module in secure metal case after primary wiring was installed between channels and RJ45 terminals

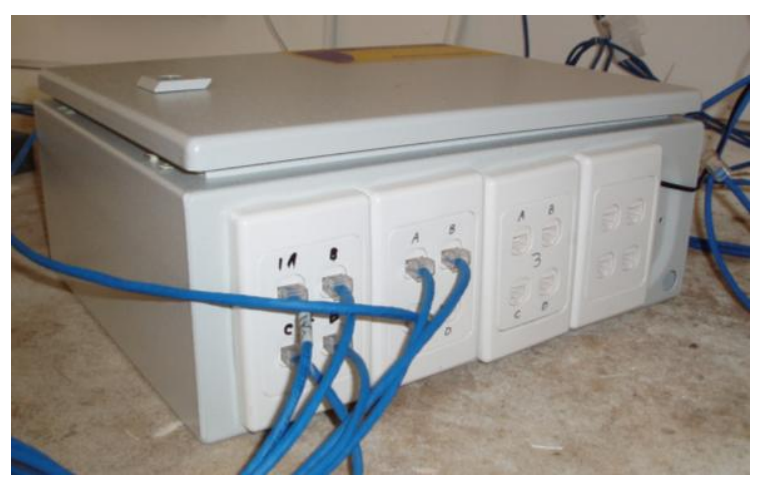

Figure 4.99 - Exterior view of metal data logger box and RJ45 sockets

From August 2006 to August 2009, five generations of wiring within the data logger metal box occurred. This was due to a balanced combination of maintenance, accessibility and time in considering the methods used to connect wires. With each generation of wiring, the data logger appeared cleaner and more professional in approach. 


\section{Data Logger Programming}

Each data logger was programmed to be able to communicate with the sensors which recorded the environmental data. A sample of one of the data logger programs is shown in Figure 4.100. The data logger program was broken up into five distinct sections (Figure 4.100). The first section establishes protocols within the data logger for operation. The second section defines the spans for the data logger operation. If a measuring device specifies a span number, the data logger looks in the span table to establish a resultant value for what is being measured. In the example shown in Figure 4.100, there are three types of spans shown. Below is a description of how span 4 is applied:

- Spans S4 to S7 for solar irradiation devices. The span defined 0,1,0,156 " $\mathrm{kW} / \mathrm{m}^{2}$ " informs the data logger that there is a reading of zero equals zero kilowatts and a reading of 156 equals 1.0 kilowatts of solar radiation. Any measured value above or below 156 is converted to a respective kilowatt value

The third section is very important, as it defines the date and time. As the research included three separate buildings and a site weather station, all data loggers were synchronised. This was established at this stage of the programming, where the logger date and time were synchronized with the attached computer.

The fourth section laid down the time step between measurements and the data loggers understanding of the measuring devices that were attached. The command 'RA10M D T' informs the data logger that it is to record a reading every ten minutes and that the recorded data is to have a date and time stamp (Bowman \& Lomas 1985). The Channel Allocation spreadsheet, as shown in Figure 4.100, was an intrinsic tool for data logger programming. The eighth column of the spreadsheet amalgamated all the information about the environmental measuring device into a programming and text form. An example of a line of programming is below:

\section{5+AD590("P4NWC1200 AirT",X,N)}

The line of text can be broken down into its constituent parts:

- 5+: the channel of the data logger that the device was attached to 
- AD590: coding that informed the logger of what type of data the logger would record. Another primary descriptor was $\mathrm{V}$ for volts

- $\quad$ "P4NWC1200 AirT": a text descriptor of the environmental measuring device

- $\quad \mathrm{X}, \mathrm{N}$ : Commands to inform the logger on how to deal with data

The fifth section of the data logger programming instructs the data logger to commence operating.

During the course of this research, minor modifications to data logger programming were made. One example was that, as the research progressed, particular measurements were changed from a ten minute spot reading to an average reading for the ten minute period. This required the addition of the 'ave' command to an individual device programming text. If the average mode was defined, the data logger would take measurements from the required devices continuously, but only record the average value for the ten minute measuring cycle. This method was adopted for the measurement of electricity usage, as it allowed for a more thorough understanding of when particular electrical services were in use. 


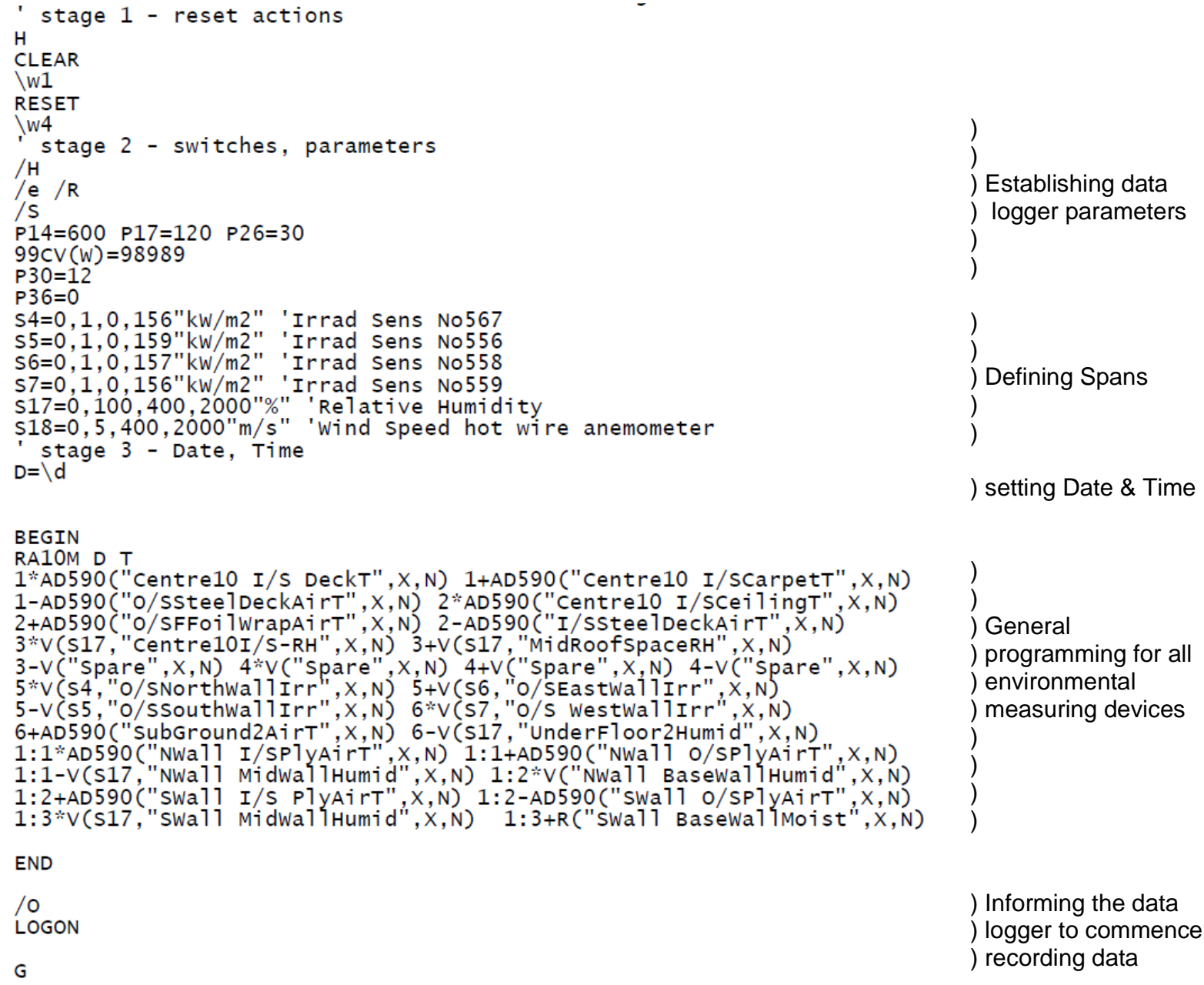

) Establishing data

) logger parameters

Figure 4.100 - Sample of data logger programming

\section{Connecting the Sensors to the Data Loggers}

The system cabling method, as shown in Figure 4.94, utilised high quality eight wire data cable between the data logger RJ45 outlets and Krone terminals (Figure 4.101) near the individual or group of measuring device. As this was a new method of connecting environmental measuring equipment and a precise level of accuracy in measurement was required, a range of tests were undertaken before installing these in the test cells. Initially plain bell wire was used over varying distances to test the concept. As confidence grew, the shift to eight wire data cable occurred. As many of the points of measurement included four or more sensors, the eight wire data cable allowed for four sensors to be connected in a much easier format, where each wire colour within the data cable was allocated to a single sensor. The cable was laid out in varying lengths in both indoor and outdoor environments. The cable 
was laid over other active data cables and electrical services to measure any interference between cables. For exterior environmental testing, the cable was laid near to and across high voltage electrical services to record any interference that may occur. Generally no effect or distortion of measurements was measured in cable distances less than ten metres. Distortions that could potentially affect the sensor signal did occur, when that data cable ran alongside or crossed over electrical services. It was observed that if the cable was shielded when it crossed over electrical services, the distortion to the sensor signal was alleviated. Once there was a confidence in the new format of cabling, a final test included the parallel comparison of sensor readings, where one sensor was cabled from DT500 to the actual sensor, via the data cable, RJ45 terminals and Krone blocks and the comparison sensor were connected by a high quality two wire approach, in which the sensor was directly connected to the data logger.

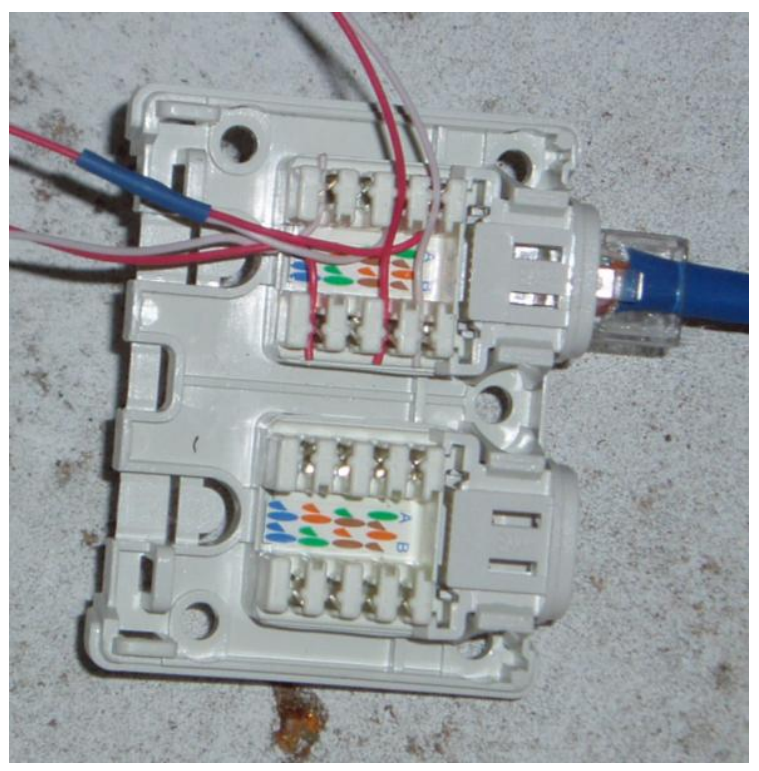

Figure 4.101 - Krone terminal: RJ45 type data plug with eight wire data cable on the right and red/white bell wire, which connects to an individual sensor, connected to the Krone terminal

To maintain a simple testing regime during the installation of the equipment within the thermal performance test cells, a simple step-by-step procedure was developed to enable efficient and reliable installation. The process was broken into two distinct stages involving either the data logger wiring or the wiring to an individual sensor.

The process for the installation of wiring within the data logger metal box was: 
- Step 1: Empty data logger. Data logger tests were run and checked to ensure that all channels read zero.

- Step 2: The data logging program was installed into the data logger and all channels were checked to ensure that a zero reading was still being recorded. The zero value depended on the type of signal provided by the sensor to be installed on a particular channel.

- Step 3: Resistors and other wiring was installed to individual channels of the data logger. The data logger was tested to ensure a zero value was still being recorded.

- Step 4: Earth and reference wires were installed. The data logger was tested to ensure a zero value was still being recorded.

- Step 5: The data cables were attached to the RJ45 terminal blocks and the data logger was tested to ensure a zero value was still being recorded.

This method of installing wiring from the data logger channel to the RJ45 terminal block allowed the removal or repair of any item which may not be giving a true or clean signal. During the data collection period, occasional testing of the data loggers was completed in which all cables leaving the RJ45 terminals were removed and all wires were tested to ensure all data logger channels were still reading a zero value.

The process of installing individual sensors was as follows:

- Step 1: A new piece of data cable, which was cut to the desired length, had an RJ45 plug placed on one end. The RJ45 plug was plugged into the RJ45 terminal block on the data logger metal box. The data logger was tested to ensure a zero value was still being recorded.

- Step 2: An RJ45 plug was attached to the other end of the data cable and the data logger was tested to ensure a zero value was still being recorded.

- Step 3: The new RJ45 plug was placed on Krone terminal block and the data logger was tested to ensure a zero value was still being recorded. 
- Step 4: Depending on sensor type, two methods occurred at this stage: For environmental sensors which had the bell wire soldered to output terminals, the two bell wires from the individual sensor were attached to the krone block and a signal was then received from the individual environmental sensor. For environmental sensors which had screw type terminals, the bell wires were attached to the Krone terminal block and the data logger was tested to ensure a zero value was still being recorded. The wires were then connected to the individual environmental sensor and a signal was then received at the data logger.

- Step 5: Output readings were then compared between data from data cabled sensor and data from a direct wired sensor in the same location. This was to check for any variation in data readings. If there was a variation, individual sensors were replaced

This method of installing individual environmental sensors allowed for a simple process of error recognition. Often the error was the result of a poorly terminated data cable. This was either from the data cable and RJ45 plug or from a poorly attached wire in the Krone terminal block. For the data cable, the cable would be trimmed and a new RJ45 plug would be attached and the cable re-tested. For the Krone Block terminations the wires were removed, trimmed and re-terminated.

\section{Local Area Network (LAN) Connection and Logger Automation}

The long term plan for the data collection from the thermal performance test cells was to allow for remote management of the data loggers and the automated download of data to a server located at a different site within the research centre's offices. This required a data logger, which could communicate with the DT500 data loggers and had the capability to communicate with an external server. The DataTaker DT80 had the capacity to connect limited digital and analogue devices, be programmed to collect data from the DT500 data loggers and to act as a server to send and receive data from computers and servers located within the research centre offices.

Another problem that affected data collection was the occasional disruption to power supply at the test cell site. Short interruptions were compensated for by the DT500 battery power supply. However, longer power disruptions caused data losses, which became more apparent 
in the enclosed-perimeter platform-floored test cell. Closer examination revealed that the weather station devices quickly drained the battery power from the data logger and caused logger failure and data losses. To alleviate the power drain and data losses from the data logger, a separate data logger was acquired for the weather station.

The DT80 data logger provided an answer to both problems. The DT80 provided the automation and communication needs of the research and was able to provide the data acquisition functions for the site weather station. The cabling method required to connect the DT500 data loggers to the DT80 data logger was a parallel circuit. The parallel connection required two wires between each data logger with the wiring terminating at the DT80 data logger (Figure 4.102). The DT80 was than connected to the University LAN \& WAN networks via a standard eight wire data cable.

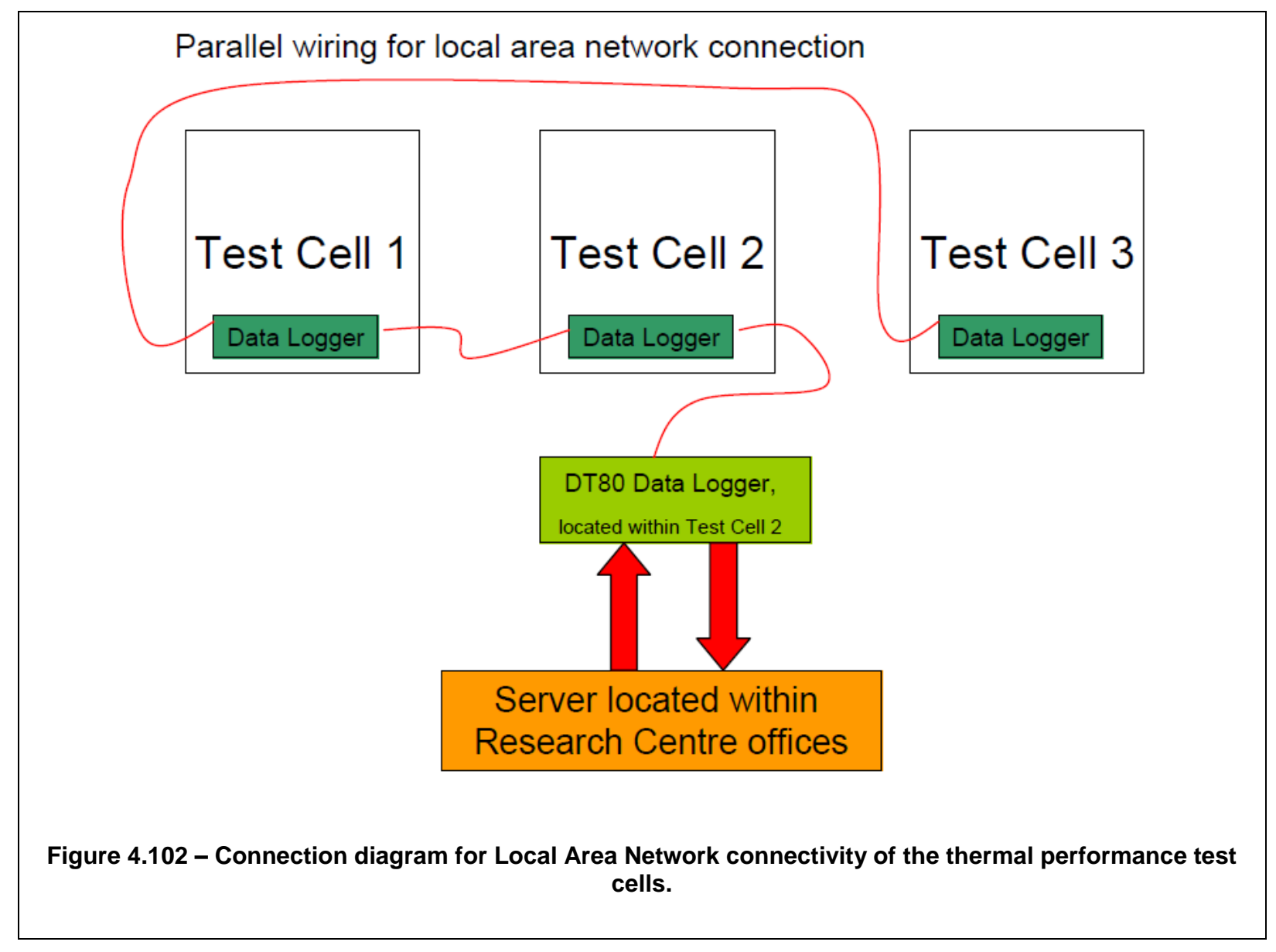




\subsubsection{Calibration of Environmental Measuring Equipment}

Calibration has often been discussed as an area of fault in empirical validation (Bowman \& Lomas 1985). The calibration of the environmental measuring equipment occurred at least three times during the research discussed in this thesis. Each device was tested before and during installation as described in Section 4.3.10. During the operation of the test cells, devices were added and removed as the research progressed. In many instances the data logger was reprogrammed and each device was rechecked against a sample device. When a single device started showing erratic data or jumps in data, the checking and calibration included:

- $\quad$ Testing of whole data logger

- Testing of particular channel group on data logger

- Testing of individual channel on the data logger

- Testing of cabling from data logger to device as described above in Section 4.3.10

- The individual device output was compared to the output from a similar device

During the eighteen months of thermal performance test cell operation particular to this research each device was checked at least twice.

\subsubsection{Operational Control of the Thermal Performance Test Cells}

The operational control of the thermal performance test cells included a detailed log of activity within the test cells and methods of controlling the temperature within the test cell room. Each thermal performance test cell included a fan assisted electric resistance heater capable of heating the test cell room. This would allow for future research to examine the differential heat energy required to condition the different thermal performance test cells and to progress the empirical validation into the energy calculation side of the house energy rating software (Torcellini et al. 2005a).

Within the eighteen months the test cells were operated in various modes. These included: free-running, continuously heated and cyclic heating. Each of these methods is discussed 
below. It should be noted, however, that the data used for the empirical validation examines an extended period of free-running operation (Lomas 1991a).

The term 'Free-running' refers to building operation where:

- No thermostatically controlled methods are used to condition the spaces within the building through either cooling or heating

- No ventilation methods are invoked via doors windows or other means

- No internal electrical loads (i.e., stove, refrigerator, television) are added to any space within the building.

This method allowed the building to respond naturally to the external environment. This method was appropriate for empirically validating the AccuRate software as this research is focused on the thermal simulation engine and not on the energy calculations of the software (Bowman \& Lomas 1985; Strachan et al. 2006). The first step to empirically validate house energy rating software is the examination of the thermal simulation engine (Lomas 1991b). Only when there is confidence in the thermal simulation engine's calculation of zone temperatures, can a further investigation into the energy required to condition a space, (through either heating or cooling) be explored. The thermal performance test cells were operated primarily in free-running mode throughout the majority of the eighteen months of operation particular to this research.

As mentioned above, each test cell was equipped with an electric heater. The heater was sized based on the thermal simulation of the unenclosed-perimeter platform-floored test cell. A discussion of the method undertaken to choose and size the heater is discussed in Chapter 4. A $3.6 \mathrm{~kW}$ wall heater was installed within each thermal performance test cell room (Figure 4.104). During the first few months of operation several trials at controlling test cell temperature using the inbuilt thermostat control of each heater was attempted (Dewsbury, Nolan \& Fay 2007). It was found that there was little similarity between dial positions and temperature set point between each of the three heaters. To add further confusion the cut in and cut out activity of the inbuilt thermostatic controls of the heaters was unreliable. To overcome these, and for a more precise heating control, an electrical relay was installed. 
Several methods were trialled over a few months but the simplest method which provided adequate heating control required (Figure 4.103):

- The installation of a relay switch within the box enclosing current transducer sensors (Figure 4.105).

- The rerouting of heater power supply via the relay switch.

- The programming of an alarm based on the temperature being measured by the dry bulb air temperature sensor located in the middle of the test cell room. The programming of the reading of data from this sensor was modified from a spot reading each ten minutes to a constant reading.

- When the air temperature dropped $0.1^{0} \mathrm{C}$ below the programmed value, the alarm would send a signal to a relay to close a circuit, providing electricity supply to the heater.

- When the air temperature increased to $0.1^{0} \mathrm{C}$ above the programmed value, the alarm would send a signal to a relay to open a circuit, stopping the provision of electricity supply to the heater.

- The internal thermostat controls of the heaters were modified by the principal researcher, such that they would not impede heater operation. 


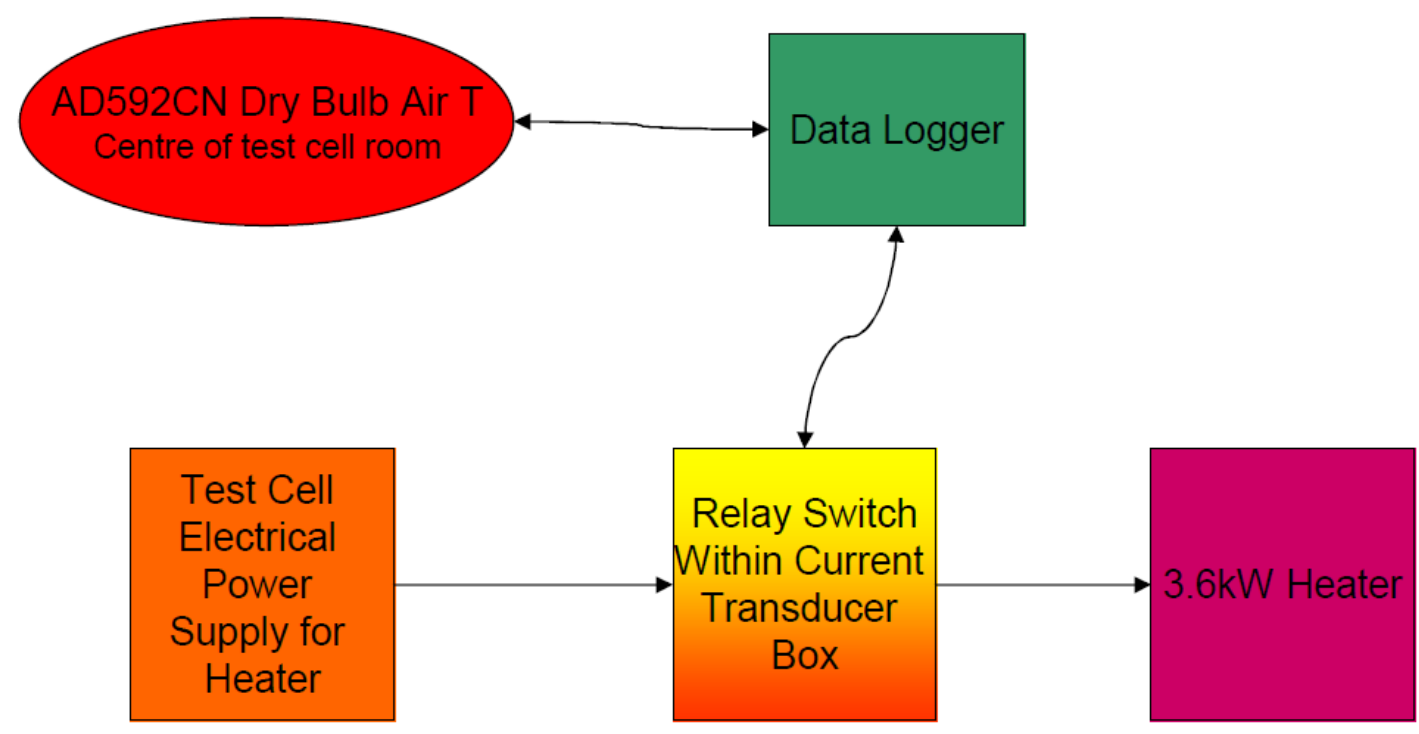

Figure 4.103 - Wiring diagram for relay control of thermal performance test cell room heater

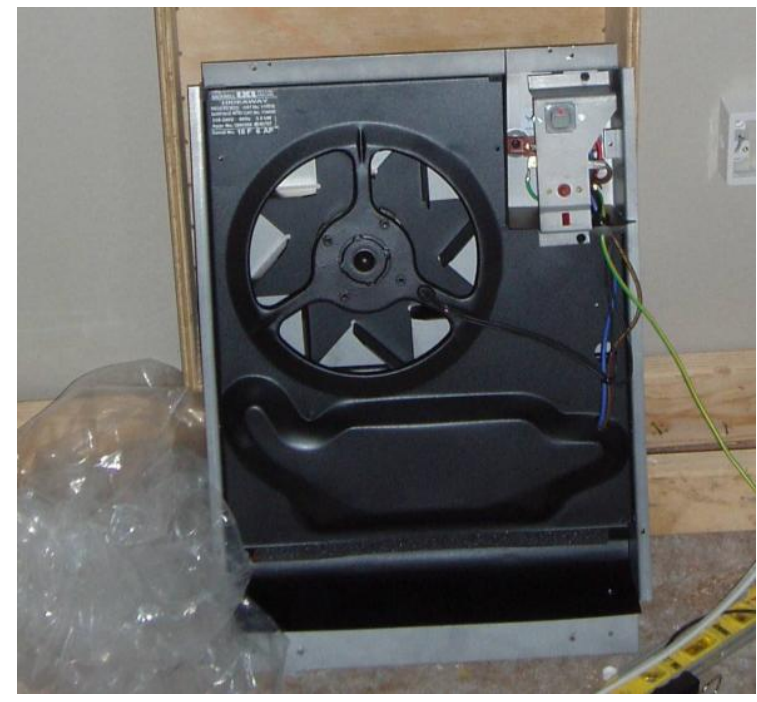

Figure $4.104-3.6 \mathrm{~kW}$ wall heater being installed during thermal performance test cell construction

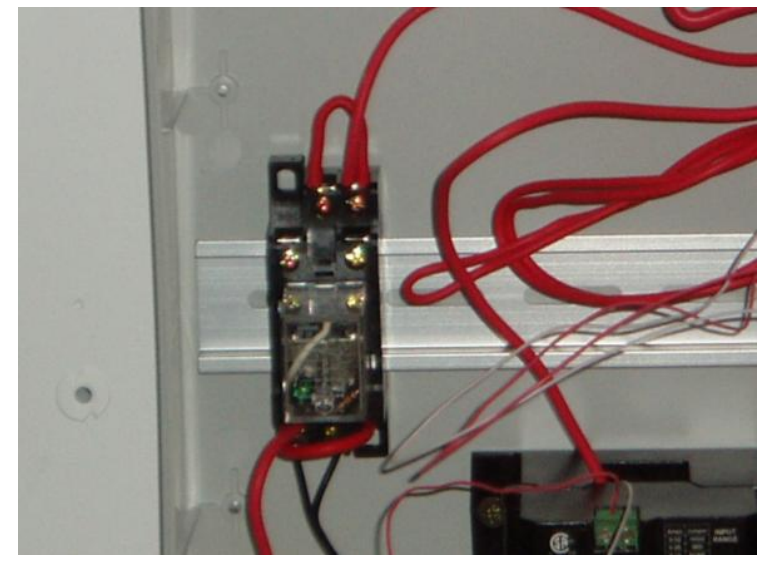

Figure 4.105 - Relay control for heater installed within box enclosing current transducer sensors

Once the method of controlling the heaters was established and installed, two methods of heating the room of the thermal performance test cell were tested. The two methods were to continuously heat the test cell room and to cyclically heat the test cell room. 
The continuous method of heating a test cell room involved programming the data logger to a fixed alarm or temperature setting. Once the program was loaded, it was found that the temperature was maintained by the heater with minor variations between test cells. The concrete slab-on-ground floored test cell had the most even temperature, with variations of $+/$ $0.1^{0} \mathrm{C}$. The enclosed-perimeter platform-floored test cell would increase to $+0.1^{0} \mathrm{C}$ but would occasionally drop to $-0.2^{0} \mathrm{C}$ before the heat in the room became distributed. Due to the lightness of fabric in the unenclosed-perimeter platform-floored test cell, the temperature would increase to $+0.1^{0} \mathrm{C}$, but would occasionally drop to $-0.3^{0} \mathrm{C}$ before the heat in the room became distributed. Throughout this research this method was used to recognise relative loss of heat between the three thermal performance test cells and for thermal imaging where thermal bridging was analysed. However, no data from this preliminary research of constantly heated thermal performance test cells is included in the empirical validation process.

The original research plan included an assessment of the relative energy required to provide cyclic heating for each of the thermal performance test cells. In a normal house situation the house energy rating protocol ( $\mathrm{ABCB} 2006 \mathrm{~b})$ defines the times when a room type is heated and the temperature that the room is heated to. The house energy rating software calculates an under or over heating hours value, which it uses to calculate the energy required to maintain the room at the thermostat setting and leads to a resultant star rating. To assess whether the energy use calculation part of the house energy rating software was functioning appropriately, it was envisaged that a study of the three thermal performance test cells in a cyclic heating mode would be undertaken. Due to the complexities and time involved in the empirical validation process, the cyclic heating research was planned for the future and is not covered in this research.

Once the method of providing a constantly heated thermal performance test cell room was achieved with appropriate levels of temperature control, the method required to heat a test cell room cyclically was explored. This was only undertaken in a preliminary way during the research. After some initial problems with the data logger programming, it was possible to have the scripting of the alarm, which controlled the heater relay switch, overlaid with a time clock control. This allowed for the data logger to activate and de-activate heater control, based on time of day. Via the specification of the time settings in the data logger program, it was confirmed that the test cell room could be heated from 07:00 to $24: 00$ to $20.0^{\circ} \mathrm{C}$ mimicking the house energy rating protocol requirements of a living room (ABCB 2006b). 


\subsubsection{Thermal Performance Test Cell Data}

The data acquisition process required several steps and was further developed during the research to improve data management. The management of the data included the development and implementation of systems for the:

- Data loggers

- Download methods

- Research Centre data storage

- Data cleaning and averaging

\section{Data Logger Data Acquisition}

The DT500 data logger had an on-board memory capacity which could store between two and three weeks of data, depending on the data being collected. This was the first method used for initial data collection from the environmental measuring devices. The test cell room was accessed at fortnightly intervals to download the data from the data logger. The data was saved in two formats to reduce the risk of data being amended during the research process. The data was saved in a native format of the data logger and as a comma separated file. To open the data logger native format file required the renaming of the file. This method ensured data integrity. During the data cleaning process the reference file was always the data logger native format file.

After a series of data losses due to unannounced or unexpected electricity supply disruptions at the University, static memory cards were purchased and added to the data loggers. This method of data storage involved the data logger saving recorded environmental information directly to the static memory card. Even if the logger had a total failure or there was an extended power outage, the data on the static memory card was retained. The static memory card was able to store nearly six weeks of logging data. The static memory capacity had some positive attributes, as it reduced the need to access the test cell room to download data but it also increased the amount of faulty data. The fortnightly download of data allowed for a quick scan of the downloaded data, which made the researcher aware of any environmental 
measuring devices which were not functioning correctly. A better method was still required to both store data and to recognise faults promptly.

As the research progressed the DT80 data logger was acquired and installed on site. The installation of the DT80 data logger established a new paradigm for data collection and storage (Figure 4.102). Initially the programming of the DT80 data logger allowed for the data from all three thermal performance test cells to be collated on a single data logger. Only one test cell required access to download the data. This improved test cell operation but once again did not provide an adequate means for the researcher to be aware of environmental measurement faults, until some time after the fault commenced. Once the local area network infrastructure was established between the thermal performance test cells and the Newnham campus and the wide area network infrastructure was established between the Newnham and Inveresk campuses automated downloading of data was established. The data storage process, as discussed below, required the acquisition of a suitable server. The server was installed with appropriate software and programming to enable the server to communicate directly with the DT80 data logger. Once this link was established, data from the test cells was automatically downloaded to the offsite server every ten minutes. The download program was further amended to automatically check data and raise an alarm when measuring devices provided data out of expected ranges, or when there was too dramatic a step between ten minute readings.

Table 4.14: Data Storage Methods

\begin{tabular}{|l|l|l|}
\hline \multicolumn{1}{|c|}{ Data Storage Method } & \multicolumn{1}{c|}{ Collection Period } & \multicolumn{1}{c|}{ Data Storage Capacity } \\
\hline Data Logger 'on board' memory & Maximum of every ten minutes & 2-3 weeks data \\
\hline Data Logger with Static memory card & Maximum of every ten minutes & Up to 6 weeks data \\
\hline DT80 Data Logger: Stage 1 & $\begin{array}{l}\text { Copied from DT500 data loggers } \\
\text { every ten minutes }\end{array}$ & Up to 8 weeks data \\
\hline DT80 Data Logger: Stage 2 & $\begin{array}{l}\text { Copied from DT500 data loggers } \\
\text { every ten minutes } \\
\text { Transmitted to Research Centre } \\
\text { Server every ten minutes }\end{array}$ & $\begin{array}{l}\text { Unlimited (server dependent) } \\
\text { Back up of up to 6 weeks of data } \\
\text { still stored on static memory card }\end{array}$ \\
\hline
\end{tabular}

To create a secure environment for data storage, the new server which stored the downloaded data was password protected to limit access. The programming was further developed such that the downloaded data was placed in one file and a second mirror file was created which research staff could use to access and analyse data. 


\section{Data Storage}

The management and storage of data collected from the thermal performance test cells was an integral part of the research program. There were three thermal performance test cells and for the first twelve months of the research there were two data loggers per building. As the quantity of files increased and the dedicated server was acquired, new systems were put in place.

During the first stages of the research prior to the DT80 data logger being installed, all data was downloaded by the researcher. A simple naming convention was placed on all files which consisted of date and building descriptors:

- 2006-08-23TC1A: date of data download was the $23^{\text {rd }}$ of August 2006 and the data came from data logger A from test cell 1

- To simplify documentation the northern most thermal performance test cell, unenclosed-perimeter platform-floored test cell, was named Test Cell 1. As the site was a north-south layout, the enclosed-perimeter platform-floored test cell was named Test Cell 2 and the concrete slab-on-ground floored test cell was named test cell 3.

Each download was completed in the native format of the data logger and in comma separated files. All files were kept on the researcher's computer with a backup copy located on a computer within the research centre and a second backup copy on an offsite computer. The tripling of copies of the data was a result of the experiences of the researcher, where personal computers became faulty and requiring replacement and the research centres server failed on several occasions resulting in the loss of data.

Towards the end of 2007, all the individual fortnightly downloaded comma separated files were combined into annual and thermal performance test cell specific single spreadsheet files. By this time the arrival and installation of the new server was imminent and the server was to include database software. By combining the files into single annual files stretched the capabilities if the spreadsheet program to its limits with files 52,560 rows and up to 60 columns of data but it allowed for a simple migration to data base tables. When the server was installed an automated back up to an offsite server was put in place to reduce the chances of 
data loss. A few months after the server was installed, there was a major computer failure within the research centre but a full copy of the data was retrieved from the off site back up.

When the DT80 data logger and server connectivity was completed, a self appending table was developed with the server. There was a separate table for each data logger and the data within the table was configured to a new table per calendar year.

\section{Data Cleaning}

The planning of methods and processes required for the cleaning of thermal performance test cell data commenced in mid 2007. An assessment of data quantities, computer hardware requirements, database software requirements and methods of cleaning the data were investigated.

The quantity of data that was collected was large and was increasing in volume with each 10 minute download. The data was simple in form. The combining of thermal performance test cell data into annualised spreadsheets created files in excess of fifty megabytes in size. This most basic form of the data required three hundred megabytes of data storage capacity before any data cleaning could commence. The server which was acquired had a hard disk greater than one terabyte in size.

Two principal forms of software were required for the server. The first was the software required to enable the automated downloading of data from the DT80 data logger located with the thermal performance test cells. The software for this purpose was governed by the type of data loggers in use and was provided by the manufacturer of the DT80 data logger. The second software which was required was a suitable database software. A brief of preferred capabilities of the database software was developed and after an analysis of current database software in 2007, the MYSQL form of database was acquired. Once the new database software was installed, templates for tables within the database were created. Each table was for a separate data logger and tables relative to a particular thermal performance test cell were linked together. The spreadsheet data was then imported into table templates. The relevant data for the empirical validation process was now all located within a few files and in a form ready for data cleaning. 
In consultation with CSIRO scientists, a data cleaning procedure was developed for the test cell data. Table 4.15 below details the step by step process undertaken to clean the test cell and site weather station data. A more detailed description of the data cleaning process is located in Appendix 4. Throughout the process a new version of the database was created with the completion of each step. This enabled a history of the data cleaning process to be kept for future reference. Based on this method, Version 1 of the database was the original raw data and Version 10 was the final data set for empirical validation purposes. Throughout this process the researcher performed none of the data checking, to avoid personal biases, based on previous building science experience. The researcher did analyse all errors raised by the data checking staff and made amendments to data when required, in co-operation with the information technology staff. For most measurement locations, the data checking involved the cross-comparison of data from a nearby similar device and/or data from the site weather station.

As the data cleaning progressed, data from key test cell measuring devices was separated from the overall data. Much of the data within the database was supporting data to be used to better understand the test cell physical thermal activity when dramatic variations in the AccuRate predictions were encountered. The key data points which were extracted to form the final empirical validation data set were:

- Centre of roof space dry bulb air temperature

- $\quad 1800 \mathrm{~mm}$ centre of test cell room dry bulb air temperature

- $\quad 1200 \mathrm{~mm}$ centre of test cell room dry bulb air temperature

- $\quad 1200 \mathrm{~mm}$ centre of test cell room mean radiant temperature

- $600 \mathrm{~mm}$ centre of test cell room dry bulb air temperature

- mid subfloor dry bulb air temperature (unenclosed and enclosed-perimeter platformfloored test cells)

- Site weather station environmental measurements 
Table 4.15: Data Cleaning Method

\begin{tabular}{|c|c|c|}
\hline Stage & Title & Description \\
\hline 1 & 10 Minute Data Range Check & $\begin{array}{l}\text { Each environmental measuring device was allocated an expected } \\
\text { range of measurement. All data for each device was checked to ensure } \\
\text { it was within the expected range. }\end{array}$ \\
\hline 2 & $\begin{array}{l}10 \text { Minute Data Null Value } \\
\text { Check }\end{array}$ & $\begin{array}{l}\text { All data was analysed to ascertain periods with missing data or } \\
\text { corrupted data. All values for these periods were converted to a null } \\
\text { value. }\end{array}$ \\
\hline 3 & $\begin{array}{l}10 \text { Minute Data Step Value } \\
\text { Check }\end{array}$ & $\begin{array}{l}\text { Each environmental measuring device was allocated a step value, } \\
\text { which was an estimate of the expected change in measurement } \\
\text { between each ten minute reading. All data for each device was } \\
\text { checked, to ensure that the data did not have steps in value greater } \\
\text { than those defined. }\end{array}$ \\
\hline 4 & $\begin{array}{l}\text { Modification of Test Cell Data } \\
\text { Based on Test Cell Log Book } \\
\text { Entries }\end{array}$ & $\begin{array}{l}\text { The log books of the thermal performance test cells were analysed and } \\
\text { an additional notes column was added to the test cell database tables. } \\
\text { If there was activity within a thermal performance test cell, which would } \\
\text { affect the free-running nature of the data, the data was modified to a } \\
\text { null value. }\end{array}$ \\
\hline 5 & $\begin{array}{l}10 \text { Minute Data Graphical } \\
\text { Analysis }\end{array}$ & $\begin{array}{l}\text { A final checking process for the ten minute data was the use of } \\
\text { graphing software, which converted the data into graphical form. This } \\
\text { analysis allowed for the researchers to notice any phase shift or other } \\
\text { anomalies in the pattern of the data. }\end{array}$ \\
\hline 5 & $\begin{array}{l}\text { Averaging } 10 \text { Minute Data into } \\
\text { Average Hourly format }\end{array}$ & $\begin{array}{l}\text { The data from the } 40 \text { minute, } 50 \text { minute, } 0 \text { minute, } 10 \text { minute, } 20 \\
\text { minute and } 30 \text { minute readings were averaged to establish a new } \\
\text { average hourly value. The only exception to this method was the wind } \\
\text { direction which used a mix of mode, mean and wind speed to establish } \\
\text { an average hourly wind direction value. }\end{array}$ \\
\hline 6 & $\begin{array}{l}\text { Average Hourly Data Range } \\
\text { Check }\end{array}$ & $\begin{array}{l}\text { Each environmental measuring device was allocated with an expected } \\
\text { range of measurement. All data for each device was checked to ensure } \\
\text { it was within the expected range. }\end{array}$ \\
\hline 7 & $\begin{array}{l}\text { Average Hourly Data Step } \\
\text { Value Check }\end{array}$ & $\begin{array}{l}\text { Each environmental measuring device was allocated with a step value, } \\
\text { which was an estimate of the expected change in measurement } \\
\text { between each average hourly data value. All data for each device was } \\
\text { checked to ensure that the data did not have steps in value greater } \\
\text { than those defined. }\end{array}$ \\
\hline 8 & $\begin{array}{l}\text { Average Hourly Graphical } \\
\text { Analysis }\end{array}$ & $\begin{array}{l}\text { A final checking process for the average hourly data was the use of } \\
\text { graphing software which converted the data into graphical form. This } \\
\text { analysis allowed for the researchers to notice any phase shift or other } \\
\text { anomalies in the pattern of the data. }\end{array}$ \\
\hline 9 & Test Cell Notes Cross Check & $\begin{array}{l}\text { A final cross check of the thermal performance test cell log book entries } \\
\text { was undertaken, to ensure that no data which would be affected by test } \\
\text { cell access had a value within the final data set. }\end{array}$ \\
\hline
\end{tabular}

\subsubsection{Empirical Data Summary}

The primary objective of the environmental measurement process was to provide an adequate empirical data set of site-measured data for the empirical validation of the house energy rating software AccuRate. To achieve this objective, detailed internal and external environmental measurement of the thermal performance test cells and the test cells site were taken. The data collected required appropriate levels of cleaning to ensure its suitability for the empirical validation process. 
The entire environmental measurement stage commenced with system design in June 2006 and the data cleaning was completed in December 2008. Further analysis of the site-measured environmental data identified anomalies which occurred in late June of 2007. With these items in mind and the required integrity of the data set for empirical validation, the final data consisted of relevant site and thermal performance test cell environmental measurements from January 1 to June 23, 2007.

This stage of the research collected the critical empirical measurements to allow for the comparison between empirical and simulated data. The next section (4.4) discusses the detailed simulation of the test cells using the AccuRate HER software, which provided the simulation data sets. Section 4.5, then discusses methods that were explored to compare and analyse the two data sets. 


\subsection{Detailed Thermal Simulation by AccuRate}

\subsubsection{Introduction}

The observed temperatures from the zones of the thermal performance test cells provided the empirical data for the validation process. The building thermal simulation data set was produced by the AccuRate software. The standard house energy rating simulation with the AccuRate software was not suitable for empirical validation purposes. A more detailed thermal simulation was required to produce a suitable data set for empirical validation purposes (AccuRate 2007; Dewsbury 2009; DewsburySoriano et al. 2009; LomasEppel et al. 1994; Stazi et al. 2007; Torcellini et al. 2005b). This chapter discusses the steps taken to complete the detailed thermal simulation of the test cells.

The AccuRate house energy rating software included a range of simplified input parameters, default values and assumptions which are used in a standard house energy rating simulation (Delsante 1996; Soebarto \& Williamson 2001). Variables that could have a significant impact on the simulation were modified and prior to empirical validation, other national and international research projects were examined (Allen et al. 1985; Bannister 2009). This examination revealed significant differences in approach and at times, a misunderstanding of the type of validation undertaken. In this research the thermal simulation using the AccuRate house energy rating software had three key components:

- A detailed knowledge of the materials and construction of the test cells

- The application of this detailed knowledge in the AccuRate simulation

- A correctly formatted climate file which comprised site-observed data, which was synchronised with the building environmental measurements.

The initial AccuRate simulation was completed in December 2008. The process was a cooperative effort between the University of Tasmania and the CSIRO AccuRate software developers. From this initial simulation model several improvements were made to the input variables, throughout 2009 and 2010. During this process the thermal modelling of the test cells was revised and improved. 


\subsubsection{Objectives of the AccuRate Detailed Thermal Simulation}

The empirical validation process required the production of suitable data sets for comparison of simulated and observed temperatures. The simulated data set was produced by the AccuRate HER software, in the form of an output text file detailing an hour by hour temperature for each zone of the test cell for a period of one year. Within the framework of this study, the primary objective of the detailed thermal simulation was to provide an informed AccuRate output temperature data set suitable for empirical validation.

The AccuRate software includes many default values to make standard house energy ratings simple and quick to undertake (ABSA 2005). However previous research has shown significant variance in simulation results and to achieve an informed output temperature data set, a number of default parameters required amendment (Guyon, G 1997). This required an understanding of the data input parameters to the AccuRate software and the impacts they have on the thermal simulation process. This established a second tier of objectives, as follows:

- Determine 'as built' values for roof, ceiling, wall and floor assemblages to modify fabric thermal properties

- Determine 'as built' values for shading elements that would affect fabric thermal performance

- Obtain observed data for site shading elements

- Determine appliance-generated heat loads that occurred within the test cells

- Determine infiltration values for each zone of the test cells

- Modify thermostat settings within the software to recognise the free-running operation of the thermal performance test cells

- Acquire synchronised site-measured climate data for use in the AccuRate simulation

Only when each of these values was established for each test cell, was there confidence that the output simulation temperature data from the AccuRate software would correctly reflect 
the building being modelled (Allen et al. 1985; Lomas 1991a; LomasEppel et al. 1994; Raftery, Keane \& Costa 2009; Stazi et al. 2007). Through this process, four distinctly different detailed thermal simulations, as shown in Figure 4.1, were completed for each thermal performance test cell, which is best illustrated by Figure 4.106.

\begin{tabular}{|c|c|c|c|}
\hline & \multicolumn{2}{|c|}{ Test Cell Built Fabric } \\
\hline & & Default Built Fabric & As-Built Fabric \\
\hline \multirow{2}{*}{ 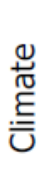 } & Default Climate File & $\begin{array}{l}\text { Default fabric / Default climate } \\
\text { (A standard house energy rating) }\end{array}$ & $\begin{array}{l}\text { As-built fabric / Default climate } \\
\text { (Mixed Inputs) }\end{array}$ \\
\hline & Site Observed Climate File & $\begin{array}{l}\text { Default fabric / Measured climate } \\
\text { (Mixed Inputs) }\end{array}$ & $\begin{array}{l}\text { As-built fabric / Measured climate } \\
\text { (Empirical Validation Simulation) }\end{array}$ \\
\hline
\end{tabular}

Figure 4.106 - AccuRate Detailed Simulation Matrix

Each type required different levels of improved data inputs for the simulation. The final version, (the As-Built / Measured Climate version) was used for the empirical validation process (Dewsbury 2009). The four AccuRate simulation types are referred to as:

- Default Fabric / Default Climate: This AccuRate simulation utilised the default values for built fabric and climate. This type of thermal simulation was the standard method used by house energy rating assessors and some past validation research exercises.

- Default Fabric / Measured Climate: This AccuRate simulation utilised the default values for built fabric but the site-observed climate data were used to create an empirical validation climate file.

- As-Built / Default Climate: This AccuRate simulation utilised an intricate assessment of the 'as-built' materials and systems, by which modifications to the default values within the AccuRate software were made. Default values for climate were used. This type of thermal simulation has been used for some past validation research exercises.

- As-Built / Measured Climate: This AccuRate simulation utilised an intricate assessment of the 'as-built' materials and systems, by which modifications to the default values within the AccuRate software were made. The site-observed climate data were used to create an empirical validation climate file. This method of building thermal simulation had been used for some past validation research activities 
(Torcellini et al. 2005a). This was the only method suitable for providing the resultant AccuRate simulation data set for comparison to the measured building thermal performance for empirical validation (Delsante 2005c; Lomas 1991a).

\subsubsection{The AccuRate House Energy Rating Software}

The AccuRate software was developed over many years within the CSIRO in Australia. A brief history of the development of AccuRate is discussed in section Chapter 3. The National House Energy Rating Scheme within Australia prescribes the requirements of HER software for Australia. NatHERS was an initiative of the Ministerial Council on Energy to develop potential energy saving measures in new Australian homes (Delsante 2005a; Drogemuller et al. 1999; Thwaites 1995). The AccuRate software was considered to be the most comprehensive of the approved second generation softwares (Isaacs, T 2005).

The AccuRate HER software requires building specific, (including a range of default), usermodifiable and non-standard modifications (NatHERS 2000, 2007). The AccuRate outputs are a mix of text and data files, which cannot be modified by the user.

The standard user-type modified inputs comprised:

- The input of a postcode which defined the climate file the software used for the thermal simulation

- The definition of roof, ceiling, wall, floor, door and window construction elements

- The definition of the zone types for all volumes within the built fabric

- The definition of external shading features

- The detailed definition of built elements and their relationships

- A general orientation of the building for infiltration calculations

In this study the non-standard modified inputs were: 
- The modification of fabric assemblages to account for framing factors

- The modification of sensible internal heat gains to account for free-running operation

- The modification of latent internal heat gains to account for free-running operation

- The modification of heating thermostat controls to account for free-running operation

- The modification of cooling thermostat controls to account for free-running operation

- The modification of infiltration values from default to observed values

- The development and use of a site observed climate file.

Once all the appropriate standard and non-standard input values were suitably modified for each thermal performance test cell, the AccuRate thermal simulation was completed. The output files included the resultant energy use and temperature by zone. The energy use by zone provided a final checking mechanism to ensure that the simulation inputs were appropriately configured for free-running operation. The resultant simulation temperature file was used for the empirical validation.

\subsubsection{AccuRate - Standard Inputs}

To validate empirically and to enable ongoing calibration to the AccuRate software required the elimination of programming or input variable simplifications and speculation, which affect the underlying physics of the building thermal simulation (Agami Reddy 2006; Ahmad, M \& Culp 2006; Bannister 2009; Clarke 2001; Donn 2001; Sullivan \& Winkelmann 1998). Previous research has documented extensive scattering of resultant data when input errors relating to fabric variations occurred (Diamond, Cappiello \& Hunn 1985; Guyon, G 1997). This required a detailed analysis of the built fabric, which enabled informed data entry modifications. The four iterations of the AccuRate model, which were developed for each of the three thermal performance test cells, were: Default Fabric / Default Climate; Default Fabric / Measured Climate; As-Built Fabric / Default Climate; and As-Built Fabric / Measured Climate modes of simulation. Each of the iterations required a greater depth of and 
modification to AccuRate data entry inputs for test cell operation, building fabric and climate data. These are discussed in Table 4.16 for the four types of AccuRate simulation undertaken.

Prior to the data entry, a critical analysis of the built fabric and nearby elements was completed for each of the thermal performance test cells. The required inputs for the empirical validation process were standard and improved front end user interface data entry and modifications to the software's 'Scratch' file. The software generated a 'scratch' file when the front end user interface data entry was completed and the 'check' button was selected. When the inputs match defined parameters for the house energy rating, the software produces a scratch file, which is used by the simulation engine to calculate house energy use, for heating and cooling. The front end user interface input modifications were performed in the same order as a standard HER process occurs. The modifications which required direct data entry within the AccuRate Scratch file were completed after the scratch file was automatically created. Each test cell had a default and As-built scratch file. This method allowed for a logical approach to what became a very complex exercise.

Table 4.16: Default Fabric / Default Climate, Default Fabric / Measured Climate, As-Built Fabric / Default Climate, As-Built Fabric / Measured Climate data entry iterations

\begin{tabular}{|c|c|c|c|}
\hline Iteration & $\begin{array}{c}\text { AccuRate Front End } \\
\text { Data Entry }\end{array}$ & Scratch File Modifications & $\begin{array}{l}\text { Default or Actual } \\
\text { Climate Data }\end{array}$ \\
\hline $\begin{array}{l}\text { Default Fabric / } \\
\text { Default Climate }\end{array}$ & $\begin{array}{l}\text { Standard data entry } \\
\text { based on plans }\end{array}$ & $\begin{array}{l}\text { thermostat, heating and } \\
\text { cooling parameters }\end{array}$ & Default climate file \\
\hline $\begin{array}{l}\text { Default Fabric / } \\
\text { Measured Climate }\end{array}$ & $\begin{array}{l}\text { Standard data entry } \\
\text { based on plans }\end{array}$ & $\begin{array}{l}\text { thermostat, heating and } \\
\text { cooling parameters }\end{array}$ & $\begin{array}{l}\text { Observed climate } \\
\text { data }\end{array}$ \\
\hline $\begin{array}{l}\text { As-Built Fabric / } \\
\text { Default Climate }\end{array}$ & $\begin{array}{l}\text { Modified conductivity } \\
\text { values based on as-built } \\
\text { analysis }\end{array}$ & $\begin{array}{l}\text { thermostat, heating, } \\
\text { cooling, internal energy } \\
\text { loads and infiltration } \\
\text { parameters }\end{array}$ & Default climate file \\
\hline $\begin{array}{l}\text { As-Built / } \\
\text { Measured Climate }\end{array}$ & $\begin{array}{l}\text { Modified conductivity } \\
\text { values based on as-built } \\
\text { analysis }\end{array}$ & $\begin{array}{l}\text { thermostat, heating, } \\
\text { cooling, internal energy } \\
\text { loads and infiltration } \\
\text { parameters }\end{array}$ & $\begin{array}{l}\text { Observed climate } \\
\text { data }\end{array}$ \\
\hline
\end{tabular}

Each of the methods and processes involved in the data entry of the variables is discussed below. The order of the discussion follows the order of data entry within the AccuRate software and includes: project data, constructions, zones, shading, elements and ventilation. More detailed tables showing data entry values and AccuRate scratch files are located in Appendix 5. 


\section{Project Data: Postcode \& Exposure}

When a new file was commenced for each thermal performance test cell, the first screen requested details which located the building within Australia and other general text descriptors for the project. In this study, the postcode for Launceston was entered and this automatically assigned the Launceston climate file to the simulations. The use of the observed climate file is discussed later. The other two key data inputs for this tab were the exposure and ground reflectance values.

The software defined exposure as:

“Exposed: Flat open country with few or no trees or buildings (this should rarely occur)

Open: Normal countryside with some trees and scattered buildings

Suburban: Low-rise built-up areas in the suburbs of towns and cities

Protected: High-density inner city or CBD, with tall buildings nearby”

(AccuRate 2007)

In consultation with CSIRO researchers, the selected exposure for the thermal performance test cells was 'open'.

The software defined ground reflectance as:

"The proportion of solar radiation that is reflected by the ground immediately adjacent to the building"

(AccuRate 2007)

The default value within the AccuRate software is 0.2 , which corresponds to a grassed surface. As the thermal performance test cells were located within a grassed area, the default value of 0.2 for ground reflectance was chosen. Table 4.17 details the values entered for each thermal performance test cell for this tab and Table 4.18 details the variations in data entered based on the AccuRate simulation iteration. 
Table 4.17: Project Data - Data entry for thermal performance test cells

\begin{tabular}{|l|c|c|c|c|c|}
\hline & Name & $\begin{array}{c}\text { Post } \\
\text { Code }\end{array}$ & $\begin{array}{c}\text { Climate } \\
\text { Zone }\end{array}$ & Exposure & $\begin{array}{c}\text { Ground } \\
\text { Reflectance }\end{array}$ \\
\hline Unenclosed-perimeter platform-floored test cell & Test Cell 1 & 7250 & 23 & Open & 0.2 \\
\hline Enclosed-perimeter platform-floored test cell & Test cell 2 & 7250 & 23 & Open & 0.2 \\
\hline Concrete slab-on-ground floored test cell & Test Cell 3 & 7250 & 23 & Open & 0.2 \\
\hline
\end{tabular}

Table 4.18: Project Data - Iteration variations for data entry

\begin{tabular}{|l|c|c|c|c|}
\hline \multicolumn{1}{|c|}{ Iteration } & $\begin{array}{c}\text { Default fabric / } \\
\text { default climate }\end{array}$ & $\begin{array}{c}\text { Default fabric / } \\
\text { Measured climate }\end{array}$ & $\begin{array}{c}\text { As Built fabric / } \\
\text { Default climate }\end{array}$ & $\begin{array}{c}\text { As Built fabric / } \\
\text { Measured climate }\end{array}$ \\
\hline Post Code & 7250 & 7250 & 7250 & 7250 \\
\hline Climate Zone & 23 (Default file) & $\begin{array}{c}23 \text { (Observed climate } \\
\text { data) }\end{array}$ & 23 (Default file) & $\begin{array}{c}23 \text { (Observed climate } \\
\text { data) }\end{array}$ \\
\hline Exposure & Open & Open & Open & Open \\
\hline Ground Reflectance & 0.2 & 0.2 & 0.2 & 0.2 \\
\hline
\end{tabular}

\section{Construction Information}

The second data entry tab in the software was constructions, where the data entry of all built fabric elements was entered. The fabric elements of the thermal performance test cells were: external walls, doors, floors, ceilings and roofs. All of the fabric elements required the selection of materials from the inbuilt materials library to create an assemblage which corresponded to the designed or as-built fabric matrixes. Once an assemblage was defined, the internal and external surface colours and solar absorptance values were selected. These values were selected jointly with CSIRO researchers. Table 4.19 details the variations in the construction data which allowed for each of the four simulation iterations.

Table 4.19: Construction Data - Iteration variations for data entry

\begin{tabular}{|l|l|l|}
\hline \multicolumn{1}{|c|}{ Iteration } & \multicolumn{1}{|c|}{ Default Built Fabric } & \multicolumn{1}{c|}{ As Built Fabric } \\
\hline External Walls & $\begin{array}{l}\text { Application of AccuRate } \\
\text { pre-determined values }\end{array}$ & $\begin{array}{l}\text { Modified values based on } \\
\text { analysis of test cell as built }\end{array}$ \\
\hline Windows & nil & Nil \\
\hline Doors & $\begin{array}{l}\text { Application of AccuRate } \\
\text { pre-determined values }\end{array}$ & $\begin{array}{l}\text { Modified values based on } \\
\text { analysis of test cell as built }\end{array}$ \\
\hline Floor & $\begin{array}{l}\text { Application of AccuRate } \\
\text { pre-determined values }\end{array}$ & $\begin{array}{l}\text { Modified values based on } \\
\text { analysis of test cell as built }\end{array}$ \\
\hline Ceiling & $\begin{array}{l}\text { Application of AccuRate } \\
\text { pre-determined values }\end{array}$ & $\begin{array}{l}\text { Modified values based on } \\
\text { analysis of test cell as built }\end{array}$ \\
\hline Internal Wall & nil & nil \\
\hline Roof & $\begin{array}{l}\text { Application of AccuRate } \\
\text { pre-determined values }\end{array}$ & $\begin{array}{l}\text { Modified values based on } \\
\text { analysis of test cell as built }\end{array}$ \\
\hline Skylight \& Roof Window & nil & nil \\
\hline
\end{tabular}




\section{Zone Types}

The zone types tab is where the zone definitions for all volumes within the thermal performance test cells were entered. The data entry in this tab comprised: the name of the zone, the type of zone, its volume, floor height and ceiling height. The selected zone type set the heating and cooling parameters (Table 4.20), and additional zone specific ventilation profiles. For the test cell with an enclosed subfloor, the cross sectional area in square millimetres of ventilation was nominated. For a living room, the chimney, down-light and other forms of infiltration and ventilation would normally be selected (AccuRate 2007).

Table 4.20: Zone types and definitions (AccuRate V1.1.4.1)

\begin{tabular}{|c|c|c|c|}
\hline Zone type & Assumptions and comments & Input Variables & Infiltration variables \\
\hline Living & $\begin{array}{l}\text { Conditioned from } 0700-2400 \\
\text { Daytime occupancy } \\
\text { No cooking heat gains }\end{array}$ & \multirow{3}{*}{$\begin{array}{l}\text { Volume } \\
\text { Floor height } \\
\text { Ceiling height }\end{array}$} & \multirow{6}{*}{$\begin{array}{l}\text { Chimney vents } \\
\text { Wall vents } \\
\text { Ceiling vents } \\
\text { Exhaust fans } \\
\text { Vented down lights } \\
\text { Un-flued gas heaters } \\
\text { Ceiling fans }\end{array}$} \\
\hline Bedroom & $\begin{array}{l}\text { Conditioned from } 1600-0900 \\
\text { Night-time occupancy }\end{array}$ & & \\
\hline Living/Kitchen & $\begin{array}{l}\text { Conditioned from } 0700-2400 \\
\text { Daytime occupancy } \\
\text { Cooking heat gains included }\end{array}$ & & \\
\hline Other (daytime usage) & $\begin{array}{l}\text { If heated and/or cooled, } \\
\text { conditioned from } 0700-2400 \\
\text { No occupancy heat gains }\end{array}$ & \multirow{3}{*}{$\begin{array}{l}\text { Volume } \\
\text { Floor height } \\
\text { Ceiling height } \\
\text { Heating } \\
\text { Cooling }\end{array}$} & \\
\hline Other (night-time usage) & $\begin{array}{l}\text { If heated and/or cooled, } \\
\text { conditioned from } 1600-0900 \\
\text { No occupancy heat gains }\end{array}$ & & \\
\hline Garage & $\begin{array}{l}\text { If heated and/or cooled, } \\
\text { conditioned from } 0700-2400 \\
\text { No occupancy heat gains }\end{array}$ & & \\
\hline Roof Space & $\begin{array}{l}\text { Invokes special roof space } \\
\text { model. }\end{array}$ & Volume & $\begin{array}{l}\text { Roof space sarking } \\
\text { Roofing material type } \\
\text { Roof space vents }\end{array}$ \\
\hline Subfloor & $\begin{array}{l}\text { Invokes special subfloor space } \\
\text { model }\end{array}$ & $\begin{array}{l}\text { Volume } \\
\text { Floor height } \\
\text { Ceiling height }\end{array}$ & $\begin{array}{l}\text { Open or enclosed } \\
\text { subfloor } \\
\text { Area of subfloor vents } \\
\text { for enclosed subfloors }\end{array}$ \\
\hline
\end{tabular}

The zone types used for the empirical validation of AccuRate are shown in Table 4.21. The selection of the 'Other (daytime usage)' zone type for the test cell room allows for scratch file modification of standard inputs for a heated and cooled room. The roof space selection included the selection of the sarked, sheet metal roof and no roof space vent options. Once the scratch file was produced with the default values, amendments could be made for the 'asbuilt' configurations. 
Table 4.21: Zone types chosen for thermal performance test cells

\begin{tabular}{|l|l|l|l|}
\hline \multicolumn{1}{|c|}{ Zone type } & \multicolumn{1}{|c|}{$\begin{array}{c}\text { Unenclosed-perimeter } \\
\text { Platform Floored }\end{array}$} & \multicolumn{1}{|c|}{$\begin{array}{c}\text { Enclosed-perimeter } \\
\text { Platform Floored }\end{array}$} & $\begin{array}{c}\text { Concrete Slab-on-ground } \\
\text { Floored }\end{array}$ \\
\hline Roof Space & Roof Space & Roof Space & Roof Space \\
\hline Test Cell Room & Other (daytime usage) & Other (daytime usage) & Other (daytime usage) \\
\hline Subfloor & Not applicable & Subfloor (enclosed) & Not applicable \\
\hline
\end{tabular}

\section{Shading Features}

All external shading features which shaded the external walls of the thermal performance test cells were defined within this tab. When the shading feature was input, it was then linked to an external wall within the 'built elements' tab of the software. Common shading features are eaves and pergolas. If the shading feature had a different height or depth for differing walls, the elements were input as a different shading feature for different walls.

The thermal performance test cells had several elements which shaded the walls: the eaves of the test cells, nearby trees and buildings. In discussions with CSIRO researchers about how the AccuRate engine operates, it was decided that the eaves would have their values input in this tab. The nearby trees and buildings would be input as independent shading devices within the 'built elements' tab. As the three thermal performance test cells had identical framing but differing wall fabric, there were two types of eave definitions established as shown in Table 4.22. Site measurements after construction was completed confirmed that the designed eave width matched the as-built eave width. The shading value included eaves and gutters. It has been found in many instances that the gutter is not included in the depth of the shading element (HER Users 2005-2011).

Table 4.22: Eave width calculations for thermal performance test cells

\begin{tabular}{|l|l|l|l|}
\hline \multicolumn{1}{|c|}{ Test Cell } & \multicolumn{1}{|c|}{$\begin{array}{c}\text { Fabric Unenclosed- } \\
\text { perimeter Platform Floored }\end{array}$} & $\begin{array}{c}\text { Enclosed-perimeter Platform- } \\
\text { floored }\end{array}$ & \multicolumn{1}{c|}{$\begin{array}{c}\text { Concrete Slab-on-ground } \\
\text { Floored }\end{array}$} \\
\hline \multirow{4}{*}{ Wall System } & Plywood Veneer Wall: & Brick Veneer Wall: & Brick Veneer Wall: \\
& $-12 \mathrm{~mm}$ Plywood & $-110 \mathrm{~mm}$ clay brick & - 110mm clay brick \\
& - Air gap vertical $21 \mathrm{~mm}$ & - Air gap vertical $50 \mathrm{~mm}$ & $\begin{array}{l}\text { - Air gap vertical } 50 \mathrm{~mm} \\
\text { - 90 Frame }\end{array}$ \\
& -90 Frame & -90 Frame & - Plasterboard 10mm \\
\hline Wall Width & - Plasterboard 10mm & - Plasterboard 10mm & $260 \mathrm{~mm}$ \\
\hline Eave Elements & Eave, Barge Board \& Gutter & Eave, Barge Board \& Gutter & Eave, Barge Board \& Gutter \\
\hline Eave Width & $710 \mathrm{~mm}$ & $580 \mathrm{~mm}$ & $580 \mathrm{~mm}$ \\
\hline
\end{tabular}




\section{Built Elements}

The input of data into the built elements tab was the most complex stage of the data entry process. This stage of the data entry created material linkages and relationships that developed the three dimensional object for the thermal simulation. Each of the zones defined within the 'zones' tab were enclosed with elements that were chosen from a list of built systems which had been defined in the 'construction information' tab. The perimeter elements of a zone were: the ground, floor, wall, ceiling or roof. The width, height and area of each plane were defined. For external walls, the azimuth was also defined for solar and wind calculations. Once the perimeter was defined, other elements within the plane were defined and for the thermal performance test cells, this included the access door located in the southern wall. To further define the impact the external environment would have on the perimeter, a range of elements, which included fixed shading and external screens were identified.

As mentioned above in external shading features, the nearby trees and buildings were to be modelled as external screens within the built elements tab. When an external screen feature is applied to a wall, the entire wall is shaded by the element depending on altitude and azimuth of the sun (NatHERS 2007). The data entry process for external screens allowed for the shading object to be defined individually for each external wall plane. The distance from horizontal offset, height and opacity of the object was defined for each month and wall. Each wall could have up to three external screens, and the number used varied from wall to wall. For a solid building or evergreen tree, $100 \%$ opacity was selected, whilst for a deciduous tree the shading percentage was modified to follow seasonal trends.

The data entry for external doors allowed for the definition of air gaps around the door which would impact on infiltration. The options available are large, medium and small which correspond to a credit card gap, paper gap or very tight fitting door (AccuRate 2007; Clarke 2001; Delsante 2006b). For the thermal performance test cells, the small option was chosen because the full perimeter of the door was weather stripped. This is an interesting definition, as many houses examined had a much wider than credit card gap on the top and sides of the door, and up to a $25 \mathrm{~mm}$ gap at the bottom of the door. 
Items that were applicable for the three thermal performance test cells are defined in Table 4.23, Table 4.24 and Table 4.25. A detailed listing of all values for each of the thermal performance test cells is located in the Appendix.

Table 4.23: Built elements' data input requirements for each zone in the Unenclosed-perimeter Test Cell

\begin{tabular}{|l|l|}
\hline \multicolumn{1}{|c|}{ Zone } & \multicolumn{1}{|c|}{ Applicable Data Input Requirements } \\
\hline Subfloor & Floor (ground) \\
& Ceiling (test cell floor) \\
\hline Test Cell Room & External Walls \\
& External Wall Fixed Shading (eaves) \\
& External Screens (nearby buildings \& trees) \\
& Floor \\
& Ceiling \\
& Doors in Walls (access door) \\
\hline Roof Space & $\begin{array}{l}\text { Floor (test cell ceiling) } \\
\text { Roof }\end{array}$ \\
\hline
\end{tabular}

Table 4.24: Built elements' data input requirements for each zone in the Enclosed-perimeter Test Cell

\begin{tabular}{|l|l|}
\hline \multicolumn{1}{|c|}{ Zone } & \multicolumn{1}{|c|}{ Applicable Data Input Requirements } \\
\hline Subfloor & External Wall \\
& External Wall Fixed Shading (eaves) \\
& External Screens (nearby buildings \& trees) \\
& Floor (ground) \\
& Ceiling (test cell floor) \\
& Doors in Walls (access door in northern wall) \\
\hline Test Cell Room & External Walls \\
& External Wall Fixed Shading (eaves) \\
& External Screens (nearby buildings \& tress) \\
& Floor \\
& Ceiling \\
& Doors in Walls (access door) \\
\hline Roof Space & Floor (test cell ceiling) \\
& Roof \\
\hline
\end{tabular}

Table 4.25: Built elements' data input requirements for each zone in the Concrete Slab-on-ground Test Cell

\begin{tabular}{|l|l|}
\hline \multicolumn{1}{|c|}{ Zone } & \multicolumn{1}{|c|}{ Applicable Data Input Requirements } \\
\hline Subfloor & NIL \\
\hline \multirow{5}{*}{ Test Cell Room } & External Walls \\
& External Wall Fixed Shading (eaves) \\
& External Screens (nearby buildings \& trees) \\
& Floor \\
& Ceiling \\
& Doors in Walls (access door) \\
\hline \multirow{2}{*}{ Roof Space } & $\begin{array}{l}\text { Floor (test cell ceiling) } \\
\text { Roof }\end{array}$ \\
\hline
\end{tabular}




\section{Ventilation}

The final tab which required standard data entry was the Ventilation tab. The data input into this tab was for the application of the simplified inbuilt natural ventilation model. The general orientation, simplified perimeter size and north facing plane of the building were confirmed. As the test cells were square in shape and facing true north, this tab required little consideration of input values.

\subsubsection{AccuRate - Non-Standard Inputs}

To simulate the thermal performance test cells in a suitable manner for empirical validation, a range of non-standard inputs were required (Agami Reddy, Maor \& Panjapornpon 2007; Bannister 2009; Lomas 1991a, 1991b). The required modifications were: climate file assignment, heating and cooling parameters, energy loads, infiltration and built fabric conductivity values (Table 4.16). These modifications were either performed by amending values via the software front end user interface, or within the output scratch file, prior to the simulation being undertaken.

\section{Modified Thermostat and Internal Heat Gains}

As the current version of the AccuRate software has been specifically developed to meet the NatHERS protocol for house energy ratings, there are zone dependant presumed times for room occupancy (ABCB 2006b). The room occupancy includes heating/cooling settings and internal heat gains. As there was to be no heating or cooling of the test cells in the freerunning stage, all thermostat settings which would invoke heating or cooling processes were removed from the test cell specific scratch file prior to simulation (Table 4.26). A check of the output energy file was completed to ensure that no heating or cooling rules had been invoked by the software.

Similarly, the sensible and latent heat loads were amended within the test cell scratch files. Normally these have values based on room type and possible occupancy levels (NatHERS 2007). However, as the test cells were to be unoccupied (Lomas 1991a) with no variable appliance loads, the value was amended to a constant value of thirty (30) watts to account for power use by the data logging equipment (Table 4.26). The amendment of the thermostat and 
internal heat gain values within the AccuRate scratch files was applied to all four simulation types.

Table 4.26: As-built Scratch File Modifications 1 - Concrete Slab-on-ground Floored Test Cell

\begin{tabular}{|l|l|l|l|}
\hline Zone & \multicolumn{1}{|c|}{ Line } & \multicolumn{1}{|c|}{ Scratch File Modification } & \multicolumn{1}{c|}{ Value } \\
\hline Test Cell & $3-1401$ & Sensible Internal Heat gains (Hours 1-12) & Modified to 30 watts \\
\hline Test Cell & $3-1402$ & Sensible Internal Heat gains (Hours 13-24) & Modified to 30 watts \\
\hline Test Cell & $3-1403$ & Latent internal heat gain (watts), [hours 1-12] & Modified to 0 watts \\
\hline Test Cell & $3-1404$ & Latent internal heat gain (watts), [hours 13-24] & Modified to 0 watts \\
\hline Test Cell & $3-1501$ & Heating thermostat settings [hours 1-12] & Modified to 0.0 deg. \\
\hline Test Cell & $3-1502$ & Heating thermostat settings [hours 13-24] & Modified to 0.0 deg. \\
\hline Test Cell & $3-1503$ & Cooling thermostat settings [hours 1-12] & Modified to 0.0 deg. \\
\hline Test Cell & $3-1504$ & Cooling thermostat settings [hours 13-24] & Modified to 0.0 deg. \\
\hline
\end{tabular}

\section{Climate File Assignment}

The climate files within AccuRate were developed from ten or more years of postcode specific BOM measured data (Delsante \& Mason 1990). The data in many cases has portions missing and mathematical methods have been utilised to fill gaps in the mean data set (Boland 1995, 2002; Delsante 1996; Delsante \& Mason 1990; Stokes 2007). As a comparative simulation tool the use of the mean data climate file is a sensible approach; however, for validation purposes much of this data is unsuitable (Lomas 1994), as variations of up to $7.0^{\circ} \mathrm{C}$ were observed between hourly values in the AccuRate climate file and site-measured data. Those variations would distort the software validation dramatically. As the Accurate built-in default climate file was unsuitable, a project specific climate file was required.

The external environment was monitored by a site weather station mounted on the roof of one of the test cells. This location ensured that security and an obstruction-free environment was provided for the equipment. The weather station took measurements every ten minutes of air temperature, relative humidity, wind speed, wind direction and global solar radiation. This data was combined with BOM data to complete a site specific climate file of one year's duration.

A typical AccuRate climate file consists of sixty columns of data. Each column provides a space for required data or flag values. When the flag values were removed, thirty nine columns of measured data were required. The first step was to identify what input values 
would be unchanged, or could use BOM data or required site observed data (Table 4.27). This stage was completed with inputs from the software developers from the CSIRO.

Table 4.27: Climate File Input Sources

\begin{tabular}{|l|l|l|}
\hline $\begin{array}{c}\text { Col. } \\
\text { No. }\end{array}$ & \multicolumn{1}{|c|}{ Description } & \\
\hline $5-6$ & Month Number & Method \\
\hline $7-8$ & Day Number & On site data acquisition \\
\hline $9-10$ & Hour Number & On site data acquisition \\
\hline $11-14$ & Dry Bulb Temperature & On site data acquisition \\
\hline $15-17$ & Moisture Content & On site data acquisition \\
\hline $18-21$ & Atmospheric (air) Pressure & Bureau of Meteorology \\
\hline $22-24$ & Wind Speed & On site data acquisition \\
\hline $25-26$ & Wind direction & On site data acquisition \\
\hline 27 & Cloud cover & Not measured \\
\hline $34-37$ & Global Solar Radiation & On site data acquisition \\
\hline $38-40$ & Diffuse Solar Radiation & Not Measured - Calculated from observed Global Solar Radiation \\
\hline $41-44$ & Normal Direct Solar Radiation & Not Measured - Calculated from observed Global Solar Radiation \\
\hline $45-46$ & Solar Altitude & Data adopted from existed Launceston Climate file \\
\hline $47-49$ & Solar Azimuth & Data adopted from existed Launceston Climate file \\
\hline
\end{tabular}

The BOM collected data from the Launceston airport at half hourly intervals. However, Launceston airport weather station was eighteen kilometres from the test cell site and at a different altitude. The Launceston airport weather station collected half hourly air pressure values and calculated mean sea level air pressure. Therefore, the mean sea level pressure was amended to account for the test cell site which was fifteen metres above sea level. The revised value was then averaged to an hourly value, to suit the AccuRate climate file.

The cloud cover was not measured on site. From discussions with BOM satellite imagery software developers, it was intended that calculated values would be used. Due to constraints of time and financial resources the BOM had not established this service within the research time frame. Discussions with CSIRO AccuRate software developers established that the cloud cover value was only used for night sky loss calculations for the roof space of a building. A series of simulations were undertaken by CSIRO software developers, with varying values for cloud cover. It was found that there was a minimal effect on test cell room temperature during these iterations. Based on these tests, a cloud cover figure of four (4) was adopted, inferring a cloud cover of $50 \%$ at night. 
At the time of this research, the site weather station included a probe measuring global solar radiation. The data from this device was used to calculate values for Diffuse and Normal Direct Beam solar radiation. After a review of mathematical methods (Bird \& Riordan 1986; Halthore \& Schwartz 2001; Halthore et al. 1996; Myers 2003; Peterson \& Dirmhirn 1981; Scanes 1974; Subhakar \& Thyagarajan 1994; Ulgen \& Hepbasli 2004), this service was performed with CSIRO software developers, using the Moriarty (Moriarty 1991) and Bolland \& Ridley (Boland, Ridley \& Brown 2007; Ridley \& Boland 2005, 2008) methods for establishing diffuse radiation and Spencer's (Spencer 1981) method for establishing direct beam radiation (Delsante 2009a; Spencer 1981). It was found that the calculated low sun angle diffuse solar radiation values were not suitable. Therefore, values for low sun angle times were manually modified to suitable values. Once the global and diffuse solar radiation values were ascertained, the normal direct beam values were calculated.

All the climate data for the AccuRate climate file were combined into a single table within the research database. A program was written to read the data from the database table and provide an output file in the correct format. Once the file was produced, it was checked against other climate files and against the observed values, which were to be included to ensure the formatting and scripting was correct. This process was repeated a few times, as faults in the scripting and data order were gradually removed before the final site-measured climate file was obtained.

The observed climate file was given the same name as the default climate file within the AccuRate software, as the software has a limited library of climate files it is able to read. The default and observed climate files were copied into the climate files folder to suit the simulation type that was undertaken.

\section{Infiltration parameters}

The AccuRate software includes zone-dependant default values for infiltration. Many studies have found considerable differences in the measured infiltration of standard and research buildings (Lomas 1991a; Stazi et al. 2007; Stein \& Meier 2000). As discussed in section 4.3.7, the Mobile Architecture and Built Environment Laboratory (MABEL) from Deakin University were engaged to measure infiltration within the test cells. This study was conducted over a two day period, under varying wind speeds and day and night conditions. 
Zones measured included the roof space and the room of all three test cells and the subfloor space of the enclosed-perimeter platform-floored test cell. Researchers from MABEL and within the School of Engineering, (University of Tasmania), calculated values for the constant and wind speed multiplier values. The default values within the test cell scratch files were then manually modified to the calculated values, for the simulations considering the as-built parameters (Table 4.28).

Table 4.28: As-built Scratch File Modifications 2 - Concrete Slab-on-ground Floored Test Cell

\begin{tabular}{|l|l|l|l|}
\hline \multicolumn{1}{|c|}{ Zone } & Line & \multicolumn{1}{|c|}{ Scratch File Modification } & \multicolumn{1}{c|}{ Value } \\
\hline Test Cell & $3-1$ & Infiltration Data: A for infiltration rate (air changes per hour) & Modified to 0.28 \\
\hline Test Cell & $3-1$ & Infiltration Data: B for infiltration rate (air changes per hour) & Modified to 0.0 \\
\hline Roof Space & $3-2$ & Infiltration Data: A for infiltration rate (air changes per hour) & Modified to 0.0 \\
\hline Roof Space & $3-2$ & Infiltration Data: B for infiltration rate (air changes per hour) & Modified to 0.275 \\
\hline
\end{tabular}

\section{Framing Factor}

To establish correct as-built conductivity values for the floor, walls and ceiling of the test cells, the AccuRate model and other internationally accepted methodologies were first analysed. The individual conductivity values for materials within the AccuRate software and the method by which the software created assemblages for thermal simulation were examined. It became apparent that the AccuRate Software, like many other house energy rating software applications around the world, did not consider the framing factor appropriately or at all (Barnaby, Spitler \& Xiao 2005; Bell \& Overend 2001; Belusko, Bruno \& Saman 2010; DewsburyWallis et al. 2009; Syed \& Kosny 2006). Figure 4.107 and Figure 4.108 illustrate the timber framing within two external walls of the concrete slab-on-ground floored test cell. The framing factor in these figures consists of bottom plates, studs, noggins, lintels, jamb studs and top plates. An analysis of the framing factor was completed for each floor, wall and ceiling of the test cells, as shown in Table 4.29.

The framing factor can have a significant effect on the thermal performance of housing (Bell \& Overend 2001; Belusko, Bruno \& Saman 2010; Cox-Smith 2001; DewsburyWallis et al. 2009; Fricker 2003; Kosny \& Childs 2002; Kosny, Yarbrough \& Childs 2006a, 2006b; Kosny et al. 2007; Lstuburek 2010). To understand the importance of the framing factor in the context of the thermal performance test cells and empirical validation, a quick analysis of the resistance values of framing elements of the thermal performance test cells was completed. 
This provided key information for two independent examinations. The first was to quantify the timber framing within a typical wall and what effect it had on the resistance value of the floor, wall or ceiling. The second was the use of the revised total resistance value for the floor, wall or ceiling (Belusko, Bruno \& Saman 2010; Trethowen, HA 2004), to modify the fabric input data within AccuRate. For the software to be validated empirically, the correct resistance values for the various fabric elements of the entire thermal performance test cell required careful consideration (Lomas 1991b).

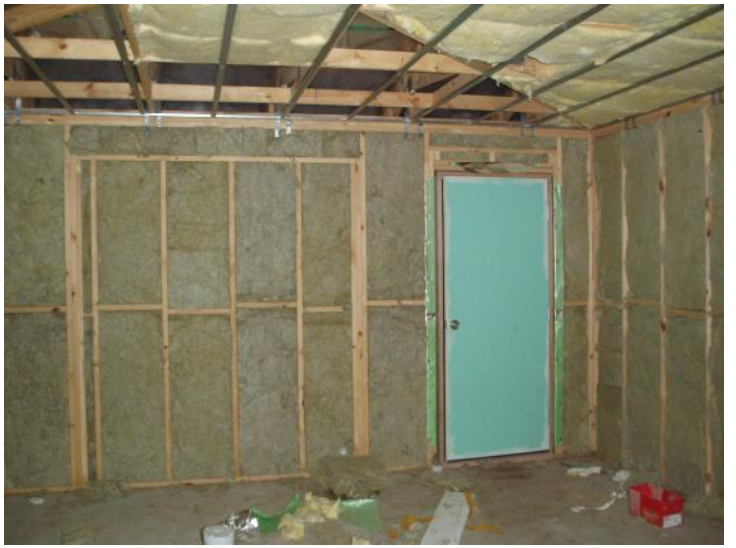

Figure 4.107 - Test Cell 3 - Southern wall

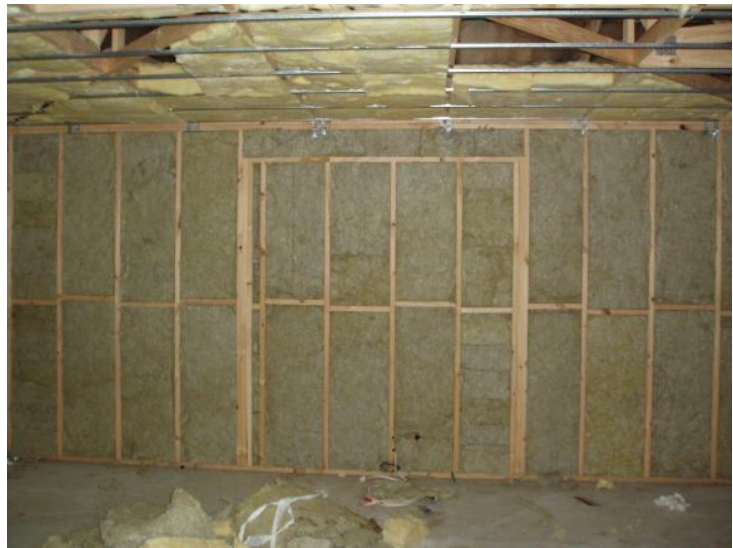

Figure 4.108 - Test Cell 3 - Northern wall 
Table 4.29: Wall-framing Area - Concrete Slab-on-ground Floored Test Cell

\begin{tabular}{|l|c|c|c|c|c|c|c|}
\hline Wall Structure & Qty & Depth & Length & Width & Area $\mathrm{m}^{2}$ & & \\
\hline \multicolumn{1}{|c|}{ Member } & 11 & 0.090 & 2.325 & 0.035 & 0.895 & 0.035 & \\
\hline Nth Wall Studs & 8 & 0.090 & 2.030 & 0.035 & 0.568 & 0.025 & \\
\hline Nth Wall 2100 & 2 & 0.090 & 5.480 & 0.035 & 0.384 & 0.006 & \\
\hline Nth Wall TP & 1 & 0.090 & 5.480 & 0.045 & 0.247 & 0.004 & \\
\hline Nth Wall BP & 1 & 0.090 & 4.905 & 0.035 & 0.172 & 0.003 & \\
\hline Nth Wall Noggins & 1 & 0.090 & 2.000 & 0.035 & 0.070 & 0.003 & \\
\hline Nth Wall Window Head & 1 & 0.063 & 2.000 & 0.200 & 0.400 & 0.013 & 2.735 \\
\hline Nth Wall Lintel & & & & & & & \\
\hline & 10 & 0.090 & 2.325 & 0.035 & 0.814 & 0.032 & \\
\hline Sth Wall Studs & 10 & 0.090 & 2.030 & 0.035 & 0.711 & 0.032 & \\
\hline Sth Wall 2100 & 2 & 0.090 & 5.480 & 0.035 & 0.384 & 0.006 & \\
\hline Sth Wall TP & 1 & 0.090 & 5.480 & 0.045 & 0.247 & 0.004 & \\
\hline Sth Wall BP & 1 & 0.090 & 3.970 & 0.035 & 0.139 & 0.003 & \\
\hline Sth Wall Noggins & 1 & 0.090 & 2.000 & 0.035 & 0.070 & 0.003 & \\
\hline Sth Wall Window Head & 1 & 0.063 & 2.000 & 0.200 & 0.400 & 0.013 & \\
\hline Sth Wall Lintel & 1 & 0.090 & 0.900 & 0.035 & 0.032 & 0.003 & \\
\hline Sth Wall Door Head Hor & 1 & 0.035 & 0.900 & 0.090 & 0.081 & 0.003 & \\
\hline Sth Wall Door Head Vertical & & & & & & & \\
\hline & 11 & 0.090 & 2.325 & 0.035 & 0.895 & 0.035 & \\
\hline East Wall Studs & 8 & 0.090 & 2.030 & 0.035 & 0.568 & 0.025 & \\
\hline East Wall 2100 & 2 & 0.090 & 5.480 & 0.035 & 0.384 & 0.006 & \\
\hline East Wall TP & 1 & 0.090 & 5.480 & 0.045 & 0.247 & 0.004 & \\
\hline East Wall BP & 1 & 0.090 & 4.905 & 0.035 & 0.172 & 0.003 & \\
\hline East Wall Noggins & 1 & 0.090 & 2.000 & 0.035 & 0.070 & 0.003 & \\
\hline East Wall Window Head & 1 & 0.063 & 2.000 & 0.200 & 0.400 & 0.013 & 2.735 \\
\hline East Wall Lintel & 1 & & & & & & \\
\hline & 1 & 0.090 & 2.325 & 0.035 & 0.895 & 0.035 & \\
\hline West Wall Studs & 1 & 0.090 & 2.030 & 0.035 & 0.568 & 0.025 & \\
\hline West Wall 2100 & 0.090 & 5.480 & 0.035 & 0.384 & 0.006 & \\
\hline West Wall TP & 1 & 5.480 & 0.045 & 0.247 & 0.004 & \\
\hline West Wall BP & 1 & 0.090 & 4.905 & 0.035 & 0.172 & 0.003 & \\
\hline West Wall Noggins & 1 & 2.000 & 0.035 & 0.070 & 0.003 & \\
\hline West Wall Window Head & 1 & 2.000 & 0.200 & 0.400 & 0.013 & & 2.735 \\
\hline West Wall Lintel & 1 & & & & \\
\hline
\end{tabular}

The thermal performance test cells included a mix of standard building materials for walls, ceiling and roof. The mix of materials is shown in Figure 4.109 and Figure 4.110. Each of the materials shown in the diagrams had a different value for conductivity and resistance. The value for conductivity describes the amount of energy that is conducted through a material (Flux), over time, to affect the temperature of the opposing surface, in steady state conditions (ASHRAE 2009; Clarke 2001). Other factors which can affect this process are: air flow, reflectance and emissivity. The air flow, reflectance and emissivity may affect how heat flow impacts on the surface of the material but not the heat flow through the material. ASHRAE describes thermal resistance as:

"the mean temperature difference between two defined surfaces of material or construction under steady-state conditions that induces a unit heat flux, in $(m 2 \cdot K) / W$."

(ASHRAE 2009), 26.1 
An example of the method to calculate a given materials conductivity and resistance values is shown in Table 4.30.

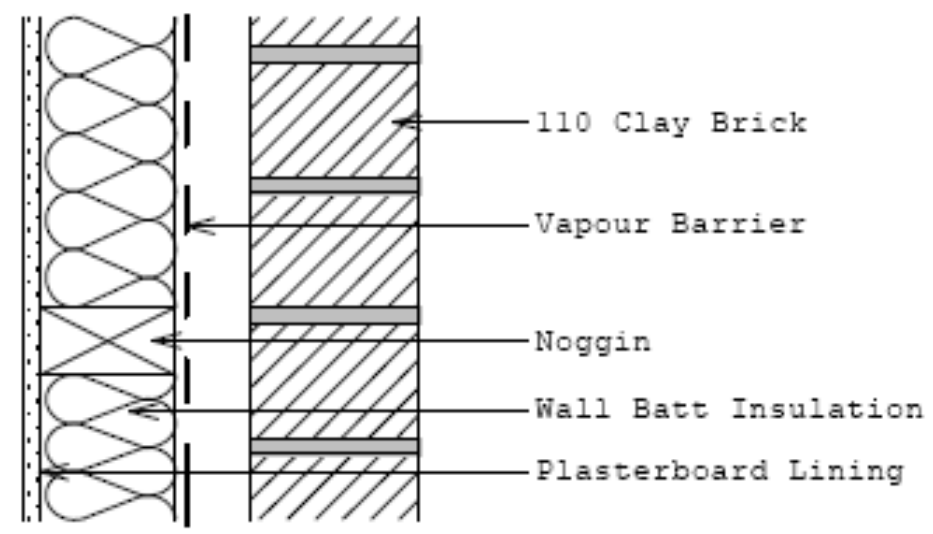

Figure 4.109 - Brick Veneer Wall Detail

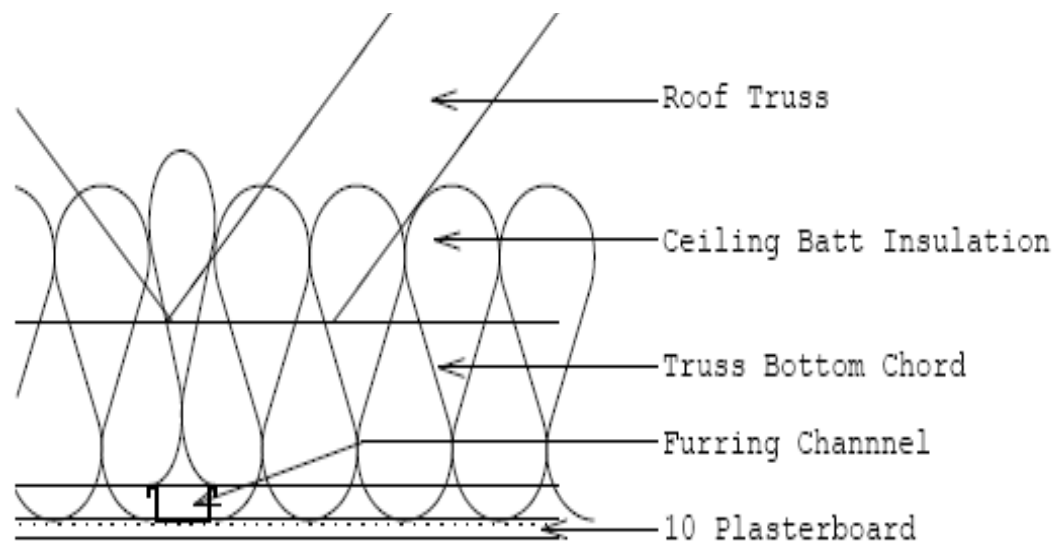

Figure 4.110 - Ceiling Detail

Table 4.30: Calculation of Conductivity and Resistance Values for Plasterboard Lining

\begin{tabular}{|c|c|}
\hline \multicolumn{2}{|c|}{$\begin{array}{l}\text { Plasterboard: } 10 \mathrm{~mm} \text { thick } \\
\text { Conductivity value: } 0.16 \mathrm{~W} / \mathrm{m} . \mathrm{K} \\
\text { To calculate Resistance value: }(\mathrm{m} 2 . \mathrm{K} / \mathrm{W})\end{array}$} \\
\hline $\begin{array}{l}\text { Method } 1 \\
\text { a. } R=(1 / K) \times \text { Depth } \\
R=(1 / 0.16) \times .010 \\
R=6.25 \times .010 \\
R=0.0625\end{array}$ & $\begin{array}{l}\text { Method } 2 \\
\text { b. } R=\text { Depth / K } \\
R=0.010 / 0.16 \\
R=0.0625\end{array}$ \\
\hline
\end{tabular}


Each of the materials used to construct the test cells, had a different conductivity value. Table 4.31 presents data from two sources for conductivity and resistance values for the materials used to construct the test cells.

Table 4.31: Conductivity and Resistance Values (D/K)

\begin{tabular}{|c|c|r|c|c|c|c|}
\hline & & \multicolumn{3}{|c|}{ AccuRate (2007) } & \multicolumn{2}{c|}{ ASHRAE (2009) } \\
\hline Material & $\begin{array}{c}\text { Depth } \\
(\mathrm{mm})\end{array}$ & $\begin{array}{c}\text { Res. } \\
1000 \mathrm{~mm}\end{array}$ & $\begin{array}{c}\text { Cond. (K) } \\
1000 \mathrm{~mm}\end{array}$ & $\begin{array}{c}\text { Res. } \\
\text { Value }\end{array}$ & $\begin{array}{c}\text { Conductivity (K) } \\
(\mathrm{W} / \mathrm{m} . \mathrm{K})\end{array}$ & $\begin{array}{c}\text { Resistance } \\
\text { Value }\end{array}$ \\
\hline Extruded Clay Brick & 0.110 & 1.63 & 0.614 & 0.18 & $0.360-1.470$ & $0.31-0.07$ \\
\hline Plasterboard & 0.010 & 5.90 & 0.170 & 0.06 & $0.160 \ldots \ldots \ldots$. & $0.06 \ldots \ldots \ldots$ \\
\hline Plywood & 0.012 & 7.14 & 0.140 & 0.09 & $0.091-0.106$ & $0.13-0.11$ \\
\hline Particle Board & 0.019 & 8.30 & 0.121 & 0.16 & $0.102-0.135$ & $0.19-0.14$ \\
\hline Pine & 0.035 & 10.00 & 0.100 & 0.35 & $0.090-0.160$ & $0.39-0.22$ \\
\hline Pine & 0.090 & 10.00 & 0.100 & 0.90 & $0.090-0.160$ & $1.00-0.56$ \\
\hline Rockwool Batt R2.5 & 0.083 & 30.30 & 0.033 & 2.52 & $0.036 \ldots \ldots \ldots$. & $2.31 \ldots \ldots \ldots$ \\
\hline Glasswool Batt R4.1 & 0.181 & 22.73 & 0.044 & 4.11 & $0.043-0.048$ & $4.21-3.77$ \\
\hline
\end{tabular}

(AccuRate 2007; ASHRAE 2009)

An analysis of methods to calculate the framing factor was undertaken in consultation with the CSIRO software developers. Three well-published methods were investigated:

- The parallel path method

- The isotherm planes method and

- The zone method

The parallel paths method is used when the differing materials of the built plane have similar conductivity values (ASHRAE 2009; DewsburyWallis et al. 2009; Standards New Zealand 2006). The insulated ceiling space and wall frames of the thermal performance test cells had materials of differing conductivity values, ranging from 0.033 to 0.614 (Table 4.31). Sample walls and ceilings were analysed with the parallel path method to compare resultant conductivity values of wall planes (Table 4.32).

The isotherm planes method is used when the differing materials of the built plane in question have conductivity values with a level of magnitude difference (ASHRAE 2009; Standards 
New Zealand 2006). In this method, the built plane is broken into its constituent parts and the fractional values are only applied to the elements that are different. In the insulated wall of the test cells this consists of the $90 \mathrm{~mm}$ timber stud and the R2.5 wall batt insulation. The conductivity values of the $90 \mathrm{~mm}$ stud is 0.1 and the R2.5 wall batt is 0.033 (see Table 4.31 ), illustrating a considerable difference in their order of magnitude. Sample walls and ceilings were analysed with the isotherm planes method to compare resultant conductivity values of wall planes (Table 4.32).

The zone method is used for built wall planes where the magnitude of difference in conductivity values is high. An example is a large steel structural member within a highly insulated wall, where the steel member spans from the inside skin to the outside skin of the fabric (Figure 4.111). If the isotherm planes method is used in this type of situation, the revised average resistance value can be too low (ASHRAE 2009). As no part of the thermal performance test cell, floor, walls or ceiling had this type of construction, this method was not used.

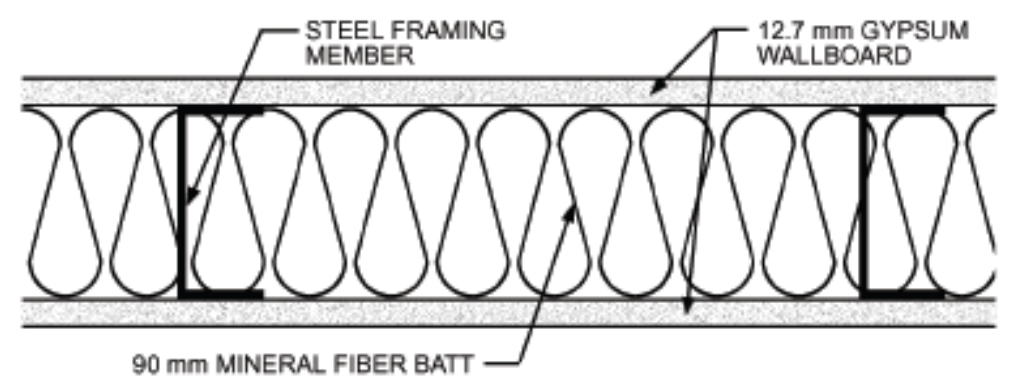

Figure 4.111 - Wall type suitable for Zone Method

(ASHRAE 2009, p. Section 27)

The analysis of the methods and their criteria for use suggested that the isotherm planes method should be used to establish the revised conductivity values for the floor, walls and ceiling of the test cells. In personal discussions with the CSIRO software developers the merits of the parallel path and isotherm planes methods were considered. In previous CSIRO research, (with uninsulated building assemblages), the parallel path method had been selected. Now that insulated assemblages were being analysed, there was a difference of magnitude 
between the materials, which suggested that the isotherm planes method should be used (Delsante 2005-2010). This was further supported by the New Zealand Standard, Methods of determining the total thermal resistance of parts of buildings (Standards New Zealand 2006), which proposed the isotherm planes method for calculating the resistance values for external walls. An example of the isotherm method is shown in Equation 4.2.

\section{Equation 4.2 - Isotherm Planes Method: Test Cell Wall}

\begin{tabular}{|c|c|c|c|c|c|c|}
\hline 1 & \multicolumn{2}{|c|}{$\begin{array}{l}\text { Select differing assemblages on parallel planes of } \\
\text { the building, where the elements will have varying } \\
\text { resistance values and number them. }\end{array}$} & \multicolumn{2}{|c|}{ R1: Insulated wall } & \multicolumn{2}{|c|}{ R2: Framed Wall } \\
\hline 2 & \multicolumn{2}{|c|}{$\begin{array}{l}\text { For each differing assemblage establish the } \\
\text { percentage fraction of total planar area that this } \\
\text { assemblage encompasses. }\end{array}$} & \multicolumn{2}{|l|}{$76 \%$} & & $24 \%$ \\
\hline 3 & \multicolumn{2}{|c|}{$\begin{array}{l}\text { Calculate the differing resistance value for each } \\
\text { assemblage }\end{array}$} & \multicolumn{2}{|c|}{$\begin{array}{l}\text { R2.5 Wall Insulation - } \\
\text { R2.5 }\end{array}$} & & $\begin{array}{l}\text { Timber - } \\
0.90\end{array}$ \\
\hline 4 & \multicolumn{2}{|c|}{$\begin{array}{l}\text { Calculate the revised resistance value for the } \\
\text { assemblage } \\
1 / R_{b}=f_{1} / R_{1}+f_{2} / R_{2}+f_{3} / R_{3}+\ldots\end{array}$} & \multicolumn{4}{|c|}{$\begin{array}{l}1 / R_{b}=0.76 / 2.5+0.24 / 0.90 \\
1 / R_{b}=0.304+0.216 \\
1 / R_{b}=0.52\end{array}$} \\
\hline 5 & \multicolumn{2}{|c|}{ Then $R_{b}=1 /\left(1 / R_{b}\right)$} & \multicolumn{4}{|c|}{$\begin{array}{l}\mathrm{R}_{\mathrm{b}}=1 /(0.52) \\
\mathrm{R}_{\mathrm{b}}=1.92\end{array}$} \\
\hline \multirow[t]{2}{*}{6} & \multicolumn{3}{|c|}{ Then $R_{T}=R_{s i}+R_{1}+R_{2}+\ldots .+R_{n}+R_{s e}$} & \multirow{2}{*}{\multicolumn{2}{|c|}{$\begin{array}{l}\text { OS Surface } \\
12 \text { Ply } \\
\text { Non Ref. Cavity } \\
\text { Bridged plane } \\
10 \text { Plasterboard } \\
\text { IS Surface } \\
\mathrm{R}_{\mathrm{T}}\end{array}$}} & 0.03 \\
\hline & Where: & \multicolumn{2}{|c|}{$\begin{array}{l}R_{T}: \text { is the total resistance } \\
R_{s i}: \text { is the internal surface resistance } \\
R_{1}+R_{2}+. .+R_{n}: \text { are the thermal resistances of each } \\
\text { layer, including the bridged layers } \\
R_{s e}: \text { is the external surface resistance }\end{array}$} & & & $\begin{array}{l}0.09 \\
0.18 \\
1.92 \\
0.06 \\
0.12 \\
2.40\end{array}$ \\
\hline
\end{tabular}

Table 4.32: Parallel Paths Method \& Isotherm Planes Method Comparison (North Wall of Enclosed-perimeter Platform-floored Test Cell)

\begin{tabular}{|l|c|l|c|}
\hline \multicolumn{1}{|c|}{ Material } & R Value & \multicolumn{1}{c|}{ Material } & R Value \\
\hline OS Surface & 0.03 & OS Surface & 0.03 \\
\hline 110 Clay Brick & 0.18 & 110 Clay Brick & 0.18 \\
\hline Reflective Cavity & 0.28 & Reflective Cavity & 0.28 \\
\hline R2.5 Insulation & 2.50 & 90 Timber & 0.90 \\
\hline 10 Plasterboard & 0.06 & 10 Plasterboard & 0.06 \\
\hline IS Surface & 0.12 & IS Surface & 0.12 \\
\hline Total & 3.17 & Total & 1.57 \\
\hline \multicolumn{4}{|c|}{ Resultant Conductivity Values } \\
\hline Framing Fraction & $80 \%$ & $\begin{array}{l}\text { Isotherm Planes Method } \\
\text { av }=2.40(\mathrm{~m} 2 \cdot \mathrm{K}) / \mathrm{W}\end{array}$ \\
\hline \multicolumn{4}{|c|}{$\begin{array}{l}\text { Parallel Path Method } \\
\text { Rav }=2.63(\mathrm{~m} 2 \cdot \mathrm{K}) / \mathrm{W}\end{array}$} \\
\hline
\end{tabular}


Once the revised average resistance value was obtained for each floor, wall and ceiling, a new version of each AccuRate building model was saved. Two plane-specific methods were then used to modify the resistance values of the as-built fabric. To amend the resistance values of the platform floors, the resistance value of the particle board floor was established. To increase the insulation of the platform floor, the thickness of the particle-board floor was increased (Equation 4.3). The revised particleboard floor thickness was used for all simulations requiring as-built inputs.

\section{Equation 4.3 - Establishing Particleboard Thickness to Suit Revised Resistance Value of Floor}

\begin{tabular}{|l|l|}
\hline Particle-Board Resistance value $(19 \mathrm{~mm})$ & $\mathrm{R} 0.16$ \\
\hline Desired Resistance value based on framing factor & $\mathrm{R} 0.18$ \\
\hline To obtain revised particle-board thickness & $\begin{array}{l}=(\mathrm{R} 0.18 / \mathrm{R} 0.16) \times 19 \mathrm{~mm} \\
=21 \mathrm{~mm}\end{array}$ \\
\hline
\end{tabular}

A similar method was used to revise the insulation values of the wall and ceiling planes. The isotherm planes method established the average resistance value for the stud/insulation or joist/insulation portions of the walls and ceiling planes respectively. For each wall and ceiling a new construction was established. For the walls, the north, east and west walls of most test cells was identical, while the south wall with the access door, had a different framing factor. This required the input of two external wall types. To modify the resistance value, rather than selecting a preset resistance value for the insulation material, the conductivity of that material was selected. Then, in a similar manner to the particle-board floor, a revised thickness for the insulation material was obtained (Equation 4.4).

\section{Equation 4.4 - Establishing Insulation Thickness to Suit Revised Resistance Value of Wall}

\begin{tabular}{|l|l|}
\hline Insulation Resistance value $(83 \mathrm{~mm})$ & $\mathrm{R} 2.5$ \\
\hline Desired Resistance value based on framing factor & $\mathrm{R} 1.795$ \\
\hline \multirow{2}{*}{ To obtain revised particle-board thickness } & $\mathrm{R}=$ Thickness $/ \mathrm{k}$ \\
Rockwool insulation ( $\mathrm{k}=0.033)$ & $\mathrm{R} \times \mathrm{k}=$ Thickness \\
& $\mathrm{R} 1.795 \times 0.033=59 \mathrm{~mm}$ \\
\hline
\end{tabular}

Once the revised thickness of the materials was established, they were modified within the constructions tab of the standard front-end user interface. In the example of the revised 
thickness of the rockwool insulation illustrated above, the rockwool thickness was defined in the material data entry process. Through this process, two scratch files were established for each test cell (Default and As-built).

\subsubsection{The AccuRate Simulations}

Once the observed climate file and the scratch files for each test cell were established, they were checked several times before the simulations were undertaken. Once the checking was completed, the thermal simulations by AccuRate commenced. The first simulation completed was the Default Fabric / Default Climate simulation. This became the check simulation and the output data was examined for logical patterns, which reflected the effects of the default climate file inputs. The second was the Default Fabric / Measured Climate simulation, which allowed for an analysis of the effect on test cell zone temperatures, of the observed climate file, as opposed to the default climate file. The third simulation was the As-Built fabric / Default Climate, which allowed for the first exploration of the effects of the as-built inputs, when the output data was compared to the Default Fabric / Default Climate output data. The final simulation completed was the As-Built Fabric / Measured Climate configuration. This was compared to the two previous simulations, using the observed climate and as-built building fabric for a progressive development change in the output temperature files. When an AccuRate simulation is completed, four output reports are provided: 'energy', 'output', 'star rating' and 'temperature' files. Each of these reports was analysed as part of the verification of simulation correctness, as discussed below.

The energy report provided the calculated energy required to maintain a particular temperature bandwidth, within conditioned zones of the simulated building. The report lists the projected energy for each hour of an annual thermal simulation cycle. For the empirical validation of AccuRate the test cells were 'Free-running': which required that the buildings' environmental condition responded to the environmental context, in which they were built (Lomas 1991c), i.e., no heating or cooling was introduced within the building. To achieve a zero energy result, the thermostat settings were changed within the scratch files, as discussed above. The Energy.txt file then became a checking mechanism to ensure that the scratch file and other inputs were correct. After each simulation, the file was checked to ensure that all energy values for heating or cooling were zero (Figure 4.112). 


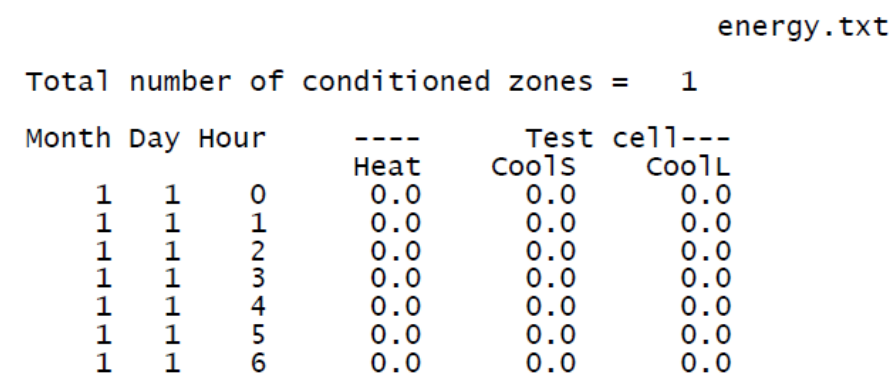

Figure 4.112 - Energy.txt AccuRate Output file

Like the energy.txt report, the output.txt report summarises the energy projections for the conditioned zones of the modelled test cell (Figure 4.113). This report provides a daily and monthly summary of the calculated heating and cooling energy requirements of the conditioned zones of the simulated building. Normally, the software utilises this data to provide a House Energy Star Rating. For the empirical validation of the test cells, this report was checked to ensure that all values were zero, as an indication that all thermostat settings had been removed.

Normally the AccuRate software produces a House Energy Star Rating report for regulatory purposes. When the test cells were simulated with no heating or cooling requirements, the software was operating outside its regulatory parameters. As the software was operating in this mode, no House Energy Star Rating report was produced.

The AccuRate software calculates the temperature of each zone of a simulated building. Once the temperature is calculated, the energy required to condition the space can be calculated. For the empirical validation project, this was the most important file, as all other output reports from the AccuRate software are calculated from this report. For the test cells the temperature report listed the calculated temperature, for each hour, and each zone of the simulated building (Figure 4.114). This report provided the data for comparison to observed data for the empirical validation analysis. 
output.txt

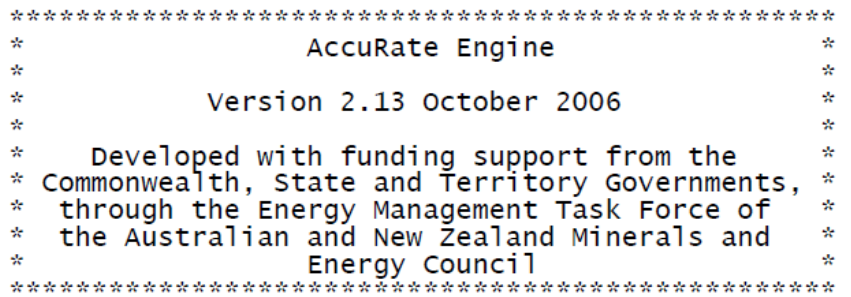

Jobname:

Weather data filename: C: \Program Files \ACCuRate aust\WEATHER \CLIMAT23.txt

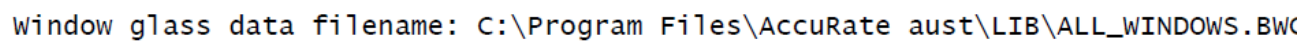

Date: $19 / 10 / 09$

Ground floor area $=30.00 \mathrm{~m} 2$

JAN 2003 DAY 1

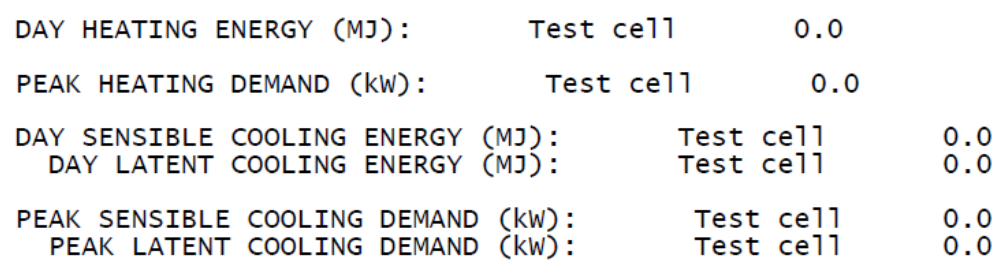

JAN 2003 DAY 2

DAY HEATING ENERGY (MJ): Test cell 0.0

PEAK HEATING DEMAND (KW): Test cell 0.0

DAY SENSIBLE COOLING ENERGY (MJ): Test cel1 110.0

DAY LATENT COOLING ENERGY (MJ): $\quad$ Test ce11 0.0

$\begin{array}{cll}\text { PEAK SENSIBLE COOLING DEMAND (kW): } & \text { Test ce } 11 & 0.0 \\ \text { PEAK LATENT COOLING DEMAND (kW): } & \text { Test ce } 11 & 0.0\end{array}$

Figure 4.113 - Output.txt AccuRate Output file

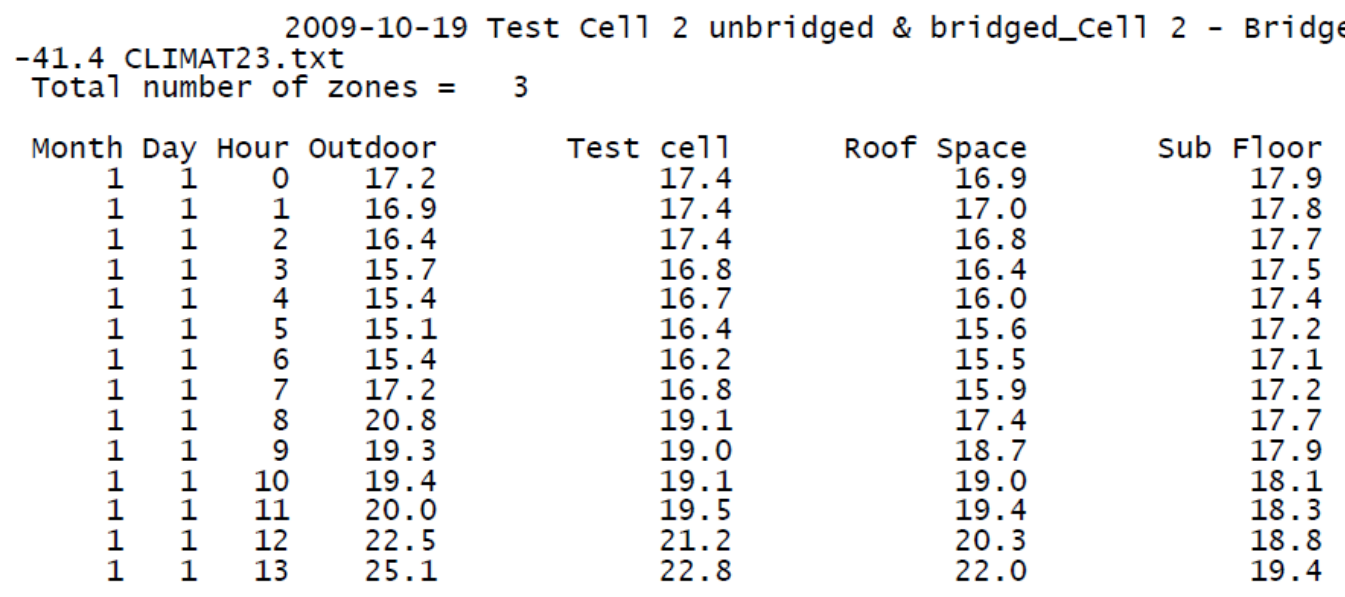

Figure 4.114 - AccuRate Temperature.tem Report 


\subsubsection{Summary of the Detailed Thermal Simulation by AccuRate}

The objective of the AccuRate detailed simulation was to provide a suitable output temperature report for each test cell, which could be used for the empirical validation analysis. The AccuRate software normally provides an output temperature report file for all simulations but this was not suitable for empirical validation.

The standard data entry included a careful consideration of all built elements. This incorporated the shading caused by the test cell on itself and by surrounding trees and buildings. The AccuRate software did not consider the effect of the framing factor on suspended floors, external walls or ceilings; hence the framing factor was the first element of non-standard data entry. The values for these external fabric elements were amended to account for the calculated insulation value, caused by the framing factor. The software then produced a scratch file for each test cell. This file was further amended with other nonstandard adjustments.

The non-standard modifications made to the scratch file changed some AccuRate default values to observed values. The thermostat settings and internal energy loads were amended to values that matched the test cell in free-running operation. The infiltration values for each test cell zone were modified from Accurate default values to those that were measured. The postcode-driven climate file was the final non-standard amendment. The default climate was unsuitable for empirical validation purposes, so a site-measured climate file was prepared from observed data. The site-measured climate file was used for all empirical validation AccuRate simulations.

The inclusion of these amendments and inclusions allowed for an 'As-Built Fabric / Measured Climate' AccuRate simulation to be completed for each test cell. The resultant output temperature report file was then suitable for further empirical analysis.

This research had now obtained a detailed simulation data set as discussed above and an empirical data set from the measurement of the test cells, as discussed in section 4.3. Before any analysis could commence to compare the two data sets, a review of methods of analysis was completed, which is discussed next. 


\subsection{Methods of Analysis}

The environmental measurement and the detailed thermal simulation of the three test cells produced two data sets: a measured data set and a simulation data set. Table 4.33 shows the type, specific environmental parameters and format of these data sets.

Table 4.33: Description of the Empirical Validation Data Used in This Study

\begin{tabular}{|l|l|l|}
\hline \multicolumn{1}{|c|}{ Data Type } & \multicolumn{1}{|c|}{ Parameter } & \multicolumn{1}{c|}{ Format } \\
\hline Measured Data & $\begin{array}{l}\text { - Temperatures from test cells } \\
\text { - Site weather station }\end{array}$ & $\begin{array}{l}\text { Numerical format, stored in database suitable } \\
\text { for comma separated values output }\end{array}$ \\
\hline Simulated Data & $\begin{array}{l}\text { - Temperatures predicted by the } \\
\text { AccuRate software }\end{array}$ & $\begin{array}{l}\text { Original output was a text file. This was } \\
\text { imported to the database. Suitable for comma } \\
\text { separated values output }\end{array}$ \\
\hline $\begin{array}{l}\text { AccuRate Default } \\
\text { Data }\end{array}$ & - Default AccuRate Climate data & Inbuilt text based TMY climate files \\
\hline
\end{tabular}

Below, the specific objectives of analysing the data gathered, and the various methods of analysis used in this study are discussed. The primary objectives for analysing the data are:

1. To compare the measured and simulated time series data;

2. To identify which of the built and environmental inputs contributed significantly to the differences, if any, between the observed and simulated data sets.

The first objective was achieved by visually examining time series graphs drawn using the graphing functions of Microsoft Office Excel (2003). As this research had collected a considerable amount of data as shown Table 4.34, viewing superimposed time series graphs was the most suitable method to determine differences in absolute values at any one time, as well as trends and patterns over a certain period.

The second objective of the analysis aimed to determine the climate or heat transfer algorithms within the software that may require improvement (Agami Reddy 2006). To undertake this task, statistical analysis was the preferred method and was conducted using the STATISTICA 7.1 software. 
Table 4.34: Quantity of External and Internal Environmental Parameters Measured

\begin{tabular}{|c|l|l|}
\hline Data Source & \multicolumn{1}{|c|}{ Element Observed } & \multicolumn{1}{c|}{ Data Quantity (hours) } \\
\hline \multirow{4}{*}{ Test Cell Buildings } & Subfloor air temperature & $\begin{array}{l}4100 \times 2 \\
\text { (unenclosed \& enclosed-perimeter } \\
\text { platform-floored test cells) }\end{array}$ \\
\cline { 2 - 3 } & Test cell room temperature & $\begin{array}{l}4100 \times 3 \\
\text { All three test cells }\end{array}$ \\
\cline { 2 - 3 } & Roof space air temperature & $\begin{array}{l}4100 \times 3 \\
\text { All three test cells }\end{array}$ \\
\hline \multirow{5}{*}{ Site Weather Station } & Air temperature & 4100 \\
\cline { 2 - 3 } & Relative Humidity & 4100 \\
\cline { 2 - 3 } & Wind Speed & 4100 \\
\cline { 2 - 3 } & Wind Direction & 4100 \\
\cline { 2 - 3 } & Solar Radiation & 4100 \\
\hline
\end{tabular}

\subsubsection{Graphical Analysis}

This type of analysis made use of superimposed time series graphs and allowed for quick visual comparisons of the measured and simulated data sets, as in Figure 4.115 (Agami Reddy 2006; Ahmad, Q \& Szokolay 1993; Clarke, Strachan \& Pernot 1994; Guyon, G, Moinard \& Ramdani 1999a; Judkoff, R, Wortman \& Burch 1983a; LomasEppel et al. 1994; Meldem \& Winklemann 1995; Moinard \& Guyon 1999; Neymark et al. 2005). As the data sets being analysed were either temperature or other environmental parameters, similarity in pattern between the two data sets was a good indicator of the AccuRate software's capacity to perform a meaningful thermal simulation (Dewsbury 2009; DewsburySoriano et al. 2009). If the values were different but the pattern similar, it could indicate a sensor calibration fault or a fault in the software's algorithm.

This form of graphical analysis was also used during the data cleaning stage of this research, as it allowed the prompt detection of outlying data and their subsequent rectification. This form of analysis was used to examine differences between:

- $\quad$ Measured on site climate data versus TMY climate data

- HER simulation types

- $\quad$ Measured and simulated zone temperatures 


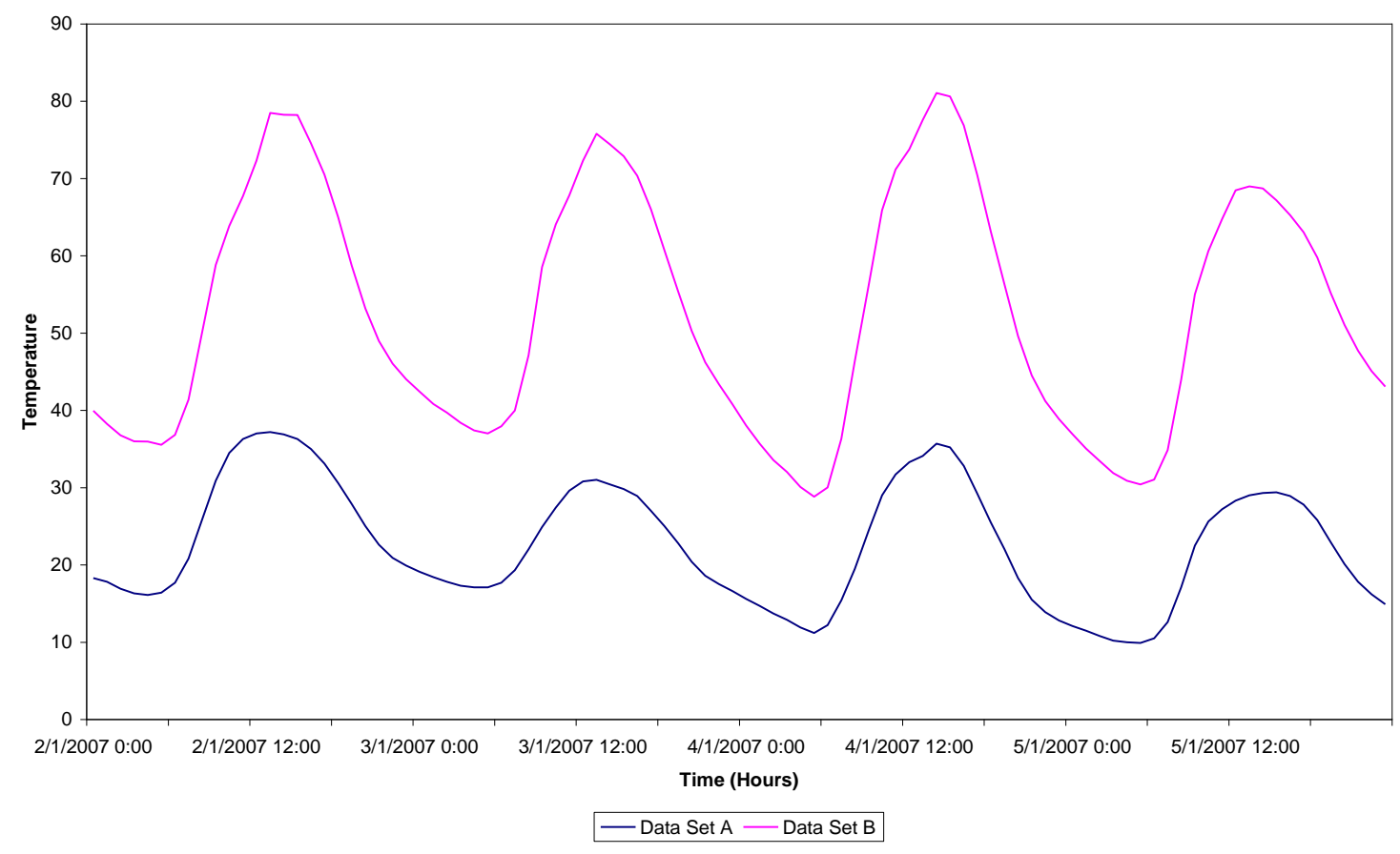

Figure 4.115 - Time-series based graphical analysis

\subsubsection{Statistical Analysis}

The linear graphical analysis discussed above provided the first illustrations of differences between data sets. However, this form of analysis only allowed for small groups of univariate data to be compared visually. Further investigation required a greater understanding of the difference between the observed and simulated data and the analysis of the interaction or noninteraction between the data sets (Palomo del Barrio \& Guyon 2002; Palomo, Marco \& Madsen 1991). Previous research projects have often referred to differences in mean averages (LomasEppel et al. 1994; Travesi et al. 2001) which is not suitable for this type of research. The primary purpose of the AccuRate HER software is to calculate the amount of energy that would be required to maintain human comfort within prescribed habitation conditions (ABCB 2006b; NatHERS 2009c, 2009e).

In comparing time series data with similar patterns and trends, the error is the difference between the measured and simulated values at any particular time. The error will be referred to from hereon as the residual value. The residual values were obtained by subtracting the simulated temperature from the measured temperature, as in Equation 4.5. 


\section{Equation 4.5 - Establishing Residual Values for a Test Cell Zone}

$T_{r}=T_{0}-T_{S}$

Where:

$\mathrm{T}_{\mathrm{r}}=$ Residual Value $\mathrm{C}^{0}$

$\mathrm{T}_{\mathrm{O}}=$ Measured Temperature $\mathrm{C}^{0}$

$\mathrm{T}_{\mathrm{S}}=$ Simulated Temperature $\mathrm{C}^{0}$

A positive residual value meant that the AccuRate software under-predicted the zone temperature, whereas, a negative residual value meant that the software over-predicted the zone temperature. Using the residual values, the following statistical graphs were used to determine algorithms that may need improvement:

- Histograms

- $\quad$ Time-series

- Scatter plots

The research data suggested the usefulness of two types of statistical illustration: the first was the provision of a simple graph illustrating any relationships between data sets based on time. The second was the capacity to analyse and illustrate any instance of correlation between observed and residual values.

The exposition of data relationships via a statistical framework provided valuable insights regarding the meaning of the data and provided possible future directions for research (Ahmad, M \& Culp 2006; del Mar Izquierdo et al. 1995; Dewsbury 2009; DewsburySoriano et al. 2009; Palomo del Barrio \& Guyon 2002; Palomo, Marco \& Madsen 1991). Rather than relying on an abstract understanding of the data linear graphical analysis, univariate and multivariate statistical analysis allowed for the data to be viewed in a more coherent manner, which reveals trends and patterns and allows for a richer understanding of the data. To provide these forms of analysis three primary types of statistical analysis were utilised, namely: histograms, time series plots and scatter plots.

After several preliminary statistical data analyses were completed (Dewsbury 2009), a final schedule for the univariate and multivariate analysis was established, as shown in Table 4.35. These methods allowed for a staged analysis, which: 
- checked the capability of the AccuRate simulation engine and

- provided the capacity for in-depth analyses of the difference between the simulated and measured temperatures, which could reveal relationships between zones and climatic variables.

Table 4.35: Univariate and Multivariate Analysis Tasks Completed

\begin{tabular}{|l|l|l|}
\hline \multicolumn{1}{|c|}{ Statistical Analysis Type } & Elements Compared & \multicolumn{1}{c|}{ Purpose } \\
\hline $\begin{array}{l}\text { Scatter plot Diagram } \\
\text { - Observed / Simulated }\end{array}$ & All test cell zones & $\begin{array}{l}\text { Show correlation between the calculated } \\
\text { and observed temperatures }\end{array}$ \\
\hline Residual Histogram Show & All test cell zones & Show zone residual values \\
\hline Time Series Plot & All test cell zones & $\begin{array}{l}\text { Show zone residual values based on } \\
\text { time }\end{array}$ \\
\hline $\begin{array}{l}\text { Scatter plot Diagram } \\
- \text { Zone A Residual / Zone B Residual }\end{array}$ & Adjoining test cell zones & $\begin{array}{l}\text { Show correlation between zone residual } \\
\text { values }\end{array}$ \\
\hline $\begin{array}{l}\text { Scatter plot Diagram } \\
\text {-Zone Residual / Climate Variable }\end{array}$ & All test cell zones & $\begin{array}{l}\text { Show correlation between zone residual } \\
\text { values and observed climate variable }\end{array}$ \\
\hline
\end{tabular}

\section{Histograms}

To better understand and illustrate the volume of data being analysed, histograms were used to plot the residual value for each test cell zone (Anderson, A 1989; Ramsey \& Schafer 2002; Rees, D 1989). The histograms were used to illustrate the density of the residual values along the $\mathrm{X}$ axis for each zone. The histograms allowed for the assessment of normality, skewness or kurtosis within the residual graphs (Mansour, Jutten \& Ohnishi 1998).

\section{Time-series Analysis}

Time series analysis was the second statistical method used. The use of time series graphs allowed for the comparison of residual values individually in a single test cell and of zones in different test cells (Clarke, Strachan \& Pernot 1994; Jimenez \& Madsen 2008; Jimenez, Madsen \& Andersen 2008).

A greater understanding of the residual values was gained through the observation of patterns relative to climatic inputs. In cases where the trend and/or pattern behaved in an unexpected way, this was compared to the graphs of adjoining zones in the same test cell and other test cells. 


\section{Scatter plots}

The previous forms of analysis were all of a univariate, that is: it involved a single variable. The scatter plot diagram was used as a preliminary multivariate analysis method to examine correlations between two variables (Agami Reddy 2006; Palomo, Marco \& Madsen 1991). The use of the scatter plot diagram form of analysis commenced in the analysis process and allowed for the identification of:

- unexpected differences that informed AccuRate input correction or improvement before the final empirical validation data set was obtained. As the scratch file was a character spaced input file written in Fortran format, any modifications that were not entered correctly would affect the AccuRate thermal simulation

- outlying data that required further cleaning or removal from the data analysis

- defining data relationships as homoscedastic - A scatter plot showing a homoscedastic pattern indicates a finite variance between the data on the $\mathrm{X}$ and $\mathrm{Y}$ axes. This infers a strong relationship between the two variables and can inform further investigations.

- defining data relationships as heteroscedastic - A scatter plot showing a heteroscedastic relationship indicates a variability in the relationship between the data on the $\mathrm{X}$ and $\mathrm{Y}$ axes, which may include sub-groupings of data. This may indicate that there is no relationship between the data sets or that there are other variables interfering with the data. When there are sub-groupings of data, this can indicate that the data needs to be broken into smaller groups before further analysis can occur.

\subsection{Conclusion to Methodology}

Empirically validation of the house energy rating software AccuRate for lightweight housing in a cool temperate climate, required the development of a suitable validation methodology based on the examination of previous Australian and international research. The method established in this research comprised of the following:

- construction of suitable test buildings;

- measurement of the test buildings and their external climate to obtain empirical data; 
- detailed Accurate house energy rating software simulation, which provided suitable outputs for comparison; and

- adoption of suitable methods to analyse and compare the empirical and simulated data sets.

The objective of constructing the thermal performance test cells was to provide test buildings constructed according to contemporary Australian building practices, as discussed in section 4.2. The three test cells that were constructed for this research adhered to contemporary Australian building practices and the BCA. The close supervision of their construction ensured a good quality of construction and provided information for the as-built data inputs in the detailed house energy rating thermal simulation.

The second objective was to obtain suitably measured empirical data from the test buildings, as was discussed in section 4.3. To meet this requirement an array of synchronised environmental measurements were obtained from each of the test cells and the external climate. The data from key test cell zone temperature sensors and the site climate was cleaned and provided the empirical data for comparison with the detailed AccuRate thermal simulation. The empirical climate data were used to develop a synchronised site climate file for use in the AccuRate software.

The detailed thermal simulation using the AccuRate HER software is discussed in section 4.4. The final As-built Fabric / Measured Climate AccuRate Envelope Thermal Simulation considered many inputs of a standard and non-standard nature to limit variables which could affect the calculated zone temperatures. Non-standard inputs included modifications to reflect: a free-running building, the framing factor and infiltration rates for each zone of the test cells. The resultant output temperature file from AccuRate provided a suitable data set for each zone, for comparison with the empirical data obtained from the test cell measurements.

The final objective of the methodology was to provide suitable methods to explore similarities or dissimilarities between the observed and simulated data sets, was discussed in section 4.5. The graphs provided an intuitive platform from which to discuss the research results and analysis. The use of linear, graphical, correlation scatter plot diagrams and other forms of univariate and multivariate residual analysis allowed for the exposition of differences between 
The Empirical Validation of House Energy Rating (HER) software for lightweight housing in cool temperate climates.

Dewsbury

the simulated and empirical data sets. This analysis provided a robust exposition of the complex and large volumes of data analysed. 


\section{Results, Analysis and Discussion of Empirical Validation}

\subsection{Introduction}

This chapter presents and discusses selected data that were collected and analysed in graphical form. The data are presented in four distinct analytical groupings, as follows:

1. The AccuRate default climate file is compared with data from the site weather station.

2. The various AccuRate simulation types are compared to demonstrate the appropriateness of using the As-built Fabric / Measured Climate simulation type for empirical validation.

3. Temperature measurements from each test cell zone are compared with the AccuRate simulated temperature data.

4. Statistical analysis of simulated and measured values.

The quantity of data collected and analysed was large. All data sets were of a consistent format to allow for comparison. This chapter presents only key data which reveal general trends and variations. Appendix 6 contains the complete collection of graphical and statistical analyses for the six-month empirical validation task.

The detailed simulations performed with the HER software AccuRate in this study were more comprehensive than previous HER validation activities in Australia. However, this previous research was not deemed sufficient for empirical validation, as research projects in the past used limited input adjustments such as climate, wall fabric and ventilation. However, none combined all the input variables sufficiently for an empirical validation activity (Delsante 2005-2010). Delsante (2005b; 2006a) reported the need to validate empirically the AccuRate HER software, to explore the similarity or dissimilarity between simulated and measured temperatures, for the purpose of determining algorithms within the AccuRate HER software that may require improvement.

The data for empirical validation came from both site environmental measurements and an AccuRate simulation. The output from the AccuRate software was in the form of a text file that listed the simulated hourly temperature for each zone, for a calendar year. The ten-minute 
environmental measurements were cleaned and processed into average hourly values, to accommodate the AccuRate software input requirements (The data cleaning process is described in section 4.3).

The data presented here are limited to key data gathered from as few as five sensors out of a total number of 69 sensors in each test cell. Data from the remaining sensors provide supporting data, which are not discussed in this thesis, but in the future could be used to provide further analysis and guidance as to why variations between the simulated and measured data may be occurring. 


\subsection{Climate Data}

The AccuRate software has an in inbuilt climate file for 70 differing climates within Australia. Each of these climate files was developed through the averaging of twenty or more years of data and is called a Typical Meteorological Year (TMY). In many cases there are gaps in the available data used to establish the TMY file, therefore mathematical methods were used to fill in values (Boland 1995; Stokes 2007). The gap-filling and averaging of many years of climate data create a climate file (which could be a sum of averages), which may not reflect the low and high climatic conditions of a standard day. This is examined in this section by comparing TMY: air temperature, global solar radiation and diffuse solar radiation with the corresponding site-measured values.

In discussions with CSIRO researchers, it was established that only a few key inputs were important for the detailed AccuRate thermal simulation of the test cells thermal performance. The test cells were windowless boxes and were not heated or cooled, hence there was no need to consider climatic effects on the ventilation, cooling and heating models. The levels of importance of individual climate file parameters are summarised in Table 5.1.

Similarly, the values for calendar year, moisture content and atmospheric pressure were deemed as not relevant to this research based on advice from CSIRO researchers (Delsante 2005-2010), as follows:

- The year number is not used during the envelope simulation

- The moisture content of the air is only used within the ventilation model for the simulation of evaporative cooling benefits. As these elements were not a part of this research, their values were included in the climate file but were not required to be exact.

- At the time of this research, the value for atmospheric pressure was not used during the envelope simulation 
Table 5.1: Levels of importance of climatic values for AccuRate simulation

\begin{tabular}{|c|c|c|}
\hline Critical importance & Not Important & Not Known \\
\hline $\begin{array}{l}\text { Month, } \\
\text { Day } \\
\text { Hour } \\
\text { Air temperature } \\
\text { Wind speed } \\
\text { Wind direction } \\
\text { Global solar radiation } \\
\text { Diffuse solar radiation } \\
\text { Normal direct solar } \\
\text { Radiation } \\
\text { Solar altitude } \\
\text { Solar azimuth }\end{array}$ & $\begin{array}{l}\text { Year } \\
\text { Moisture content } \\
\text { Atmospheric pressure }\end{array}$ & $\begin{array}{l}\text { Cloud cover } \\
\text { (Cloud cover is only used for the } \\
\text { night time Sol-Air calculations of the } \\
\text { building's roof space } \\
\text { (Delsante 2005-2010). }\end{array}$ \\
\hline
\end{tabular}

At the time of this undertaking, there was no method of establishing night time cloud cover for the location of the test cells. In consultation with CSIRO researchers, a cloud cover value of four (4) was adopted to indicate a night sky cloud coverage of 50\%. The selection of this value was based on studies by CSIRO researchers involving simulations with differing values for cloud cover (Delsante 2005-2010). Their studies found that there was a very small difference, (considered to be of no significance in room temperature), when different values for cloud cover were used. The data used to establish the measured climate file for this study were: a combination of site environmental measurements, mathematically derived values and the default climate file within the AccuRate software (Table 5.2).

Table 5.2: Sources of Data for Climate File

\begin{tabular}{|l|l|l|}
\hline TMY Climate file & \multicolumn{1}{|c|}{ Site-measured Values } & \multicolumn{1}{|c|}{ Mathematically Derived } \\
\hline Month & Air Temperature & Diffuse Solar Radiation \\
Day & Atmospheric Pressure & Normal Direct Solar Radiation \\
Hour & Wind speed & \\
Moisture Content & Wind Direction & \\
& Global Solar Radiation & \\
\hline
\end{tabular}

Global solar radiation was measured on site and the measured values were used by CSIRO researchers to calculate diffuse solar radiation and normal direct solar radiation values, as disused in section 4.4 . 
The graphs below were selected for discussion purposes from the complete data set in Appendix 6 . The graphs present typical comparisons of the TMY file and site-measured data for air temperature, global solar radiation and diffuse solar radiation.

\subsubsection{Air Temperature}

Figure 5.1 compares site-measured and TMY air temperatures from midnight on February 19, 2007 to midnight on February 24, 2007, which was near the end of summer and traditionally the hottest period of the year. The two data sets are significantly different in pattern and temperature value. The data sets have obvious differences in value, with the maximum temperatures for the TMY data normally following a generally curved form, whereas the measured temperatures show the dramatic effects of cloud cover or other events which have produced a more dynamic form to the graphed data. The form of the curve for the minimum temperatures was generally similar for the measured and TMY data sets. However, the diurnal range between the measured and TMY data sets are significantly different.

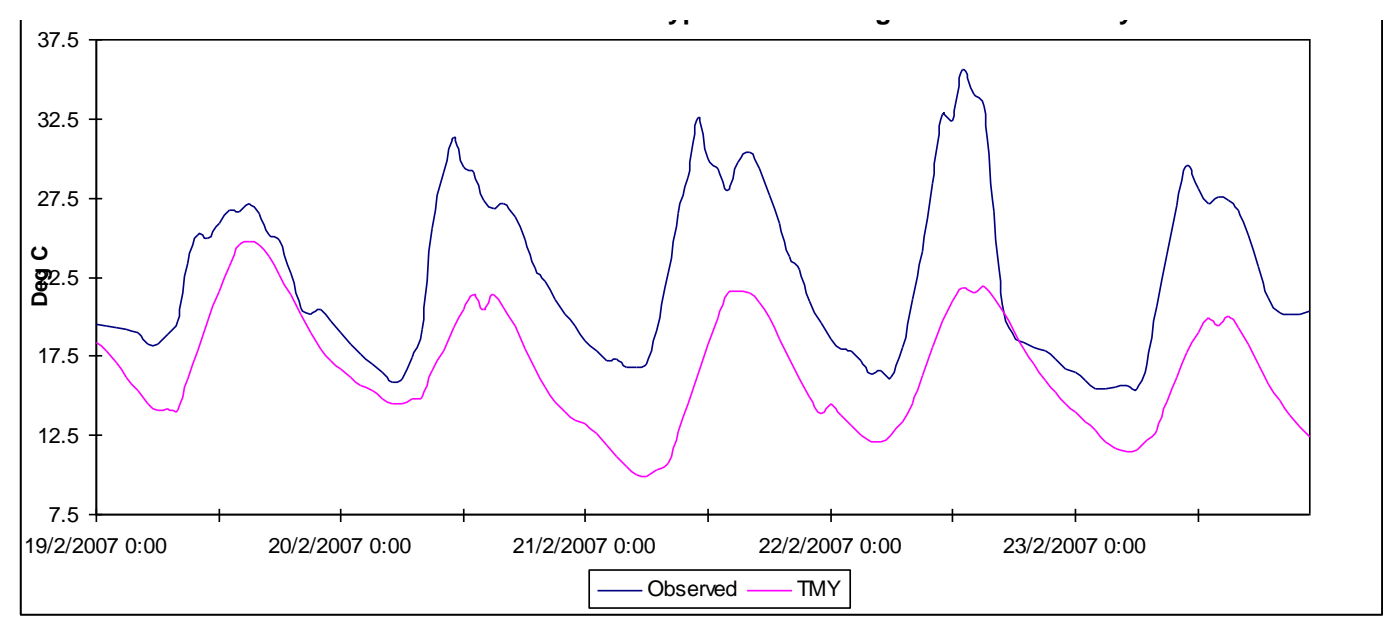

Figure 5.1 - Graph of Measured \& TMY Air Temperature Values: February 2007

Table 5.3 shows a $1.4^{0} \mathrm{C}$ difference on February 20th but for the other days the difference between default and measured minimums was between $4.1^{\circ} \mathrm{C}$ and $6.9^{\circ} \mathrm{C}$. The daily maximum air temperature also varied dramatically on a daily basis, where the variation between measured and default climate file values ranged from 2.5 to 13.7 degrees Celsius. 
Table 5.3: Measured and TMY Climate File Air Temperatures (19/02/2007 - 24/02/2007)

\begin{tabular}{|c|r|r|r|r|r|r|}
\hline Date & $\begin{array}{c}\text { TMY } \\
\text { Min. }\end{array}$ & $\begin{array}{c}\text { Measured } \\
\text { Min. }\end{array}$ & $\begin{array}{c}\text { Variation } \\
\text { (M-TMY) }\end{array}$ & $\begin{array}{c}\text { TMY } \\
\text { Max. }\end{array}$ & $\begin{array}{c}\text { Measured } \\
\text { Max. }\end{array}$ & $\begin{array}{c}\text { Variation } \\
(\text { M-TMY) }\end{array}$ \\
\hline $19 / 02 / 2007$ & $14.1^{\circ} \mathrm{C}$ & $18.3^{\circ} \mathrm{C}$ & $4.2^{\circ} \mathrm{C}$ & $24.7^{\circ} \mathrm{C}$ & $27.2^{\circ} \mathrm{C}$ & $2.5^{\circ} \mathrm{C}$ \\
\hline $20 / 02 / 2007$ & $14.5^{\circ} \mathrm{C}$ & $15.9^{\circ} \mathrm{C}$ & $1.4^{\circ} \mathrm{C}$ & $21.4^{\circ} \mathrm{C}$ & $31.3^{\circ} \mathrm{C}$ & $9.9^{\circ} \mathrm{C}$ \\
\hline $21 / 02 / 2007$ & $9.9^{\circ} \mathrm{C}$ & $16.8^{\circ} \mathrm{C}$ & $6.9^{\circ} \mathrm{C}$ & $21.6^{\circ} \mathrm{C}$ & $32.6^{\circ} \mathrm{C}$ & $11.0^{\circ} \mathrm{C}$ \\
\hline $22 / 02 / 2007$ & $12.1^{\circ} \mathrm{C}$ & $16.2^{\circ} \mathrm{C}$ & $4.1^{\circ} \mathrm{C}$ & $21.9^{\circ} \mathrm{C}$ & $35.6^{\circ} \mathrm{C}$ & $13.7^{\circ} \mathrm{C}$ \\
\hline $23 / 02 / 2007$ & $11.5^{\circ} \mathrm{C}$ & $15.4^{\circ} \mathrm{C}$ & $3.9^{\circ} \mathrm{C}$ & $20.0^{\circ} \mathrm{C}$ & $29.6^{\circ} \mathrm{C}$ & $9.6^{\circ} \mathrm{C}$ \\
\hline
\end{tabular}

Figure 5.2 shows a comparison of data from midnight on June 19, 2007 to midnight on June 24, 2007. June is the first month of winter and this data set includes the winter solstice. This week was the coldest week of the period of observation. The measured minimum temperatures are consistently lower than those of the TMY data, whereas the maximum values are somewhat similar. The pattern of the rise and fall between the maximum and minimum values is distinctly different between the two data sets.

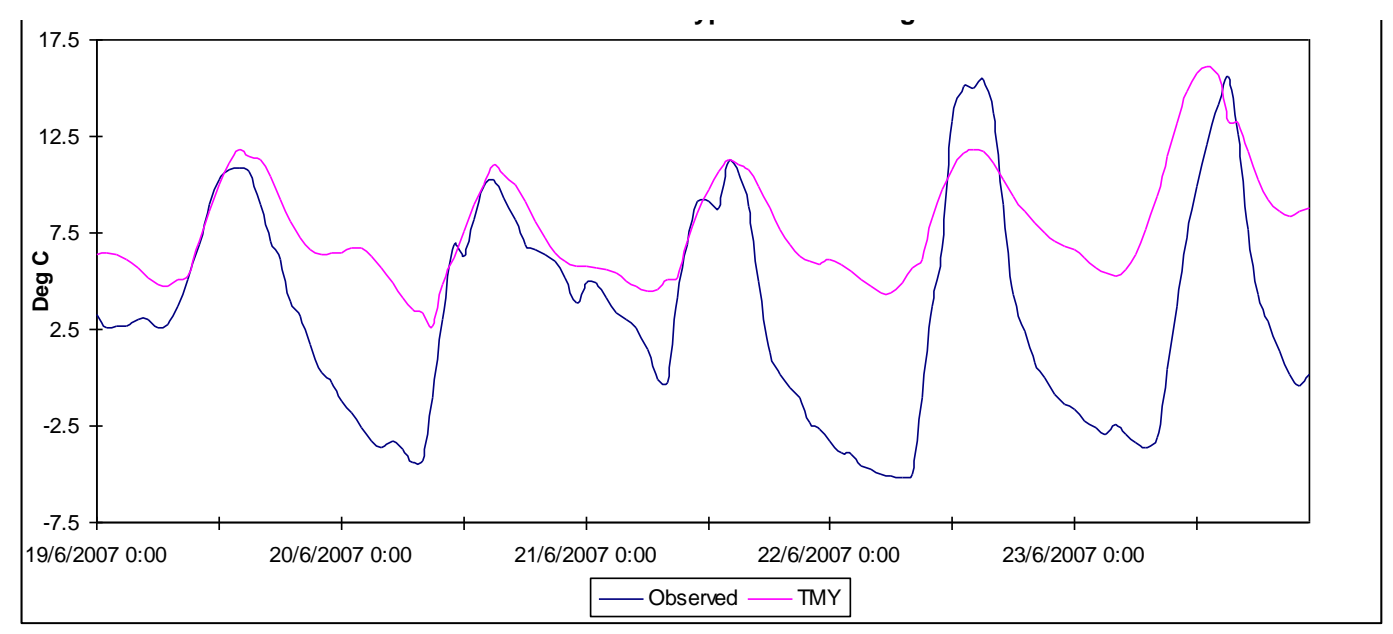

Figure 5.2 - Graph of Measured \& TMY Air Temperature Values: June 2007

Table 5.4 shows the variation in the minimum values across the five days ranged from -2.2 to -9.6 degrees Celsius and the variation between maximum values ranged from -0.9 to 3.6 degrees Celsius. 
Table 5.4: Measured and Default Climate File Air Temperatures (19/06/2007 - 23/06/2007)

\begin{tabular}{|c|c|r|r|r|r|r|}
\hline Date & $\begin{array}{c}\text { Default } \\
\text { Min. }\end{array}$ & $\begin{array}{c}\text { Measured } \\
\text { Min. }\end{array}$ & $\begin{array}{c}\text { Variation } \\
\text { (Ob-Def) }\end{array}$ & $\begin{array}{c}\text { Default } \\
\text { Max. }\end{array}$ & $\begin{array}{c}\text { Measured } \\
\text { Max. }\end{array}$ & $\begin{array}{c}\text { Variation } \\
\text { (Ob-Def) }\end{array}$ \\
\hline $19 / 06 / 2007$ & $4.8^{\circ} \mathrm{C}$ & $2.6^{\circ} \mathrm{C}$ & $-2.2^{\circ} \mathrm{C}$ & $11.8^{\circ} \mathrm{C}$ & $10.9^{\circ} \mathrm{C}$ & $-0.9^{\circ} \mathrm{C}$ \\
\hline $20 / 06 / 2007$ & $2.7^{\circ} \mathrm{C}$ & $-4.4^{\circ} \mathrm{C}$ & $-7.1^{\circ} \mathrm{C}$ & $11.0^{\circ} \mathrm{C}$ & $10.3^{\circ} \mathrm{C}$ & $-0.7^{\circ} \mathrm{C}$ \\
\hline $21 / 06 / 2007$ & $4.5^{\circ} \mathrm{C}$ & $-0.3^{\circ} \mathrm{C}$ & $-4.8^{\circ} \mathrm{C}$ & $11.3^{\circ} \mathrm{C}$ & $11.3^{\circ} \mathrm{C}$ & $0.0^{\circ} \mathrm{C}$ \\
\hline $22 / 06 / 2007$ & $4.4^{\circ} \mathrm{C}$ & $-5.2^{\circ} \mathrm{C}$ & $-9.6^{\circ} \mathrm{C}$ & $11.8^{\circ} \mathrm{C}$ & $15.4^{\circ} \mathrm{C}$ & $3.6^{\circ} \mathrm{C}$ \\
\hline $23 / 06 / 2007$ & $5.3^{\circ} \mathrm{C}$ & $-3.6^{\circ} \mathrm{C}$ & $-8.9^{\circ} \mathrm{C}$ & $16.1^{\circ} \mathrm{C}$ & $15.6^{\circ} \mathrm{C}$ & $-0.5^{\circ} \mathrm{C}$ \\
\hline
\end{tabular}

The trends in the figures show that the general daily pattern is similar, but that the maximum and minimum values are consistently different. This would cause a considerable difference between HER simulations using either the default climate file or the measured air temperature data.

\subsubsection{Global Solar Radiation}

Figure 5.3 shows a comparison of site-measured and TMY global solar radiation from midnight on April 16, 2007 to midnight on April 21, 2007. The graph shows several key features, which include: the beginning and end of positive solar radiation values are identical; the maximum values differ daily by significant quantities and the TMY data shows a mathematically derived smooth form; whereas the measured data shows the daily effects of cloud cover and other events which affect global solar radiation.

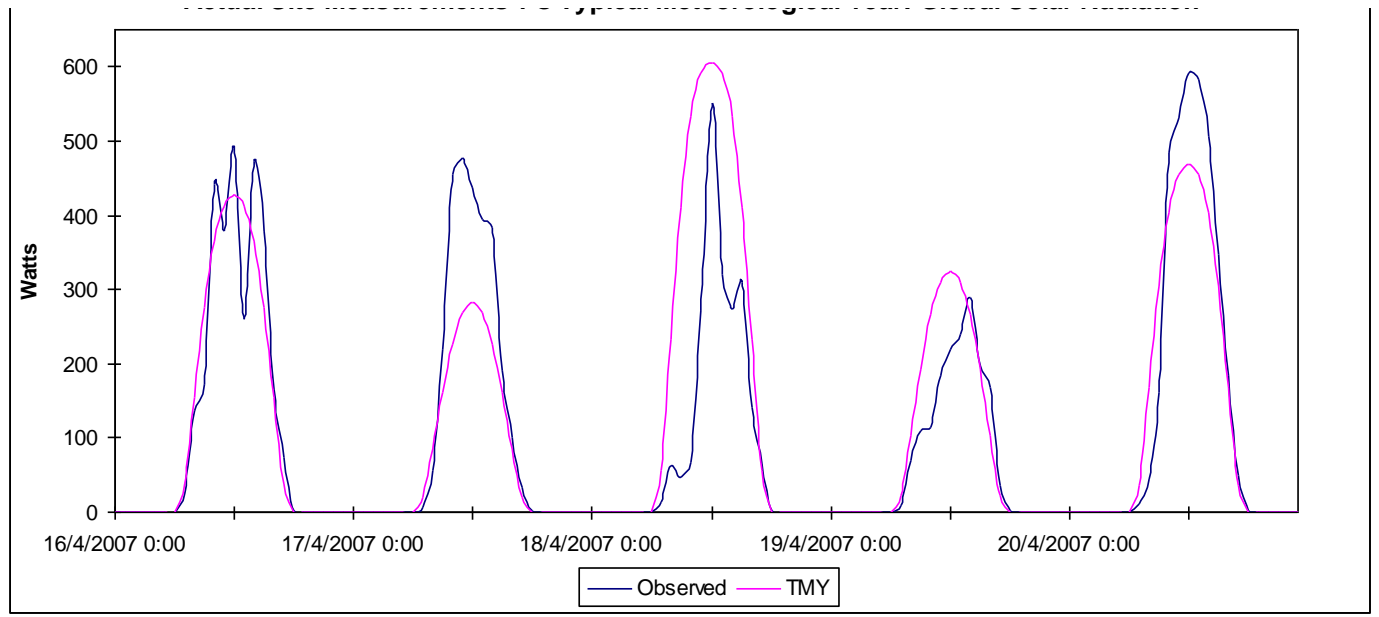

Figure 5.3 - Graph of Measured \& TMY Global Solar Radiation Values: April 2007

Table 5.5 shows the daily variation between the maximum values for the TMY and measured global solar radiation ranged from -54 to 195 Watts. 
Table 5.5: Measured and TMY Climate File Global Solar Radiation (16/04/2007-20/04/2007)

\begin{tabular}{|c|c|c|r|}
\hline Date & $\begin{array}{c}\text { TMY } \\
\text { Max. }\end{array}$ & $\begin{array}{c}\text { Measured } \\
\text { Max. }\end{array}$ & $\begin{array}{c}\text { Variation } \\
\text { (M-TMY) }\end{array}$ \\
\hline $16 / 04 / 2007$ & $428 \mathrm{~W}$ & $491 \mathrm{~W}$ & $63 \mathrm{~W}$ \\
\hline $17 / 04 / 2007$ & $282 \mathrm{~W}$ & $477 \mathrm{~W}$ & $195 \mathrm{~W}$ \\
\hline $18 / 04 / 2007$ & $606 \mathrm{~W}$ & $552 \mathrm{~W}$ & $-54 \mathrm{~W}$ \\
\hline $19 / 04 / 2007$ & $324 \mathrm{~W}$ & $289 \mathrm{~W}$ & $-35 \mathrm{~W}$ \\
\hline $20 / 04 / 2007$ & $469 \mathrm{~W}$ & $592 \mathrm{~W}$ & $123 \mathrm{~W}$ \\
\hline
\end{tabular}

Figure 5.4 shows a comparison of site-measured and TMY global solar radiation from midnight on June 19, 2007 to midnight on June 24, 2007. Similar to the discussion for Figure 5.3, this graph shows that the maximum values vary consistently between the measured and TMY data sets. Likewise, the mathematically derived form of the TMY data is by contrast starkly different to the measured data. In this sample the maximum values are significantly higher, with the variation, as shown in Table 5.6, ranging from 75 to 204 Watts values.

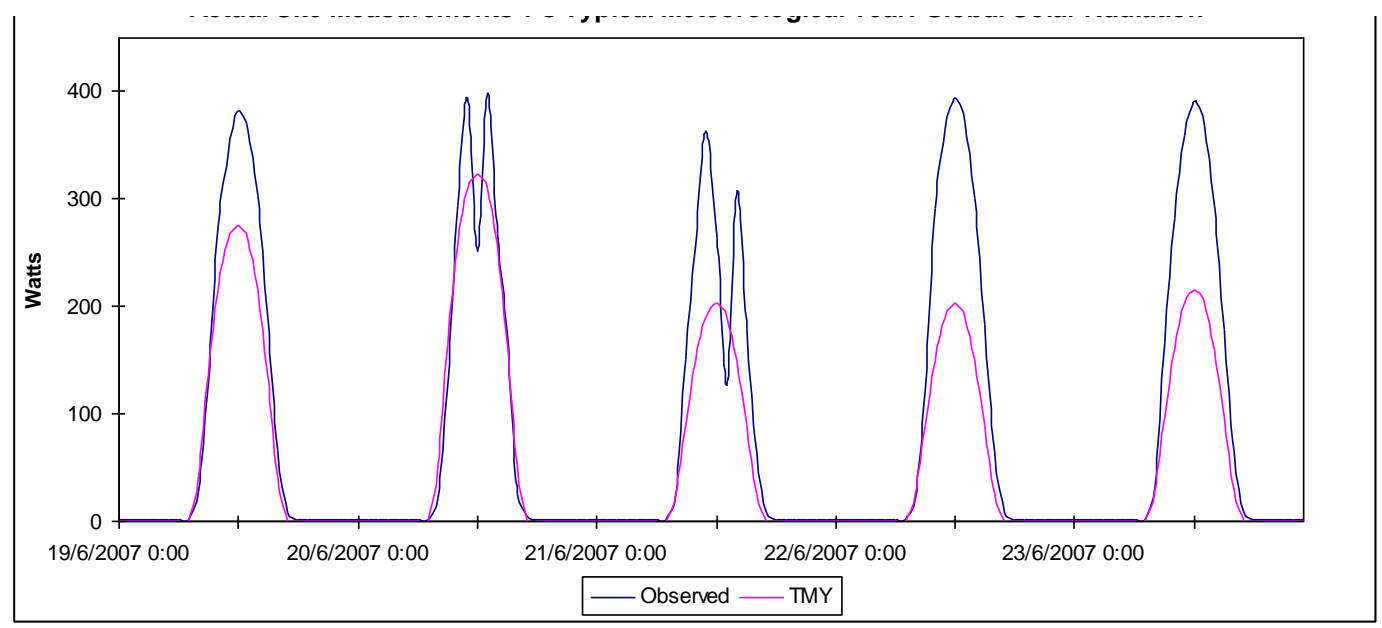

Figure 5.4 - Graph of Measured \& TMY Global Solar Radiation Values: June 2007

Table 5.6: Measured and TMY Climate File Global Solar Radiation (19/06/2007-23/06/2007)

\begin{tabular}{|c|c|c|r|}
\hline Date & $\begin{array}{c}\text { Default } \\
\text { Max. }\end{array}$ & $\begin{array}{c}\text { Measured } \\
\text { Max. }\end{array}$ & $\begin{array}{c}\text { Variation } \\
\text { (Ob-Def) }\end{array}$ \\
\hline $19 / 06 / 2007$ & $276 \mathrm{~W}$ & $382 \mathrm{~W}$ & $106 \mathrm{~W}$ \\
\hline $20 / 06 / 2007$ & $324 \mathrm{~W}$ & $399 \mathrm{~W}$ & $75 \mathrm{~W}$ \\
\hline $21 / 06 / 2007$ & $204 \mathrm{~W}$ & $364 \mathrm{~W}$ & $160 \mathrm{~W}$ \\
\hline $22 / 06 / 2007$ & $190 \mathrm{~W}$ & $394 \mathrm{~W}$ & $204 \mathrm{~W}$ \\
\hline $23 / 06 / 2007$ & $216 \mathrm{~W}$ & $392 \mathrm{~W}$ & $176 \mathrm{~W}$ \\
\hline
\end{tabular}

When comparing the two types of data, the presence of a single smooth peak in the default climate file contrasts with the measured multiple peaks. The site-measured data (at times) has dramatic falls and rises due to the effect of cloud cover. However, the default climate file values do not 
appear to account for the effect of cloud cover at all. The smooth peaks of the default climate files curve reveal that the data might have been mathematically smoothed, most likely from daily satellite values. The measured radiation varies dramatically from hour to hour; hence the impact on the thermal model would be significantly different from simulations where the more erratic solar radiation values have been smoothed, as in the case of the default climate file.

\subsubsection{Diffuse Solar Radiation}

Figure 5.5 shows a comparison of the mathematically derived diffuse solar radiation, which was calculated from the site-measured global solar radiation, and the TMY climate file diffuse solar radiation values from midnight on January 14, 2007 to midnight on January 19, 2007. As with the graphs which compared global solar radiation values, the pattern of the measured data is significantly different from the pattern of the TMY data in this graph. One difference is the result of the mathematically derived smooth form of the TMY data, as opposed to the fluctuating pattern of the site-measured data and the second is the significant difference in the maximum values, as shown in Table 5.7, which vary day to day, with the variation ranging from -27 to -231 Watts.

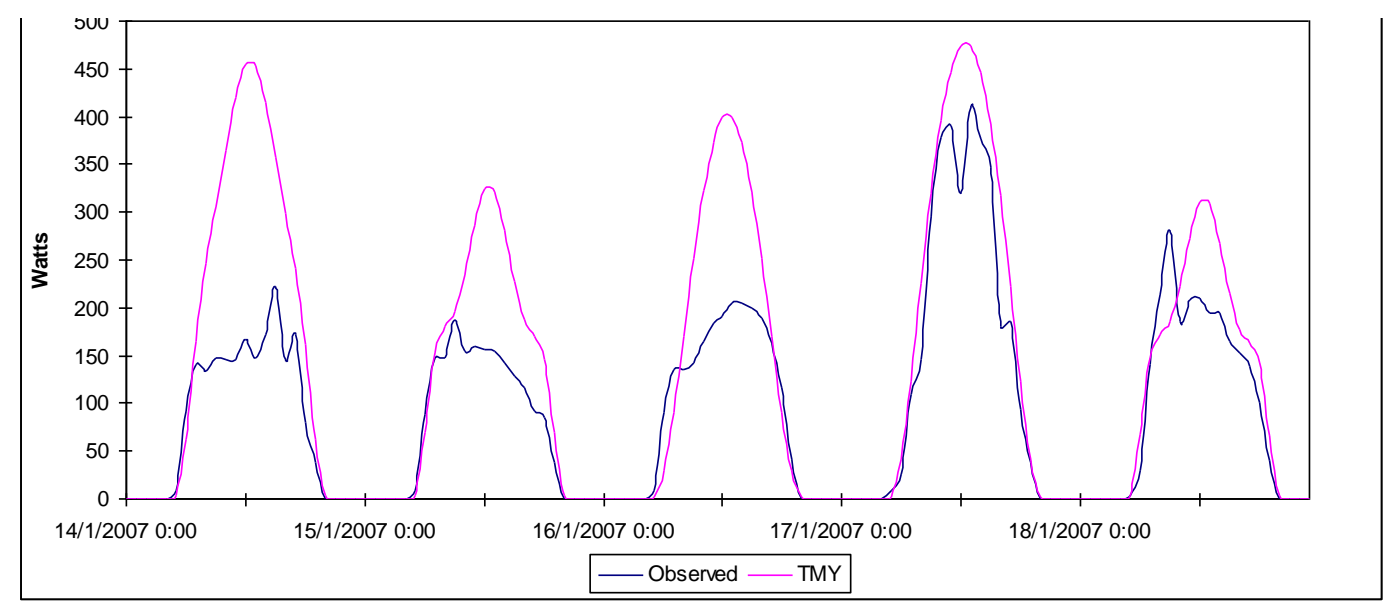

Figure 5.5 - Graph of Measured \& TMY Diffuse Solar Radiation Values: January 2007

Table 5.7: Measured and TMY Climate File Global Solar Radiation (14/01/2007-18/01/2007)

\begin{tabular}{|c|c|r|r|}
\hline Date & $\begin{array}{c}\text { TMY } \\
\text { Max. }\end{array}$ & $\begin{array}{c}\text { Measured } \\
\text { Max. }\end{array}$ & $\begin{array}{c}\text { Variation } \\
\text { (M-TMY) }\end{array}$ \\
\hline $14 / 01 / 2007$ & $454 \mathrm{~W}$ & $223 \mathrm{~W}$ & $-231 \mathrm{~W}$ \\
\hline $15 / 01 / 2007$ & $322 \mathrm{~W}$ & $188 \mathrm{~W}$ & $-134 \mathrm{~W}$ \\
\hline $16 / 01 / 2007$ & $399 \mathrm{~W}$ & $205 \mathrm{~W}$ & $-194 \mathrm{~W}$ \\
\hline $17 / 01 / 2007$ & $474 \mathrm{~W}$ & $412 \mathrm{~W}$ & $-62 \mathrm{~W}$ \\
\hline $18 / 01 / 2007$ & $309 \mathrm{~W}$ & $282 \mathrm{~W}$ & $-27 \mathrm{~W}$ \\
\hline
\end{tabular}


Figure 5.6 compares the mathematically derived diffuse solar radiation and default climate file diffuse solar radiation values from midnight on February 19, 2007 to midnight on February 24, 2007. The two data sets present very little in common, with the exception of sunrise and sunset. The measured data show the dramatic effects of cloud cover and other events that cause shifts between global and diffuse solar radiation. The TMY data once again present a mathematically derived smoothed form to the data. The graph shows that the maximum values vary consistently, with the variation ranging from 66 to 275 Watts, as shown in Table 5.8.

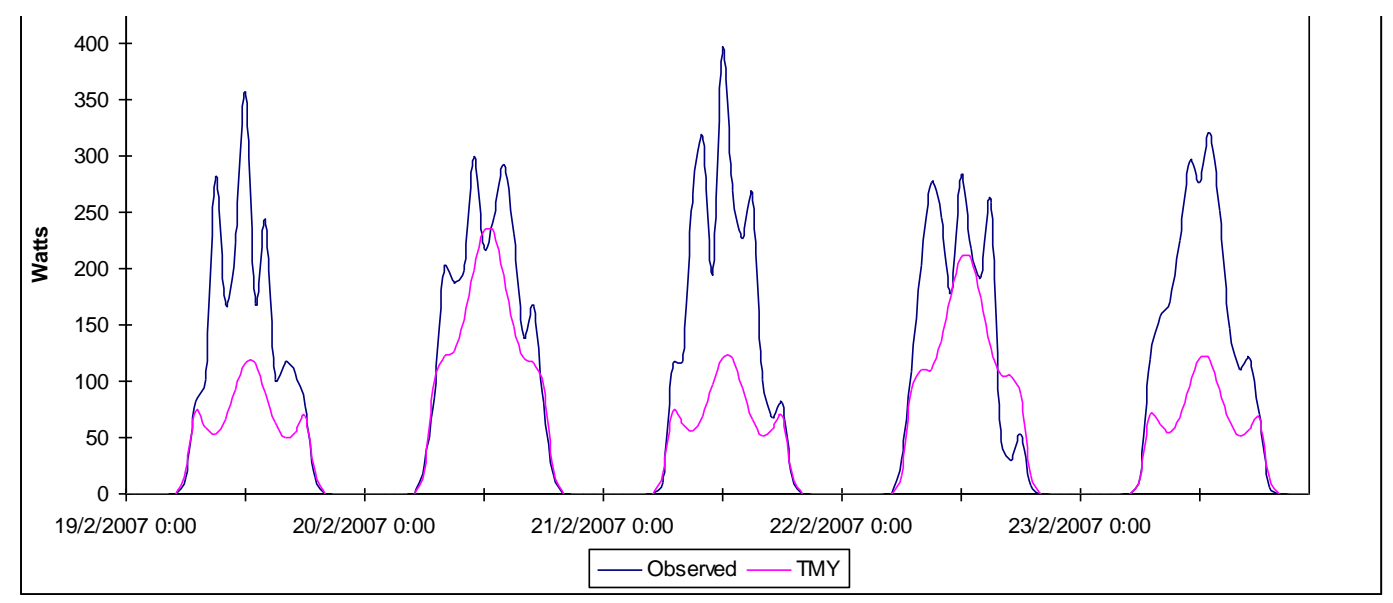

Figure 5.6 - Graph of Measured \& TMY Diffuse Solar Radiation Values: February 2007

Table 5.8: Measured and Default Climate File Global Solar Radiation (19/06/2007-23/06/2007)

\begin{tabular}{|c|c|c|r|}
\hline Date & $\begin{array}{c}\text { Default } \\
\text { Max. }\end{array}$ & $\begin{array}{c}\text { Measured } \\
\text { Max. }\end{array}$ & $\begin{array}{r}\text { Variation } \\
\text { (Ob-Def) }\end{array}$ \\
\hline $19 / 02 / 2007$ & $116 \mathrm{~W}$ & $357 \mathrm{~W}$ & $241 \mathrm{~W}$ \\
\hline $20 / 02 / 2007$ & $234 \mathrm{~W}$ & $300 \mathrm{~W}$ & $66 \mathrm{~W}$ \\
\hline $21 / 02 / 2007$ & $121 \mathrm{~W}$ & $396 \mathrm{~W}$ & $275 \mathrm{~W}$ \\
\hline $22 / 02 / 2007$ & $211 \mathrm{~W}$ & $284 \mathrm{~W}$ & $73 \mathrm{~W}$ \\
\hline $23 / 02 / 2007$ & $119 \mathrm{~W}$ & $320 \mathrm{~W}$ & $201 \mathrm{~W}$ \\
\hline
\end{tabular}

As in the global solar radiation values, the shape of the peaks for diffuse solar radiation reveal the significant difference between the measured and default climate file values. The values for diffuse solar radiation, derived mathematically from site-measured global solar radiation, differ consistently and dramatically from hour to hour and from the default climate file values. The multi-peaked pattern of the diffuse radiation impacted on the fabric of the building continuously, hence the actual thermal gains on the test cell external fabric would be different compared to the gentle curves of the default climate which must affect the thermal gains of the test cell. 


\subsubsection{Summary}

The site-measured air temperature and global solar radiation were significantly different from their corresponding values in the TMY climate file. Similarly, the mathematically-derived values for the diffuse solar radiation showed significant differences compared to their corresponding values in the TMY climate file. Variations of this magnitude would impact on the AccuRate thermal simulation for empirical validation purposes (Judkoff, R 1985). To confirm this hypothesis, the four simulation methods, (as discussed in section 4.4) were completed for each test cell and are presented in Section 5.3. 


\subsection{Variation between Simulation Types}

There is an ongoing discussion, within Australia and abroad, about the appropriateness of the methodology used to validate empirically building energy rating software. Researchers and software developers have suggested the use of site-measured climatic data and as-built fabric inputs to account for more realistic climate and construction variables than the default values in the building energy rating software (CSTB 1990). To better understand the effect of these input variables, four types of simulation were undertaken, namely:

\section{- Default Fabric / TMY Climate}

- Default Fabric / Measured Climate

- As-built Fabric / TMY Climate

- As-built Fabric / Measured Climate

As discussed in section 4.4, the amendments to the input parameters for the AccuRate simulations are insulation value (based on the actual percentage of framing factor), and infiltration rates. Two types of climate files and two types of software 'Scratch' files were created. The two climate files were the TMY climate file and a measured climate file. The two scratch files were a default scratch file and an 'as-built' scratch file. These files were mixed and matched, based on the type of HER simulation that was undertaken.

In the following sections, all four simulation types are superimposed in one graph for comparison. The graphs presented here are selected to present key trends. The complete collection of graphs is found in Appendix 6.

For all graphs the legend is:

- B-B: Default Fabric / TMY Climate

- B-C: Default Fabric / Measured Climate

- AB-B: As-built Fabric / TMY Climate

- AB-C: As-built Fabric / Measured Climate 


\subsubsection{Test Cell Subfloor}

The subfloor condition varied for each test cell. The subfloor of the unenclosed-perimeter platform-floored test cell (see Appendix 6) is the most affected by the external environment, whilst the concrete slab-on-ground floored test cell room is the most affected by the ground temperature. As expected there is an apparent heat loss through the uninsulated platform floors (Harris, D \& Dudek 1997). The subfloor of the enclosed-perimeter platform-floored test cell is affected by the ground and environmental temperatures.

This discussion concentrates on test cell 2, which had an enclosed subfloor zone. The variation between simulation types for the subfloor of the enclosed-perimeter platform-floored test cell (Figure 5.7) is significant. Compared to the changes in the fabric inputs, the measured climate has a more significant effect in the simulation. Compared to the unenclosed-perimeter (see Appendix 6) there was an obvious difference in AccuRate HER simulation results in the enclosed-perimeter test cell, when the As-built fabric data was applied to the model.

The As-built / Measured Climate simulation produced a colder subfloor zone, taking into account the much cooler temperatures measured on-site. The variation between the As-built and Default fabric for this zone was principally caused by the infiltration rate and interaction with the test cell room. It can be seen that as each modification was made, (climate type and as-built fabric), the simulated temperatures became significantly cooler for this four day period.

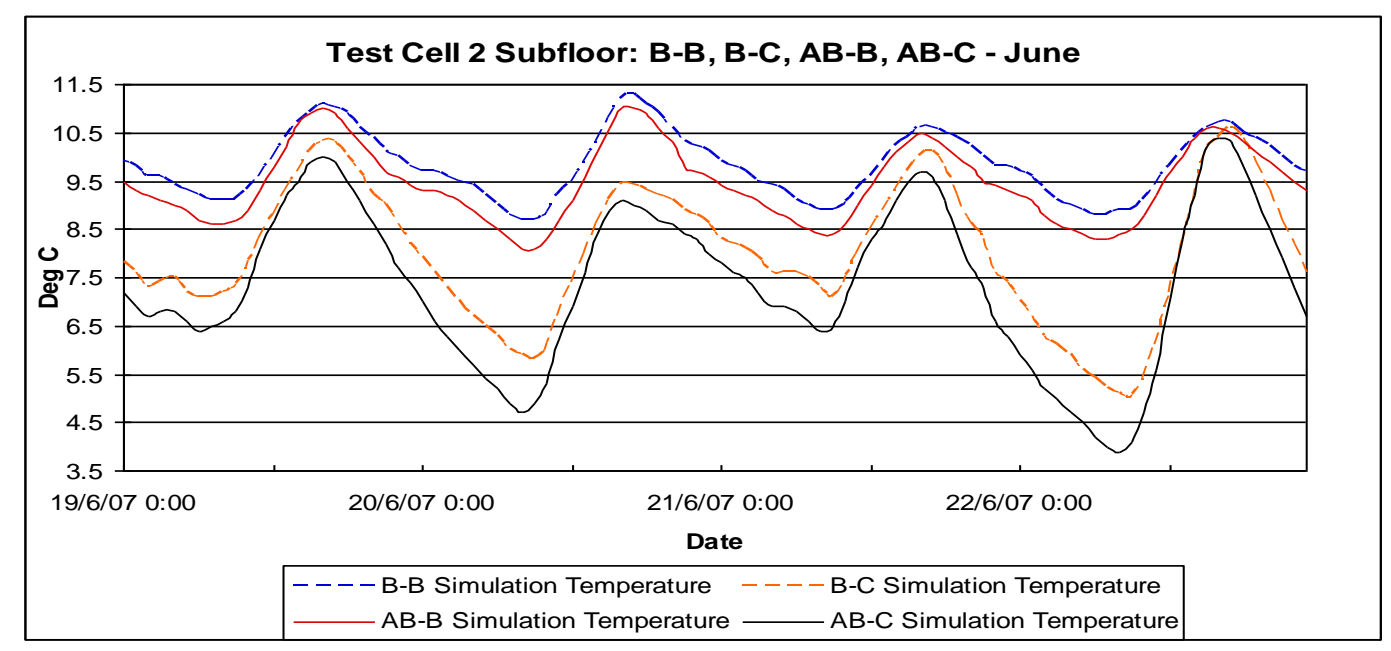

Figure 5.7 - Test Cell 2 Subfloor: B-B, B-C, AB-B, AB-C Results: June 2007 
An analysis of the daily minimum subfloor air temperatures, as shown in Table 5.9, illustrates that the minimum simulation temperature for June 19, ranged from a highest minimum value of $9.1{ }^{\circ} \mathrm{C}$ for the Default Fabric / TMY Climate (B-B) simulation, to a lowest minimum value of $6.4^{\circ} \mathrm{C}$ for the As-built Fabric / Measured Climate (AB-C) simulation. For all four days the highest minimum air temperature was produced by the Default Fabric / TMY Climate (B-B) simulation and the lowest minimum air temperature was produced by the As-built Fabric / Measured Climate (AB-C) simulation.

Table 5.9: Test Cell 2: Comparison of Minimum \& Maximum Values of Simulated Subfloor Air Temperature $(19 / 06 / 2007-22 / 06 / 2007)$

\begin{tabular}{|c|r|r|r|r|r|r|r|r|r|r|}
\hline Date & $\begin{array}{c}\text { B-B } \\
\text { Min }\end{array}$ & $\begin{array}{c}\text { B-B } \\
\text { Max }\end{array}$ & $\begin{array}{c}\text { AB-B } \\
\text { Min }\end{array}$ & $\begin{array}{c}\text { AB-B } \\
\text { Max }\end{array}$ & $\begin{array}{c}\text { B-C } \\
\text { Min }\end{array}$ & $\begin{array}{c}\text { B-C } \\
\text { Max }\end{array}$ & $\begin{array}{c}\text { AB- } \\
\text { C } \\
\text { Min }\end{array}$ & $\begin{array}{c}\text { AB-C } \\
\text { Max }\end{array}$ \\
\hline $19 / 06 / 2007$ & 9.1 & 11.0 & 8.6 & 11.0 & 7.1 & 10.3 & 6.4 & 10.0 \\
\hline $20 / 06 / 2007$ & 8.7 & 11.3 & 8.1 & 11.0 & 5.8 & 6.4 & 4.7 & 9.1 \\
\hline $21 / 06 / 2007$ & 8.9 & 10.6 & 8.4 & 10.5 & 7.1 & 7.1 & 6.4 & 6.5 \\
\hline $22 / 06 / 2007$ & 8.8 & 10.6 & 8.3 & 10.6 & 5.0 & 10.4 & 3.9 & 10.5 \\
\hline
\end{tabular}

An analysis of the daily maximum zone air temperature values, as shown in Table 5.9, illustrates that the maximum simulation temperature, (for June 20), varied from $11.3^{\circ} \mathrm{C}$ for the Default Fabric / TMY Climate (B-B) simulation to a minimum of $9.1^{\circ} \mathrm{C}$ for the As-built / Measured Climate (ABC) simulation. For all four days in this table the highest maximum air temperature is produced by the Default Fabric / TMY Climate (B-B) simulation and the lowest maximum is generally produced by the As-built Fabric / Measured Climate (AB-C) simulation.

The above mentioned trends for the subfloor zone maximum and minimum simulation air temperatures of the enclosed-perimeter platform-floored test cell were common for the months of May and June but as for the subfloor simulations of the unenclosed-perimeter platform-floored test cell, the trend varies from month to month (see Appendix 6).

As shown in Figure 5.7, the use of the measured climate data significantly shifts the simulated temperature curve. Hence, if the measured climate data is not used in the simulation and then compared to measured temperatures from the subfloor zone, the comparison would be unreliable for empirical validation purposes. What is apparent for the enclosed-perimeter subfloor zone is the need to include the As-built fabric inputs and measured infiltration. In simulations using measured climate data, the difference in temperatures with default fabric inputs compared to As-built fabric 
inputs ranges from $0^{\circ} \mathrm{C}$ to $2^{\circ} \mathrm{C}$. The purpose of empirical validation is to improve or fine-tune the HER software (Strachan, Kokogiannakis \& MacDonald 2005). These results demonstrate that if As-built Fabric and Measured on-site Climate inputs were used in the validation process, more realistic trends and climatic effects can be adequately examined to inform the process of improving HER software.

\subsubsection{Test Cell Room}

The main variation in the AccuRate HER simulation output air temperatures of the concrete slabon-ground floored test cell room appears to be caused by the climate data (Figure 5.8). The two simulations which applied the TMY climate file are similar. The same observation can be made for the two simulation types which applied the measured climate data. For this test cell room the effect of the As-built Fabric modifications is quite visible, with consistent differences between the HER simulation types. During this four day period the As-built / Measured climate simulation produced significantly warmer air temperatures for the test cell room.

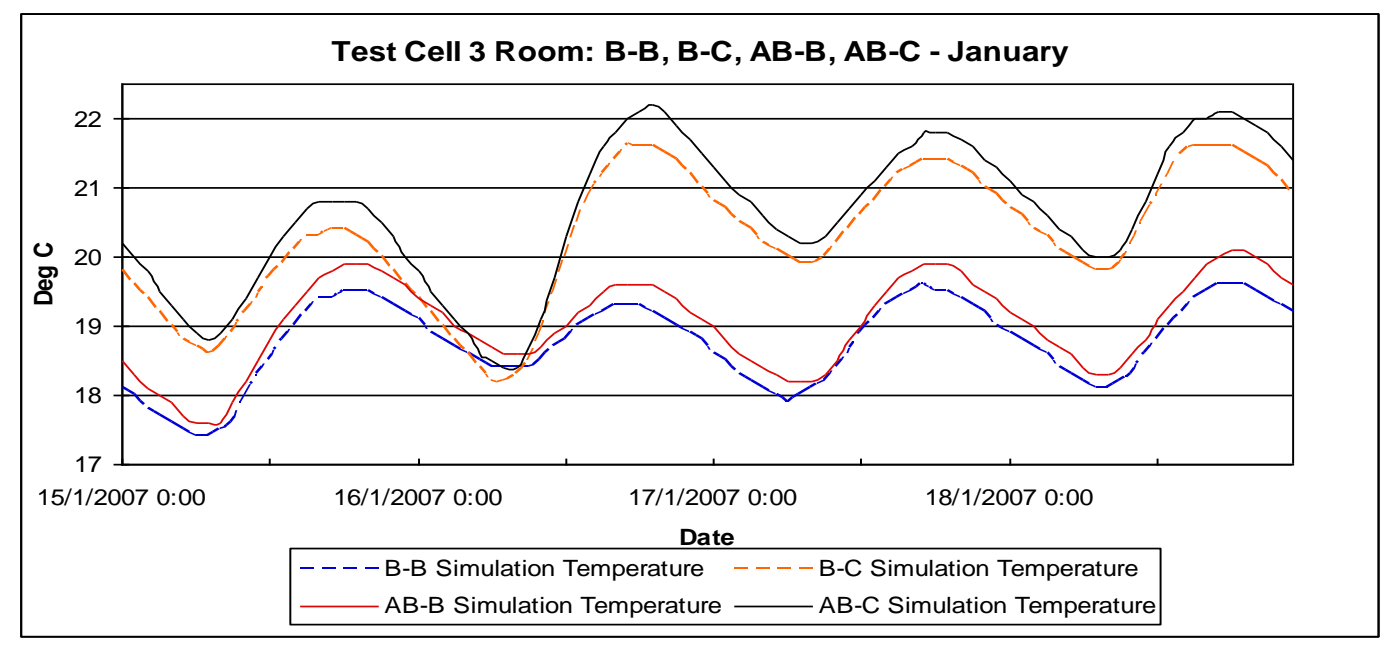

Figure 5.8 - Test Cell 3 Room: B-B, B-C, AB-B, AB-C Results: January 2007

An analysis of the daily minimum and maximum HER simulation values, as shown in Table 5.10, illustrates that on January 17, the variation in minimum simulation air temperatures ranged from $17.9^{\circ} \mathrm{C}$ to $20.2^{\circ} \mathrm{C}$ and the maximum air temperatures varied from $19.6^{\circ} \mathrm{C}$ to $21.8^{\circ} \mathrm{C}$. This data reveals two distinct trends: 
- the data presented from the various HER simulations for the $15^{\text {th }}$ to the $18^{\text {th }}$ of January varied by up to $2.2^{\circ} \mathrm{C}$ for the maximums and up to $2.3^{\circ} \mathrm{C}$ for the minimums

- when the site climate file was used, the maximum HER simulation temperatures were consistently much higher in value than the default climate file.

The As-built / Measured Climate (AB-C) simulated air temperatures for this test cell room were consistently warmer than the Default Fabric / TMY Climate (B-B) simulations from January to May 2007. For the month of June this pattern was reversed, with the As-built / Measured Climate $(\mathrm{AB}-\mathrm{C})$ and the Default Fabric / Measured Climate (B-C) simulations, having a lower maximum temperature than the Default Fabric / TMY Climate (B-B) and the As-built Fabric / TMY Climate (AB-B) simulations (see Appendix 6). The shift in pattern reinforces the earlier observation that the TMY climate file may be reducing the climatic temperature differences between winter and summer.

Table 5.10: Test Cell 3: Comparison of Minimum Values of Simulated Test Cell Room Air Temperature $(15 / 01 / 2007-18 / 01 / 2007)$

\begin{tabular}{|c|c|c|c|c|c|c|c|c|c|c|c|}
\hline Date & $\begin{array}{c}\text { B-B } \\
\text { Min }\end{array}$ & $\begin{array}{c}\text { B-B } \\
\text { Max }\end{array}$ & $\begin{array}{c}\text { AB-B } \\
\text { Min }\end{array}$ & $\begin{array}{c}\text { AB-B } \\
\text { Max }\end{array}$ & $\begin{array}{c}\text { B-C } \\
\text { Min }\end{array}$ & $\begin{array}{c}\text { B-C } \\
\text { Max }\end{array}$ & $\begin{array}{c}\text { AB-C } \\
\text { Min }\end{array}$ & $\begin{array}{c}\text { AB-C } \\
\text { Max }\end{array}$ \\
\hline $15 / 01 / 2007$ & 17.4 & 19.5 & 17.6 & 19.9 & 18.6 & 20.4 & 18.8 & 20.8 \\
\hline $16 / 01 / 2007$ & 18.4 & 19.3 & 18.6 & 19.6 & 18.2 & 21.6 & & 18.4 & 22.2 \\
\hline $17 / 01 / 2007$ & 17.9 & 19.6 & 18.2 & 19.9 & 19.9 & 21.4 & 20.2 & 21.8 \\
\hline $18 / 01 / 2007$ & 18.1 & 19.6 & 18.3 & 20.1 & 19.8 & 21.6 & & 20.0 & 22.1 \\
\hline
\end{tabular}

Considering all three test cell rooms, the analysis of the results from the four types of AccuRate HER simulation revealed that if a measured on-site climate file is not used for the simulation, unacceptable variations in simulation output data would occur, making the comparison of measured test cell room and HER simulation temperatures very unreliable.

What is also apparent from the analysis of data for the test cell room simulations is the varying impact of the As-built Fabric inputs. The inputs had the least visible impact on the unenclosed platform-floored test cell room and a greater impact was observable on the enclosed-perimeter platform-floored and concrete slab-on-ground floored test cell rooms. 


\title{
5.3.3. Test Cell Roof Space
}

Although the subfloor and external wall materials and systems varied for the three thermal performance test cells, the roof space construction was identical. Each had a timber truss roof, sarking and sheet metal roofing, with bulk insulation on the ceiling to the room below. During the empirical validation period, each roof space was exposed to the same level of solar radiation, external air temperature and wind. Principal elements that could cause differences in the HER simulation of the three roof spaces included the infiltration rate and heat flow to or from the test cell room below. The infiltration method used by the AccuRate HER software utilises the formula shown in Equation 5.1 (AccuRate 2007; Delsante 2006b). As the three test cells had the same terrain category (Clarke 2001) and the same external wind speed, the only difference was the measured infiltration rates. The measurement of the infiltration rates for the three test cells is discussed in section 4.3. The calculated values of A and B infiltration factors (which were based on the tracer gas measurements) are shown below in Table 5.11.

\author{
Equation 5.1 - Infiltration Formula Used by the AccuRate HER Software \\ Infiltration in Air Changes per Hour (ACH) \\ $\operatorname{Inf} .=A+B^{*} v$ \\ Where: \\ $A=$ Infiltration Constant $(\mathrm{ACH})$ \\ $\mathrm{B}=$ Increased effect based on wind speed $(\mathrm{ACH})$ \\ $\mathrm{V}=$ wind speed in $\mathrm{m} / \mathrm{s}$ multiplied by a terrain factor \\ (Delsante 2006b)
}

Table 5.11: Measured Roof Space Infiltration Rates

\begin{tabular}{|l|c|c|}
\hline \multicolumn{1}{|c|}{ Test Cell } & $\mathrm{A}(\mathrm{ACH})$ & $\mathrm{B}$ \\
\hline $\begin{array}{l}\text { Unenclosed-perimeter platform-floored test cell } \\
\text { (Test cell 1) }\end{array}$ & 0.438 & 0.568 \\
\hline $\begin{array}{l}\text { Enclosed-perimeter platform-floored test cell } \\
\text { (Test cell 2) }\end{array}$ & 0.160 & 0.190 \\
\hline $\begin{array}{l}\text { Concrete slab-on-ground floored test cell } \\
\text { (Test cell 3) }\end{array}$ & 0.000 & 0.275 \\
\hline
\end{tabular}

This diversity in infiltration rate is surprising, considering the constructed similarity of the roof spaces. While there are several possible explanations, and this would require further testing, one likely cause may be variations in the eave construction. This difference in infiltration rates should be evident in the results for the Accurate HER simulations. 
The results of the roof space HER simulations for the enclosed-perimeter platform-floored test cell (Figure 5.9) reveal that the primary factor affecting roof space air temperature is the climate. However, as much as the minimum values are alike for simulations using the same climate file, there is an obvious difference between the mid to maximum temperatures when the As-built and Default Fabric simulations are compared. For this four day period the hottest roof space temperatures result from the As-built Fabric / Measured Climate (AB-C) simulation and the significantly different coolest roof space results from the Default Fabric / TMY Climate (B-B) simulation.

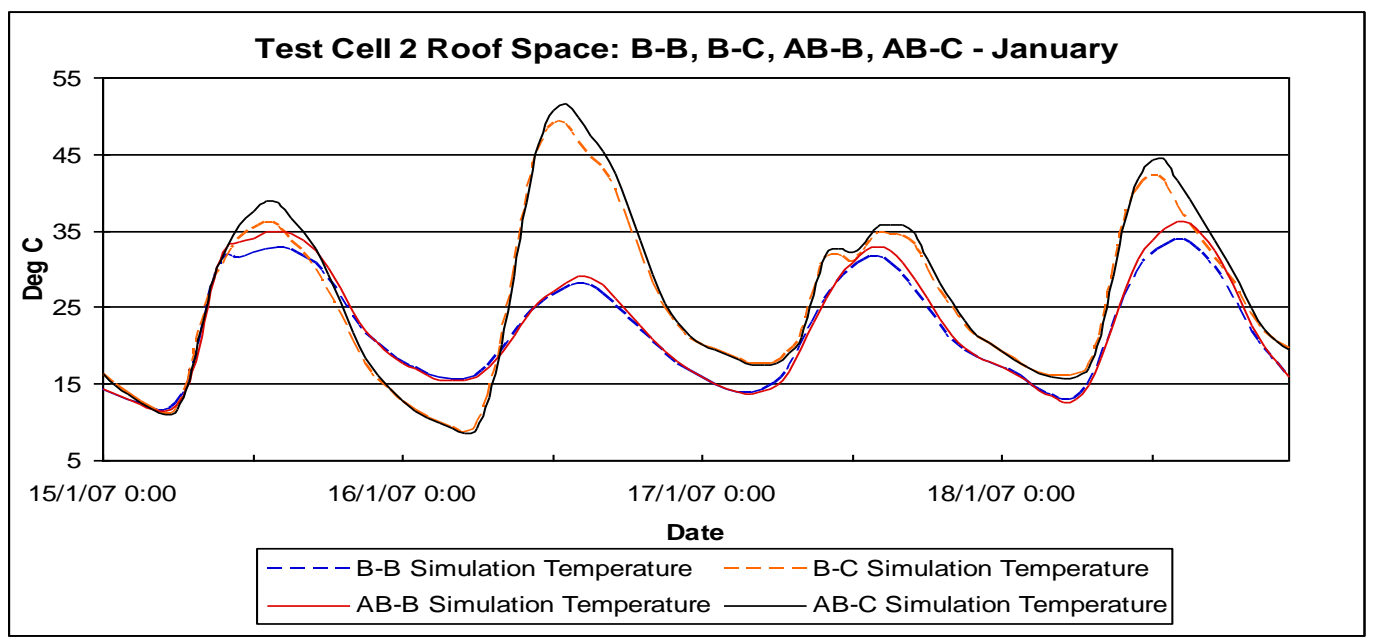

Figure 5.9 - Test Cell 2 Roof Space: B-B, B-C, AB-B, AB-C Results: January 2007

For the enclosed-perimeter platform-floored test cell, Table 5.12 shows that the minimum temperatures ranged from 8.6 to 15.4 degrees Celsius and the maximum values ranged from $28.0^{\circ} \mathrm{C}$ to $51.6^{\circ} \mathrm{C}$ on January 16 . The simulated minimum temperatures for the Default and Asbuilt simulations are identical for each type of climate file. The Default and As-built maximum values vary by up to $2.8^{\circ} \mathrm{C}$ which can be attributed to the As-built Fabric modifications.

Table 5.12: Test Cell 2: Comparison of Minimum \& Maximum Values of Simulated Test Cell Roof Space Air Temperature (15/01/2007-18/01/2007)

\begin{tabular}{|c|c|c|c|r|r|r|r|r|r|r|}
\hline Date & $\begin{array}{c}\text { B-B } \\
\text { Min }\end{array}$ & $\begin{array}{c}\text { B-B } \\
\text { Max }\end{array}$ & $\begin{array}{c}\text { AB-B } \\
\text { Min }\end{array}$ & $\begin{array}{c}\text { AB-B } \\
\text { Max }\end{array}$ & $\begin{array}{c}\text { B-C } \\
\text { Min }\end{array}$ & $\begin{array}{c}\text { B-C } \\
\text { Max }\end{array}$ & $\begin{array}{c}\text { AB-C } \\
\text { Min }\end{array}$ & $\begin{array}{c}\text { AB-C } \\
\text { Max }\end{array}$ \\
\hline $15 / 01 / 2007$ & 11.5 & 32.7 & & 11.5 & 34.8 & 11.0 & 36.1 & 11.0 & 38.9 \\
\hline $16 / 01 / 2007$ & 15.4 & 28.0 & & 15.4 & 29.1 & 8.6 & 48.8 & 8.6 & 51.6 \\
\hline $17 / 01 / 2007$ & 17.4 & 31.5 & 17.4 & 33.0 & 17.5 & 34.4 & 17.5 & 35.7 \\
\hline $18 / 01 / 2007$ & 16.0 & 33.8 & & 16.0 & 36.3 & 15.8 & 42.0 & 15.8 & 44.3 \\
\hline
\end{tabular}


For all three test cells, the roof space HER simulations were most affected by the climate file in use, with $23.6^{\circ} \mathrm{C}$ difference in maximum temperature, (on January 16), for Test Cell 2. When comparing the data from the other roof space graphs in Appendix 6, the HER simulation which incorporates the Measured Climate and As-built Fabric inputs has higher maximum values until either May or June. During the months of May and June the maximum values are lower for the HER simulations using the site-measured climate file. This further supports the notion that the default climate file has reduced the peak temperatures of the warmer months and raised the minimum temperatures of the colder months.

\subsubsection{Summary}

When all the data from the four types of HER simulation of the three test cells are examined, some definitive trends are observable, namely:

- Regardless of zone type and the temperature ranges, climate has the greatest impact on the HER simulation output. If a site-measured climate file were not used for empirical validation purposes, differences of up to $+12.5^{\circ} \mathrm{C}$ and $-16.8^{\circ} \mathrm{C}$ would significantly effect any envelope simulation and compromise any comparison.

- The As-built Fabric inputs had a wide range of effects on the simulation results, primarily on the maximum values for the zone temperatures. In most cases the minimum temperature values were unchanged, which is an interesting phenomenon requiring further investigation. The subtle differences created by the inclusion of the As-built Fabric inputs in the HER simulations were apparent and demonstrate a requirement for their inclusion for the envelope simulation.

- In the warmer months, all the AccuRate simulations which used the TMY climate file tended to have calculated temperatures which were cooler than the simulations using the site-measured climate file. In the cooler months, all the AccuRate simulations which used the TMY climate file tended to have calculated temperatures which were warmer than the simulations using the site-measured climate file. This indicates that there has been a flattening of the maximum and minimum temperature values, during the development of the TMY climate files used by the software. Using the TMY climate file will therefore lead to an underestimation of cooling and heating requirements. 
- Other research has shown that the conductivity values for built assemblages and individual materials can differ from the values built into the HER software (Ahmad, Q \& Szokolay 1993; Guyon, G, Moinard \& Ramdani 1999a; LomasEppel et al. 1994). This could be a factor in the differences shown here between the measured and simulated temperatures and requires further investigation. 


\subsection{Empirical Validation Graphs}

\subsubsection{Unenclosed-perimeter Platform-floored Test Cell}

It has been shown that for empirical validation purposes, the simulation used should be of the AsBuilt Fabric / Measured Climate (AB-C) type. In the following discussions, the term "simulation" refers to the AB-C type.

The unenclosed-perimeter platform-floored test cell has three zones, namely: a subfloor, a room and a roof space. It was expected that this test cell would have the greatest range of temperatures because it is, relatively, the most lightweight of the three test cells and it is the most open to the external environment. The unenclosed subfloor was in a direct environmental exchange with the external climate, with some heat loss to or gain from the test cell room and the ground. The roof space was affected by:

- the external environmental temperature

- day time solar radiation gains and night time losses, and

- heat gain from or losses to the room.

The test cell room exchanged heat with the external environment through the walls, as well as the subfloor and roof space. To simplify the analysis, as shown in Table 5.13, below, details the average differences between the measured and simulated minimum and maximum temperatures from the three zones of the unenclosed-perimeter platform-floored test cell. Thus to better understand the relationship between the adjacent zones, the data below is presented in the order: subfloor; roof space; room. 
Table 5.13: Average Difference between Measured and Simulated Minimum \& Maximum Temperatures (Unenclosed-perimeter Platform-floored Test Cell)

\begin{tabular}{|c|r|r|r|r|r|r|}
\hline & \multicolumn{3}{|c|}{$\begin{array}{c}\text { Daily Minimum Temperature } \\
\text { (Measured - Simulated) }\end{array}$} & \multicolumn{3}{c|}{$\begin{array}{c}\text { Daily Maximum Temperature } \\
\text { (Measured - Simulated) }\end{array}$} \\
\hline & Subfloor & \multicolumn{1}{|c|}{ Room } & \multicolumn{1}{c|}{ Roof } & \multicolumn{1}{c|}{ Subfloor } & \multicolumn{1}{c|}{ Room } & \multicolumn{1}{c|}{ Roof } \\
\hline January & 2.64 & 5.08 & 5.44 & 0.65 & 2.3 & 0.98 \\
\hline February & 2.56 & 4.96 & 5.48 & -2.29 & 1.73 & -0.98 \\
\hline March & 2.97 & 4.70 & 4.95 & 1.47 & 3.28 & 1.91 \\
\hline April & 2.58 & 4.43 & 4.94 & -0.75 & 1.98 & 1.31 \\
\hline May & 1.98 & 3.75 & 5.37 & 1.16 & 2.95 & 3.53 \\
\hline June & 3.24 & 4.38 & 3.58 & -0.32 & 1.48 & 1.16 \\
\hline
\end{tabular}

\section{Test Cell Subfloor}

Figure 5.10 to Figure 5.13 show the variation between the simulated and measured temperatures in the subfloor zone of this test cell. The graphs show that the measured maximum value was:

- lower than simulated values in the hottest month of February

- of a similar value in the months of April and June

- higher in value in the months of March and May

- However, in all three graphs, the simulated minimum temperatures are significantly lower than the measured temperatures.

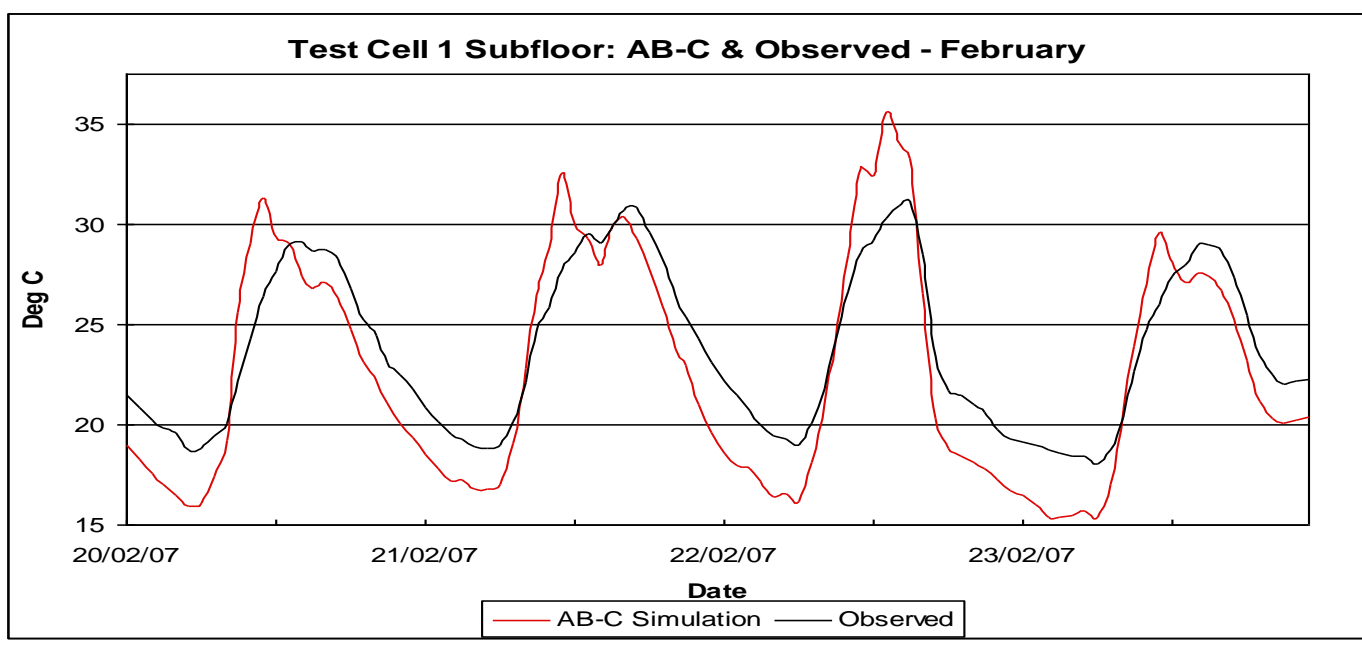

Figure 5.10 - Test Cell 1 Subfloor: AB-C \& Measured Results: February 2007 
Figure 5.10 shows the variation between the assumed subfloor condition, where it is the same as the on-site climate and the micro-climate that has been established by the test cell building. The temperature within the subfloor zone does not get as hot or as cold as the on-site climate. On February 22 there was a $5^{\circ} \mathrm{C}$ difference between the measured and simulated maximum temperature. The differences for the maximum temperatures fluctuate from month to month, as shown in Table 5.13 and there seems to be no obvious link to seasonal conditioning.

In the graph for May 2007 (Figure 5.12) the simulated temperature of the subfloor zone is $1.5^{\circ} \mathrm{C}$ to $2.0^{\circ} \mathrm{C}$ warmer when compared to measured for both day and night time conditions. However, for all months the difference in the minimum values ranged from $1.98^{\circ} \mathrm{C}$ to $3.24^{\circ} \mathrm{C}$, with the highest difference being in June (Figure 5.13). The month to month variation can be explained largely by the fact that the AccuRate software assumed that the temperature of the subfloor zone was the same temperature as the site air temperature (Delsante 2005-2010).

The results in this study show that this is not the case. The results could indicate that in the hotter months (January to March) there is a partial ground keying effect that cools the subfloor in the day time and due to environmental thermal lag, warms the subfloor at night. This concept is further reinforced in the cooler months (May to June) when the measured temperature is warmer than the simulated temperature during both day and night, indicating that some heat is given off by the ground to the subfloor, creating an intermediate subfloor zone temperature, softening the full effect of the cool winter air temperature. Whether the intermediate ground zone effect fluctuates will be explored in further analysis.

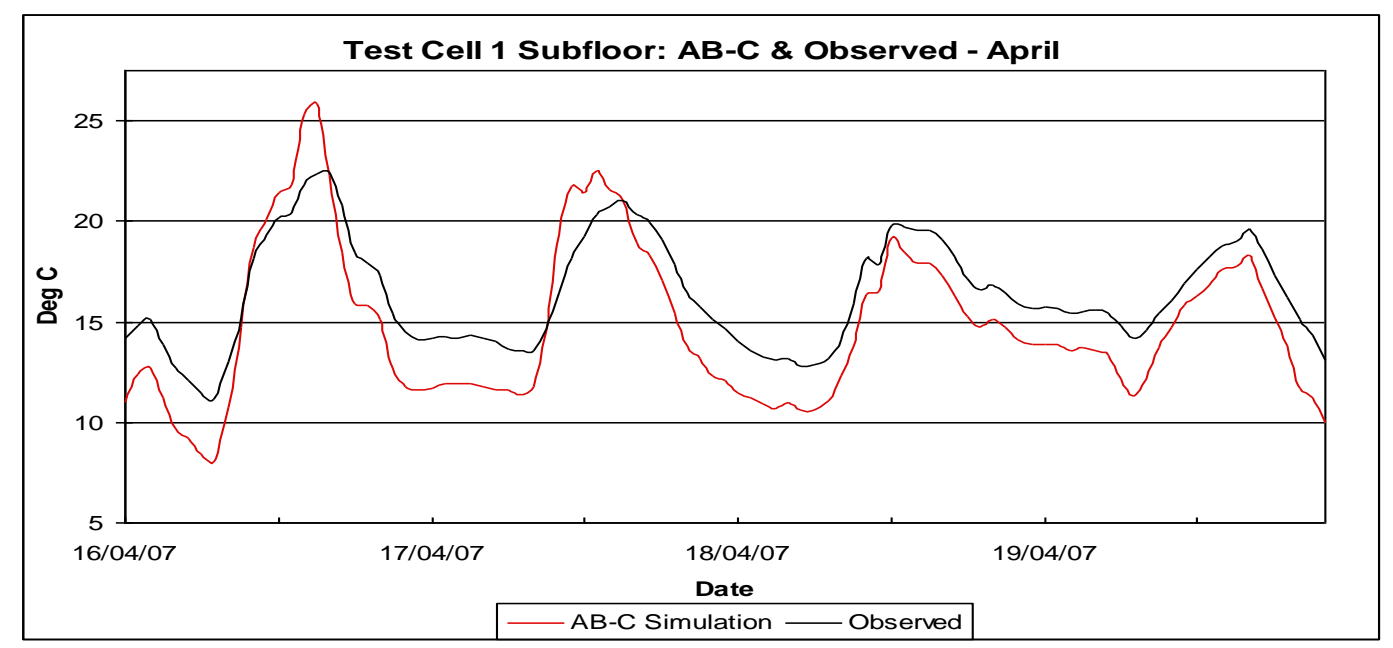

Figure 5.11 - Test Cell 1 Subfloor: AB-C \& Measured Results: April 2007 


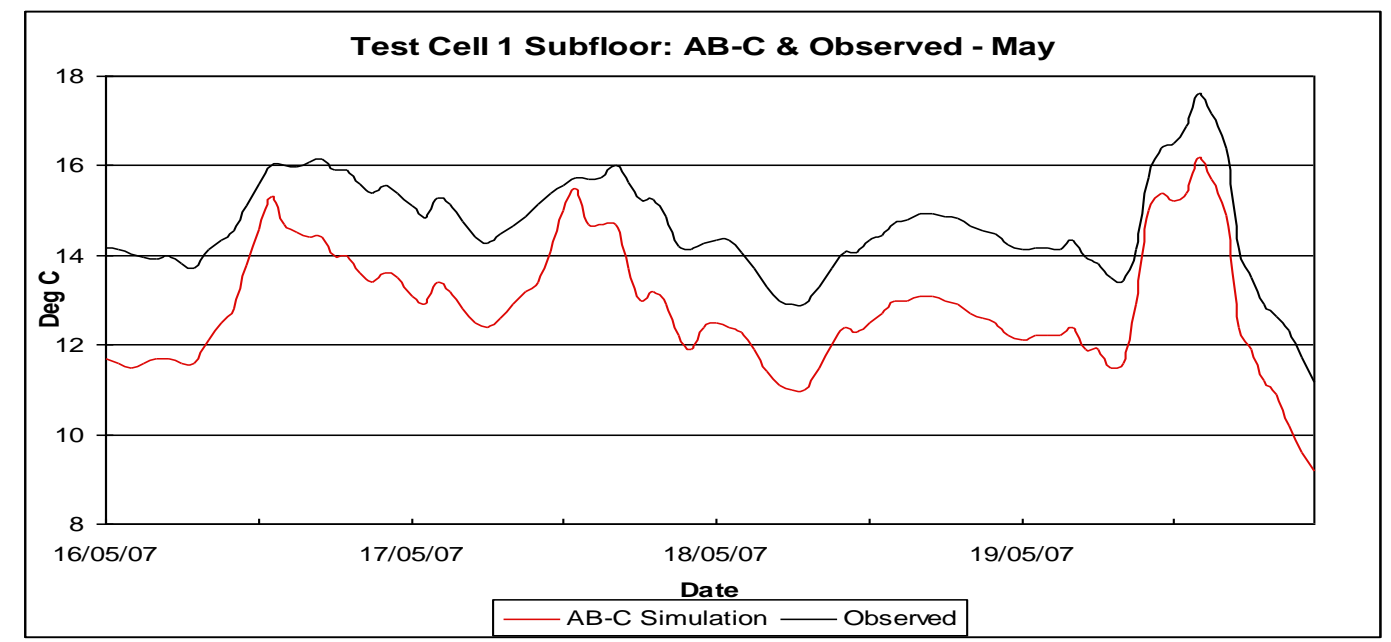

Figure 5.12 - Test Cell 1 Subfloor: AB-C \& Measured Results: May 2007

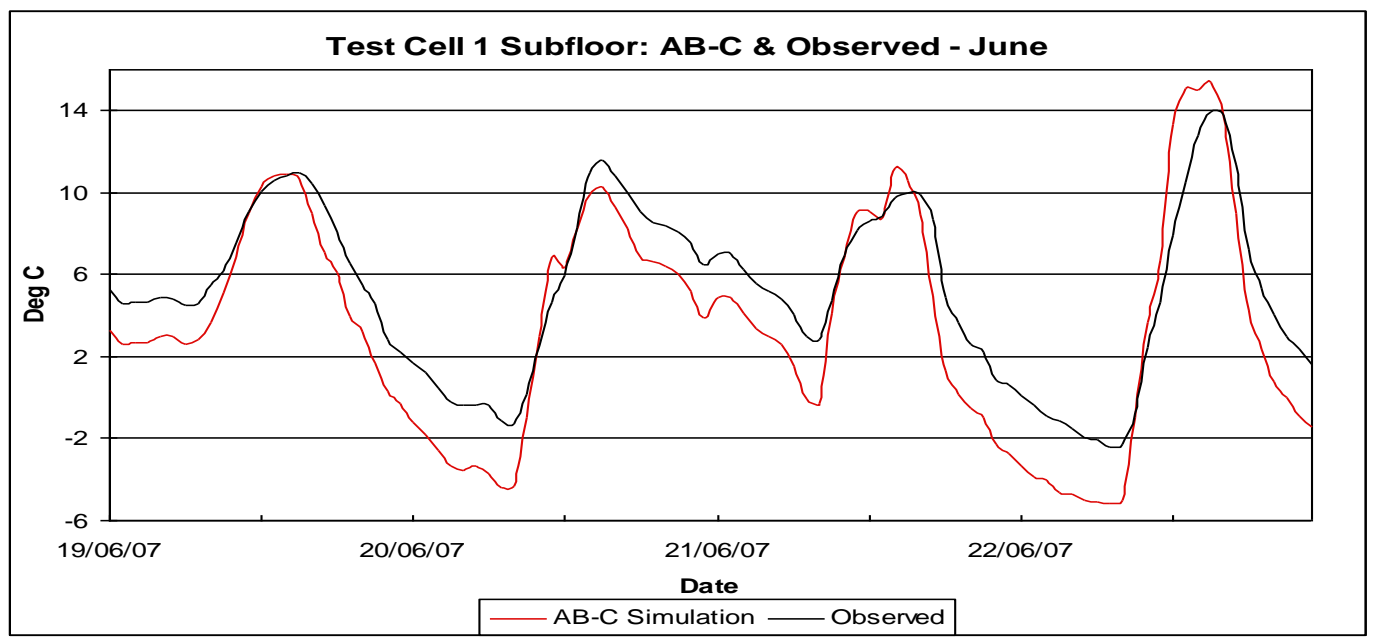

Figure 5.13 - Test Cell 1 Subfloor: AB-C \& Measured Results: June 2007

If there is a partial ground keying effect in the test cell, (which is quite small in size, compared to a standard house), the much larger footprint of a standard house would produce a much larger intermediate subfloor zone. The effect of this variation in subfloor zone temperature on test cell room temperature will be examined further using statistical analysis in Section 5.5.4. 


\section{Test Cell Roof Space}

Figures 147 to 150 show the variation between the simulated and measured temperatures in the roof space for the months of February, April, May and June. The general shape of the simulated data is somewhat similar to the measured, indicating that the simulation is reasonably accounting for the heat transfers in this zone. A closer examination revealed that the maximum measured and simulated temperatures are often somewhat similar but the minimum values in all graphs, vary dramatically, by up to $5.44^{\circ} \mathrm{C}$ (Table 5.13). This difference in the minimum temperatures is evident in all six months (Appendix 6). This may indicate that either the roof space is better insulated, hence less heat losses to the night sky, or that there is a heat gain from the room.

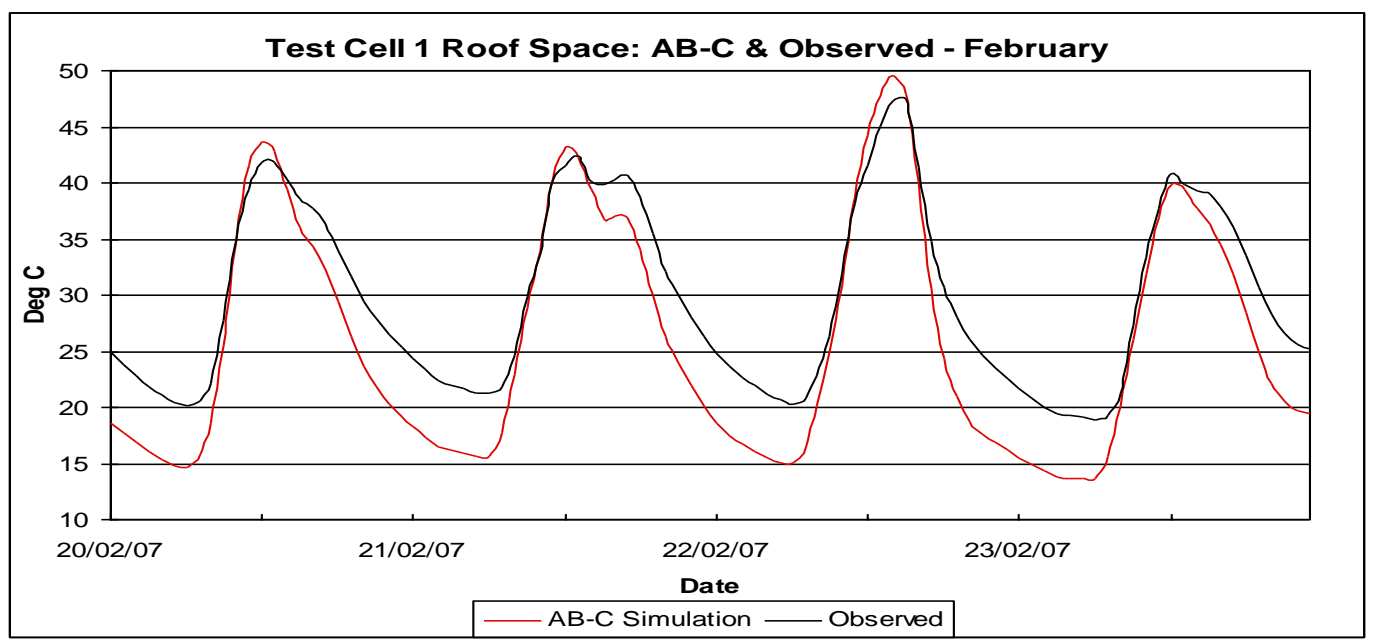

Figure 5.14 - Test Cell 1 Roof Space: AB-C \& Measured Results: February 2007

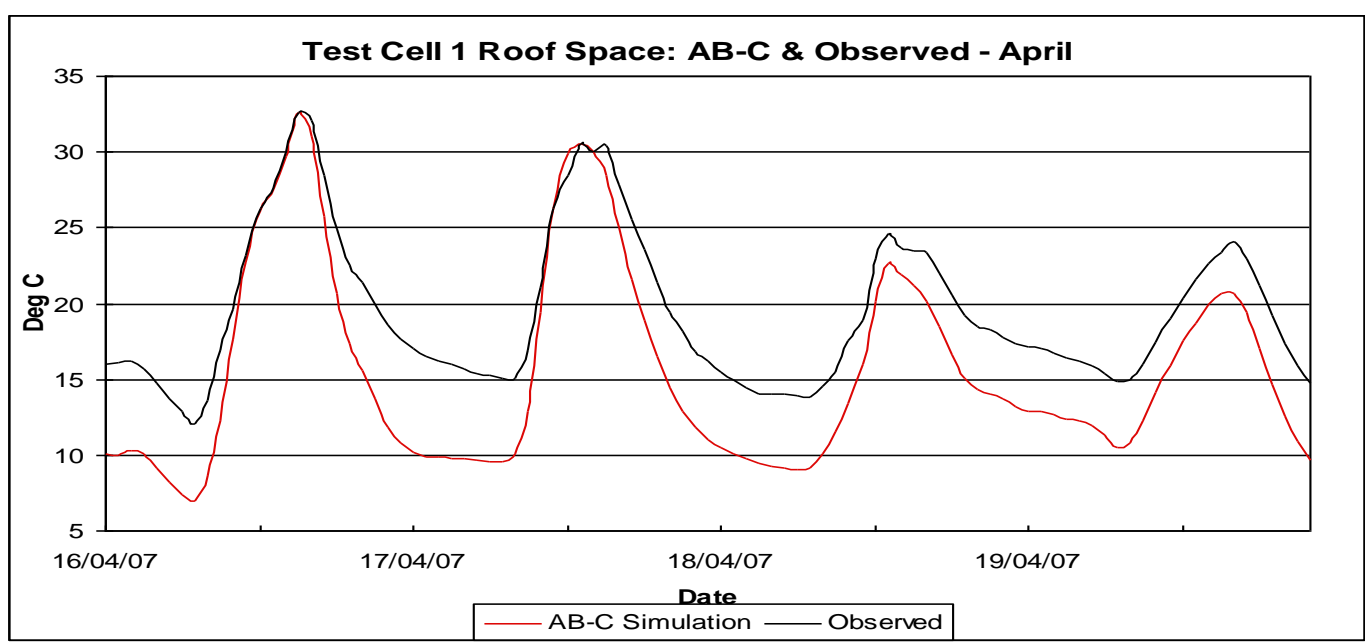

Figure 5.15 - Test Cell 1 Roof Space: AB-C \& Measured Results: April 2007 
As shown in Table 5.13, the difference between measured and simulated maximum temperatures does appear to have some form of climatic conditioning where the hottest month of February has a negative average residual value of $-0.98^{\circ} \mathrm{C}$, whilst the residual value for May is much higher at $3.53^{\circ} \mathrm{C}$. This indicates that further analysis is required to ascertain whether this might reflect a relationship to the adjoining room, or occur as a result of site climate conditions. The effect of wind speed and direction are suggested as possible contributing causes to the differences observed at this point, however further analysis is required.

Table 5.13 shows that the average difference between daily minimum measured and simulated temperature are relatively larger than the average difference in daily maximum temperatures. This indicates that the heat transfer model for night time conditions appears to be more accurate than the day time model for this zone.

There is no obvious trend that can be explained by seasonal temperature swings, hence further analysis will be conducted to examine the effects of:

- wind speed and direction

- effects of southern shading by the relative position of the test cells

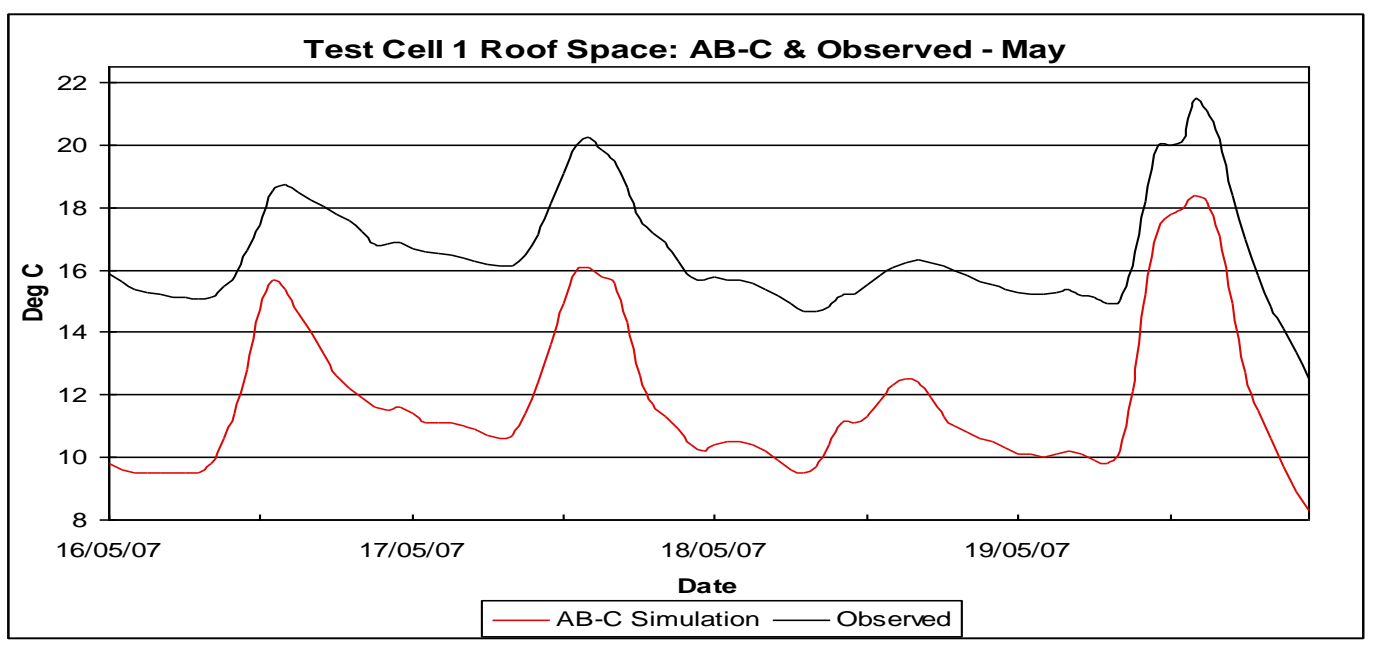

Figure 5.16 - Test Cell 1 Roof Space: AB-C \& Measured Results: May 2007 
The data entry for the roof space simulation did not include inputs for roof shading and eaves, as is evident in the fabric input requirements discussed in Section 4.4. Advice from CSIRO researchers confirmed that the software did not consider any form of shading of the roof elements (Delsante 2009b). The thermal performance test cells were constructed with an eave, as in Figure 5.18, having a compressed fibre cement sheet soffit area of approximately $11.6 \mathrm{~m}^{2}$ and a resistance value of R0.01. It was expected that these two items could have an additional cooling affect to the roof space which is not apparent in the differences between the measured and simulated temperatures presented here. However this requires further investigation.

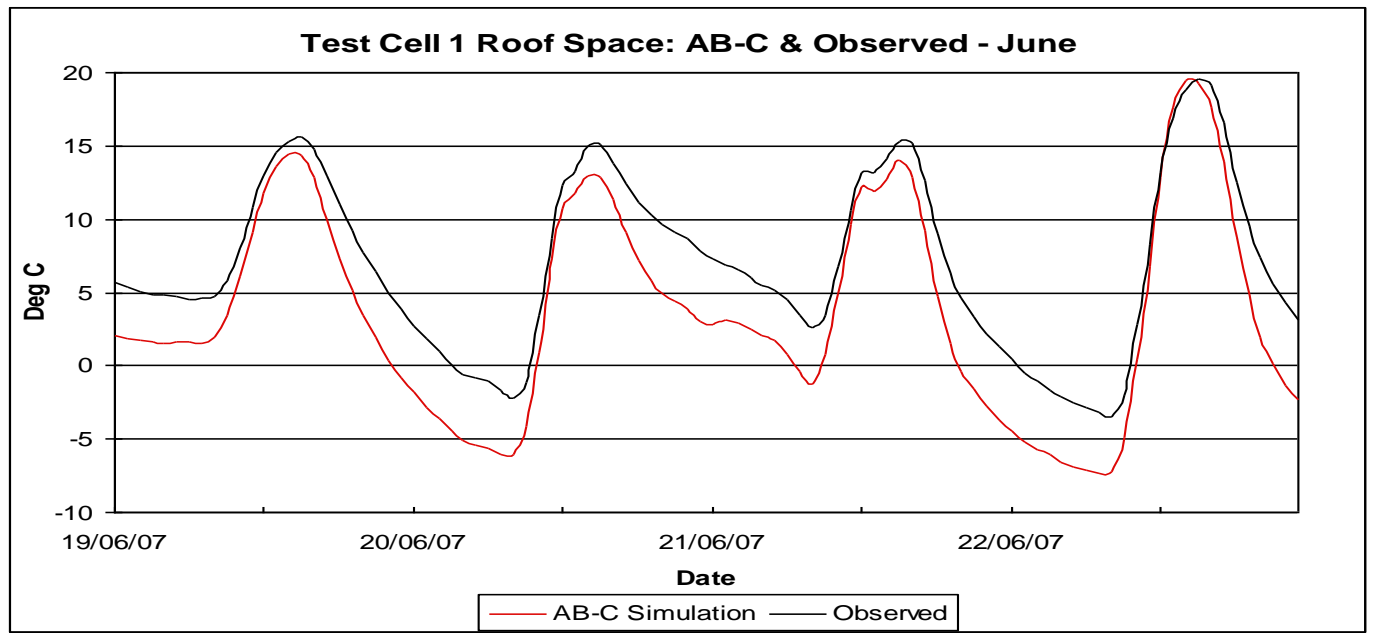

Figure 5.17 - Test Cell 1 Roof Space: AB-C \& Measured Results: June 2007

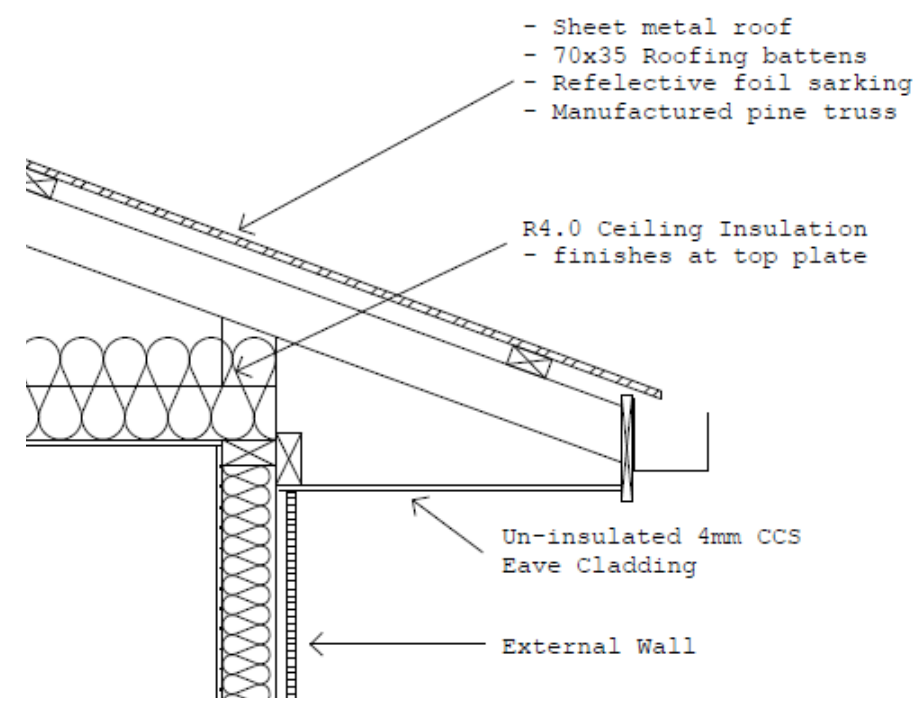

Figure 5.18 - Un-insulated Eave with Compressed Cement Sheet Cladding 


\section{Test Cell Room}

The similarity in the general shapes of the two data sets (as shown in figures 5.19 to 5.22) indicates that the AccuRate HER software is accounting reasonably well for various climatic and built fabric effects. This is particularly reinforced by the graph in Figure 5.21, where both data sets tracked evenly the distinct change between a relatively cool day (May 18) and a relatively warm day (May 19). This suggests that the model is able to account for the effects of subtle external environmental impacts.

Figures 5.19 to 5.22 illustrate that the measured maximum temperatures were nearly always warmer than the simulated temperatures. On February 22 (Figure 5.19) and June 22 (Figure 5.22) the maximum values are very similar. Future examination of the external climatic conditions during these two days will provide an explanation for the close resemblance of the simulated and measured maximum temperatures. However, even on these two days there is a $5{ }^{\circ} \mathrm{C}$ or more variation in the minimum temperatures. The difference between the measured and simulated minimum values during the empirical validation period ranged from $3.75^{\circ} \mathrm{C}$ to $5.07^{\circ} \mathrm{C}$ (Table 5.13). This difference in minimum temperature would have a substantial impact on the energy required to maintain comfort and the resultant House Energy Star Rating. The difference between measured and simulated maximum values is a little smaller though, with an average of $1.48^{\circ} \mathrm{C}$ to $3.28^{\circ} \mathrm{C}$ (Table 5.13).

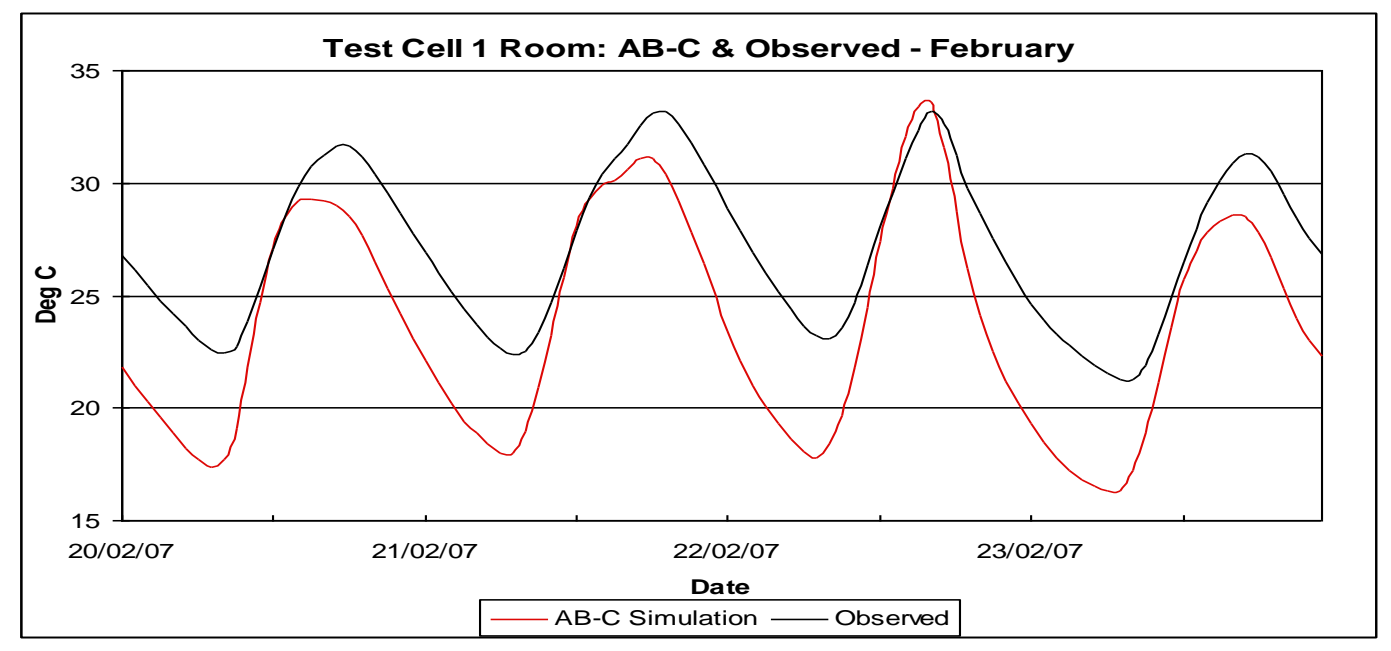

Figure 5.19 - Test Cell 1 Room: AB-C \& Measured Results: February 2007 
The test cell room temperature is affected by the external environment through its walls, and its interaction with the sub floor and roof space. It was noted above, in Figure 5.10 and Figure 5.11, that the maximum measured subfloor temperatures were cooler than the simulated temperature in February. As the maximum measured room temperatures in February were warmer than the simulated temperatures there seems to be little interaction between the two zones in the daytime. However the measured minimum subfloor temperatures in February were warmer than the simulated temperatures, which could account for some of the difference between simulated and measured room minimum temperatures. In May, the measured temperatures for the subfloor (Figure 5.12) were consistently warmer than the simulated temperatures for the subfloor and the temperatures for the test cell room (Figure 5.21) show a similar difference between the measured and simulated temperatures. This could indicate a relationship between the subfloor and room that requires further examination. The possible relationship between the room and subfloor is explored further in the statistical analysis section.

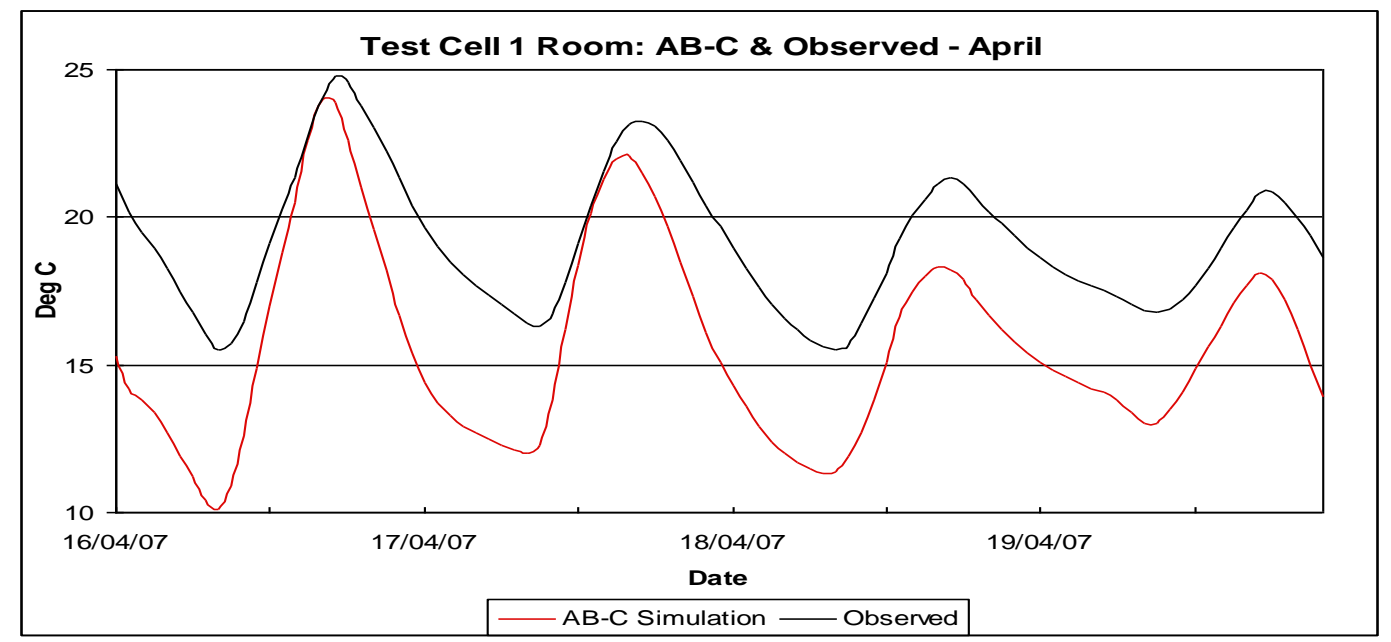

Figure 5.20 - Test Cell 1 Room: AB-C \& Measured Results: April 2007 


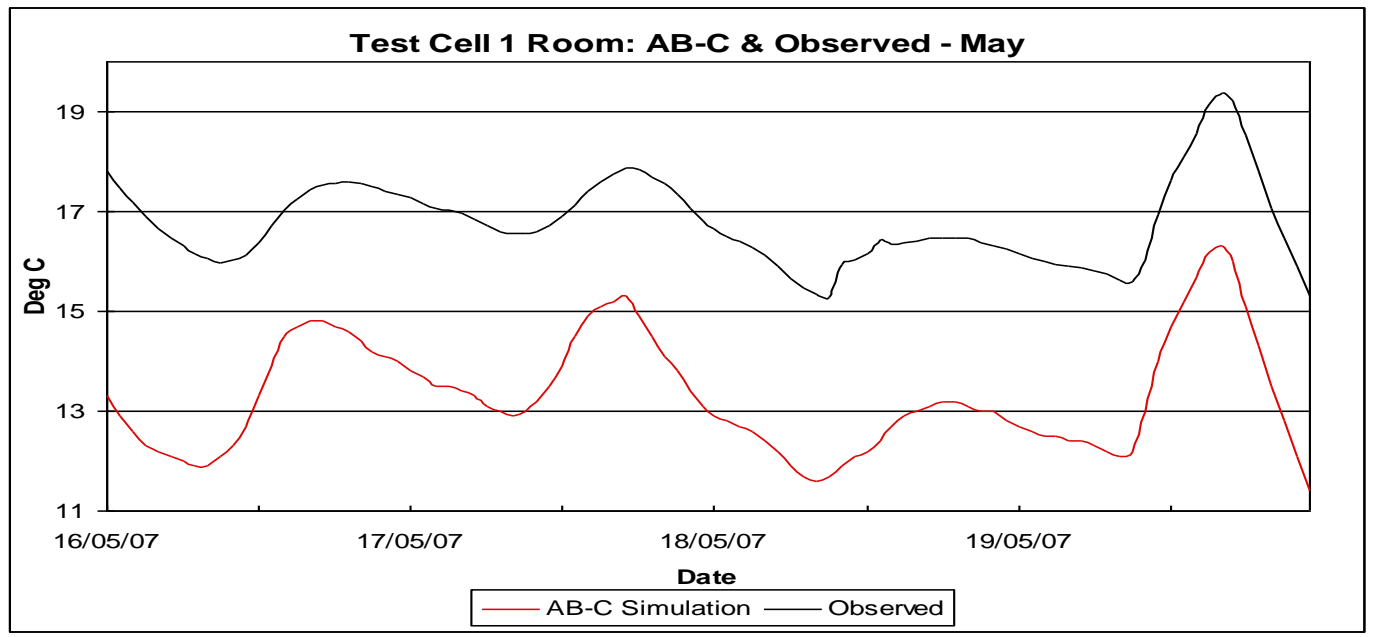

Figure 5.21 - Test Cell 1 Room: AB-C \& Measured Results: May 2007

It was noted that, except for the month of May, the maximum measured roof space temperatures were often similar in value to the simulated values: i.e., the maximum measured and simulated roof space temperatures were quite similar but the room measured temperatures were warmer than those simulated. This may indicate a heat transfer effect between the roof space and room, which is not accounted for fully and requires further investigation. However, it was also noted above that the roof space measured temperatures (Figures 5.14 to 5.17) never became as cool as the simulated temperatures. As the test cell room minimum measured temperatures were warmer than the minimum simulated temperatures, this may indicate that there is either a reduced heat loss to, or gain from, the roof space. On February 22 (Figure 5.19) the measured minimum test cell room temperature was $23.1^{\circ} \mathrm{C}$, which was warmer than both the subfloor and roof spaces (Table 5.14). This may indicate that it is not a heat gain but a reduced heat loss, or a thermal mass effect that has not been considered. When the heat transfer concept is considered in the context of data from May 19 (Figure 5.21) a similar result is noticed: that is, the test cell room was warmer than the subfloor and roof spaces (Table 5.14). To ascertain if there is a relationship between the differences in the measured and simulated temperatures of the room and roof zones, further investigation is undertaken in the statistical analysis section. If there is a thermal mass effect at play, further analysis of the structural mass of the test cell is required. 


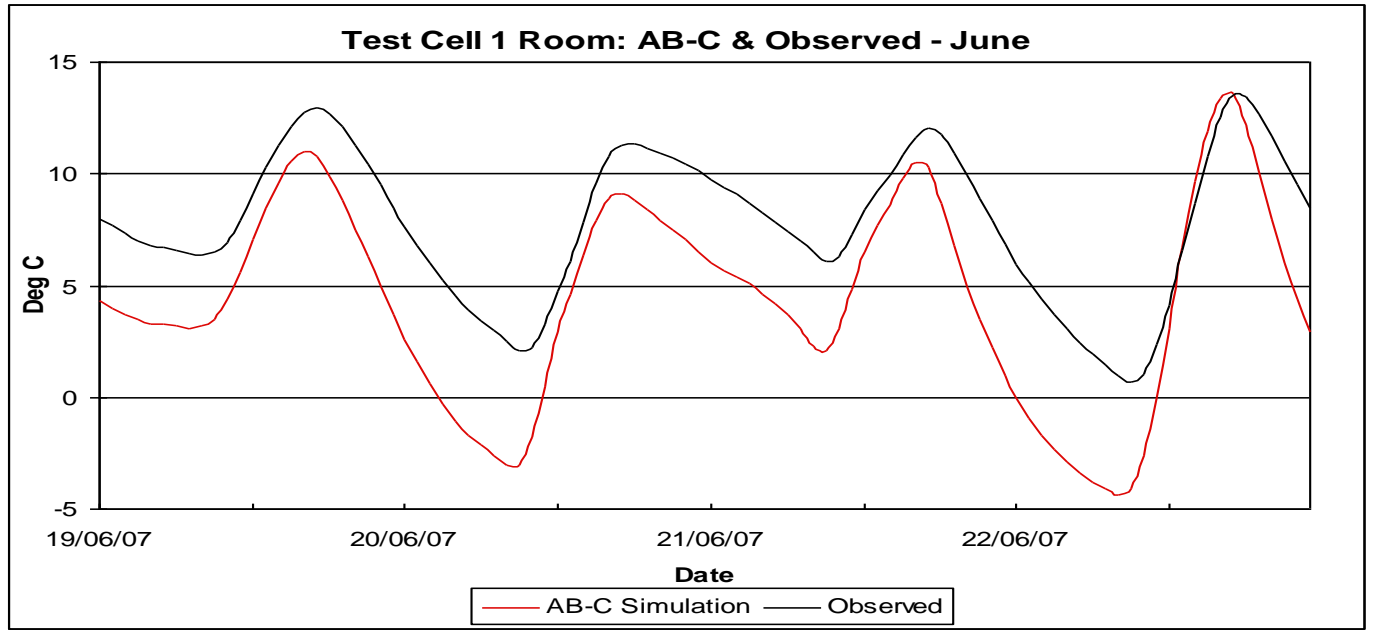

Figure 5.22 - Test Cell 1 Room: AB-C \& Measured Results: June 2007

Table 5.14: Minimum Measured Temperatures Unenclosed-perimeter Platform-floored Test Cell (February 2 \& May 19, 2007)

\begin{tabular}{|l|r|r|}
\hline \multicolumn{1}{|c|}{ Zone } & 22/02/2007 & $19 / 05 / 2007$ \\
\hline Roof Space & 20.3 & 15 \\
\hline Room & 23.1 & 15.6 \\
\hline Subfloor & 19 & 13.4 \\
\hline
\end{tabular}

\subsubsection{Enclosed-perimeter Platform-floored Test Cell}

This test cell has an enclosed subfloor zone, a room and a roof space. The key differences between this test cell and the unenclosed-perimeter platform-floored test cell are the enclosure of the subfloor and the external cladding. The external walls of the unenclosed-perimeter platformfloored test cell are plywood cladding, whereas the external walls of this test cell are brick veneer, which provided cladding and subfloor enclosure. Like the previous test cell, the roof space temperature was affected by: the external environment, day time solar radiation, night time losses and heat gain or losses to the test cell room. The test cell room temperature was affected by the external environmental temperature through its walls and received a tempered environmental effect from the subfloor and roof space.

Table 5.15 below summarizes the average difference between the daily measured and simulated minimums and maximums for each month. When compared to the data presented in Table 5.13, the following was observed: 
- there is a significant increase in the differences between the measured and simulated minimum and maximum temperatures for the subfloor zone

- the differences between the measured and simulated minimum values for the room are similar. However, there is a significant increase in difference between the measured and simulated maximum temperatures

- there is a significant increase in the differences between the measured and simulated minimum and maximum temperatures for the subfloor zone

In all graphs, there is a similarity in pattern, which gives the researcher confidence that the software is adequately considering the mix of multi-variant climatic inputs.

Table 5.15: Average Difference between Measured and Simulated Minimum \& Maximum Temperatures (Enclosed-perimeter Platform-floored Test Cell)

\begin{tabular}{|c|r|r|r|r|r|r|}
\hline & \multicolumn{3}{|c|}{$\begin{array}{c}\text { Daily Minimum Temperature } \\
\text { (Measured - Simulated) }\end{array}$} & \multicolumn{3}{c|}{$\begin{array}{c}\text { Daily Maximum Temperature } \\
\text { (Measured - Simulated) }\end{array}$} \\
\hline & Subfloor & Room & \multicolumn{1}{c|}{ Roof } & Subfloor & \multicolumn{1}{c|}{ Room } & Roof \\
\hline January & & 4.65 & & & 4.18 & \\
\hline February & & 4.48 & & & 3.40 & 3.45 \\
\hline March & 4.75 & 5.58 & 9.24 & 4.83 & 5.40 & 3.25 \\
\hline April & 4.31 & 4.90 & 8.85 & 3.13 & 4.00 & 6.31 \\
\hline May & 3.93 & 4.50 & 8.87 & 3.83 & 4.55 & $3.07 \#$ \\
\hline June & 5.67 & 4.08 & 8.76 & 3.66 & 3.08 & \\
\hline \\
\# This does not include the maximum value for June 22 \\
$\begin{array}{l}\text { Note: The measured data for the months of January and February is unavailable for the } \\
\text { subfloor and roof space. }\end{array}$
\end{tabular}

\section{Test Cell Subfloor}

The enclosed subfloor zone has wall vents to minimise moisture levels. The perimeter wall creates a zone that is conditioned by the exterior climate, ground and test cell room temperatures. The external walls of the enclosed subfloor comprise a single skin clay brick wall with an area of $33.41 \mathrm{~m}^{2}$. This comprises $15.9 \%$ of the subfloor surface area (Table 5.16). The ground temperature was cooler than air temperature in summer but warmer than air temperature in winter. The ground surface area comprises $44.3 \%$ of the surface area of the subfloor zone. Even though the external wall comprises a small portion of the subfloor zone surfaces, it has a lower resistance value and is 
in direct contact with the external environment through the wall vents. Note that the measured infiltration rates were used for the subfloor detailed simulation.

Table 5.16: Enclosed-perimeter Platform-floored Test Cell Subfloor Surface Areas

\begin{tabular}{|l|c|c|c|}
\hline \multicolumn{1}{|c|}{ Surfaces } & $\mathrm{M}^{2}$ & $\%$ area & $\begin{array}{c}\text { Resistance } \\
\text { value }\end{array}$ \\
\hline Subfloor - test cell room & 30.03 & $39.8 \%$ & $\mathrm{R} 0.90$ \\
\hline Subfloor - external walls & 11.93 & $15.9 \%$ & $\mathrm{R} 0.18$ \\
\hline Subfloor - ground & 33.41 & $44.3 \%$ & \\
\hline
\end{tabular}

Figures 5.23 to 5.26 show the variation between the simulated and measured temperatures in the subfloor zone of this test cell. The graphs show that for all months the measured temperatures were always warmer than the simulated temperatures. Each of the graphs show that the measured minimum and maximum temperatures are always warmer than the simulated temperatures.

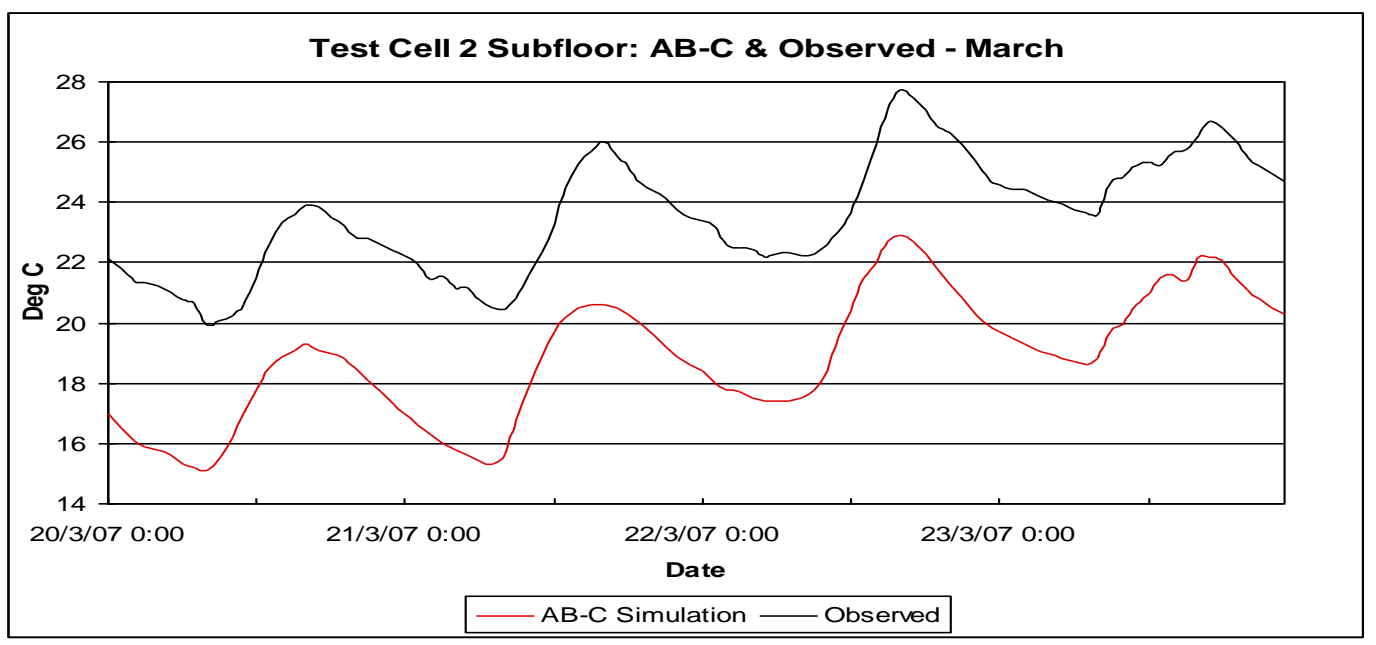

Figure 5.23 - Test Cell 2 Subfloor: AB-C \& Measured Results: March 2007 


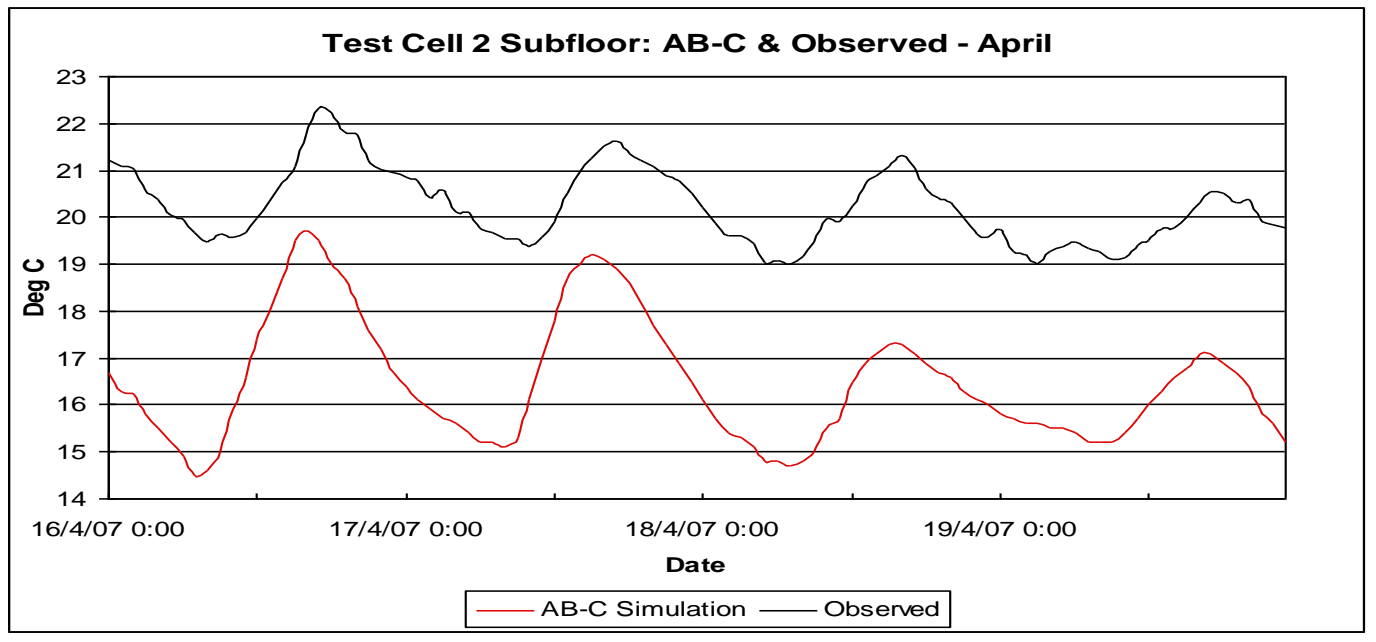

Figure 5.24 - Test Cell 2 Subfloor: AB-C \& Measured Results: April 2007

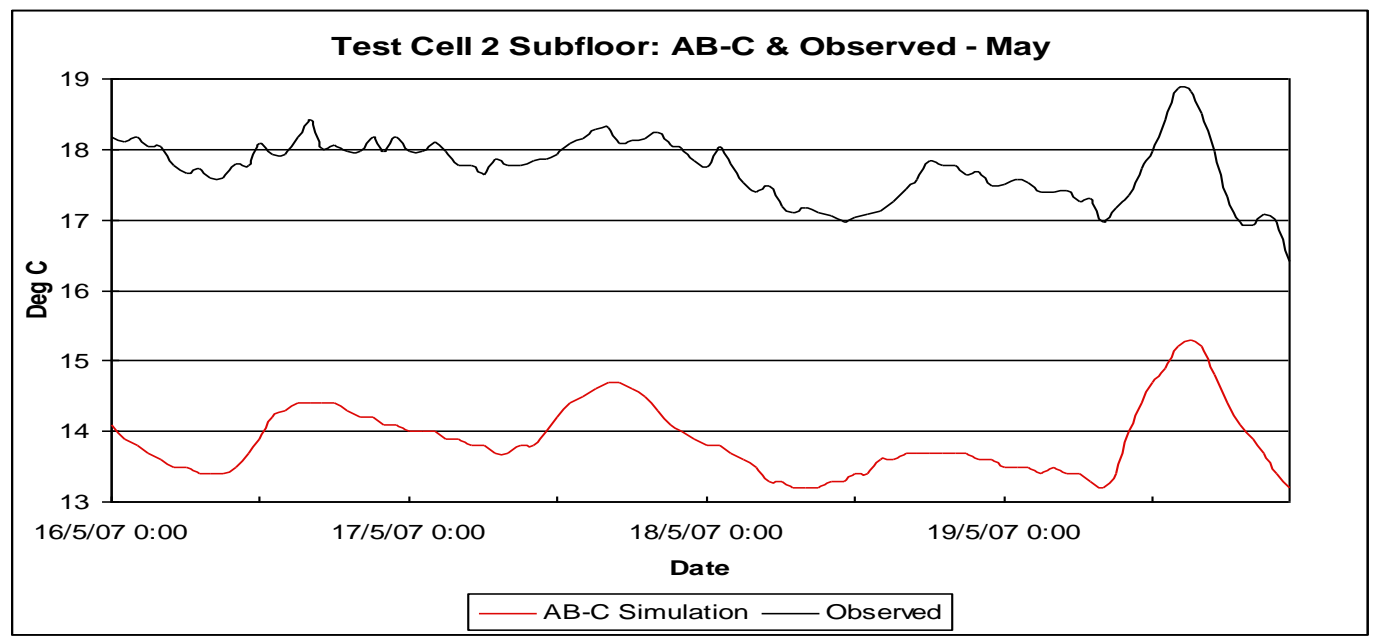

Figure 5.25 - Test Cell 2 Subfloor: AB-C \& Measured Results: May 2007 


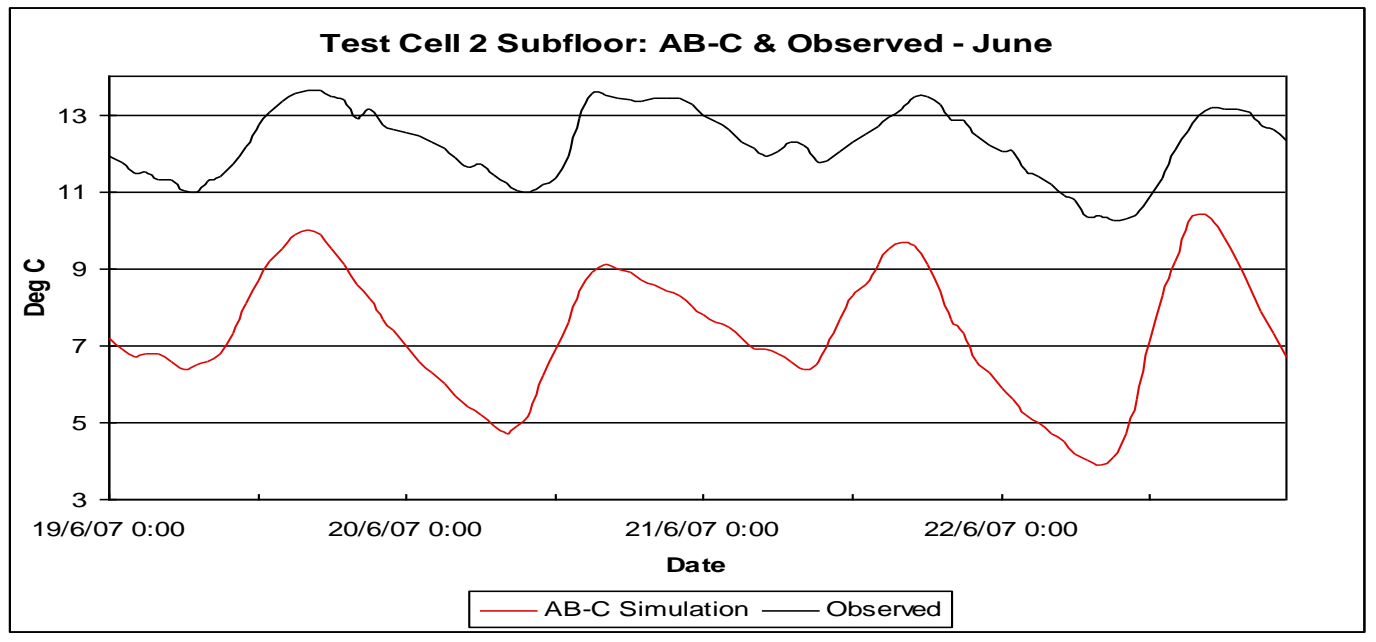

Figure 5.26 - Test Cell 2 Subfloor: AB-C \& Measured Results: June 2007

The data analysis in Table 5.15 reveals some noticeable patterns. It is commonly accepted that the ground temperature is an average of the diurnal average temperature of a location (Delsante 20052010). If this is the case, then the effect of the ground temperature model on the maximum subfloor zone temperature would be most obvious in March, the hottest month for subfloor measurements and as it is the last of the hotter months, there may be a cooling effect. This is supported by the data in Table 5.15, where the greatest maximum difference in subfloor temperature occurs in March. This could indicate that the AccuRate subfloor model is not considering the ground effect appropriately, or that the ground model is not giving a true ground temperature. This hypothesis can be tested against the minimum values in Table 5.15. If the subfloor model is not considering the ground effect appropriately in winter, the minimum values would show the greatest difference. For the month of April, May and June, the differences in the minimum temperatures were $4.75^{\circ} \mathrm{C}, 4.30^{\circ} \mathrm{C}$ and $3.93^{\circ} \mathrm{C}$ degrees, respectively. For the month of June the difference was $5.67^{\circ} \mathrm{C}$. This could indicate that the subfloor model requires further examination, as a constant difference between the simulated and measured temperatures of the subfloor can impact on the test cell room temperature.

As with the subfloor zone of the unenclosed-perimeter platform-floored test cell, a similar concern is raised here. If the subfloor model and/or the ground model is not providing a true indication of the subfloor air temperature, the much larger footprint of a standard house would produce a much larger intermediate subfloor zone. Therefore the effect the variation in subfloor zone temperature has on test cell room temperature is explored further in the statistical analysis. 


\section{Test Cell Roof Space}

The roof spaces of all three test cells were constructed alike. The results presented for the enclosed-perimeter platform-floored test cell roof space (Figure 5.27 to Figure 5.30) show the variation between the simulated and measured temperatures. The general shape of the simulated data is somewhat similar to the measured data, indicating that the simulation considered most of the environmental thermal impacts.

The graphs show that, at times, the simulated and maximum temperatures are similar, as on March 21 (Figure 5.27), April 16 (Figure 5.28) and June 22 (Figure 5.30). However, for most of the time the maximum values are different, which is in contrast to the graphs for the unenclosed-perimeter platform-floored test cell, where the maximum values were very similar. The average difference between the measured and simulated maximum values ranged from $3.25^{\circ} \mathrm{C}$ to $6.31^{\circ} \mathrm{C}$ (Table 5.15). The higher differences occurred in the colder months of May (Figure 5.29) and June (Figure 5.30). This is a point when the roof space is in full sun, as the southern trees only shaded the roof in

January. Conversely, the average minimum difference in all the graphs (Figures 5.27 to 5.30) is of a much greater magnitude and ranges from $8.76^{\circ} \mathrm{C}$ to $9.24^{\circ} \mathrm{C}$, with the greatest difference occurring in March. This discrepancy could indicate several different scenarios, including:

- The roof space is retaining more heat than expected;

- More heat is being conducted from the test cell room;

- The roof model is not allowing the true amount of heat energy to enter the roof space; and

- The calculated night-time losses are incorrect. 


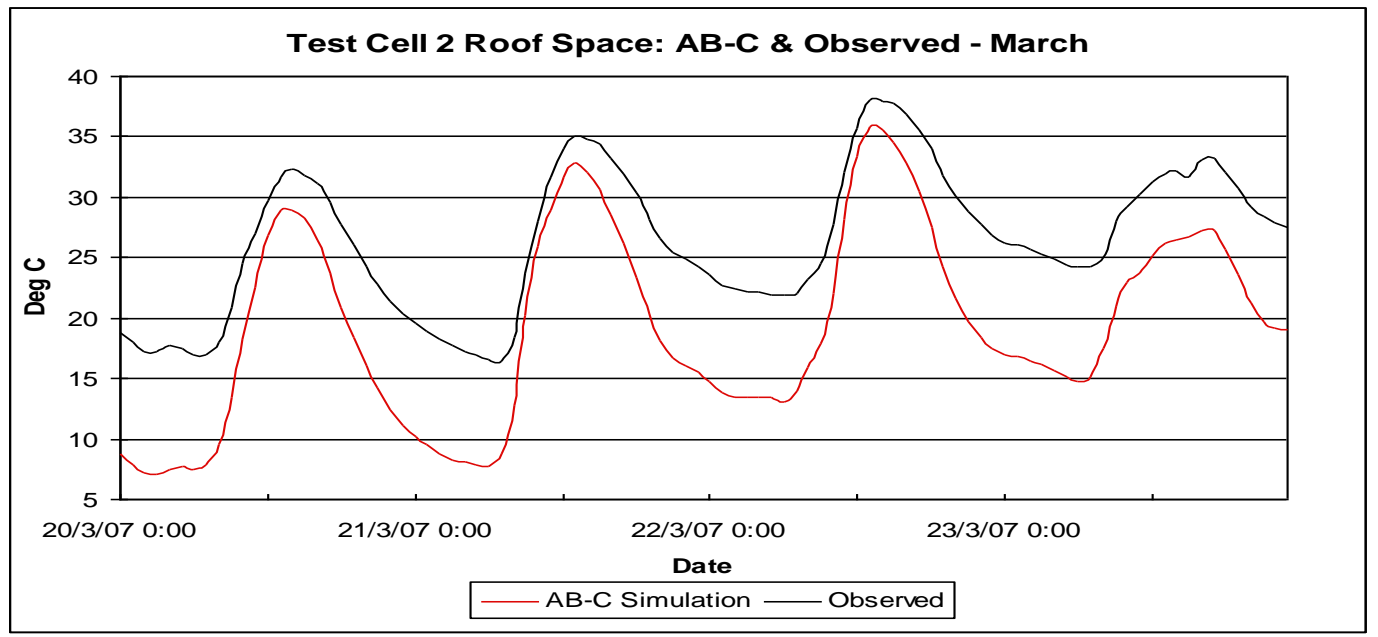

Figure 5.27 - Test Cell 2 Roof Space: AB-C \& Measured Results: March 2007

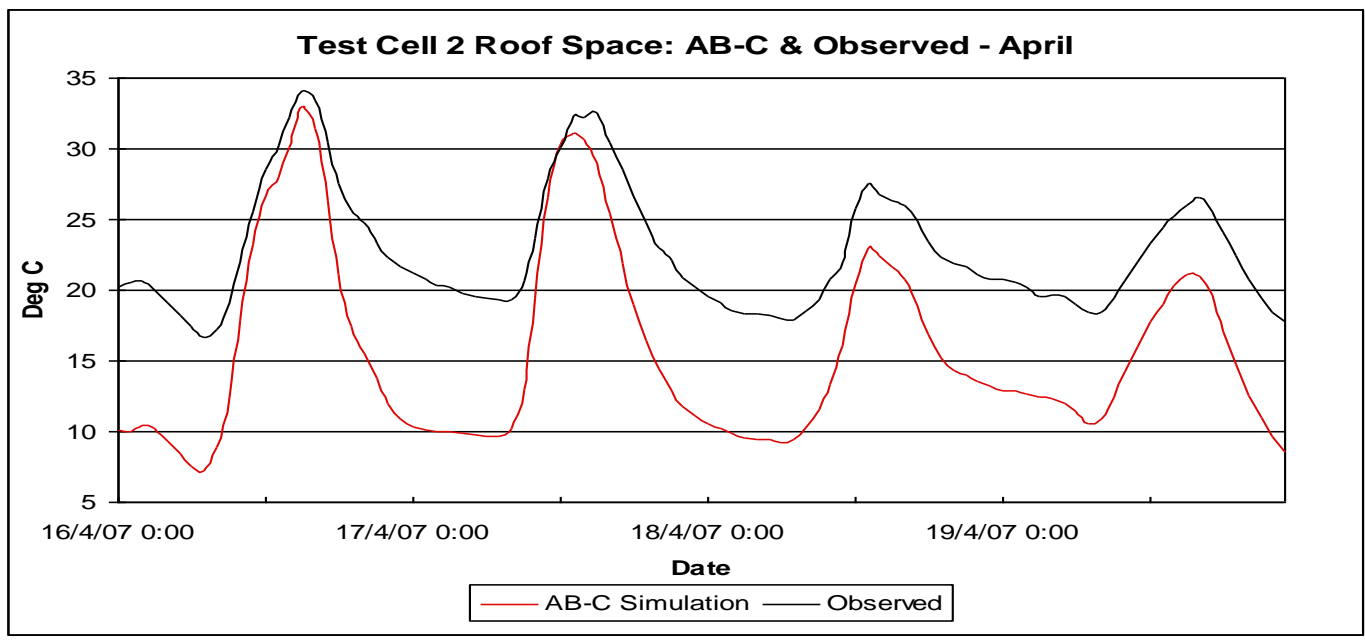

Figure 5.28 - Test Cell 2 Roof Space: AB-C \& Measured Results: April 2007 


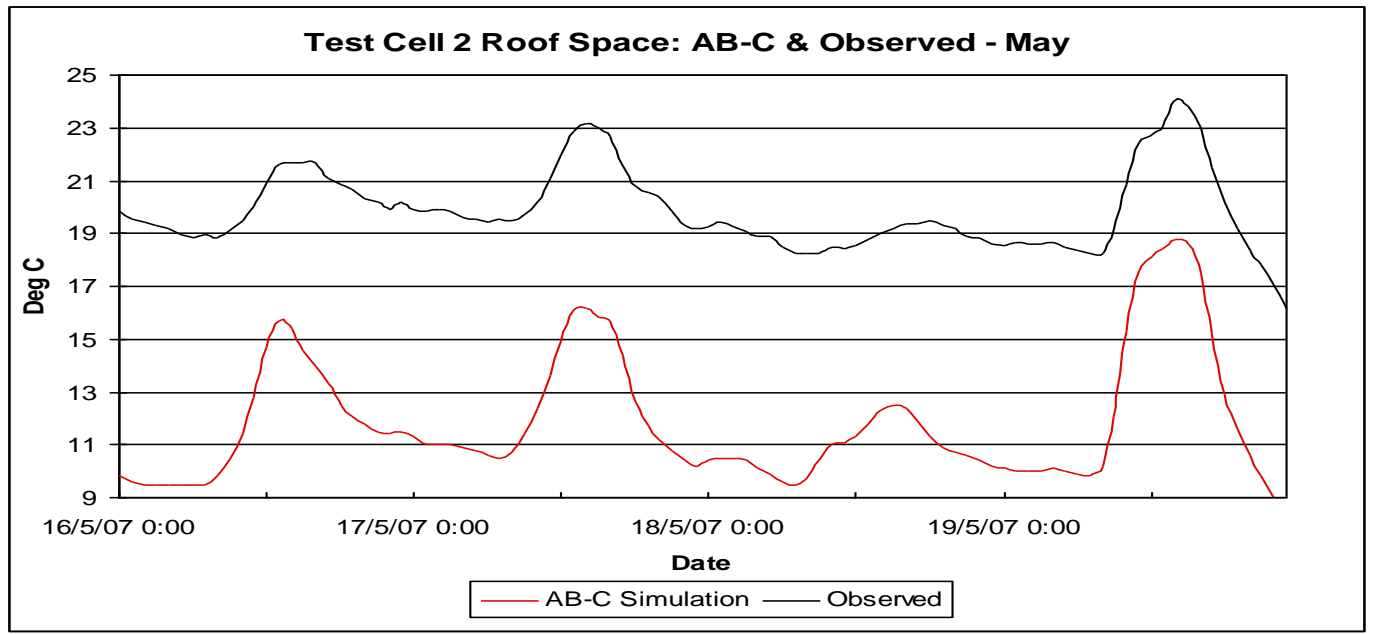

Figure 5.29 - Test Cell 2 Roof Space: AB-C \& Measured Results: May 2007

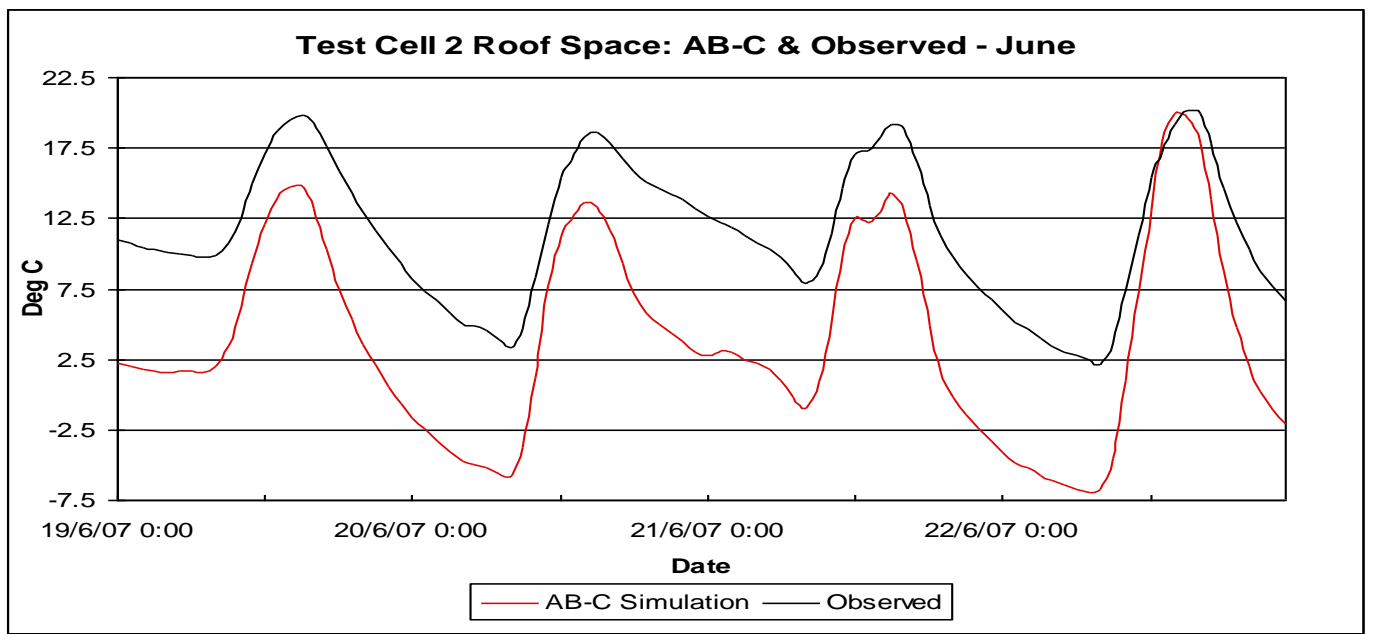

Figure 5.30 - Test Cell 2 Roof Space: AB-C \& Measured Results: June 2007

The differences in this data are also of concern, as the much lower resistance value of the eave to the outside air, which was not modelled in the simulation, should have made the measured values for the roof space cooler than the simulated values in winter, due to night and day time conductive losses. This is not apparent in the data and requires further examination in the future.

The section below discusses the test cell room. Differences in the roof space temperature of this magnitude may have had some impact on the measured temperatures of the room. 


\section{Test Cell Room}

As with this test cell's roof space and subfloor, there is a seemingly constant difference between the measured and simulated values for the test cell room (Figure 5.31 to Figure 5.34). The general shape of the two data sets is similar, reflecting that the AccuRate software is taking into account various climatic and built fabric effects. There is an anomaly in Figure 5.33, where the measured data documents a rise in room temperature on May 19, which is not reflected in the simulated data. This will be investigated further.

Simulated and measured temperatures of the test cell room illustrate that for all months of the empirical validation process, the measured temperatures were always warmer than the simulated temperatures. The test cell room temperature was affected by the external environment through its walls and its interaction with the subfloor and roof space. It was noted above that the minimum measured temperatures of the test cell subfloor and roof space zones were always warmer than the simulation results. The surface area of the test cell room, as shown in Table 5.17, is evenly split between the external walls $(46.8 \%)$ and the roof and subfloor $(53.2 \%)$. This could indicate either a heat gain from or at least a reduced heat loss to the subfloor and roof space zones.

Table 5.17: Enclosed-perimeter Platform-floored Test Cell Room Surface Areas

\begin{tabular}{|l|c|c|c|}
\hline \multicolumn{1}{|c|}{ Surfaces } & $\mathrm{M}^{2}$ & $\%$ area & $\begin{array}{c}\text { Resistance } \\
\text { value }\end{array}$ \\
\hline Test Cell Room - Roof Space & 30.03 & $26.6 \%$ & $\mathrm{R} 3.59$ \\
\hline Test cell Room - External walls & 52.68 & $46.8 \%$ & $\mathrm{R} 2.50$ \\
\hline Test cell room - Subfloor & 30.03 & $26.6 \%$ & $\mathrm{R} 0.90$ \\
\hline
\end{tabular}




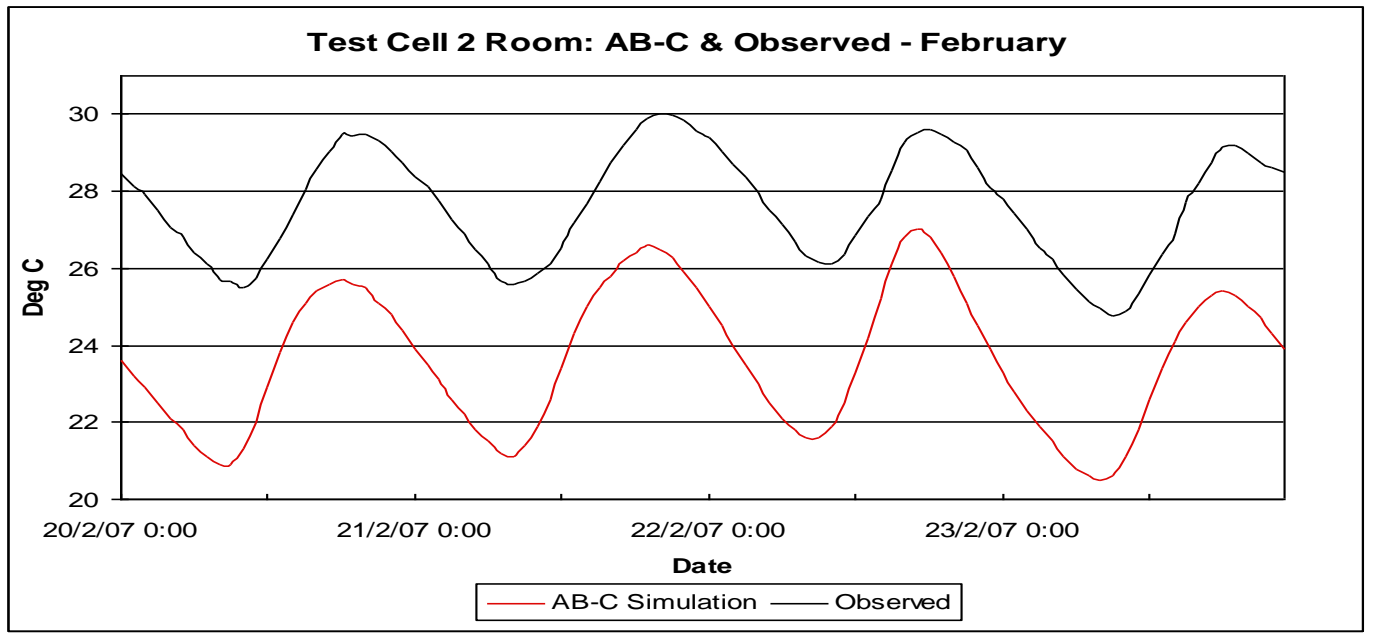

Figure 5.31 - Test Cell 2 Room: AB-C \& Measured Results: February 2007

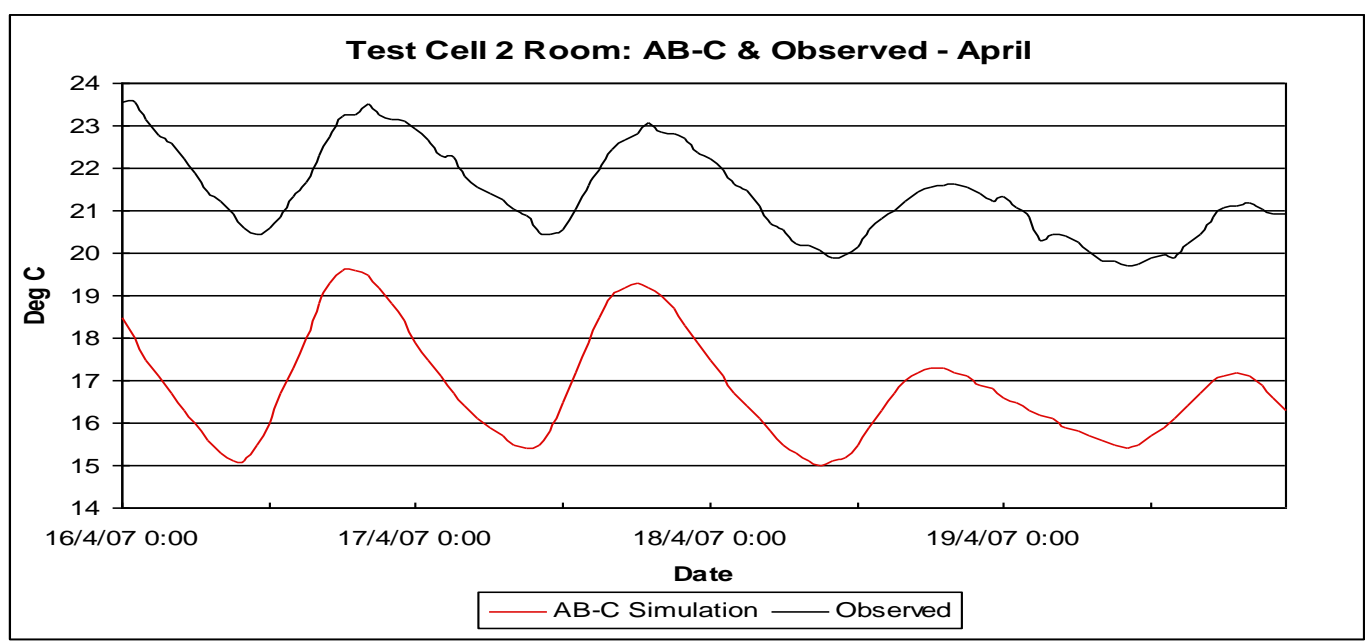

Figure 5.32 - Test Cell 2 Room: AB-C \& Measured Results: April 2007 


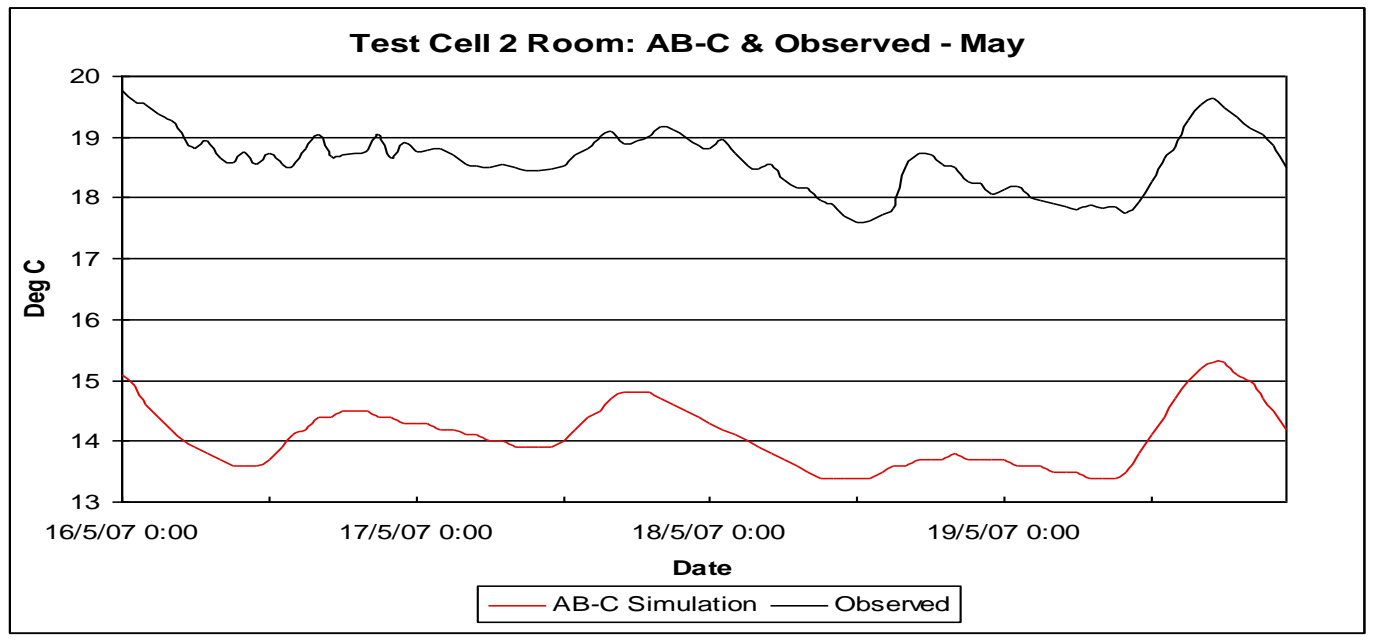

Figure 5.33 - Test Cell 2 Room: AB-C \& Measured Results: May 2007

When the difference between measured and simulated minimum and maximum values for the test cell room are compared to the subfloor and roof space zones, some key elements become apparent (Table 5.15). For the test cell room, differences in the average minimum temperatures range from $4.08^{\circ} \mathrm{C}$ to $5.58^{\circ} \mathrm{C}$ and the differences in the average maximum temperatures ranged from $3.08^{\circ} \mathrm{C}$ to $5.40^{\circ} \mathrm{C}$. The average differences in the minimum and maximum temperatures for the subfloor were $4.67^{\circ} \mathrm{C}$ and $3.86^{\circ} \mathrm{C}$, respectively. In addition, the test cell room average minimum and maximum temperature differences are higher than the subfloor temperature differences for March, April and May. In June the higher value of the differences between the test cell room and the subfloor move in favour of the subfloor, indicating an increasing, unaccounted for, thermal influence in the subfloor zone.

The comparison of the differences between measured and simulated temperatures for the roof space are also of interest, where the difference in the roof space minimum temperatures was always higher than the like value for the test cell room. In March and April, the maximum difference between the simulated and measured roof space temperatures was less than the like values for the room, but in May and June the differences for the roof space temperatures were higher. 


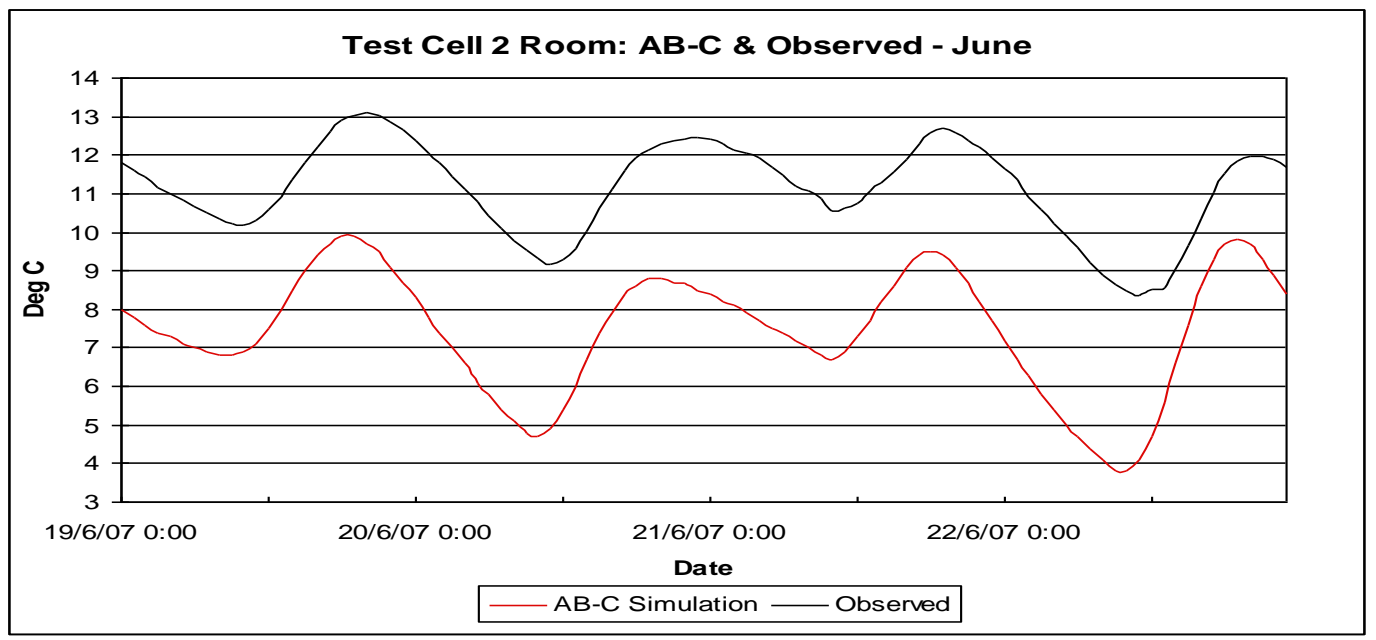

Figure 5.34 - Test Cell 2 Room: AB-C \& Measured Results: June 2007

These observations between the measured and simulated temperatures and their differences could indicate a few different scenarios, as follows:

- The measured subfloor temperature is always warmer than the simulated subfloor temperature implying that the heat loss from the test cell room to the subfloor could be reduced;

- The difference between the maximum values for the measured and simulated subfloor temperatures is always positive, indicating that there may be some heat given off by the subfloor to the test cell room in winter (June) when the difference is higher in the subfloor;

- $\quad$ The difference between the maximum values for the measured and simulated temperatures for the roof and test cell room is greater in May and June, indicating there may be a greater amount of heat given off by the roof space to the test cell room;

- The average difference between the roof space and test cell room minimum temperatures is constantly greater than the average difference in maximum temperatures, indicating there may be a reduced quantity of heat loss from the test cell room to the roof space at times of cooler temperatures.

These propositions will be examined in the statistical analysis (see section 5.5). 


\subsubsection{Concrete Slab-on-Ground Floored Test Cell}

The concrete slab-on-ground floored test cell was the simplest of the three test cells, since it included only the room and a roof space. The key differences between this test cell and the platform-floored test cells, is the absence of the subfloor zone and the inclusion of an uninsulated concrete slab-on-ground floor. Like the enclosed-perimeter platform-floored test cell, this test cell had a brick veneer cladding and its roof space received the temperature effects of the external environment, solar radiation day time gains and night time losses and heat gain or losses to the test cell room. The test cell room was affected by the external environment through the walls, and received a tempered environmental effect from the roof space, and its floor temperature was conditioned by the ground temperature.

Table 5.18 details the average differences between the measured and simulated minimums and maximums for the empirical validation graphs. To better understand relationships between the roof space and test cell room, the graphs below are presented with the roof space first, followed by the test cell room.

Table 5.18: Average Difference between Measured - Simulated Minimum \& Maximum Temperatures (Concrete Slab-on-ground Floored Test Cell)

\begin{tabular}{|l|r|r|r|r|}
\hline \multirow{2}{*}{ Month } & \multicolumn{2}{|c|}{$\begin{array}{c}\text { Daily Minimum } \\
\text { Temperature } \\
\text { (Measured - Simulated) }\end{array}$} & \multicolumn{2}{c|}{$\begin{array}{c}\text { Daily Maximum Temperature } \\
\text { (Measured - Simulated) }\end{array}$} \\
\hline & Room & Roof Space & \multicolumn{1}{c|}{ Room } & Roof Space \\
\hline January & 4.15 & 7.96 & 4.3 & 1.93 \\
\hline February & 4.88 & 8.17 & 4.98 & 0.80 \\
\hline March & 4.65 & 7.95 & 4.68 & 3.06 \\
\hline April & 4.45 & 8.84 & 4.30 & 4.10 \\
\hline May & 3.48 & 7.61 & 3.58 & 5.28 \\
\hline June & 1.85 & 4.87 & 1.35 & 3.08 \\
\hline
\end{tabular}

\section{Test Cell Roof Space}

The test cell roof space was constructed alike for all three test cells. The earlier discussion on eave and shading HER modelling matters also applies to this test cell. The results presented for the concrete slab-on-ground floored test cell roof space (in Figures 5.35 to 5.37) shows the variation between the simulated and measured temperatures. The general shape of the simulated data is 
somewhat similar to the measured data, indicating that the simulation has considered most of the environmental thermal impacts.

The resultant graphs for the slab-on-ground floored test cell roof space are very similar in shape to those of the other two test cells. For this roof space on particular days in February (Figure 5.35) and June (Figure 5.37) the measured and maximum temperatures are very similar; however, there are also many times where there is a significant difference, as on April 19 (Figure 5.36) and May 16 to 19 (Figure 5.37). In all the graphs there is a significant difference between the measured and simulated minimum temperatures.

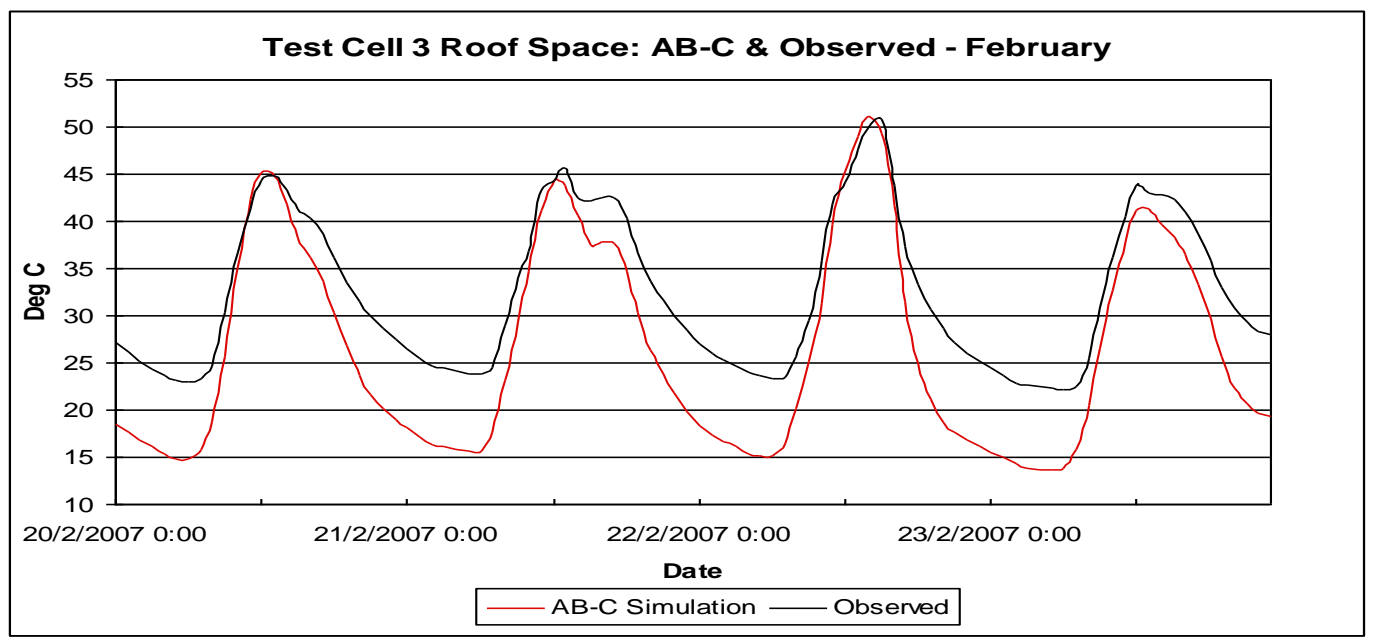

Figure 5.35 - Test Cell 3 Roof Space: AB-C \& Measured Results: February 2007

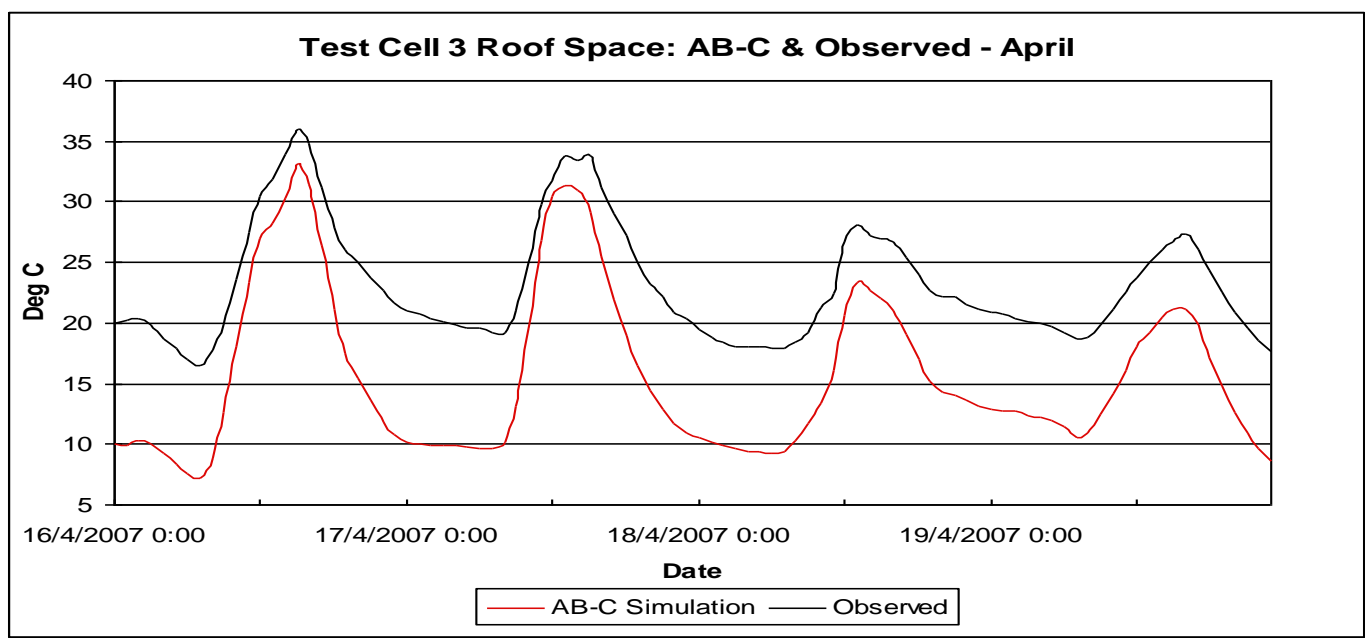

Figure 5.36 - Test Cell 3 Roof Space: AB-C \& Measured Results: April 2007 


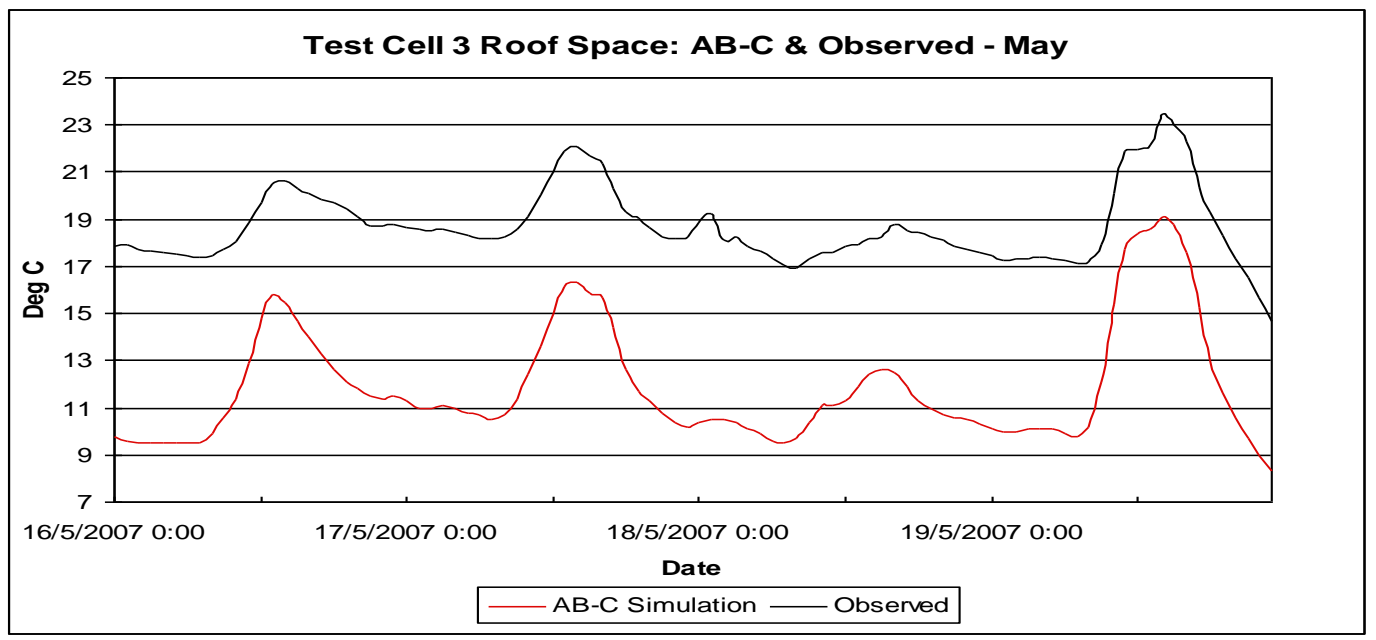

Figure 5.37 - Test Cell 3 Roof Space: AB-C \& Measured Results: May 2007

The average difference between the measured and simulated maximum temperatures ranged from $0.8^{\circ} \mathrm{C}$ to $5.28^{\circ} \mathrm{C}$ (Table 5.18). There appear to be some monthly or climatic effects, as the maximum measured and simulated roof space temperatures are very similar in value in the hottest month, February, and May, one of the cooler months. However, the data for June shows a reduced difference, which may indicate that it is not just a seasonal modelling issue. The difference between the measured and simulated minimum temperatures tells a different story and is very similar to the previous test cell roof spaces, where the average difference for the months of January, February, March, April and May are close to or greater than $8^{\circ} \mathrm{C}$, and for the month of June $4.87^{\circ} \mathrm{C}$. These differences must affect the heat energy exchange between the test cell room and the test cell roof space. Similar to the enclosed-perimeter platform-floored test cell, these discrepancies could indicate several different scenarios including:

- The roof space is retaining more heat than expected;

- More heat is being gained from the test cell room;

- The roof model is representing the true amount of heat energy transferring into the roof; and

- The calculated night time losses may be incorrect, particularly affecting the minimum temperatures. 


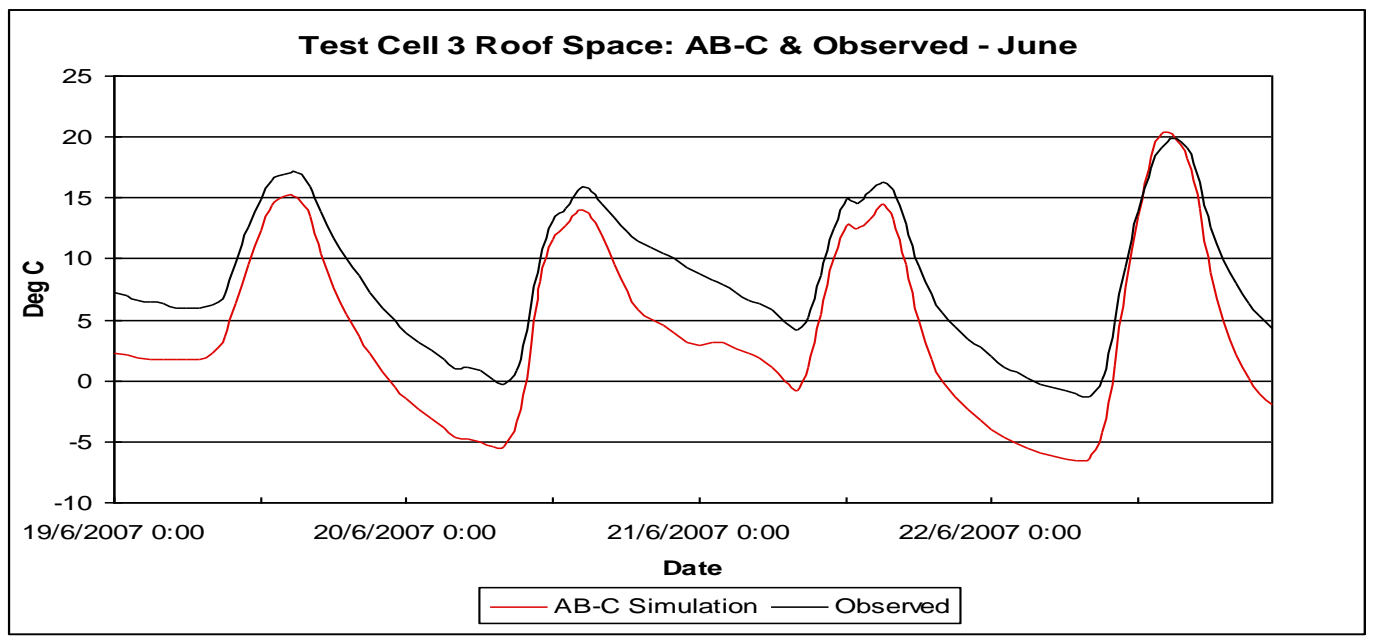

Figure 5.38 - Test Cell 3 Roof Space: AB-C \& Measured Results: June 2007

This roof space received early morning shading in the months of January and February, yet this is not reflected in either the simulated or measured data. This indicates that the roof space temperature is not greatly affected by the reduced solar radiation in the morning. As discussed for the roof space of the other two test cells, the much lower resistance value of the eave to the outside air, (which was not modelled in the simulation), should have made the measured values for the roof space cooler than the simulated values in winter, due to night and day time conductive losses. This is not apparent in the data and requires further examination in the future.

\section{Test Cell Room}

There is a seemingly constant difference between the measured and simulated temperatures for the room of this test cell, in all months (Figure 5.39 to Figure 5.42). The general shape of the two data sets is similar, reflecting that the AccuRate HER software is taking into account various climatic and built fabric affects.

The test cell room simulated and measured temperatures illustrate that for all months of this research, the measured temperatures were always warmer than the simulated temperatures. The test cell room temperature was affected by the external environment through its walls, and its interaction with the ground (Anderson, B 1991) and roof space. It was noted above, that the measured temperatures of the test cell roof space were always warmer than the simulated temperatures. The surface area of the test cell room is evenly split between the external walls 
$(46.8 \%)$ and the roof and subfloor (53.2\%) as shown in Table 5.19. This may indicate either a heat gain from or a reduced heat loss to the roof space zone.

Table 5.19: Concrete Slab-on-ground Floored Test Cell Room Surface Areas

\begin{tabular}{|l|c|c|c|}
\hline \multicolumn{1}{|c|}{ Surfaces } & $\mathrm{M}^{2}$ & $\%$ area & $\begin{array}{c}\text { Resistance } \\
\text { value }\end{array}$ \\
\hline Test Cell Room - Roof Space & 30.03 & $26.6 \%$ & $\mathrm{R} 3.59$ \\
\hline Test cell Room - external walls & 52.68 & $46.8 \%$ & $\mathrm{R} 2.50$ \\
\hline Test cell room - Ground & 30.03 & $26.6 \%$ & $\mathrm{R} 0.90$ \\
\hline
\end{tabular}

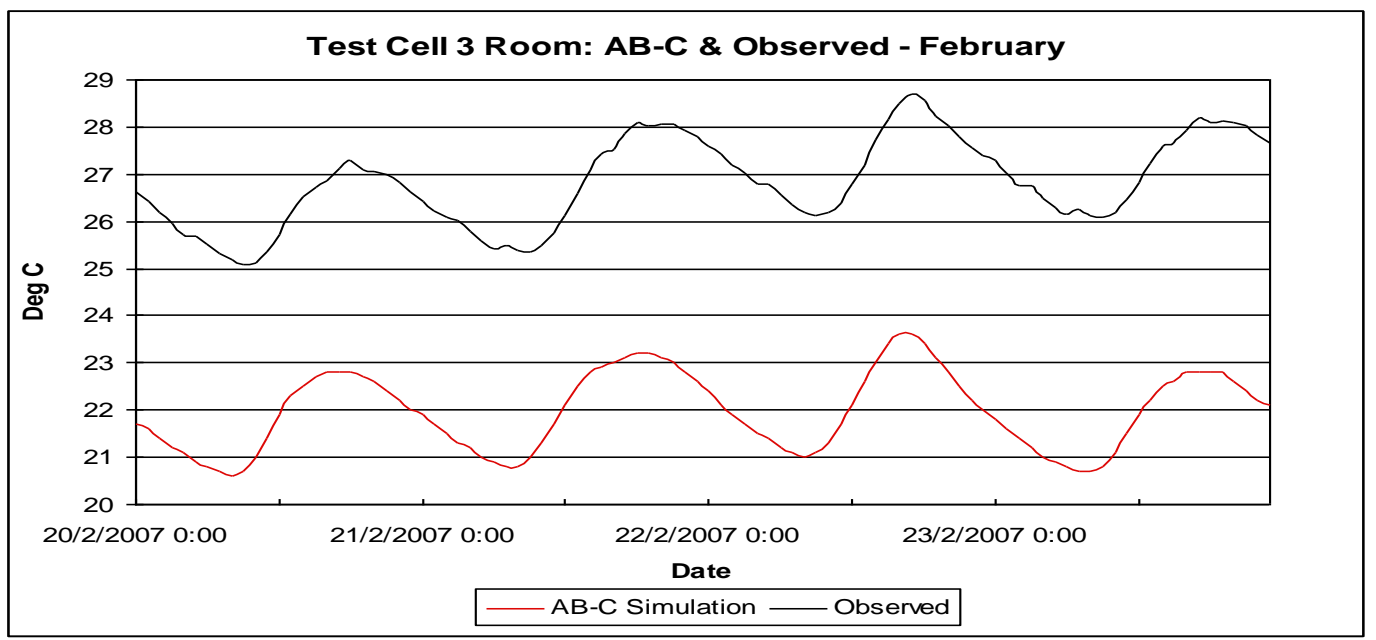

Figure 5.39 - Test Cell 3 Room: AB-C \& Measured Results: February 2007

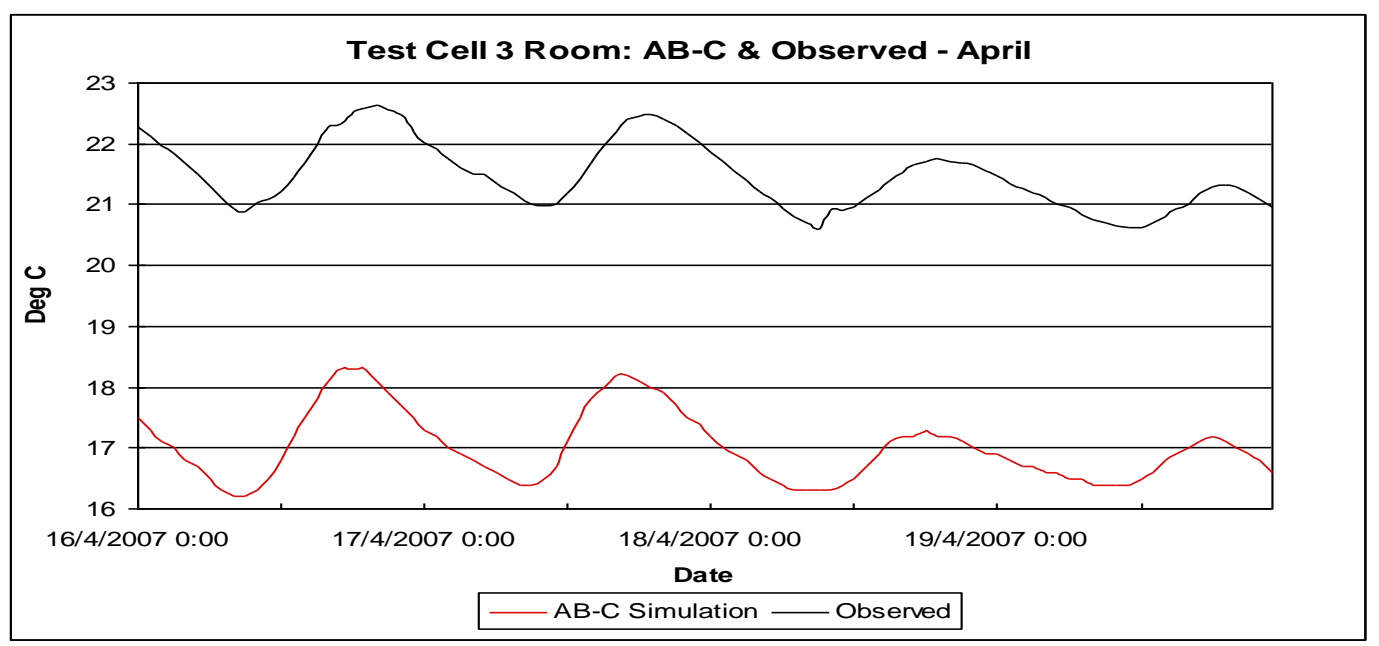

Figure 5.40 - Test Cell 3 Room: AB-C \& Measured Results: April 2007 


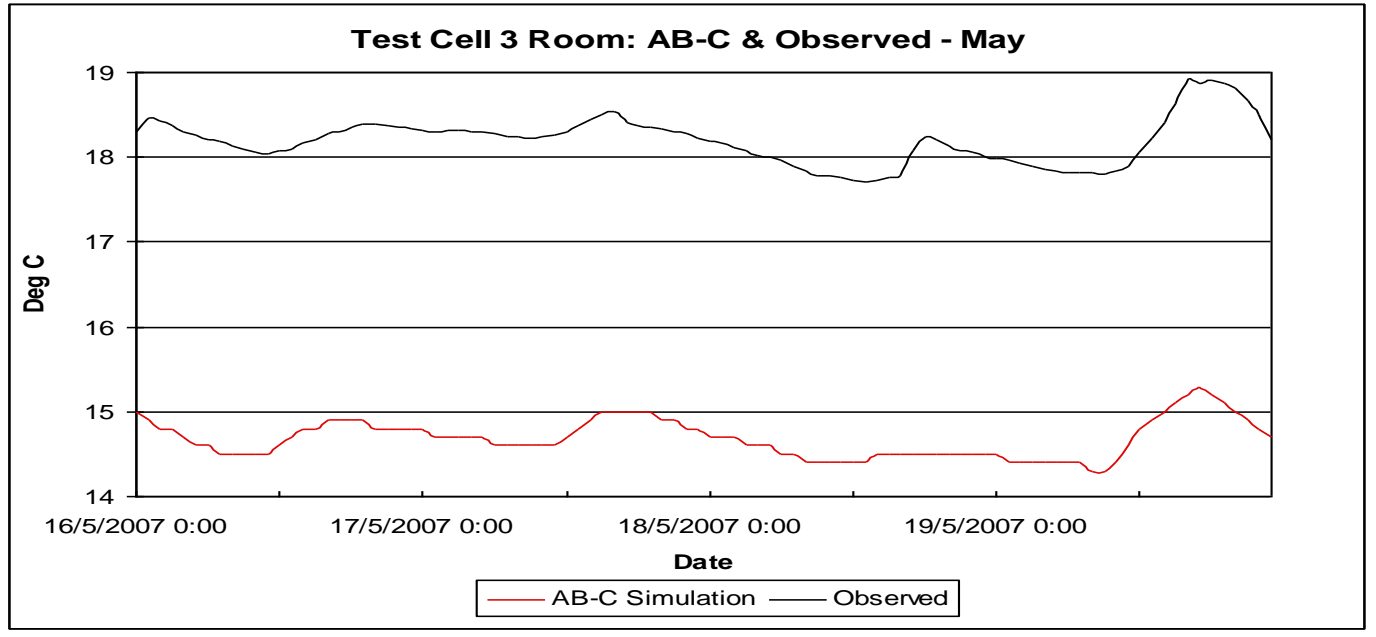

Figure 5.41 - Test Cell 3 Room: AB-C \& Measured Results: May 2007

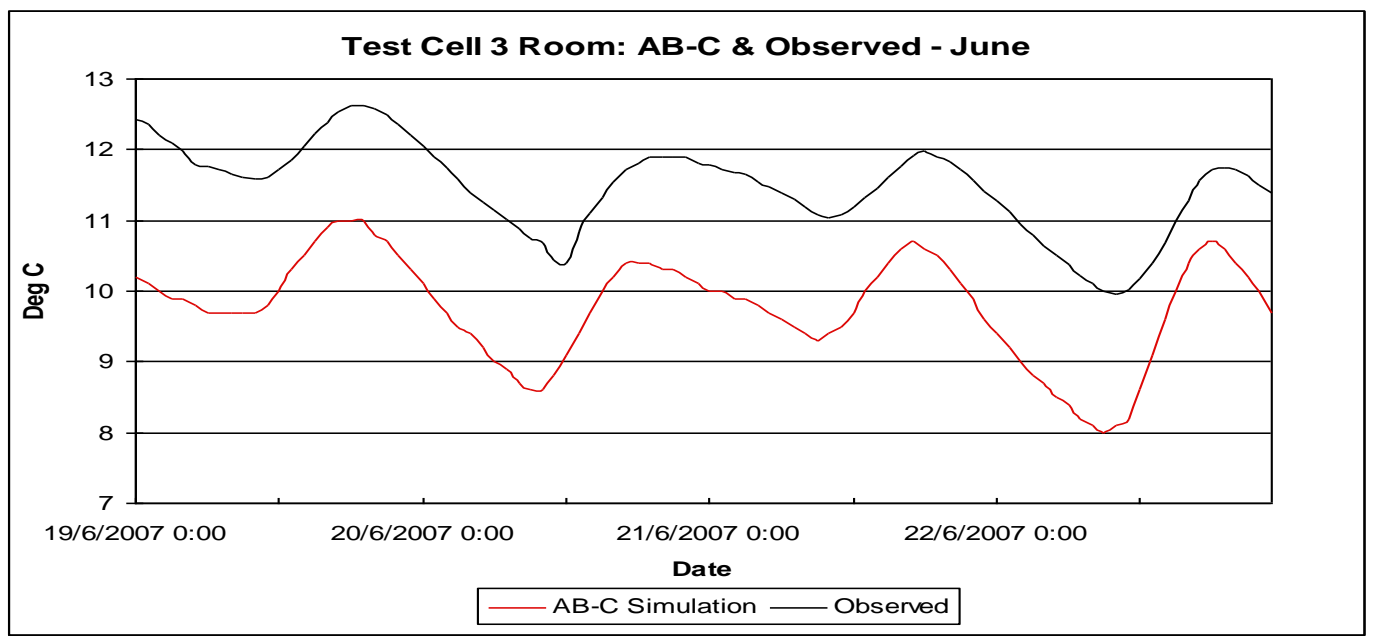

Figure 5.42 - Test Cell 3 Room: AB-C \& Measured Results: June 2007

When the average difference between measured and simulated minimum temperatures for the test cell room are analysed, several key elements become apparent (Table 5.18). The first is that the average differences of the minimum temperatures of the test cell room differ from $4.15^{\circ} \mathrm{C}$ to $4.88^{\circ} \mathrm{C}$ for the months of January to April, with the average difference dropping $3.48^{\circ} \mathrm{C}$ and $1.85^{\circ} \mathrm{C}$ for May \& June respectively. The second is that the average differences of the maximum temperatures are extremely similar in value and range to the minimum difference values. The average difference in the maximum temperatures for the test cell room range from $4.30^{\circ} \mathrm{C}$ to 
$4.98^{\circ} \mathrm{C}$ for the months of January to April and the average difference reduced to $3.58^{\circ} \mathrm{C}$ and $1.35^{\circ} \mathrm{C}$ for May \& June respectively.

This monthly or seasonal pattern and the average differences between measured and simulated temperatures may indicate that the AccuRate HER software is modelling thermal performance more accurately in the cooler months, as the data shows the greatest average difference between measured and simulated temperatures occurring in the hottest month and the smallest difference occurring in the coldest month.

Another aspect which requires further investigation is the ground model and its interaction with the concrete slab-on-ground floor. Delsante has developed improvements to the ground model in Accurate (Delsante 1988, 1989, 1993; Delsante, Stokes \& Walsh 1983) but if there is an anomaly in the ground model, which has been discussed in the context of the subfloor spaces of the other two test cells, there may be an influence on the relative ground-keying affect of the concrete floor for this test cell.

\subsubsection{Summary for Empirical Validation Graphs}

The variations between the measured and simulated temperatures for all zones in all three test cells are significant. Some suggest monthly climatic or seasonal influences, whilst others seem to indicate a general under-acknowledgement of a number of inputs affecting the heat energy flows within the test cells. This is clearly apparent in the two platform-floored test cells, where the subfloor model (and perhaps the ground model), appear not to be considering real-life interactions.

The measured minimum subfloor temperatures are consistently warmer than the simulated temperatures. This consistent under-estimation of the subfloor temperatures could indicate that the subfloor provides heat to or a reduced heat loss from the test cell room. This could indicate an error in the subfloor model and the partial ground keying affect of the ground, or an error in the ground model. If there is an error in the ground model, then the simulation of the concrete slab-onground floored test cell is also questionable.

The roof zone data appears to show monthly climatic or seasonal trends for the average difference between the measured and simulated maximum temperatures in each test cell. The average difference between the measured and simulated minimum temperatures for all three test cells was 
consistently positive. As with the subfloor, this may indicate additional heat transfer to or reduced heat loss from the test cell room.

The detailed Accurate HER simulation of all three test cells consistently underestimated the room zone temperature. The difference between the measured and simulated minimum values was often $4^{\circ} \mathrm{C}$ to $5^{\circ} \mathrm{C}$. If this was a conditioned room in a normal HER assessment, differences of this magnitude would have a large impact on the energy calculation and the resultant House Energy Star Rating.

The purpose of the empirical validation graphs was to examine whether the Accurate HER software was considering environmental and built fabric energy flows and whether there were similarities between measured and simulated values. The visual analysis of the empirical validation graphs gives some confidence that the software is accounting for substantial environmental and built fabric inputs as the two data sets often ran parallel to each other. However, this simple analysis also revealed some significant differences between the measured and simulated temperatures. Most of these differences were an under-estimation of zone temperatures by the software. This under-estimation was observed in the subfloor, roof and test cell room zones of all three test cells.

The subfloor and ground modelling method and capacity of many thermal simulation softwares has been called into question (Adjali et al. 2000; Akinyemi \& Mendes 2008; Barnaby, Spitler \& Xiao 2005; Deru 2003; dos Santos \& Mendes 2003; Rock \& Ochs 2001; Williamson, T \& Delsante 2006) and depending on the type of ground model used, it has been shown that results can differ by between $15 \%$ and 60\% (Crowley 2009; Neymark et al. 2009). The differences shown in these graphs may indicate that this aspect of the AccuRate software requires further investigation and improvement.

To examine these differences in terms of interaction between zones, the following statistical analysis section assesses whether the difference between the measured and simulated temperatures in the subfloor and roof spaces have a relationship with the differences observed in the test cell room temperatures. The statistical analysis also explores any relationship between key external environmental parameters and the differences between measured and simulated temperatures which have been identified. 


\subsection{Statistical Analyses}

The graphical analysis provided a basis for an initial assessment of the responsiveness of the AccuRate HER software to environmental influences and its capacity to predict zone temperatures. In this section, more detailed analyses of the differences between measured and simulated data were conducted using statistical analyses. The results discussed below are based on selected graphs from the full dataset of analyses (Appendix 6). The residual values (Measured - Simulated) for each zone of the three test cells are examined. The purpose of the analyses is to investigate the relationships between the residual value (or error) for a zone and the residual value for its adjoining zone, or a climatic variable. The analyses conducted were:

- Correlations between the measured and simulated temperatures for each test cell zone;

- Histogram and time series analyses of the residual values for each test cell zone;

- Correlations of the residual values of adjoining zones; and

- Correlations between residual values for each test cell zone and measured climatic conditions.

These forms of analysis were conducted using data from the entire validation period, and monthly data. Previous research has used the mean temperatures for a given period to examine differences between the measured and simulated data sets. It will be shown here that there is little value in using mean temperatures. Instead, the residual values were analysed to examine daily and seasonal trends. After preliminary analyses of the full data set (January to June) were completed, monthly data subsets were also examined. This revealed distortions in the full data set for each variable, thus highlighting any seasonal influences or misrepresentations (Frank \& Althoen 1994).

\subsubsection{Scatter Plot of Measured and Simulated Temperatures}

These analyses compared the measured and simulated temperatures for each zone within the three test cells. Scatter plots and determining the line of best fit are used to determine how or if two variables are related, and to indicate the strength of that relationship (Palomo, Marco \& Madsen 1991). A second key factor for this type of analysis was the consideration that AccuRate was principally an energy balance program. The software calculates energy flows 
within a building until balance is achieved. If the software under-predicts the temperature of a zone, the software assumes that either this additional energy is not transferred from another zone, or is correspondingly transferred to adjoining zones, depending on the other zone's temperature, fabric conductivity, emittance and infiltration values. Likewise, if the software over-predicts a zone temperature, it assumes that the zone proportionately absorbs energy from an adjoining zone, or is not transferring energy to an adjoining zone, depending on the other zone's temperature, fabric conductivity, emittance and infiltration values. These assumptions (Kokogiannakis, Strachan \& Clarke 2008) are the basis of the algorithms, which may need to be improved. If the software has a problem in particular algorithms or a zone, it will also impact on the residual values of adjoining zones. If there is a strong correlation between the residual values of adjoining zones, improving the algorithm in one zone can reduce the level of error in the other zones.

In the following discussions of scatter plots, the $\mathrm{X}$ axis is the measured temperature and the $\mathrm{Y}$ axis is the simulated temperature. To best illustrate the correlation between data sets, the scales on the $\mathrm{X}$ and $\mathrm{Y}$ axes of the scatter plots vary.

\section{Unenclosed-perimeter Platform-floored Test cell}

The scatter plots for the unenclosed-perimeter platform-floored test cell (Figures 5.43 to 5.48) show a strong positive linear correlation between the measured and simulated values. On closer examination of Figures 5.43, 5.45 and 5.47, (which include data from January to June), a few elements become apparent. The trend lines show a difference between the measured and simulated temperatures of $0^{\circ} \mathrm{C}$ to $2^{\circ} \mathrm{C}$ for the subfloor, $2^{\circ} \mathrm{C}$ to $4^{\circ} \mathrm{C}$ for the test cell room and $1^{\circ} \mathrm{C}$ to $4^{\circ} \mathrm{C}$ test cell roof spaces. In all cases, the variance increases with higher measured temperatures. The data below the trend line in all three zones is quite defined and this could suggest a boundary condition that is working effectively in this model. The data above the trend line for all zones becomes dispersed when compared to the data below the trend line. 


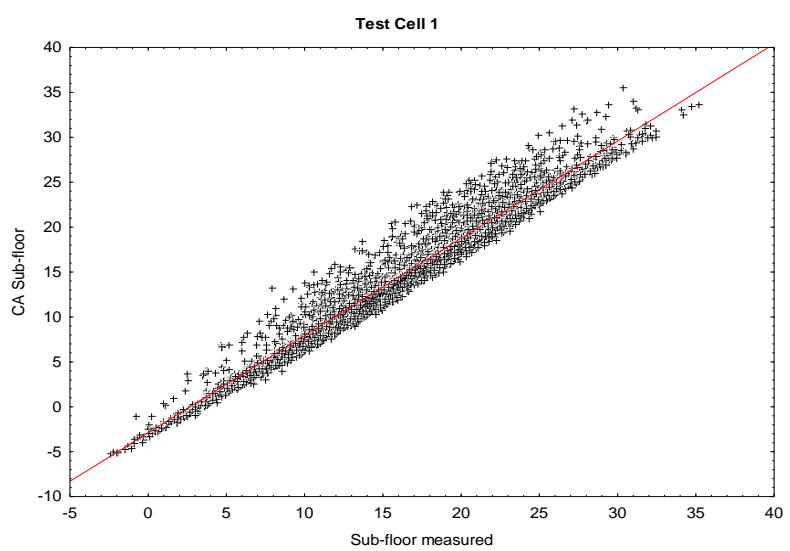

Figure 5.43 - TC1 Subfloor Measured v Simulated: January to June 2007 ( $r=0.97)$

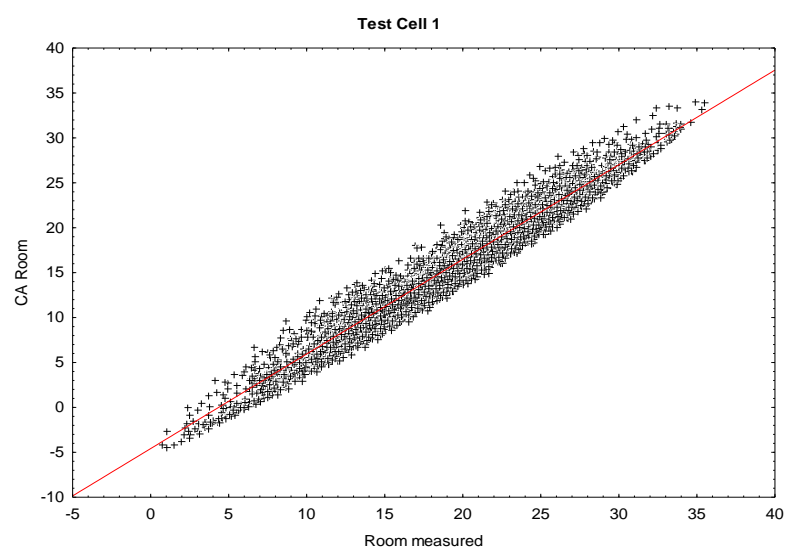

Figure 5.45 - TC1 Room Measured v Simulated: January to June $2007(r=0.97)$

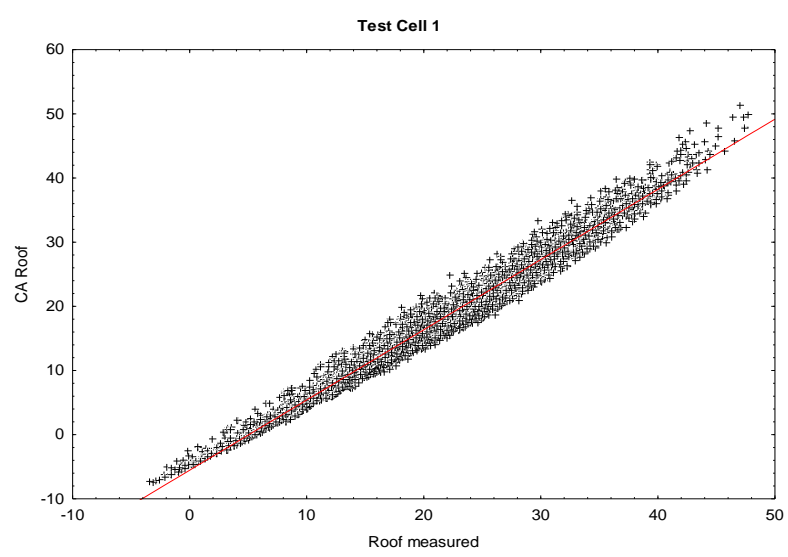

Figure 5.47 - TC1 Roof Measured v Simulated: January to June $2007(r=0.99)$

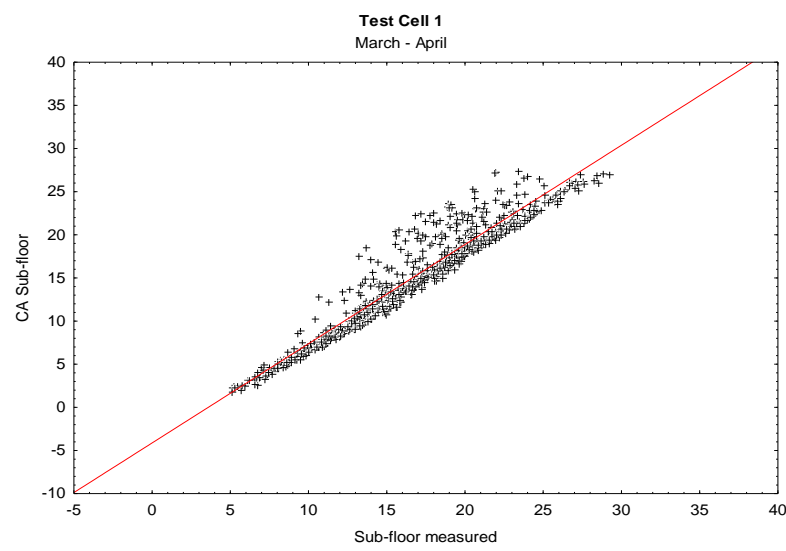

Figure 5.44 - TC1 Subfloor Measured v Simulated: March/April $2007(r=0.96)$

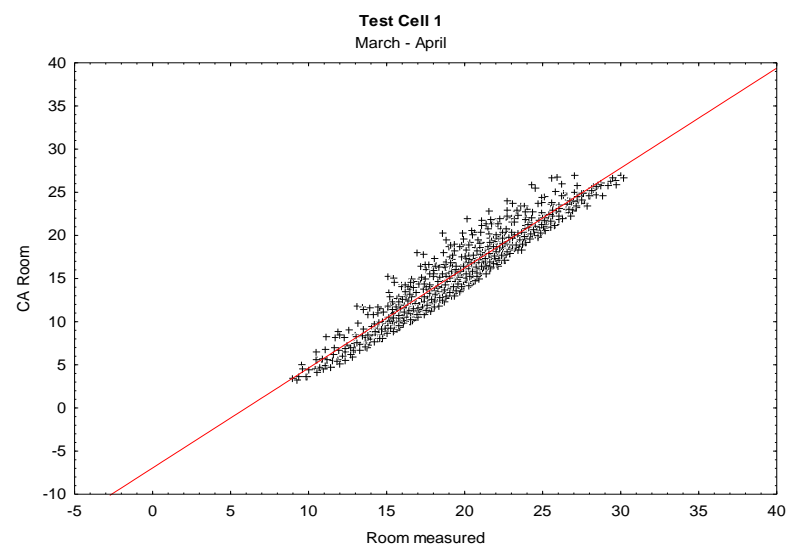

Figure 5.46 - TC1 Room Measured v Simulated: March/April $2007(r=0.96)$

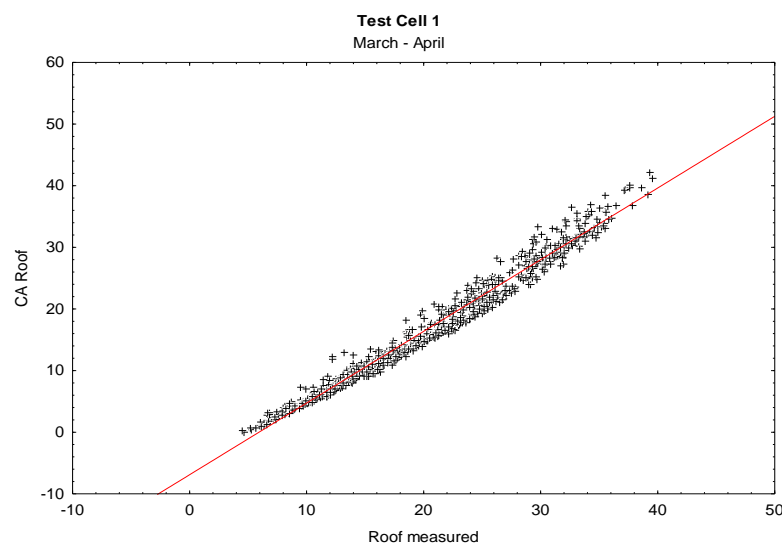

Figure 5.48 - TC1 Roof Measured v Simulated: March/April $2007(r=0.99)$ 
When the scatter plots which show the data from mid-March to mid-April (Figures 5.44, 5.46 and 5.48) are examined, this observation is prominent in the subfloor scatter plot. The test cell room data (Figure 5.46) above the trend line shows some disparity but not as broad as for the subfloor (Figure 5.44). The test cell roof space (Figure 5.48) has the widest range of measured and simulated data, due to the degree of exposure to external environment and the thermal properties of the roof space fabric. In addition, similar to the other zones, the data above the trend line is more dispersed than data below the trend line.

The correlation ratios for this test cell are all very strong, as in Table 5.20, which also shows the variation that occurs between different subsets of the data. In the case of the subfloor, the ratio sits comfortably between 0.96 and 0.97 . However, the test cell room ratio declines from 0.96 in January to 0.93 in June, indicating a possible seasonal influence. The roof space has a similar trend to the test cell room: where the ratio declines from the value of 0.99 for January, February, March and April to 0.97 and 0.98 for May and June, respectively. This table illustrates the inherent risks when analysing the full data set, especially in the case of the test cell room, where the full data set had a ratio of 0.97 , but none of the individual monthly data sets had a ratio of a similar value.

Table 5.20: Test Cell 1 Measured Temperature and Simulated Temperature Correlation Ratios

\begin{tabular}{|c|c|c|c|}
\hline & Subfloor & Room & Roof Space \\
\hline Full Data Set & $r=0.97$ & $r=0.97$ & $r=0.99$ \\
\hline January & $r=0.96$ & $r=0.96$ & $r=0.99$ \\
\hline March/April & $r=0.96$ & $r=0.96$ & $r=0.99$ \\
\hline May & $r=0.97$ & $r=0.95$ & $r=0.97$ \\
\hline June & $r=0.96$ & $r=0.93$ & $r=0.98$ \\
\hline
\end{tabular}

If the variance is not constant, it means the data are heteroscedastic and in that case, correlation is not a good measure of association. Based on the observations of all six cases, it is apparent that there seems to be a temperature above which the relationship between the measured temperature and simulated temperature tends to be more variable: that is, there seems to be a boundary condition operating. These scatter plots also show that the data under the line of best fit is homoscedastic, whilst the data above the line of best fit becomes heteroscedastic. 


\section{Enclosed-perimeter Platform-floored Test Cell}

The scatter plots for this test cell (Figures 5.49 to 5.54) are somewhat different in character to those of the unenclosed-perimeter platform-floored test cell. The subfloor zone, (Figure 5.49), has a broad data spread above and below the line of best fit. The scatter plot up to $15^{\circ} \mathrm{C}$ has a distinctly different shape to the data above $15^{\circ} \mathrm{C}$. This temperature is very close to the ground temperature of this locality (BOM 2010). This could indicate some form of heat exchange between the ground and subfloor zone that is not accounted for fully. The correlations between the measured and simulated values of the test cell room (Figure 5.51) are much tighter. However, similar to the subfloor zone, there is a bend in the data pattern below $15^{\circ} \mathrm{C}$ indicating some relationship between the observations noted in the subfloor and the test cell room. The roof space correlation graph (Figure 5.53) shows a strong correlation between the measured and simulated data sets until the temperature reaches $25^{\circ} \mathrm{C}$, at which point the data becomes more dispersed. As discussed earlier, due to technical difficulties the data for the roof space and the subfloor zones for this test cell were not available until March. To facilitate the comparison of the scatter plots for the test cell room from all three test cells, the time period included in the analysis is identical (i.e., March/April). However, the data analysis for the roof space and the subfloor zones for this test cell were conducted with monthly subsets (i.e., March, April, May, June). If correlations or other sub groupings of data became apparent, future research could redefine the date-based groupings of the data.

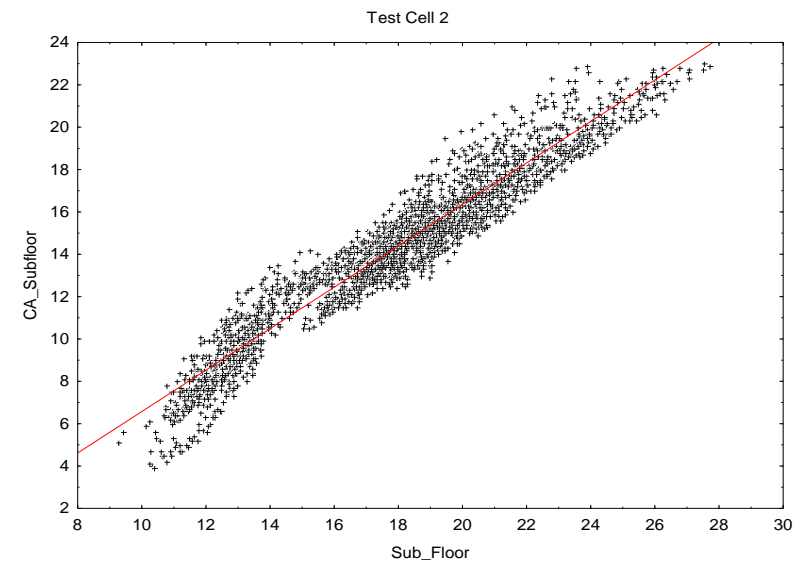

Figure 5.49 - TC2 Subfloor Measured v Simulated: March to June $2007(r=0.96)$

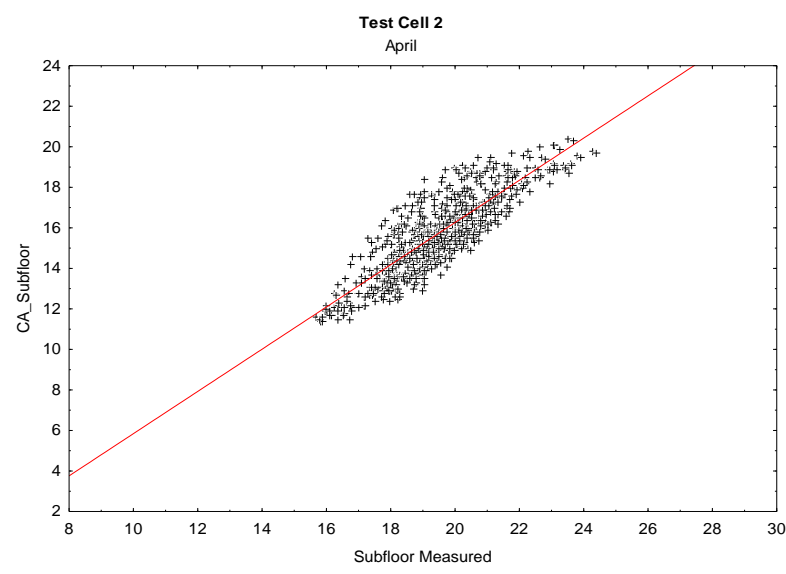

Figure 5.50 - TC2 Subfloor Measured v Simulated: April $2007(r=0.85)$ 


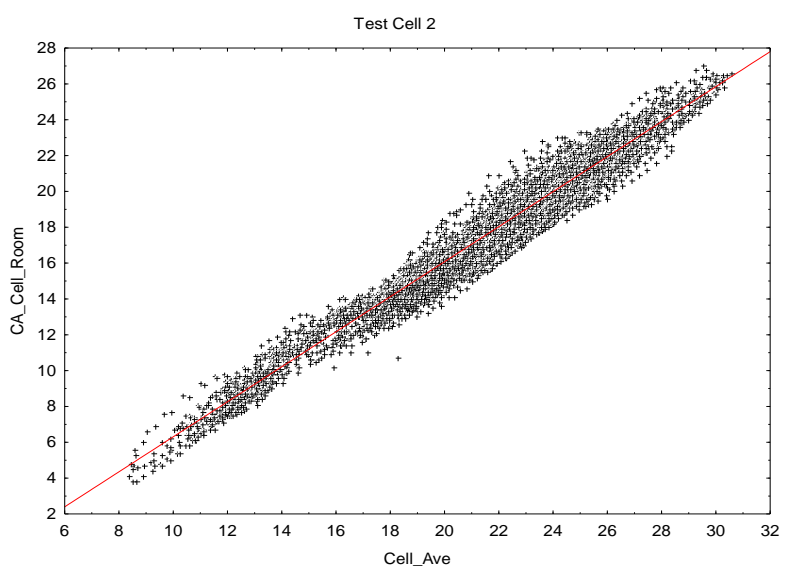

Figure 5.51 - TC2 Room Measured v Simulated: January to June $2007(r=0.98)$

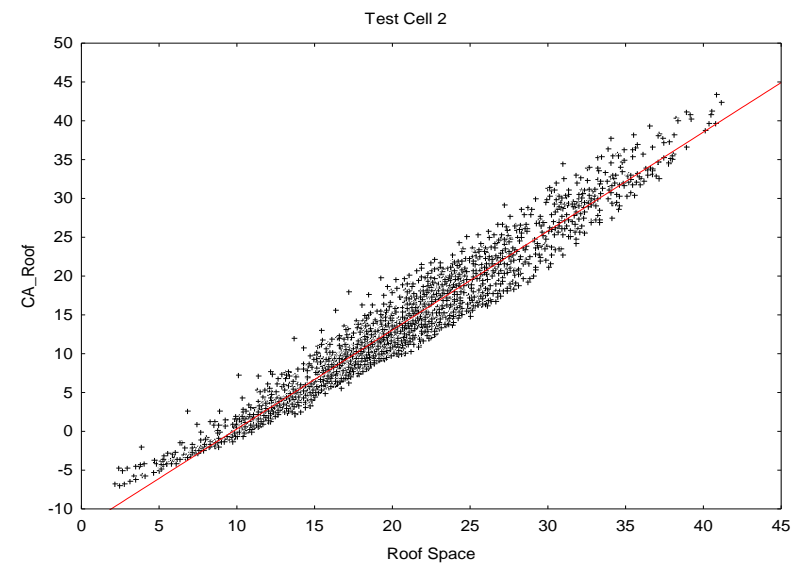

Figure 5.53 - TC2 Roof Measured v Simulated: March to June $2007(r=0.97)$

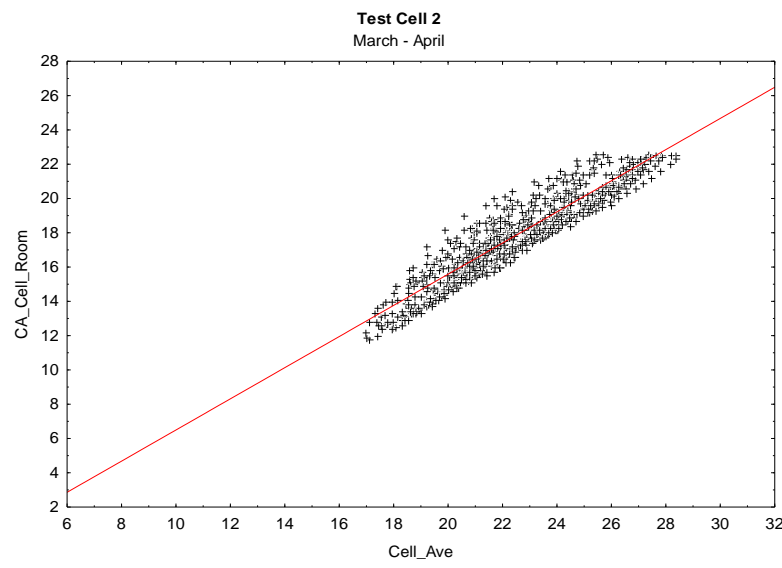

Figure 5.52 - TC2 Room Measured v Simulated: March/April $2007(r=0.93)$

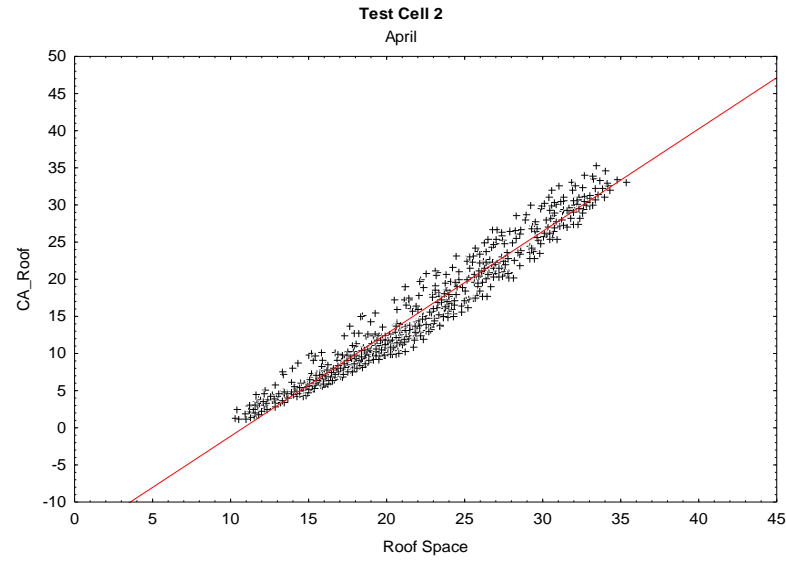

Figure 5.54 - TC2 Roof Measured v Simulated: April $2007(r=0.98)$

When the data sets from mid-March to mid-April are analysed, these trends become more evident. In the case of the subfloor zone (Figure 5.50) the data above and below the trend line becomes ovoid, with the widest range being between $18^{\circ} \mathrm{C}$ to $22^{\circ} \mathrm{C}$. This indicates that there was a wide range of variance above and below the trend line from $18^{\circ} \mathrm{C}$ to $22^{\circ} \mathrm{C}$. Below $18^{\circ} \mathrm{C}$ and above $22^{\circ} \mathrm{C}$ the variation from the trend line reduces.

The test cell room data for mid-March to mid-April retains a similar pattern to the room of the unenclosed-perimeter platform-floored test cell, where the data under the trend line is quite solid, but the data above becomes more dispersed (Figure 5.52). 
The correlation between the roof space measured and simulated temperatures for mid-March to mid-April (Figure 5.54), for this test cell appears more dispersed than the unenclosedperimeter platform-floored test cell roof space (Figure 5.48).

The correlation ratios for this test cell, (as in Table 5.21) show the variation that occurs between different subsets of the data. In contrast to the stable ratios of the unenclosedperimeter test cell, the subfloor of this test cell has a ratio of 0.90 for March and April, but a lower ratio of 0.85 and 0.86 for the cooler months of May and June, respectively. The ratios for the test cell room are quite similar for most months with the exception of May where a lower ratio exists. The roof space has a slight trend, where the ratio declines from the value of 0.97 for March and April to 0.95 and 0.96 for May and June, respectively. As noted with the previous test cell, there is a risk in only analysing the full data set, where for this test cell the full data set ratios for the subfloor and room are significantly different from the monthly ratios.

Table 5.21: Test Cell 2 Measured Temperature and Simulated Temperature Correlation Ratios

\begin{tabular}{|c|c|c|c|}
\hline & Subfloor & Room & Roof Space \\
\hline Full Data Set & $r=0.96$ & $r=0.98$ & $r=0.97$ \\
\hline January & & $r=0.93$ & \\
\hline March/April & $r=0.90$ & $r=0.93$ & $r=0.97$ \\
\hline May & $r=0.85$ & $r=0.88$ & $r=0.95$ \\
\hline June & $r=0.86$ & $r=0.92$ & $r=0.96$ \\
\hline
\end{tabular}

\section{Concrete Slab-on-Ground Floored Test Cell}

The scatter plots for the room of this test cell (Figures 5.55 to 5.58) show a strong linear correlation between the measured and simulated values. The data for the test cell room (Figure 5.55) is quite tightly grouped along the trend line, much more so than for the previous two test cell rooms. This could be in part due to the much smaller range of temperatures, where the room temperature of the unenclosed-perimeter platform-floored test cell ranged from $10^{\circ} \mathrm{C}$ to $40^{\circ} \mathrm{C}$, whereas this room's temperature ranges from $10^{\circ} \mathrm{C}$ to $28^{\circ} \mathrm{C}$. The strength of the correlation is reflected, with this test cell room having the highest correlation ratio of 0.99, as compared to strong ratios of 0.97 and 0.98 for the previous test cell rooms. As this test cell does not have a subfloor, climatic elements can only affect the external walls and roof 
space. The test cell room scatter plot shows some interesting data groupings with differing relationships to the trend line. The distinct groupings of data are from $10^{\circ} \mathrm{C}$ to $12^{\circ} \mathrm{C} ; 12^{\circ} \mathrm{C}$ to $16^{\circ} \mathrm{C} ; 16^{\circ} \mathrm{C}$ to $20^{\circ} \mathrm{C}$; and all measured data above $20^{\circ} \mathrm{C}$. This is somewhat similar to the observation noted for the subfloor of the enclosed-perimeter platform-floored test cell. This test cell does not have a subfloor, but the concrete slab-on-ground floor is keyed directly to the ground. The ground temperature ranges from approximately $18^{\circ} \mathrm{C}$ in February to $11^{\circ} \mathrm{C}$ in June (BOM 2010). When the measured temperatures for the room were below the ground temperature, the room would be cooler than the ground temperature and would be warmed by the ground. This could indicate that the ground model for the ground keyed slab requires calibration. Matters pertaining to the ground model within various softwares, internationally, has been explored and discussed by researchers, who have identified this as an area requiring improvement and calibration (Deru 2003; Krarti \& Ihm 2009; NeymarkJudkoffBeausoleilMorrison et al. 2008), which has included revisions to the IEA BESTEST documentation (NeymarkJudkoffBeausoleil-Morrison et al. 2008). This should be explored in the context of the AccuRate software.

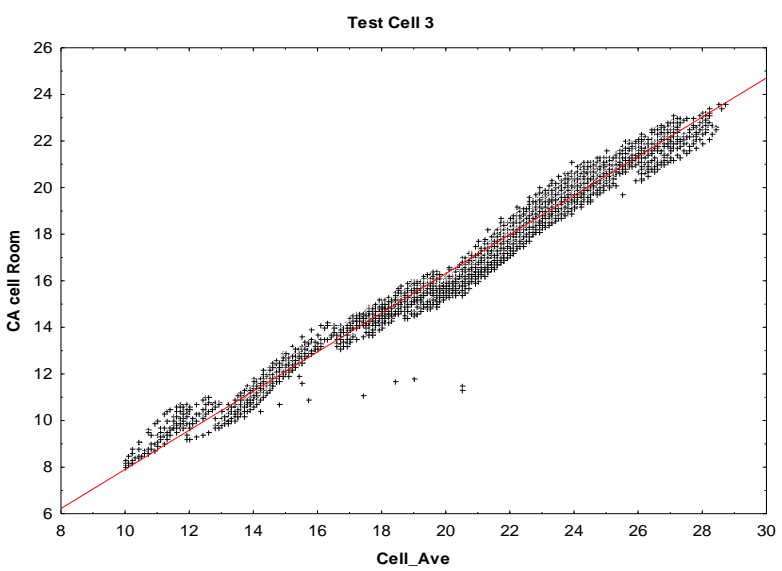

Figure 5.55 - TC3 Room Measured v Simulated: January to June 2007 ( $r=0.99)$

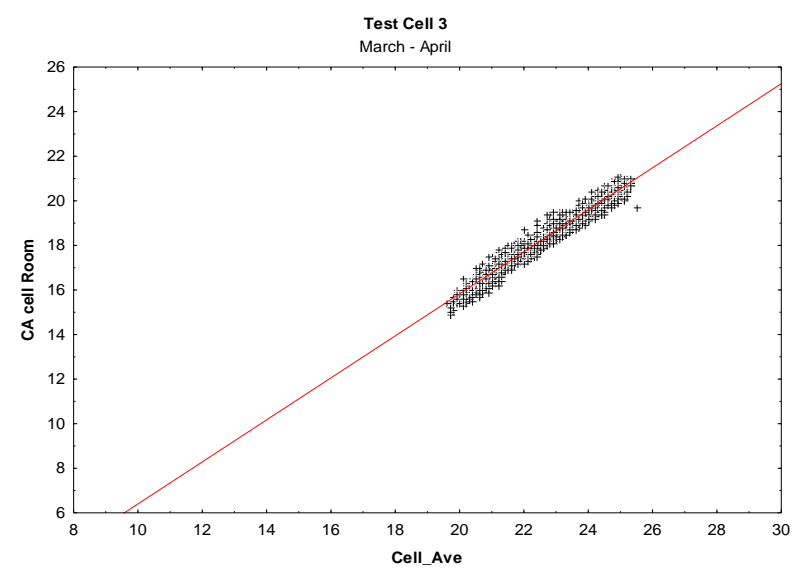

Figure 5.56 - TC3 Room Measured v Simulated: March/April $2007(r=0.98)$

The test cell roof space (Figures 5.57 and 5.58) shows similar trends to the previous two test cells. However, the two scatter plots show some distinctly different patterns. The full data set (Figure 5.57) shows a curvilinear relationship where the curve is below the trend line and the March and April data has the curve above the trend line. In the full data set there is a distinct shift in the pattern below $10^{\circ} \mathrm{C}$ when this phenomenon occurs. 


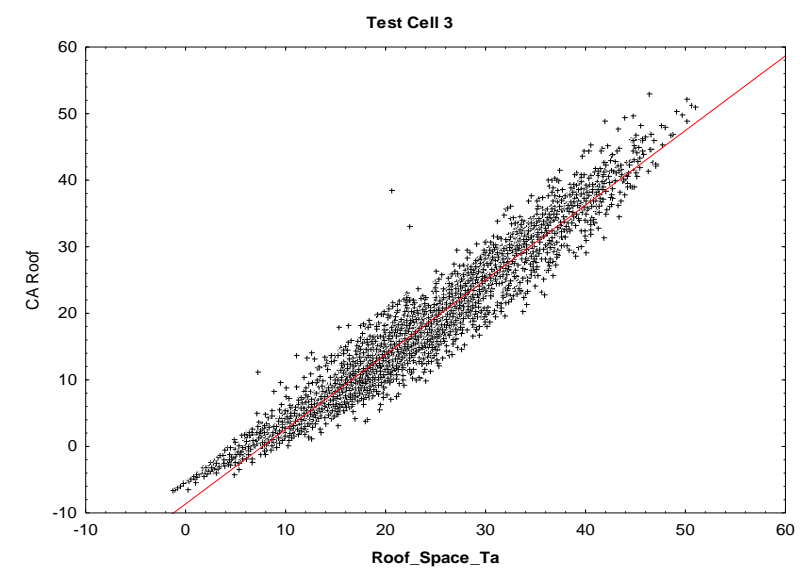

Figure 5.57 - TC3 Roof Measured v Simulated: January to June 2007 ( $r=0.97)$

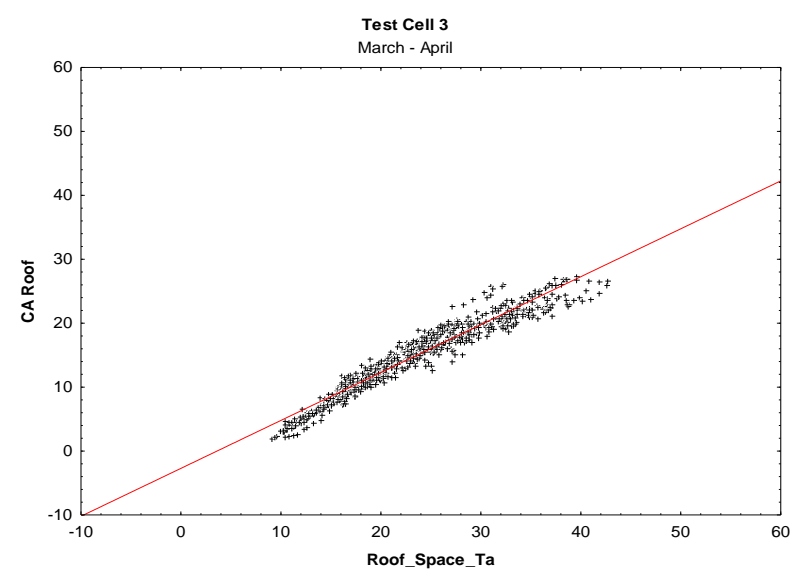

Figure 5.58 - TC3 Roof Measured v Simulated: March/April $2007(r=0.97)$

As noted for the previous test cells, the full data set correlation ratio can be notably different to the ratio for individual months, as shown in Table 5.22. With the exception of the March/April data, the test cell room ratios decline in value from 0.96 in January to 0.89 in June; this could indicate the ground temperature hypothesis mentioned above, or some seasonal effect. The roof space correlation ratios for each month are more inconsistent than the test cell room in terms of indicating any monthly trends.

Table 5.22: Test Cell 3 Measured Temperature and Simulated Temperature Correlation Ratios

\begin{tabular}{|c|c|c|}
\hline & Room & Roof Space \\
\hline Full Data Set & $r=0.99$ & $r=0.97$ \\
\hline January & $r=0.96$ & $r=0.94$ \\
\hline February & $r=0.94$ & $r=0.99$ \\
\hline March/April & $r=0.98$ & $r=0.97$ \\
\hline May & $r=0.92$ & $r=0.92$ \\
\hline June & $r=0.89$ & $r=0.97$ \\
\hline
\end{tabular}

\section{Summary}

- The correlation ratio for the zones of the three test cells ranged from 0.85 to 0.99 , indicating a very strong correlation between the measured and simulated temperatures. The Accurate HER software is under-estimating the temperature for subfloor, test cell room and roof space zones, consistently and frequently.

- In most cases, the data points are concentrated below the trend line, implying that the model works best within a boundary condition. However, the data above the trend line 
and at higher temperatures often becomes more dispersed. This could suggest that particular algorithms are not appropriately considering some inputs.

- There is a shift in the relationship of the measured and simulated temperatures in the subfloor zone, and it occurs when the measured temperature drops below the ground temperature. This requires further investigation as it appears to affect the room temperature within the enclosed-perimeter platform test cell. A similar effect is noticeable in the concrete slab-on-ground floored test cell.

- The correlation of the full January to June data sets is not a good indicator of association as the data are heteroscedastic and the monthly scatter plots show a different ratio for each month.

\subsubsection{Residual Histograms}

This analysis was completed to enable a quick visualisation of the difference, hereafter referred to as the residual value, between the measured temperature and simulated temperature. In all cases, the residual value has been obtained by subtracting the simulated temperature from the measured temperature (Measured Temperature - Simulated Temperature $=$ Residual Value). To best illustrate the residual values, the scales on the $\mathrm{X}$ and Y axes of the histograms vary.

\section{Unenclosed-perimeter Platform-floored Test Cell}

The temperature of the subfloor for the period of January to June (Figure 5.59) had a predominant residual value of $1^{\circ} \mathrm{C}$ to $3^{\circ} \mathrm{C}$, with more than $2650(65 \%)$ observations having a $2^{\circ} \mathrm{C}$ variation (Table 5.23). When the data for January (Figure 5.60) is examined, a very similar profile to the six month data set was recognisable.

The residual values for the test cell room (Figure 5.61) are concentrated between $2^{\circ} \mathrm{C}$ to $6^{\circ} \mathrm{C}$, with an average residual value of $3.5^{\circ} \mathrm{C}$ (Table 5.23). There were nearly 2,900 observations where the residual value was $3^{\circ} \mathrm{C}(72 \%)$ or higher. As each observation is equivalent to one hour of simulation or measured time, this equates to 2,900 hours where the simulated temperature was lower than the measured room temperature by more than $3^{\circ} \mathrm{C}$. The data from mid-March to mid-April (Figure 5.62) reinforces this observation, where the majority of the 
residual values were between $2^{\circ} \mathrm{C}$ and $7^{\circ} \mathrm{C}$. This level of error would have a dramatic affect on the calculation of energy for heating or cooling.

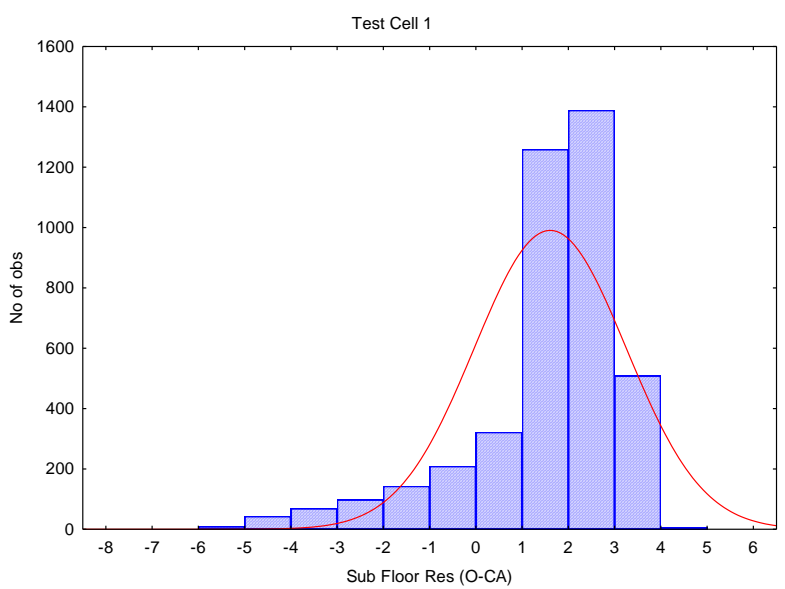

Figure 5.59 - TC1 Subfloor Residual January to June 2007

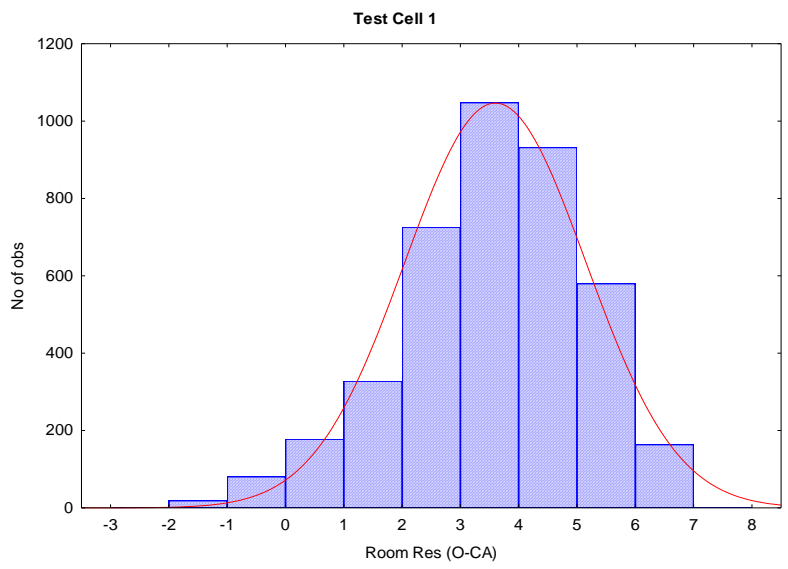

Figure 5.61 - TC1 Room Residual January to June 2007

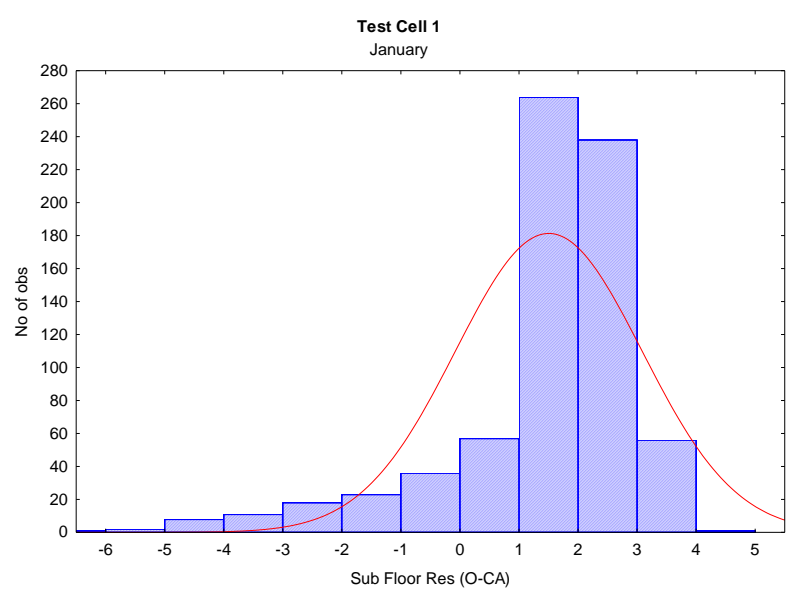

Figure 5.60 - TC1 Subfloor Residual January 2007

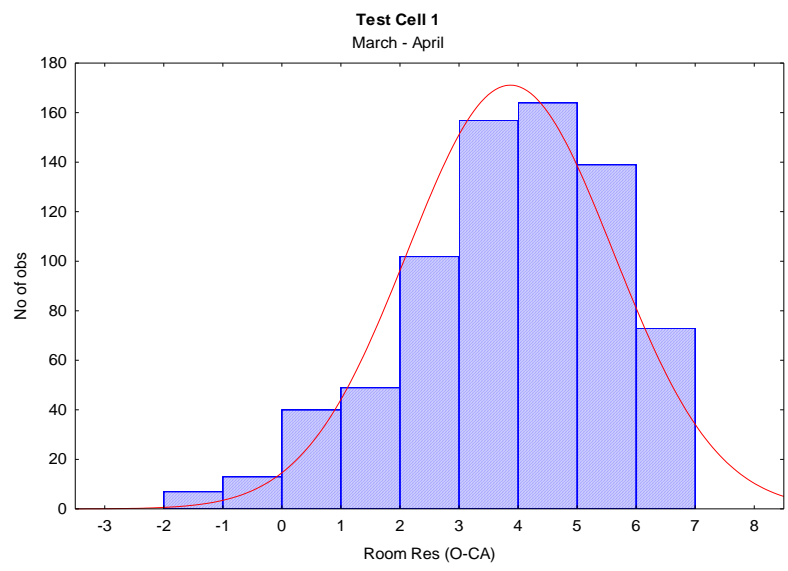

Figure 5.62 - TC1 Room Residual March/April 2007

The residual values for the roof space (Figure 5.63) show similar trends to those in the subfloor and test cell room, with an average residual value of $3.5^{\circ} \mathrm{C}$ (Table 5.23). In a similar pattern to the test cell room, the roof space residual values for the six month data set range from $-6^{\circ} \mathrm{C}$ to $9^{\circ} \mathrm{C}$, with the majority of the values between $2^{\circ} \mathrm{C}$ and $6{ }^{\circ} \mathrm{C}$. The residual values from January (Figure 5.64) also have the majority of the data in the range of $2^{\circ} \mathrm{C}$ to $7^{\circ} \mathrm{C}$. Note however, that the roof space residual histograms are slightly skewed negatively, and the mean 
value is used here for the purpose of preliminary examination. The mean monthly data is also presented in the table for comparison.

Although there was no insulation between the subfloor and the test cell room, there was R4.0 glasswool insulation in the ceilings of the test cells, providing a thermal break between the room and roof space. This level of insulation would have tempered the exchange of heat between the room and roof spaces. If there is a relationship between the roof space residuals and room residuals, a similar principle of heat flow would apply to all three test cells. To assess whether or not there is any correlation between the residual values of adjoining zones, a correlation study was conducted, as discussed later in Section 5.5.4.

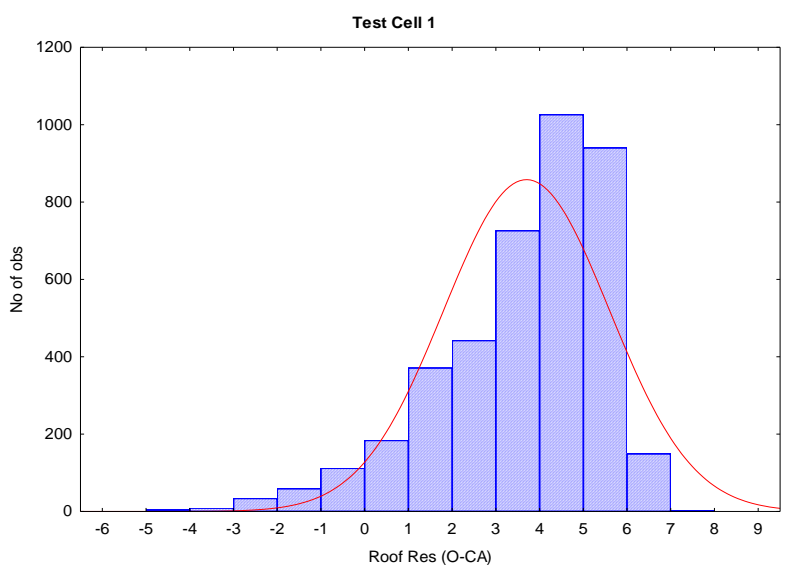

Figure 5.63 - TC1 Roof Space Residual January to June 2007

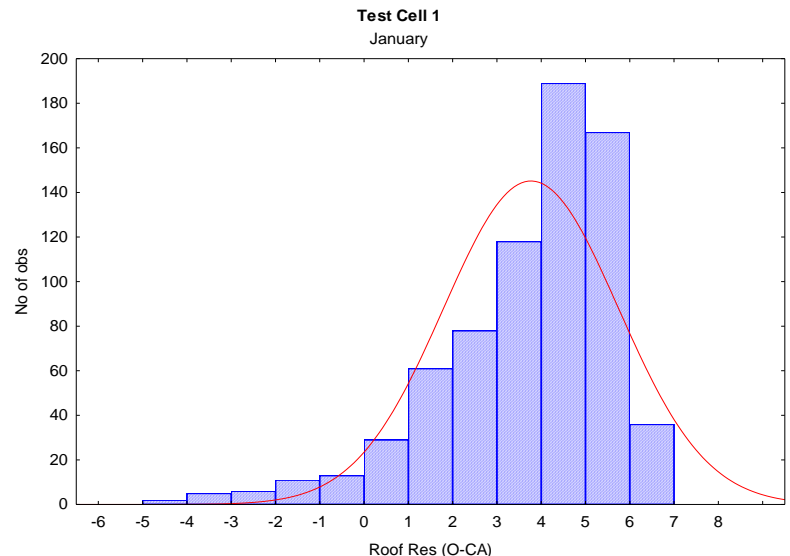

Figure 5.64 - TC1 Roof Space Residual January 2007

Table 5.23: Unenclosed-perimeter Platform-floored Test Cell Mean Residual Values

\begin{tabular}{|l|c|c|}
\hline & $\begin{array}{c}\text { Mean Residual Value } \mathrm{T}^{\mathrm{O}} \mathrm{C} \\
\text { Full Data Set }\end{array}$ & $\begin{array}{c}\text { Mean Residual Value } \mathrm{T}^{\mathrm{O}} \mathrm{C} \\
\text { Monthly Sample }\end{array}$ \\
\hline Subfloor & $2.0^{\circ} \mathrm{C}$ & $1.5^{\circ} \mathrm{C}$ (January) \\
\hline Room & $3.5^{\circ} \mathrm{C}$ & $4.0^{\circ} \mathrm{C}$ (March/April) \\
\hline Roof Space & $3.5^{\circ} \mathrm{C}$ & $3.5^{\circ} \mathrm{C}$ (January) \\
\hline
\end{tabular}




\section{Enclosed-perimeter Platform-floored Test Cell}

Similar to the unenclosed-perimeter platform-floored test cell, this test cell had significant residuals. The subfloor residuals principally ranged from $2^{\circ} \mathrm{C}$ to $5^{\circ} \mathrm{C}$ (Figure 5.65 and Figure 5.66), with an average residual of $3.5^{\circ} \mathrm{C}$ (Table 5.24).

The test cell room residuals were within a similar range, with residual values for a large portion of the data being between $2.5^{\circ} \mathrm{C}$ and $4.5^{\circ} \mathrm{C}$ (Figure 5.67) and an average residual value of $3^{\circ} \mathrm{C}$ (Table 5.24). The data from mid-March to mid-April had an average residual value closer to $5^{\circ} \mathrm{C}$ (Figure 5.68). Based on the six month histogram, there were more than 1,650 $(40 \%)$ hours when the test cell room was $3^{\circ} \mathrm{C}$ warmer than the simulated temperature.

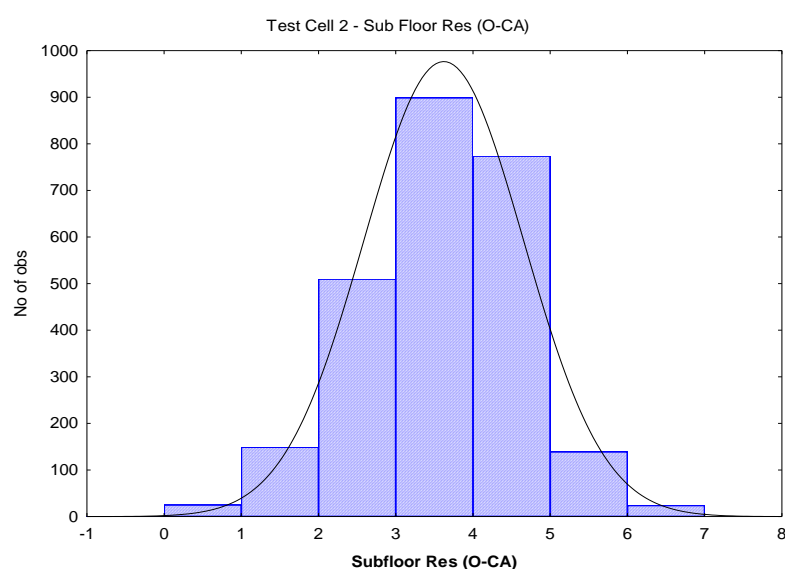

Figure 5.65 - TC2 Subfloor Residual March to June 2007

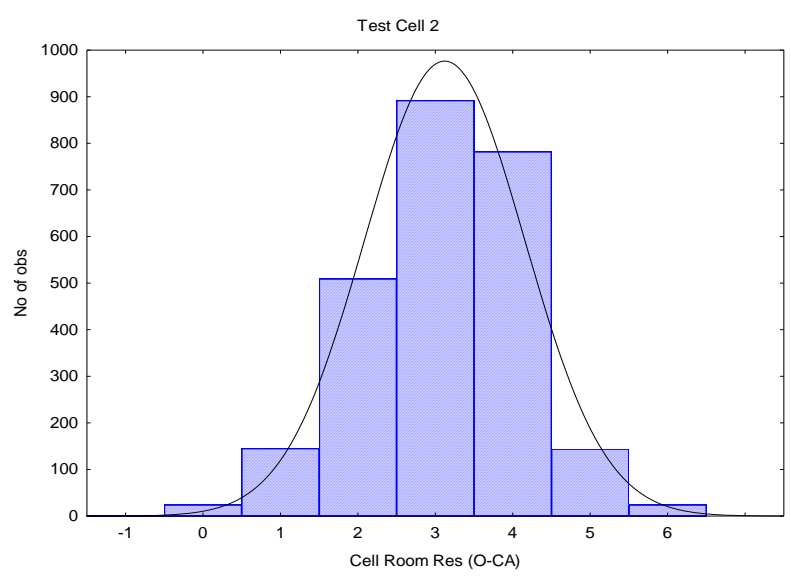

Figure 5.67 - TC2 Room Residual January to June 2007

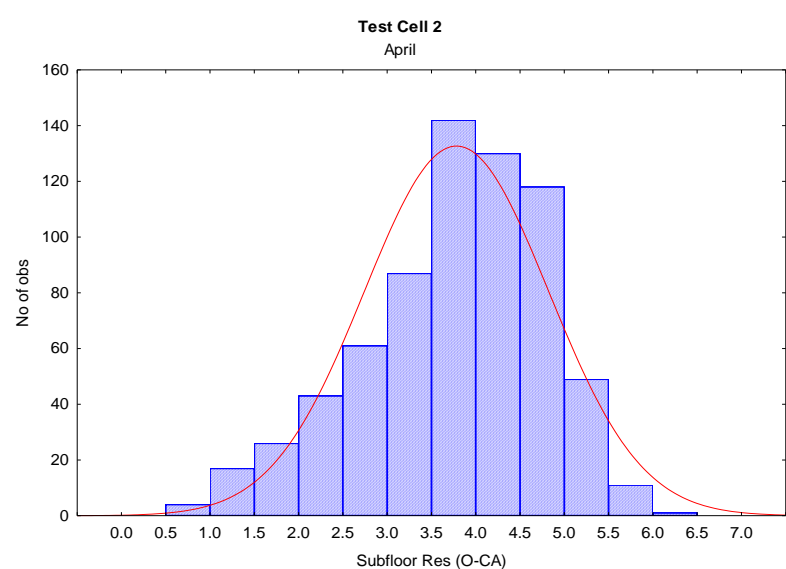

Figure 5.66 - TC2 Subfloor Residual April 2007

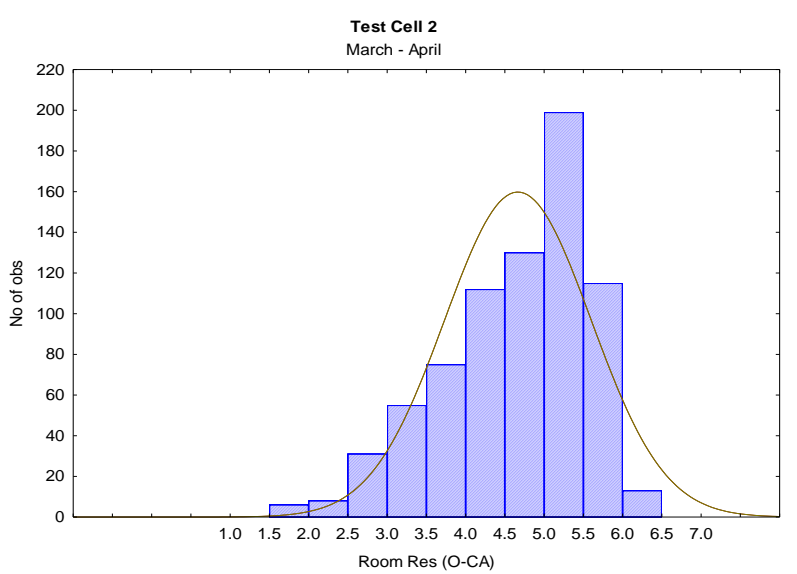

Figure 5.68 - TC2 Room Residual March/April 2007 
The roof space of this test cell had a much greater average residual value than the previous test cell, with considerable quantities of data having a residual value $4^{\circ} \mathrm{C}$ to $10^{\circ} \mathrm{C}$ (Figure 5.69), and an average residual of $6.5^{\circ} \mathrm{C}$ (Table 5.24).

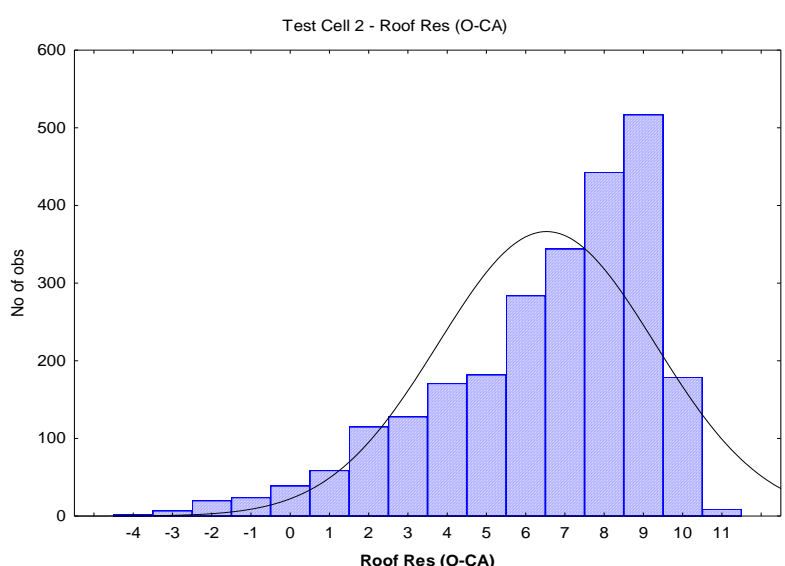

Figure 5.69 - TC2 Roof Space Residual March to June 2007

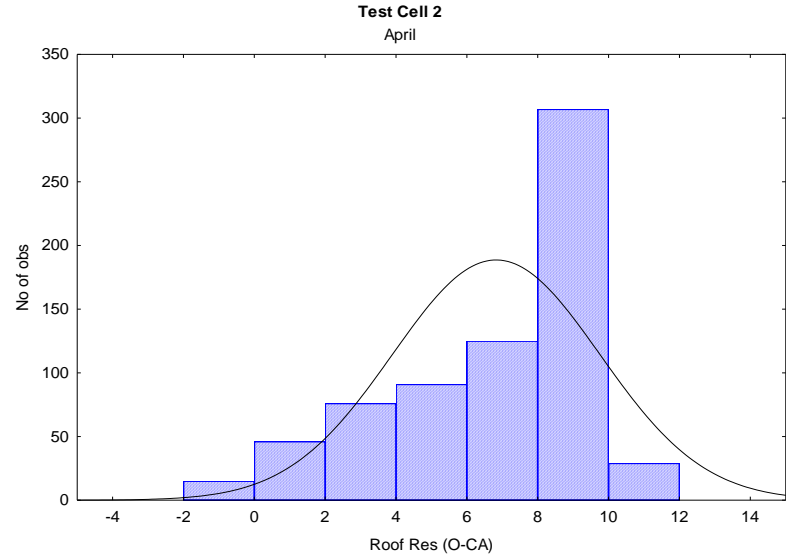

Figure 5.70 - TC2 Roof Space Residual April 2007

Table 5.24: Enclosed-perimeter Platform-floored Test Cell Mean Residual Values

\begin{tabular}{|l|c|c|}
\hline & $\begin{array}{c}\text { Mean Residual Value } \mathrm{T}^{\circ} \mathrm{C} \\
\text { Full Data Set }\end{array}$ & $\begin{array}{c}\text { Mean Residual Value } \mathrm{T}^{\circ} \mathrm{C} \\
\text { Monthly Sample }\end{array}$ \\
\hline Subfloor & $3.5^{\circ} \mathrm{C}$ & $3.75^{\circ} \mathrm{C}$ (April) \\
\hline Room & $3.0^{\circ} \mathrm{C}$ & $4.75^{\circ} \mathrm{C}$ (March/April) \\
\hline Roof Space & $6.5^{\circ} \mathrm{C}$ & $6.50^{\circ} \mathrm{C}$ (April) \\
\hline
\end{tabular}

\section{Concrete Slab-on-Ground Floored Test Cell}

The AccuRate simulation of the concrete slab-on-ground floored test cell provided output temperatures for two zones only, namely, the test cell room and the roof space. Similar to the two previous test cells, the histograms consistently presented positive residual values. The test cell room had significant residual values, ranging from $3^{\circ} \mathrm{C}$ to $5^{\circ} \mathrm{C}$ (Figure 5.71 ), with an average residual value of $3.75^{\circ} \mathrm{C}$ (Table 5.25). The residual values for mid-March to midApril (Figure 5.72) were higher, with an average of $4.25^{\circ} \mathrm{C}$. There were in excess of 3,500 
(85\%) hours when the simulated temperature was lower than the measured temperature by $3^{\circ} \mathrm{C}$ or more.

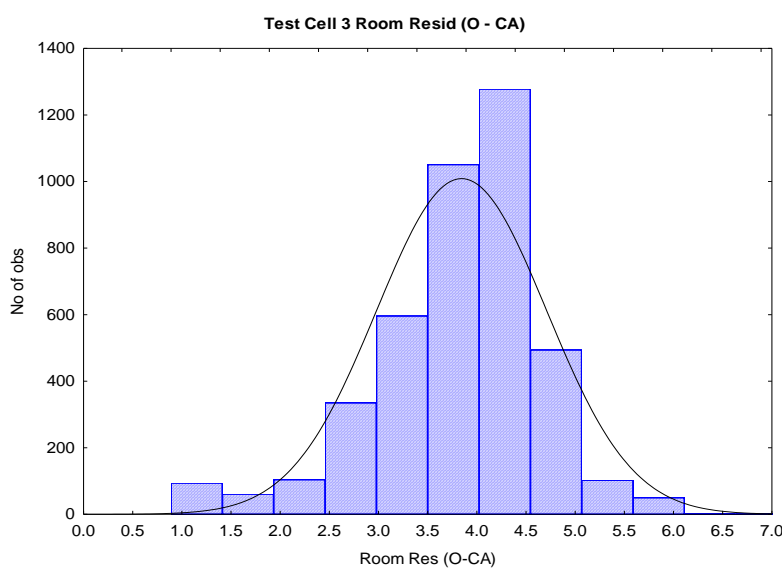

Figure 5.71 - TC3 Room Residual January to June 2007

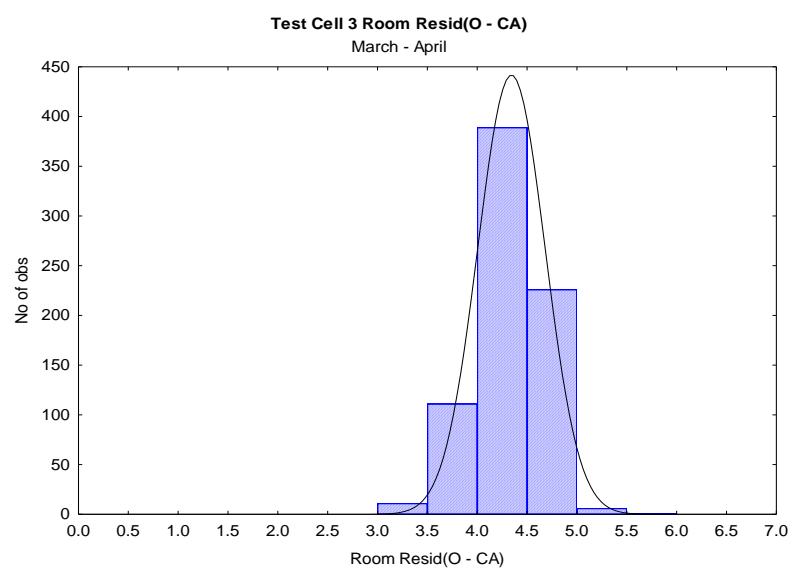

Figure 5.72 - TC3 Room Residual March/April 2007

The residual values for the roof space of this test cell were somewhere between the values from the two previous test cells, with a range of $2^{\circ} \mathrm{C}$ to $10^{\circ} \mathrm{C}$ (Figures 206 and 207), with an average of $6.0^{\circ} \mathrm{C}$ (Table 5.25).

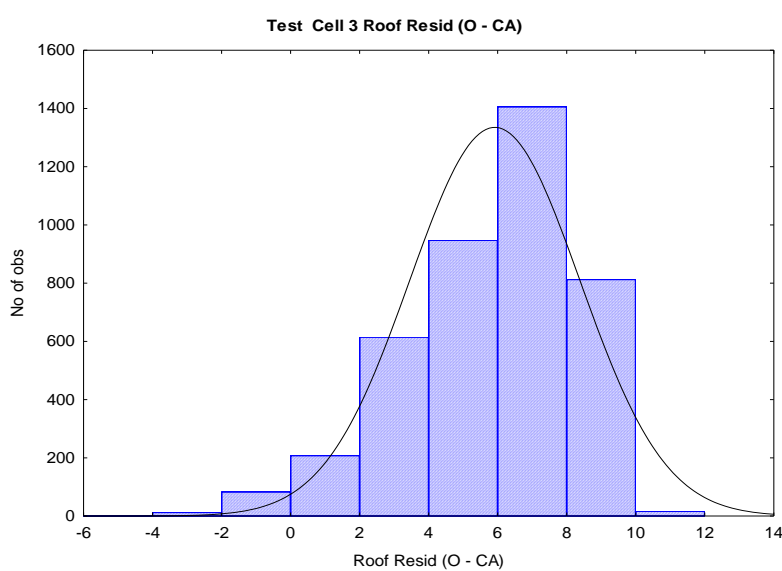

Figure 5.73 - TC3 Roof Space Residual January to June 2007

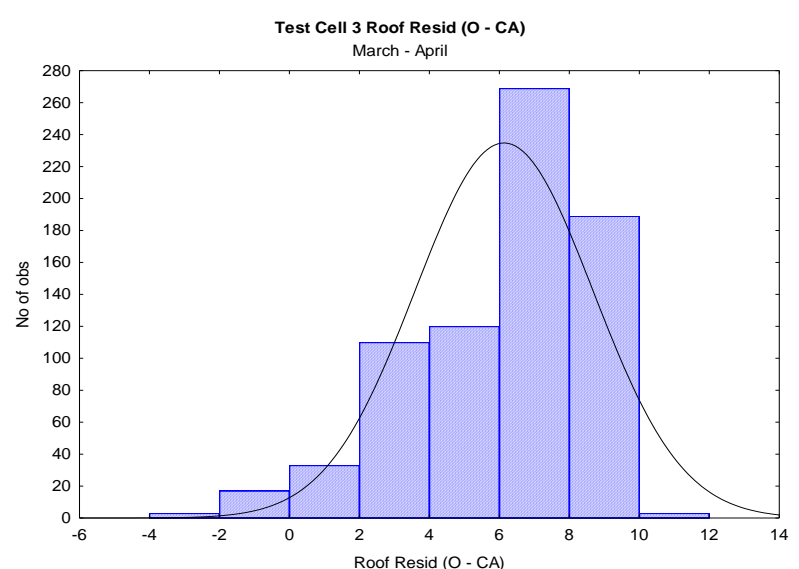

Figure 5.74 - TC3 Roof Space Residual March/April 2007 
Table 5.25: Concrete Slab-on-Ground Floored Test Cell Mean Residual Values

\begin{tabular}{|c|c|c|}
\hline & $\begin{array}{c}\text { Mean Residual Value } \mathrm{T}^{\mathrm{O}} \mathrm{C} \\
\text { Full Data Set }\end{array}$ & $\begin{array}{c}\text { Mean Residual Value } \mathrm{T}^{\mathrm{O}} \mathrm{C} \\
\text { Monthly Sample }\end{array}$ \\
\hline Room & $3.75^{\circ} \mathrm{C}$ & $4.25^{\circ} \mathrm{C}$ (March/April) \\
\hline Roof Space & $6.00^{\circ} \mathrm{C}$ & $6.00^{\circ} \mathrm{C}$ (March/April) \\
\hline
\end{tabular}

\section{Summary}

- For all three test cells the average residual value for the test cell room was $3^{\circ} \mathrm{C}$ or higher. This may be caused by an error in the algorithms.

- The subfloor spaces of the unenclosed-perimeter and enclosed-perimeter platformfloored test cells had an average residual value of $2^{\circ} \mathrm{C}$ and $3{ }^{\circ} \mathrm{C}$ respectively. This level of error for the simulated subfloor can impact on the test cell room temperatures.

- The roof spaces for the three test cells, even though constructed alike, performed quite differently. Similar to the subfloor residual values, the consistent under-prediction of the roof space temperatures could have some impact on the simulated room temperatures.

- In all cases the histograms were not normal, but skewed to the right or the negative. This requires further investigation, as it indicates that the software was consistently under-predicting all zone temperatures.

\subsubsection{Residual Value Time Series Plots}

This analysis was completed to enable a quick visualisation of any long term trends, short term cyclical movements, seasonal patterns, and unexplained fluctuations. To best illustrate the changing residual values and the periods of data analysis, the scales on the $\mathrm{X}$ and $\mathrm{Y}$ axes of the time series plots vary.

\section{Unenclosed-perimeter Platform-floored Test Cell}

The time series plots for the unenclosed-perimeter platform-floored test cell (Figures 5.75 to 5.77) revealed the strong trend along the $2^{\circ} \mathrm{C}$ value for the subfloor and the $4^{\circ} \mathrm{C}$ value for the 
test cell room and roof spaces. Depending on the zone, the residual values ranged from $-6^{\circ} \mathrm{C}$ to $+7^{\circ} \mathrm{C}$ (Table 5.26). The roof space had the widest range of residual values above and below the average, whilst the subfloor graph shows many residual values dropping well into the negative values, indicating times where the software has over-predicted the zone temperature.

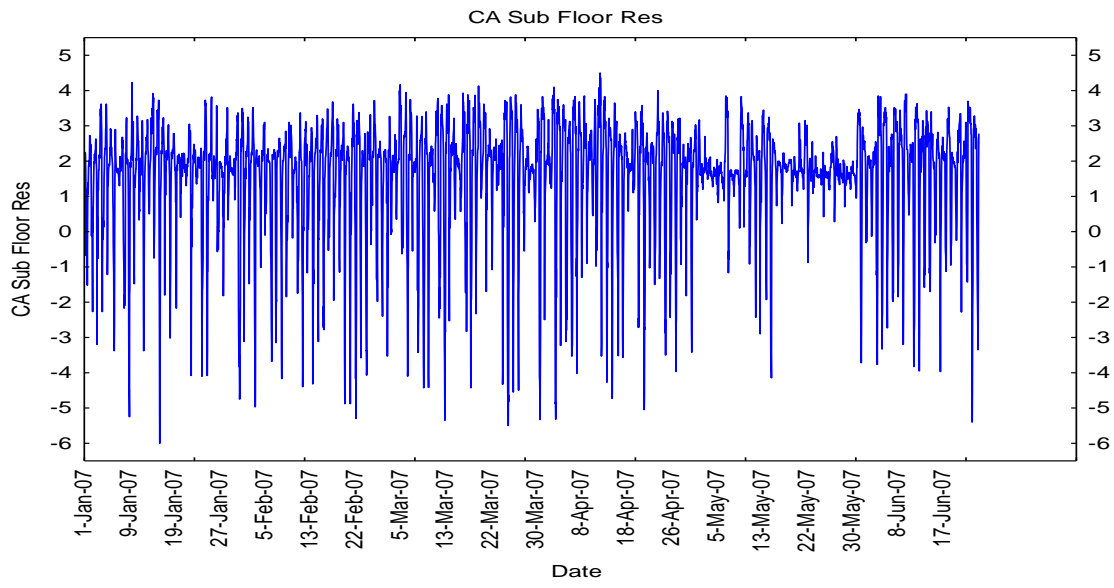

Figure 5.75 - TC1 Subfloor Residual Time Series Plot January to June 2007

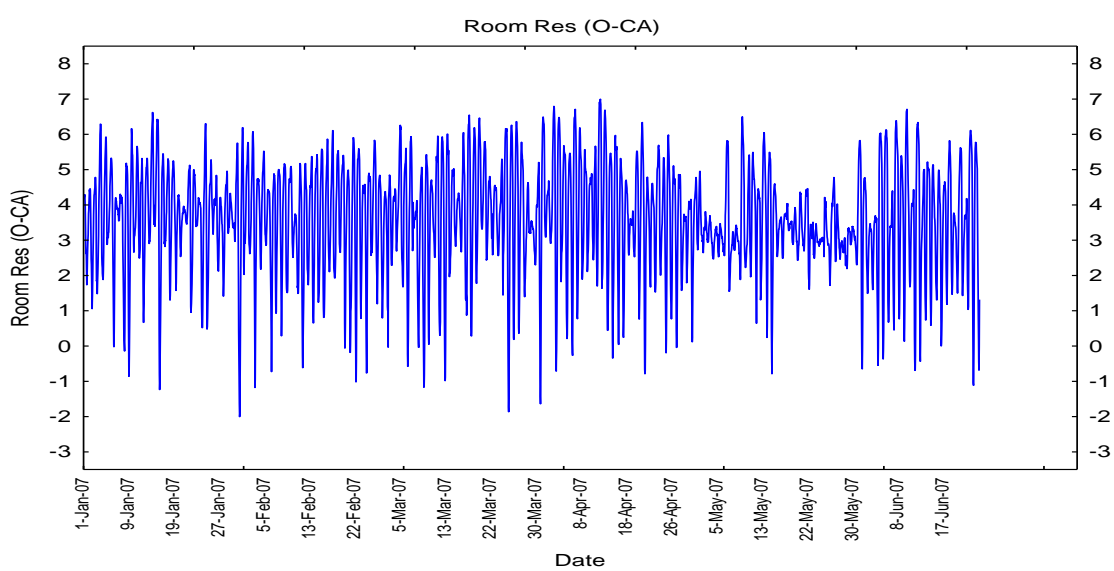

Figure 5.76 - TC1 Room Residual Time Series Plot January to June 2007

Table 5.26: Unenclosed-perimeter Platform-floored Test Cell Minimum and Maximum Residual Values $\left({ }^{\circ} \mathrm{C}\right)$

\begin{tabular}{|c|c|c|}
\hline & Minimum & Maximum \\
\hline Subfloor & -6 & +4 \\
\hline Room & -2 & +7 \\
\hline Roof Space & -5 & +7 \\
\hline
\end{tabular}




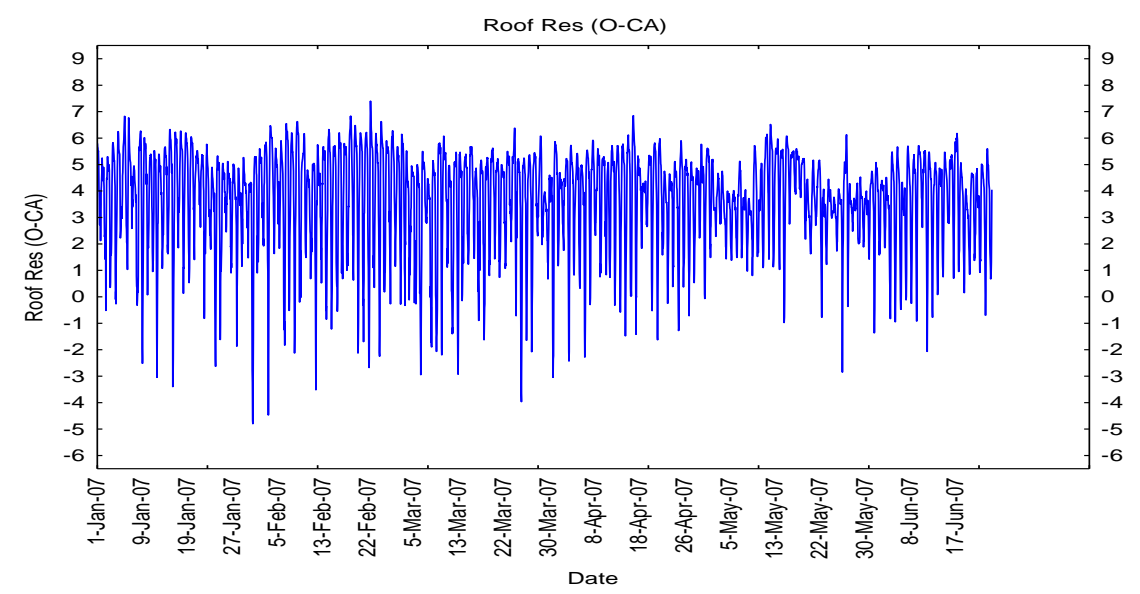

Figure 5.77 - TC1 Roof Space Residual Time Series Plot January to June 2007

The other notable aspect from the time series graphs of this test cell is the two short periods (in early and late May), when the range of residual values became more confined. This occurrence is observable in the time series plot for all three zones, and as the data has been collected from two different data loggers and five different temperature probes, this indicates a phenomenon that requires further investigation.

\section{Enclosed-perimeter Platform-floored Test Cell}

The residual time series plots for the enclosed-perimeter platform-floored test cell revealed similar trends to those of the previous test cell, however this time the residual values are greater for the subfloor (Figure 5.78) and test cell room (Figure 5.79) zones. The subfloor presents continuously increasing residual value in late June, which can be related to the ground temperature, discussed earlier. In particular instances, the minimum and maximum residual values in the subfloor occur at the same time (as in the room zone). This could indicate that the residual value of one zone is impacting on the residual value of the adjoining zone. The roof space residual time series plot (Figure 5.80) is more similar to that of the unenclosed-perimeter platform-floored test cell than the concrete slab-on-ground floored test cell. Despite these similarities and differences, the residual values ranged from $-4^{\circ} \mathrm{C}$ to $+7^{\circ} \mathrm{C}$ (Table 5.27) in all three zones. 


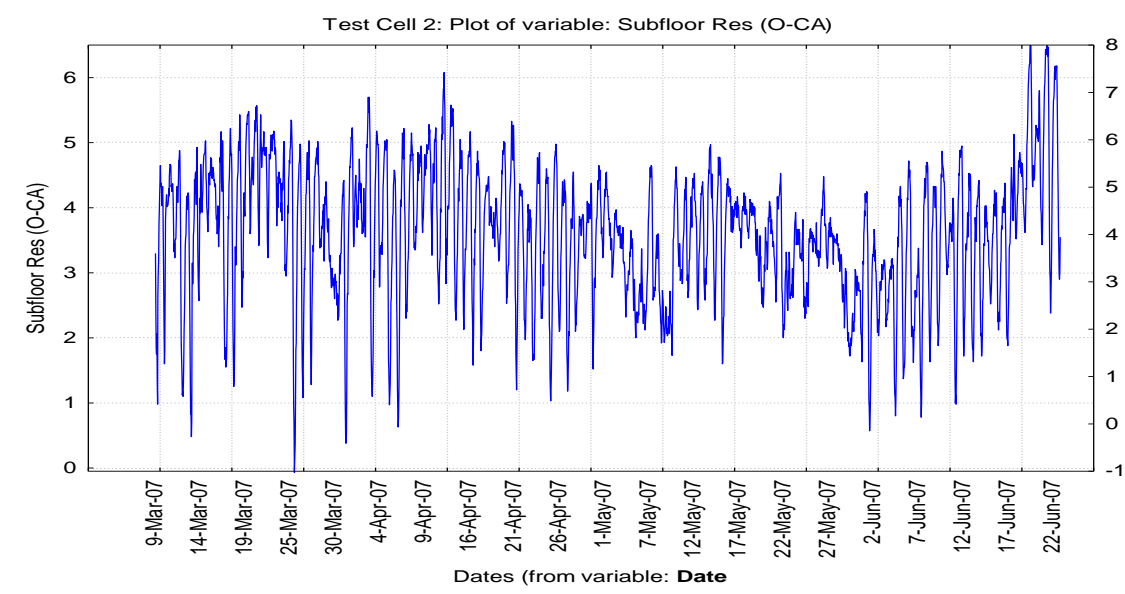

Figure 5.78 - TC2 Subfloor Residual Time Series Plot March to June 2007

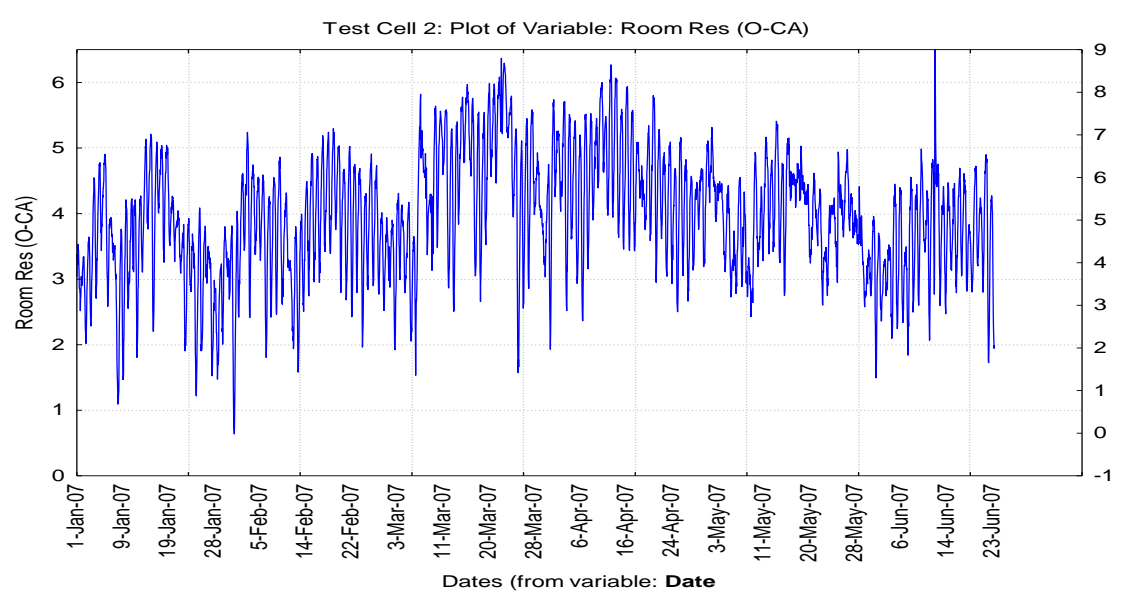

Figure 5.79 - TC2 Room Residual Time Series Plot January to June 2007

Table 5.27: Enclosed-perimeter Platform-floored Test Cell Minimum and Maximum Residual Values $\left({ }^{\circ} \mathrm{C}\right)$

\begin{tabular}{|c|c|c|}
\hline & Minimum & Maximum \\
\hline Subfloor & 0.0 & +6.0 \\
\hline Room & 0.5 & +6.5 \\
\hline Roof Space & -4.0 & +7.0 \\
\hline
\end{tabular}




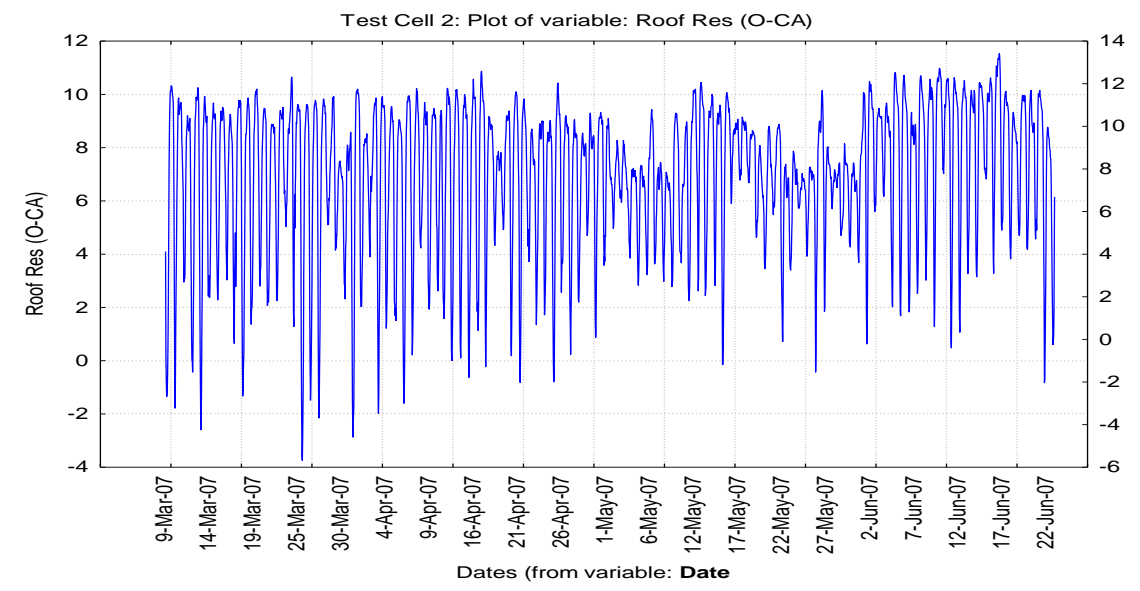

Figure 5.80 - TC2 Roof Space Residual Time Series Plot March to June 2007

As with the plots for the unenclosed-perimeter platform test cell, two distinct patterns are observable, namely:

- the daily shift between the minimum and maximum residual values; and

- the two periods in May when the data became much more condensed and closer to the average residual value.

\section{Concrete Slab-on-Ground Floored Test Cell}

The residual time series plots for the room of the concrete slab-on-ground floored test cell were somewhat different in appearance to the two previous test cells. This test cell had the highest thermal mass and an uninsulated ground keyed concrete floor, resulting in a much tighter range in the daily temperatures (as expected).

In the residual time series plot for the test cell room (Figure 5.81) there is a peak in late February, which corresponds to the hottest week during the research. This same occurrence is observable, but not as pronounced, in the time series plots for the room of the other two test cells (Figure 5.76 and Figure 5.79). This can indicate an increasing thermal gain and/or reduced heat loss that the software is not recognising. This could be related to a thermal mass algorithm and requires further investigation. 
The roof space residual time series plot (Figure 5.82) is very similar in pattern and nature to the roof space of the unenclosed-perimeter platform-floored test cell.

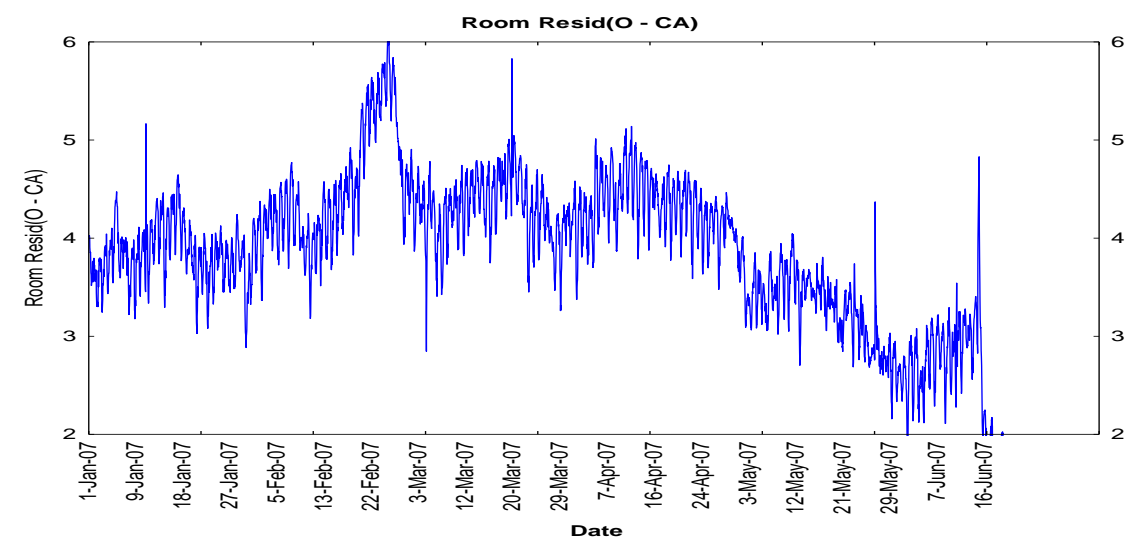

Figure 5.81 - TC3 Room Residual Time Series Plot January to June 2007

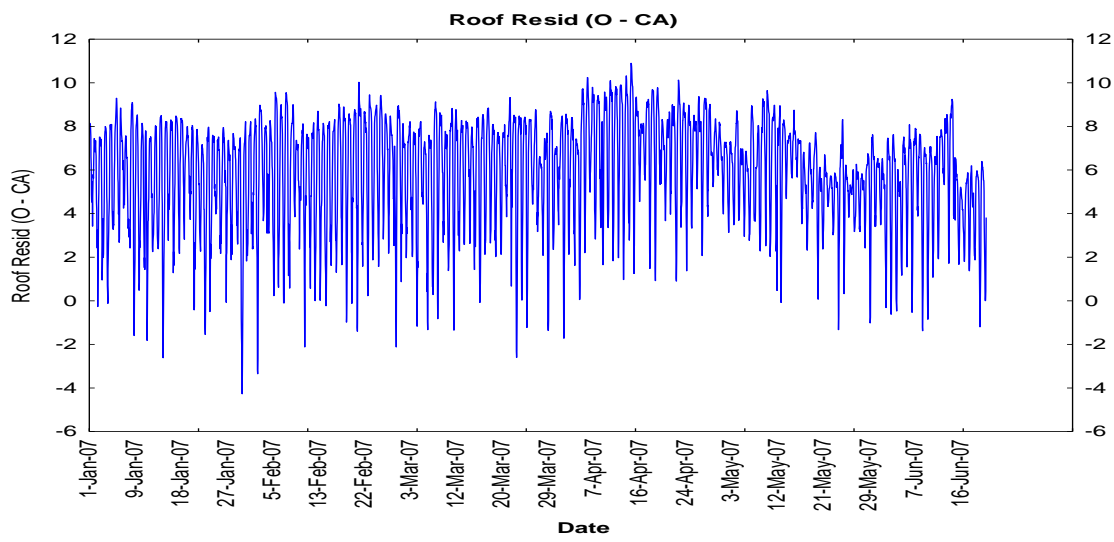

Figure 5.82 - TC3 Roof Space Residual Time Series Plot January to June 2007

Table 5.28: Enclosed-perimeter Platform-floored Test Cell Minimum and Maximum Residual Values $\left({ }^{\circ} \mathrm{C}\right)$

\begin{tabular}{|c|c|c|}
\hline & Minimum & Maximum \\
\hline Room & 0.0 & +6.0 \\
\hline Roof Space & -4.0 & +10.0 \\
\hline
\end{tabular}

Depending on zone, the residual values for this test cell ranged from $-4^{\circ} \mathrm{C}$ to $+10^{\circ} \mathrm{C}$ (Table 5.28). Similar to the plots from the two previous test cells, there was:

- a daily shift between the minimum and maximum residual values; and 
- condensing of data during the two short periods in May, (which occurred in the other two test cells), is less noticeable in the plot for this test cell, indicating that the anomaly could be the result of the subfloor and/or the thermal mass algorithms.

\section{Summary of Residual Value Time Series plots}

The eight time series plots reveal some key characteristics of the residual values from the three test cells, namely:

- An event in mid and late May that created a much tighter range in the residual values for all three test cells.

- There is a consistency of data trends, which was collected by fourteen different temperature probes connected to six different data loggers, providing confidence in the data collection process.

- there is an observable daily pattern where the software is under-predicting and overpredicting the zone temperatures.

\subsubsection{Correlation of Adjoining Zone Residual Values}

The purpose of this correlation analysis was to ascertain if there was any relationship between the residual values of adjoining test cell zones (Palomo, Marco \& Madsen 1991). The previous analysis consistently documented positive residual values, that is: the software was predominantly under-predicting the temperature within all three zones.

The AccuRate software calculates temperature based on an energy balance within a building. In the context of the test cells, this energy balance equation considers: the zone temperature, fabric conductivity and emittance values, infiltration, thermal capacitance and climatic inputs. If the software has not appropriately considered an energy input, the zone model will in reality store, receive or give more energy to adjoining zones than the software has predicted. As the residual values for the test cell zones have been predominantly positive in nature, this implies that the zone or zones receive or store more energy than the software predicts. Conversely, when the residual is negative, the zone receives or stores less energy than the 
software has predicted. The additional energy being received or lost may be transferred in or out of an adjoining zone. The use of correlation analysis in this context could indicate that the residual value, or simulation error, in one zone may be impacting on the residual value, or simulation error, of an adjoining zone.

As with the previous analysis, this analysis provides scatter plots for the full data set and a sample month to illustrate differences or similarities between the two types of data. To best illustrate the correlation between data sets, the scales on the $\mathrm{X}$ and $\mathrm{Y}$ axes of the scatter plots vary.

\section{Unenclosed-perimeter Platform-floored Test Cell}

The unenclosed-perimeter platform-floored test cell had three zones with possible correlations between:

- the test cell room and subfloor

- the test cell room and the roof space

In each of the four correlation diagrams (Figures 5.83 to 5.86) the plots have a general ovoid form, but with varying numbers of outlying data. The trend line has a positive slope, indicating that an increase in error in one zone is associated with an increase in error in the adjoining zone.

The subfloor / test cell room scatter plots for January to June (Figure 5.83) and March/April (Figure 5.84) have correlation factors of 0.68 and 0.71 respectively, indicating a medium to strong relationship between the residual values. The two diagrams illustrate three visible profiles, as follows:

- There is a strong cluster of data having an ovoid shape when the subfloor residual values are above $1^{\circ} \mathrm{C}$. This sub-group of data would provide a higher correlation ratio if considered on its own.

- When the subfloor residual value is less than $1{ }^{\circ} \mathrm{C}$, the data is dispersed, hence a much lower correlation ratio. 
- There is a significant subgroup of data, more vertical in form, when the subfloor residual value is $2^{\circ} \mathrm{C}$, which should be investigated further (Figure 5.84).

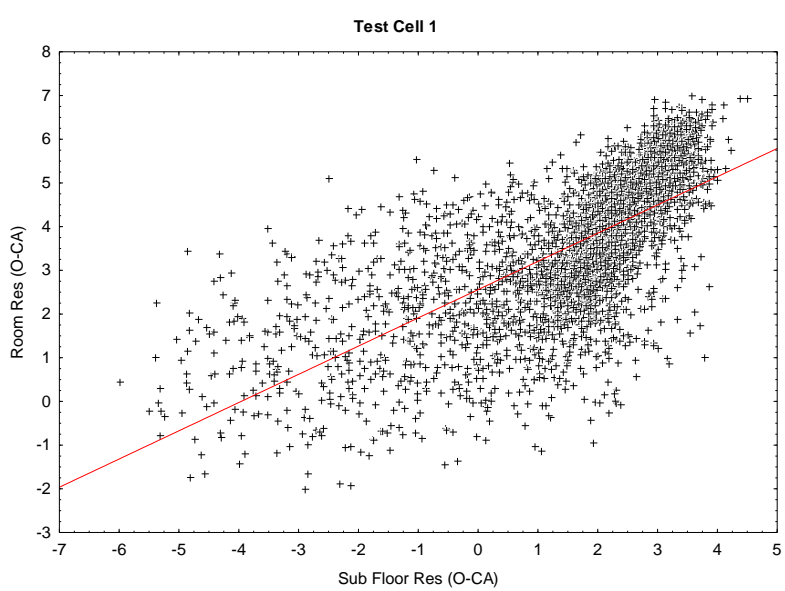

Figure 5.83 - TC1 Room \& Subfloor Residual Correlation: January to June $2007(r=0.68)$

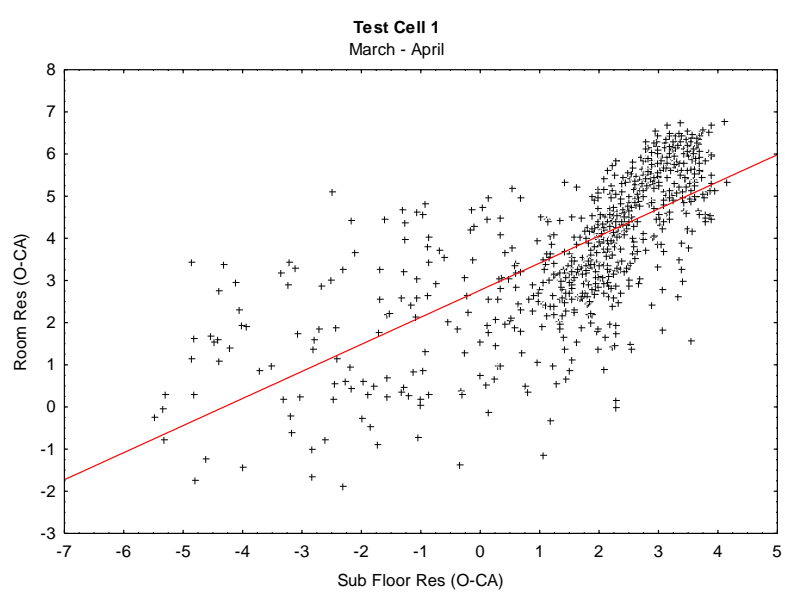

Figure 5.84 - TC1 Room \& Subfloor Residual Correlation: March/April 2007 ( $r=0.71)$

The relationship between roof space and test cell room residual values (Figures 5.85 and 5.86) are distinctly different in form from the subfloor and room correlation discussed above, with much stronger correlation factors of 0.77 and .078 respectively. Similar to the subfloor, when the roof space residual value falls below $1{ }^{\circ} \mathrm{C}$, the scatter plots become more dispersed.

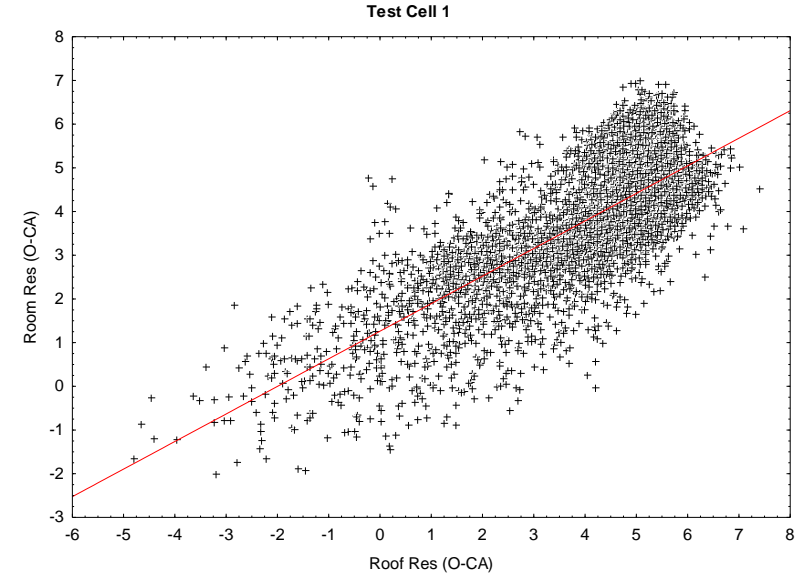

Figure 5.85 - TC1 Room \& Roof Space Residual Correlation: January to June $2007(r=0.77)$

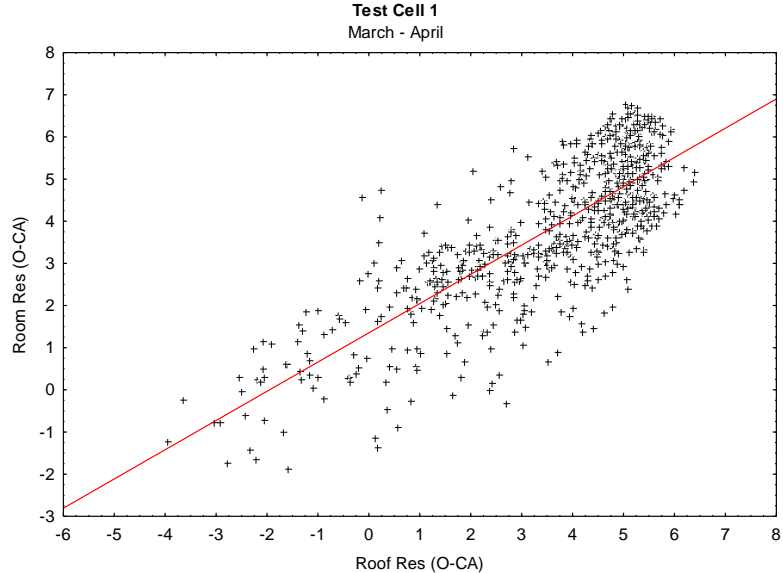

Figure 5.86 - TC1 Room \& Roof Space Residual Correlation: March/April $2007(r=0.78)$ 


\section{Enclosed-perimeter Platform-floored Test Cell}

The enclosed-perimeter platform-floored test cell has three zones with possible correlations between:

- the test cell room and subfloor zones

- the test cell room and the roof space zones

The four correlation scatter plots (Figures 5.87 to 5.90) are generally ovoid in shape but with varying numbers of outlying data. The trend line has a positive slope indicating that an increase in residual in one zone is associated with an increase in the other zone. However, the subfloor/room scatter plots, for this test cell, have significantly different shapes compared to the roof/room scatter plots.

The two scatter plots comparing the subfloor test cell room residuals for March to June (Figure 5.87) and April (Figure 5.88) show a very strong correlation with factors of 0.85 and 0.88 , respectively. They are more ovoid and tightly grouped, compared to the unenclosedperimeter platform-floored test cell (Figure 5.83) indicating a stronger correlations.

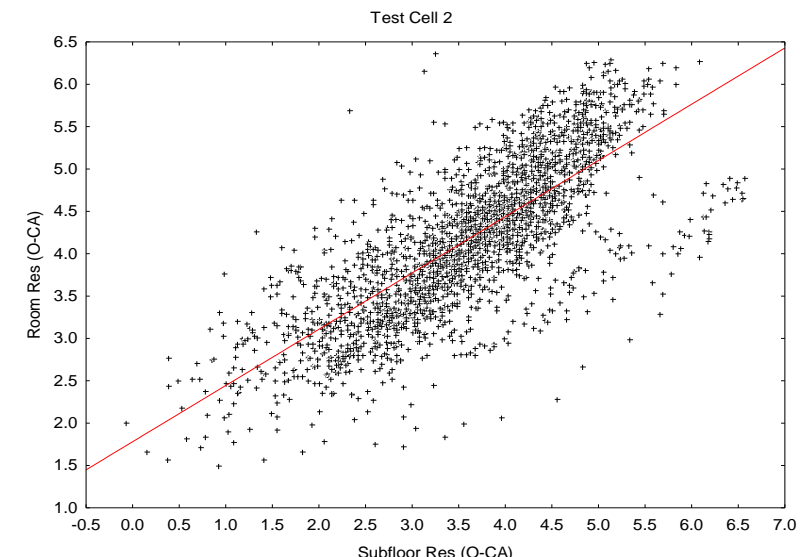

Figure 5.87 - TC2 Room \& Subfloor Residual Correlation: March to June $2007(r=0.85)$

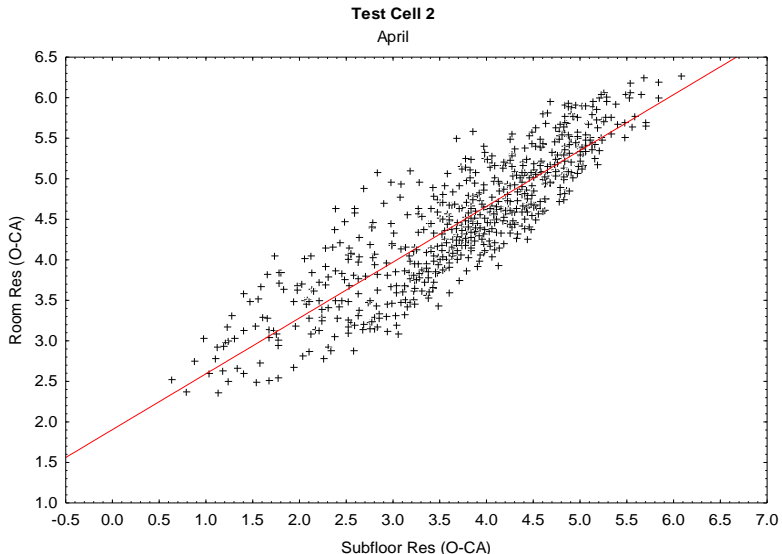

Figure 5.88 - TC2 Room \& Subfloor Residual Correlation: April $2007(r=0.88)$

The roof space / test cell room scatter plots for March to June (Figure 5.89) and April (Figure 5.90) presented much lower correlation factors: 0.37 and 0.50 , respectively. These scatter plots were quite different in form to the subfloor / room residual scatter plots, with the data 
being spread quite widely above and below the trend line, reflecting a much weaker linear relationship.

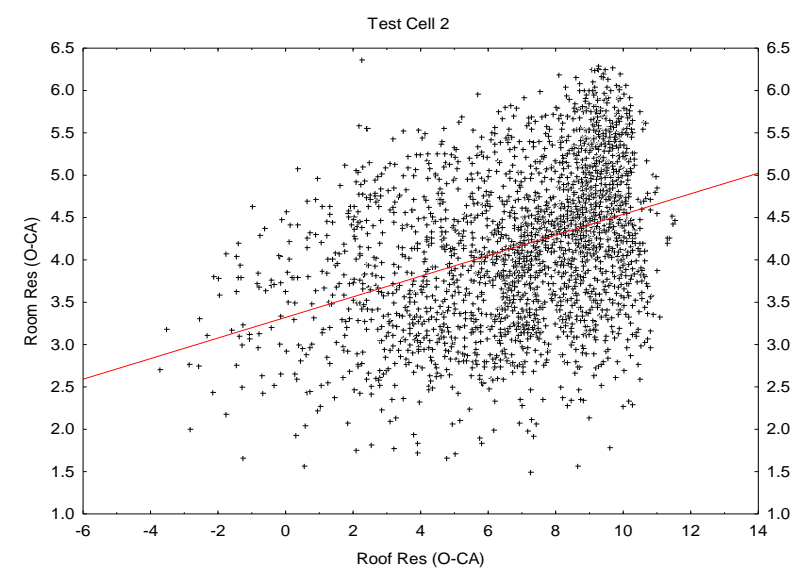

Figure 5.89 - TC2 Room \& Roof Space Residual Correlation: March to June $2007(r=0.37)$

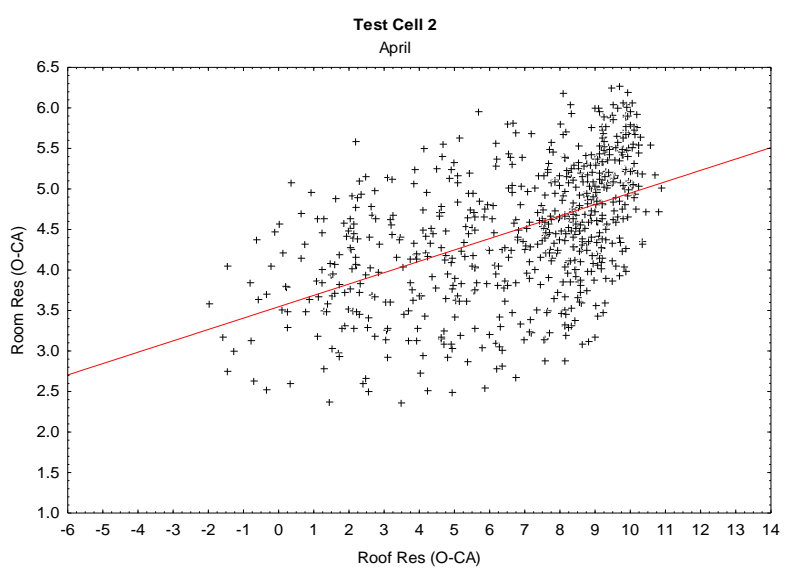

Figure 5.90 - TC2 Room \& Roof Space Residual Correlation: April $2007(r=0.50)$

Both the subfloor and roof space residual values show a positive relationship to the residual value of the test cell room. The correlation co-efficient and tightness of scatter plot indicate a much stronger relationship between the subfloor and room zones than that between the roof space and room zones.

\section{Concrete Slab-on-ground Floored Test Cell}

As this test cell did not have a subfloor space, there is only one type of residual scatter plot for this test cell, namely, the roof space and the test cell room. The correlation scatter plots for January to June (Figure 5.91) and March/April (Figure 5.92) for this test cell are flatter than the graphs from the previous test cells. The correlation factors vary from month to month for this analysis. This is best observed by the more solid ovoid form of Figure 5.91, which includes data from the full research period and has a weak correlation ratio of 0.42 . The data from March /April shows a medium correlation, at 0.64. For this test cell, the monthly residual correlation diagrams vary for each month (see Appendix 6). This may indicate a seasonal variation, which is not easily teased out when viewing residual scatter plots for the full data set. 


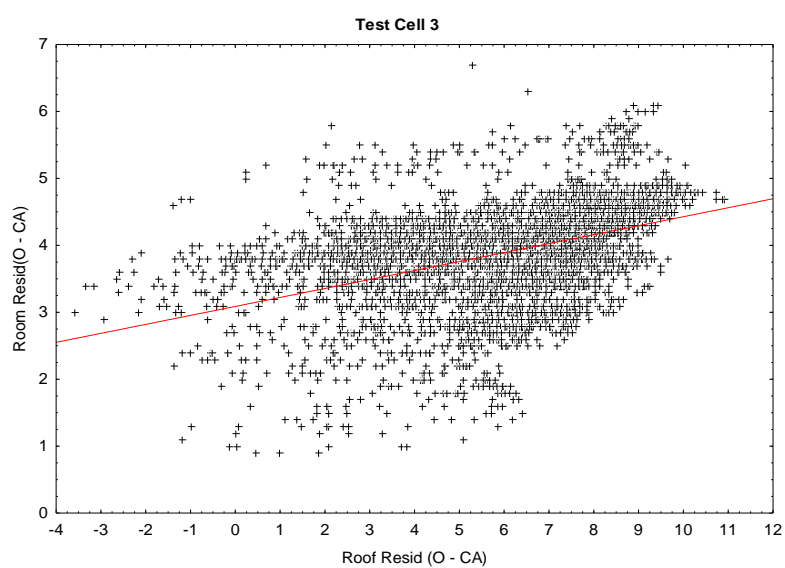

Figure 5.91 - TC3 Room \& Roof space Residual Correlation: January to June $2007(r=0.42)$

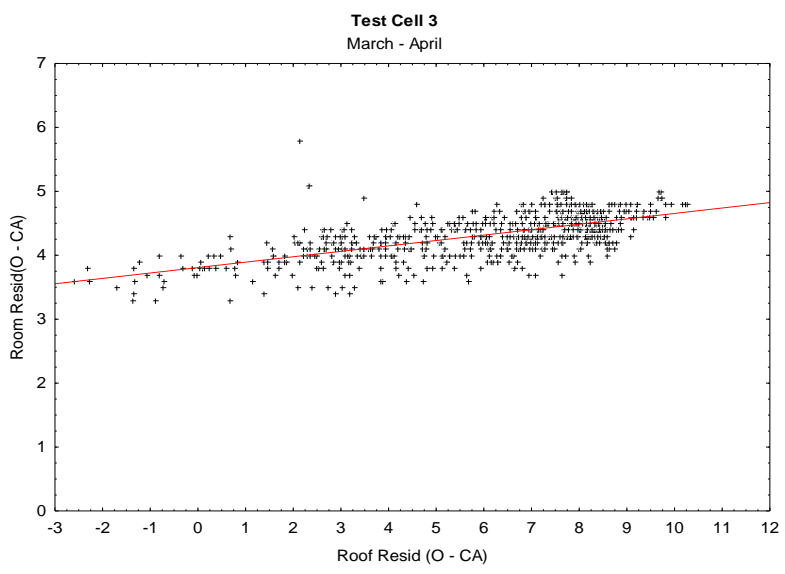

Figure 5.92 - TC3 Room \& Roof space Residual Correlation: March/April $2007(r=0.64)$

\section{Summary}

- In all cases, whether it was in reference to the relationship between the subfloor and test cell room, or the roof space and test cell room, there was a positive linear relationship.

- The correlation ratios for the subfloor and test cell room residual values ranged from 0.68 to 0.88 , indicating a medium to strong relationship for the unenclosed-perimeter platform-floored test cell and a strong relationship for the enclosed-perimeter platform-floored test cell.

- The correlation ratios, for the roof space and test cell room analysis ranged from a weak value of 0.37 to a strong value 0.78 , exposing dramatically different relationships for each test cell. The correlation ratios improved in scatter plots of monthly data subsets.

As these analyses documented a strong correlation between the residual values of the subfloor and test cell room of the two platform-floored test cells, algorithms in these zones require examination. The ground model algorithm should also be reviewed, as it was shown here that monthly climatic effects on the subfloor were correlated to the room temperature residuals.

The next stage of the statistical analysis was the analysis exploring any correlation between climatic inputs and the residual values for each of the test cell zones. 


\subsubsection{Correlation of External Air Temperature and Zone Residuals}

This analysis was intended to examine the correlation between the site-measured air temperature and the calculated residual values for each zone of the test cells. To best illustrate the correlation between data sets, the scales on the $\mathrm{X}$ and $\mathrm{Y}$ axes of the scatter plots vary.

\section{Subfloor Residual and Air Temperature Correlations}

Figures 5.93 and 5.94 are scatter plots of the subfloor residuals and air temperature for the unenclosed-perimeter subfloor; Figures 5.95 and 5.96 are scatter plots of the subfloor residuals and air temperature for the enclosed-perimeter subfloor and Table 5.29 summarises the correlation ratios for both subfloors.

The scatter plots of the unenclosed-perimeter (Figures 5.93 and 5.94) and the enclosedperimeter (Figures 5.95 and 5.96) platform-floored test cells show a general negative linear relationship between the external air temperature and the subfloor zone residual values. This means that the simulation error in the subfloor decreases at higher outside temperature. This negative relationship is especially important for the unenclosed-perimeter subfloor, as the AccuRate software assumes that the unenclosed subfloor zone is the same temperature as the outside environment. Figures 5.93 to 5.94 show that the relationship of subfloor temperature residual and external air temperature is more heteroscedastic if longer periods are considered. There seems to be a concentration of negative residuals around $20^{\circ} \mathrm{C}$ to $25^{\circ} \mathrm{C}$ outside air temperature. The data that falls outside the general ovoid form should be examined first, to establish what differing climatic conditions are occurring and how the unenclosed subfloor zone is being affected.

The monthly analysis reveals a significant increase in correlation factor, compared to the full data set. Table 5.29 shows that for the full data set, the correlation ratio was 0.52 , where-as for the monthly data sets, the ratio varied from a medium value of -0.57 for January, to a strong value of -0.76 for June, revealing some distinct monthly or seasonal trends. Another observation in the scatter plot for mid-March to mid-April (Figure 5.94) and the full data set (Figure 5.93) is the dispersal of data below the trend line, compared to those above the trend line. 


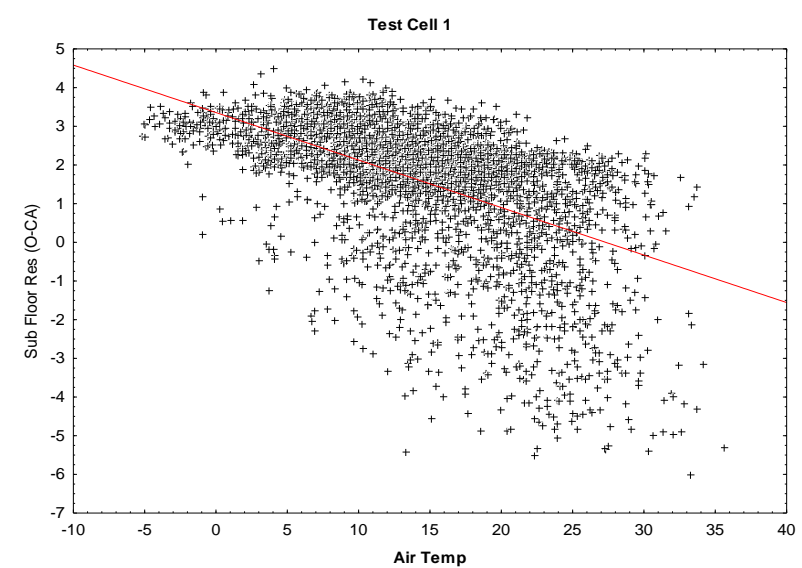

Figure 5.93 - TC1 Subfloor Residual \& Air Temperature Correlation: January to June 2007 $(r=-0.52)$

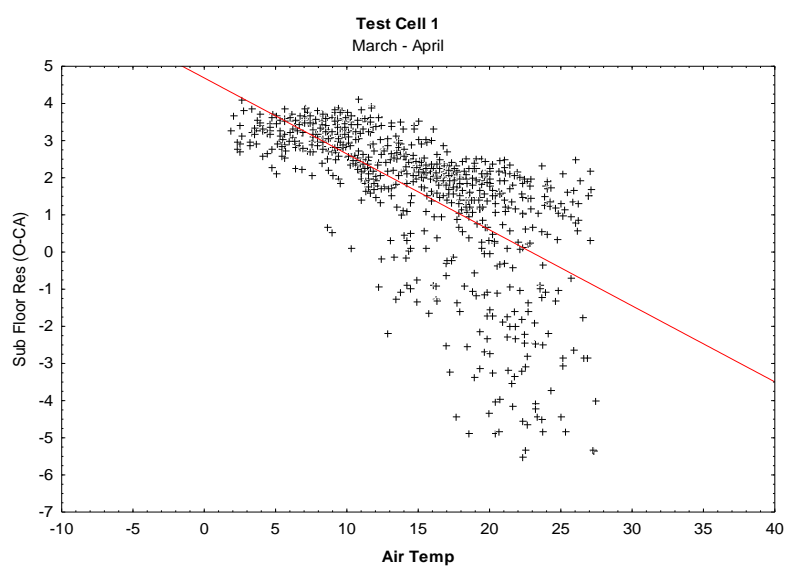

Figure 5.94 - TC1 Subfloor Residual \& Air Temperature Correlation: March/April 2007 ( $r=-0.65)$

By contrast, the scatter plots for the enclosed-perimeter subfloor (Figures 5.95 and 5.96), have a more ovoid form, without the tail of negative residuals present in the unenclosed-perimeter subfloor. There appears to be a pattern of higher residuals occurring at times of lower outside temperature and lower residuals at times of higher outside air temperature. The correlation ratio for the four months of data ranged from a weak value of -0.39 in May to a strong value of 0.79 in June, with the correlation ratios for March and April being -0.53 and -0.76 respectively (Table 5.29). The difference between the full data set and monthly subsets of data reinforces the requirement that detailed analysis should be conducted on smaller subsets of data.

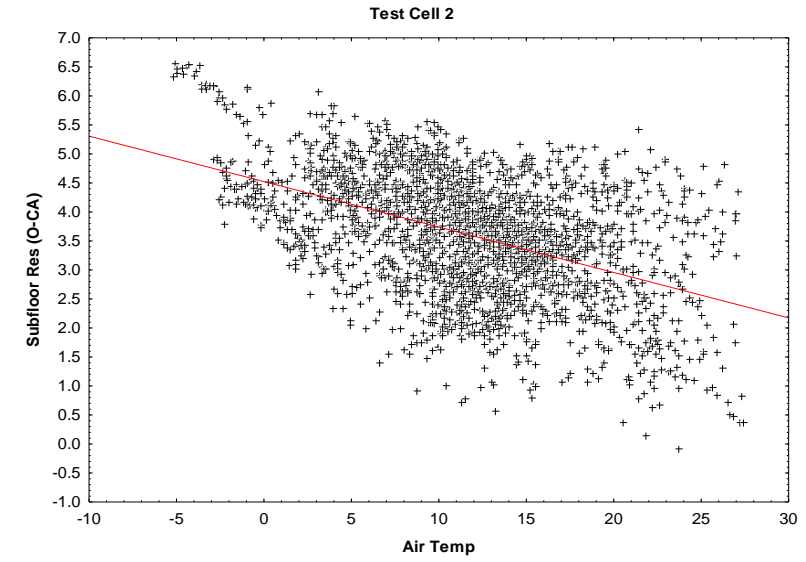

Figure 5.95 - TC2 Subfloor Residual \& Air Temperature Correlation: March to June $2007(r=-0.47)$

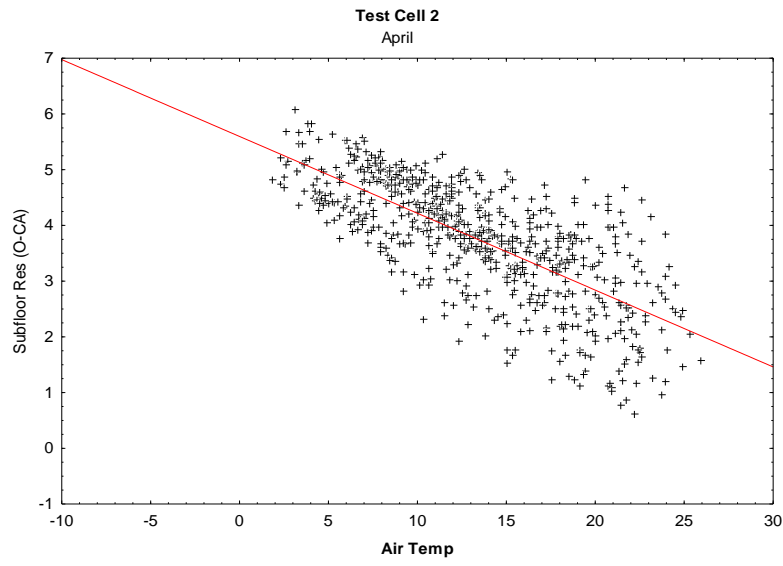

Figure 5.96 - TC2 Subfloor Residual \& Air Temperature Correlation: April $2007(r=-0.76)$ 
Table 5.29: Test Cell Subfloor and Air Temperature Correlation Ratios

\begin{tabular}{|c|c|c|}
\hline & Test Cell 1 & Test Cell 2 \\
\hline Full Data Set & -0.52 & -0.47 \\
\hline January & -0.57 & $\#$ \\
\hline March & -0.65 & -0.53 \\
\hline April & -0.66 & -0.76 \\
\hline May & -0.62 & -0.39 \\
\hline June & -0.76 & -0.79 \\
\hline \multicolumn{3}{|c|}{ \# Data only available from March } \\
\hline
\end{tabular}

\section{Test Cell Room Residual and Air Temperature Relationships}

Figures 5.97 and 5.98 are scatter plots of the room residuals and air temperature for the unenclosed-perimeter platform-floored test cell; Figures 5.99 and 5.100 are scatter plots of the room residuals and air temperature for the enclosed-perimeter platform-floored test cell; Figures 5.101 and 5.102 are scatter plots of the room residuals and air temperature for the concrete slab-on-ground floored test cell; and Table 5.30 is a summary of correlation ratios for the entire data set as well as monthly subsets.

The correlation between the site air temperature and the test cell room residual value was different for each building. The scatter plot of the full data set for the unenclosed and enclosed-perimeter platform-floored test cells, as shown in Figure 5.97 and Figure 5.99 respectively, documented a negative linear correlation between site and room air temperatures. On the other hand, the scatter plot of the full data set for the concrete slab on ground floored test cell shows a positive linear correlation (Figure 5.101). It is interesting to note that each of the monthly scatter plots for the concrete slab-on-ground floored test cell exposed a negative linear correlation.

The full data set scatter plot for the unenclosed-perimeter platform-floored test cell (Figure 5.97) has a general ovoid form. The negative linear relationship reveals that as the outside air temperatures decrease the room residual increases and conversely, as the outside air temperature increases, the room residuals decrease. The scatter plot for March/April (Figure 5.98) is fairly linear in form but with a heteroscedastic tail. The lowest and negative residual values occur when the outside air temperature is highest. The full data set correlation ratio is 
a medium value of -0.59 , whereas the monthly correlation ratios ranged from 0.76 to 0.92 , indicating the need for monthly analysis.

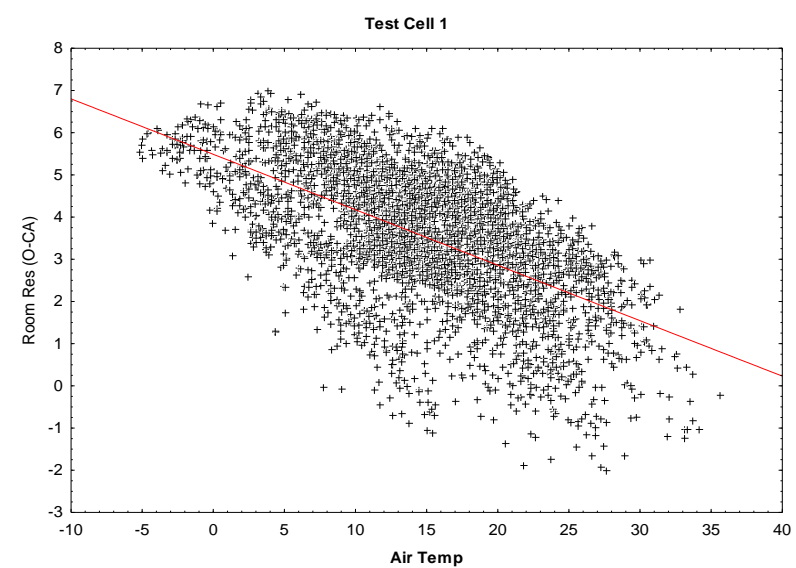

Figure 5.97 - TC1 Room Residual \& Air Temperature Correlation: January to June $2007(r=-0.59)$

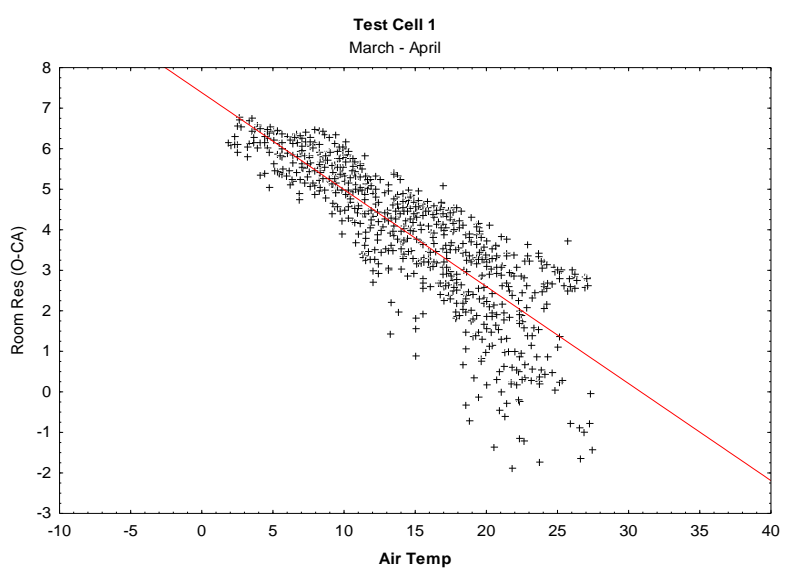

Figure 5.98 - TC1 Room Residual \& Air Temperature Correlation: March/April 2007 $(r=-0.83)$

The scatter plots for the enclosed-perimeter platform-floored test cell are considerably different in form from those of the unenclosed-perimeter platform-floored test cell. This could (in part), be due to the difference in external wall systems. The clay brick veneer of this test cell, as opposed to the previous test cell's plywood cladding, should provide some thermal lag, causing a reduction in the immediate impact of the outside air temperature on the inner fabric of the building. The full data set scatter plot (Figure 5.99) is more circular than ovoid with low correlation ratio of -0.27 , whereas the scatter plot for March/April (Figure 5.100) is skewed, heteroscedastic and arrowhead shaped where the data becomes more dispersed above $5^{\circ} \mathrm{C}$. The other monthly scatter plots in Appendix 6 vary in form between ovoid and heteroscedastic. The full data set correlation ratio is a medium value of -0.59 , whereas the monthly correlation ratios ranged from 0.76 to 0.92 , indicating a stronger correlation and the need for monthly analysis. The room of this test cell has a similar trend to the previous test cell for the monthly correlation ratios, where the coolest month of June, has the highest correlation ratio (Table 5.30). 


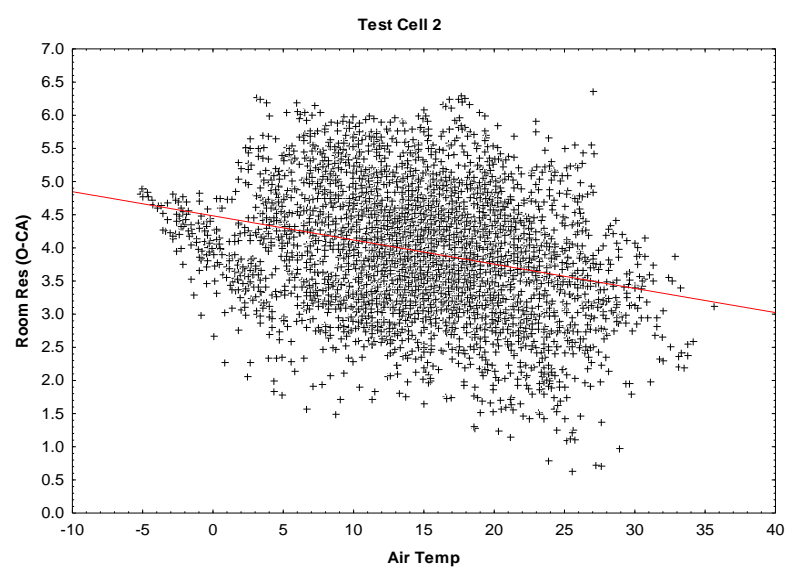

Figure 5.99 - TC2 Room Residual \& Air Temperature Correlation: January to June $2007(r=-0.27)$

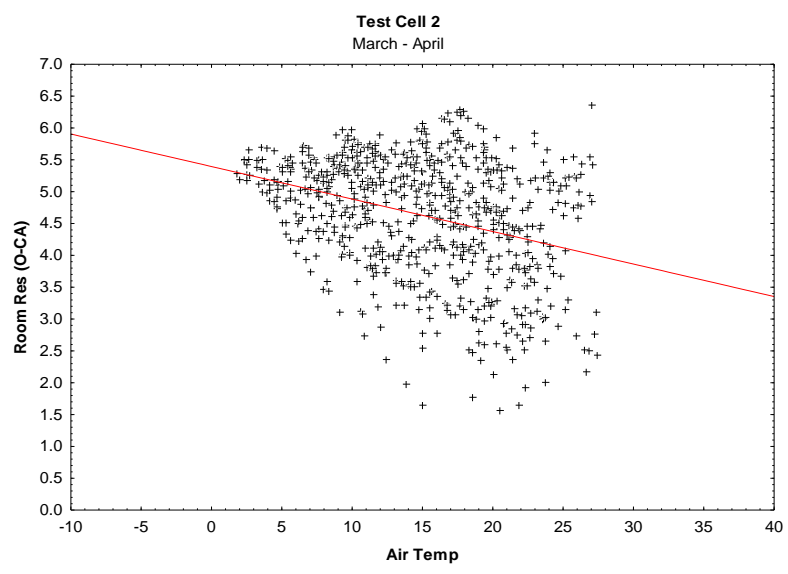

Figure 5.100 - TC2 Room Residual \& Air Temperature Correlation: March/April $2007(r=-0.33)$

The correlation scatter plots for the concrete slab-on-ground floored test cell room are significantly different from the previous two buildings. The six month data set (Figure 5.101) shows a positive correlation and the scatter plot shows horizontal stratification of data, as opposed to a general random distribution form as observed in the previous test cells. When individual monthly data sets are analysed (Figure 5.102 and Appendix 6) the trend shifts to a strong linear and negative correlation. The shift to a negative linear correlation occurs for all the monthly data sets for this test cell room and heightens the need, not only to assess data for long periods of time, but also to examine data for seasonal and other short term trends. The data is well-grouped along the trend line, showing a linear relationship with a very subtle negative correlation ratio of -0.37 . The scatter plot (Figure 5.102) illustrates that when the outside air temperature was between $0^{\circ} \mathrm{C}$ and $25^{\circ} \mathrm{C}$, the room air temperature residual either increased or decreased by $1{ }^{\circ} \mathrm{C}$. This suggests that the outside air temperature had little association with the test cell room residual value. The weak correlation between the room and outside air temperature for this test cell is supported by the other monthly correlation ratios, which ranged from -0.32 to -0.11 (Table 5.30). 


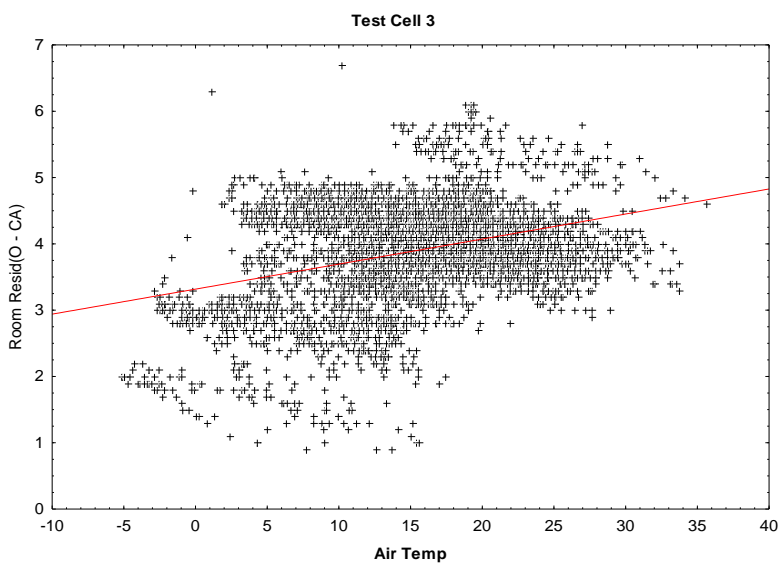

Figure 5.101 - TC3 Room Residual \& Air Temperature Correlation: January to June $2007(r=0.33)$

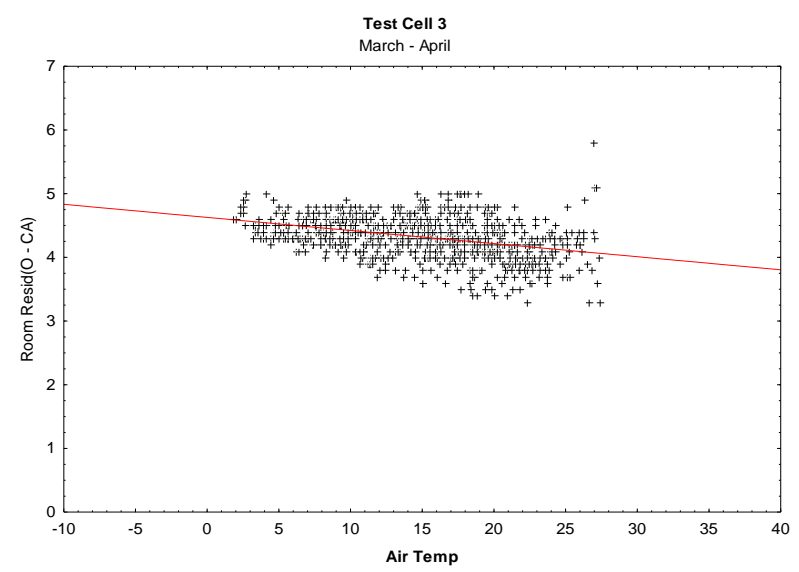

Figure 5.102 - TC3 Room Residual \& Air Temperature Correlation: March/April $2007(r=-0.37)$

Table 5.30: Test Cell Room and Air Temperature Correlation Ratios

\begin{tabular}{|c|c|c|c|}
\hline & Test Cell 1 & Test Cell 2 & Test cell 3 \\
\hline Full Data Set & -0.59 & -0.27 & +0.33 \\
\hline January & -0.76 & -0.27 & -0.32 \\
\hline March & -0.83 & -0.33 & -0.37 \\
\hline May & -0.80 & -0.22 & -0.11 \\
\hline June & -0.92 & -0.57 & -0.17 \\
\hline & & & \\
\hline
\end{tabular}

\section{Roof Space Residual and Air Temperature Relationships}

Figures 5.103 and 5.104 are scatter plots of the roof space residuals and air temperature for the unenclosed-perimeter platform-floored test cell; Figures 5.105 and 5.106 are scatter plots of the roof space residuals and air temperature for the enclosed-perimeter platform-floored test cell; Figures 5.107 and 5.108 are scatter plots of the roof space residuals and air temperature for the concrete slab-on-ground floored test cell; and Table 5.31 is a summary of correlation ratios for the entire data set, as well as monthly subsets.

The roof space scatter plots for each test cell have a similar semi-circular shape and negative linear correlations between outside air temperature and the residual values for the roof space air temperatures. Each of the scatter plots for the full data set illustrated a heteroscedastic pattern. 
The full data set scatter plot for the unenclosed-perimeter platform-floored test cell (Figure 5.103) has a semicircular top to the data which inclines slightly from $5^{\circ} \mathrm{C}$ to $20^{\circ} \mathrm{C}$, at which point the data declines toward the trend line. The bottom of the scatter plot is more linear in form, when compared to the semi-circular top. These two distinctly different patterns to the data produce the heteroscedastic form. The March/April (Figure 5.104) scatter plot for this test cell is more ovoid in form and retains the semicircular nature to the top of the data. There is a tail of low residuals at times of higher outside air temperatures. Similar to previous analyses the higher residual values occur at times of lower outside air temperature and the lowest residuals occur at times of higher outside air temperature. Another significant aspect to this scatter plot is that when the outside air temperature is less than $5^{\circ} \mathrm{C}$, all the data is below the trend line. The correlation ratio of the full data set for the unenclosed platform-floored test cell is of a medium value of -0.46 (Table 5.31). Similar to the previous analyses, the monthly correlation ratios are much stronger, with values ranging from -0.58 to -0.74 .

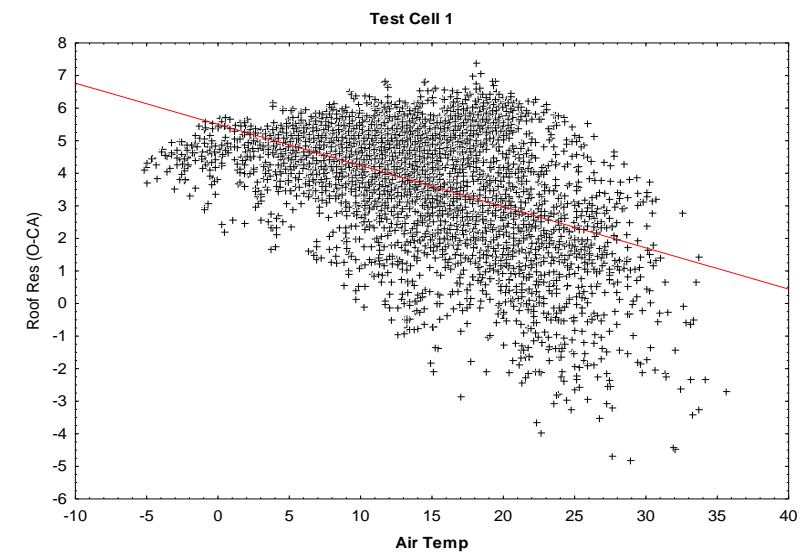

Figure 5.103 - TC1 Roof Space Residual \& Air Temperature Correlation: January to June $(r=-0.46)$

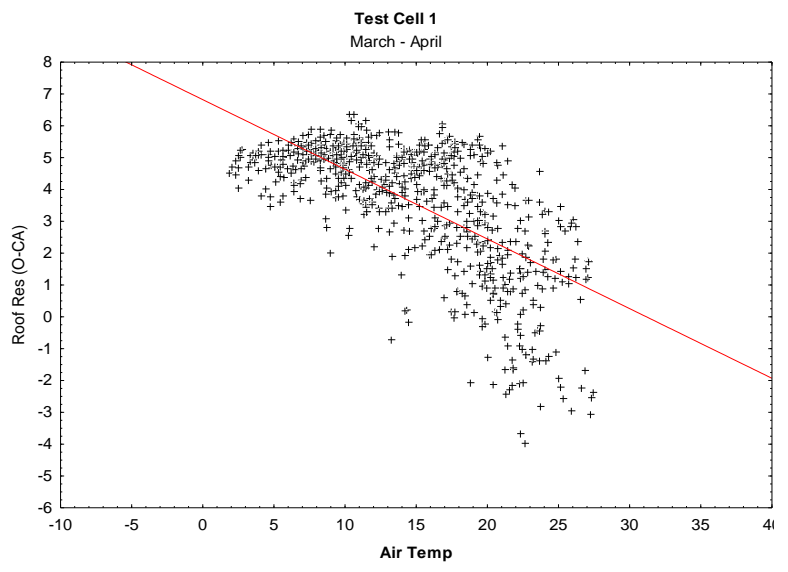

Figure 5.104 - TC1 Roof Space Residual \& Air Temperature Correlation: March/April 2007 $(r=-0.66)$

The general shape of the full data set scatter plot (Figure 5.105) for the enclosed-perimeter platform-floored test cell retains the semicircular top and heteroscedastic form that was observed in the previous test cell's scatter plot. The scatter plot for March/April (Figure 5.106) appears more linear, but retains the semicircular pattern to the top edge of the data. Similar to the trend in the unenclosed-perimeter test cell, when the outside air temperature is $5^{\circ} \mathrm{C}$ or lower, all the data is below the trend line and there is a consistency of high residuals at times of low outside air temperature, and low residuals at times of high outside air 
temperature. The correlation ratio of the full data set for the enclosed platform-floored test cell room is much stronger than the previous test cell with a value of -0.72 (Table 5.31). Unlike the previous analyses, the monthly correlation ratios for this test cell are very similar to that for the full data set, with values ranging from -0.66 to -0.76 .

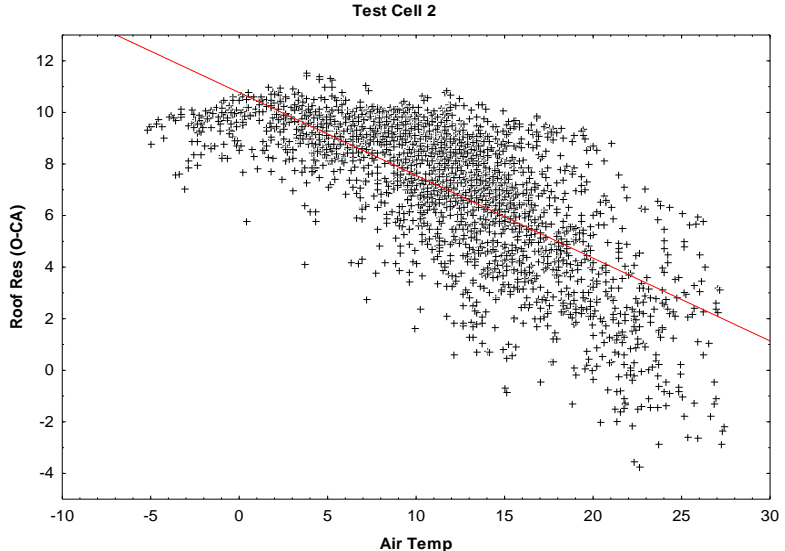

Figure 5.105 - TC2 Roof Space Residual \& Air Temperature Correlation: March to June 2007 $(r=-0.72)$

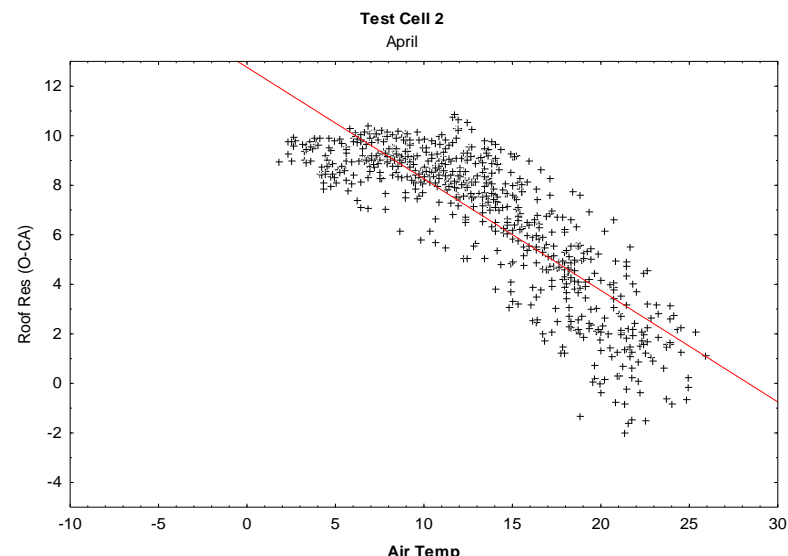

Figure 5.106 - TC2 Roof Space Residual \& Air Temperature Correlation: April $2007(r=-0.76)$

The full data set correlation diagram of the concrete slab-on-ground floored test cell (Figure $5.107)$ is very similar in pattern and ratio to the previously discussed unenclosed platformfloored test cell. Like the other two roof spaces, the bottom edge of the diagram is consistently dispersed. The March/April data set for this test cell provides a more linear grouping of the data along the negative trend line (Figure 5.108) very similar in pattern to the enclosed-perimeter platform-floored test cell discussed above, namely; when the outside air temperature was below $5^{\circ} \mathrm{C}$ all the data is below the trend line, and predominantly the higher residuals occur at times of lower outside air temperature and the lower residuals occur at times of higher outside air temperature. The correlation ratio of the full data set for this test cell was a medium value of -0.50 (Table 5.31). Similar to the previous analyses, the monthly correlation ratios are much stronger with values ranging from -0.58 to -0.74 . 


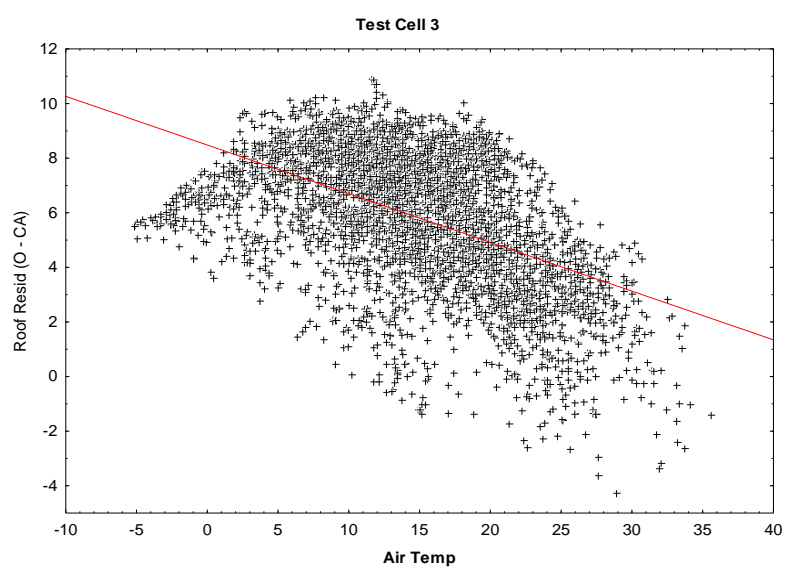

Figure 5.107 - TC3 Roof Space Residual \& Air Temperature Correlation: January to June 2007 $(r=-0.50)$

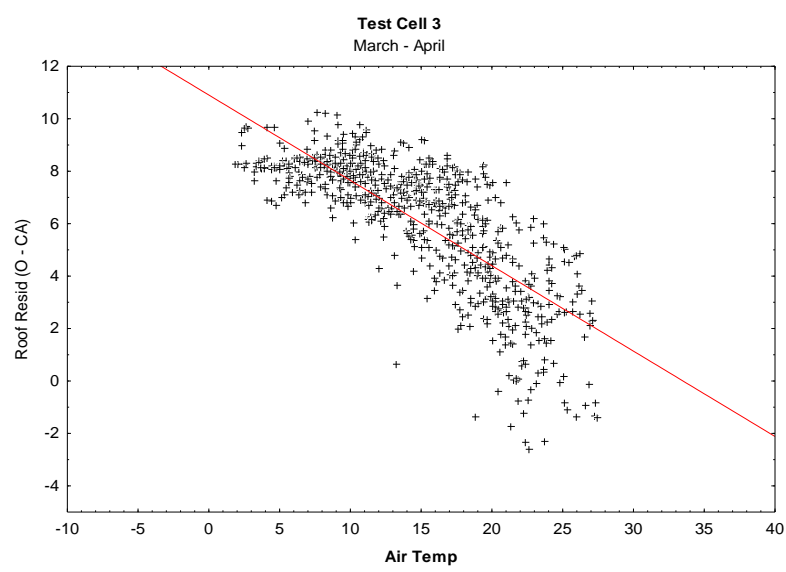

Figure 5.108 - TC3 Roof Space Residual \& Air Temperature Correlation: March/April 2007 ( $r=-0.77)$

Table 5.31: Test Cell Roof space and Air Temperature Correlation Ratios

\begin{tabular}{|c|c|c|c|}
\hline & Test Cell 1 & Test Cell 2 & Test cell 3 \\
\hline Full Data Set & -0.46 & -0.72 & -0.50 \\
\hline January & -0.58 & $\#$ & -0.70 \\
\hline March/April & -0.66 & -0.76 & -0.77 \\
\hline May & -0.61 & -0.66 & -0.58 \\
\hline June & -0.74 & -0.75 & -0.67 \\
\hline \# - No data available
\end{tabular}

\section{Summary}

For all zones, there was a negative linear correlation between the outside air temperature and the subfloor, room and roof space residual values for each test cell. All of these scatter plots show a linear correlation, where the higher positive residual values occur when the outside air temperature is low; as the air temperature increases the scatter plot becomes more dispersed and the residual values often shift to a negative value. This phenomenon requires further investigation. The monthly correlation ratios were significantly lower in value than the monthly data subsets, reinforcing the need for further analysis to occur at the monthly data set level.

The level of correlation varied dramatically between each zone and each test cell. Some key findings included: 
- Generally, the subfloor zone residual values and site air temperature correlations documented medium to strong ratios, which should be investigated further.

- The software's presumption that the outdoor and subfloor air temperature for the unenclosed-perimeter platform-floored test cell are the same, should be examined, as previously discussed analysis in this chapter and this correlation analysis show that negative residuals occur in the unenclosed-perimeter subfloor as temperature increases, but not in the enclosed-perimeter subfloor.

- The test cell room residual values and site air temperature correlations varied significantly for each test cell. The correlation ratios for the unenclosed platformfloored test cell were the highest and very strong, whereas the enclosed platformfloored test cell room documented low correlation ratios and the concrete slab-onground floored test cell demonstrated the lowest correlation ratios.

- The roof space residual values and site air temperature correlations documented a strong correlation ratio for the unenclosed and enclosed-perimeter platform-floored test cells. The concrete slab-on-ground floored test cell had a medium correlation ratio for the full data set, but the monthly data sets generally provided stronger correlation ratios.

\subsubsection{Correlation of Wind Speed and Test Cell Residuals}

This analysis was completed to examine any correlation that may exist between the site wind speed and the calculated residual values from each zone of the test cells. Figures 5.109 to 5.112 are the scatter plot analyses for the unenclosed-perimeter platform-floored test cell; Figures 5.113 to 5.116 are the scatter plot analyses for the enclosed-perimeter platformfloored test cell; and Figures 5.117 to 5.121 are the scatter plot analyses for the concrete slabon-ground floored test cell. To best illustrate the correlation between data sets, the scales on the $\mathrm{X}$ and $\mathrm{Y}$ axes of the scatter plots vary.

\section{Unenclosed-perimeter Platform-floored Test Cell}

Figure 5.109, 5.110 and 5.111 are the full data set scatter plots of wind speed and the subfloor, test cell room and roof spaces, respectively; Figure 5.112 is the month of May 
subset scatter plot of wind speed and test cell room residuals; and Table 5.32 is a summary of correlation ratios for this test cell.

The scatter plots for the unenclosed-perimeter platform-floored test cell show some interesting results (Figures 5.109 to 5.112). The analyses for the January to June data set produced scatter plots with an arrowhead form. The greatest negative and positive residual values for all zones occurred when there was little or no wind speed. As the wind speed increased the data became more aligned to the trend lines. Negative residuals are sparse compared to positive ones, and are concentrated at lower wind speeds. These are very clear examples of heteroscedastic residuals, often described as "bell" shaped. The only exception was the month of May (Figure 5.112), where the breadth of the residual values is at its narrowest for all three zones. This phenomenon is discussed further in the summary for this section.

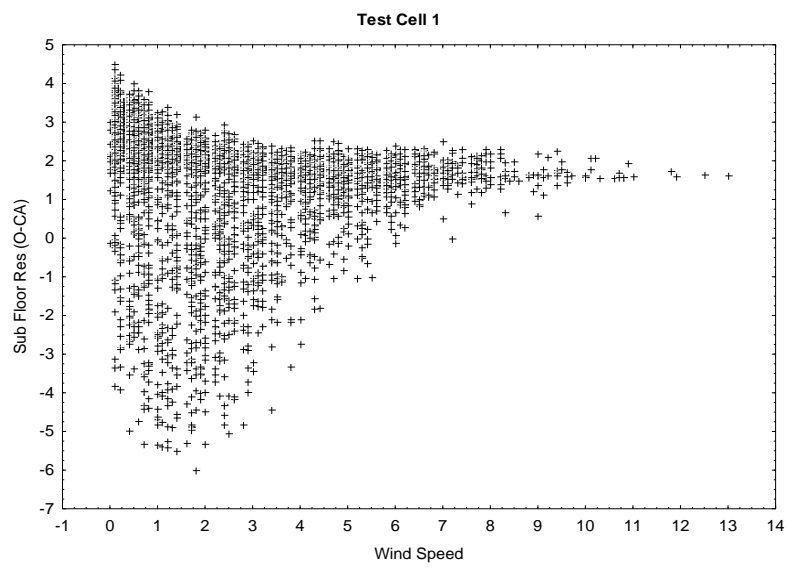

Figure 5.109 - TC1 Subfloor Residual \& Wind Speed Correlation: January to June $2007(r=-0.17)$

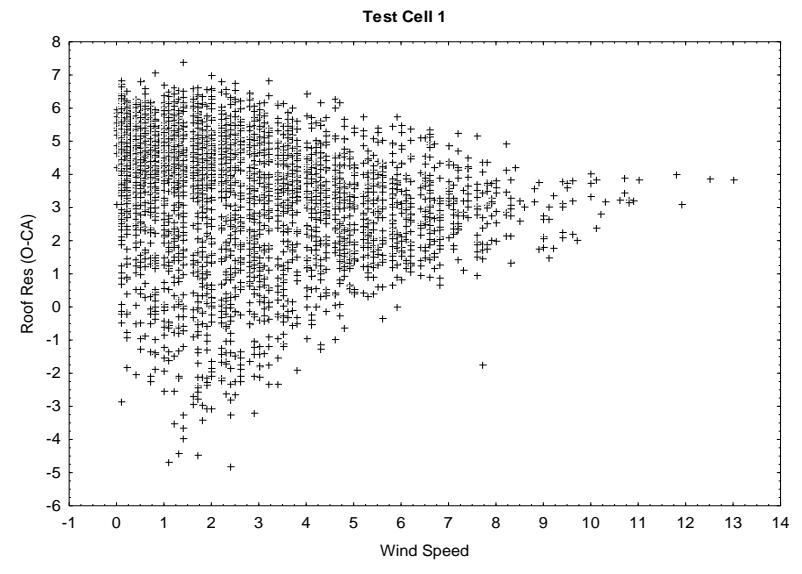

Figure 5.110 - TC1 Roof Space Residual \& Wind Speed Correlation: January to June $2007(r=-0.31)$

The correlation ratios for this test cell, including the full and monthly data set analyses are listed in Table 5.32. The correlation ratios vary between each zone and all are negative. The negative correlation would make sense for this climate, as the wind would provide an additional cooling function. There is a general trend in the correlation ratio values, from a lowest and weak value in January, to higher and medium values in May and June. This would indicate some season trends that require further investigation; however, as the data is heteroscedastic, the correlation ratios are unreliable, due to the non linear relationship that 
exists between the two variables being analysed. The correlation ratios are still included for general information.

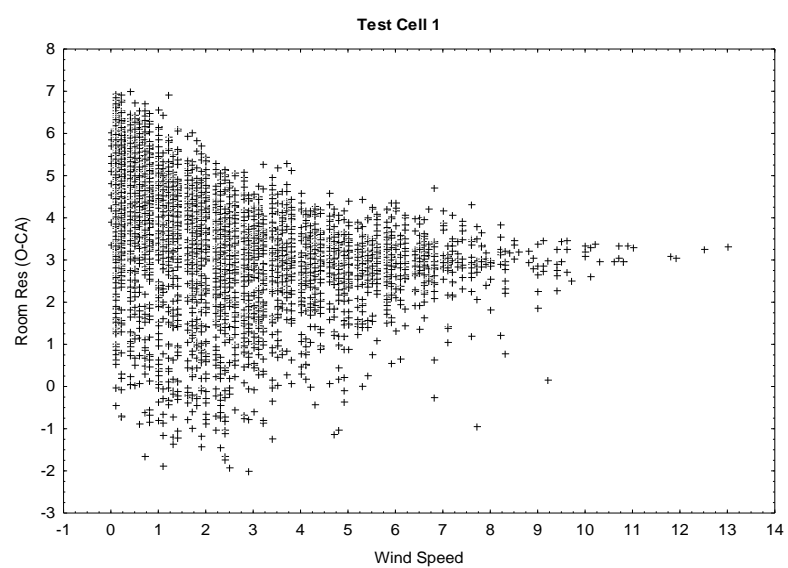

Figure 5.111 - TC1 Room Residual \& Wind Speed Correlation: January to June $2007(r=-0.40)$

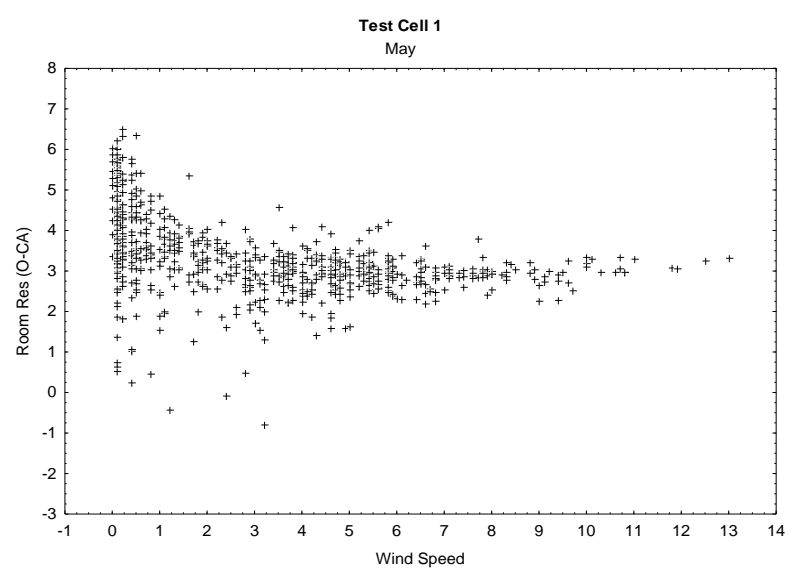

Figure 5.112 - TC1 Room Residual \& Wind Speed Correlation: May $2007(r=-0.43)$

Table 5.32: Test Cell 1 Zone Residual Values and Wind Speed Correlation Ratios

\begin{tabular}{|l|c|c|c|}
\hline & Subfloor & Cell Room & Roof Space \\
\hline Full Data Set & -0.17 & -0.40 & -0.31 \\
\hline January & -0.06 & -0.38 & -0.24 \\
\hline March/April & -0.22 & -0.50 & -0.37 \\
\hline May & -0.25 & -0.43 & -0.48 \\
\hline June & -0.37 & -0.42 & -0.46 \\
\hline
\end{tabular}

\section{Enclosed-perimeter Platform-floored Test Cell}

Similar in nature to the unenclosed platform-floored test cell, the residual to wind speed scatter plots for the subfloor (Figure 5.113); roof space (Figure 5.114); and test cell room (Figure 5.115) of this test cell produced heteroscedastic arrowhead forms. In all cases, the greatest negative and positive residual values for all zones occurred when there was little or no wind speed. As the wind speed increased, the data became more aligned to the trend lines. The subfloor scatter plot for this test cell is less defined when compared to that of the unenclosed-perimeter subfloor and this should be expected due to the enclosure of the subfloor. A similar irregularity in the form of the scatter plot occurs in May (Figure 5.116) 
where the correlation ratio is much higher and the diagram is more horizontal and condensed in form.

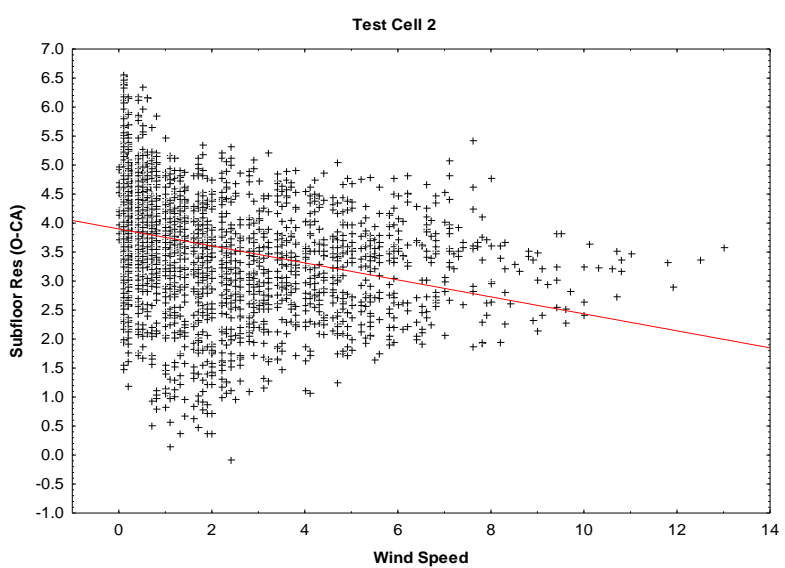

Figure 5.113 - TC2 Subfloor Residual \& Wind Speed Correlation: March to June $2007(r=-0.31)$

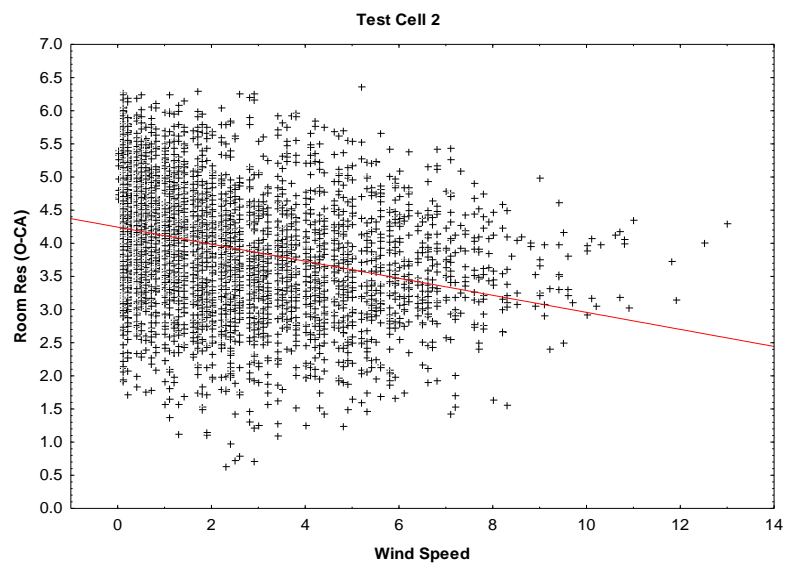

Figure 5.115 - TC2 Room Residual \& Wind Speed Correlation: January to June $2007(r=-0.30)$

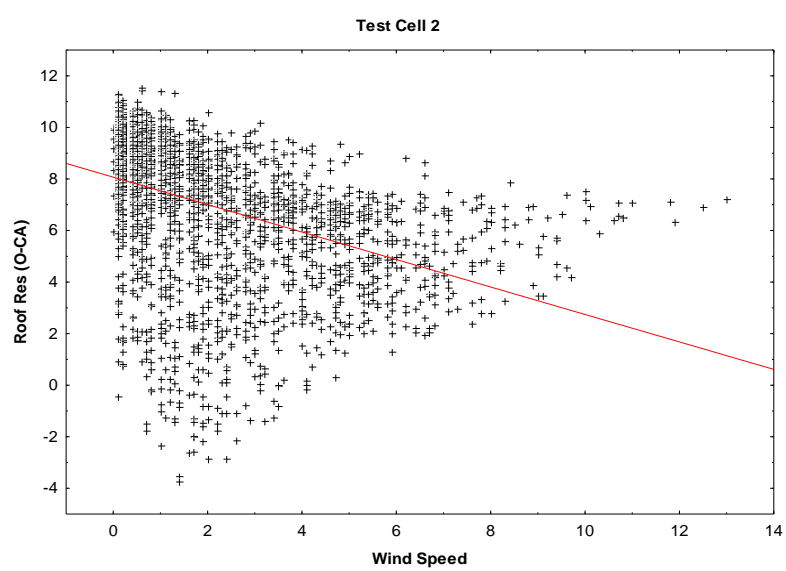

Figure 5.114 - TC2 Roof Space Residual \& Wind Speed Correlation: March to June $2007(r=-0.42)$

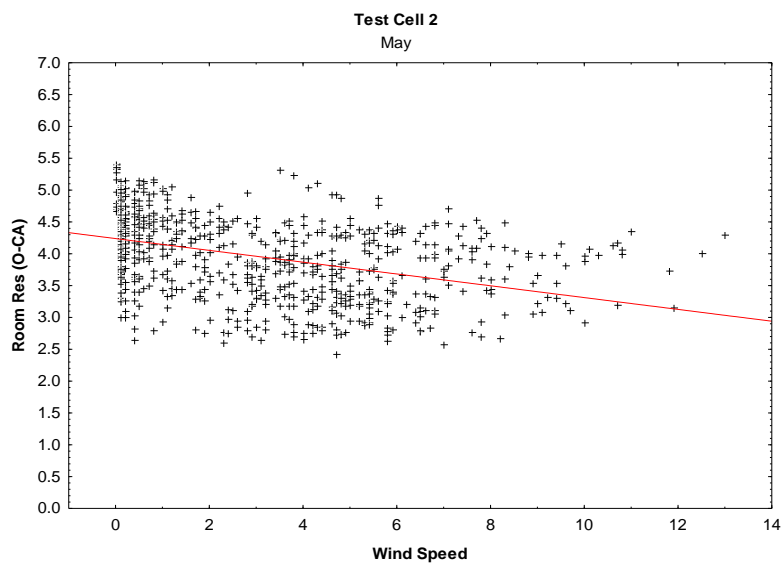

Figure 5.116 - TC2 Room Residual \& Wind Speed Correlation: May $2007(r=-0.40)$

As observed for the previous test cell, the heteroscedastic nature of the scatter plots reflects the non-linear relationship between these two variables, making the correlation ratios unreliable. However, the correlation ratios are still included for general information in Table 5.33 . 
Table 5.33: Test Cell 2 Zone Residual Values and Wind Speed Correlation Ratios

\begin{tabular}{|l|c|c|c|}
\hline & Subfloor & Cell Room & Roof Space \\
\hline Full Data Set & -0.31 & -0.30 & -0.42 \\
\hline January & $\#$ & -0.35 & $\#$ \\
\hline March/April & -0.24 & -0.20 & -0.48 \\
\hline May & -0.50 & -0.40 & -0.45 \\
\hline June & -0.21 & -0.22 & -0.37 \\
\hline \# - No data available
\end{tabular}

\section{Concrete Slab-on-Ground floored Test Cell}

Similar in nature to the two previous test cells, the zone residual and wind speed scatter plots for the test cell room (Figure 5.117); and the roof space (Figure 5.118) for this test cell produced heteroscedastic arrowhead forms. A similar anomaly in the form occurs in May (Figure 5.120) where the scatter plot is more horizontal and condensed along the trend line. However, another key pattern is observable in the correlation diagrams for this test cell, where in Figures 5.119 to 5.121 there is a shift in the pattern of the diagram, such that:

- the data from February forms the top portion of the horizontal arrowhead

- the data from May forms the middle portion of the horizontal arrowhead and

- the data from June forms the bottom portion of the horizontal arrowhead

The occurrence of this phenomenon between the monthly data sets strengthens the notion that any further analysis must consider monthly subsets of data. 


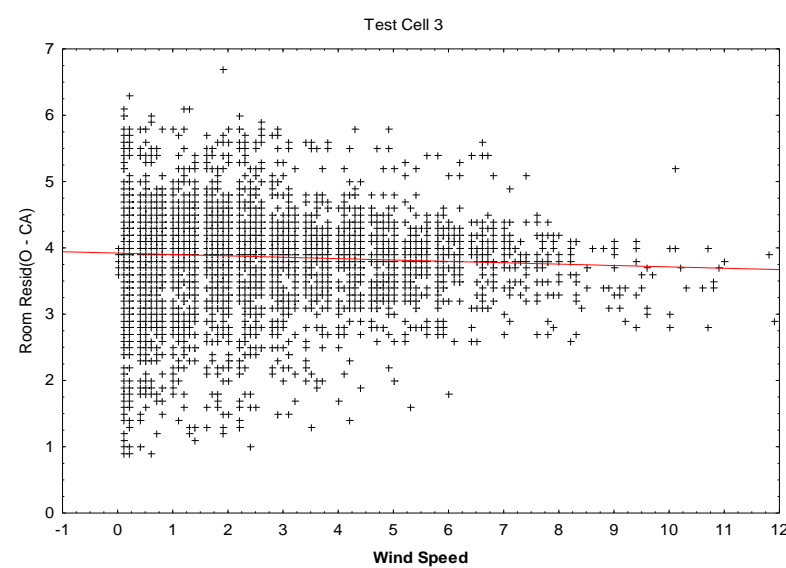

Figure 5.117 - TC3 Room Residual \& Wind Speed Correlation: January to June $2007(r=-0.06)$

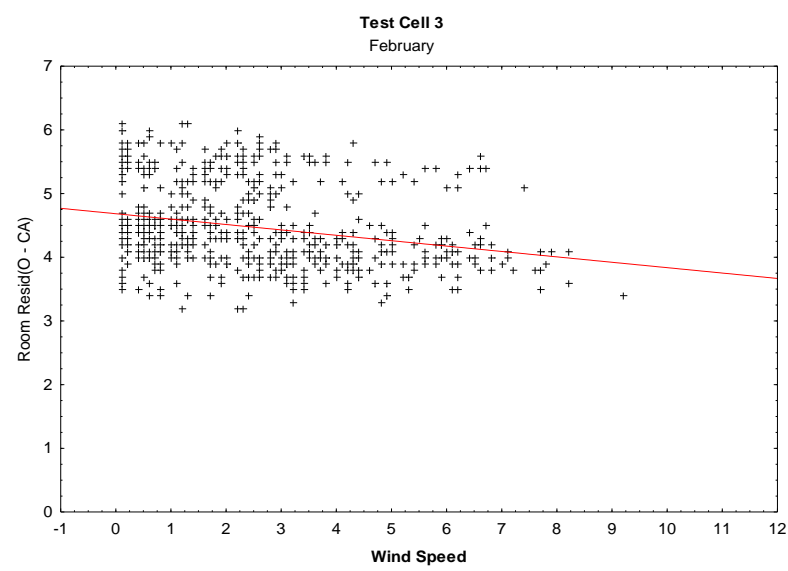

Figure 5.119 - TC3 Room Residual \& Wind Speed Correlation: February $2007(r=-0.26)$

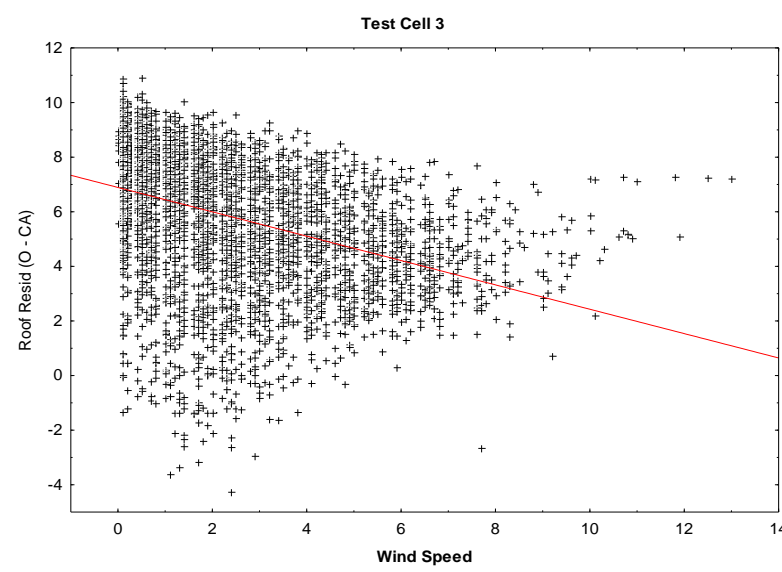

Figure 5.118 - TC3 Roof Space Residual \& Wind Speed Correlation: January to June $2007(r=-0.40)$

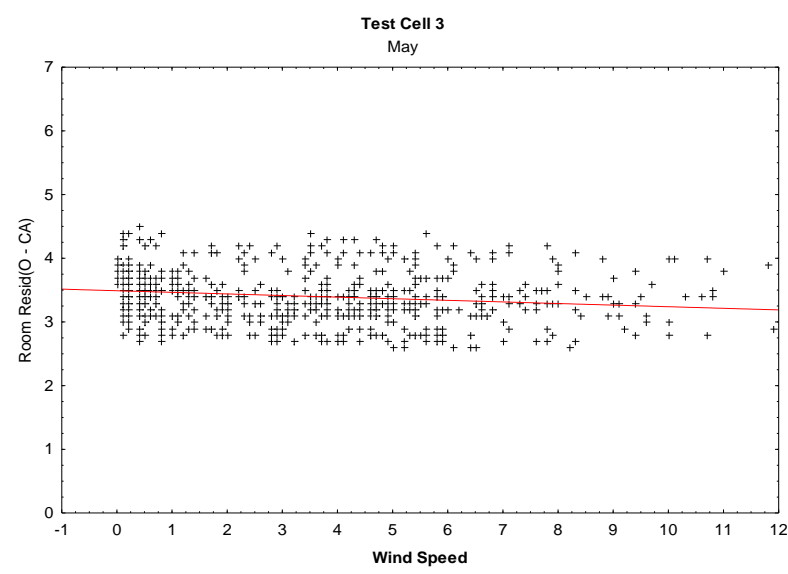

Figure 5.120 - TC3 Room Residual \& Wind Speed Correlation: May $2007(r=-0.18)$

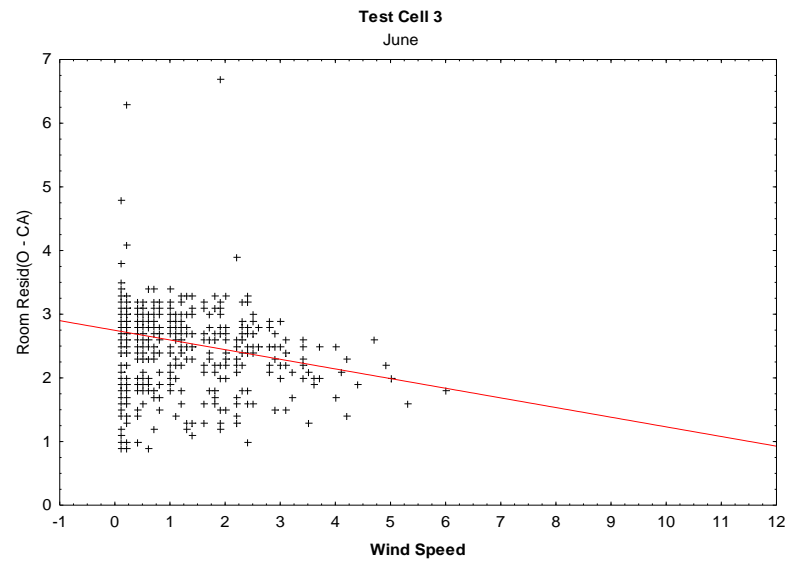

Figure 5.121 - TC3 Room Residual \& Wind Speed Correlation: June 2007 ( $r=-0.21)$ 
The correlation ratios for this test cell are listed in Table 5.34 but as raised above in the discussion for the previous two test cells, these ratios are unreliable, due to the heteroscedastic non-linear relationship between the two variables.

Table 5.34: Test Cell 3 Zone Residual Values and Wind Speed Correlation Ratios

\begin{tabular}{|l|c|c|}
\hline & Cell Room & Roof Space \\
\hline Full Data Set & -0.06 & -0.40 \\
\hline January & -0.21 & -0.37 \\
\hline March/April & -0.29 & -0.53 \\
\hline May & -0.18 & -0.40 \\
\hline June & -0.21 & -0.39 \\
\hline
\end{tabular}

\section{Summary}

- For all zones of the three test cells there was a negative correlation between wind speed and residual values.

- For most cases the bivariate analysis produced scatter plots which were heteroscedastic in pattern.

- The form of the heteroscedastic pattern illustrates that the broadest range of residual values occurs when the wind speed is low or nil. As the wind speed increases, the residuals move closer to the trend line.

- As the variables produced a non-linear relationship, the correlation ratios are unreliable for this analysis.

- The wind speed is used to calculate surface heat transfer and infiltration. The strongly heteroscedastic pattern of the scatter plots can indicate an error in algorithms, hence requires further investigation.

- These results indicate that further analysis should examine relationships which include: wind speed, terrain category and the zone residual values. Previous research has documented variations in the effect of terrain categories and site-measured wind speed in building envelope thermal simulations (Guyon, G et al. 1999; Moghtaderi 2005; Palmiter \& Francisco 1996; Pereira \& Ghisi 2009). 
- Many HER softwares have simplified infiltration models which have been found to affect the energy balance equations significantly (Deru \& Burns 2003). These results indicate that further analysis should examine relationships which include: wind speed, wind direction and the zone residual values.

\subsubsection{Correlation of Wind Direction and Test Cell Residuals}

This analysis aimed to examine any correlation that may exist between the measured site wind direction and the residuals from each zone of the test cells. The climate file within AccuRate incorporated numerical values for wind direction. A zero value for wind direction indicates that there was no wind speed for that hour (ACDB 2006). When there was a measured wind speed, a value of 1 to 16 was assigned, dependent on wind direction (Clarke 2001). As the test cells are detached buildings on flat terrain without adjacent buildings and trees, it was expected that wind direction could affect their thermal performance. Figures 5.122 to 5.124 are the scatter plot analyses for the unenclosed-perimeter platform-floored test cell; Figures 5.125 to 5.127 are the scatter plot analyses for the enclosed-perimeter platform-floored test cell; and Figures 5.128 and 5.129 are the scatter plot analyses for the concrete slab-on-ground floored test cell. To best illustrate the correlation between data sets, the scales on the X and Y axes of the scatter plots vary.

\section{Unenclosed Platform-floored Test Cell}

The zone residual and wind direction correlation scatter plots for all zones of this test cell are heteroscedastic and show an inverted triangle pattern. The scatter plots of the full data for the subfloor (Figure 5.122) and roof space (Figure 5.124) zones, are quite flat along the top, or the upper positive residual values, but form a downward facing arrowhead for the negative residual values. The diagram for the test cell room (Figure 5.123) follows the same general form as the subfloor and roof space zones; however it is more tempered due to this zone being more removed from the external climate than the subfloor and roof space zones. This same pattern appears in each of the monthly diagrams, with the exception of May (see Appendix 6). This arrowhead relationship is significantly associated with negative residual values and appears to relate to times when the wind was coming from a southerly direction. 
The scatter plots document no wind coming from directions 1 and 2, which would be highly unlikely and requires further investigation.

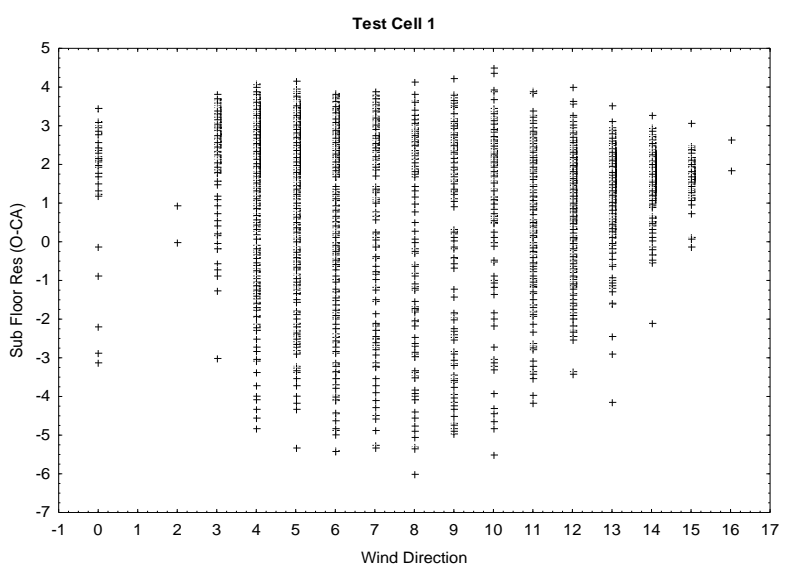

Figure 5.122 - TC1 Subfloor Residual \& Wind Direction Correlation: January to June 2007

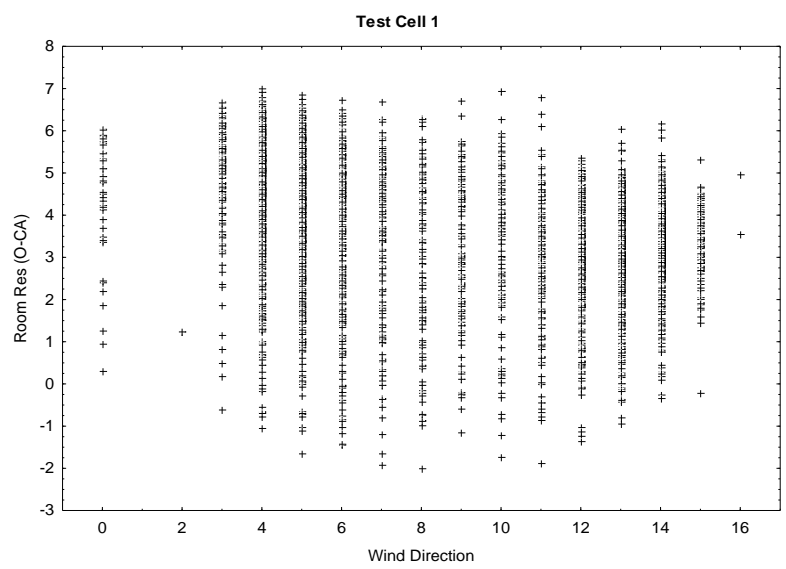

Figure 5.123 - TC1 Room \& Wind Direction Correlation: January to June 2007

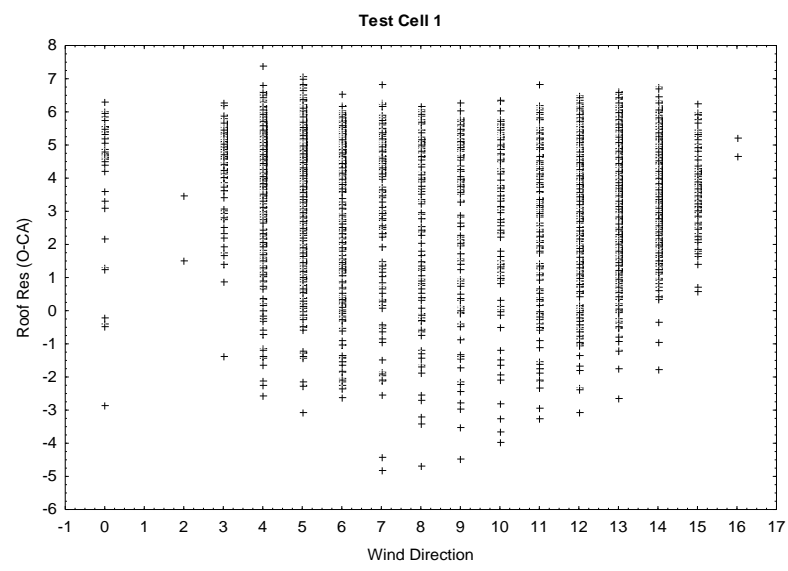

Figure 5.124 - TC1 Roof Space Residual \& Wind Direction Correlation: January to June 2007

The scatter plots are heteroscedastic and show a non-linear relationship between the two variables, and correlation ratios are not good indicators of association between residuals and wind direction. However, they are still included in Table 5.35 for general interest. The correlation ratios for the three zones of this test cell vary from month to month. 
Table 5.35: Test Cell 1 Zone Residual Values and Wind Direction Correlation Ratios

\begin{tabular}{|l|c|c|c|}
\hline & Subfloor & Cell Room & Roof Space \\
\hline Full Data Set & -0.08 & -0.30 & -0.15 \\
\hline January & -0.04 & -0.24 & -0.07 \\
\hline March/April & -0.12 & -0.44 & -0.19 \\
\hline May & -0.29 & -0.52 & -0.49 \\
\hline June & -0.19 & -0.26 & -0.21 \\
\hline
\end{tabular}

\section{Enclosed-perimeter Platform-floored Test Cell}

The zone residual and wind direction correlation scatter plots for the subfloor (Figure 5.125) and roof space (Figure 5.126) zones in this test cell are generally of a similar form to those of the previous test cell, with a tempered, skewed, inverted triangle pattern to the data. The tempering of the subfloor zone should be expected due to the semi-enclosed nature of the subfloor. The roof space tempering could be caused by the differing infiltration rates. The results from the tracer gas tests of the test cells produced significantly different constant and multiplier infiltration values for the roof spaces. The infiltration rate, in air changes per hour, is specified as $\mathrm{A}+\mathrm{B}^{*} \mathrm{v}$, where $\mathrm{v}$ is the wind speed multiplied by a terrain category factor. The constant and multiplier infiltration values, as listed in Table 5.36 are one third the value of the unenclosed-perimeter platform-floored test cell. This smaller level of infiltration, when compared to the roof space of the unenclosed-perimeter platform-floored test cell, should impact the relative infiltration of the two differing roof spaces.

Table 5.36: Calculated Roof Space Infiltration Values

\begin{tabular}{|c|c|c|}
\hline & A Value & B Value \\
\hline Test Cell 1 & 1.260 & 0.700 \\
\hline Test Cell 2 & 0.400 & 0.258 \\
\hline Test Cell 3 & 0.340 & 0.156 \\
\hline
\end{tabular}




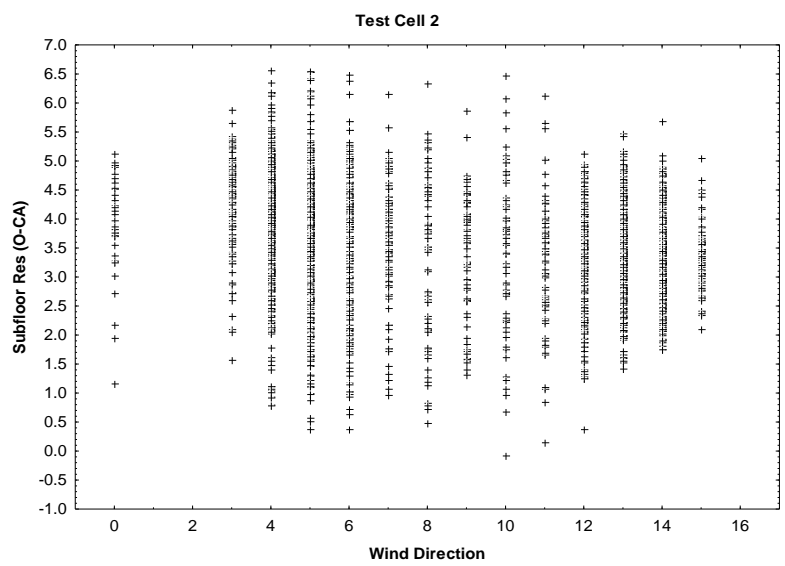

Figure 5.125 - TC2 Subfloor Residual \& Wind Direction Correlation: January to June 2007

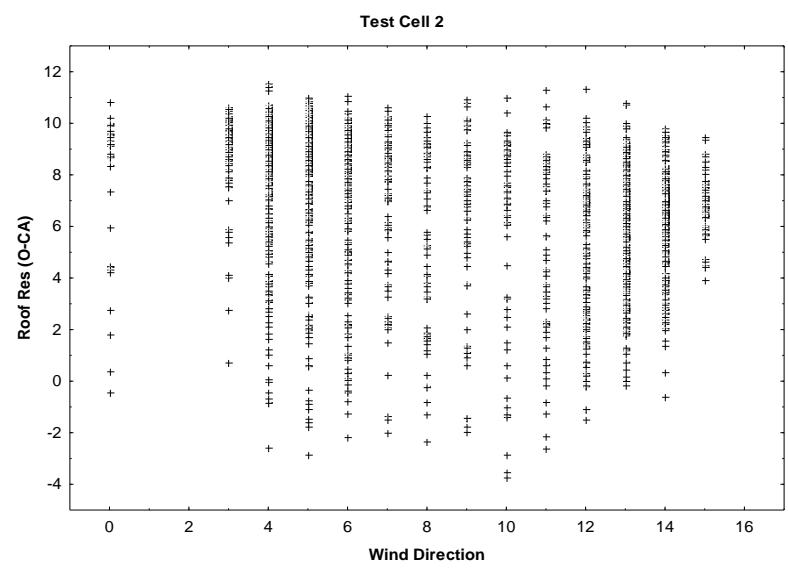

Figure 5.126 - TC2 Roof Space Residual \& Wind Direction Correlation: March to June 2007

The scatter plot for this test cells room (Figure 5.127) is quite mixed in form, with a dip in both the high and low residual values for times when the wind was from a southerly direction. This could be caused by a wind shading effect from the concrete slab-on-ground floored test cell. With the exception of periods when the wind was from a due south direction, the scatter plot forms the downward facing arrowhead. The general tempering of the diagram for this zone would reflect the greater insulation of the test cell room from the external climate.

With the exception of May, the monthly scatter plots produce the same pattern for each of the correlation scatter plots, for each zone (see Appendix 6).

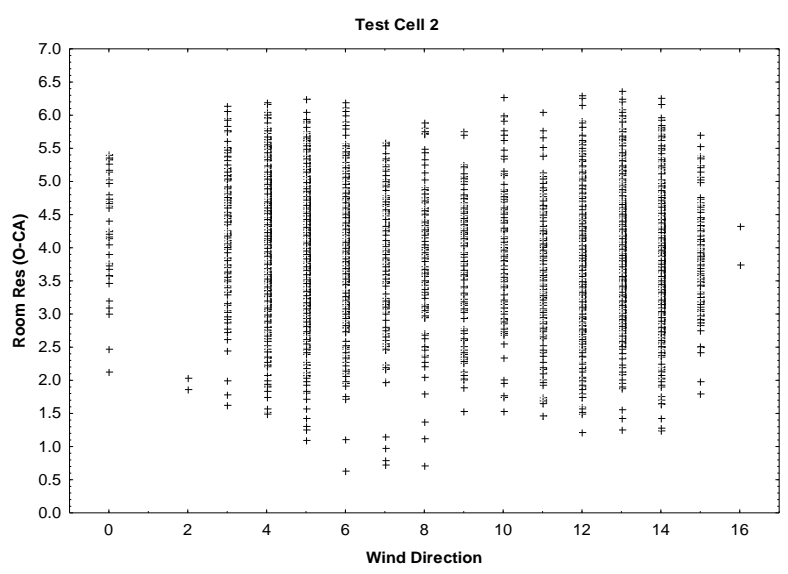

Figure 5.127 - TC2 Room Residual \& Wind Direction Correlation: January to June 2007 
As with the previous test cell, the scatter plots are heteroscedastic and show a non-linear relationship, causing the correlation ratios to be unreliable. However, they are included for general information and except for the month of May, the zone residual and wind speed correlation ratios for this test cell are quite weak (Table 5.37). For all three zones the ratios for May are much stronger with values of $-0.58,-0.50$ and -0.48 for the subfloor, test cell room and roof space zones respectively.

Table 5.37: Test Cell 2 Zone Residual Values and Wind Direction Correlation Ratios

\begin{tabular}{|l|c|c|c|}
\hline & Subfloor & Cell Room & Roof Space \\
\hline Full Data Set & -0.24 & -0.16 & -0.34 \\
\hline January & $\#$ & -0.20 & $\#$ \\
\hline March/April & -0.14 & -0.10 & -0.29 \\
\hline May & -0.58 & -0.50 & -0.48 \\
\hline June & -0.06 & -0.11 & -0.21 \\
\hline \# - No data available
\end{tabular}

\section{Concrete Slab-on-Ground Floored Test Cell}

The scatter plots for the room of the concrete slab-on-ground floored test cell show the least correlation (Figure 5.128). The dip in the maximum and minimum residual values when the wind came from a southerly direction could reflect wind shading caused by the established trees to the south of this test cell, but this requires further investigation. Otherwise, the scatter plot for this room is very similar in heteroscedastic pattern to that of the enclosed-perimeter platform-floored test cell. The roof space residual value and wind direction scatter plot for this test cell (Figure 5.129) was very similar in heteroscedastic pattern to that of the enclosedperimeter platform-floored test cell. This would strengthen the link between the calculated infiltration rates and the diagram pattern discussed for the previous test cell. Both scatter plots for this test cell show a non-linear relationship between the two variables. As with the previous two test cells, the monthly analyses produced similar forms of scatter plot for each zone, with the exception May (see Appendix 6). 


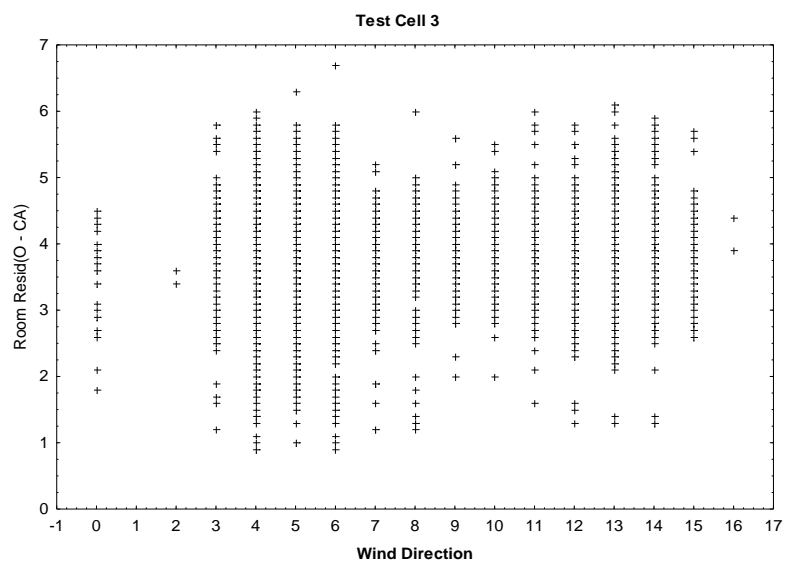

Figure 5.128 - TC3 Room Residual \& Wind Direction Correlation: January to June 2007

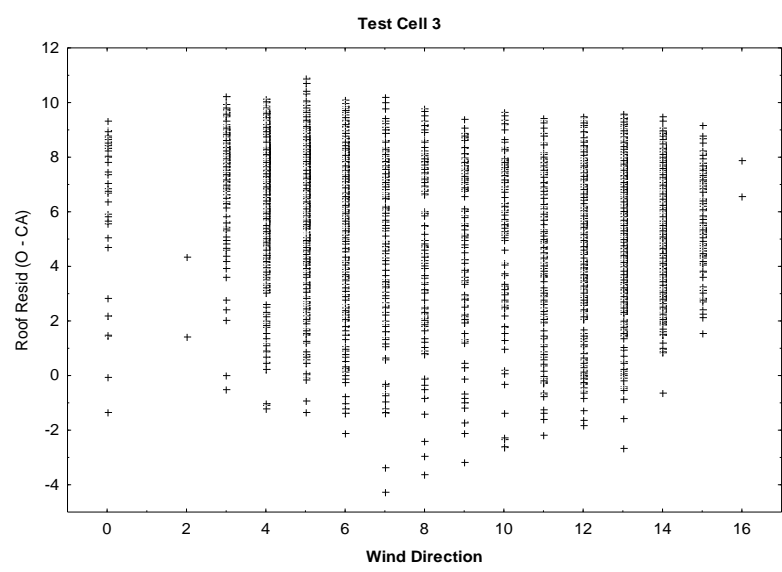

Figure 5.129 - TC3 Roof Space Residual \& Wind Direction Correlation: January to June 2007

The correlation ratios for this test cell are unreliable, due to the non-linear relationship between the two variables and are only included for general information in Table 5.38.

Table 5.38: Test Cell 3 Zone Residual Values and Wind Direction Correlation Ratios

\begin{tabular}{|c|c|c|}
\hline & Cell Room & Roof Space \\
\hline Full Data Set & -0.01 & -0.24 \\
\hline January & -0.08 & -0.20 \\
\hline March/April & -0.17 & -0.34 \\
\hline May & -0.28 & -0.45 \\
\hline June & -0.08 & -0.21 \\
\hline
\end{tabular}

\section{Summary Test Cell Residual Analysis - Wind Direction}

- All graphs show a lack of data for wind from directions 1, 3 and 16. This requires further investigation.

- As all the scatter plots are heteroscedastic and non-linear, the correlation ratios are unreliable for the purpose of establishing any relationship between the wind direction and zone residual values

- The scatter plots often documented greater negative residuals when the wind was not coming from a northerly direction (4 to 12). If the software is not adequately considering the movement of wind around the test cell walls, the calculations for 
surface conduction would be affected. Further analysis is required and must include surface temperature data from each wall.

- Any further analysis would need to include zone residual, wind speed and wind direction in a multivariate analysis.

\subsubsection{Correlation of Global Solar Radiation and Test Cell Residuals}

This analysis examined any correlation that may exist between the site-measured global solar radiation and the residual values for each zone of the test cells. Past research has shown this to be an area requiring calibration in other softwares (LomasEppel et al. 1994; Loutzenhiser et al. 2007; Manz, HL, P; Frank, T; Strachan, P; Bundi, R; Maxwell, G; 2005; Travesi et al. 2001). All the scatter plots show a negative linear relationship between the zone residual value and the measured global solar radiation. Figures 5.130 to 5.135 are the scatter plot analyses for the unenclosed-perimeter platform-floored test cell; Figures 5.136 to 5.139 are the scatter plot analyses for the enclosed-perimeter platform-floored test cell; and Figures 5.140 to 5.145 are the scatter plot analyses for the concrete slab-on-ground floored test cell. To best illustrate the correlation between data sets, the scales on the $\mathrm{X}$ and $\mathrm{Y}$ axes of the scatter plots vary.

\section{Unenclosed-perimeter Platform-floored Test Cell}

The full data set (Figure 5.130) and March/April (Figure 5.131) correlation scatter plots for the subfloor zone of this test cell show an apparent boundary condition from a residual value of around $4^{\circ} \mathrm{C}$ to $5^{\circ} \mathrm{C}$ at $0 \mathrm{~W} / \mathrm{m}^{2}$, dropping down to a constant value of around $3^{\circ} \mathrm{C}$ from $200 \mathrm{~W} / \mathrm{m}^{2}$ onwards. The scatter plots show a strong grouping of the data up to $200 \mathrm{~W} / \mathrm{m}^{2}$, at which point the data becomes heteroscedastic. Another observable phenomenon is the steep positive increase in residual values as the global solar radiation value fell below $100 \mathrm{~W}$. 


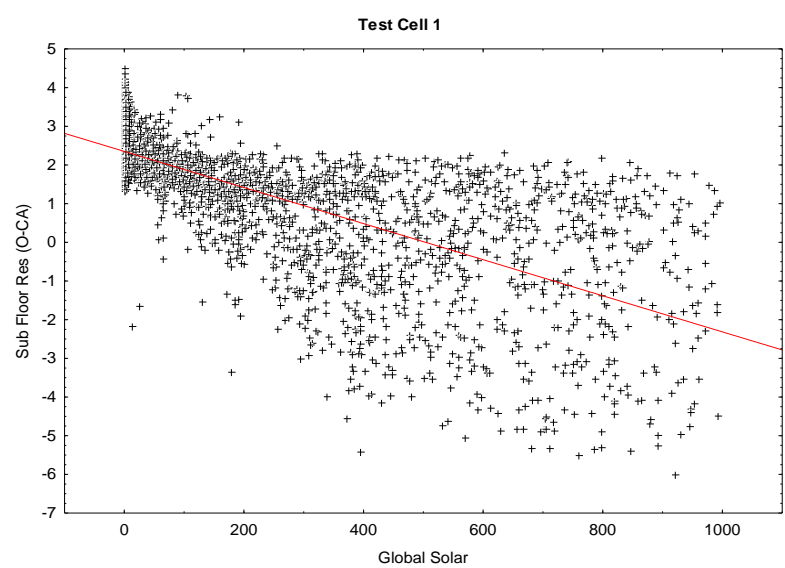

Figure 5.130 - TC1 Subfloor Residual \& Global Solar Radiation Correlation: January to June 2007

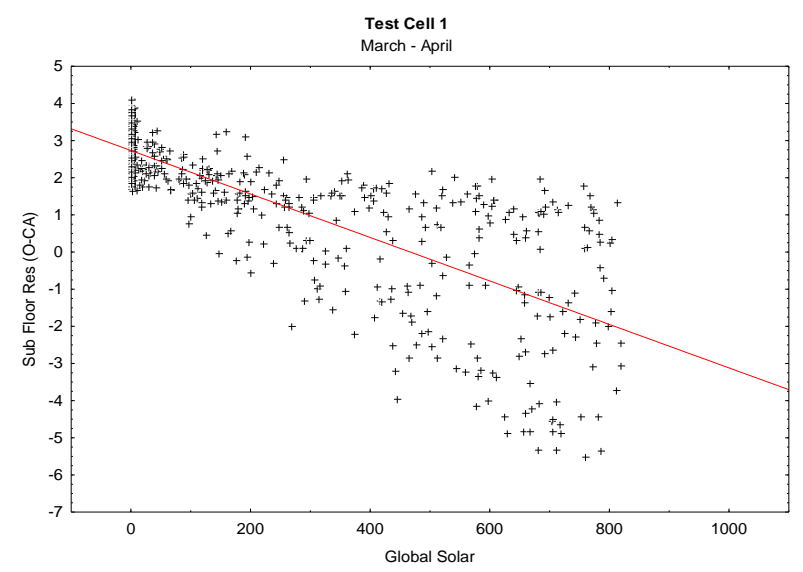

Figure 5.131 - TC1 Subfloor Residual \& Global Solar Radiation Correlation: March/April 2007

The test cell room residual and global solar radiation correlation scatter plots Figure 5.132 and 5.133) for this test cell are still heteroscedastic; however this did not have the top boundary condition that is observable in the scatter plots for the subfloor but a broad negative linear grouping of data. The monthly May scatter plot (Figure 5.133) shows the distinct wideranging residual values when the solar radiation value is zero and a nearly horizontal trend in the data at around the $3^{0} \mathrm{C}$ residual value. This pattern appears in most scatter plots for all three test cells and it shows that when there is no solar radiation, large quantities of measurements are associated with simulation errors, ranging from $1^{\circ} \mathrm{C}$ to $7^{\circ} \mathrm{C}$.

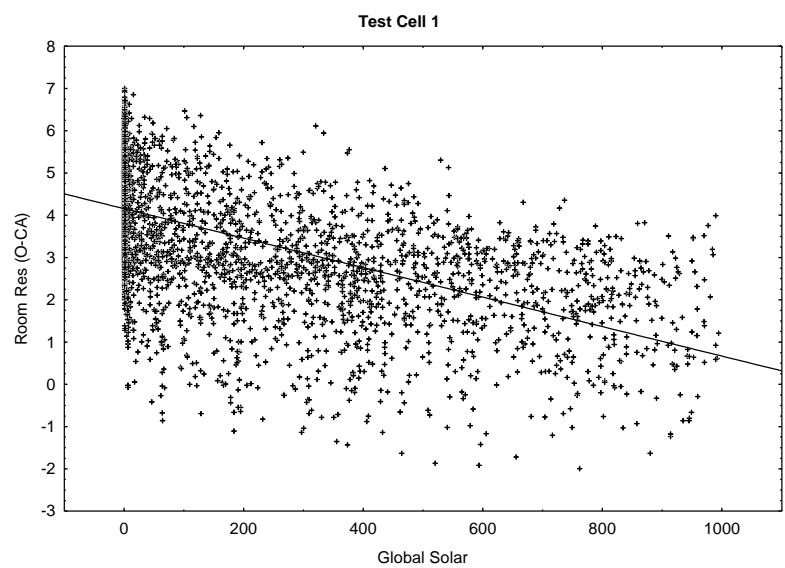

Figure 5.132 - TC1 Room Residual \& Global Solar Radiation Correlation: January to June 2007

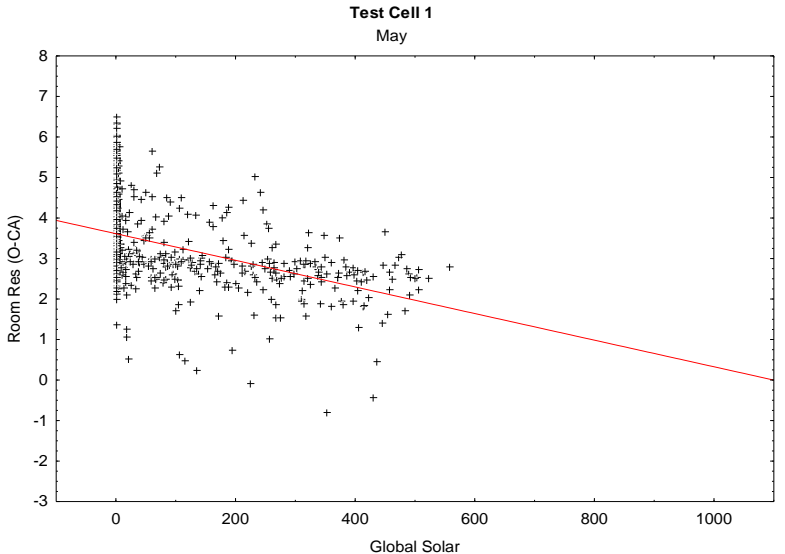

Figure 5.133 - TC1 Room Residual \& Global Solar Radiation Correlation: May 2007 
The form of the correlation scatter plots for the roof space of this test cell (Figure 5.134 and 5.135) shows a reasonably well-grouped pattern of negative linear related data. This pattern was observable in both the full data set (Figure 5.134) and the March/April data set (Figure 5.135). The scatter plots of the other monthly data sets in Appendix 6 show similar patterns. The pattern of this scatter plot shows a higher linear correlation than the subfloor or room of this test cell. As with the other two zones of this test cell, there appears to be a boundary condition in action between $0 \mathrm{~W}$ and $200 \mathrm{~W}$, after which the data becomes more dispersed.

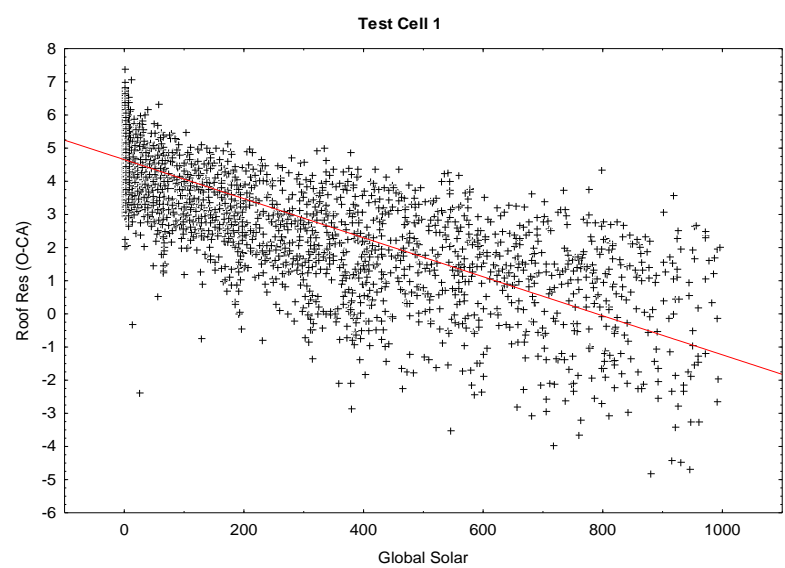

Figure 5.134 - TC1 Roof Space Residual \& Global Solar Radiation Correlation: January to June 2007

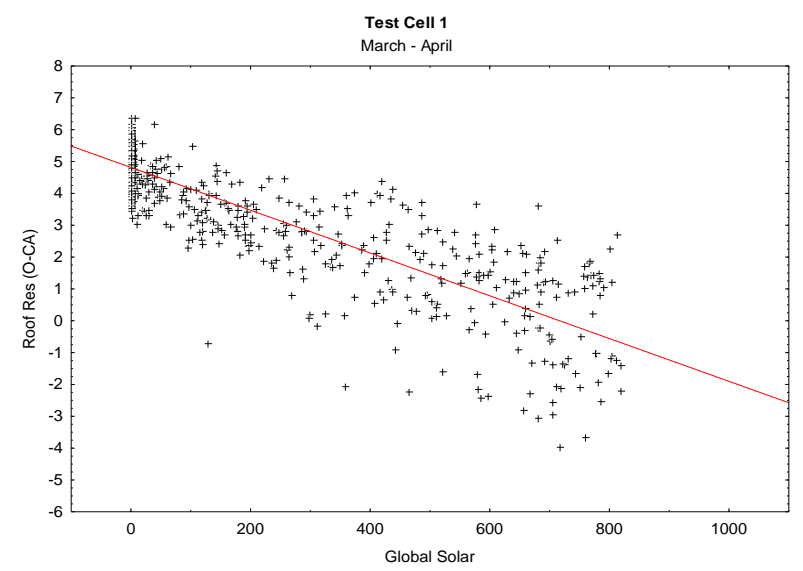

Figure 5.135 - TC1 Roof Space Residual \& Global Solar Radiation Correlation: March/April 2007

As the scatter plots for the subfloor and test cell room are heteroscedastic correlation ratios in Table 5.39 are unreliable. However, the roof space scatter plots show a more homoscedastic form, giving some value to their correlation values. For the subfloor, with the exception of May, all the correlation ratios are strong. If the ratio for May is discounted, the ratios progress from -0.70 to -0.91 , as the climate moves from summer to winter. The ratios for the test cell room, with the exception of May, are much more stable and provide a similar correlation ratio for most months. The roof space correlation ratios are strong for all months, including May.

Table 5.39: Test Cell 1 Residual Value and Global Solar Radiation Correlation Ratios

\begin{tabular}{|l|c|c|c|}
\hline & Subfloor & Cell Room & Roof Space \\
\hline Full Data Set & -0.72 & -0.57 & -0.79 \\
\hline January & -0.70 & -0.66 & -0.83 \\
\hline March/April & -0.79 & -0.65 & -0.87 \\
\hline May & -0.62 & -0.45 & -0.73 \\
\hline June & -0.91 & -0.58 & -0.87 \\
\hline
\end{tabular}




\section{Enclosed-perimeter Platform-floored Test Cell}

The global solar radiation correlation scatter plots for the subfloor (Figure 5.136) and test cell room (Figure 5.137) of this test cell are very similar in form to the room of the unenclosedperimeter platform-floored test cell. There is a broad sweep of negative linear correlated data and a broad range of positive and negative residual values when the solar radiation value was zero in both the full and monthly data sets (see Appendix 6).

The scatter plot for the subfloor (Figure 5.136) is significantly different to that of the unenclosed-perimeter platform-floored test cell. In many respects, it is similar to the room of this test cell (Figure 5.137) and the unenclosed-perimeter platform-floored test cell discussed above (Figure 5.132). The subfloor and room scatter plots for this test cell show a very broad range of residual values: from around $1.5^{\circ} \mathrm{C}$ to $6.5^{\circ} \mathrm{C}$ when the solar radiation is $0 \mathrm{~W} / \mathrm{m}^{2}$. For the subfloor, this represents the residuals with the highest value. For the room, this represents the residuals with both the highest and lowest value. From $0 \mathrm{~W} / \mathrm{m}^{2}$ to $200 \mathrm{~W} / \mathrm{m}^{2}$ there appears to be a subtle funnelling of the data towards the trend line before the general dispersed pattern of the data along the trend line continues for the rest of the solar radiation values. Aside from the condition at $0 \mathrm{w} / \mathrm{m}^{2}$, the remainder of the data patterns for both scatter plots appears to show a broad linear relationship.

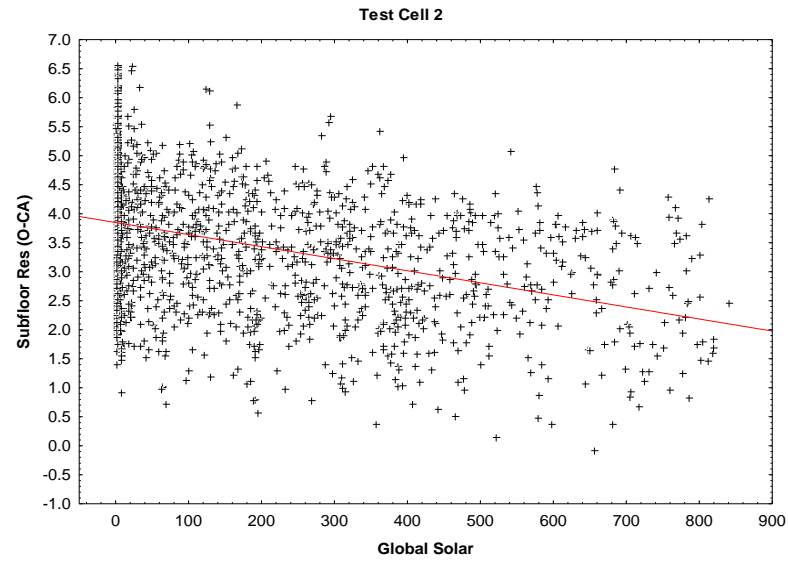

Figure 5.136 - TC2 Subfloor Residual \& Global Solar Radiation Correlation: March to June 2007

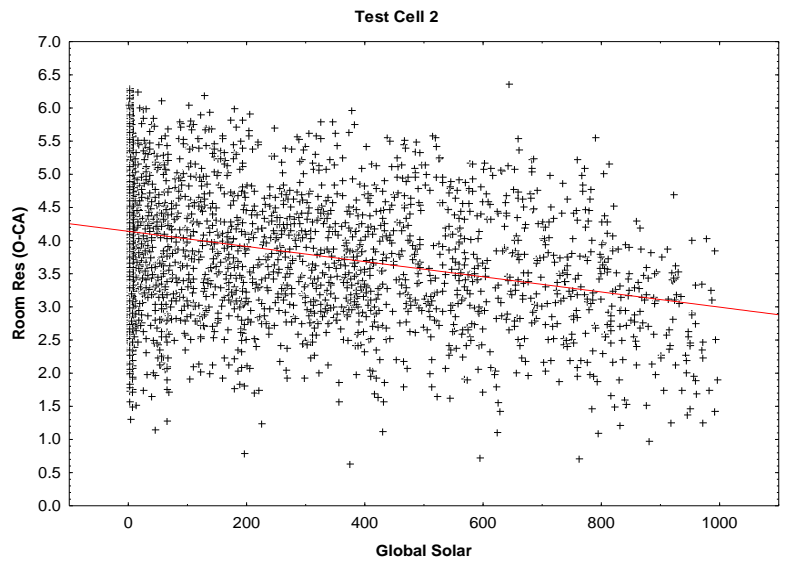

Figure 5.137 - TC2 Room Residual \& Global Solar Radiation Correlation: January to June 2007

The roof space residual and global solar radiation correlation scatter plots for this test cell (Figure 5.138 and Figure 5.139) show a clear negative correlation, similar in nature to the 
scatter plots of the unenclosed-perimeter platform-floored test cell, where the negative residuals occur only when the global solar radiation is greater than $300 \mathrm{~W} / \mathrm{m}^{2}$. Similar to the subfloor, the highest residual values occur when the solar radiation has a value of $0 \mathrm{~W} / \mathrm{m}^{2}$. Aside from this anomaly, the remainder of the scatter plots retain a negative linear relationship.

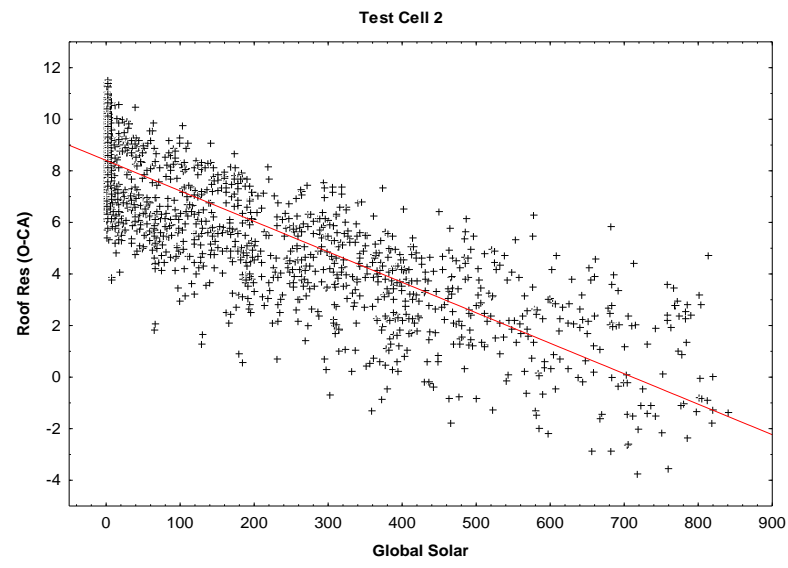

Figure 5.138 - TC2 Roof Space Residual \& Global Solar Radiation Correlation: March to June 2007

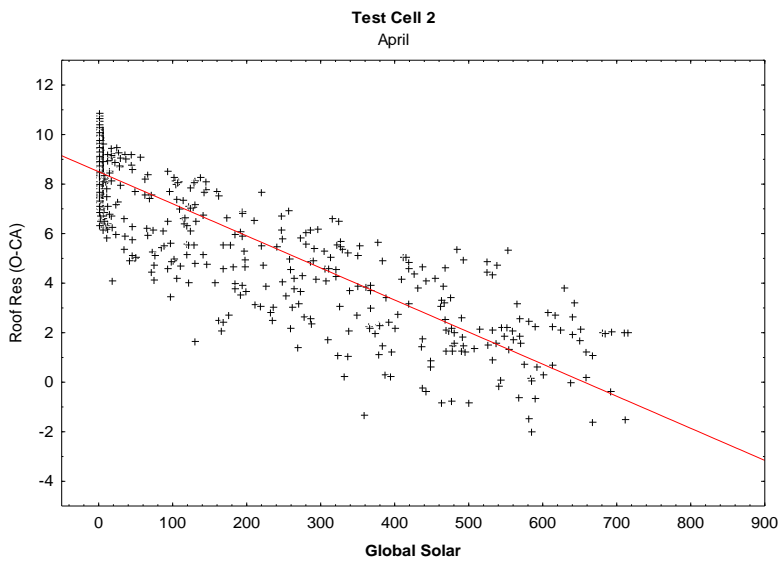

Figure 5.139 - TC2 Roof Space Residual \& Global Solar Radiation Correlation: April 2007

The correlation ratios for this test cell (Table 5.40) are significantly different from the unenclosed-perimeter platform-floored test cell discussed above. The subfloor scatter plot is slightly heteroscedastic in form, due to the anomaly when the solar radiation is $0 \mathrm{w} / \mathrm{m}^{2}$ giving some unreliability to the correlation ratios. However, the scatter plots for the room and roof spaces are more homoscedastic in pattern, making the correlation ratios more useful. The room correlation ratios decline in value from 0.44 to 0.17 from January to June, indicating some form of seasonal variation. The roof space correlation ratios, with the limited data available, have the lowest correlation ratio for the June data subset.

Table 5.40: Test Cell 2 Residual Values and Global Solar Radiation Correlation Ratios

\begin{tabular}{|l|c|c|c|}
\hline & Subfloor & Cell Room & Roof Space \\
\hline Full Data Set & -0.39 & -0.31 & -0.84 \\
\hline January & $\#$ & -0.44 & $\#$ \\
\hline March/April & -0.55 & -0.29 & -0.88 \\
\hline May & -0.33 & -0.25 & -0.77 \\
\hline June & -0.35 & -0.17 & -0.84 \\
\hline \# - No data available
\end{tabular}




\section{Concrete Slab-on-Ground Floored Test Cell}

The test cell room residual and global solar radiation correlation scatter plots for this test cell (Figure 5.140 and Figure 5.141) are significantly different from those of the previous two test cells. There is a general horizontal grouping of data along the trend line, representing the average residual value for this zone, which may be reflecting the effect of the thermal mass and ground keying of the concrete slab-on-ground floor. The scatter plot pattern for the full data set of the test cell room (Figure 5.140) highlights the wide breadth of residual values when the global solar radiation value is $0 \mathrm{~W} / \mathrm{m}^{2}$, which may indicate some unaccounted for thermal mass benefit, or other inputs in the night time model may not be functioning appropriately. When the monthly subset scatter plots for the room of this test cell are analysed, a distinct pattern appears, where:

- The hottest month, February (Figure 5.141), provides the upper residual values in the full data set scatter plot

- The months of January (Appendix 6), March/April (Figure 5.142) and May (Appendix 6) provide the infill residuals in the full data set scatter plot

- The coldest month, June (Figure 5.143) provides the lowest residual values in the full data set scatter plot

This may indicate some form of seasonal variation that requires further investigation.

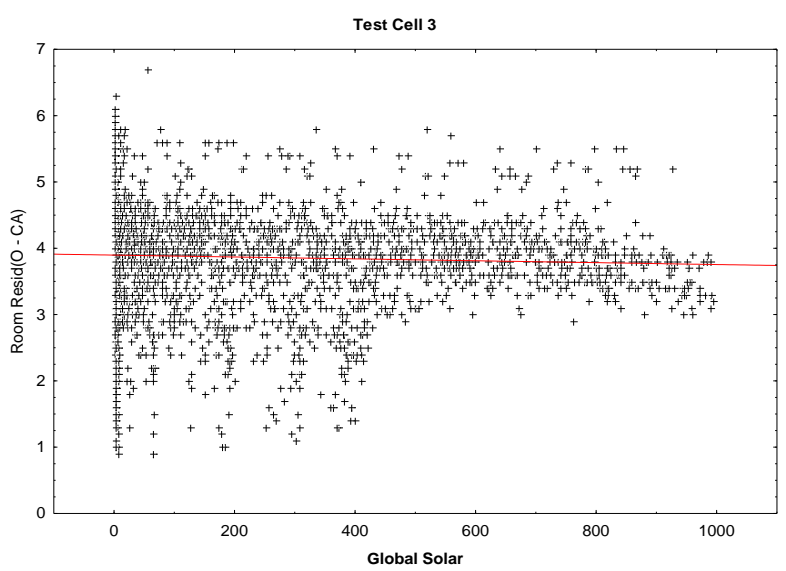

Figure 5.140 - TC3 Room Residual \& Global Solar Radiation Correlation: January to June 2007

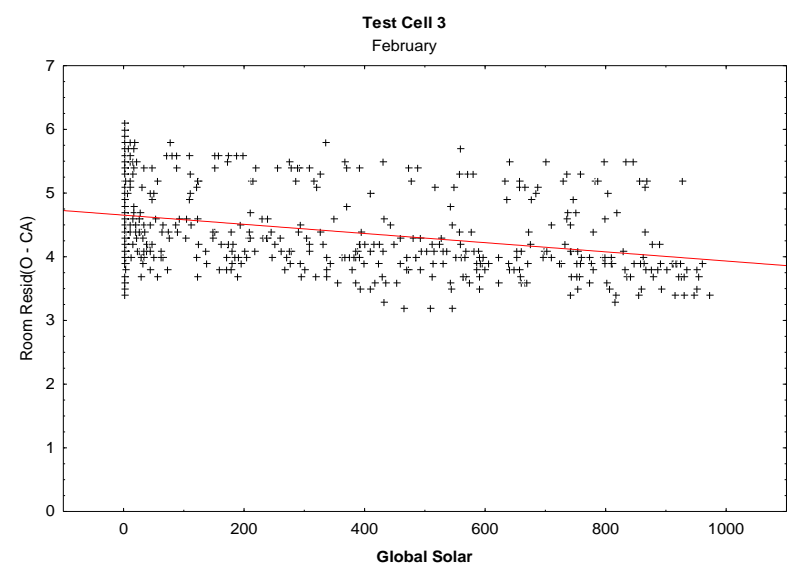

Figure 5.141 - TC3 Room Residual \& Global Solar Radiation Correlation: February 2007 


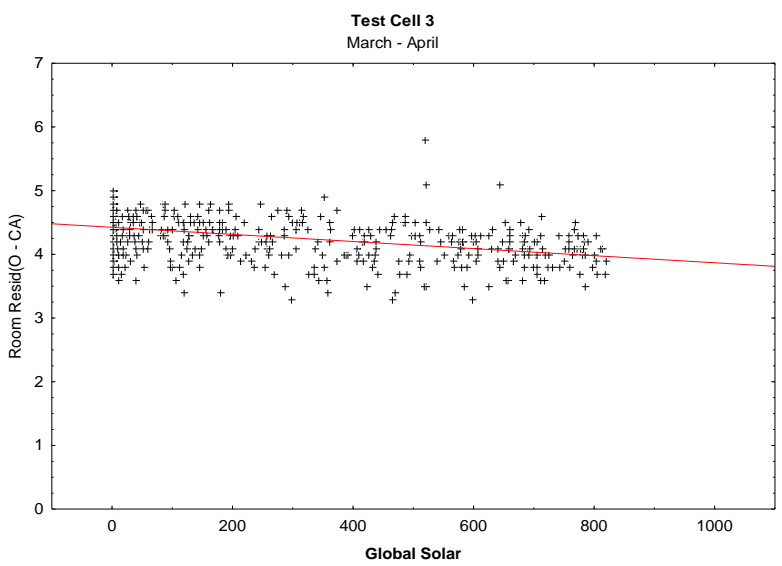

Figure 5.142 - TC3 Room Residual \& Global Solar Radiation Correlation: March/April 2007

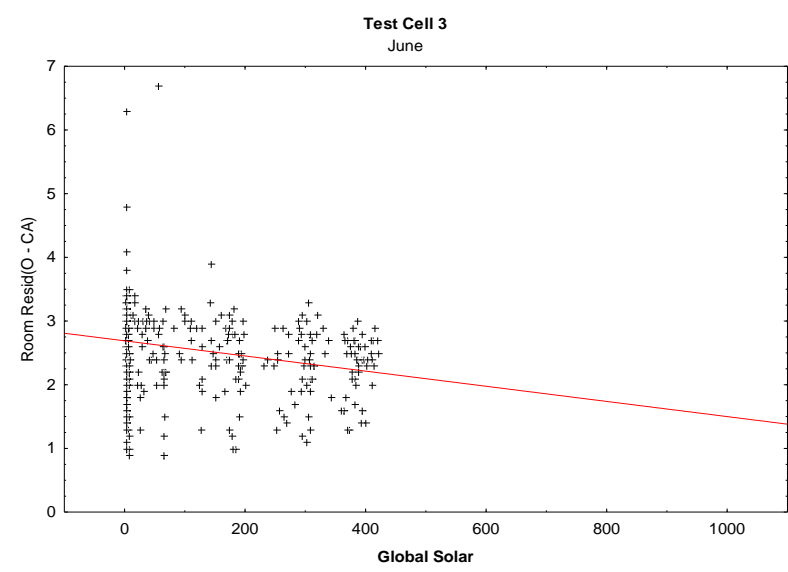

Figure 5.143 - TC3 Room Residual \& Global Solar Radiation Correlation: June 2007

The roof space residual and global solar radiation correlation scatter plots for this test cell (Figure 5.144 and 5.145) are reasonably similar in form and nature to those of the of the previous two test cells, with a negative linear relationship and wide ranging residual values when the solar radiation value was zero. For this test cell, the residuals include negative values for the roof space, which do not occur in the test cell room.

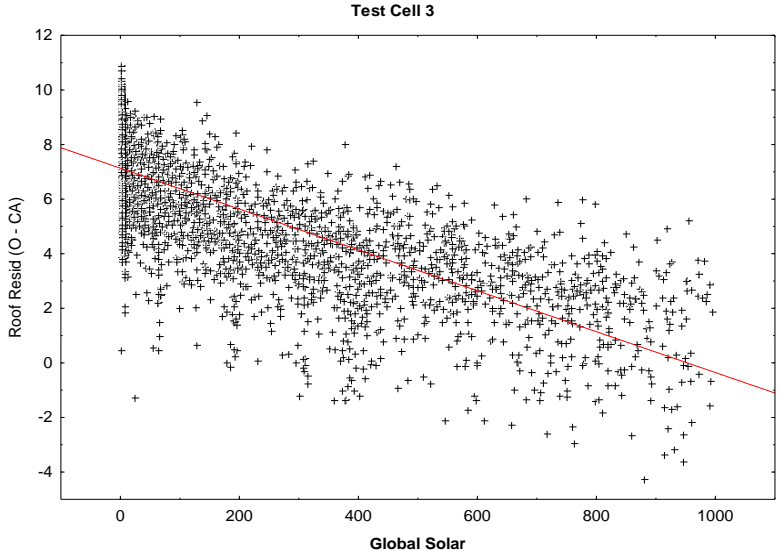

Figure 5.144 - TC3 Roof Space Residual \& Global Solar Radiation Correlation: January to June 2007

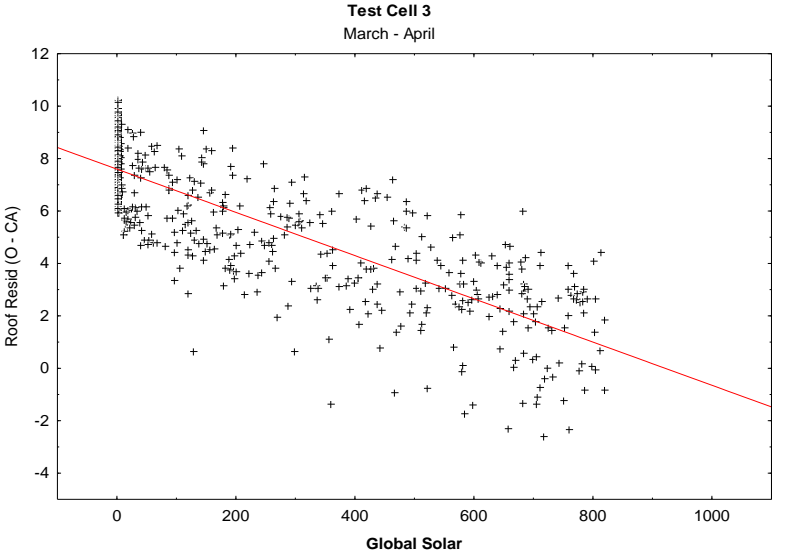

Figure 5.145 - TC3 Roof Space Residual \& Global Solar Radiation Correlation: March/April 2007

The correlation ratios for this test cell (Table 5.41) provide two distinctly different profiles. The correlation ratios for the full data set are not reliable due to the heteroscedastic form of the scatter plots; however, most of the monthly subset scatter plots are more homoscedastic in distribution, making their correlation ratios more reliable. The ratios for the test cell room 
commence with a reasonably high medium value of -0.58 in January and then progress downward continually to -0.20 in June. This could reflect the conflicting forces of the solar radiation, the ground keyed concrete floor or a thermal mass effect. However this requires further investigation. The ratios for the roof space also reflect some form of seasonal or monthly variation but again, this requires further analysis.

Table 5.41: Test Cell 3 Residual Values and Global Solar Radiation Correlation Ratios

\begin{tabular}{|l|c|c|}
\hline & Cell Room & Roof Space \\
\hline Full Data Set & -0.05 & -0.77 \\
\hline January & -0.58 & -0.85 \\
\hline March/April & -0.43 & -0.88 \\
\hline May & -0.24 & -0.67 \\
\hline June & -0.20 & -0.78 \\
\hline
\end{tabular}

\section{Summary}

- There is a negative relationship between the global solar radiation and most zone residuals. This generally shows that the highest residual values occur at the time of lowest global solar radiation and conversely: the lowest residuals occur at the time of highest global solar radiation (with the exception of $0 \mathrm{~W} / \mathrm{m}^{2}$ ). Similar to the discussion on the relationship between outside air temperature and the zone residuals, it would be expected that for the majority of the time when the global solar radiation increases, that the test cell room temperature increases or decreases respectively. The negative correlation indicates that the software is either under-predicting the zone temperature, or over-predicting zone temperature at times of high global solar radiation. Previous research has observed an un-accounted for solar radiation effect, which appears to be occurring in these graphs (Djunaedy, Hensen \& Loomans 2005; Guyon, G, Moinard \& Ramdani 1999a; Guyon, G \& Rahni 1997; Moghtaderi 2005; Pollard, O'Driscoll \& Pinder 2001; Zweifel \& Zelenka 2007).

- There appears to be a boundary condition in some zones for global solar radiation values ranging from $0 \mathrm{~W} / \mathrm{m}^{2}$ to approximately $200 \mathrm{~W} / \mathrm{m}^{2}$, which require further examination. 
- The range of residual values when the global solar radiation value is zero (Table 5.42) is quite large when the monthly correlation diagrams are examined (see Appendix 6). There may be algorithms within the night time model that require further examination.

- The significantly different scatter plots for the room of the concrete slab-on-ground floored test cell, where a monthly stratification of the data is visible, indicate some unaccounted for seasonal effect, which could include the ground model, thermal mass or other climatic influences. This requires further investigation.

- Previous research has queried the measured values for global solar radiation and the mathematical methods used to calculate normal direct and diffuse solar radiation (LomasEppel et al. 1994). In this research, each pyranometer was tested and calibrated, and the latest methodology for calculating diffuse radiation to minimise errors that could occur, was used.

Table 5.42: Variation in Zone Residual Value when Global Solar Radiation Equals Zero

\begin{tabular}{|l|c|c|c|}
\hline Subfloor & $\begin{array}{c}\text { Unenclosed-perimeter } \\
\text { Platform Floored }\end{array}$ & $\begin{array}{c}\text { Enclosed-perimeter } \\
\text { Platform Floored }\end{array}$ & $\begin{array}{c}\text { Concrete Slab on } \\
\text { Ground Floored }\end{array}$ \\
\hline Room & $-1.0^{\circ} \mathrm{C}$ to $4.5^{\circ} \mathrm{C}$ & $1.5^{\circ} \mathrm{C}$ to $6.5^{\circ} \mathrm{C}$ & \\
\hline Roof Space & $0.0^{\circ} \mathrm{C}$ to $7.0^{\circ} \mathrm{C}$ & $1.5^{\circ} \mathrm{C}$ to $6.5^{\circ} \mathrm{C}$ & $1.0^{\circ} \mathrm{C}$ to $6.0^{\circ} \mathrm{C}$ \\
\hline
\end{tabular}

\subsubsection{Correlation of Diffuse Solar Radiation and Test Cell Residuals}

This analysis examined any correlation between the calculated diffuse solar radiation and the residual values from each zone of the test cells. The diffuse solar radiation values were calculated from the observed global solar radiation values. Figures 5.146 to 5.151 are the scatter plot analyses for the unenclosed-perimeter platform-floored test cell; Figures 5.152 to 5.157 are the scatter plot analyses for the enclosed-perimeter platform-floored test cell; and Figures 5.158 to 5.161 are the scatter plot analyses for the concrete slab-on-ground floored test cell. To best illustrate the correlation between data sets, the scales on the $\mathrm{X}$ and $\mathrm{Y}$ axes of the scatter plots vary. 


\section{Unenclosed-perimeter Platform-floored Test Cell}

Similar in nature to the global solar radiation correlation analyses, there appears to be a boundary condition on the maximum residual values in subfloor model (Figure 5.146), which is less defined in the monthly data sets (Figure 5.147 and Appendix 6). The other significant observation is the generally heteroscedastic distribution that shifts between a negative linear relationship and a near vertical relationship at the diffuse radiation value of $100 \mathrm{~W} / \mathrm{m}^{2}$ to $200 \mathrm{~W} / \mathrm{m}^{2}$.

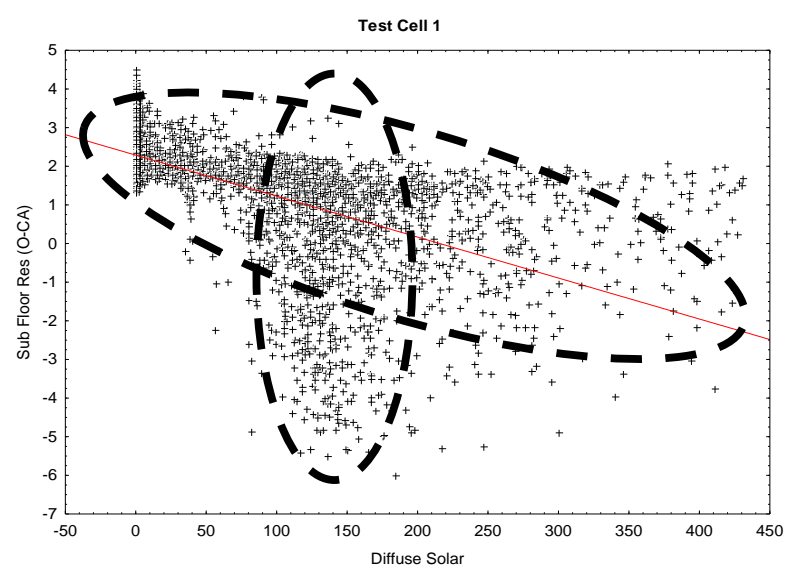

Figure 5.146 - TC1 Subfloor Residual v Diffuse Solar Radiation January to June 2007

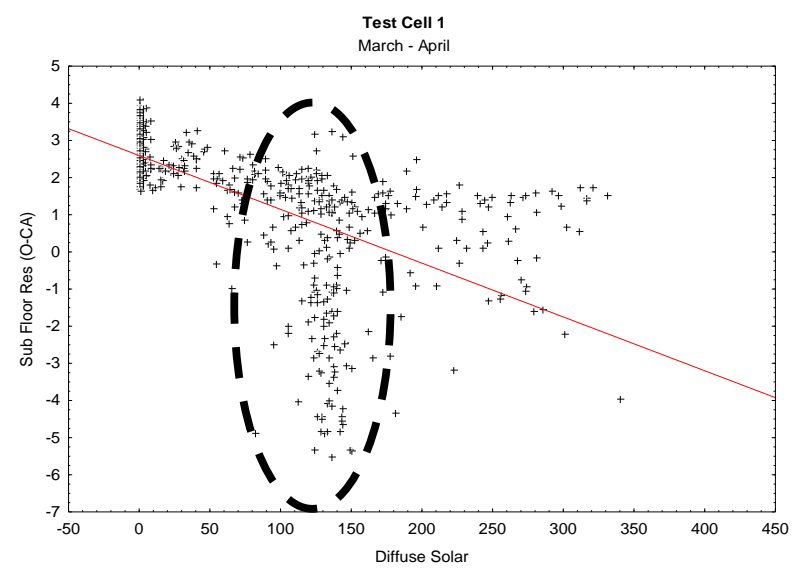

Figure 5.147 - TC1 Subfloor Residual v Diffuse Solar Radiation March/April 2007

The full data set scatter plot for the room of this test cell (Figure 5.148) is considerably different in form to those of the subfloor. The data has a much wider spread across the residual values for all diffuse solar radiation values, revealing larger variances. However, the diagram for March/April data (Figure 5.149) reveals a tempered version of the vertical alignment of data, observed in the subfloor scatter plots, when the diffuse radiation values were between $100 \mathrm{~W} / \mathrm{m}^{2}$ to $200 \mathrm{~W} / \mathrm{m}^{2}$. 


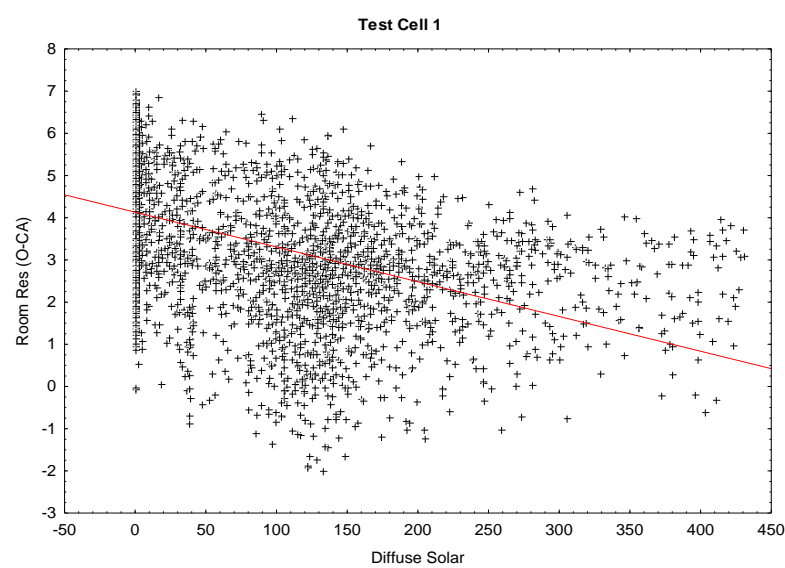

Figure 5.148 - TC1 Room Residual v Diffuse Solar Radiation January to June 2007

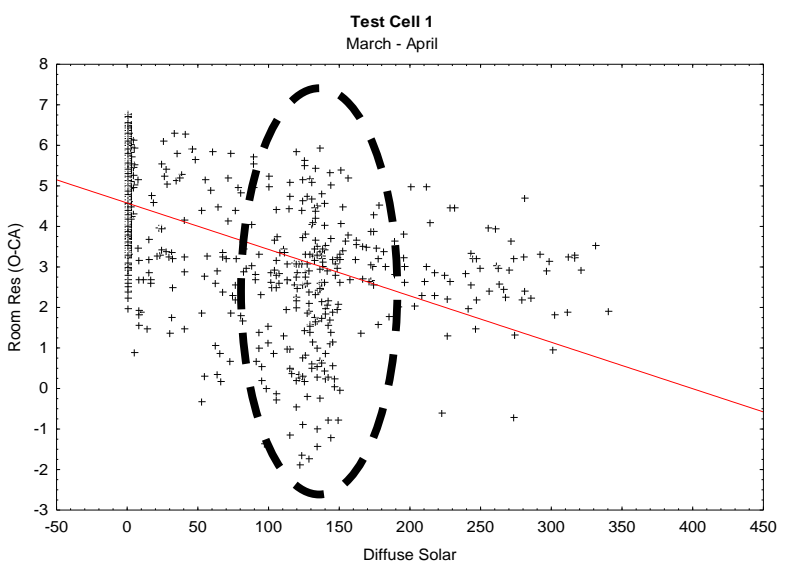

Figure 5.149 - TC1 Room Residual v Diffuse Solar Radiation March/April 2007

The scatter plots for the roof space and diffuse solar radiation of this test cell presented some significant similarities to the subfloor diagrams for this test cell, including: the negative linear trend, the heteroscedastic form and the vertical alignment of data when the diffuse radiation values were between $100 \mathrm{~W} / \mathrm{m}^{2}$ to $200 \mathrm{~W} / \mathrm{m}^{2}$. The other significant observation in the roof space diagrams is the spread of residual values when the diffuse radiation had a value of zero, which is similar in nature to the subfloor and was discussed earlier in the global solar radiation correlation analysis.

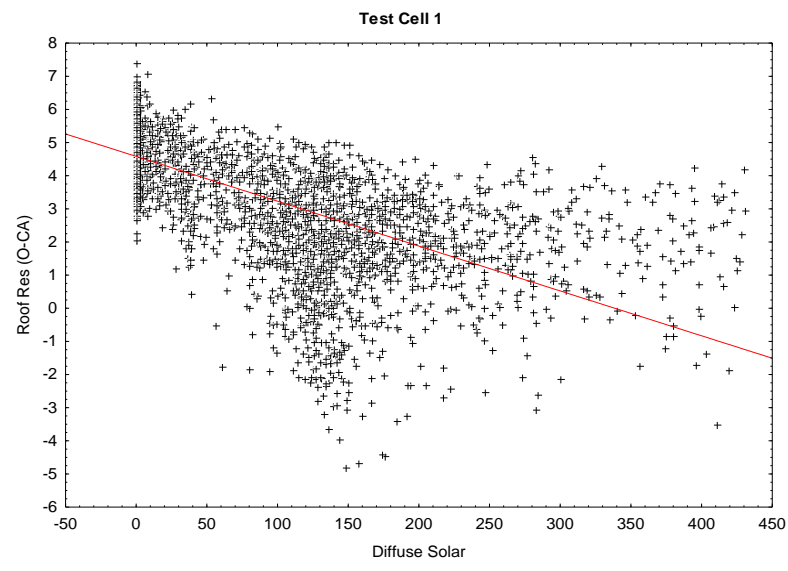

Figure 5.150 - TC1 Roof Space Residual v Diffuse Solar Radiation January to June 2007

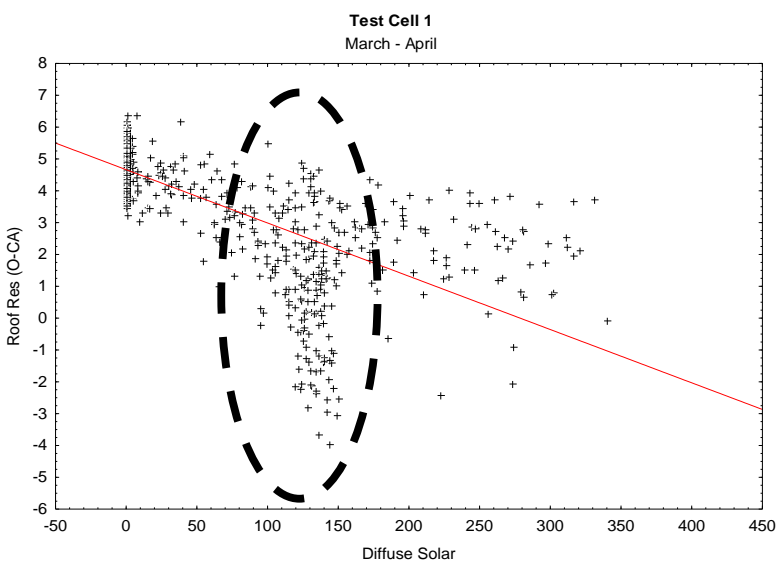

Figure 5.151 - TC1 Roof Space Residual v Diffuse Solar Radiation March/April 2007 
The correlation ratios for this test cell, in Table 5.43, are interesting but unreliable, due to the heteroscedastic distribution of the scatter plots and are included for general information and not detailed analysis.

Table 5.43: Test Cell 1Residual Values and Diffuse Solar Radiation Correlation Ratios

\begin{tabular}{|l|c|c|c|}
\hline & Subfloor & Cell Room & Roof Space \\
\hline Full Data Set & -0.61 & -0.50 & -0.67 \\
\hline January & -0.51 & -0.35 & -0.63 \\
\hline March/April & -0.62 & -0.54 & -0.69 \\
\hline May & -0.57 & -0.40 & -0.67 \\
\hline June & -0.83 & -0.56 & -0.80 \\
\hline
\end{tabular}

\section{Enclosed-perimeter Platform-floored Test Cell}

The correlation scatter plots for the diffuse solar radiation and the subfloor (Figure 5.152) and room (Figure 5.153) of this test cell are significantly different from those of the previous test cell. However, there are two significant observations: the wide range of positive and negative residual values when the solar radiation value is zero and the vertical alignment of data along the lower residual values when the radiation levels were $100 \mathrm{~W} / \mathrm{m}^{2}$ to $200 \mathrm{~W} / \mathrm{m}^{2}$. This is clearly visible in Figure 5.154 but also observable in Figures 5.152 to 5.157 and is similar in nature to this phenomenon identified in the diagrams from the previous test cell.

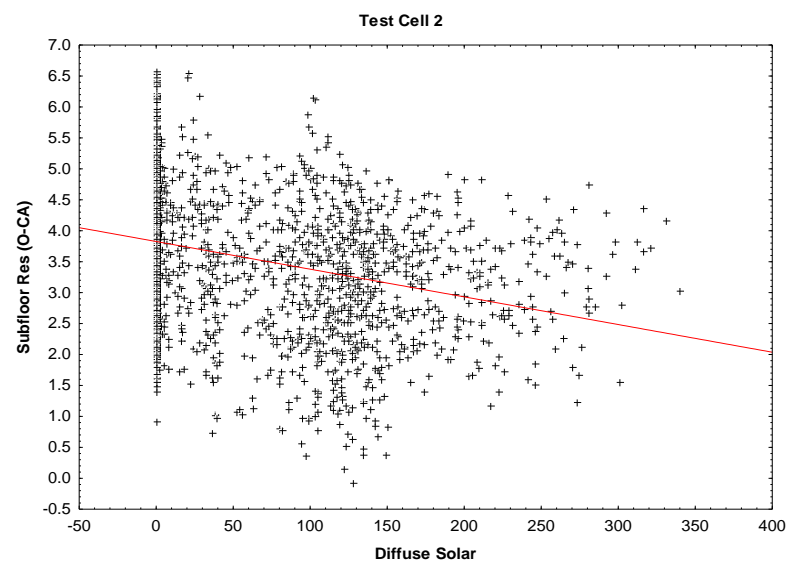

Figure 5.152 - TC2 Subfloor Residual v Diffuse Solar Radiation March to June 2007

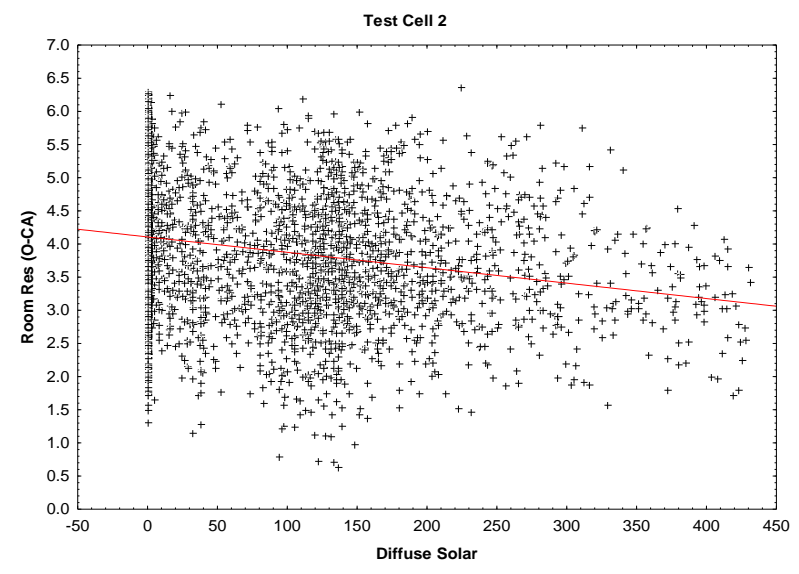

Figure 5.153 - TC2 Room Residual v Diffuse Solar Radiation January to June 2007 


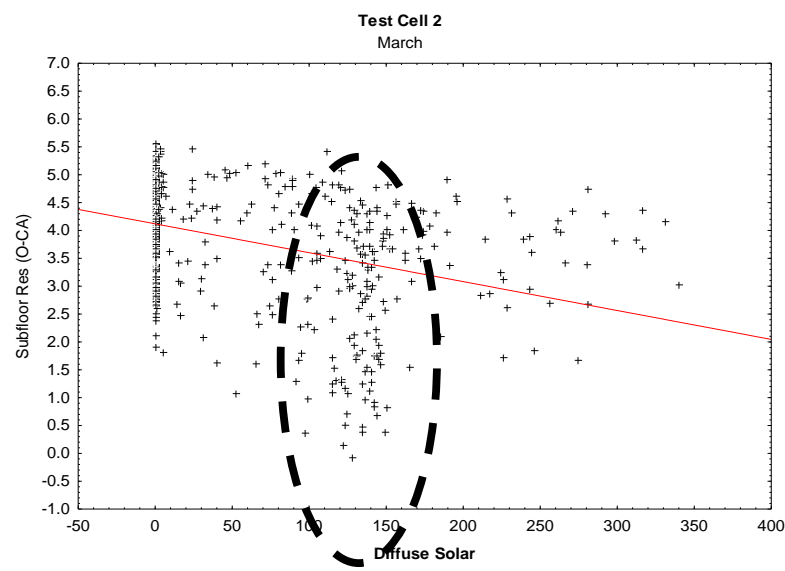

Figure 5.154 - TC2 Subfloor Residual v Diffuse Solar Radiation March 2007

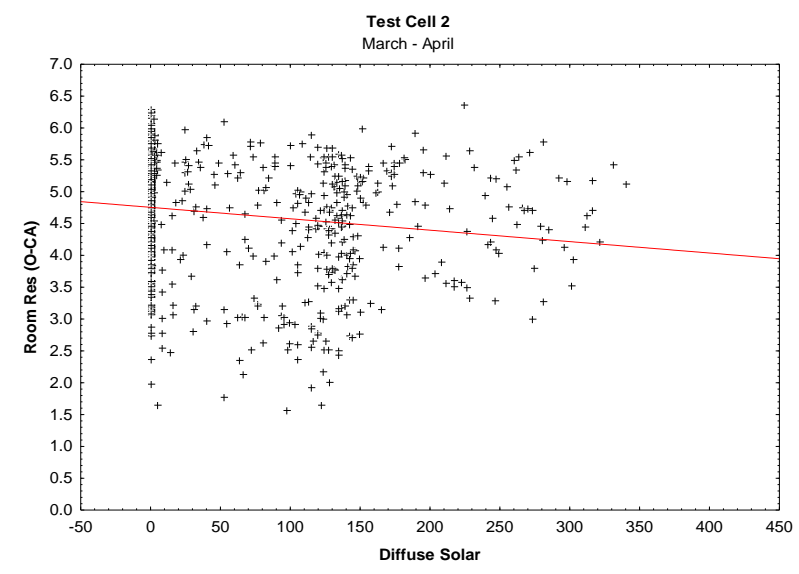

Figure 5.155 - TC2 Room Residual v Diffuse Solar Radiation March/April 2007

The scatter plots for the roof space residual and diffuse solar radiation for this test cell (Figure 5.156 and Figure 5.157) show a negative correlation, though it is heteroscedastic and includes the vertical alignment of data between $100 \mathrm{~W} / \mathrm{m}^{2}$ and $200 \mathrm{~W} / \mathrm{m}^{2}$, similar in nature to that of the roof space in the previous test cell. Similarly, there is a wide range of residual values when the diffuse radiation value was zero.

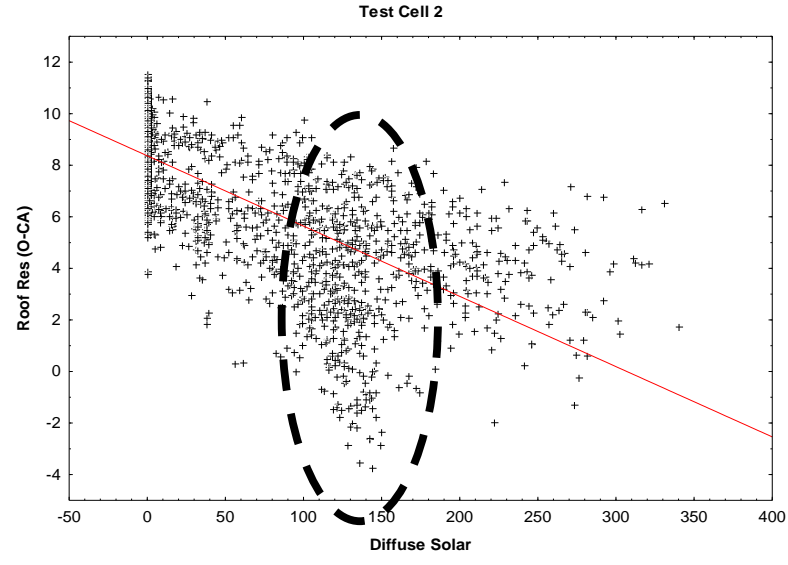

Figure 5.156 - TC2 Roof Space Residual v Diffuse Solar Radiation March to June 2007

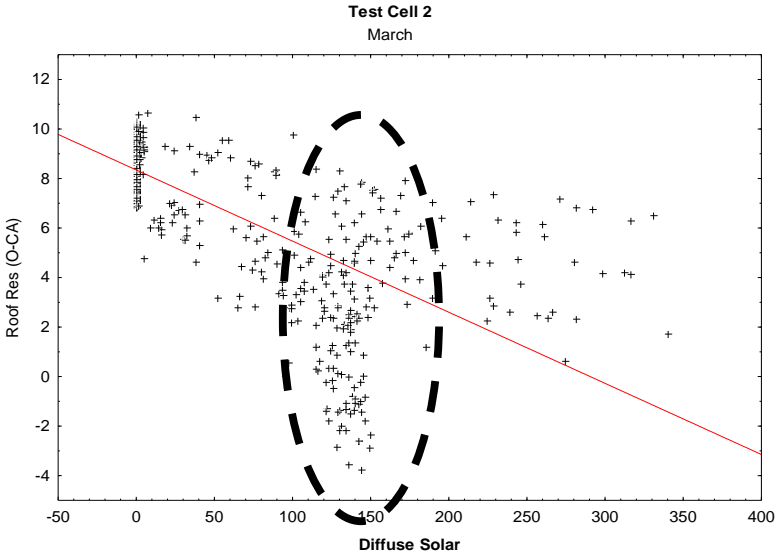

Figure 5.157 - TC2 Roof Space Residual v Diffuse Solar Radiation March 2007

The correlation ratios for this test cell, in Table 5.44, are interesting but unreliable, due to the heteroscedastic pattern of the scatter plots and are included for general information and not detailed analysis. 
Table 5.44: Test Cell 2 Residual Values and Diffuse Solar Radiation Correlation Ratios

\begin{tabular}{|l|c|c|c|}
\hline & Subfloor & Cell Room & Roof Space \\
\hline Full Data Set & -0.31 & -0.24 & -0.72 \\
\hline January & $\#$ & -0.25 & $\#$ \\
\hline March/April & -0.38 & -0.16 & -0.69 \\
\hline May & -0.24 & -0.17 & -0.68 \\
\hline June & -0.32 & -0.15 & -0.75 \\
\hline \# - No data available
\end{tabular}

\section{Concrete Slab-on-Ground Floored Test Cell}

For this test cell, the correlation scatter plot of the full data set for the test cell room (Figure 5.158) illustrates a stronger convergence of data along the almost horizontal trend line, that is, no distinct relationship. However, in the full data set there is a subtle vertical grouping of data between $100 \mathrm{~W} / \mathrm{m}^{2}$ and $200 \mathrm{~W} / \mathrm{m}^{2}$ and a very wide spread of positive and negative residual values when the radiation level is zero, which is not visible in the March/April data set (Figure 5.159). Similar to the scatter plots for the global solar radiation correlations for this test cell, there is stratification within the full data set which is made up of monthly subsets.

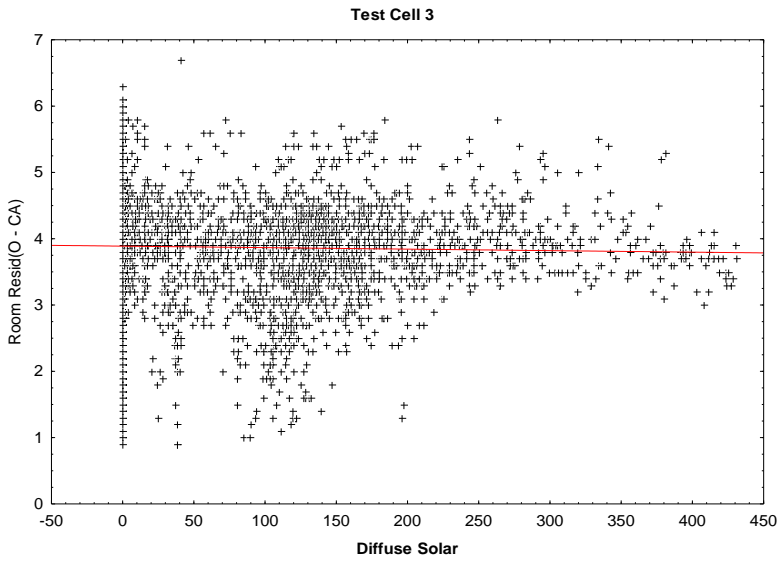

Figure 5.158 - TC3 Room Residual v Diffuse Solar Radiation January to June 2007

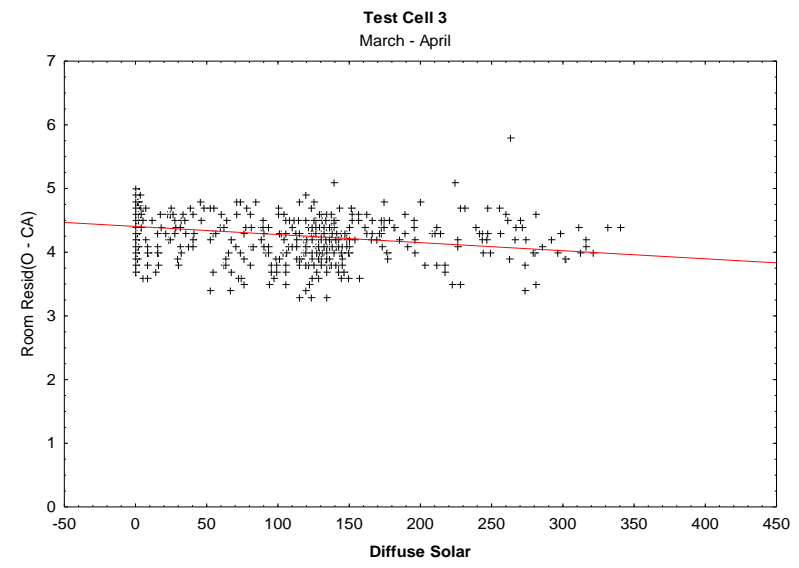

Figure 5.159 - TC3 Room Residual v Diffuse Solar Radiation March/April 2007

The correlation scatter plots for the roof space of this test cell (Figure 5.160 and Figure 5.161) document a negative correlation with a heteroscedastic form, a wide range of residual values when the diffuse radiation value is zero and a vertical alignment of data, between $100 \mathrm{~W} / \mathrm{m}^{2}$ and $200 \mathrm{~W} / \mathrm{m}^{2}$, similar in nature to that of the roof space in the previous two test cells. 


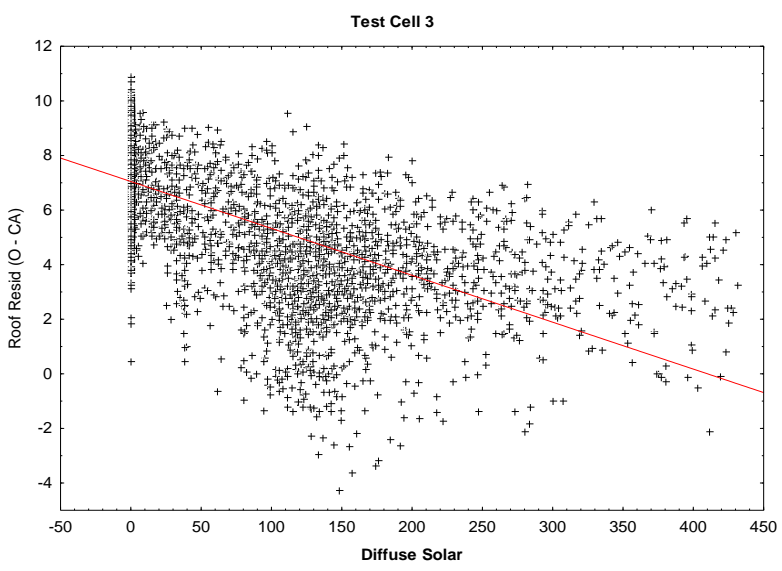

Figure 5.160 - TC3 Roof Space Residual v Diffuse Solar Radiation January to June 2007

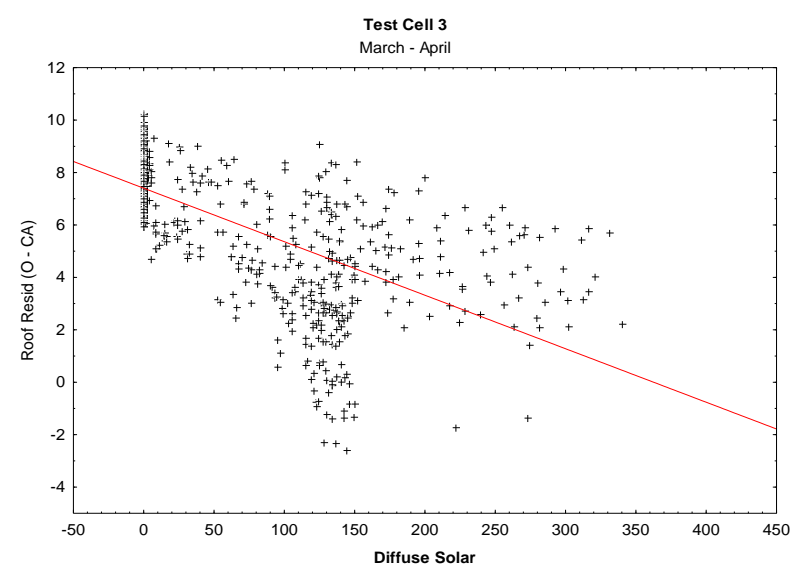

Figure 5.161 - TC3 Roof Space Residual v Diffuse Solar Radiation March/April 2007

Similar to the two previous test cells, the correlation ratios for this test cell, (see Table 5.45), are interesting but unreliable, due to the heteroscedastic pattern of the scatter plots and are included for general information and not detailed analysis.

Table 5.45: Test Cell 3 Residual Values and Diffuse Solar Radiation Correlation Ratios

\begin{tabular}{|l|c|c|}
\hline & Cell Room & Roof Space \\
\hline Full Data Set & -0.03 & -0.66 \\
\hline January & -0.44 & -0.66 \\
\hline March/April & -0.31 & -0.66 \\
\hline May & -0.17 & -0.62 \\
\hline June & -0.18 & -0.70 \\
\hline
\end{tabular}

\section{Summary}

- Similar in some aspects to the analyses involving the global solar radiation, there was a negative linear relationship between the residual values for each zone and the value for diffuse solar radiation, however, their distribution was heteroscedastic.

- With the exception of $0.0 \mathrm{~W} / \mathrm{m}^{2}$, higher positive residual values occurred when the global solar radiation values are low.

- With the exception of $0.0 \mathrm{~W} / \mathrm{m}^{2}$, lower positive and negative residual values occur when the global solar radiation values are high, indicating that the software is under- 
predicting the zone temperatures at specific values of diffuse solar radiation measurements, in this case between $100 \mathrm{~W} / \mathrm{m}^{2}$ and $200 \mathrm{~W} / \mathrm{m}^{2}$.

- The other significant observation in these analyses was the heteroscedastic distribution and the vertical grouping of data for times when the diffuse solar radiation value was between $100 \mathrm{~W} / \mathrm{m}^{2}$ and $200 \mathrm{~W} / \mathrm{m}^{2}$. This phenomenon requires further investigation. 


\subsection{Summary for Results, Analysis and Discussion}

Many important and relevant elements have been identified during this empirical validation research which has been discussed in this chapter. A summary of key findings are as follows:

\section{Climate Data Analysis (Section 5.2).}

- There were significant differences between the individual climate values of the TMY data and site-measured climate, for air temperature, wind speed, global solar radiation and diffuse solar radiation.

- The smooth curved form of the graphed TMY global and diffuse solar radiation values bear little resemblance to the measured global solar radiation and calculated diffuse solar radiation values, (as shown in 5.2.2 and 5.2.3). .

- The measured climate has distinct saw-tooth peaks and troughs but there appears to be a general flattening of the minimum and maximum temperature values within the TMY climate file, (as shown in 5.2.1). This could create a thermally beneficial situation for house energy star ratings, where the minimum cold temperatures of winter and the maximum warm temperatures of summer are disregarded in a standard simulation.

\section{Detailed Envelope Simulation (Section 5.3)}

- Measured climate data input had the greatest impact on the simulated temperatures in all zones.

- The inclusion of the as-built fabric details had a varying impact on the detailed house energy rating simulations, in part dependent on building fabric and zone type.

- The impact of the as-built fabric details particularly affected the maximum and minimum simulated temperature values.

- The current method of roof modelling in the AccuRate software does not include the input of eaves or roof shading and this is suggested as a detail which might reduce the residual temperature in the test cell rooms, (as discussed in 5.3.3). 


\section{Empirical Validation Graphs (Section 5.4)}

- The empirical validation graphs show that the AccuRate software substantially accounted for fabric and environmental inputs, as shown by the similarity in wave pattern between simulated and measured temperature data.

- The empirical validation graphs illustrate that the simulated temperatures for each zone were consistently different from the measured temperatures.

- The empirical validation graphs show that the AccuRate software under-predicted and over-predicted the maximum temperature and predominantly under-predicted the minimum temperature for the subfloor zone of the unenclosed-perimeter platformfloored test cell, (as shown in 5.4.1).

- The empirical validation graphs show that the AccuRate software consistently underpredicted the temperatures for the subfloor zone of the enclosed-perimeter platformfloored test cell, (as shown in 5.4.2).

- The empirical validation graphs show that the AccuRate software consistently underpredicted temperatures for the test cell room of the unenclosed platform, enclosed platform and the concrete slab-on-ground floored test cells, (as shown in 5.4.1 to 5.4.3).

- The empirical validation graphs show that the AccuRate software consistently underpredicted the minimum temperatures for the test cell roof space of the unenclosed platform, enclosed platform and the concrete slab-on-ground floored test cells, (as shown in 5.4.1 to 5.4.3).

\section{Statistical Analysis (Section 5.5)}

- The scatter plots show that the simulated and measured data for each zone of the test cells demonstrated very strong linear relationships and high correlation ratios, confirming the software's capacity to model the multi-variant inputs, (as shown in 5.5.1). 
- The residual histograms show mostly normal and some skewed distribution for each zone of the three test cells. These results would impact greatly on energy calculations and subsequent house energy star ratings, (as shown in 5.5.2).

- The residual time series analysis illustrates a daily pattern of shifting between minimum and maximum values, (as shown in 5.5.3).

- The residual time series analysis show a constant thermal gain during the hottest week of February within the concrete slab-on-ground floored test cell.

- The residual time series analysis show periods in May where a factor or factors significantly affected the residual values for all zones of the three test cells.

- All the scatter plots of the residual values for the adjoining zones of the test cell subfloor and test cell room had a positive linear relationship with strong correlation ratios, indicating a relationship exists between the simulation errors in these two zones, (as shown in 5.5.4).

- All the scatter plots of the residual values for the adjoining zones of the test cell room and the test cell roof space had a positive linear relationship with correlation ratios varying monthly: from medium to very strong in value, indicating a relationship exists between the simulation errors of these two zones.

- All the scatter plots of the zone residual values and the site air temperature had a negative linear relationship with correlation ratios that varied each month and between zones, indicating a relationship between these values, (as shown in 5.5.5).

- All the scatter plots which analysed the zone residual values and the site air temperature show the occurrence of high positive residual values occurring at low outside air temperature and low residual values occurring at high outside temperature for the roof space and subfloor zones of all three test cells. This occurrence is also apparent in the room of the unenclosed platform-floored test cell.

- All the scatter plots of the zone residual values and the site wind speed were heteroscedastic and had a horizontal arrowhead shape, where there were a wide range of positive and negative residual values at times when the wind speed was low; in 
addition the data concentrated along the negative linear trend line as the wind speed increased, (as shown in 5.5.6).

- The shape of scatter plots of the zone residual values and the site wind direction varied between months and zones, where several had a downward arrowhead shape, documenting a relationship between negative residual values and wind from the southerly direction, (as shown in 5.5.7).

- All the scatter plots of the zone residual values and global solar radiation documented varying levels of negative correlation. The shape varied for each zone, with many of the roof space scatter plots exhibiting a heteroscedastic distribution, (as shown in 5.5.8).

- Many of the scatter plots of the zone residual values and diffuse solar radiation show a negative relationship, with varying values for the correlation ratio and are heteroscedastic in distribution as the radiation value increased, (as shown in 5.5.9). Another significant observation of many of these analyses was a vertical cluster of data, when the value for diffuse solar radiation was between $100 \mathrm{~W} / \mathrm{m}^{2}$ and $200 \mathrm{~W} / \mathrm{m}^{2}$. Both of these phenomena require further investigation.

- The scatter plot analyses of the zone residual values and global /diffuse solar radiation presented a broad range of data range of residual values, when the radiation values were zero.

\section{Linking of Specific Analyses}

- Previous research has documented differences between the conductivity values of the individual materials used to construct a building, their gross conductivity value as a assemblage and the value given to them by the HER software (Ahmad, Q \& Szokolay 1993; Guyon, G, Moinard \& Ramdani 1999a; LomasEppel et al. 1994; Moinard \& Guyon 1999). This effect is expected to be minor but could be a factor within this research and requires further investigation.

- Similarly, previous research has questioned assumptions with respect to internal surface heat transfer (Barnaby, Spitler \& Xiao 2005; Beausoleil-Morrison \& Strachan 
1999; Davies et al. 2005; LomasEppel et al. 1994; Neymark et al. 2005; Strachan et al. 2006; Wong 1990). In Section 4.3.9 it was noted that for the test cells there was a surface film conductance of $338 \mathrm{~W} / \mathrm{K}$. If the assumed values are incorrect this would impact on the differences between measured and simulated temperatures.

- The statistical analysis show that the subfloor model of the unenclosed-perimeter platform-floored test cell requires further examination of the relationship between subfloor and room residual values.

- The statistical analysis shows that the subfloor model of the enclosed-perimeter platform-floored test cell requires further examination of the relationship between subfloor and room residual values.

- As the results show that the room of the concrete slab-on-ground floored test cell had similar residual values to those of the enclosed-perimeter platform-floored test cell, the errors observed in the subfloors and test cell rooms may be due to errors in the subfloor model or the ground model.

- Internationally (Adjali et al. 2000; Akinyemi \& Mendes 2008; Crowley 2009; dos Santos \& Mendes 2003; Krarti \& Ihm 2009; Neymark et al. 2009; Rantala 2005; Rock \& Ochs 2001; Shadd 2009; Trethowen, H \& Delsante 2000; Winkelmann 1998; Zoras \& Kosmopoulos 2009) and in Australia (Chen, White \& Wonhas 2010; Delsante 1988, 1989, 1993; Landman \& Delsante 1987; Williamson, T \& Delsante 2006) there has been concern raised about and a continual improvement of subfloor and ground models within detailed simulation programs. The limited development support and the simplifications applied within the AccuRate software, and the results discussed above, indicate that the subfloor and ground model aspects require further investigation.

- An aspect that has not been discussed is thermal mass. The current AccuRate roof model does not consider any thermal mass effect from the roofing structure. Some of the graphs for the simulated roof space temperature could become more similar to the measured temperatures if a thermal mass effect was considered. Similarly there is no consideration of the thermal contribution of structural elements for the test cell room and subfloor. The subfloor structure of the platform-floored test cells may be storing 
more energy than currently considered. This has not been explored in this research but should be investigated further (Barnaby, Spitler \& Xiao 2005).

- The irregular distribution that appears to exist in the residual values from day time or night time operation, which is reflected in the analyses for solar radiation, indicates that there may be a night time modelling error. This notion is supported by the daily shifts between positive and negative residual values that were observed in the residual time series plots. For further analysis, the day and night time data should be separately analysed, so that the night sky losses, fabric heat flows and the climatic inputs can be better analysed. 


\section{Conclusion}

The aim of this research was to validate empirically the AccuRate house energy rating software for lightweight buildings in a cool temperate climate. This has involved the establishment of several key components and methods, namely:

- The construction of three thermal performance test buildings in Launceston, which has been identified as a cool temperate climate. The building types were an unenclosedperimeter platform-floored test cell, an enclosed-perimeter platform-floored test cell and a concrete slab-on-ground floored test cell, built to Australian standards and regulations.

- The installation of equipment to measure the internal and site environmental conditions, which included the installation of data acquisition and storage systems

- The use of the AccuRate HER software to complete detailed building envelope simulations for each of the three test buildings

- The collation and cleaning of a measured and simulated data sets

- The graphical and statistical analysis of the measured and simulated data sets

This research established four key hypotheses to address the concerns of government and industry as discussed in Section 2.5. The findings for each of these are detailed below.

The first hypothesis was that the predicted temperature produced by a detailed thermal simulation, using the AccuRate software, is not identical to the observed temperature within a lightweight detached building located in a cool temperate climate. This research documented that the measured zone temperatures differed significantly from the simulated zone temperatures. The analysis of the differences between the measured and simulated temperatures for the test cell rooms were $3^{0} \mathrm{C}$ or more for $2900(72 \%)$ hours (unenclosedperimeter platform floored test cell), 1650 (40\%) hours (enclosed-perimeter platform-floored test cell) and 3500 (85\%) hours (concrete slab-on-ground floored test cell). This observed difference would have a significant effect on energy calculations, if the buildings were simulated for house energy star rating purposes. The analysis of differences between the measured and simulated temperatures for the subfloor and roof spaces, of each test cell, also 
documented significant differences, which would impact on the thermal performance of the test cell rooms. This would indicate that improvements or calibration is required for the roof space, subfloor and ground models prior to any further development of the test cell room model.

The second hypothesis was that the external environmental inputs representing the climate are not appropriately accounted for by the AccuRate software. The variety and types of correlations shown in the graphical and statistical analysis indicates that the AccuRate software may not be accounting for climatic inputs appropriately, which would be contributing to the discrepancies between the measured and simulated zone temperatures for each zone, namely:

- This research documented significant differences between the site-measured and TMY climate inputs. The analysis showed that there appears to be a flattening of the TMY temperature data, which is reducing the maximum (up to $13.7^{\circ} \mathrm{C}$ ) and increasing the minimum (up to $6.9^{\circ} \mathrm{C}$ ) temperatures for each day, and has established mathematically smooth profiles for solar radiation, which often bears little resemblance to measured values. For many Australian climates there is a limited need for heating or cooling during the average temperature of each day. However, during the times of maximum or minimum temperatures, heating or cooling is required and differences in outside air temperature of this magnitude would significantly affect the envelope simulation and subsequent energy requirements to heat or cool a building.

- The graphical analysis of the measured and simulated temperatures for each zone of the three test cells often documented a similarity in profile giving assurance that the software was considering the climatic inputs. However, the graphical analysis also documented varying and significant differences between the simulated and measured temperatures for each zone of the three test cells.

- Statistical analysis of relationships between zone residual values and site measured air temperature, wind speed, wind direction, global solar radiation and calculated diffuse solar radiation established significant differences in the type and form correlation. The linearity of the relationships was often negative indicating that the software may be under-valuing some inputs. Many factors require further investigation, including 
seasonal variations but the greatest variability appears to occur at times of low wind speed and zero solar radiation.

The third hypothesis was that the effect of infiltration through the built fabric and its relationship to the external climate are not appropriately accounted for by the AccuRate software. The detailed envelope simulation included the input of measured infiltration rates for the enclosed subfloor, rooms and roof spaces of the three test cells. The statistical analysis documented significant range $\left(8^{0} \mathrm{C}\right)$ in the variability in the residual values at times of low wind speed, which became more correlated at times of higher wind speed. This indicates that the infiltration model requires further calibration generally but especially for times of low wind speed.

The fourth hypothesis was that the elements of the built fabric of contemporary lightweight detached housing area not accounted for by the AccuRate software. Some aspects including thermal mass and the conductivity values for individual elements and assemblages have been found as areas requiring calibration in other softwares and still require further investigation. However, this research identified software input requirements that were lacking, namely:

- The AccuRate software did not include default or other values for the framing factor. The framing factor was manually calculated for the platform floors, external walls and ceilings of each test cell. The inclusion of the framing factor for the external walls reduced the average thermal resistance value by up to $25 \%$. The analysis of default inputs versus as-built inputs showed the significant effect of the reduced levels of insulation on daily minimum and maximum temperatures. For this research the affect was limited due to the free-running nature of the test cells but if the test cells were heated, these differences would significantly affect the resultant thermal performance.

- At the time of this research the method of inputting data for the roof space in Accurate did not include a provision for eaves. The roof space only considered a floor to the room below and a roof material. Many houses have eaves ranging from $200 \mathrm{~mm}$ to $900 \mathrm{~mm}$, which dependent on house size can provide a large amount of the roof space with a low thermal resistance value to the outside air temperature. The effect of this was not quantified in this research and requires further investigation. 
- At the time of this research the data entry for shading elements in AccuRate was applied to the external walls but not the roof. Any element that provides shade would significantly affect the incidence of solar radiation on the roof and the subsequent simulated temperature of the roof space. As this research identified a correlation between the residual value of the roof space and test cell room, any reduced heat in the roof space would lessen day time heat flows to the test cell room.

This research has identified the urgent need to re-examine the TMY methodology, the ground model, subfloor model and roof models of the AccuRate software. Concern of the capacity of each of these aspects was established through the graphical and statistical analysis of the measured and simulated temperatures. Once the associated algorithms have been improved, the simulations should be undertaken a second time to establish if the zone temperatures have become closer to or further from the observed temperatures. Only then should further calibration of the room model commence.

When these findings are compared to other international examples, the need for a continuous and ongoing improvement and empirical validation process is required for quality assurance purposes for AccuRate and other Australian envelope and energy simulation softwares (Kummert, Bradley \& McDowell 2004; Strachan, Kokogiannakis \& MacDonald 2005).

The research has identified significant differences in simulated temperatures resulting from default climate file, building fabric input and algorithm simplifications. These would significantly affect the simulation of zone temperatures and therefore the calculated heating and/or cooling energy requirements. Consequently, the tool's ability to predict energy use may be compromised and its capacity to rank the intricacies of built fabric assemblies. These problems are common to all building simulation programs and only through ongoing research and international collaboration can the performance of software tools be improved and that improvement verified in a scientifically consistent manner.

\section{Areas for Future Research}

This research established significant differences between simulated and measured temperatures from the three purpose built test cells in Launceston. The research has shown the need for further investigation in several areas, namely: 
1. A detailed analysis of ground temperatures under buildings (unenclosed-perimeter, enclosed-perimeter and concrete slab-on-ground) compared to the assumed ground temperatures within the AccuRate software

2. The further development of the subfloor model to reduce the variation between simulated and measured temperatures identified in this research

3. The further development of the roof model, together with the inclusion of roof shading and eaves, to reduce the variation between simulated and measured temperatures identified in this research

4. The need to examine the algorithms within the AccuRate software that use the wind speed values to reduce the level of error that occurs at times of low wind speed.

5. The method for establishing infiltration values from tracer gas tests should also be investigated, in case the cause of the relationship between residual values and wind speed lies within this process.

6. The choice of terrain category within the AccuRate software and its effect on the building relative to wind direction and wind speed should be examined further.

7. Previous research has documented differences between the assumed conductivity and internal surface film conductance values when compared to those in test buildings. If the assumed values within the AccuRate software are incorrect, this would impact on the amount of difference between the measured and simulated temperatures. This infers the need to examine the radiant heat flow through and thermal capacitance of contemporary building materials to ensure that the current models within the software are appropriate.

8. This research identified varying relationships between zone residual values and global solar radiation and diffuse solar radiation, all of which require further investigation.

9. The analysis documented periods when the simulated and measured temperatures were very similar. This needs to be investigated further, as it might provide indicators to algorithms which require calibration. 
10. This research analysed data from only 14 of the 207 sensors installed within the test cells. There is a large amount of empirical data which could be used to further inform the thermal properties of buildings and to assist with the questions raised in this research.

11. The initial research plan included empirically testing the thermal performance of the test cells under varying heating profiles. This was to explore the relationships between the three building types, their varying thermal mass and its impact on the energy required to maintain room temperatures in accordance with NatHERS prescribed values. This research requires action, as it is the second logical step in the process and allows for the empirical validation of heating and energy calculation algorithms within the AccuRate software.

12. The test buildings were constructed such that various insulation, wall fabric, glazing and thermal mass elements could be added and removed to provide empirical data. To act as a quality assurance tool, an ongoing research program is required to empirically validate and calibrate envelope and building energy simulation programs for existing and future building materials and HVAC equipment. This would enable the comparison of different construction and glazing systems and their relative impact in thermal performance.

13. Further research should be conducted on whole houses to examine relationships between multiple rooms and the external climate, as the level of complexity is much greater than that analysed in these single room test cells.

14. This research identified a variety of approaches to validation within Australia. An empirical validation guide is required, such that funding bodies can make informed decisions on current and future projects, such that a suitable data set of measured buildings can be developed.

15. Due to research program limitations, analysis using the Williamson (1995) confirmation technique was not undertaken. The data from this research could be of benefit to test Williamson's method and to further test the capability of the AccuRate software. 
Based on current Australian residential thermal performance requirements the fifteen items above have been prioritised, as shown in Figure 6.1. However, if this same method was used for residential buildings constructed prior to 2000 the certainty of effect and perceived importance values would change due to the significantly different envelope thermal performance requirements.

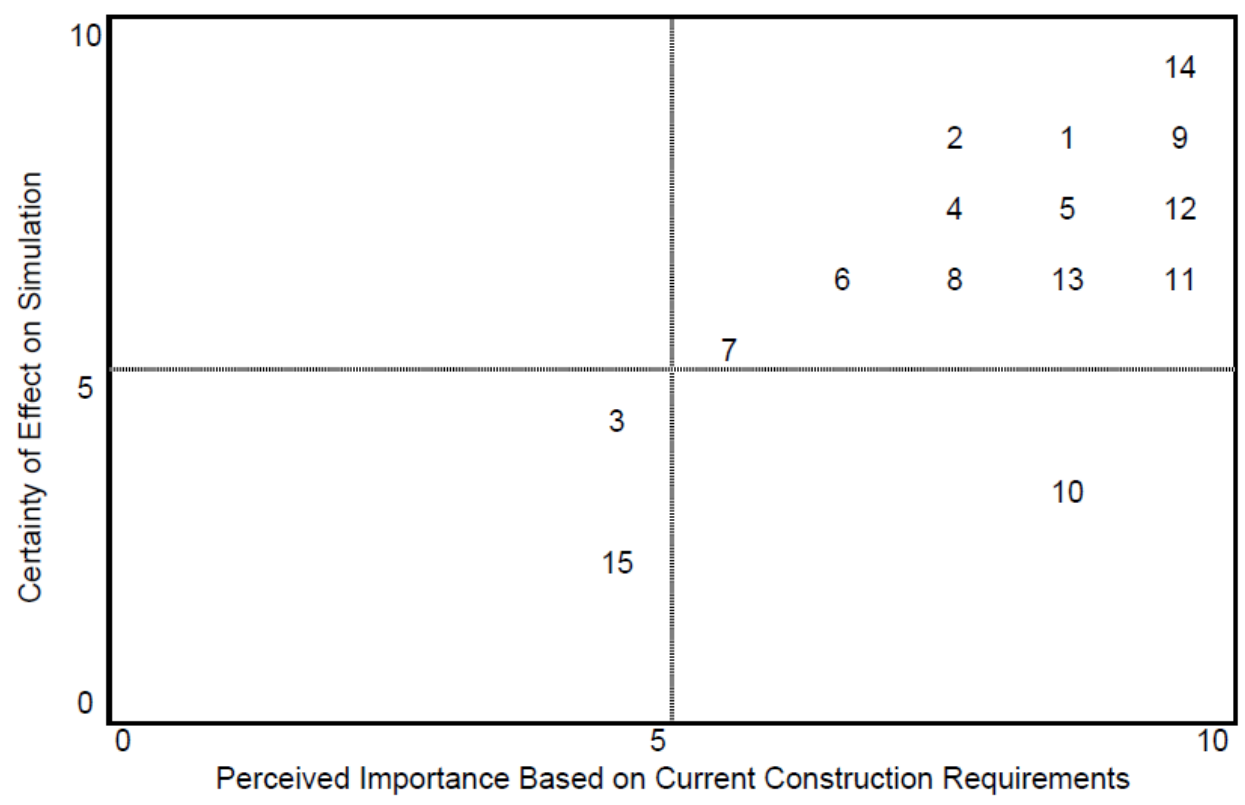

Figure 6.1 - Ranking of Areas for Future Research 


\section{Bibliography}

ABCB 2000, International survey of building energy codes, Office of the Australian Building Codes Board for the Australian Greenhouse Office

---- 2002, The building code of Australia: 1996 amendment 11, Volume 2. Australian Building Codes Board

---- 2003a, The building code of Australia: 1996 amendment 12, Volume 2. Australian Building Codes Board

---- 2003b, The building code of Australia: 1996 amendment 13, Volume 2. Australian Building Codes Board

---- 2004, The building code of Australia, Volume 2. Australian Building Codes Board.

---- 2005a, The Building Code of Australia, Volume 2, Australian Building Codes Board.

---- 2005b, Protocol for house energy rating software V2005.1, Australian Building Codes Board.

---- 2006a, The building code of Australia, Volume 2, Australian Building Codes Board

---- 2006b, Protocol for house energy rating software V2006.1, Australian Building Codes

Board

---- 2006c, Regulation impact statement (RIS 2006-01): proposal to amend the building code of Australia to increase the energy efficiency requirements for houses, Australian Building Codes Board

---- 2007, The building code of Australia Guide, Australian Building Codes Board.

---- 2009a, The building code of Australia, Volume 2. Australian Building Codes Board.

---- 2009b, BCA Maps. Australian Building Codes Board

---- 2009c, Building improvements to raise house energy ratings from 5.0 stars, Australian Building Codes Board.

---- 2009d, Communications update: proposed energy efficiency measures for BCA 2010. Australian Building Codes Board

---- 2009e, Guide to the BCA: 2005, Australian Building Codes Board

---- 2010, The building code of Australia, Volume 2, Australian Building Codes Board

ABS 2008a, Dwelling units approved in Australia, Australian Bureau of Statistics.

---- 2008b, Type of dwellings, Australia, Australian Bureau of Statistics.

ABSA 2005, ABSA assessor procedures building thermal performance residential NSW, Version 0.2, ABSA, Sydney.

AccuRate 2007, AccuRate Version 1.1.4.1.

ACDB 2006, Climate file production: Australian climate data base.

Adjali, M, Davis, M, Rianin, M \& Ni 2000, 'In situ measurements and numerical simulation of heat transfer beneath a heated ground floor slab', Energy and Buildings, vol. 33, no. 1, pp. $75-83$.

AFIA 2004, Guidelines and assumptions for the calculation of the R-Values for assemblies with reflective foil, Aluminium Foil Insulation Association, Cheltenham, Australia.

Agami Reddy, T 2006, 'Literature review on calibration of building energy simulation programs: Uses, Problems, Procedures, Uncertainty, and Tools', ASHRAE Transactions, vol. 112, pp. 226-357.

Agami Reddy, T, Maor, I \& Panjapornpon, C 2007, 'Calibrating detailed building energy simulation programs with measured data - Part I: general methodology (RP-1051)', HVAC\&R Research, vol. 13, no. 2, pp. 221-241.

AGO 1998, The national greenhouse strategy: strategic response for advancing Australia's greenhouse response, Commonwealth of Australia 
---- 1999, Australian residential building sector greenhouse gas emissions 1990-2010, Commonwealth of Australia.

---- 2000a, Energy research for the building code of Australia volume 1, Australian Greenhouse Office.

---- 2000b, Impact of minimum energy performance requirements for class 1 buildings in Victoria, Australian Greenhouse Office.

---- 2002a, Australia's national greenhouse gas inventory, 1990, 1995 and 1999: end use allocation of emissions, vol. 1, Australian Greenhouse Office.

---- 2002b, Australia's national greenhouse gas inventory, 1990, 1995 and 1999: end use allocation of emissions, vol. 2, Australian Greenhouse Office.

---- 2004a, AGO comments on submission \#28 (Dr T. Williamson), Australian Greenhouse Office.

---- 2004b, Productivity commission inquiry into energy efficiency, Australian Greenhouse Office.

---- 2005, National greenhouse gas inventory: analysis of recent trends and greenhouse indicators 1990 to 2003, Australian Greenhouse Office, Department of Environment and Heritage, Australian Government.

---- 2007a, An assessment of the need to adapt buildings for the unavoidable consequences of Climate Change, Branz Limited.

---- 2007b, Australian national greenhouse accounts: national inventory report volume 1, Australian Greenhouse Office.

Ahmad, M \& Culp, C 2006, 'Un-calibrated building energy simulation modeling results', HVAC\&R Research, vol. 12, no. 4, pp. 1141-1155.

Ahmad, Q \& Szokolay, S 1993, 'Thermal design tools in Australia: a comparative study of TEMPER, CHEETAH, ARCHIPAK and QUICK', paper presented to BS1993, Adelaide, Australia.

Akinyemi, O \& Mendes, N 2008, 'Ground temperature and moisture distribution using different weather patterns', Journal of Building and Performance Simulation, pp. 257-274.

Alasha'ary, H, Moghtaderi, B, Page, A \& Sugo, H 2009, 'A neuro-fuzzy model for prediction of the indoor temperature in typical Australian residential buildings', Energy and Building.

Allan, A, Pullen, S \& Wyeld, T 2003, 'Energy rating legislation in South Australia: a planner's perspective', paper presented to 37th Australian and New Zealand Architectural Science Association (ANZAScA) Conference, University of Sydney.

Allen, E, Bloomfield, D, Bowman, N, Lomas, K, Allen, J, Whittle, J \& Irving, A 1985, 'Analytical and empirical validation of dynamic thermal building models', paper presented to Building Simulation 1985.

Anderson, A 1989, Interpreting data: a first course in statistics, Chapman \& Hall, London.

Anderson, B 1991, 'Calculation of the steady-state heat transfer through a slab-on-Ground Floor', Building and Environment, vol. 26, no. 4, pp. 405-415.

Anderson, C 2002, 'Energy efficiency newsletter July 2002', viewed 2008.

Anis, W, Quirouette, R \& Rousseau, J 2007, Air barriers \& vapor barriers.

Arreaza, T, Reyes, V \& Almao, N 2007, 'Going beyond local regulations on the built environment: considerations and implications in the design process for city of Maracaibo, Venezuela', paper presented to Sun, Wind and Architecture, The Proceedings of the 24th International Conference on Passive and Low Energy Architecture, National University of Singapore, 22-24 Nov, 2007.

ARUP Research \& Development 2005, UK housing and climate change: heavyweight vs. lightweight construction, Ove Arup \& Partners Ltd.

ASHRAE 1997, 1997 ASHRAE handbook fundamentals, SI edition, American Society of Heating, Refrigeration and Air-Conditioning Engineers, Inc, Atlanta. 
---- 2001, ANSI/ASHRAE Standard 140-2004: Standard method of test for the evaluation of building energy analysis computer programs, American Society of Heating, Refrigeration and Air-Conditioning Engineers, Inc, Atlanta.

---- 2004a, ASHRAE Standard 55: Thermal environmental conditions for human occupation, American Society of Heating, Refrigeration and Air-Conditioning Engineers, Inc, Atlanta.

---- 2004b, Testing with ANSI/ASHRAE Std 140, American Society of Heating, Refrigeration and Air-Conditioning Engineers, Inc, Atlanta.

---- 2005, 2005 ASHRAE handbook fundamentals, SI edition, American Society of Heating, Refrigeration and Air-Conditioning Engineers, Inc. , Atlanta.

---- 2009, 2009 ASHRAE handbook : fundamentals, SI edition, American Society of Heating, Refrigeration and Air-Conditioning Engineers, Inc. , Atlanta.

ATTMA 2006, The air tightness testing and measurement association, technical standard 1: measuring air permeability of building envelopes, 03/03/06, Technical Standard.

AURORA 2006, Energy saving advice, Aurora.

Australian Bureau of Statistics 2007, 'Building activity Australia, June Quarter 2006 Item No. 8752.0', viewed 20 June 2007.

Baker, J 2008, 'Wall cavity thermal performance ', University of Tasmania.

Baker, P 2003, 'The thermal performance of a prototype dynamically insulated wall', Building Serv. Eng. Res. Technol., vol. 24, no. 1, pp. 25-34.

---- 2008, 'Evaluation of round-robin testing using the PASLINK test facilities', Building and Environment, vol. 43, no. 181-188.

Baker, P \& van Dijk, H 2008, 'PASLINK and dynamic outdoor testing of building components', Building and Environment, vol. 43, pp. 143-151.

Ballinger, J \& Cassell, D 1994, 'Solar efficient housing and NatHERS: an important marketing tool', paper presented to Solar '94 Secrets of the Sun Proceedings of the Annual Conference of the Australian and New Zealand Solar Energy Society, Sydney, NSW, 30 Nov - 3 Dec, 1994.

Bannister, P 2009, 'The application of simulation in the prediction and achievement of absolute building energy performance', paper presented to Building Simulation 2009, Eleventh International IBPSA Conference, Glasgow, Scotland, July 27-30, 2009.

Barnaby, C, Spitler, J \& Xiao, D 2005, 'The residential heat balance method for heating and cooling load calculations', ASHRAE Transactions, vol. 111, no. Career and Technical Education.

Bassett, M \& Stoecklein, A 1998, 'A new thermal design guide for New Zealand houses', paper presented to IPENZ Conference, Auckland, NZ.

BCB 2009, Review the appropriateness of building code of Australia climate zones for Tasmania, Building Control Branch, Workplace Standards, Department of Justice, Tasmania.

Beausoleil-Morrison, I, Griffith, B, Vesanen, T \& Weber, A 2009, ' A demonstration of the effectiveness of inter-program comparative testing for diagnostic and repairing solution and coding errors in building simulation programs', Journal of Building and Performance Simulation, vol. 2, no. 1, pp. 63-73.

Beausoleil-Morrison, I \& Strachan, P 1999, 'On the significance of modeling internal surface convection in dynamic whole-building simulation programs', ASHRAE Transactions, no. 105, pp. 929-940.

Bell, M \& Overend, P 2001, 'Building regulation and energy efficiency in timber frame housing', paper presented to RICS Foundation Construction and Building Research Conference, Glasgow, Scotland, 3-5 September, 2001.

Belusko, M, Bruno, F \& Saman, W 2010, 'Investigation of the thermal resistance of timber attic spaces with reflective foil and bulk insulation, heat flow up', Applied Energy.

Bennet, B 1999, 'Green housing', Ecos, no. 101, pp. 25-29. 
Biggs, K \& Bennie, I 1988, 'Ventilation studies of some Australian houses', Australian Refrigeration, Air Conditioning and Heating, vol. 42, no. 1, pp. 15-21.

Biggs, K, Bennie, I \& Michell, D 1987, 'Air infiltration rates of some Australian houses', Australian Institute of Building papers, vol. 2, pp. 49-61.

Billington, N 1951, 'The use of electrical analogies in heating research', paper presented to Building Research Congress.

Bird, R \& Riordan, C 1986, 'Simple solar spectral model for direct and diffuse irradiance on horizontal and tilted planes at the Earth's surface for cloudless atmospheres', Journal of Climate and Applied Meteorology, vol. 25, no. January 1986, pp. 87-97.

Birdsall, B 1985, A comparison of DOE-2.1C prediction with thermal mass test cell measurements, LBL-18981, Lawrence Berkeley Laboratory.

Birkeland, J 2002, Design for sustainability: a sourcebook of integrated ecological solutions, Earthscan Publications Ltd, London.

Blanchard, S \& Reppe, P 1998, 'Life cycle analysis of a residential home in Michigan', University of Michigan.

Bloomfield, D 1988, An investigation into analytical and empirical validation techniques for dynamic thermal models of buildings. Vol. 1, Executive Summary SERC/BRE Final Report, UK: BRE, Garston, Watford.

---- 1999, 'An overview of validation methods for energy and environmental software', ASHRAE Transactions, vol. 105, no. 2.

BMW 2009, Energy efficiency rating software, www.bmw.wa.gov.au/files/building_energyefficiency.pdf>.

Boardman, B, Darby, S, Killip, G, Hinnells, M, Jardine, C, Palmer, J \& Sinden, G 2005, 40\% House, Environmental Change Institute, University of Oxford.

Boland, J 1995, 'Synthetic climate data sets for locations with low measured data densities', paper presented to Solar 95', 29 Nov 1995.

---- 2002, 'The analytic solution of the differential equations describing heat flow rate in houses', Building and Environment, vol. 37, no. 11, pp. 1027-1035.

Boland, J, Ridley, B \& Brown, B 2007, 'Models of diffuse solar radiation', Renewable Energy, vol. 33, pp. 575-584.

BOM 2005a, Climate statistics for Australian locations: Launceston (Ti Tree Bend), Bureau of Meteorology, 2005, <http://www.bom.gov.au/climate/averages/tables/cw_091237.shtml>.

--- 2005b, Cool temperate climate definition, Bureau of Meteorology, $<$ http://www.bom.gov.au/climate/environ/travel/cooltem.shtml $>$.

---- 2010, Below ground surface temperature measurements: various locations in Tasmania, Bureau of Meteorology.

Bowman, N \& Lomas, K 1985, 'Empirical validation of dynamic thermal computer models of buildings', Building Services Engineering Research and Technology, vol. 6, no. 4, pp. 153162.

BREDEM 2006, Are our energy models outdated? A response to AECB, BREDEM.

Brohus, H, Heiselberg, P, Hesselholt, A \& Rasmussen, H 2009, 'Application of partial safety factors in building energy performance assessment', paper presented to Building Simulation 2009, Eleventh International IBPSA Conference, Glasgow, Scotland, July 27-30, 2009.

Bromberek, Z, Beall, J \& Hinds, M 2003, 'Housing trends and their implications for tourists accommodation in Australia', paper presented to 37th Australian and New Zealand Architectural Science Association (ANZAScA) Conference, University of Sydney.

Bruckmeyer, F 1951, 'Cooling and warming of buildings', paper presented to Building Research Congress. 
Building Control Branch 2009, Minimising the impact of 5 \& 6 star building code of Australia deemed to satisfy provisions on timber flooring, Building Control Branch, Department of Justice, Tasmania.

Burch, D, Remmert, W, Krintz, D \& Barnes, C 1982, 'A field study of the effect of wall mass on heating and cooling loads of residential buildings', paper presented to Building Thermal Mass Seminar, Knoxville, TN, 2-3June 1982.

Cadima, P 2007, 'The European strategy towards sustainability in the built environment', paper presented to Sun, Wind and Architecture, The Proceedings of the 24th International Conference on Passive and Low Energy Architecture, National University of Singapore, 2224 Nov, 2007.

Camilleri, M, Jaques, R \& Isaacs, N 2001, 'Climate change impacts on building performance', paper presented to CIB World Building Congress, Wellington, NZ, April 2001.

Campbell, I, Macfarlane, I \& Macdonald, I 2006, 'Timber industry welcomes ministerial rejection of flawed 5-star system', National Forest \& Timber, vol. 15, no. 1, p. 11.

Carbon Trust 2006, Integrated building design, Carbon Trust, London.

Carslaw, H \& Jaeger, J 1947, Conduction of heat in solids, Oxford University Press

Carter, R \& de Freitas, C 2007, 'Climate change: climate science and the stern review', World Economics, vol. 8, no. 2, pp. 161-182.

Chadderton, D 2000, Building services engineering second edition, E \& FN SPON, London.

Chappells, H \& Shove, E 2005, 'Debating the future of comfort: environmental sustainability, energy consumption and the indoor environment ', Building research \& Information, vol. 33, no. 1 , pp. 32-40.

Chasar, D, Moyer, N \& Rudd, A 2002, 'Measured cooling performance of two-storey homes in Dallas, Texas: insulated concrete form versus frame construction', Improving Building Systems in Hot and Humid Climates.

Chen, D, White, S \& Wonhas, A 2010, Subfloor modelling in the Chenath engine, CSIRO.

CIE 2007, Capitalising on the building sector's potential to lessen the costs of a broad based GHG emissions cut, Centre for International Economics, Canberra.

Clark, M, Sugo, H \& Page, A 2003, 'Thermal performance of Australian masonary housing - a preliminary study', paper presented to The Ninth North American Masonry Conference, Clemson, South Carolina, 1-4 June 2003.

Clarke, J 2001, Energy simulation in building design, 2 edn, Butterworth - Heinemann, Oxford.

Clarke, J, Strachan, P \& Pernot, C 1994, 'An approach to the calibration of building energy simulation models'.

CMHS 1982, Energy-efficient housing construction, Canada Mortgage and Housing Corporation.

COAG 2009, National strategy on energy efficiency, Council of Australian Governments.

Colborne, W, Hall, J \& Wilson, N 1984, 'The validation of DOE-2 for application to singlefamily dwellings', ASHRAE Transactions, vol. 90, no. 2 b.

Coldicutt, A, Coldicutt, S, Coldicutt, E \& White, D 1978, Thermal performance of life-time costs of public housing units in Victoria and Tasmania, Australian Housing Research Council project 57, Department of Architecture and Building, University of Melbourne for the Australian Housing Research Housing Council, Melbourne.

Cosmulescu, C 1997, 'Experimental procedure to evaluate air leakage through different building materials', Concordia University.

Cox-Smith, I 2001, 'Whole-wall R-Values', paper presented to The CIB World Building Congress, Wellington, New Zealand, April 2001. 
Crawford, R \& Treloar, G 2003, 'Validation of the use of Australian input-output data for building embodied energy simulation', paper presented to Eighth International IBPSA Conference, Eindhoven, Netherlands, August 11-14, 2003.

Crawley, D, Hand, J, Kummert, M \& Griffith, B 2005, Contrasting the capabilities of building performance simulation programs, United States Department of Energy, University of Strathclyde, and University of Wisconsin.

Crawley, D, Lawrie, K, Pederson, C, Liesen, R, Fisher, D, Strand, R, Taylor, R, Winkelmann, F, Buhl, W, Huang, Y \& Erdem, A 1999, 'EnergyPlus: a new-generation building energy simulation program ', paper presented to Renewable and Advanced Energy Systems for the 21st Century Lahaina, Maui, Hawaii, April 11-15, 1999.

Crowley, M 2009, 'A reference model for ground coupled heat transfer', Building Simulation 2009, pp. 1522-1529.

CSIRO 1997, CSIRO: Towards greenhouse-friendly buildings, Sydney.

CSR 2003, Design guide: building residential \& commercial, CSR Bradford Insulation, Melbourne.

CSTB 1990, The PASSYS project phase 1: subgroup simplified design tolls final report 19861989, EUR 12998 EN - 081-89-PASSYS-SDT-FP-020, Commission of the European Communities Directorate-General XII for Science, Research and Development.

Currie, J 2005, BCAB \#1003 August 19, 1988 - Vapour barrier, Subsection 9.26.5.

D'Cruz, N \& Duncan, P 1994, 'A comparative analysis of domestic energy consumption in three sub-divisions in Kingsley, Western Australia', paper presented to Solar'94 Secrets of the Sun, Sydney N.S.W., 30/11/1994-3/12/1994.

Daly, P 2007, 'Integrating energy rating and carbon limitation in Irish building regulations a comparative analysis of Ireland and UK/ (Eng/Wales)', paper presented to Sun, Wind and Architecture, The Proceedings of the 24th International Conference on Passive and Low Energy Architecture, National University of Singapore, 22-24 Nov, 2007.

Danter, E 1974, 'Heat exchanges in a room and the definition of room temperature', BSE, vol. 41, pp. 232-245.

Davies, M 1974, 'Discussion', BSE, vol. 42, pp. 51-54.

---- 1990, 'Room heat needs in relation to comfort temperature: simplified calculation methods', Building Services Engineering Research and Technology, vol. 11, no. 4, pp. 129139.

Davies, M, Martin, C, Watson, M \& Ni Riain, C 2005, 'The development of an accurate tool to determine convective heat transfer co-efficiencies in real buildings', Energy and Buildings, no. 37, pp. 141-145.

Davis, M 2005, 'House energy rating and the building code of Australia', paper presented to Building Australia's Future 2005, 4 August 2005.

DCC 2009, Australia's national greenhouse accounts: national greenhouse gas inventory accounting for the Kyoto target May 2009, Department of Climate Change.

de Carli, M \& Olesen, B 2002, 'Field measurements of operative temperatures in buildings heated or cooled by embedded water-based radiant systems', ASHRAE Transactions, vol. 108, pp. 714-725.

de Souza, C, Knight, I, Dunn, G \& Marsh, A 2006, 'Modelling buildings for energy use: a study of the effects of using multiple simulation tools and varying levels of input detail', paper presented to International Conference on Electricity Efficiency in Commercial Buildings (IEECB 2006), Frankfurt, Germany, April 2006.

del Mar Izquierdo, M, Lefebvre, G, Palomo, E, Boudaud, F \& Jeandel, A 1995, 'A statistical methodology for model validation in the ALLAN.tm simulation environment', paper presented to BS1995, Madison, Wisconsin, U.S.A, 14-16 August, 1995. 
Delsante, A 1988, 'Theoretical calculations of the steady-state heat losses through a slab-onground floor', Building and Environment, vol. 23, no. 1, pp. 11-17.

---- 1989, 'Steady-state heat losses from the core and perimeter regions of a slab-on-ground floor', Building and Environment, vol. 24, no. 3, pp. 253-257.

---- 1993, 'The effect of water table on steady-state heat transfer through a slab-on-ground floor', Building and Environment, vol. 28, no. 3, pp. 369-372.

---- 1995a, 'A comparison of Chenath, the nationwide house energy rating scheme simulation engine, with measured test cell data', paper presented to Solar '95 Renewable Energy: the Future is Now, Proceedings of the Annual Conference of the Australian and New Zealand Solar Energy Society, Hobart, Tasmania, 29 Nov - 1 Dec, 1995.

---- 1995b, 'Using the building energy simulation test (BESTEST) to evaluate CHENATH, the nationwide house energy rating scheme simulation Engine', paper presented to Solar '95 Renewable Energy: the Future is Now, Proceedings of the Annual Conference of the Australian and New Zealand Solar Energy Society, Hobart, Tasmania, 29 Nov - 1 Dec, 1995.

---- 1996, 'The Australian nationwide house energy rating scheme', IBPSA NEWS, vol. 8, no. 1, pp. 17-20.

---- 1997, The development of an hourly thermal simulation program for use in Australian nationwide house energy rating scheme, CSIRO Division of Building Constriction and Engineering, Victoria.

---- 2005a, 'The AccuRate simulation engine', paper presented to NatHERS Conference, 2005.

---- 2005b, Building performance measurements for empirical validation of nationwide housing energy rating scheme software - a guidance note.

---- 2005c, 'Building performance measurements for software validation - a guidance note', paper presented to NatHERS Conference, 3-4 August 2005.

---- 2005d, 'Is the new generation of building energy rating software up to the task? - a review of AccuRate (Powerpoint Presentation)', paper presented to ABCD Conference 'Building Australia's Future 2005', Surfers Paradise, 11-15 Sep, 2005.

---- 2005e, 'Is the new generation of building energy rating software up to the task? a review of AccuRate', paper presented to ABCB Conference 'Building Australia's Future 2005', Surfers Paradise, 11-15 September 2005.

---- 2005f, Submission to productivity commission public enquiry into energy efficiency: comments on section 7.8 of the draft report CSIRO.

---- 2005-2010, Launceston thermal performance test cells: advice and discussions to M Dewsbury.

---- 2006a, 'A comparison of 'AccuRate' predictions with measured data from a mud brick house', paper presented to proceedings of the IBPSA Australasia 2006 Conference, Adelaide.

---- 2006b, 'Description of input data file for the AccuRate simulation engine V2.13', CSIRO.

---- 2007, A comparison of NatHERS, FirstRate and AccuRate predictions of the difference between slab-on-ground floors and suspended timber floors, PN04.1008, Forest and Wood Products Research and Development Corporation.

--- 2009a, 'Extraterrestrial radiation'.

---- 2009b, RE: shading by tree's to M Dewsbury, 1 OCT 2009.

Delsante, A \& Mason, M 1990, 'Expanded climatic database', Australian Refrigeration, Air Conditioning and Heating, pp. 27-33.

Delsante, A, Stokes, A \& Walsh, P 1983, 'Application of Fourier transforms to periodic heat flow into the ground under a building', CSIRO, pp. 121-132.

Demeritt, D 2010, 'The construction of global warming and the politics of science', Annals of the Association of American Geographers vol. 91, no. 2, pp. 307-337.

Department of Public Works 1850, Floor plan of school building and dwelling, State Library of Tasmania, 2008. 
---- 1926, Floor plans of residence, State Library of Tasmania, 2008.

Deru, M 2003, A model for ground-coupled heat and moisture transfer from buildings NREL/TP-550-33954, National Renewable Energy Laboratory, Colorado.

Deru, M \& Burns, P 2003, 'Infiltration and natural ventilation model for whole-building energy simulation of residential buildings', paper presented to ASHRAE Conference, Missouri, 28 June to J July, 2003.

DEWHA 2008, Energy use in the Australian residential sector: 1986-2020, Department of the Environment, Water, Heritage and the Arts, Canberra.

Dewsbury, M 2005-2010, Measured room temperatures in student housing, as observed by students in the Building Technology in Design subject.

---- 2006, No Bills House and Best Five Star House project, Tasmanian Timber Promotion Board - Board Room, 23 March 2006.

---- 2009, 'A preliminary comparison of test cell thermal performance and the empirical validation of AccuRate in a cool temperate climate '.

Dewsbury, M, Fay, R, Nolan, G, Vale \& R 2007, 'The design of three thermal performance test cells in Launceston', paper presented to The 41st Annual Conference of the Architectural Association ANZAScA, Geelong.

Dewsbury, M, Fay, R \& Nolan, G 2008, 'Thermal performance of light-weight timber test buildings', paper presented to World Congress of Timber Engineering, Miyazaki.

Dewsbury, M, Nolan, G \& Fay, R 2007, Test cell thermal performance - August to December 2006, FWPRDC Project PN04.1009, Centre for Sustainable Architecture with Wood, School of Architecture, University of Tasmania, Launceston.

Dewsbury, M, Soriano, F, Nolan, G \& Fay, R 2009, Comparison of test cell thermal performance and the empirical validation of AccuRate in a cool temperate climate, PNA0010405, Forest and Wood Products Australia Limited.

Dewsbury, M, Wallis, L, Fay, R \& Nolan, G 2009, 'The influence of residential framing practices on thermal performance', paper presented to ANZAScA 2009: 43rd Annual Conference of the Architectural Science Association, University of Tasmania, 25-27 Nov, 2009.

Diamond, S, Cappiello, C \& Hunn, B 1985, 'User effect validation tests of the DOE-2 building energy analysis computer program', ASHRAE Transactions, vol. 91, no. 2.

Djunaedy, E, Hensen, J \& Loomans, M 2005, 'External coupling between CFD and energy simulation: implementation and validation', ASHRAE Transactions, vol. 111, no. 1, p. 612624.

Do, V, Young, A, Kienzl, N \& Pade, G 2007, 'The development of energy efficiency building codes in the ASEAN area - a quarter-century review and the proposal for a design tool for commercial buildings in Vietnam', paper presented to Sun, Wind and Architecture, The Proceedings of the 24th International Conference on Passive and Low Energy Architecture, National University of Singapore, 22-24 Nov, 2007.

Donn, M 2001, 'Tools for quality control in simulation', Building and Environment, pp. 673680.

---- 2007, 'Simulation quality assurance - challenges for the simulation community', IBPSA NEWS, vol. 17 , no. 2 , pp. 25-55.

dos Santos, G \& Mendes, N 2003, 'The Solum programs for predicting temperature profiles in soils: mathematical models and boundary conditions analyses', paper presented to Eighth International IBPSA Conference, Eindhoven, Netherlands, August 11-14, 2003.

Downey, L, Slezak, J, Michael, J \& Wonhas, A 2008, An Australian cost curve for greenhouse gas reduction, McKinsey and Company Australia. 
Drogemuller, R, Delsante, A, Moller, S, Sharpe, R, Blackmore, J \& Oakes, S 1999, Scoping study of minimum energy performance requirements for incorporation into the building code of Australia, Australian Greenhouse Office.

Eckstein, D 2006, 'BASIX - lessons from implementation in NSW', paper presented to Building Council of Sustainable Energy National Conference, Brisbane, Australia, 4 May 2006.

Ellis, P 2003, 'Development and validation of the unvented trombe wall model in EnergyPlus', University of Illinois at Urbana-Champaign, 2003.

Energy Partners 2006, Rules of thumb for attaining 5 star energy rating for timber-floored dwellings, Energy Partners.

---- 2007, Matching of climate data with postcodes for building related energy rating: interim report on climate zone boundaries

enHealth 2007, Health effects of unflued gas heater use in Australia, Commonwealth of Australia, Canberra.

EU 2003, 'Directive 2002/91/EC of the European Parliament and of the Council of 16 December 2002 on the Energy Performance of Buildings ', Official Journal of the European Communities (L1), vol. 46, pp. 65-71.

Fay, R, Treloar, G \& Iyer-Raniga, U 2000, 'Life-cycle energy analysis of buildings: a case study', Building Research and Information, vol. 28, no. 1, pp. 31-41.

Feustel, H \& Rayner-Hooson, A 1990, COMIS fundamentals, LBL-28560, Lawrence Berkeley Laboratory, Berkeley, California.

Flohn, H 1980, Possible climatic consequences of a man-made global warming, rr-80-30, International Institute for Applied Systems Analysis, Laxenburg.

Foliente, G, Seo, S \& Tucker, S 2004, 'A guide to environmental design and assessment tools', Environment Design Guide, vol. 57, pp. 1-8.

Frank, H \& Althoen, S 1994, Statistics: concepts and applications, Cambridge University Press, Cambridge.

Fricker, J 2003, Report on thermal bridging of insulated building systems for ACIMA, i170a.

Fung, J, Porteous, C \& Sharpe, T 2007, 'Lifestyle as a key determinant of the home environment', paper presented to Sun, Wind and Architecture, The Proceedings of the 24th International Conference on Passive and Low Energy Architecture, National University of Singapore, 22-24 Nov, 2007.

Gann, D, Wang, Y \& Hawkins, R 1998, 'Do regulations encourage innovation? - the case of energy efficiency in housing', Building research \& Information, vol. 26, no. 4, pp. 280-296.

Gettings, M, McCold, L \& Schlegel, J 1988, Field test evaluation of conservation retrofits of low-income, single-family buildings in Wisconsin: blower-door-directed infiltration reduction procedure, field test implementation and results, ORNL/CON-228/P5, Oak ridge National Laboratory.

Ghatti, V, Scheatzle, D, Bryan, H \& Addison, M 2003, 'Passive performance of a high-mass residence: actual data vs. simulation', ASHRAE Transactions, no. 109, pp. 598-605.

Girault, P 1994, Description of ETNA cells: physical and geometrical configuration (measuring cells), HE-14/94/054, Department Applications de l'Electricite dans les Batiments, Direction des Etudes et Recherches, Service Applications de l'Electricite et Environnement, Electricte de France, France.

Goldberg, L 1985, 'A comparative validation of the long term energy consumption predictions of five residential building energy simulation programs in a heating climate', paper presented to Building Simulation 1985.

Green, D 2006, 'Beyond Montreal - what next? the UK business perspective', paper presented to BCSE National Conference 2006, Brisbane, Australia. 
Gullu, D, Caglar, A \& Akdeniz, F 2001, 'Recent energy studies and energy policies in Turkey', Energy Sources, no. 23, pp. 495-510.

Guyon, G 1997, 'Role of the model user in results obtained from simulation software program', paper presented to BS1997, Prague, Czech Republic, 8-10 September, 1997.

Guyon, G, Girault, P, Delille, S, Hoareau, D \& Villain, J 1999, 'Influence of turbulent wind on air change rates an application with CLIM2000 software program', paper presented to BS1999, Kyoto, Japan, 13-15 September, 1999.

Guyon, G, Moinard, S \& Ramdani, N 1999a, 'Empirical validation of buildings energy analysis tools by using tests carried out in small cells', paper presented to Building Simulation 1999, Proceedings of the International IBPSA Conference, Kyoto, Japan, 13-15 September, 1999.

---- 1999b, 'Validation of the CLIM2000 software program by using analytical verification', paper presented to BS1999, Kyoto, Japan, 13-15 September, 1999.

Guyon, G, Moinard, S.,\& Ramdani, N. 1999, 'Empirical validation of building energy analysis tools by using test carried out in small cells '.

Guyon, G \& Rahni, N 1997, 'Validation of a building thermal model in CLIM2000 simulation software using full-scale experimental data, sensitivity analysis and uncertainty analysis', paper presented to BS1997, Prague, Czech republic, 8-10 September, 1997.

Haberl, J 2004, Literature review of uncertainty of analysis methods (DOE-2 Program), Texas Commission on Environmental Quality, Texas.

Haddad, K \& Beausoleil-Morrison, I 2001, 'Results of the HERS BESTEST on an energy simulation computer program', ASHRAE Transactions, vol. 107, no. Career and Technical Education, pp. 713-721.

Halthore, R \& Schwartz, S 2001, 'Comparison of model estimated and measured diffuse downward surface irradiance in cloud-free skies', Journal of Geophysical Research, vol. 105, no. D15, pp. p. 20165-20177

Halthore, R, Schwartz, S, Michalsky, J, Bergin, M, Ferrare, R, Holben, B \& ten Brink, H 1996, 'A closure experiment: prediction and measurement of direct-normal solar irradiance at the ARM site', paper presented to American Geophysical Union Fall Meeting, San Francisco, December 15-19, 1996, .

Hamilton, C 2007, Scorcher, the dirty politics of climate change, Black inc. Agenda.

Hancock, E, Norton, P \& Hendron, B 2002, Building America system performance test practices: Part 2, air-exchange measurements, National Renewable energy laboratory, Colorado.

Handisyde, C \& Melluish, D 1971, Thermal insulation of buildings, Directorate of Research and Information.

Harrington, L \& Foster, R 1999, Australian residential building sector greenhouse gas emissions 1990-2010 appendices 1999, Final Report, Australian Greenhouse Office, Canberra.

Harris, D \& Dudek, S 1997, 'Heat losses from suspended timber floors', Building Research and Information, vol. 25, no. 4, pp. 226-233.

Harris, J, Diamond, R, Iyer, M, Payne, C, Blumstein, C \& Siderius, H 2008, 'Towards a sustainable energy balance: progressive efficiency and the return of energy conservation', Energy Efficiency, vol. 1, pp. 175-188.

Harvey, P 2006, 'Transcript: the castle', 60 Minutes.

Hassall, D 1977, Reflective insulation and the control of thermal environments (metric edition), ST Regis - ACI, Sydney.

Hastings, R \& Wall, M 2007, Sustainable solar housing: volume 1 - strategies and solutions, Earthscan, London. 
Hayez, S, Dalibart, C, Guyon, G \& Feburie, J 2001, 'HVAC BESTEST: CLIM2000 and CASIS results', paper presented to Seventh International IBPSA Conference, Rio de Janeiro, Brazil, 13-15 August, 2001.

Heathcote, K \& Moor, G 2007, 'Comparative analysis of the thermal performance of three test buildings', paper presented to Adobe USA 2007, New Mexico, 2007.

Henderson, L 2005, Proposal for 5 star houses. RD 2004-02 to A The Executive Director, 12 May 2005.

Hendron, R, Farrar-Nagy, S, Anderson, R, Reeves, P \& Hancock, E 2003, 'Thermal performance of unvented attics in hot-dry climates: Results from Building America ', paper presented to International solar energy conference, Hawaii, March 15-18, 2003.

Henninger, R \& Witte, M 2004, EnergyPlus testing with ANSI/ASHRAE standard 140-2001 (BESTEST), Ernest Orlando Lawrence Berkeley National Laboratory, Berkeley, California.

Henninger, R, Witte, M \& Crawley, D 2003, 'Experience testing EnergyPlus with the IEA HVAC BESTEST E100-E200 series', paper presented to Eighth International IBPSA Conference, Eindhoven, Netherlands, August 11-14, 2003.

Henriksen, J 2003, 'Two thermal models and reality', paper presented to the 37th Australian \& new Zealand Architectural Science Association (ANZAScA) Conference, Sydney, 1-4 November 2003.

HER Users 2005-2011, Personal discussions with HER software users to M Dewsbury.

HIA 2004, Response to supplementary submission to Productivity Commission public enquiry into energy efficiency, Housing Industry Association.

Holden, T 1963, 'The calculation of fluctuating heat flow in buildings', Proceedings Australian Computer Conference, vol. C.24, no. 1.

Horne, R \& Hayles, C 2008, 'Towards global benchmarking for sustainable homes: an international comparison of the energy performance of housing', Springer Science and Business, no. 23, pp. 119-130.

Hui, S 2003, 'Effective use of building energy simulation for enhancing building energy codes', paper presented to Eighth International IBPSA Conference, Eindhoven, Netherlands, August 11-14, 2003.

IEA 2001a, Dealing with climate change: policies and measures in IEA member countries, International Energy Agency.

---- 2001b, Energy policies of IEA countries: Australia 2001 review, International Energy Agency.

IPCC 2001, Climate change 2001: the scientific basis.

---- 2007, Fourth assessment report: climate change 2007 (AR4), Intergovernmental Panel on Climate Change.

Isaacs, N 1999, 'Performance-based building energy efficiency Code', paper presented to Building Control Commission International Convention, Melbourne, Australia, April 12-15, 1999.

Isaacs, T 2005, ACCURATE: 2nd generation nationwide house energy rating software, BDP Environmental design guide.

---- 2008, Evaluation of AccuRate simulations of various design strategies to improve house thermal performance in Darwin and Alice Springs, For the Northern Territory Department of Planning and Infrastructure

Iskra, B 2004, 'Lightweight houses \& the 5-star energy standard', October 2004.

James, G, Anda, M \& Mathew, K 2004, 'Thermal performance of the passive solar designed Subiaco sustainable demonstration home', paper presented to Solar 2004, Perth, December 2004. 
---- 2006, 'Monitored thermal performance of passive solar designed display homes in Perth, Western Australia', paper presented to ANZSES 44th National Conference: Solar 2006, Canberra.

Jeeninga, H \& Kets, A 2004, 'Evolution of energy policy in the Netherlands: past, present and future', Building research \& Information, vol. 32, no. 1, pp. 38-41.

Jimenez, M \& Madsen, H 2008, 'Models for describing the thermal characteristics of building components', Building and Environment, vol. 43, pp. 152-162.

Jimenez, M, Madsen, H \& Andersen, K 2008, 'Identification of the main thermal characteristics of building components using MATLAB', Building and Environment, vol. 43, pp. 170-180.

Johansson, D \& Bagge, H 2009, 'Simulation energy use in multi-family dwellings with measured, non constant heat gains from household electricity', paper presented to Building Simulation 2009, Eleventh International IBPSA Conference, Glasgow, Scotland, July 27-30, 2009.

Judkoff, R 1985, 'International Energy Agency building simulation comparison and validation study', paper presented to Building Simulation 1985.

---- 2008, Testing and validation of building energy simulation tools, National Renewable Energy Laboratory Colorado.

Judkoff, R \& Neymark, J 1995, International Energy Agency building energy simulation test (BESTEST) and diagnostic method, National Renewable Energy Laboratory.

---- 1999, 'Adaptation of the BESTEST intermodel comparison method for proposed ASHRAE Standard 140P: method of test for building energy simulation programs', ASHRAE Transactions, vol. 105, no. 2, pp. 1-16.

---- 2006, 'Model validation and testing: the methodological foundation of ASHRAE Standard 140', paper presented to ASHRAE 2006 Annual Meeting, Canada, June 24-29 2006.

Judkoff, R, Wortman, D \& Burch, J 1983a, Empirical validation using data from the SERI Class-A validation house, Solar Energy Research Institute, U.S. Department of Energy, Colorado.

---- 1983b, Measured versus predicted performance of the SERI Test House: a validation study, SERI/TP-254-1953, Solar Energy Research Institute.

Kalamees, T, Kurnitski, J, Vinha, J \& Korpi, M 2008, 'Indoor climate conditions in lightweight detached houses in cold climate'.

Kane, A, Fuller, R \& Treloar, G 2006, 'Predicted impact of user behaviour on household energy savings', paper presented to 40th Annual Conference of the Architectural Science Association ANZAScA, Adelaide.

Kavgic, M, Mumovic, D, Davies, M, Stevnovic, Z \& Djurovic-Petrovic, M 2009, 'A framework for comparative analysis of Belgrade housing stock- determinants of carbon reduction strategy', Building Simulation 2009, pp. 1075-1082.

Kim, J \& Moon, J 2009, 'Impact of insulation on building energy consumption', Building Simulation 2009, pp. 674-680.

Kokogiannakis, G, Strachan, P \& Clarke, J 2008, 'Comparison of the simplified methods of the ISO 13790 standard and detailed modelling programs in a regulatory context', Journal of Building Performance Simulation, vol. 1, no. 4, pp. 209-219.

Konstantinos, T, Papakostas, A \& Vlahakis, I 2005, 'Optimisation of thermal protection in residential buildings using the variable base degree-days method', International Journal of Sustainable Energy, vol. 24, no. 1, pp. 19-31.

Kordjamshidi, M \& King, S 2006, 'A comparative analysis of the simulated thermal performance of dwellings in moderate climate', paper presented to IPBSA Australasia Conference 2006, Adelaide. 
---- 2009, 'Overcoming problems in house energy ratings in temperate climates: a proposed new rating framework', Energy and Building, vol. 41, no. 1, pp. 125-132.

Kordjamshidi, M, King, S \& Prasad, D 2005, 'Towards the development of a home rating scheme for free running buildings', paper presented to Solar 2005.

Kosny, J \& Childs, P 2002, 'Making steel framing as thermally efficient as wood', Most current Developments from ORNL.

Kosny, J, Yarbrough, D \& Childs, P 2006a, 'Couple secrets about how framing is effecting the thermal performance of wood and steel-framed walls', pp. 1-12.

---- 2006b, 'Effects of framing on the thermal performance of wood and steel-framed walls'.

Kosny, J, Yarbrough, D, Childs, P \& Mohiuddin, S 2007, 'How the same wall can have several different R-Values: relations between amount of framing and overall thermal performance in wood and steel-framed walls', ASHRAE, pp. 1-9.

Kostof, S 1995, A history of architecture: settings and rituals, Oxford University Press, Oxford.

Krarti, M \& Ihm, P 2009, 'Implementation of a building foundation heat transfer model in EnergyPlus', Journal of Building and Performance Simulation, vol. 2, no. 2, pp. 127-142.

Kummert, M, Bradley, D \& McDowell, T 2004, 'Combining different validation techniques for continuous software improvement - implications in the development of TRNSYS 16', paper presented to E-SIM, June 2004.

Lambeck, K 2008, Developing infrastructure for the low-carbon economy a submission to 'Infrastructure Australia discussion paper 1: Australia's future infrastructure requirements', Australian Academy of Science.

Landman, KA \& Delsante, A 1987, 'Steady-state heat losses from a building floor slab with vertical edge insulation-II', Building and Environment, vol. 22, no. 1, pp. 49-55.

Leal, V \& Maldonado, E 2008, 'The role of the PASLINK test cell in the modelling and integrated simulation of an innovative window', Building and Environment, vol. 43, pp. 217227.

Lee, T, Snow, M, Boland, J, Ridley, B \& Stokes, B 2005, 'The Australian climatic data bank', paper presented to NatHERS National Conference, Melbourne.

Lee, T, Snow, M \& Stokes, B 2005, 'The Australian solar resource updated: the Australian solar radiation data handbook - Edition 4', paper presented to Solar 2005, 2005.

Leopold, C 1948a, 'Hydraulic analogue for the solution of problems of thermal storage, radiation, convection, and conduction', ASHVE Transactions, vol. 54, no. 1, pp. 391-424.

---- 1948b, 'Hydraulic analogue for the solution of problems of thermal storage, radiation, conduction, and convection', Heat. Pip. Air Condit. , no. 20, pp. 105-111.

Li, Y \& Delsante, A 2001, 'Natural ventilation induced by combined wind and thermal forces', Building and Environment, vol. 36, no. 1, pp. 59-71.

Li, Y, Delsante, A, Chen, Z, Sandberg, M, Andersen, A \& Bjerre, M 2001, 'Some examples of solution multiplicity in natural ventilation', Building and Environment, vol. 36, no. 7, pp. 851858.

Li, Y, Delsante, A \& Symons, J 2000, 'Prediction of natural ventilation in buildings with large openings', Building and Environment, vol. 35, no. 3, pp. 191-206.

Lomas, K 1991a, 'Availability of monitored hourly building performance data for validating dynamic thermal models of buildings', Building Services Engineering Research and Technology, vol. 12, no. 2, pp. 71-74.

---- 1991b, IEA Task VIII empirical validation: a critical appraisal, International Energy Agency.

---- 1991c, Summary and appraisal of high quality data sets in the U.K., International Energy Agency. 
---- 1994, Empirical validation of thermal building simulation programs using test room data: volume 3 - working reports, IEA Energy Conservation in Buildings and Community System Program Appendix 21 and IEA Solar Heating and Cooling Programme Task 12, U.K.

Lomas, K, Eppel, H, Martin, C \& Bloomfield, D 1994, Empirical validation of thermal building simulation programs using test room data: volume 1 - final report, IEA Energy Conservation in Buildings and Community System Program Appendix 21 and IEA Solar Heating and Cooling Programme Task 12.

Lomas, K, Martin, C, Eppel, H, Watson, M \& Bloomfield, D 1994, Empirical validation of thermal building programs using test room data: volume 2 - empirical validation package, IEA Energy Conservation in Buildings and Community System Program Appendix 21 and IEA Solar Heating and Cooling Programme Task 12.

Lomas, K, Oreszcyn, T, Shipworth, D, Wright, A \& Summerfield, A 2010, 'Carbon reduction in buildings $(\mathrm{CaRB})$ - understanding the social and technical factors that influence energy use in UK homes', Institute of Energy and Sustainable Development, De Montfort University Loudon, A 1970, 'Summertime temperatures in buildings without air-conditioning ', J.I.H.V.E., vol. 37, pp. 280-292.

Loutzenhiser, P, Manz, H, Felsmann, C, Strachan, A, Felsmann, C, Frank, T, Maxwell, G \& Oelhafen, P 2006, 'An empirical validation of modeling solar gains through a glazing unit using building energy simulation programs', HVAC \& R Research, vol. 12, no. 4, pp. 10971116.

Loutzenhiser, P, Manz, H, Felsmann, C, Strachan, P, Frank, T \& Maxwell, G 2007, 'Empirical validation of models to compute solar irradiance on inclined surfaces for building energy simulation', Solar Energy, no. 81, pp. 254-276.

Loutzenhiser, P, Manz, H \& Maxwell, G 2007, Empirical validations of shading/daylighting/load interactions in building energy simulation tools: a report for the International Energy Agency's SHC Task 34/ECBCS Annex 43 Project C.

Lstiburek, J 2004, Insulations, sheathings and vapor retarders, 0412, Building Science Corporation.

---- 2006, 'Understanding attic ventilation', ASHRAE Journal, vol. 48, no. April 2006, pp. 3645.

---- 2007, 'Thermodynamics: it's not rocket science', ASHRAE Journal, no. December 2007, pp. 58-60.

Lstiburek, J 2010, 'Advanced Framing', Insight, vol. 030, pp. 1-7.

Luther, M \& Atkinson, S 2008, 'Ventilation case studies of Australian homes', paper presented to ABSA Conference, Melbourne.

Luther, M \& Horan, P 2009, 'Simultaneous presentation of measured and calculated environmental results', paper presented to 43rd Annual conference of the Architectural Science Association ANZAScA Launceston, 25-27 November.

Macdonald, I, Macfarlane, I \& Campbell, I 2005, Proposed 'five-star' energy ratings seriously flawed.

Mackey, C 1951, 'The steady periodic state - a review of some computational methods', paper presented to Building Research Congress.

Mackey, C \& Wright, L 1944, 'Periodic heat flow-homogeneous walls or roofs.' Transactions American Society of Heating and Ventilating Engineers, vol. 50, no. 1, pp. 293-312.

---- 1946, 'Periodic heat flow-composite walls or roofs', Transactions American Society of Heating and Ventilating Engineers, vol. 52, no. 1, pp. 283-296.

Major, J 2006, Building design: working out with the stars, http://www.solve.csiro.au/0206/article8.htm, 10 Feb 2006.

Mansour, A, Jutten, C \& Ohnishi, N 1998, 'Kurtosis: definition and properties', paper presented to Fusion "98 International Conference 
Manz, H, Loutzenhiser, P, Frank, T, Strachan, P, Bundi, R \& Maxwell, G 2006, 'Series of experiments for empirical validation of solar gain modeling in building energy simulation codes - experimental setup, test cell characterization, specifications and uncertainty analysis', Building and Environment, vol. 41, pp. 1784-1797.

Manz, HL, P; Frank, T; Strachan, P; Bundi, R; Maxwell, G; 2005, 'Series of experiments for empirical validation of solar gain modeling in building energy simulation codes experimental setup, test cell characterization, specifications and uncertainty analysis', Building and Environment, vol. 41, no. 12, pp. 1784-1797.

Marceau, J, Cook, N, Gerasimou, E, Xue, Q \& Dalton, B 1999, The capacity of the building and construction product system to encourage and undertake energy efficient building design and construction, Australian Expert Group in Industry Studies (AEGIS), Sydney.

Marker, T 2005, '2nd generation NatHERS', paper presented to NatHERS 2005 National Conference, Melbourne.

Martin, P 2009, 'Home truth: Australia trumps US when it comes to McMansions', Sydney Morning Herald, Nov, 29th, 2009.

MBA 2008, Concern at push to make houses more energy efficient, Master Builders Association Tasmania Branch, ABC News, viewed 17/11/2008.

McWilliams, J 2002, Review of air flow measurement techniques, LBNL-49747, Lawrence Berkeley National Laboratory, Berkeley, California.

Meldem, R \& Winklemann, F 1995, Comparison of DOE-2 with measurements in the Pala test houses, LBL-37979, Energy \& Environment Division, Lawrence Berkley National Laboratory.

---- 1998, 'Comparison of DOE-2 with temperature measurements in the Pala test houses', Energy and Building, vol. 27, no. 1, pp. 69-81.

Milbank, N \& Harrington-Lynn, J 1974, 'Thermal response and the admittance procedure', Building Research Establishment Current Paper, vol. 42, no. May 1974, pp. 38-54.

Millis, A 2006, 'The national framework for energy efficiency - progress and achievements', paper presented to BCSE Annual Conference 2006, 4/05/2006.

Mithraratne, NV, B. Vale, R. 2007, Sustainable living: the role of whole life costs and values, Elsevier, Oxford.

Moghtaderi, B 2005, 'Validation of AccuRate software', paper presented to NatHERS National Conference Melbourne.

Moinard, S \& Guyon, G 1999, Empirical validation of EDF ETNA and GENEC test-cell models: a report of Task 22 building energy analysis tools T.22.A.3, International Energy Agency

Moriarty, W 1991, 'Estimation of diffuse from measured global solar radiation', Solar Energy, vol. 47, no. 2, pp. 75-82.

Mumovic, D, Ridley, I, Oreszczyn, T \& Davies, M 2005, 'Condensation risk: comparison of steady-state and transient methods'.

Muncey, $\mathrm{R}$ 1953, 'The calculation of temperatures inside buildings having variable external conditions', Australian Journal of Applied Science, vol. 4, pp. 189-196.

---- 1979, Heat transfer calculations for buildings, Applied Science Publishers Ltd, Essex, England.

Muncey, R \& Holden, T 1967, 'The calculation of internal temperatures - a demonstration experiment', Building Science, vol. 2, no. 3, pp. 191-196.

Muncey, R \& Spencer, J 1966, 'Calculation of non-steady heat flow: considerations of radiation within the room', Journal of the Institution of Heating and Ventilation Engineers, vol. 34, no. 01, pp. 35-38.

---- 1969, 'Calculation of temperatures in buildings by the matrix method: some particular cases ', Building Science, vol. 3, pp. 227-229. 
Murphy, C, Head, D, Fisher, N, Caswell, T, Edwards, T, McInnes, R, Pearce, B, Ainley, R, Collison, K, Dunn, A, Gay, J, Boyd, P, Oughton, M, Davies, R, Gunnersen, P, McCormack, G, Tregoning, D \& Neville-Smith, J 2005, Reconsideration of ABCB's decision to implement 5-star nationally from 1 May 2006 to P Laver, 23 Dec 2005.

Myers, D 2003, 'Solar radiation modeling and measurements for renewable energy applications: data and model quality', paper presented to International Expert Conference on Mathematical Modeling of Solar Radiation and Daylight - Challenges for the 21st Century, Edinburgh, Scotland, September 15-16, 2003.

NAHB 1999, Insulating concrete forms: comparative thermal performance, U.S. Department of Housing and Urban Development Office of Policy Development and Research.

NatHERS 2000, User guide for NatHERS: the computer simulation tool for house energy rating.

---- 2007, Procedure for accrediting software under the nationwide house energy rating scheme, part A - software incorporating the Australian government endorsed calculation engine, NatHERS National Administrator.

---- 2009a, Climate zones, Nationwide House Energy Rating Scheme Administrator, viewed 28/08/2009.

---- 2009b, HER Starbands, National House Energy Rating Scheme Administrator.

---- 2009c, Internal sensible and latent loads Nationwide House Energy Rating Scheme Administrator, viewed 29/07/2009.

---- 2009d, NatHERS star rating scale, Nationwide House Energy Rating Scheme Administrator, viewed 29/07/2009.

---- 2009e, Occupancy settings, Nationwide House Energy Rating Scheme Administrator, viewed 29/07/2009.

Neymark, J, Girault, P, Guyon, G, Judkoff, R, LeBerre, R, Ojalvo, J \& Reimer, P 2005, 'The "ETNA Bestest" empirical validation data set', paper presented to Building Simulation 2005, Ninth International IBPSA Conference, Montreal, Canada, August 15-18, 2005.

Neymark, J \& Judkoff, R 1997, 'A comparative validation based certification test for home energy rating system software', paper presented to Building Simulation 1997, International IBPSA Conference, Prague, Czech Republic, September 8-10, 1997.

Neymark, J, Judkoff, R, Alexander, D, Felsman, C, Strachan, P \& Wijsman, A 2008, International Energy Agency building energy simulation test and diagnostic method (IEA BESTEST) - multi-zone non-airflow in-depth diagnostic cases: MZ320-MZ360, NREL/TP$550-43827$.

Neymark, J, Judkoff, R, Beausoleil-Morrison, I, Ben-Nakhi, A, Crowley, M, Deru, M, Henninger, H, Ribberink, J, Thornton, J, Wijsman, A \& Witte, M 2009, 'IEA Bestest in-depth diagnostic cases for ground coupled heat transfer related to slab-on-grade construction', paper presented to Building Simulation 2009, Glasgow, 27-30 July 2009.

Neymark, J, Judkoff, R, Beausoleil-Morrison, I, Ben-Nakhi, A, Crowley, M, Deru, M, Henninger, R, Ribberink, H, Thornton, J, Wijsman, A \& Witte, M 2008, International Energy Agency building energy simulation test and diagnostic method (IEA BESTEST) - in-depth diagnostic cases for ground coupled heat transfer related to slab-on-ground construction, NREL/TP-550-43388, National Renewable Energy Laboratory.

NIFES Consulting Group 1993, The energy saver: the complete guide to energy efficiency London.

Nolan, G 2005, Occasional report 5 stars, UTAS, Launceston.

---- 2006a, 'The No Bills House \& Best 5 Star House project: test cell configuration', Timber Research Unit, School of Architecture, University of Tasmania.

---- 2006b, Result of the Advisory Committee for the No Bills and Best Value Five Star Project to M Dewsbury, 23 March 2006. 
Nolan, G \& Dewsbury, M 2007, 'Improving the thermal performance of light weight timber construction: A review of approaches and impediments relevant to six test buildings', paper presented to 40th Annual Conference of the architectural Association ANZAScA, Geelong.

Norton, T \& Williams, O 1990, Climate change in Australia: environmental, socio-economic and political considerations, Resource and Environment Studies No.3, Centre for Resource and Environment Studies.

O'Brien, B 1990, Postponing greenhouse: climate change-facts, issues and policies, O'Brien Brian. J.

OEENR 2004, Air leakage control: why should I worry about air-leakage problems?, Office of Energy Efficiency of Natural Resources, Canada.

Olesen, B 2007, 'The philosophy behind EN15251: indoor environment criteria for design and calculation of energy performance of buildings', Energy and Buildings, vol. 39, no. 7, pp. 740-749.

Palmiter, L \& Francisco, P 1996, Modeled and measured infiltration: phase III - a detailed case study of three homes, TR-106228, Electric Power Research Institute, Palo Alto.

Palomo del Barrio, E \& Guyon, G 2002, Using parameters space analysis techniques for diagnostic purposes in the framework of empirical model validation: a report of Task 22, Subtask A, building energy analysis tools.

Palomo, E, Marco, J \& Madsen, H 1991, 'Methods to compare measurements and simulations', paper presented to BS1991, Nice, France, 20-22 August, 1991.

Papamichael, K 2000, 'Green building performance prediction / assessment', building research \& Information, vol. 28, no. 5/6, pp. 394-402.

Papanek, V 1995, The Green Imperative: natural design for the real world, Thames and Hudson, New York.

Parker, P, Rowlands, I \& Scott, D 2003, 'Innovations to reduce residential energy use and carbon emissions: an Integrated approach', Canadian Geographer, vol. 47, no. 2, p. 169.

Paschkis, V 1942, 'Periodic heat flow in buildings walls determined by electrical analogy method.' ASHVE Transactions, vol. 48, no. 1, pp. 75-90.

Paschkis, V \& Baker, H 1942, 'A method for determining unsteady-state heat transfer by means of an electrical analogy', Transactions American Society of Mechanical Engineers vol. 64, pp. 105-112.

Pearman, G 1987, Greenhouse; planning for climate change, CSIRO.

Pearson, C 2002, Thermal imaging of building fabric: a best practice guide for continuous insulation, BSRIA.

Pereira, C \& Ghisi, E 2009, 'Calibration of a computer model of a naturally-ventilated house located in southern Brazil', Building Stimulations, pp. 1490-1496.

Peterson, W \& Dirmhirn, I 1981, 'The ratio of diffuse to direct solar radiation (perpendicular to the sun's rays) with clear skies - a conserved quantity throughout the day ', Journal of Applied Meteorology, vol. 20, no. July 1981, pp. 826-828.

Pitt \& Sherry 2010, The pathway to 2020 for low-energy, low-carbon buildings in Australia: Indicative stringency study Department of Climate Change \& Energy Efficiency.

Pittock, A 2009, Climate change: the science, impacts and solutions, CSIRO.

Pollard, A, O'Driscoll, R \& Pinder, D 2001, 'The impact of solar radiation on the air temperature within a residential building', paper presented to International Solar Energy Society 2001 Solar World Congress, Adelaide, Australia, November, 2001.

Potter, I 1999, Envelope integrity demonstration study, BSRIA.

Potter, N \& Knights, C 2004, Air tightness testing for new dwellings: a practical guide for builders and testers BSRIA.

Productivity Commission 2004, Inquiry into energy efficiency: transcript of proceedings, 24/11/2004. 
Q-BEARS 2009, Newsletter, 25/09/2009, <www.qbears.com.au/newsletter.html>.

Quirouette, R 1986, 'The air barrier defined', paper presented to Building Science Insight '86, An Air Barrier for the Building Envelope, Canada.

Raftery, P, Keane, M \& Costa, A 2009, 'Calibration of a detailed simulation model to energy monitoring system data: a methodology and case study', paper presented to Building Simulation 2009, Eleventh International IBPSA Conference, Glasgow, Scotland, July 27-30, 2009.

Rahni, N, Ramdani, N, Candau, Y \& Guyon, G 1999, 'New experimental validation and model improvement tools for the CLIM2000 energy simulation software program', paper presented to BS1999, Kyoto, Japan.

Ramsey, F \& Schafer, D 2002, The statistical sleuth: a course in methods of data analysis, 2 edn, Duxbury, California.

Rantala, J 2005, 'Estimation of the mean temperature distribution underneath a slab-onground', Journal of Building Physics, vol. 29, no. 1, pp. 51-68.

Rao, K \& Chandra, P 1966, 'Digital computer determination of thermal frequency response of building sections', Building Science, vol. 1, no. 4, pp. 299-307.

Rees, D 1989, Essential statistics, 2 edn, Chapman \& Hall, London.

Rees, S, Xiao, D \& Spitler, J 2002, 'An analytical verification test suite for building fabric models in whole building energy simulation programs', ASHRAE Transactions, no. 108, pp. 30-42.

Ridley, B \& Boland, J 2005, 'Development of climate data for building related energy rating software ', paper presented to Solar 2005, 2005.

---- 2008, 'A modelling tool for estimating diffuse solar radiation with multiple predictors', paper presented to ISESAP-08 (3rd international Solar Energy Society Conference, Asia Pacific Region, Sydney.

Ritter, C 1817, Allgemeine erdkunde: vorlesungen an der universitat zu Berlin (Comparative geography), W. Blackwood, Edinburgh.

Robertson, D 1985, 'Comparisons of four computer models with experimental data from test buildings in northern Mexico', ASHRAE Transactions, vol. 91, no. 2.

Rock, B \& Ochs, L 2001, 'Slab-on-grade heating load factors for wood framed buildings', Energy and Buildings, vol. 33, no. 8, pp. 759-768.

Roujol, S, Fleury, E, Marchio, D, Millet, J \& Stabat, P 2003, 'Testing the energy simulation building model of Consoclim using BESTEST method and experimental data', paper presented to Eighth International IBPSA Conference, Eindhoven, Netherlands, August 11-14, 2003.

Rowell, T 2006-2008, Personal discussions with the Tasmanian state government representative for the $\mathrm{ABCB}$.

Rudd, A, Chandra, S \& Tooley, J 1993, 'Measured air-tightness and thermal insulation quality of 11 industrialized houses', paper presented to 1993 EEBA?NESEA Conference on Building Solutions, Boston, March 3-6, 1993.

Sahlin, P, Eriksson, L, Grozman, P, Johnson, H, Shapovalov, A \& Vuolle, M 2003, 'Will equation-based building simulation make it? experiences from the introduction of IDA indoor climate and energy', paper presented to Eighth International IBPSA Conference, Eindhoven, Netherlands, August 11-14, 2003.

Saman, W, Oliphant, M, Mudge, L \& Halawa, E 2008, Study of the effect of temperature settings on AccuRate cooling energy requirements and comparison with monitored data, Residential Building Sustainability, Department of the Environment, Water, Heritage and the arts, Canberra. 
Scanes, P 1974, 'Climate design data for use in thermal calculations for buildings- estimated clear sky solar radiation versus measured solar radiation', Building Science, vol. 9, no. 3, pp. 219-225.

Schellnuber, H, Cramer, W, Nakicenovic, N, Wigley, T \& Yohe, G 2006, Avoiding dangerous climate change, Cambridge University Press, Cambridge.

SEAV 2004, Energy efficiency improvement in the residential sector, Sustainable Energy Authority of Victoria.

Seo, S, Tucker, S, Ambrose, M, Mitchell, P \& Wang, C 2005, Technical evaluation of environmental assessment rating tools, PN05.1019, Forest and Wood Products Research and Development Corporation, Victoria.

Shadd, E 2009, Re: change both U-Eff \& UF/UWMat? to Bldg-sim, 18 September 2009

Sherman, M 1998, Air infiltration measurement techniques, LBL-10705, Lawrence Berkeley Laboratory, University of California, Berkeley, California.

---- 2006, Air tightness of US homes: model development, LBNL- 59202, Lawrence Berkeley National Laboratory, University of California, Berkeley, California.

Soebarto, V \& Williamson, T 2001, 'Multi-criteria assessment of building performance: theory and implementation', Building and Environment, vol. 36, no. 6, pp. 681-690.

Sorrell, F, Luckenback, T \& Phelps, T 1985, 'Validation of hourly building energy models for residential buildings', ASHRAE Transactions, vol. 91, no. 2.

Spencer, J 1981, 'A comparison of methods for estimating hourly diffuse solar radiation from global solar radiation', Solar Energy, vol. 29, no. 1, pp. 19-32.

Standards Australia 1992, AS 3999-1992: Thermal insulation of dwellings - bulk insulation installation requirements Standards Australia International Ltd.

---- 1996, AS 2870 Residential slabs and footings - construction, Standards Australia International Ltd.

---- 1999, AS 1684.1-1999: Residential timber-framed construction - design criteria, Standards Australia International LTD.

---- 2006, AS 1684.2-2006: Residential timber-framed construction - non-cyclonic areas, Standards Australia International LTD.

Standards New Zealand 2006, NZS 4214 Methods of determining the total thermal resistance of parts of buildings, New Zealand Standards.

Stazi, F, Di Perna, C, Del Prete, L \& Stazi, A 2007, 'Comparison between monitoring and simulating: an important step forward for model reliability', paper presented to Building Simulation 2007 Beijing, China, 3-6 September, 2007

Stein, J 1997, Accuracy of home energy rating systems, Building Energy Analysis Group, Bldg 90-2000, Environment Energy Technology Division Lawrence Berkeley National Library, Berkeley, CA

Stein, J \& Meier, A 2000, 'Accuracy of home energy rating systems', Energy vol. 25, no. 4, pp. Pp 339-354

Stern, N 2006, Stern review: the economics of climate change.

Stoecklein, A, Pollard, A \& Bishop, S 1998, 'Energy end-use in New Zealand houses', paper presented to ACEEE Summer Study, Asilomar, Monterey, CA, USA, August 1998.

Stoecklein, A, Pollard, A, Isaacs, N, Bishop, S \& James, B 1998, 'Energy end-use and socio/demographic occupant characteristics of New Zealand households', paper presented to IPENZ Conference, Auckland, NZ.

Stokes, B 2007, Make ACDB Software for windows - user guide, Australian Greenhouse Office

Strachan, P 2000, ESP-r: summary of validation studies, Energy Systems Research Unit, University of Strathclyde, Scotland. 
---- 2008, 'Simulation support for performance assessment of building components', Building and Environment, vol. 43, pp. 228-236.

Strachan, P \& Baker, P 2008, 'Outdoor testing, analysis and modeling of building components', Building and Environment, vol. 43, pp. 127-128.

Strachan, P, Kokogiannakis, G \& MacDonald, I 2005, 'Encapsulation of validation tests in the ESP-r simulation program', paper presented to Building simulation 2005: ninth international IBPSA Conference, Montreal, 15-18 August 2005.

Strachan, P, Kokogiannakis, G \& Macdonald, I 2008, History and development of validation with the ESP-r simulation program, NRCC-50322, National Research Council Canada.

Strachan, P, Kokogiannakis, G, Macdonald, I \& Beausoleil- Morrison, I 2006, 'Integrated comparative validation tests as an aid for building simulation tool users and developers', ASHRAE Transactions, no. 112, pp. 395-408.

Strachan, P \& Vandaele, L 2008, 'Case studies of outdoor testing and analysis of building components', Building and Environment, vol. 43, pp. 129-142.

Subhakar, D \& Thyagarajan, K 1994, 'Estimation of solar radiation', paper presented to Solar '94 Secrets of the Sun Proceedings of the Annual Conference of the Australian and New Zealand Solar Energy Society, Sydney, NSW, 30 Nov - 3 Dec 1994.

Sugo, H 2005-2009, Test cell design and measurement to M Dewsbury.

---- 2006a, 'Construction and instrumentation details of dedicated thermal test modules located at the University of Newcastle', University of Newcastle.

---- 2006b, Re: MABEL \& U Newcastle test cells to M Dewsbury, 17 November 2006.

---- 2007, 'Construction and instrumentation details of dedicated thermal test modules located at the University of Newcastle'.

Sugo, H, Page, A \& Moghtaderi, B 2004, 'A comparative study of the thermal performance of cavity and brick veneer construction', paper presented to 13th International Brick and block Masonry Conference, Eindhoven, Holland, August 2004.

---- 2005, 'The study of heat flows in masonary walls in a thermal test building incorporating a window', paper presented to 10th Canadian Masonary Symposium, Banff, Alberta, June 8122005.

Sullivan, R \& Winkelmann, F 1998, Validation studies of the DOE-2 building energy simulation program: final report, LBNL-42241, Earnest Orlando Lawrence Berkeley National Laboratory: Environmental Energy Technologies Division, Oak Ridge.

Swinton, M, Brown, W \& Chown, G 1990, 'Controlling the transfer of heat, air and moisture through the building envelope', paper presented to Building Science Insight '90, Small Buildings: Technology in Transition, Canada.

Syed, A \& Kosny, J 2006, 'Effect of framing on clear wall R-value for wood and steel framed walls', Journal of Building Physics, vol. 30, no. 2, pp. 163-180.

Tawa, M 1988, 'Architecture and the greenhouse effect in South Australia', paper presented to Greenhouse '88: Planning for Climate Change, Adelaide.

Thomas, H 2010, 'Software glitch undermines green houses', The Australian, 27 July 2010.

Thwaites, T 1995, 'Energy: nationwide house energy solutions', Building Innovation, vol. 4, pp. 20-21.

Torcellini, P, Pless, S, Griffith, B \& Judkoff, R 2005a, Evaluation of the energy performance and design of the thermal test facility at the National Renewable Energy Laboratory, Colorado.

---- 2005b, Evaluation of the energy performance and design process of the thermal test facility at the National Renewable Energy Laboratory, NREL/TP-550-34832, National Renewable Energy Laboratory, Colorado.

TPC 2005, Inquiry into housing construction sector and related Issues: submission 52 (Timber Promotion Council of Victoria) - impact of Victorian 5 star energy efficiency 
regulations on the building and timber industries, Victorian Competition \& Efficiency Commission.

Travesi, J, Knabe, G, Felsmann, C, Acheman, M \& Behne, M 2001, Empirical validation of Iowa energy resource station building energy analysis simulation tools: a report of Task 22, Subtask A, building energy analysis Tools, project A.1 empirical validation.

Trethowen, H 2004, Effect of thermal bridging on heat losses of roofs in Australian houses, Project Report for the Australian Building Codes Board.

Trethowen, H \& Delsante, A 2000, 'A four-year site measurement of heat flow in slab-onground floors with wet soils', paper presented to 7th Thermal Performance of Building Envelopes Conference, Florida USA, December 7-11, 1998.

Tsai, G \& Milne, M 2003, HEED validated against the ASHRAE/BESTEST standard, UCLA Department of Architecture and urban design.

Tucker, S, Newton, P, Delsante, A, Ambrose, D, Johnston, S, Allen, B, Rasheed, B \& Remmers, T 2002, AGO-CSIRO greenhouse efficient design, CSIRO.

Tuomaala, P \& Piira, K 1997, 'The main features of a new generation building simulation tool', paper presented to Building Simulation 1997, Prague, Czech Republic, 8-10 September 1997.

Ulgen, K \& Hepbasli, A 2004, 'Solar radiation models. part 1: a review', Energy Sources, no. 26, pp. 507-520.

UN 1987, Report of the World Commission on Environment and Development: our common future, United Nations, New York.

UNEP 2010, 'United Nations Environment Program', viewed 2010.

US DOE 2000, Weather-resistive barriers: how to select and install house wrap and other types of weather-resistive barriers, Office of Building Technology, State and Community Programs, Energy Efficiency and Renewable Energy, U.S. Department of Energy.

US EPA 2010, 2010 Draft U.S. greenhouse gas inventory.

Vale, B \& Vale, R 1991, Green architecture: design for a sustainable future, Thames and Hudson, London.

Van Dijk, H \& van der Linden, G 1993, "The PASSYS method for testing passive solar components', Building and Environment, vol. 28, no. 2, pp. 115-126.

Van Gorcum, A 1950, 'Theoretical considerations on the conduction of fluctuating heat flow', Applied Scientific Research, vol. A2, no. 272, pp. 272-281.

Vincent, B \& Huang, Y 1996, Analysis of the energy performance of cooling retrofits in Sacramento public housing using monitored data and computer simulations, 500-93-053, CEC R\&D Office.

Wagner, b 1984, 'Comparisons of predicted and measured energy use in occupied buildings ', ASHRAE Transactions, vol. 90, no. 2 b.

Walsh, P 1988, 'Australian energy policy and the greenhouse effect', paper presented to Greenhouse '88: Planning for Climate change, Adelaide.

Walsh, P \& Delsante, A 1983, 'Calculation of the thermal behaviour of multi-zone buildings', Energy and Buildings, vol. 5, no. 4, pp. 231-242.

Watson, R, Albritton, D, Barker, T, Bashmakov, I, Canziani, O, Christ, R, Cubasch, U \& etal 2001, Climate change 2001: synthesis report (summary for policymakers). An assessment of the Intergovernmental Panel on Climate Change, Intergovernmental Panel on Climate Change.

White, R 2004, 'Managing and interpreting uncertainty for climate change risk', Building research \& Information, vol. 32, no. 5, pp. 438-448.

Wilkenfield, G, Hamilton, C \& Saddler, H 1995, Australia's greenhouse strategy: can the future be rescued? Discussion Paper No3, The Australian Institute, Canberra. 
Williamson, T 1995, 'A confirmation technique for thermal performance simulation models', paper presented to Building Simulation 1995, International IBPSA Conference, Madison, Wisconsin, USA, August 14-16, 1995.

---- 2004, Submission to the productivity commission public enquiry into energy efficiency energy-efficiency standards in residential buildings: a plea for evidence-based policy making, School of Architecture, Landscape Architecture \& Urban Design, The University of Adelaide Williamson, T \& Beauchamp, B 2005, Insulation solutions to enhance the thermal resistance of suspended timber floor systems in Australia, PN05.1014, Forest and Wood Product Research and Development Corporation

Williamson, T, Coldicutt, S, Bennetts, H \& Rees, J 1995, Energy efficient design: theory and the real world, Department of architecture, Adelaide.

Williamson, T \& Delsante, A 2006, 'Investigation of a model for the ventilation of suspended floors', paper presented to 40th Annual Conference of the Architectural Science Association ANZAScA, Adelaide.

Williamson, T, Orkina, N \& Bennetts, H 2009, 'A Comparison of accredited second generation NatHERS software tools', paper presented to 43rd Annual Conference of the Architectural Science Association, ANZASCA 2009, University of Tasmania.

Williamson, T, Plaves, Y \& Hart, R 2007, 'An evaluation of the nationwide house energy rating scheme (NatHERS)', paper presented to Towards solutions for a liveable future: progress, practice, performance, people: Proceedings of the 41st Annual Conference of the Architectural Science Association ANZAScA, Geelong, Australia, November 14-16 2007.

Willrath, H 1997, 'Thermal sensitivity of Australian houses to variations in building parameters', paper presented to Solar '97 Australian and New Zealand Solar Energy Society.

---- 1998, 'Comparison of the thermal performance of free running and conditioned houses in the Brisbane climate', paper presented to The 32nd Australian \& New Zealand Architectural Science Association (ANZAScA) Conference.

Winkelmann, F 1998, 'Underground surfaces: how to get a better underground surface heat transfer calculation in DOE-2.1E', Building Energy Simulation: User News, vol. 19, no. 1 (Spring 1998), pp. 6-13.

Witte, M \& Henninger, R 2004, 'Experience testing EnergyPlus with the ASHRAE 1052-RP building fabric analytical tests', paper presented to SimBuild 2004, IBPSA-USA Conference, Boulder, CO, 4-6 Aug 2004.

Witte, M, Henninger, R, Glazer, J \& Crawley, D 2001, 'Testing and validation of a new building energy simulation program', paper presented to Building simulation 2001: Seventh International IBPSA Conference, Rio de Janeiro, August 13-15, 2001.

Wong, S 1990, 'Simulation of simultaneous heat and moisture transfer by using the finite difference method and verified tests in a test chamber', ASHRAE Transactions, pp. 472-486.

Zoras, S \& Kosmopoulos, P 2009, 'Application of the three-dimensional numerical generation of response factors (NGRF) method of multi-year based conductive temperatures in soil and passive cooling earth contact components', Building Simulation 2009, pp. 1588-1595.

Zweifel, G \& Zelenka, A 2007, 'Influence of solar radiation data processing on building simulation results', paper presented to Building Simulation 2007. 

